\title{
Permeameter Studies of Water Flow Through Cement and Clay Borehole Seals in Granite, Basalt and Tuff
}

Manuscript Completed: August 1986

Date Published: October 1986

Prepared by

D. L. South, J. J. K. Daemen

Department of Mining and Geological Engineering niversity of Arizona

. ucson, AZ 85721

\section{Prepared for}

Division of Engineering Safety

Office of Nuclear Regulatory Research

U.S. Nuclear Regulatory Commission

Washington, DC 20555

NRC FIN B6627

Under Contract No. NRC-04-78-271 


\section{DISCLAIMER}

This report was prepared as an account of work sponsored by an agency of the United States Government. Neither the United States Government nor any agency thereof, nor any of their employees, make any warranty, express or implied, or assumes any legal liability or responsibility for the accuracy, completeness, or usefulness of any information, apparatus, product, or process disclosed, or represents that its use would not infringe privately owned rights. Reference herein to any specific commercial product, process, or service by trade name, trademark, manufacturer, or otherwise does not necessarily constitute or imply its endorsement, recommendation, or favoring by the United States Government or any agency thereof. The views and opinions of authors expressed herein do not necessarily state or reflect those of the United States Government or any agency thereof. 


\section{DISCLAIMER}

Portions of this document may be illegible in electronic image products. Images are produced from the best available original document. 


\section{ABSTRACT}

Boreholes near a repository must be sealed to prevent rapid migration of radionuclide contaminated water to the accessible environment. The objective of this research is to assess the performance of borehole seals under laboratory conditions, particularly with regard to varying stress fields.

Flow through a sealed borehole is compared with flow through intact rock. Cement or bentonite seals have been tested in granite, basalt, and welded tuff.

The main conclusion is that under laboratory conditions, existing commercial materials can form high quality seals. Triaxial stress changes about a borehole do not significantly affect seal performance if the rock is stiffer than the seal. Temperature but especially moisture variations (drying) significantly degrade the quality of cement seals. Performance partially recovers upon resaturation.

A skillfully sealed borehole may be as impermeable as the host rock. Analysis of the influence of relative seal-rock permeabilities shows that a plug with permeability one order of magnitude greater than that of the rock results in a flow increase through the hole and surrounding rock of only $11 / 2$ times compared to the undisturbed rock. Since a borehole is only a small part of the total rock mass, the total effect is even less pronounced. The simplest and most effective way to decrease flow through a rock-seal system is to increase the seal length, assuming it can be guaranteed that no dominant by-pass flowpath through the rock exists. 


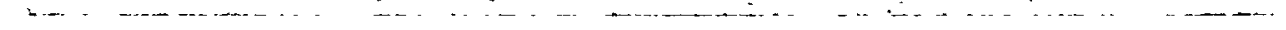


TABLE OF CONTENTS

$\underline{\text { Page }}$

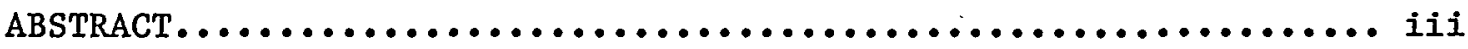

LIST OF ILLUSTRATIONS.............................viii

LIST OF TABLES................................. xii

ACKNOWLEDGEMENTS $\ldots \ldots \ldots \ldots \ldots \ldots \ldots \ldots \ldots \ldots \ldots \ldots \ldots \ldots \ldots \ldots \ldots \ldots$ xv

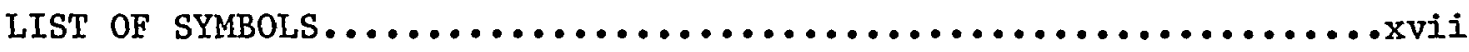

EXECUTIVE SUMMARY................................. 1

1. Introduction................................. 1

2. Water Flow Through Cement and Clay Borehole Seals in

Granite, Basalt and Tuff.......................... 1

2.1. Introduction.............................. 1

2.2. Experimental Procedures........................ 1

2.3. Experimental Results......................... 3

2.4. Plug Impermeability Requirements................ 10

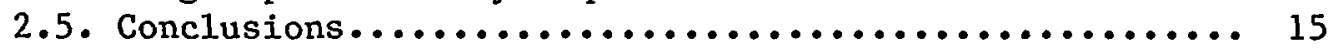

2.6. Remaining Uncertainties in Penetration Sealing....... 15

CHAPTER ONE: INTRODUCTION.......................... 17

1.1 objective.............................. 17

1.2 Scope and Limitations........................... 18

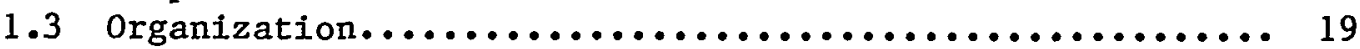

1.4 Rock Mass Sealing Contract No. NRC-04-78-271 -

Reports Issued.............................. 19

CHAPTER TWO: BOREHOLE SEALING...................... 23

2.1 Introduction............................... 23

2.2 Borehole Sealing and Nuclear Waste Isolation.......... 25

2.2.1 High-Level Nuclear Waste Isolation Research

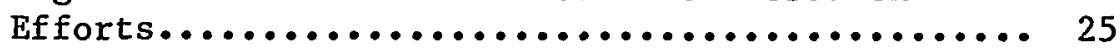

2.2.2 Borehole Sealing Considerations.............. 25

2.2.3 Research Objectives....................... 26

2.3 Borehole Sealing: Current Practice and Recent Studies.. 27

2.3.1 Introduction ......................... 27

2.3.2 Borehole Sealing Methods................... 27

2.3.2.1 Well Cementing Methods............... 28

2.3.2.1.1 0i1 and Gas Well Cementing... 28

2.3.2.1.2 Plugging of 0il Wells and

Degasification Holes in

Penetrating Appalachian

Coal Mines................ 33 
TABLE OF CONTENTS--Continued

$\underline{\text { Page }}$

2.3.2.1.3 Implications for Nuclear

Waste Disposal............ 33

2.3.2.2 Borehole Sealing with Clay........... 35

2.3.3 Studies Regarding Borehole Sealing for Nuclear

Waste Isolation........................ 36

2.3.3.1 The Bell Canyon Test and Subsequent

WIPP Studies.................... 36

2.3.3.2 The Work of D'Appolonia Consulting

Engineers, Inc./IT Corporation........ 39

2.3.3.3 Wellbore Damage Zone Studies by

Terra Tek......................... 45

2.3.3.4 Research at The Pennsylvania State University...................... 46

2.3.3.5 The PSU/WES Interlaboratory Study...... 50

2.3.3.6 Research at the Waterways Experiment Station........................ 50

2.3.3.7 Research at Oak Ridge National

Laboratory..................... 53

2.3.3.8 Studies at Woodward-Clyde Consultants for the Basalt Waste Isolation Project.. 55

2.3.3.9 Information Base for Waste Repository Design............................ 56

2.3.3.10 Research at the University of Arizona.. 57

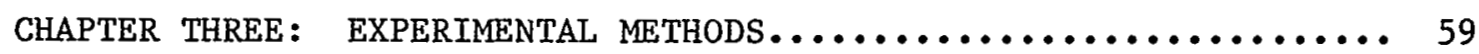

3.1 Materials.................................. 61

3.1.1 Rock Types........................... 61

3.1.1.1 Oracle Granite.................... 61

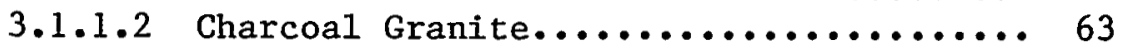

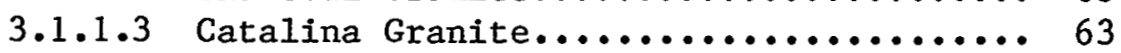

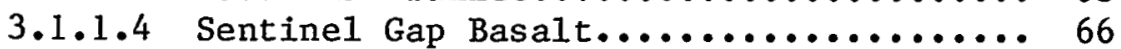

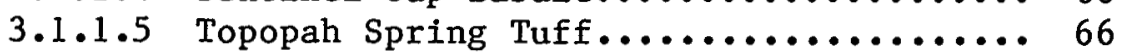

3.1 .2 Seal Materials......................... 69

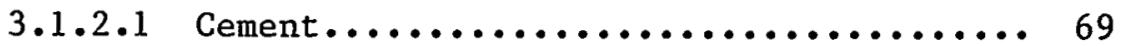

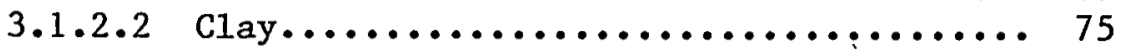

3.2 Experimental Apparatus....................... 76

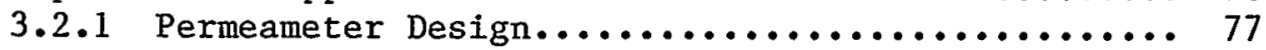

3.2 .2 Pump Design.......................... 82

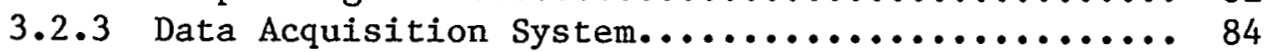

3.3 Experimental Procedure........................ 84

3.3.1 Sample Preparation and Loading.................... 84

3.3 .2 Testing............................. 85

CHAPTER FOUR: EXPERIMENTAL RESULTS................... 88

4.1 Tests on Cement Plugs........................ 90

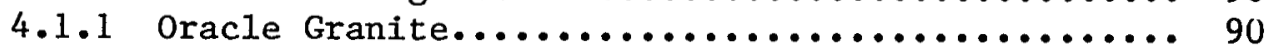

4.1.1.1 Tests with Rock Bridge in Place....... 90 
TABLE OF CONTENTS--Continued

Page

4.1.1.2 Tests without Rock Bridge............99 93

4.1.1.3 Tests with Cement P1ug............... 93

4.1.1.4 Experimental Procedure Modifications.... 93

4.1.2 Charcoal Granite....................... 95

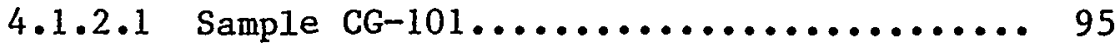

4.1.2.2 Sample CG-102.................... 99

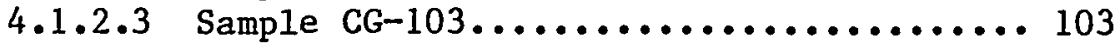

4.1.3 Sentinel Gap Basalt....................... 109

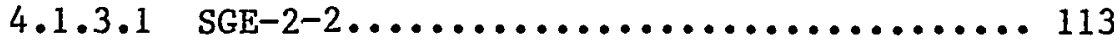

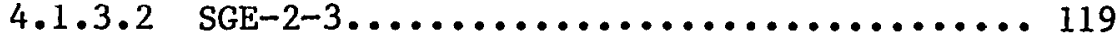

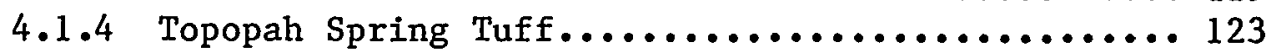

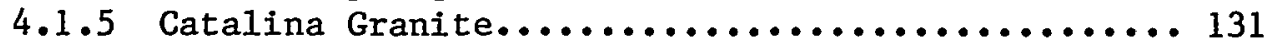

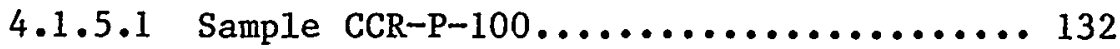

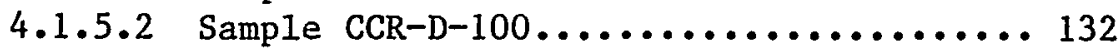

4.2 Tests on Bentonite Plugs in a Charcoal Granite Cylinder. 140

CHAPTER FIVE: ANALYSIS OF EXPERIMENTAL RESULTS.............. 148

5.1 Analysis of Tests on Cement Plugs................. 148

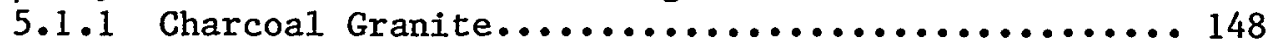

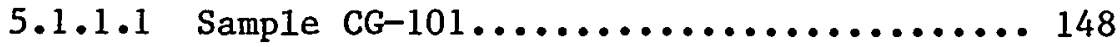

5.1 .1 .2 Samples $C G-102$ and $C G-103 \ldots \ldots \ldots \ldots \ldots \ldots 151$

5.1 .1 .3 Sample CG-104.................... 158

5.1 .1 .4 Comparison of $\mathrm{CG}-103$ and $\mathrm{CG}-104 \ldots \ldots \ldots \ldots 158$

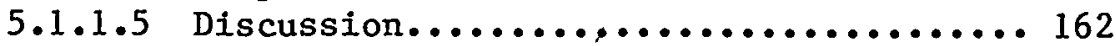

5.1 .2 Sentinel Gap Basalt....................... 164

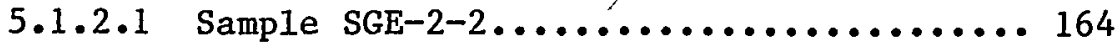

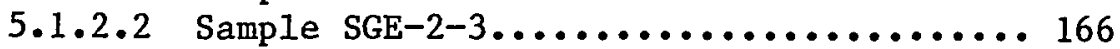

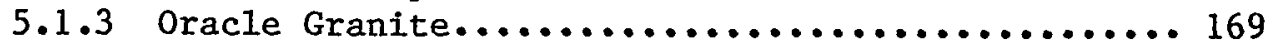

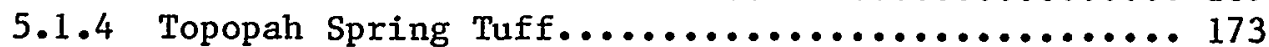

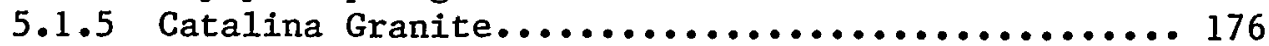

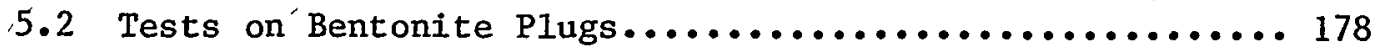

5.3 Influence of Relative Plug-Rock Permeabilities......... 180

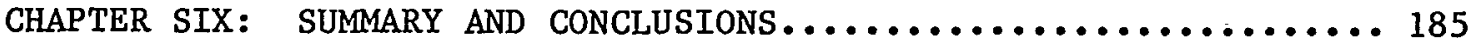

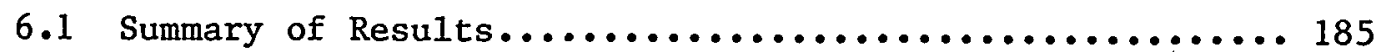

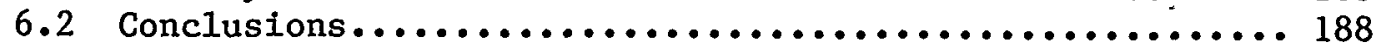

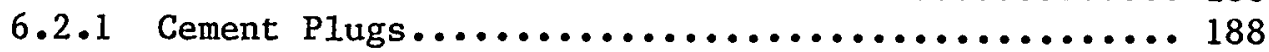

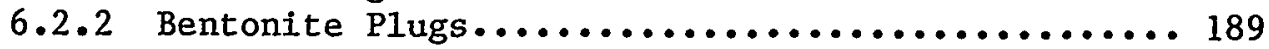

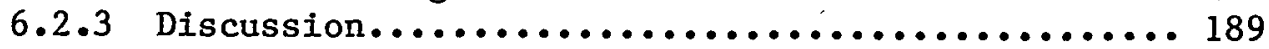

6.3 Uncertainties, Information Needs, and Research

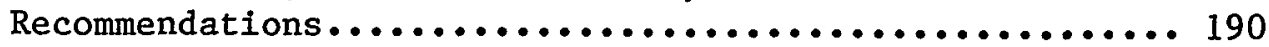

6.4 Suggestions for Further Research................... 191

REFERENCES...................................... 193

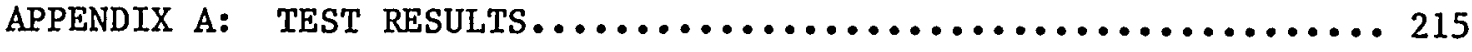

vii 


\section{LIST OF FIGURES}

Figure

$\underline{\text { Page }}$

Executive Summary

1. Experimental method: flow through an intact rock bridge remaining near the center of a rock cylinder is compared to flow through the rock clyinder when the bridge has been replaced by a borehole plug......... 2

2. Radial permeameter assembly drawing............... 4

3. Sample CG-101, Charcoal granite, flow rate in vs. injection pressure............................ 5

4. Sample CG-102, Charcoal granite, flow rate in vs. injection pressure........................... 6

5. Sample CG-103, Charcoal granite, flow rate in vs. injection pressure.......................... 7

6. Flow rate vs. time, sample SGE-2-2, Sentinel Gap basalt................................... 8

7. Flow rate vs. time, sample SGE-2-3, Sentinel Gap basalt................................... 9

8. Flow net for intact rock, $\mathrm{K}_{\mathrm{P}}=\mathrm{k}_{\mathrm{R}} \ldots \ldots \ldots \ldots \ldots \ldots \ldots \ldots \ldots 12$

9. Flow net for plug more permeable than rock, $\mathrm{K}_{\mathrm{P}}=10 \mathrm{~K}_{\mathrm{R}} \ldots \ldots 13$

10. Flow net for plug less permeable than rock, $\mathrm{K}_{\mathrm{P}}=0.1 \mathrm{~K}_{\mathrm{R}} \ldots 14$ Chapters 1 through 6

2.1 Open-hole plugging: the balance method............ 30

2.2 Open-hole plugging: the dump bailer............... 31

2.3 Open-hole plugging: the two-plug method............ 32

3.1 Experimental method: flow through intact rock is compared to flow through sealed rock............... 60

3.2 Photomicrograph of Oracle Granite................ 62

3.3 Photomicrograph of Charcoal Granite................. 62

3.4 Photomicrograph of Catalina Granite................ 65 


\section{LIST OF FIGURES--Continued}

Figure

Page

3.5 Photomicrograph of Sentinel Gap Basalt.............. 65

3.6 Photomicrograph of Topopah Spring Tuff............... 70

3.7 Diagram of Ruska Iiquid permeameter............... 71

3.8 Expansive stress vs. time for Cement System $1 \ldots \ldots \ldots \ldots . . .73$

3.9 Radial permeameter assembly drawing............... 78

3.10 Constant pressure pump assembly drawing............. 83

4.1 Sample OAZ-M1 (Oracle Granite cylinder) - dimensions..... 91

4.2 Sample CG-101, flow rate in vs. injection pressure, Charcoal granite............................ 97

4.3 Sample CG-101 (Charcoal granite cylinder) - dimensions... 98

4.4 Sample CG-102, flow rate in vs. injection pressure, Charcoal Granite..............................101

4.5 Sample CG-102 (Charcoal granite cylinder) - dimensions... 102

4.6 System 1 Cement plug in sample CG-102............... 104

4.7 Diametric view of cement plug, sample CG-102.......... 105

4.8 Photomicrograph of plug in Sample CG-102............. 105

4.9 Sample CG-103, flow rate in vs. injection pressure, Charcoal Granite............................. 107

4.10 Sample CG-103 (Charcoal granite) - dimensions........... 108

4.11 Pulse test data, Charcoal granite sample CG-103, Cement 1 plug, June $9,1982 \ldots \ldots \ldots \ldots \ldots \ldots \ldots \ldots \ldots \ldots \ldots \ldots$

4.12 Pulse test data, CG-103, Cement 1 plug, June 10, 1982.... 111

$4.13 \quad$ CG-103, sketch of dye penetration................. 112

4.14 Flow rate vs. time, sample sGE-2-2............... 115

4.15 Sample SGE-2-2 (Sentinel Gap basalt) - dimensions....... 116

4.16 Sample SGE-2-2, flow rate vs. time, Cement 1 plug, after drying for 42 days at $54^{\circ} \mathrm{C} \ldots \ldots \ldots \ldots \ldots \ldots \ldots \ldots \ldots$

4.17 Flow rate vs. time, sample SGE-2-3............... 121 


\section{LIST OF FIGURES--Continued}

4.18 Sample SGE-2-3 (Sentinel Gap basalt) - dimensions....... 122

4.19 Sample SGE-2-3, dye test....................... 124

4.20 Topopah Spring welded tuff Sample NTS-TPTS-101, flow rate vs. top pressure for rock bridge............... 127

4.21 Topopah Spring welded tuff Sample NTS-TPTS-101, flow rate vs. time, Cement System 1 plug................. 128

4.22 Sample NTS-TPTS-101 (Topopah Spring welded tuff) dimensions....................................... 129

4.23 Topopah Spring welded tuff Sample NTS-TPTS-101 showing fractures and lithophysal cavities................ 130

4.24 Sample CCR-P-100 (Catalina granite, percussion drilled hole) - (dimensions........................... 133

4.25 Sample CCR-P-100, dye test, showing greater penetration of the granite than of the cement plug.............. 136

4.26 Sample CCR-D-100 (Catalina granite cylinder with diamond cored holes) - dimensions................... 137

4.27 Sample CCR-D-100, flow rate in vs. injection pressure.... 139

4.28 Sample CG-104, flow rate in vs. injection pressure...... 141

4.29 Sample CG-104 test results on second and third clay plugs..................................... 142

4.30 Sample CG-104 (Charcoal granite) - dimensions,.......... 143

4.31 Fracture in Charcoal granite cylinder Sample CG-104..... 147

5.1 Axisymmetric finite element mesh used with program FREESURF I to simulate radial permeameter tests of rock bridge and plug flow rates...................... 149

5.2 Sample CG-101, calculated flow rate vs. permeability for injection pressure, $P_{\mathrm{T}}$, of $10.0,7.0$ and $3.5 \mathrm{MPa} \ldots .150$

5.3 Sample CG-101, variation in flow rate with variation in the ratio of the plug permeability, $\mathrm{K}_{\mathrm{p}}$ to rock

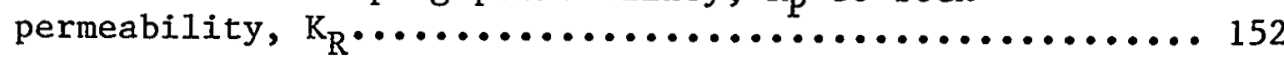

5.4 Sample CG-102, flow rate vs. permeability for injection pressures, $\mathrm{P}_{\mathrm{T}}$, of $10.1,7.0$ and $3.5 \mathrm{MPa} \ldots \ldots \ldots \ldots \ldots \ldots 153$ 


\section{LIST OF FIGURES--Continued}

Figure

Page

5.5 Sample CG-102, variation in flow rate with variation in the ratio of the plug permeability, $\mathrm{K}_{\mathrm{P}}$, to rock

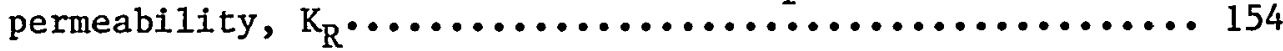

5.6 Sample CG-103, flow rate vs. permeability for injection pressures, $\mathrm{P}_{\mathrm{T}}$, of $10.1,7.0$ and $3.4 \mathrm{MPa} \ldots \ldots \ldots \ldots \ldots \ldots \ldots$

5.7 Charcoal granite Sample CG-103, variation in flow rate with variation in the ratio of $\mathrm{plug}$ permeability, $\mathrm{K}_{\mathrm{p}}$, to rock permeability to rock permeability, $\mathrm{K}_{\mathrm{R}} \ldots \ldots \ldots \ldots 156$

5.8 Charcoal granite Sample CG-104, rock bridge, permeability vs. first stress invariant, $I_{1} \ldots \ldots \ldots \ldots \ldots \ldots \ldots \ldots \ldots$

5.9 Charcoal granite Sample CG-103, rock bridge, permeability vs. first stress invariant, $I_{1} \ldots \ldots \ldots \ldots \ldots \ldots \ldots \ldots 16 \ldots \ldots \ldots$

5.10 Sentinel Gap basalt Sample SGE-2-2, variation in flow rate with variation in the ratio of plug permeability,

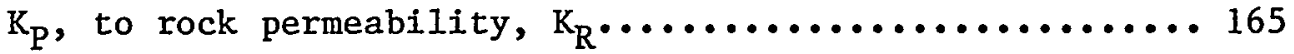

5.11 Sentinel Gap basalt Sample SGE-2-3, variation in flow rate with variation in the ratio of plug permeability, $\mathrm{K}_{\mathrm{P}}$, to rock permeability, $\mathrm{K}_{\mathrm{R}} \ldots \ldots \ldots \ldots \ldots \ldots \ldots \ldots \ldots \ldots \ldots$

5.12 Charcoal granite Sample CG-104, calculated variation in flow rate with variation in the ratio of plug permeabi1ity, $\mathrm{K}_{\mathrm{P}}$, to rock permeability, $\mathrm{K}_{\mathrm{R}} \ldots \ldots \ldots \ldots \ldots \ldots \ldots \ldots \ldots$

5.13 Flow net for intact rock, $\mathrm{K}_{\mathrm{P}}=\mathrm{K}_{\mathrm{R}} \ldots \ldots \ldots \ldots \ldots \ldots \ldots \ldots \ldots 1$

5.14 Flow net for plug more permeable than rock, $\mathrm{K}_{\mathrm{P}}=10 \mathrm{~K}_{\mathrm{R}} \ldots 183$

5.15 Flow net for plug less permeable than rock, $\mathrm{K}_{\mathrm{P}}=0.1 \mathrm{~K}_{\mathrm{R}} \cdots 184$ 
Executive Summary

1. Summary of Rock and Plug Permeability............... 11

\section{Chapters 1 through 6}

3.1 Physical Properties of Oracle Granite................ 64

3.2 Physical Properties of Charcoal Granite.............. 64

3.3 Physical Properties of Sentinel Gap Basalt........... 67

3.4 Brazilian Tensile Strengths, $\mathrm{T}_{0}$, Sentinel Bluffs

Basalt................................... 68

3.5 Mechanical Properties of System 1 Cement............. 70

3.6 Expansion Experiment Data - System 1 Cement........... 74

3.7 Radial Permeameter Parts List.................... 80

3.8 Nominal Test Schedule........................ 86

4.1 Oracle Granite - Test Results for Convergent Flow

with Rock Bridge.......................... 92

4.2 Oracle Granite - Test Results for Divergent Flow with

Rock Bridge................................ 92

4.3 Oracle Granite - Test Results for Convergent Flow -

Hollow Cylinder............................. 94

4.4 Oracle Granite - Test Results for Divergent Flow -

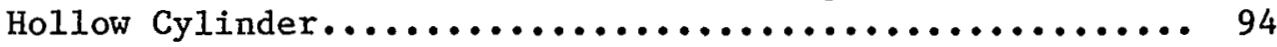

4.5 Summary of Test Results for Sample CG-101............ 96

4.6 Summary of Test Results for Sample CG-102............ 100

4.7 Summary of Test Results for Sample CG-103............ 106

4.8 Summary of Test Results for Sample SGE-2-2........... 114

4.9 Summary of Test Results for Sample SGE-2-3.......... 120

4.10 Summary of Test Results for Sample NTS-TPTS-101....... 125 
LIST OF TABLES--Continued

Table

$\underline{\text { Page }}$

4.11 Test Results for Sample NTS-TPTS-101, Cement System 1 Plug..................................... 126

4.12 Test Results for Sample CCR-P-100................. 134

4.13 Summary of Test Results for Sample CCR-D-100......... 138

4.14 Summary of Test Results for Sample CG-104............. 145

5.1 Summary of Permeability Values Calculated for the Charcoal Granite............................. 157

5.2 Estimated and Measured Flow Rates and Permeabilities

for Sample CG-104 with Rock Bridge................. 159

5.3 Sample CG-103 - Comparison of Measured Flow Rate through Plugged Sample with Estimated Flow Rate through Sample with Rock Bridge................... 163

5.4 Sample SGE-2-2 - Permeabilịty of Cement System 1

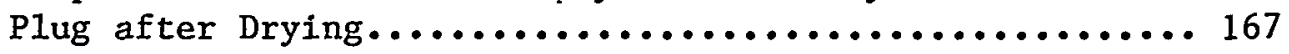

5.5 Oracle Granite; Top Hole, Radial Permeability in Convergent Flow with Rock Bridge.................. 170

5.6 Oracle Granite; Top Hole, Radial Permeability in Divergent Flow with Rock Bridge................... 170

5.7 Oracle Granite; Radial Permeability in Convergent

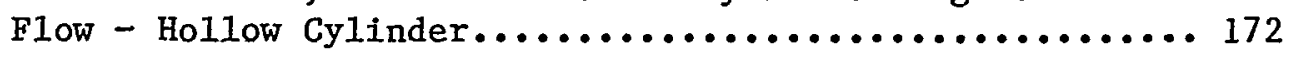

5.8 Oracle Granite; Radial Permeability in Divergent Flow - Hollow Cylinder.......................... 172

5.9 Topopah Srping Welded Tuff Sample NTS-TPTS-101, Rock Bridge; Upper Bound Permeability............... 175

5.10 Test Results for Oracle Granite Samples CCR-P-100 and CCR-D-100................................... 177

6.1 Summary of Rock and Plug Permeability.............. 186 Appendix A

A.1 Test Results for Sample CG-101.................... 216

A.2 Test Results for Sample CG-102................... 222

A.3 Test Results for Sample CG-103.................... 227 


\section{LIST OF TABLES--}

Table

A.4 Test Results for Sample SGE-2-2.................. 233

A.5 Test Results for Sample SGE-2-3.................. 239

A.6 Test Results for Sample NTS-TPTS-101............... 243

A.7 Test Results for Sample CCR-P-100................. 248

A.8 Test Results for Sample CCR-D-100................ 250

A.9 Test Results for Sample CG-104................... 257 


\section{ACKNOWLEDGEMENTS}

The research reported on has been performed by the University of Arizona, Department of Mining and Geological Engineering, for the U.S. Nuclear Regulatory Commission (NRC). Project monitor for the NRC is $\mathrm{Mr}$. Jacob Philip. The project is under Mr. Leon L. Beratan, Chief, Earth Sciences Branch, Division of Radiation Programs and Earth Sciences, Office of Nuclear Regulatory Research.

Dr. Jaak J.K. Daemen, Associate Professor, Department of Mining and Geological Engineering, University of Arizona, is the Principal Investigator. Dr. James G. McCray, Acting Director, Nuclear Fuel Cycle Research Program, Department of Nuclear and Energy Engineering, University of Arizona, has provided project management assistance and nuclear waste technical assistance. David L. South has performed the theoretical and experimental work as part of his Ph.D. degree requirements. Experimental assistance has been provided by laboratory technicians and undergraduate assistants Carolyn Audilet, Doug Knight, Moises J. Chongolola, Behrooz Kousari and Judy Bertucca. Mike Porter has assembled, typed and produced the report.

We gratefully acknowledge the assistance of the Dowell Division of Dow Chemical, U.S.A., in providing cement and additives, and especially the technical help provided by Erik B. Nelson.

American Colloid Company supplied precompressed Volclay ${ }^{\circledR}$ bentonite tablets. Valuable technical discussions with Chris Jepsen, Mark Bertane and Todd Harriet of American Colloid are gratefully acknowledged. 



\section{LIST OF SYMBOLS}

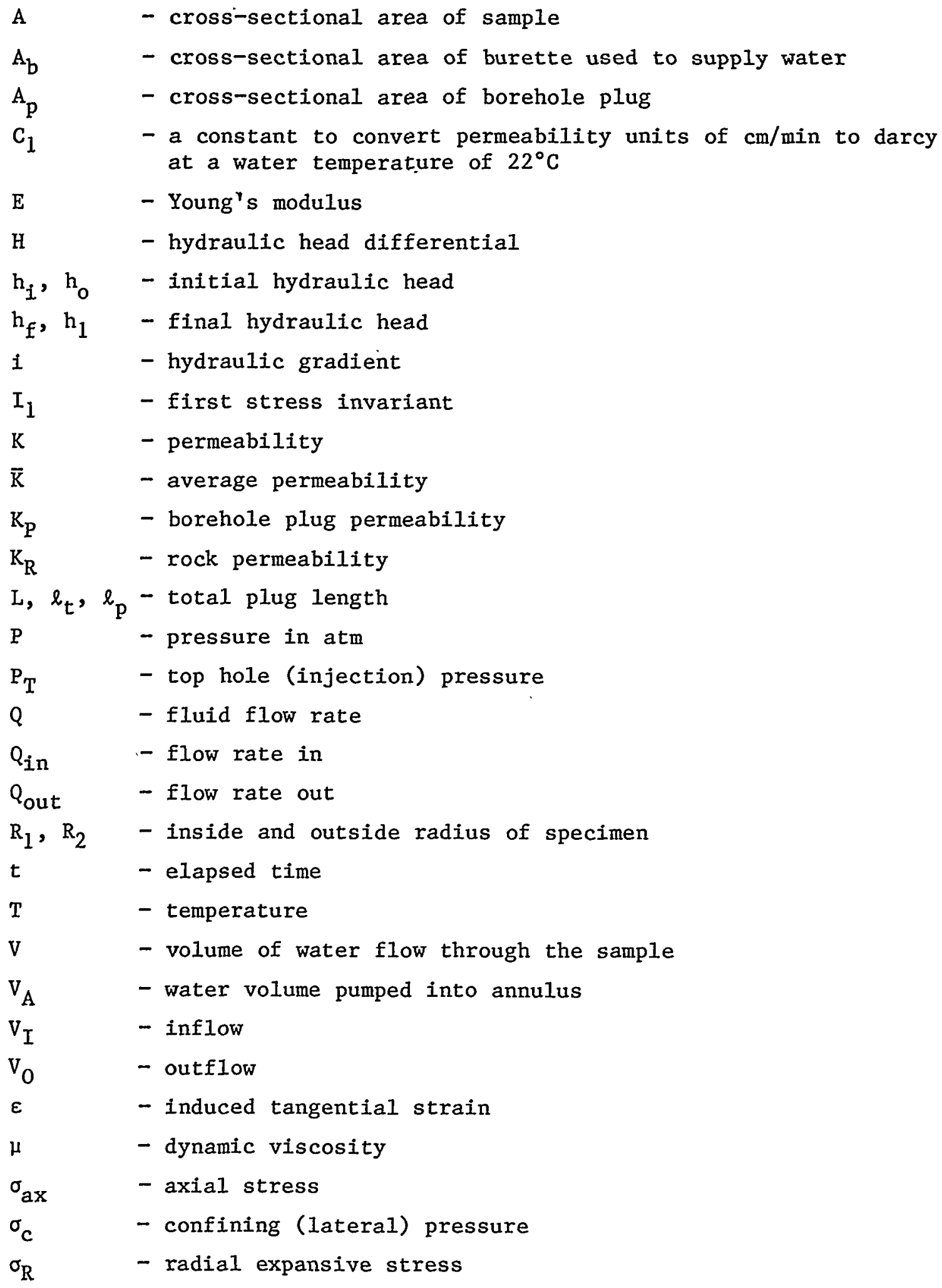

xvii 


\section{EXECUTIVE SUMMARY}

\section{Introduction}

Boreholes in the vicinity of a nuclear waste repository must be sealed reliably to prevent rapid migration of radionuclide contaminated water. Although borehole sealing has been performed for many years by the oil and gas industry, few measured data are available regarding its effectiveness. The objective of this research is to assess the performance of borehole seals under laboratory conditions, i.e. to obtain experimental data regarding sealing effectiveness. Seal performance under varying stress fields is investigated; temperature is held constant and saturated conditions are obtained.

\section{Water Flow Through Cement and Clay Borehole Seals in Granite, Basalt and Tuff}

\subsection{Introduction}

Radial permeameter testing allows performance assessments of borehole plugs under a variety of stress conditions applied to the plugged rock sample. Changing the stress conditions sequentially makes it possible to impose severe conditions on the plug-rock interface. The applied stressfield makes it feasible to operate at high differential pressures across the plug, as well as to simulate in-situ stress states. In this project, permeameter testing has been the main approach to the sealing performance assessment of borehole plugs.

\subsection{Experimental Procedures}

To evaluate borehole seal performance, water flow through a sealed borehole in rock is compared with flow through the rock itself. Rock cores $15 \mathrm{~cm}$ ( 6 inches) in diameter and $30 \mathrm{~cm}$ (12 inches) long have 2.54 $\mathrm{cm}$ ( 1 inch) diameter holes drilled from each end, leaving a rock bridge in the center of the specimen (Figure 1a). Water pumped into the top hole flows through the specimen to the bottom hole. Steady-state flow rates are recorded. The rock bridge is drilled from the sample, replaced with a seal, and the experiment is repeated (Figure lb). This allows direct comparison of the flow rate through intact rock with the flow rate through the same rock after a small portion of the rock has been removed and replaced by a seal.

A main interest is the performance of the seal under varying stress conditions. The intact rock specimen is placed under axial and confining stresses approximating a lithostatic stress field at a depth of about $1000 \mathrm{~m}$. The intact rock is tested, the rock bridge is cored from the specimen, and a seal is placed and tested while the specimen remains under this stress field. Axial and confining stresses are then lowered to simulate depths of about $600 \mathrm{~m}$ and $300 \mathrm{~m}$, respectively, and flow through the seal/rock system is measured at each of these stress 


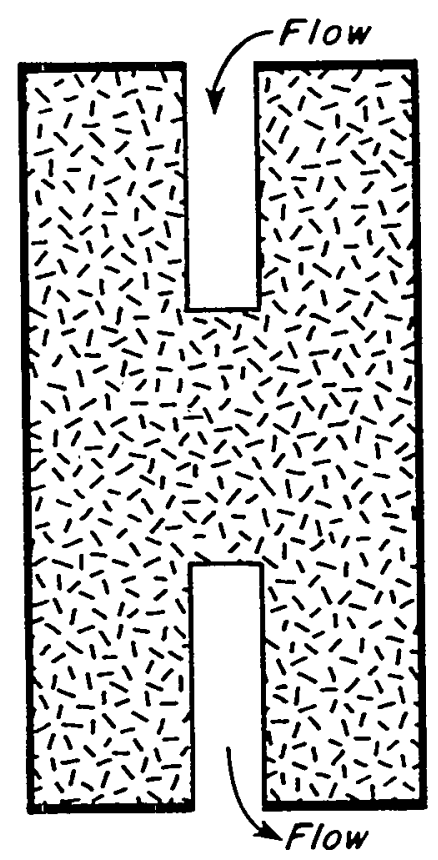

o. Sample with rock bridge.

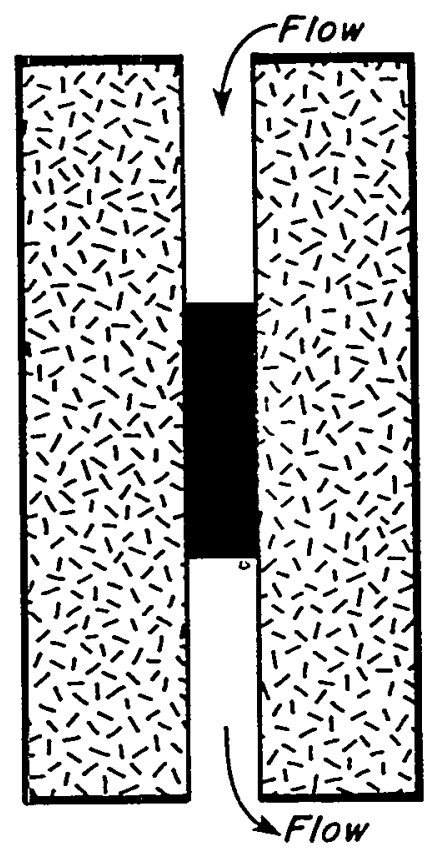

b. Sample with seal replocing rock bridge.

Figure 1. Experimental method: flow through an intact rock bridge remaining near the center of a rock cylinder is compared to flow thrugh the rock cylinder when the bridge has been replaced by a borehole plug. Heavy lines on outside, top and bottom of cylinder indicate no-flow boundaries. 
levels. Lowering the stress field is a severe testing condition with respect to the seal/rock interface, because it reduces the compressive radial stresses across the interface.

\subsection{Experimental Results}

Five rock types and two seal materials were used. Three of the rock types were granite: Oracle granite, Charcoal granite, and Catalina granite. A basalt from the Sentinel Gap area on the Columbia Plateau was tested, and also a sample from the Topopah Spring member of the Paintbrush tuff (Nevada Test Site). Portland cement and bentonite were the two seal materials used.

Two main items of apparatus, a permeameter and a constant pressure pump, were designed and four each were constructed by the Central machine shop, University of Arizona Instrument Shops. A data acquisition system was assembled and software written to collect the required data.

Figure 2 is an assembly drawing of the permeameter. Axial stress is applied to the sample by tightening the bolts, forcing the top and bottom plates towards each other. Confining stress is applied by pumping fluid into the annulus between the sample and the pressure cel1. Water is pumped into the top hole and flows through the sample to the bottom hole, where it is collected. Access to the interior of the sample in order to core out the rock bridge and place a seal is obtained by removing the piston plug and bottom plug. Axial and confining stresses may be maintained during this operation.

Nominal maximum axial stress, confining stress, and fluid injection pressure is $21 \mathrm{MPa}$.

Three samples of Charcoal granite were tested with cement seals. All show similar results: a decrease in flow through the sealed sample as compared to flow through the intact rock at the initial axial and confining stresses (Figures 3 through 5). As the axial and confining stresses were reduced, flow through the sealed sample increased, probably due to increased rock permeability resulting from opening of pores and microfractures in the rock as the stress levels decreased rather thn to increased flow through the seal. Only when axial and confining stresses were reduced to one-third their initial values did flow through the sealed sample exceed flow through the intact rock at the initial stress level.

Microscopic examination of the cement seal of sample CG-102 revealed a distinct crack along the interface between the seal and the rock. It is believed that this crack resulted from drying of the cement during preparation for microscopic examination. Drying of the seal resulted in complete decoupling of the cement from the rock. No bond existed between the cement and the rock.

Two samples of Sentinel Gap (Columbia Plateau) basalt, both drilled from the same block, were tested using cement seals (Figures 6 and 7). The samples exhibited very low flow rates when the rock bridge was in place, 


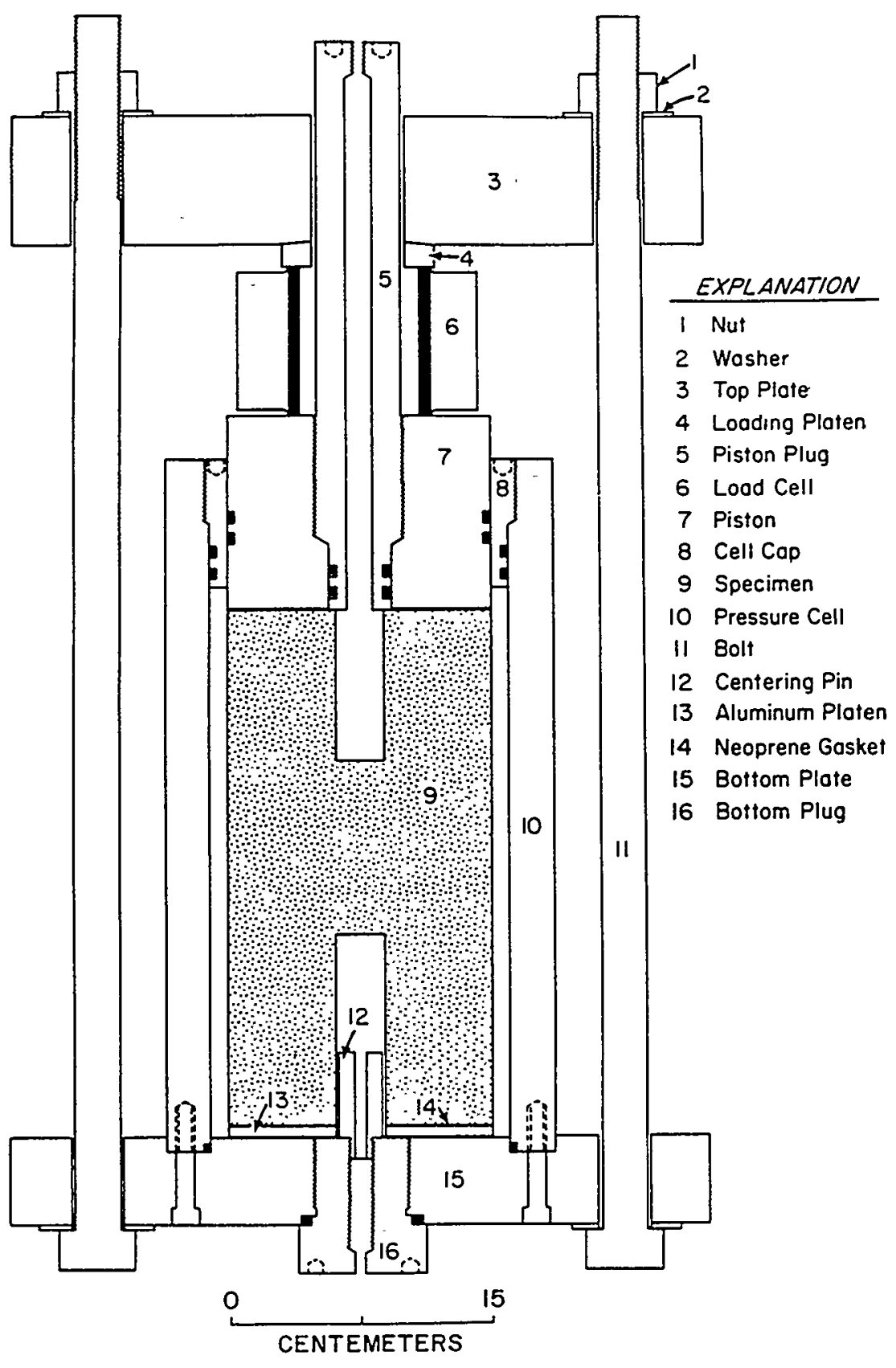

Figure 2. Radial permeameter assembly drawing. Small black rectangles indicate 0-ring seals. Rock cylinder (9) is stressed axially and laterally. Water is injected through the top hole in the cylinder, and collected in the bottom hole. 


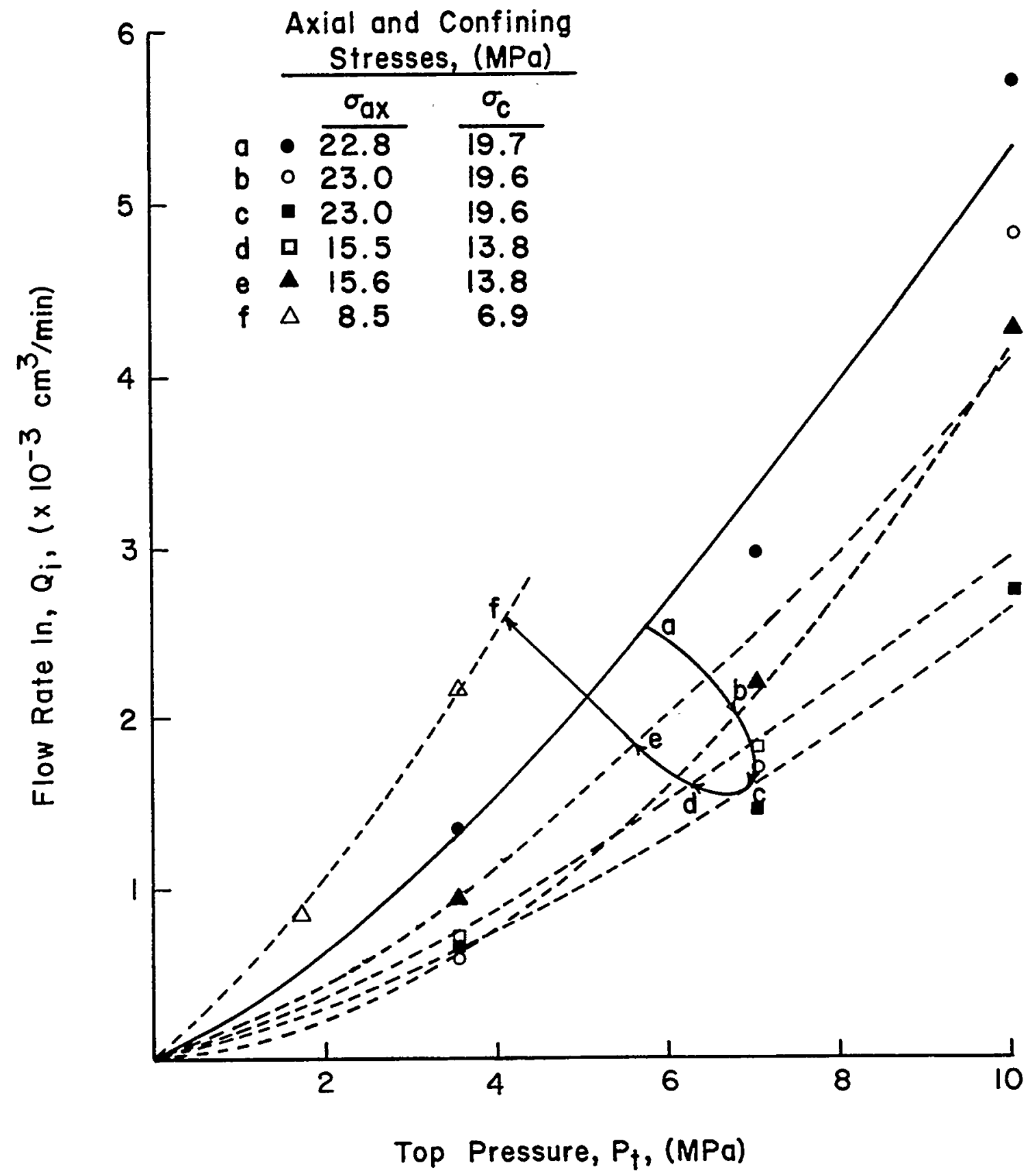

Figure 3. Sample CG 101, Charcoal granite, flow rate in vs. injection pressure. Solid line indicates flow rate through the bridge, dashed lines indicate System 1 cement plug. Letters indicate order of testing. 


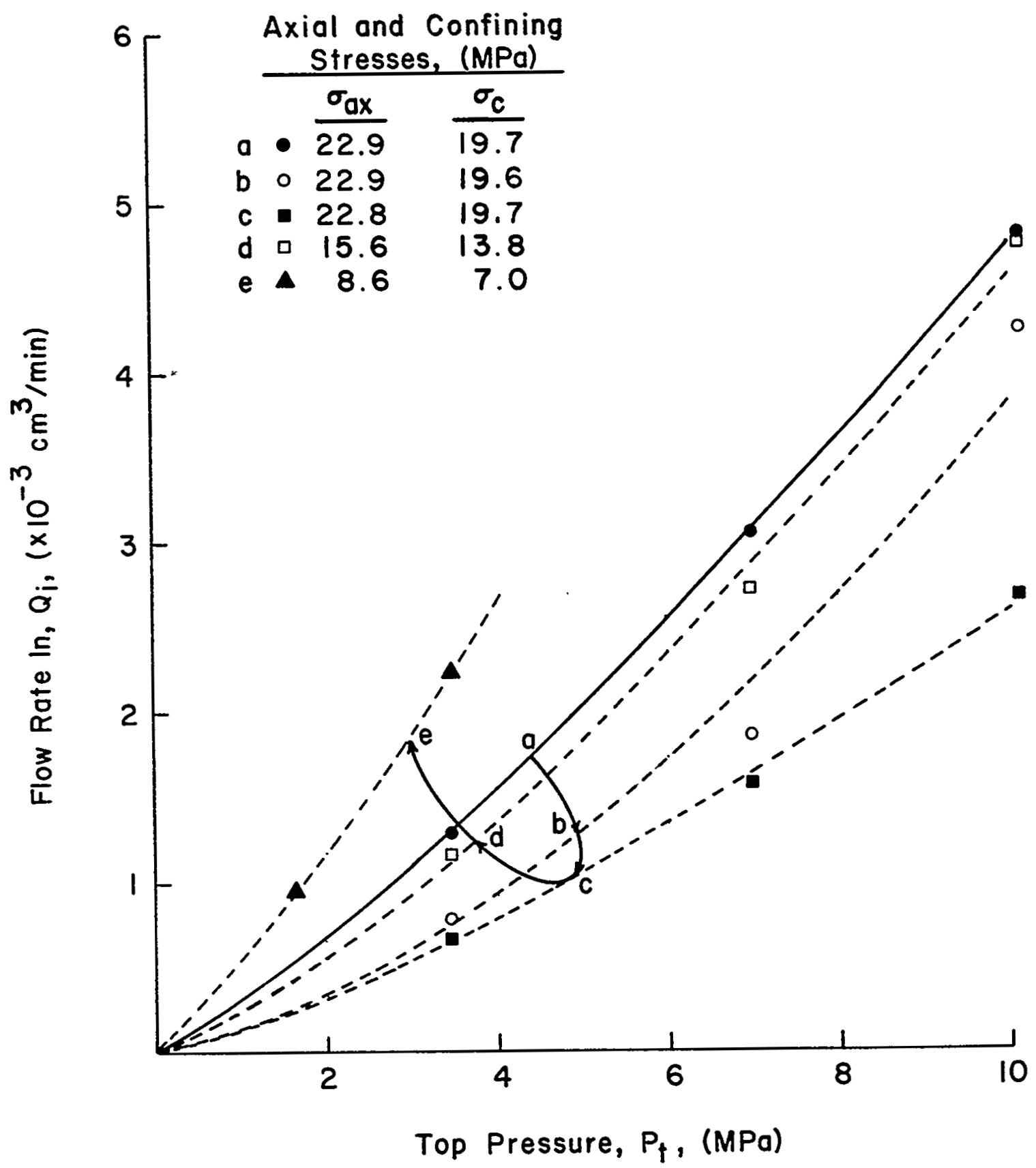

Figure 4. Sample CG-102, Charcoal granite, flow rate in vs. injection pressure. Solid line indicates flow rate through the bridge, dashed lines indicate System 1 cement plug. Letters indicate order of testing. 


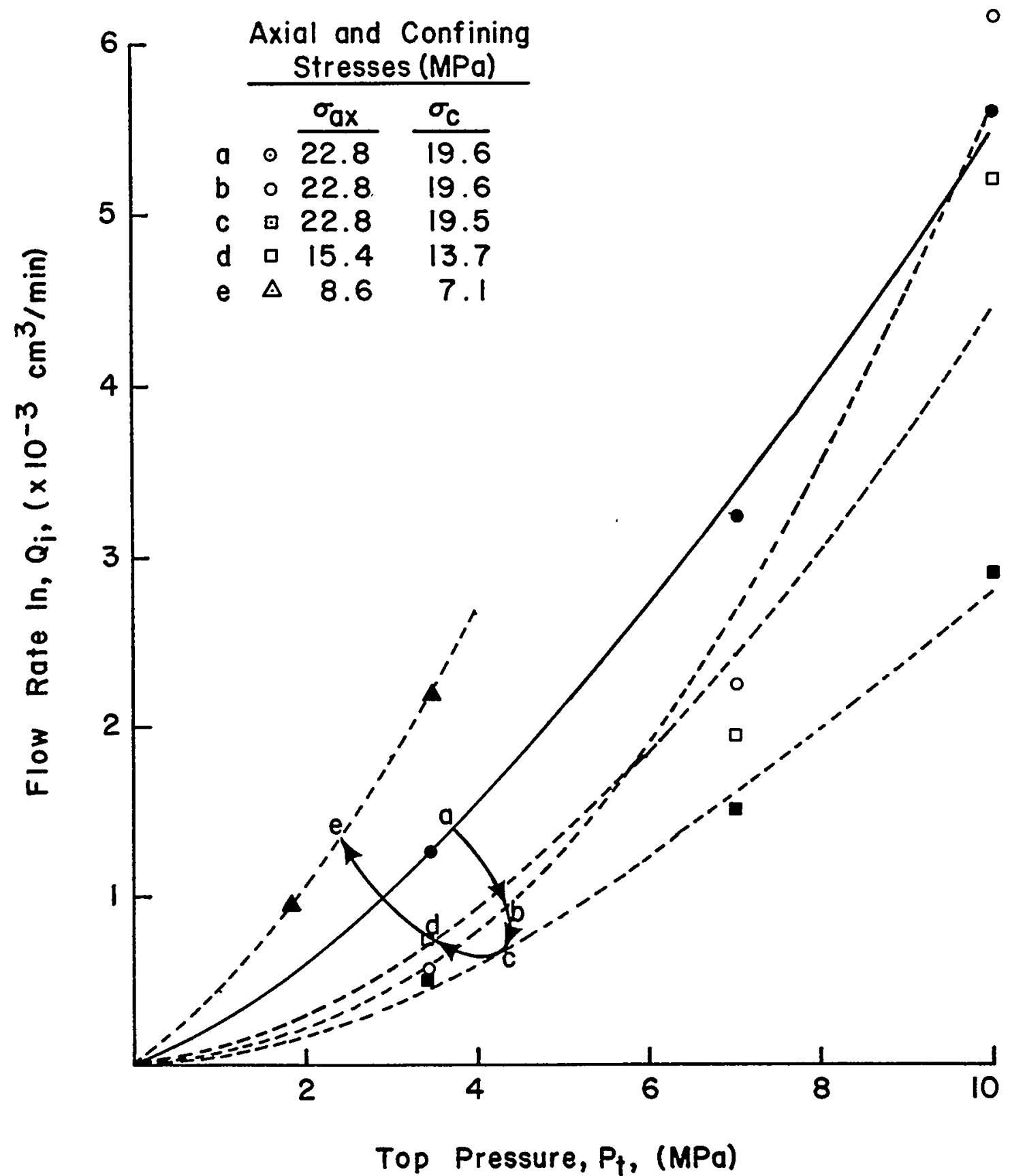

Figure 5. Sample CG-103, Charcoal granite, flow rate in vs. injection pressure. Solid line indicates flow rate through the bridge, dashed lines indicate System 1 cement plug. Letters indicate order of testing. 


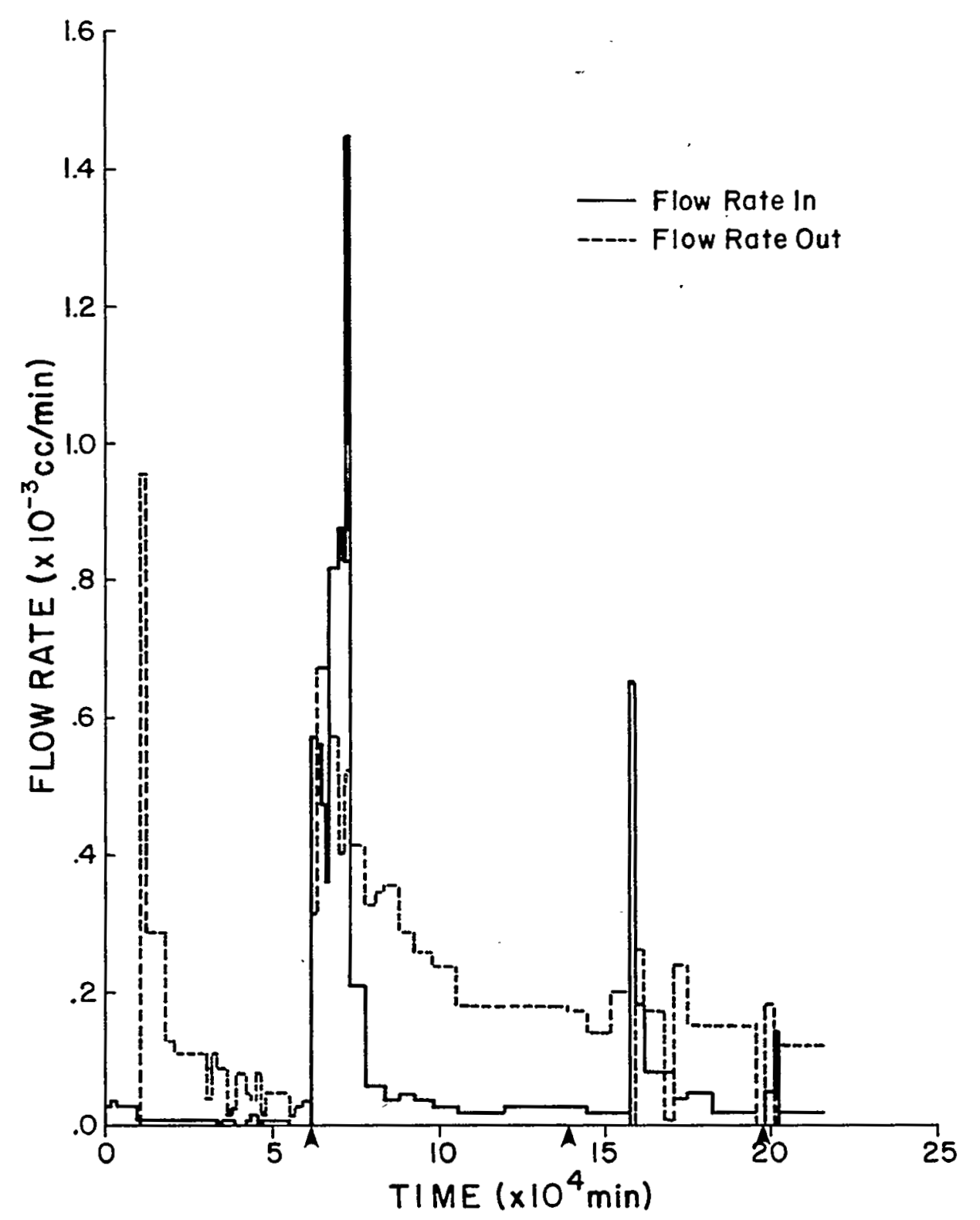

Figure 6. Flow rate vs. time, sample SGE-2-2, Sentinel Gap (Columbia Plateau) basalt. Arrows indicate (a) cement plug emplacement, 7/7; (b) stress change, $9 / 14$; and (c) stress change, $10 / 25$. 


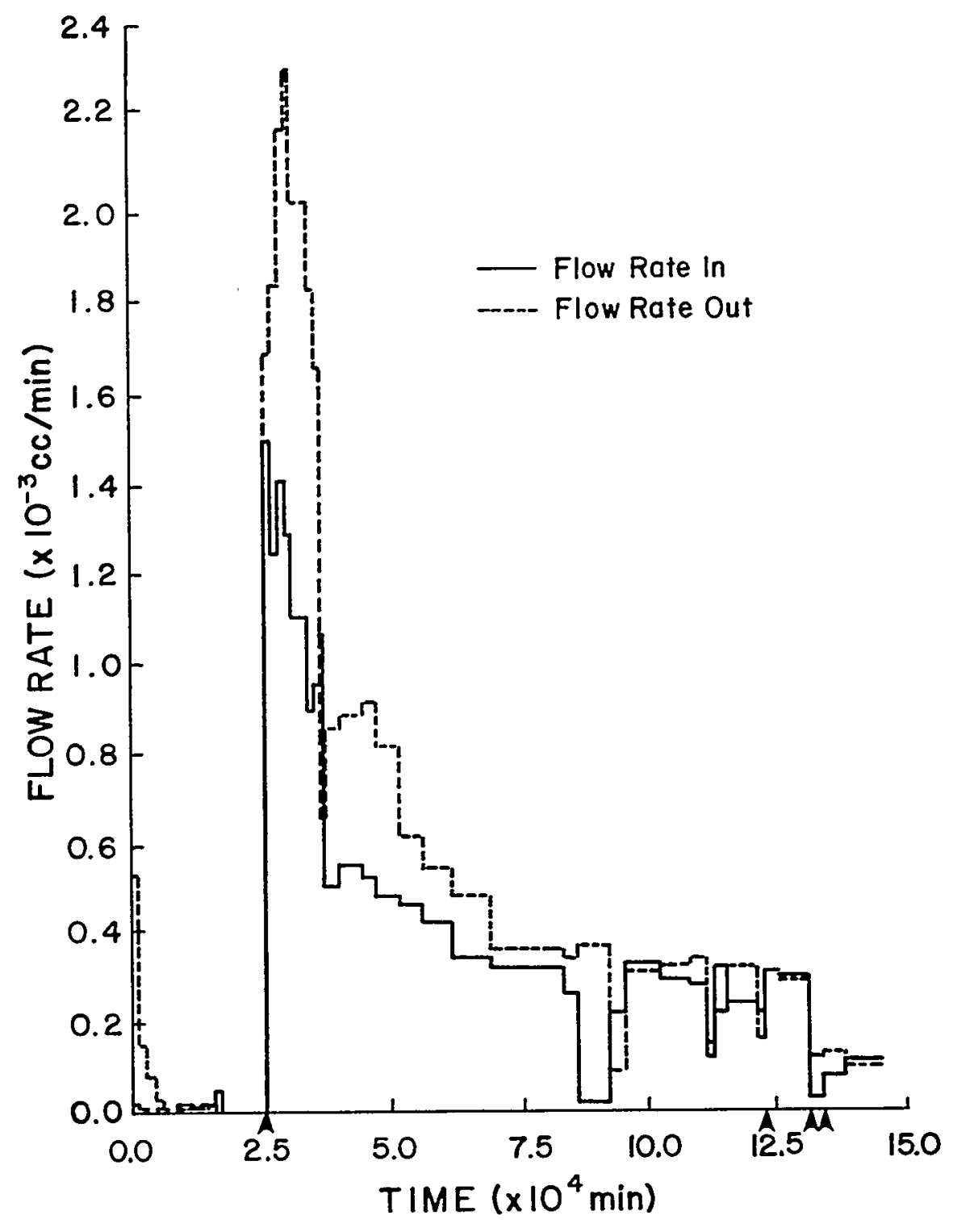

Figure 7. Flow rate vs. time, sample SGE-2-3, Sentinel Gap (Columbia Plateau) basalt. Arrows indicate (a) cement plug emplacement, 7/7; (b) stress change, 9/28; (c) stress change, $10 / 4$; and (d) stress change, $10 / 6$. 
less tha $0.05 \times 10^{-3} \mathrm{cc} / \mathrm{min}$. Flow rates increased greatly after emplacement of the cement seal, to rates on the order of $0.2 \times 10^{-3}$ $\mathrm{cc} / \mathrm{min}$. Flow through the basalt with cement seal was greater than through intact basalt, but still less than the flow rates measured for intact Charcoal granite samples. Lowering the stress field did not significantly affect the flow rates.

One sealed sample was dried at $54^{\circ} \mathrm{C}$ for 42 days. Flow rates through the seal after drying were over two orders of magnitude greater than before drying. Flow rates decreased as testing continued (and the sample resaturated), but not to the previously observed (extremely low) values.

The Topopah Spring tuff exhibited over an order of magnitude increase in initial flow rate through the sealed sample as compared to the flow through rock. After one month the flow rate through the sealed sample had declined to the same order of magnitude as the rate through the intact rockk. The initially high flow rates may be due to alkaliaggregate reaction between the cement and the rock.

Two samples of Catalina granite were tested, one with a percussiondrilled center hole, the other with a diamond-drilled center hole. Both were sealed with cement. Little difference was seen in the flow rates between the two samples, indicating percussion drilling does not induce a significantly different damage zone about the borehole with respect to permeability, compared to diamond drilling. Drying of the percussiondrilled sample at room temperature for 27 days slightly impaired plug performance.

One sample of Oracle granite was tested. Flow rates through the sealed sample were an order of magnitude greater than through the intact rock. In addition, during rock bridge testing, flow from the annulus to the top hole of the specimen was four orders of magnitude greater than flow from the annulus to the bottom hole due to a (hairline, barely visible) fracture which intersected the top hole but not the bottom hole. This points out the wel1-known dominance of fractures on the permeability of a rock mass in which intact rock has a low permeability.

Several clay plugs were placed in a Charcoal granite sample. All had permeabilities in the range of "impervious" clay, even though clay plug installation was deliberately kept extremely simple.

Table 1 is a summary of rock and plug permeability data calculated from the test results.

\subsection{Plug Impermeability Requirements}

Generic sensitivity calculations have been performed of the sealing performance of a borehole (shaft, drift) plug in order to assess the significance of the seal permeability relative to that of the surrounding rock mass. Representative results are given in Figures 8 through 10. If the seal permeability is not more than one order of magnitude larger than the permeability of the rock in which it is installed, the flow through the plug and rock immediately surrounding it 
Table 1. Summary of Rock and Plug Permeability

\begin{tabular}{|c|c|c|c|}
\hline Rock Type & $\begin{array}{c}\text { Rock Permeability } \\
\left(\mathrm{x} 10^{-9} \text { darcy }\right)\end{array}$ & $\begin{array}{l}\text { Equivalent } \\
\text { Plug Permeability } \\
\text { (x } 10^{-9} \text { darcy) }\end{array}$ & Comments \\
\hline Charcoal granite & $52-85$ & Less than rock & Cement plugs \\
\hline Sentinel Gap basalt & $0.16-0.17$ & $10-73$ & Cement plugs \\
\hline $\begin{array}{l}\text { Oracle Granite } \\
\text { with fracture } \\
\text { without fracture }\end{array}$ & $\begin{array}{c}60,000 \\
9\end{array}$ & $8,000^{* * *}$ & Cement plug \\
\hline Topopah Spring tuff & $1700-4800$ & $\left(2.5 \times 10^{-6}\right)-2000$ & Cement plug \\
\hline & & 95 & $\begin{array}{c}\text { Cement core tested } \\
(\mathrm{Ch} \cdot 3)\end{array}$ \\
\hline Charcoal granite & 85 & 9,000 & Bentonite plug \\
\hline
\end{tabular}

\footnotetext{
* Permeabilities were calculated assuming the plug body and the rock/plug interface are one porous body. ${ }^{* *}$ This permeability was calculated from flow assumed to be exclusively through a plug. The value is highly uncertain for reasons discussed in Section 6.1.
} 


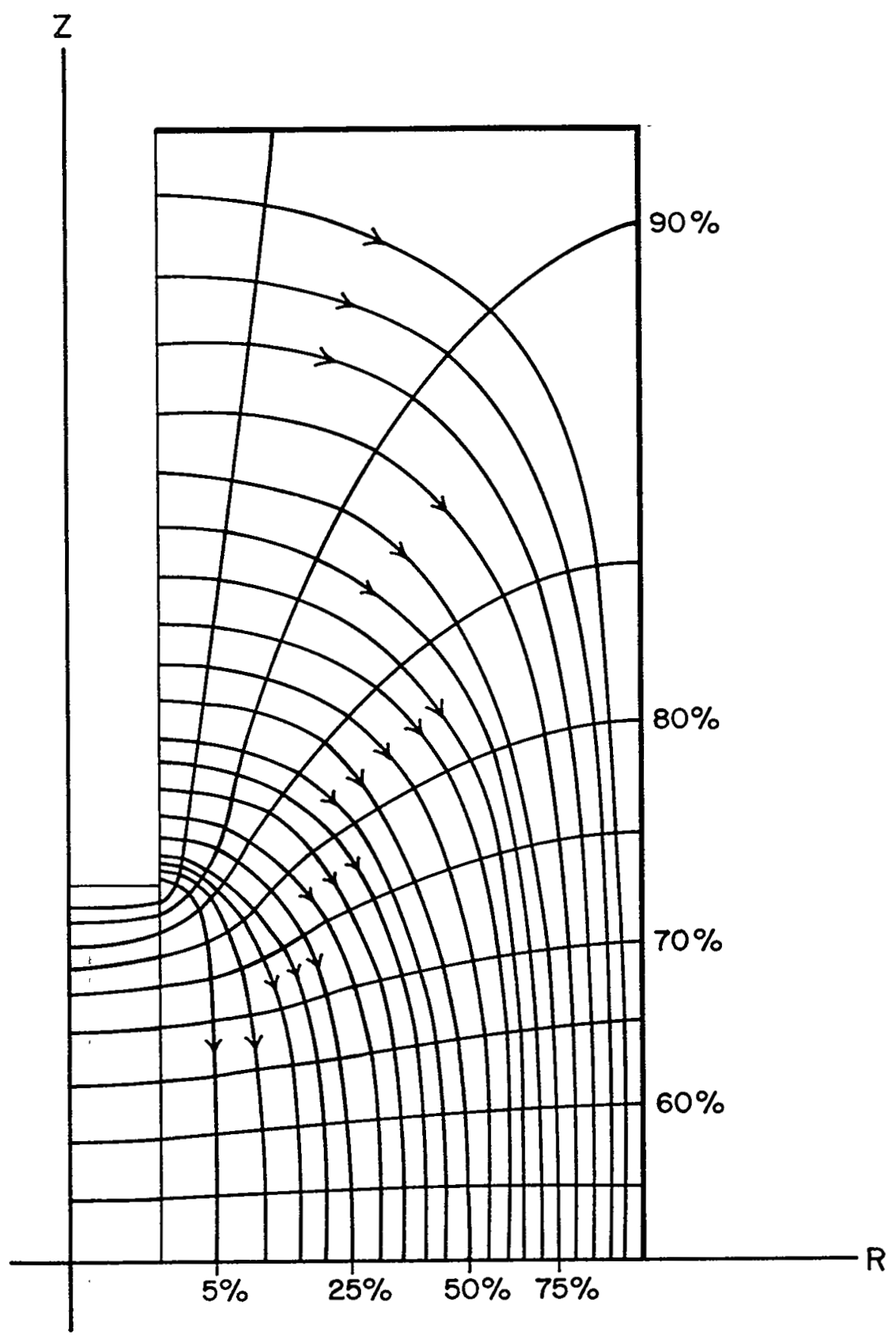

Figure 8. Flow net for intact rock, $K_{p}=K_{R}$. About $5 \%$ of the flow occurs through the "plug region". Equipotential lines show percent head with respect to center hole, which is at $100 \%$. Stream lines show percent flow occurring between the stream line and the Z-axis. Relative flow magnitude $=1.00$. Only upper half of cylinder is illustrated. Bottom hole (lower half) is at $0 \%$ head.

$\mathrm{K}_{\mathrm{P}}=$ plug permeability; $\mathrm{K}_{\mathrm{R}}=$ rock permeability. 


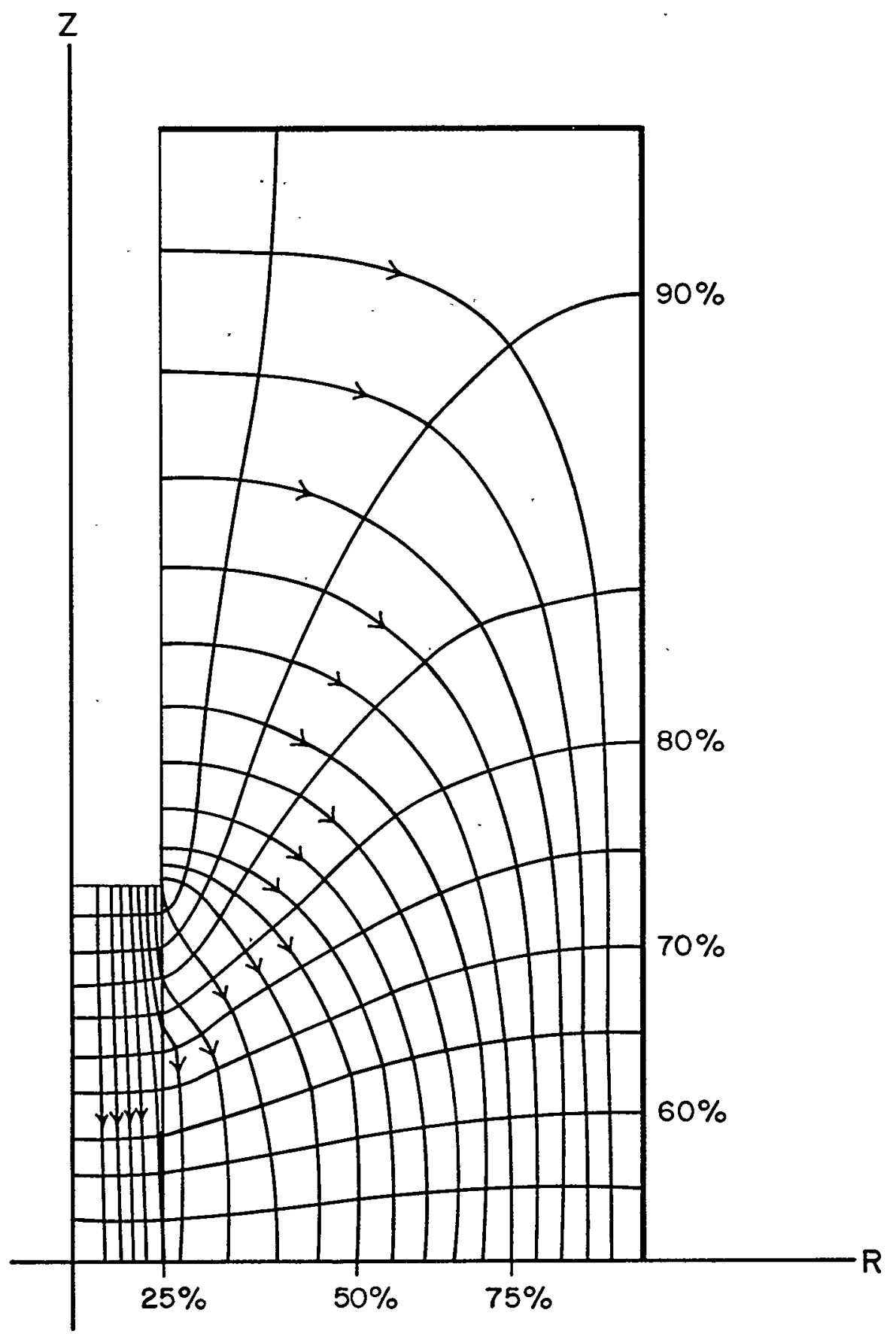

Figure 9. Flow net for plug more permeable than rock, $\mathrm{K}_{\mathrm{P}}=10 \mathrm{~K}_{\mathrm{R}}$. About $25 \%$ of the flow occurs through the plug. Equipotential lines show percent head with respect to center hole. Stream lines show percent flow occurring between the stream line and the Z-axis. Relative flow magnitude $=1.50$, i.e. flow is increased by $50 \%$, as compared to the rock bridge case $\left(\mathrm{K}_{\mathrm{P}}=\right.$ $\mathrm{K}_{\mathrm{R}}$, Figure 8 ).

$\mathrm{K}_{\mathrm{P}}=$ plug permeability; $\mathrm{K}_{\mathrm{R}}=$ rock permeability. 


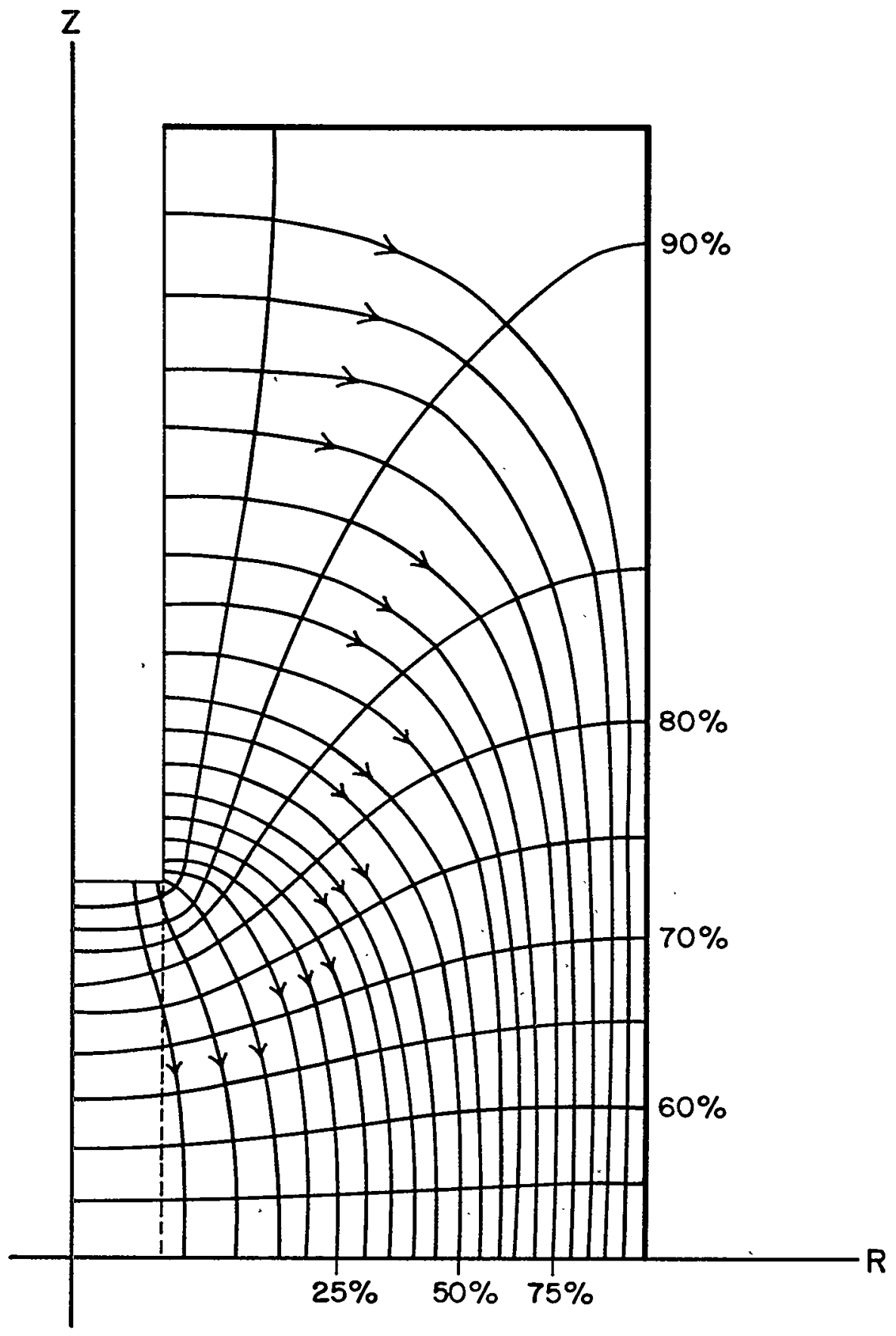

Figure 10. Flow net for plug less permeable than rock, $K_{P}=0.1 K_{R}$. Less than $5 \%$ of the flow occurs through the plug. Equipotential lines show percent head with respect to the center hole. Stream lines show percent flow occurring between the stream line and the Z-axis. Relative flow magnitude $=0.94$.

$\mathrm{K}_{\mathrm{P}}=$ plug permeability; $\mathrm{K}_{\mathrm{R}}=$ rock permeability. 
is not greatly affected, as compared to the undisturbed rock, increasing only one and one-half times. Since a sealed borehole (shaft, drift) and its surrounding rock are only a small part of the total rock mass, the total relative effect is even less pronounced. In addition, these calculations are for a seal which seals only the center one third of a rock cylinder. The simplest way to decrease flow through the system would be to increase the length of the seal. This analysis clearly confirms practical empirical design of underground plug and dam design, which emphasizes the need for adequate length, and adequate treatment of the rock surrounding the plug, usually the preferential flowpath, much more so than the plug body itself.

\subsection{Conclusions}

The main conclusion drawn from the experiments is that existing commercially available materials can form high quality seals when placed under laboratory conditions. Variation of triaxial stress state about a borehole does not significantly affect seal performance if the rock is stiffer than the seal material. Temperature and moisture variations, specifically heating in air and allowing the cement to dry, degrade cement seal performance significantly over even the relatively short term of six weeks. Performance partially recovers upon resaturation.

Cement and clay materials have a very small grain size with respect to the borehole dimensions used in these experiments, so size effects would not be expected in this regard. A larger plug involves more volume, and there is a greater chance of having a defect in the plug. Scale effects upon emplacement techniques could be significant, as methods are likely to be different if only because of the easier access in larger excavations. This should result in easier emplacement control. A large pour of concrete to form a shaft seal results in a greater thermal effect from the heat of hydration than placing a cement borehole seal.

In both shafts and tunnels, scale effects include both the greater volume of material involved and the greater interface area between the seal and the rock. Scale effects due to volume would be related to the cube of the opening size, whereas interface effects would vary as the square of the opening size. Thus, defects involving. the interface could be expected to have lesser impact on the system performance than defects involving the seal body, or, in particular, the rock volume, thus once more confirming practical experience that appropriate rock sealing must be an integral component of any repository sealing system.

\subsection{Remaining Uncertainties in Penetration Sealing}

It is shown that, under short-term laboratory conditions, readily available (i.e. commercial) cements can form borehole plugs that preclude the boreholes from being pathways that might compromise the geologic repository's ability to meet the performance objectives (10 CFR 60.134(a), U.S. Nuclear Regulatory Commission, 1983, 1985).

Significant remaining questions about plug performance include:

- influence of field emplacement techniques on plug performance, 
- influence of bypass flow through the rock surrounding a plug (and through the plug-rock interface) on overall plug performance,

- methods for treatment of bypass flow zone through rock, and their performance,

- in-situ testing and demonstration of performance of an emplaced plug,

- long-term plug performance, particularly with regard to such in-situ environmental factors as moisture content (e.g. drying out as a result of the thermal pulse), deformations and resulting stresses imposed on plugs, chemical stability and consequences of alteration,

- radionuclide sorption capabilities of the sealant material, and

- scale effects. 
CHAPTER ONE

INTRODUCTION

1.1 Objective

The fundamental objective of this "Rock Mass Sealing" research project is to assess experimentally the performance of existing products and methods for sealing rock masses, in the current phase of the project to conduct an experimental evaluation of borehole plug performance. This work is aimed at determining the feasibility of sealing boreholes intersecting a repository rock mass to a level where it can reasonably be assured that the plugged boreholes will not become preferential radionuclide migration paths. This project studies experimentally the likelihood of preventing such migrations by sufficiently reducing the hydraulic conductivity of the plugged borehole (including the plug-rock interface and the rock directly around the plug). The work performed provides direct input to an assessment as to whether or not 10. CFR 60.134 (U.S. Nuclear Regulatory Commission, 1983, and, as amended, 1985) is likely to be satisfied by any particular proposed sealing methods. Some aspects of this study have broader implications, e.g. directly for $10 \mathrm{CFR} .133$ (d), and indirectly for $10 \mathrm{CFR} .133$ (a)(1), (2),(f) (U.S. Nuclear Regulatory Commission, 1983, and as amended, 1985), (h).

The study is being conducted primarily in order to establish a factual data basis on borehole sealing performance. Although some types of borehole sealing have been performed for many years, relatively little testing and sealing verification has been done.

Concern about boreholes and their potential influence on the isolation performance of the rock mass surrounding repositories has been expressed in a number of basic reviews on underground HLW (High level radioactive waste) disposal (e.g. Atomic Energy of Canada Limited, 1978, p. 72;

Bredehoeft et al., 1978, p. 8; Committee on Radioactive Waste Management, 1978, pp. 5,10; Heineman et al., 1978, p. 4; U.S. Department of Energy, 1979, p. 3.1.328; Arnett et al., 1980, p. 139; Barbreau et al., 1980, p. 528; Burkholder, 1980, p. 15; Irish, 1980, p. 42; OECD, 1980, Foreword; Pedersen and Lindstrom-Jensen, 1980, p. 4; Kocher et a1., 1983, p. 54; National Research Council, 1983, p. 8-9, 21, 63; U.S. Department of Energy, 1983, p. 25).

It deserves pointing out that the need for borehole plugging, and particularly for very high performance (e.g. very low hydraulic conductivity), is not universally accepted, nor obvious, and certainly might be a somewhat site-dependent requirement, as shown by consequence assessments (e.g. Pedersen and Lindstrom-Jensen, 1980, p. 195;

Klingsberg and Duguid, 1980, p. 43; Intera Environmental Consultants, Inc., 1981). These authors do recognize that borehole seals will provide "... and important redundant barrier ..." or "... will satisfy the concept of multiple barriers ...". Hunter (1980) summarizes results 
from consequence assessments for the Waste Isolation Pilot Plant (WIPP). Based on four failure scenarios for defense transuranic (TRU) wastes, Hunter concludes that even highly permeable borehole "seals" would result in only negligible exposure. A panel of experts convened by the Commission of the European Communities and the OECD Nuclear Energy Agency simultaneously considers backfilling and sealing (OECD, 1984, Section III.4) and, after stressing the host rock specificity of backfill and sealing functions, states that "they would be designed so as not to present any preferential flow paths ... there is confidence that they (i.e. the functional requirements) can be met by a number of different materials." That the controversy about sealing requirements is far from resolved is particularly well illustrated by the recently published disagreements among the ONWI Exploratory Shaft Peer Review Group (Kalia, 1986, p. 14).

General guidelines for the separation of radioactive waste from the physical environment, and in particular for the acceptable radionuclide releases following repository closure, have been finalized by EPA (U.S. Environmental Protection Agency, 1986; 40 CFR 191). Detailed implementation of the requirements is governed by 10 CFR 60 (U.S. Nuclear Regulatory Commission, 1983, 1985). The research performed as part of this contract addresses specifically some of the remaining uncertainties associated with the sealing requirements in $10 \mathrm{CFR} 60$, including $\$ 60.51,(\mathrm{a}) ; \$ 60.102, \mathrm{~b}(2), \mathrm{e}(1),(2) ; \$ 60.113 ; \$ 60.133,(\mathrm{~h}), \S 60.142,(\mathrm{c})$, but particularly $\$ 60.134$, Design of seals for shafts and boreholes.

\subsection{Scope and Limitations}

This report presents results from a series of flow test experiments performed on cement and clay (bentonite) plugs installed in boreholes drilled in granite, basalt, and welded tuff. Also presented are numerical generic parametric analyses of the influence of the ratio between the permeability of a plug and the permeability of the surrounding rock on water flow through the plug-rock system. Such analyses allow making an evaluation of desirable plug permeability given a certain in-situ rock mass permeability at the location where the plug is to be installed.

The experimental (and predominant) phase of the work has been performed on rock cylinders with nominal $15 \mathrm{~cm}$ diameter and $30 \mathrm{~cm}$ length. Plugs of nominal length to diameter ratios mostly of one have been installed in $2.5 \mathrm{~cm}$ diameter coaxial holes. The rock cylinders are stressed to up to $21 \mathrm{MPa}$ prior to plug installation and testing. A main variable studied is the influence of changing this stressfield on plug performance.

Plugging materials that have been investigated are readily available and widely used commercial products. Rock types are believed to be representative generic rocks for potential repository host formations, although salt is not included as part of this effort. All flow testing has been performed with distilled or de-aired water.

Most results presented are obtained from steady-state flow conditions, although results from a few transient (pulse) tests are included. All 
flow experiments have been performed at room temperature, on plugs that have been maintained wet (with the intention to maintain saturation). Two series of flow tests are presented on cement plugs that have been allowed to dry out, one at room temperature, one at $54^{\circ} \mathrm{C}$. Nearly all experiments have been performed on plugs installed in holes drilled by diamond coring, but one series of flow tests on a percussion drilled hole is included.

\subsection{Organization}

This first chapter is introduced with a brief statement of the objectives of the work reported on, particularly within the regulatory context. In the second chapter an overview is presented of current borehole plugging practice, as well as of research performed on borehole sealing specifically within the context of high-level radioactive waste disposal in deep geological formations. Materials tested as well as experimental equipment and procedures are described in Chapter Three. Chapter Four summarizes experimental results, and supplementary details are given in Appendix A. An analysis of the experimental results is presented in Chapter Five. This chapter also includes a more generalized analysis of the influence of the hydraulic conductivity of a borehole (shaft, drift) plug relative to the hydraulic conductivity of the rock mass within which the piug is emplaced on the overall flow behavior, and hence on desirable, necessary or excessive plug performance requirements. The last chapter summarizes the work and the conclusions, and identifies topics in need of further investigations.

\subsection{Rock Mass Sealing Contract No. NRC-04-78-271 - Reports Issued}

This Technical Report is the latest in a series of reports issued for the subject contract. A complete list of reports issued (to be issued for Akgun and Daemen, 1986, and for Schaffer and Daemen, 1986) is given below, to facilitate a general overview of work performed to date and of the overall context of ongoing work.

The first four reports, as well as the seventh, are literature surveys.

The fifth report is primarily a description of planning, experimental design and some preliminary tests.

The topical report by Jeffrey (1980) gives a comprehensive theoretical (analytical) discussion of transverse plug-rock interaction, based on elastic and viscoelastic calculations. This is complemented by the axial interaction discussed in Stormont and Daemen (1983), a report which is primarily experimentally oriented, but includes extensive analytical discussions.

The topical reports by Mathis and Daemen (1982) and by Fuenkajorn and Daemen (1986) present a detailed experimental assessment of drilling damage in granites and in basalts.

Experimental flow studies under polyaxial stress conditions are described in Cobb and Daemen (1982), and on unloaded samples in Akgun and Daemen (1986). Additional data on plug performance under stressed and unstressed conditions are inclyged in virtually all other reports. 
All annual reports subsequent to (5) include a combination of experiments, results, conclusions, and plans for future work.

Quarterly progress reports are not listed as all information contained therein also is included in the annual reports.

1. South, D.L., R.G. Jeffrey, L.W. Klejbuk, and J.J.K. Daemen, 1979, "Rock Mass Sealing - Annual Report, October 1, 1978 - September 30, 1979," prepared for the U.S. Nuclear Regulatory Commission, SAFER Division, for Contract NRC-04-78-271, by the Department of Mining and Geological Engineering, University of Arizona, Tucson.

2. Daemen, J.J.K., 1979, "Rock Mass Sealing (Research in Europe)," 48 pp., Foreign Travel Trip Report to the U.S. Nuclear Regulatory Commission, SAFER Division, for Contract NRC-04-78-271, by the Department of Mining and Geological Engineering, University of Arizona, Tucson.

3. South, D.L., 1979, "Well Cementing," $75+$ vii pp., Topical Report to the U.S.' Nuclear Regulatory Commission, SAFER Division, for Contract NRC-04-78-271, by the Department of Mining and Geological Engineering, University of Arizona, Tucson.

4. Sultan, H.A., 1979, "Chemical Grouting for Rock Mass Sealing - a Literature Review," 45 + iv pp., Topical Report to the U.S. Nuclear Regulatory Commission, SAFER Division, for Contract NRC04-78-271, by the Department of Mining and Geological Engineering, University of Arizona, Tucson.

5. South, D.L., R.G. Jeffrey, S.L. Cobb, S.P. Mathis, and J.J.K. Daemen, 1979, "Rock Mass Sealing - Annual Report, October 1, 1978 - September 30, 1980," prepared for the U.S. Nuclear Regulatory Commission, SAFER Division, for Contract NRC-04-78271, by the Department of Mining and Geological Engineering, University of Arizona, Tucson.

6. Jeffrey, R.G., 1980, "Shaft or Borehole Plug-Rock Mechanical Interaction," $145+x i$ pp., Topical Report to the U.S. Nuclear Regulatory Commission, SAFER Division, for Contract NRC-04-78271, by the Department of Mining and Geological Engineering, University of Arizona, Tucson.

7. South, D.L., 1980, "Borehole Sealing with Clay (Part A). Considerations in Clay Mineral Stability (Part B)," $50+i v$ pp.; $25+i i$ pp., Topical Report to the U.S. Nuclear Regulatory Commission, SAFER Division, for Contract NRC-04-78-271, by the Department of Mining and Geological Engineering, University of Arizona, Tucson.

8. Cobb, S.L., W.B. Greer, R.G. Jeffrey, S.P. Mathis, D.L. South, and J.J.K. Daemen, 1981, "Rock Mass Sealing - Annual Report, September 1, 1980 - May 31, 1981," prepared for the U.S. Nuclear Regulatory Commission, SAFER Division, for Contract NRC-04-78- 
271, by the Department of Mining and Geological Engineering, University of Arizona, Tucson.

9. South, D.L., W.B. Greer, N.I. Colburn, S.L. Cobb, B. Kousari, S.P. Mathis, R.G. Jeffrey, C.A. Wakely, and J.J.K. Daemen, 1982, "Rock Mass Sealing - Annual Report, June 1, 1981 - May 31, 1982," prepared for the U.S. Nuclear Regulatory Commission, SAFER Division, for Contract NRC-04-78-271, by the Department of Mining and Geological Engineering, University of Arizona, Tucson.

10. Mathis, S.P. and J.J.K. Daemen, 1982, "Borehole Wall Damage Induced by Drilling: An Assessment of Diamond and Percussion Drilling Effects," 171 + xii pp., Topical Report to the U.S. Nuclear Regulatory Commission, SAFER Division, for Contract NRC-04-78271, by the Department of Mining and Geological Engineering, University of Arizona, Tucson.

11. Cobb, S.I. and J.J.K. Daemen, 1982, "Polyaxial Testing of Borehole Plug Performance," $180+x i$ pp., Topical Report to the U.S. Nuclear Regulatory Commission, SAFER Division, for Contract NRC04-78-271, by the Department of Mining and Geological Engineering, University of Arizona, Tucson.

12. Daemen, J.J.K., D.L. South, W.B. Greer, J.C. Stormont, S.A. Dischler, G.S. Adisoma, N.I. Colburn, K. Fuenkajorn, D.E. Miles, B. Kousari, J. Bertucca, 1983, "Rock Mass Sealing - Annual Report, June 1, 1982 - May 31, 1983," NUREG/CR-3473, prepared for the U.S. Nuclear Regulatory Commission, Division of Health, Siting and Waste Management, for Contract NRC-04-78-271, by the Department of Mining and Geological Engineering, University of Arizona, Tucson.

13. Stormont, J.C. and J.J.K. Daemen, 1983, "Axial Strength of cement Borehole Plugs in Granite and Basalt," NUREG/CR-3594, Topical Report to the U.S. Nuclear Regulatory Commission, Division of Health, Siting and Waste Management, for Contract NRC-04-78-271, by the Department of Mining and Geological Engineering, University of Arizona, Tucson.

14. Daemen, J.J.K., W.G. Greer, G.S. Adisoma, K. Fuenkajorn, W.D. Sawyer, Jr., A. Yazdandoost, H. Akgun, and B. Kousari, 1985, "Rock Mass Sealing - Experimental Assessment of Borehole Plug Performance," NUREG/CR-4174, Annual Report, June 1983 - May 1984, prepared for the U.S. Nuclear Regulatory Commission, Division of Health, Siting and Waste Management, for Contract NRC-04-78-271, by the Department of Mining and Geological Engineering, University of Arizona, Tucson.

15. Fuenkajorn, K. and J.J.K. Daemen, 1986, "Experimental Assessment of Borehole Wall Drilling Damage in Basaltic Rocks," NUREG/CR-4641, Technical Report to the U.S. Nuclear Regulatory Commission, Division of Radiation Programs and Earth Sciences, Office of Nuclear Regulatory Research, Contract No. NRC-04-78-271, by the 
Department of Mining and Geological Engineering, University of Arizona, Tucson.

16. Daemen, J.J.K., W.B. Greer, K. Fuenkajorn, A. Yazdandoost, H. Akgun, A. Schaffer, A.F. Kimbrel1, T.S. Avery, J.R. Williams, B. Kousari, and R.0. Roko, 1986, "Rock Mass Sealing - Annual Report, June 1984 - May 1985," NUREG/CR-4642, prepared for the U.S. Nuclear Regulatory Commission, Division of Radiation Programs and Earth Sciences, Office of Nuclear Regulatory Research, by the Department of Mining and Geological Engineering, University of Arizona, Tucson.

17. Akgun, H. and J.J.K. Daemen, 1986, "Size Influence on the Sealing Performance of Cementitious Borehole Plugs," Technical Report to the U.S. Nuclear Regulatory Commission, Division of Radiation Programs and Earth Sciences, Office of Nuclear Regulatory Research, Contract No. NRC-04-78-271, by the Department of Mining and Geölogical Engineering, University of Arizona, Tucson. (Submitted to NRC)

18. Schaffer, A. and J.J.K. Daemen, 1986, "An Experimental Assessment of the Effectiveness of Rock Fracture Grouting," Technical Report to the U.S. Nuclear Regulatory Commission, Division of Radiation Programs and Earth Sciences, Contract NRC-04-78-271, by the Department of Mining and Geological Engineering, University of Arizona, Tucson. (In preparation) 
CHAPTER TWO

BOREHOLE SEALING

\section{$\underline{2.1}$ Introduction}

With the advent of disposal of high-level nuclear wastes in underground repositories, borehole plugs assume an important role in isolating waste from the earth's surface. The most likely way by which waste contamination may reach the accessible environment is by transport in ground water. Low permeability rock surrounding the waste repository is relied upon to slow the migration of waste-contaminated water and prevent its reaching the accessible environment until the radionuclides have decayed to safe levels. An open borehole is a direct conduit from depth to the surface, as well as between various intermediate horizons, and possibly deeper ones. Boreholes in the vicinity of a waste repository must be reliably plugged. Indeed, one of the reasons for abandonment of a proposed waste repository near Lyons, Kansas, was concern about the ability to plug abandoned oil and gas wells in the area (Eilers, 1973, 1974).

Borehole plugging is particularly important if disposal strategies were to be adopted that do not emphasize the waste form and container as a barrier to release of radioactivity from the repository. Such strategies may arise due to the risks and costs involved in changing existing waste forms and containers. "The burden of protecting the public from long-term migration of nuclear wastes may then be placed primarily on the engineered features of the repository" (Bartlett and Koplik, 1979, pp. 4-4/5).

Even given an optimum waste form and container, one of the main reasons for placing the waste in an underground repository is to use the surrounding rock to isolate the waste subsequent to container release. An open borehole compromises the integrity of the rock.

Borehole plugging is also critical in the disposal of chemical wastes by deep-well injection. The most common operation in this regard is the disposal of oil-field brines back into the formations from which they were produced. Toxic chemical wastes currently are also disposed of in this manner. "Opponents of deep-well injection argue that the wastes, which are injected under extreme pressure, can flow laterally through geologic strata into poorly constructed or unplugged deep wells and then rise to contaminate subsurface water supplies" (EPA, 1980, p. 16). Piper (1969, p. 6) notes that, "Injection does not constitute permanent disposal. Rather, it detains in storage and commits to such storage for all time in the case of the most intractable wastes - underground space of which little is attainable in some areas, and which definitely is exhaustible in most areas." 
Few data exist regarding the effectiveness of borehole plugging (Christensen, 1980, p. 7). One performance assessment type report (Bechtel National, Inc., 1979, p. G-11) states that, "To evaluate the integrity of borehole seals already in common use a study was made of failures that have been experienced by the oil and gas industry in the United States. It was found (Schneider and Platt, 1974) that the probability of failure of seals on a typical oil well was $10^{-4}$ per year." Reference to Schneider and Platt (1974, p. 3.27) yields the basis of the study:

"Based on data in the Statistical Abstracts (U.S. Bureau of the Census, 1971), there are over 500,000 producing oil wells in this country. There is probably at least an equal number of abandoned wells. All have seals between the well casing and the underground strata. ${ }^{1}$ The statistics on seal failure may be available, but no known research has been done on this point to date. However, Associated Press accounts in the past year have related at least two instances of shaft seals leaking. In one case oil was coming from a well in the front lawn of a residence in Southern California. The well had been capped several decades ago. The other case was a new well in Traverse City, Michigan. These are just two of significance. There are probably more that have not been reported. Thus, the probability of a seal failure by conventional techniques is more frequent then $10^{-5}$ per well-yr."

Schneider and Platt state that an evaluation method is being discussed and they include a caveat (p. 3.1.1) against using their results to draw quantitative conclusions. This is a very small data base on which to base statistical conclusions regarding the probability of seal failure. One of the main problems is that, as Smith (1976) states, "There is no simple method of testing down-hole plugs. In most cases, plugs for abandonment or for sealing off bottom water are never tested." Similarly, Brereton and Brightman (1986, pp. 2,3) stress the difficulty of refining the experimenal in-situ assessment of the cement bond integrity beyond "good" or "poor" using conventional hydrocarbon

- industry techniques.

It is widely recognized in the oil and gas industry that it is difficult to always achieve high quality sealing: "A common problem encountered in production operations is the movement of water in channels within the cement annulus behind casing of oil and gas wells" (Arnold and Paap, 1979); "Annular and interzone gas flow ... continues to be a major problem ... these occurrences have been experienced by the industry worldwide ..." (Levine et al., 1980).

${ }^{1}$ Compare this with the statement (EPA, 1978, p. 18) on water seepage problems at the proposed nuclear waste repository near Lyons, Kansas: "Seepage was along an abandoned drill hole that, like most, had not been cased and plugged." 
Conclusions regarding borehole plugging must have a firmer data base than currently exists.

\subsection{Borehole Sealing and Nuclear Waste Isolation}

\subsubsection{Nuclear Waste Disposal}

The Nuclear Waste Policy Act (NWPA) of 1982, Public Law 97-425, requires the U.S. Department of Energy to recommend three sites for the first high-level nuclear waste repository for commercially-generated (i.e., non-defense) nuclear waste by 1985. Rock types considered for commercial nuclear waste repositories include welded and non-welded tuffs at the Nevada Test Site, northwest of Las Vegas, Nevada; basalts of the Columbia Plateau at the Hanford Reservation in southeastern Washington; and bedded and dome salt deposits in Utah, Texas, and Mississippi. The three sites presently recommended for site characterization, i.e. the leading candidates for the first repository for civilian nuclear waste, are Yucca Mountain, Nevada; Deaf Smith County, Texas; and Hanford, Washington (U.S. Department of Energy, 1986). The bill also requires the Department of Energy to recommend five sites by 1989 for a second repository. Granite formations around the Great Lakes, along the Atlantic Seaboard, and in New England are being considered. In addition to these potential commercial waste repository sites, bedded salt near Carlsbad, New Mexico, is being investigated as a repository for defense related nuclear waste. This is the Waste Isolation Pilot Plant (WIPP) (e.g. Christensen and Hunter, 1979).

\subsubsection{Borehole Sealing Considerations}

At the 1982 NWTS Program Information meeting, borehole sealing was a major topic. In their article regarding NNWSI, Scully and Rothman (1982) state that, "A well-engineered system of man-made barriers should be able to assist the natural barriers in retarding radionuclide migration. The areas where proper engineering can be most effective in protecting the biosphere in the long term include ... design of the seals to close the repository." Both shaft seals and borehole seals are important. The selection of an unsaturated waste emplacement horizon, i.e. a repository level above the water table (e.g. Johnstone et al., 1984), has significant implications for sealing objectives, functions, operational environment, and performance requirements. Containment and isolation remain primary functional requirements (Fernandez and Freshley, 1984). Based on preliminary hydrological calculations, Fernandez and Freshley (1984) conclude that water inflow through shafts and boreholes is likely to be sufficiently small to assure flow directly through the repository horizon, precluding any contact with emplaced waste or released radionuclides. They address a number of other water inflow paths (e.g. discrete fracture zones and faults) that might be encountered, and propose sealing technologies for dealing with such eventualities. Fernandez (1985) summarizes the essential NRC rule requirements, presents the primary sealing functions and technologies, and outlines in considerable detail a plan to provide reasonable assurance that acceptable sealing methods will be developed for an eventual repository at Yucca Mountain. 
Borehole sealing is also a concern in the BWIP. According to Anderson et a1. (1982), "The isolation of nuclear wastes in deep, mined repositories will. require the sealing of all penetrations such as shafts, tunnels, repository rooms, or boreholes, into and nearby the repository."

Perhaps the most sophisticated borehole sealing research in connection with nuclear waste isolation performed to date has been for the WIPP program. Both laboratory testing and field testing have been performed by Sandia National Laboratories, the Materials Research Laboratory at the Pennsylvania State University, D'Appolonia Consulting Engineers, the Waterways Experiment Station of the Army Corps of Engineers, Oak Ridge National Laboratory, and Terra Tek, Inc. Some of this work is reviewed in Section 2.3.3.

D'Appolonia Consulting Engineers, Inc. (now IT Corporation) assists in the design- of seals for a civilian waste repository in salt, and state that, "the isolation of radioactive wastes in geologic repositories requires that man-made penetrations such as shafts, tunnels, or boreholes are adequately sealed" (Kelsall et al., 1982).

Borehole sealing is also a concern of nuclear waste isolation efforts in other countries. In a paper presented at the First European Community Conference, Barbreau, Heremans, and Jensen (1980) state that, "Efficient techniques must be developed for filling and plugging shafts, tunnels, and drill holes, to assure their imperviousness over a very long period of time, and create additional geochemical barriers." The International Atomic Energy Agency has stated, "Special attention has to be paid to the sealing of boreholes and shafts after deactivation of the repository" (IAEA, 1980). Further, "To get adequate subsurface hydrologic information comprehensive drilling programmes are often needed. Then, serious consideration must be paid to the shortcircuiting effect of any borehole drilled into the repository host rocks. This is particularly important in stratified confined aquifers and in low permeability crystalline formations in which a borehole may constitute a gross perturbation to the natural undisturbed hydrogeological system."

\subsubsection{Research Objectives}

The objective of the research reported herein was to assess the performance of borehole seals under laboratory conditions. One of the prime goals was to obtain experimental data regarding the effectiveness of sealing.

Laboratory conditions represent a highly idealized approximation of field conditions. This permits the determination of the best possible sealing performance that may be expected because emplacement of a plug may be done under carefully controlled conditions. In the field plugs are emplaced in deep holes, in highly inaccessible locations, frequently in a wellbore contaminated with mud. Many variables are introduced in such a process, few of which can be controlled; some may not even be recognized. 
Laboratory testing permits a systematic, controlled variation of the parameters that influence plug behavior. In this work the parameters considered are rock type (granite, basalt, and tuff), plug type (cement and clay), and mechanical plug-rock interaction under varying stress fields.

In these experiments seal performance under varying stress fields was investigated; temperature was held constant and saturated conditions obtained. A significant part of the research effort was the development of laboratory equipment for performing the experiments. This equipment, with slight modifications, can be used to investigate both temperature and moisture variations.

\subsection{Borehole Sealing: Current Practice and Recent Studies}

\subsubsection{Introduction}

Well cementing has been practiced by the oil and gas industry for decades; grouting to seal rock and soil masses began at least in the early 1800's, and there is some evidence that the Romans were aware of the potential uses of grouting (Bowen, 1975, p. 2; 1981, p. 2). Piezometers are routinely sealed (for example, in dam foundations or in slopes) with bentonite tablets (e.g. Vaughan, 1969), although not always without some difficulty and failures.

Many products and methods are in use. All have some features or characteristics which under some external circumstances will prove to be undesirable. For a significant number the disadvantages suffice to eliminate them from further consideration. The remaining possibilities can be considered as having complementary characteristics, and it is virtually certain that an optimum borehole plug will use more than one type of material.

The most likely materials to be used in borehole plugging are portland cement and clay. These materials are the ones most commonly used by well drillers and plugging technology is well-developed. Experimental facts on past performance, however, are mostly qualitative in nature. For deep wells, portland cement is the dominant plugging material. In this chapter methods of well cementing will be discussed, followed by a review of recent studies concerning borehole sealing for nuclear waste isolation. For more information on other systems see Daemen et al. (1979, Ch. 2) for a review of existing technology and potential plugging systems; South (1979) for an in-depth review of wel1-cementing; Sultan (1979) for a review of chemical grouting techniques; and Schaffer and Daemen (1986, Ch. 3) for a review of cement grouting of rock fractures.

\subsubsection{Borehole Sealing Methods}

Well cementing is performed routinely by the oil and gas industry, using portland cement, with various additives. Cementing serves both to restrict fluid movement between formations and to bond and support casing. Cement plugs are placed when a well is abandoned. Smith (1976) describes well cementing techniques in detail. Many textbooks on 
drilling include chapters on cementing (e.g. Davenport, 1984, Chapters 9, 21, 23; Smith, 1986; Austin, 1983, Sections 3.10-3.16, 7.9, 7.10, 7.17; Allen and Roberts, 1982, Vol. 1, Ch. 4; Vol. 2, Ch. 3).

Clay is also used to seal wells, particularly for shallow wells (e.g. water wells) and in isolating well-points (piezometers).

\subsubsection{We11 Cementing Methods}

2.3.2.1.1 Oil and Gas Well Cementing. Three basic types of well cementing are performed: primary cementing, squeeze cementing, and open-hole cementing (plugging).

In primary cementing a cement slurry is pumped down inside the casing and rises in the annulus between the casing and the hole. The casing is thus cemented into position and formations sealed off.

Squeeze cementing is the most common type of remedial cementing. Hydraulic pressure is applied to force (squeeze) cement slurry into a formation void or against a porous zone to obtain a better seal between casing and formation.

Open-hole cementing is used to isolate zones in uncased sections of a hole and to plug abandoned wells. Plugging of abandoned wells is one of the primary sealing objectives in nuclear waste isolation. In the oil and gas industry problems associated with plugging may arise because a relatively small volume of cement is placed in a large volume of wellbore fluid. Mud contamination of the cement is a common cause of well cementing failures.

In placing an open hole cement plug, one must consider the type of formation in which the plug is to be placed. Plug failures can be prevented by taking the following precautions (Anderson, 1955):

(1) "Selecting, with the help of a caliper $10 \mathrm{~g}$, a gauge section of the hole.

(2) Carefully calculating cement, water, and displacement volumes, and always planning to use more than enough cement.

(3) Using a densified cement that will tolerate considerable mud contamination.

(4) Preceding the cement with sufficient flush.

(5) Rotating the tubing using tail pipe with centralizers and scratchers while placing the cement.

(6) Using drillpipe wiper plugs and plug catchers.

(7) Placing the plug with care and moving the pipe slowly out of the cement to minimize mud contamination." 
For maximum bonding, a clean, hard formation should be selected, particularly for zone isolation or abandonment. Cement plugs may be placed by the balance method, the dump bailer method, or the two-plug method. The description of the methods given below closely follows Smith (1976, pp. 99-100). The balance method, Figure 2.1, involves pumping a desired quantity of cement slurry through drillpipe or tubing until the level of cement outside is equal to that inside the string. The pipe or tubing is then pulled slowly from the slurry, leaving the plug in place. The characteristics of the mud are very important in balancing the plug in the well. Free circulation is especially vital while the cement is being pumped down the string.

The dump bailer method, Figure 2.2, is usually employed at shallow depths, although retarded cement has been bailed to depths exceeding 12,000 feet. A limit plug, cement basket, permanent bridge plug, or gravel pack (the first three being mechanical devices) is placed below the zone to be plugged. A measured quantity of cement is lowered in a dump bailer, on a wire line. Touching the mechanical plug or gravel pack opens the bailer, which is slowly raised to release the cement. Deep plugs are difficult to set by this method; mud may contaminate the cement unless the hole is circulated before dumping (this is also true of the balance method), and the bailer limits the quantity of slurry that can be placed per run.

The two-plug method, Figure 2.3, uses top and bottom tubing plugs to isolate the cement slurry from the well fluids and displacement fluids. A bridge plug is usually placed at the cement plugging depth. A special baffle tool is run on the bottom of the string and placed at the depth desired for the bottom of the cement plug. This tool permits the bottom tubing plug to pass through and out of the tubing or drillpipe. Cement is then pumped out of the string at the plugging depth and begins to fill the annulus. The top tubing plug, following the cement, is caught in the plug-catcher, which is part of the baffle tool, causing a sharp rise in the surface pressure, indicating that the plug has landed. The latching device holds the top tubing plug to help prevent cement from backing up into the string, but permits reverse circulation. This design allows the string to be pulled up after cement placement to cut off the cement plug at the desired depth by establishing reverse circulation through the plug catcher, thus allowing excess cement to be reversed up and out of the tubing. The string is then pulled, leaving a cement plug.

Advantages of the two-plug method are that it minimizes the likelihood of over-displacing the cement, it forms a tight, hard cement structure, and it permits establishing the top of the plug. The two-plug method is preferred to the balance method.

No simple method exists for testing down-hole plugs. Most plugs for abandonment or for sealing off bottom water are never tested, although tagging of some plugs is required (e.g. Smith, 1986, p. 453), and at least confirms that a plug is emplaced. Plugs set to control lost circulation or for whipstocking are tested by determining the hardness of the plug. The most common approach is to run drillpipe, either open 


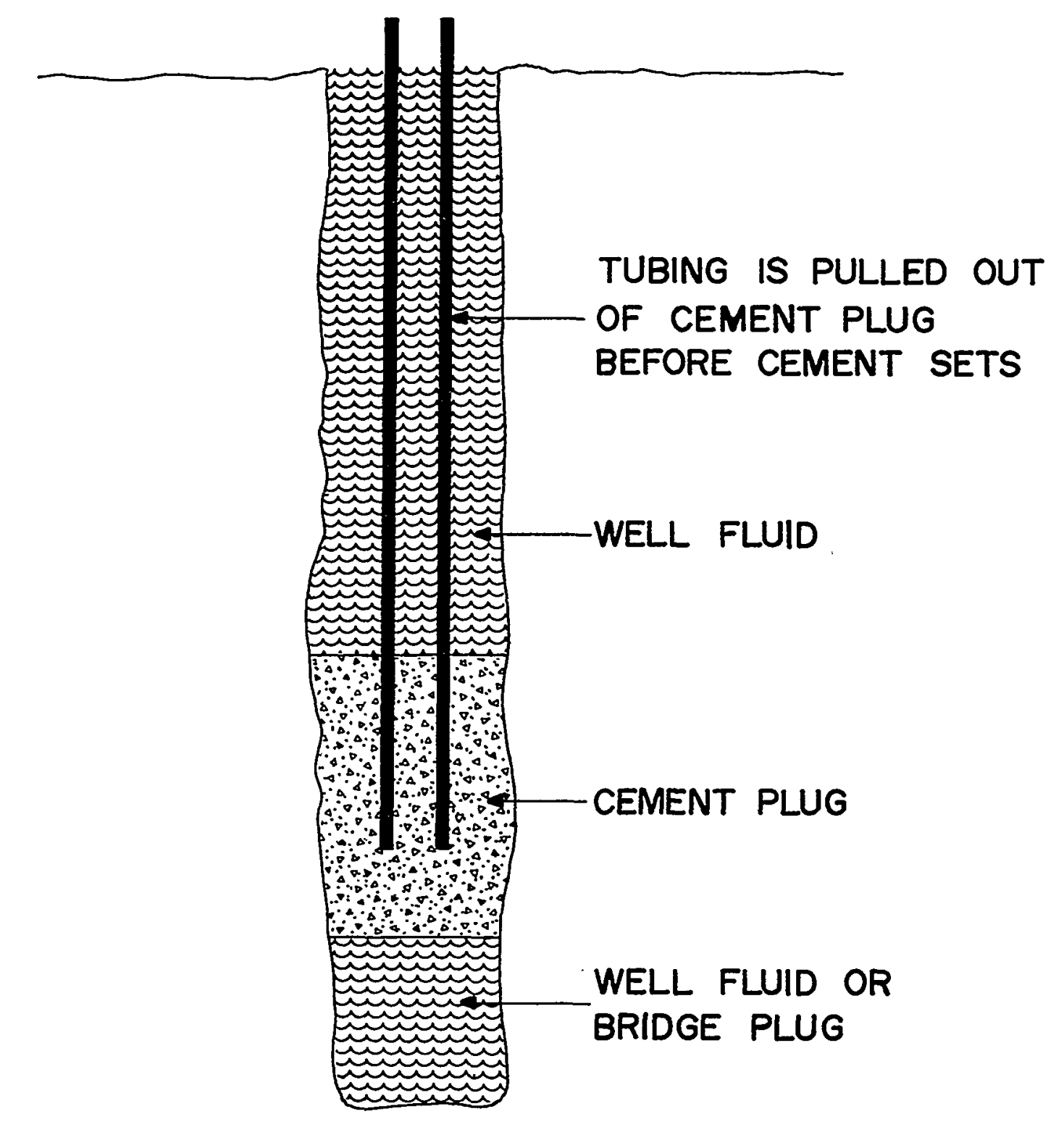

Figure 2.1 Open-hole plugging: the balance method. Cement slurry is pumped down inside tubing until levels inside and outside are equal. Tubing is pulled.

Reproduced with permission from Smith, D.K., 1976, Cementing, Figure 10.2, p. 99, Copyright 1976, Society of Petroleum Engineers of AIME, New York-Dallas. 


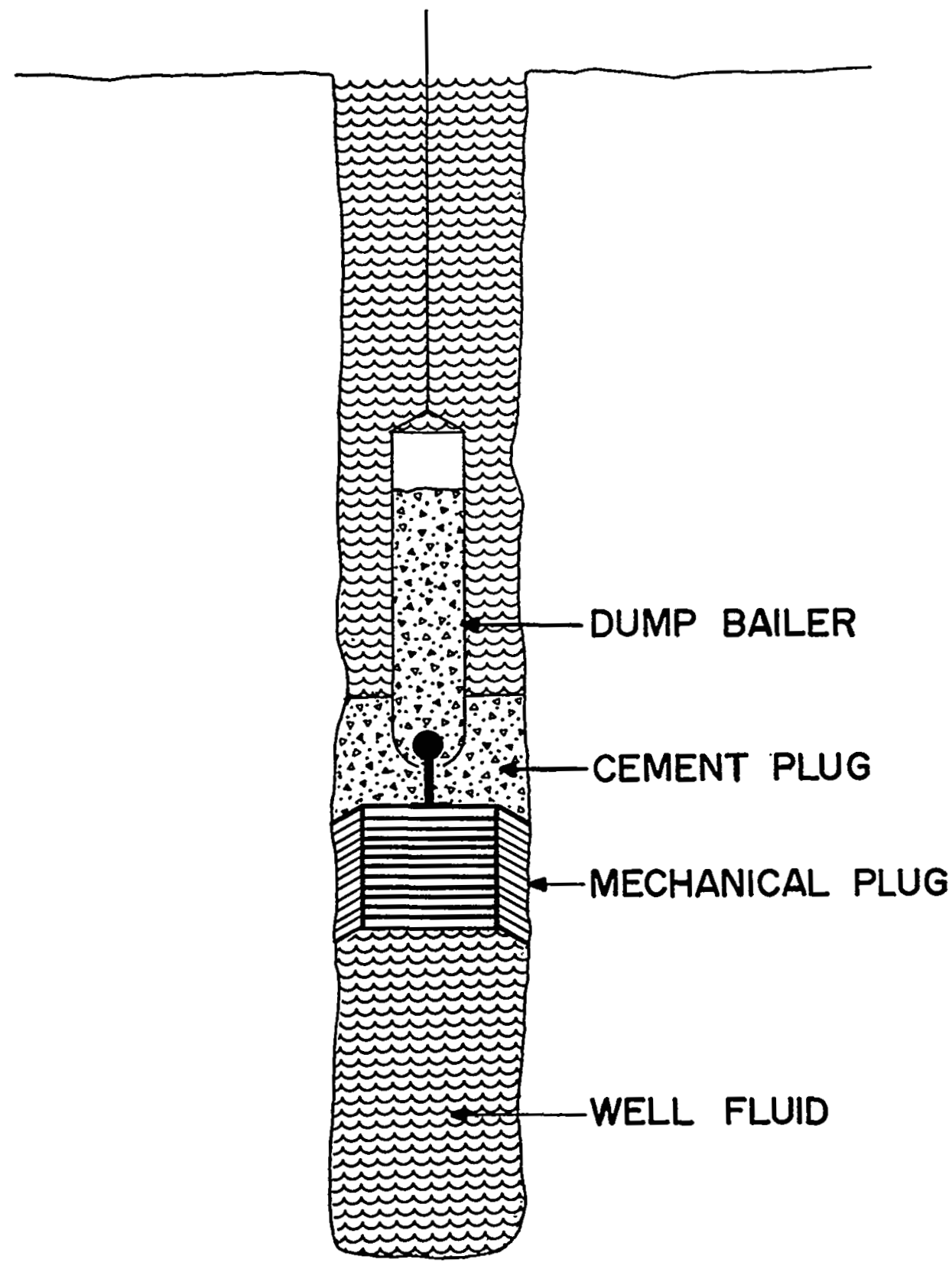

Figure 2.2 Open-hole plugging: the dump bailer. Cement slurry is lowered in bailer onto a bridge device, e.g. mechanical packer, where slurry is released when bailer stop makes contact.

Reproduced with permission from Smith, D.K., 1976, Cementing, Figure 10.3, p. 100, Copyright 1976, Society of Petroleum Engineers of AIME, New York-Dallas. 

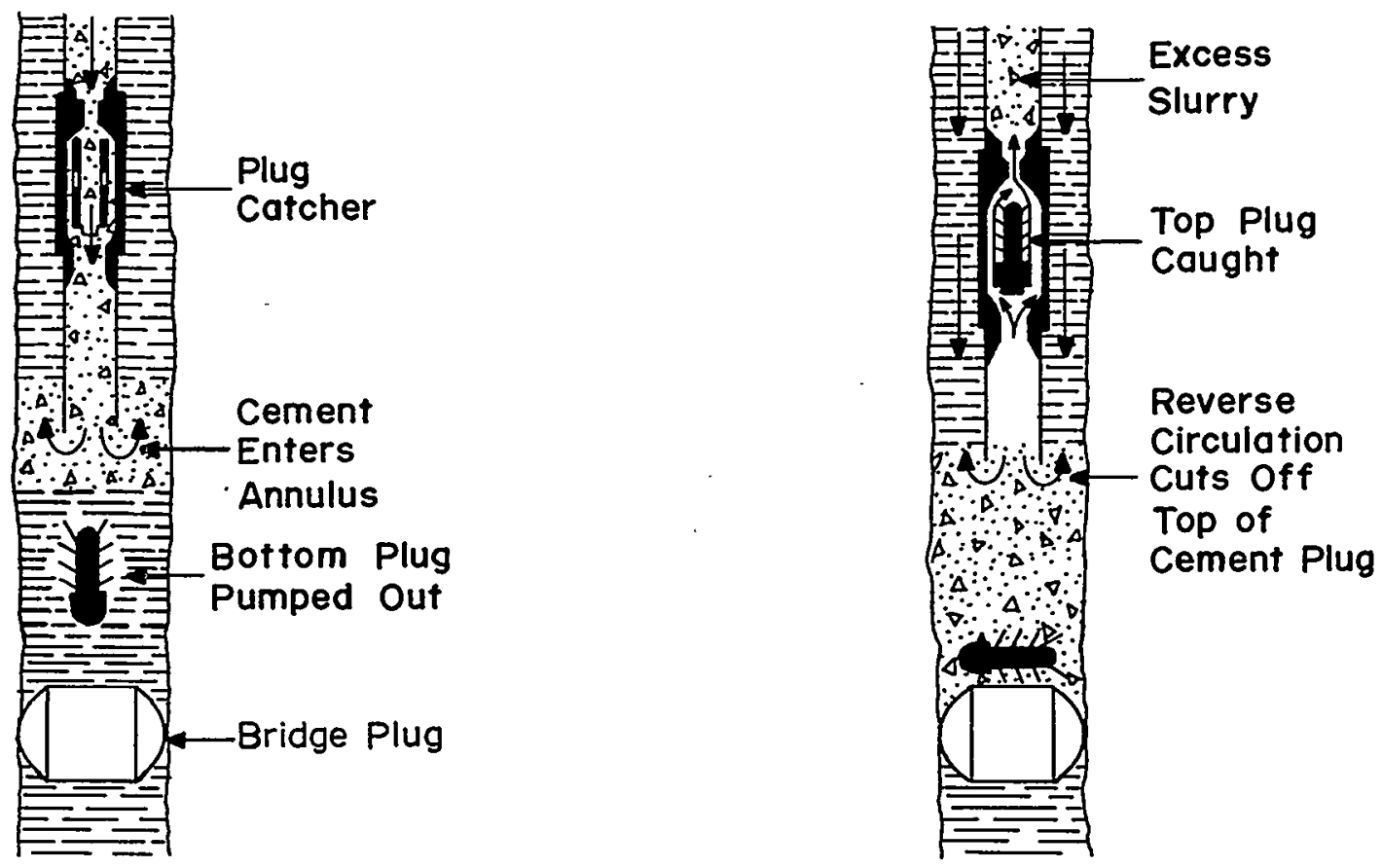

Figure 2.3 Open-hole plugging: the two plug method. Reverse circulation allows top plug level installation and control at desired depth.

Reproduced with permission from Smith, D.K., 1976, Cementing, Figure 10.4, p. 100, Copyright 1976, Society of Petroleum Engineers of AIME, New York-Dallas. 
ended or with a bit, back into the hole to locate the plug by applying weight. The method is commonly used after the plug has been allowed to set some 12 to 14 hours (Pugh, 1967). Although it is not always satisfactory, at least it gives some indication of whether some degree of plugging has been achieved in the desired location. A plug might be hard on top, but soft farther down, so that in time fluids can migrate past it.

2.3.2.1.2 Plugging of Oil Wells and Degasification Holes in Penetrating Appalachian Coal Mines. Safety plugging of wells penetrating Appalachian coal seams has been described by Rennick et al. (1972). Such wells pose a methane hazard. An oil well penetrating the Pittsburgh bituminous coalbed in northern West Virginia was plugged and safely mined through 3 months later. A sensitive chemical tracer, introduced into the oil reservoir before the test, was not detected in the mine air following the plugging nor during mining of the pillar about the well and penetration of the well. Effectiveness of the plugging in preventing reservoir gas from entering the mine through the well hole was verified by continuous monitoring of the mine air for indications of sulfur hexafluoride, an inert gas detectable in amounts as minute as 0.5 parts per billion. Expandable cement and fly ash-gel-water slurry were utilized to seal the well above and below the coal seam.

This injection of sulfur hexafluoride, plugging, and monitoring represents one of the rare instances in which a plugged, abandoned well was actually monitored for performance. This type of work is necessary to evaluate plugging performance.

Horizontal degasification holes drilled in coal mines have proven difficult to seal satisfactorily, particularly because of the great difficulty encountered in completely filling such holes (which frequently are rather long, e.g. hundreds of meters), and in preventing segregation, bleed, and the formation of an open channel along the crown of the hole (e.g. Aul and Cervik, 1979). The grouting of eight approximately horizontal holes is described by Oyler (1984). Specifications of the selected sodium silicate gel grout are given, as well as laboratory tests on the grout. Grouting performance was assessed by visual inspection of the holes after they had been mined through, and by means of pressure tubing behind packers for one hole. Most holes appeared to be filled with grout at most of the inspected sections. Some gaps on the top of the plugs were observed, as well as considerable shrinkage and grout deterioration in dry locations. There was some evidence that grouting had reduced methane flow through holes and through fractures (cleats) in the coal, but the evidence was neither strong nor convincing (Oyler, p. 1984, p. 19).

2.3.2.1.3 Implications for Nuclear Waste Disposal. The foregoing has been concerned with the techniques of cementing wells as practiced by the oil and gas industry. These same techniques, with some extra caution, are used in plugging chemical waste disposal wells.

There is general agreement that well cementing and plugging in the oil and gas industry and for chemical waste disposal wells is usually 
successful. Successful cementing of an oil or gas well, however, simply means that excessive water is not produced along with the oil or gas that there are no production problems. Once a well is plugged and abandoned there is no monitoring; problems may not be detected. As noted in Section 2.1, channel flow in the cemented annulus between casing and wellbore is a continuing problem in the oil and gas industry.

Plugging of chemical waste disposal wells for abandonment must usually be approved by a state agency. There are many such wells along the Texas Gulf Coast, and the Texas Department of Water Resources (DWR) has regulatory responsibility for these wells. Conversations with their personnel indicate no problems in 17 years of operation - a short period when considering nuclear waste disposal. Plugging designs for chemical waste wells must be approved by the Texas DWR, and the actual operation is witnessed in the field by a DWR representative. Quality assurance is obtained by tagging the plug; the plug is allowed to harden and then the drill string is lowered to touch the plug and verify its location. Plugs are a minimum of 100 feet long. Thus, a plug which is hard on top, and properly located, may have problems deeper in the hole which would not be detected by the tagging. Long term monitoring is usually not performed.

To recapitulate:

(1) Successful well-cementing is defined as an absence of problems. That is, no problems are detected.

(2) Little has been found to date to indicate quantitatively the effectiveness of well plugging. For example, how much vertical fluid migration occurs in a skillfully plugged we11?

(3) Obtaining a good plug requires experience and a good knowledge of downhole conditions and geology.

(4) Quality assurance of plugs is limited to tagging the plug, as there is no longer a hole in which to lower logging tools. In this regard the work by Rennick et al. (1972) in safety plugging of oil wells penetrating Appalachian coal mines, described in the previous section, is of interest.

(5) Long term monitoring of plugged wells to assure lack of fluid migration is rare.

(6) The critical zone in a well plug is probably the plug-rock interface, and the plug-casing interface if the hole is cased.

(7) In most applications today a plug that would last 100 years would be considered permanent. This length of time is orders of magnitude less than the time of interest for nuclear waste disposal. 


\subsubsection{Borehole Sealing with Clay}

Sodium bentonite clay is used frequently to seal shallow wells (a few hundred feet deep). In the installation of piezometers for hydrologic studies the zone of interest may be isolated by using bentonite pellets. These small tablets of highly compressed bentonite may be dropped through water and will swell to ten or fifteen times their original volume when hydrated with fresh water, thus forming a low permeability seal. The clay seal functions well when saturated, but cracks upon drying. Upon rewetting the clay swells and again forms a seal.

To maintain its performance the sodium bentonite must be in equilibrium with its surroundings. Bentonite has a high cation-exchange capacity and under certain chemical conditions the sodium may be replaced by calcium or other ions, rendering the clay more permeable. This effect can change the internal structure of the clay and lead to piping. Clays subject to this phenomenon are known as dispersive clays and are a cause of problems in earth dams. A more detailed discussion of chemical considerations is given by South (1980).

Use of compacted shale or clay to form a borehole seal has been studied by Martin (1975), Olsen and Martin (1976), Olsen (1978; 1981), and Fernandez et al. (1976). Martin conducted laboratory tests and concluded that both crushed shale and montmorillonite clay are feasible materials for sealing boreholes. A high compactive effort is necessary when using crushed shale and in the laboratory tests water flow was concentrated at the interface between the plug and the model wellbore. Compaction induced considerable damage in the shale borehole walls. Conceptual design of downhole compaction methods were static, impact, roller, vibratory, and air gun.

Fernandez et al., studied emplacement techniques as an extension of Martin's work and concluded that only static and impact compactors were feasible. A batch or bucket system would be used to supply material downhole. No commercial equipment was found suitable for either conveying material downhole or compacting it in place. Some oil-well equipment could be used as a starting point, but refinement and instrumentation would require research and development. A drawback of Fernandez's work is the assumption of a dry hole. Only at the Nevada Test Site are potential repository horizons entirely above the water table.

Compacted clay plugs are mentioned by Kelsall et al. (1982a, p. 67) as a possible component of a vertical borehole seal, but methods of emplacement are not discussed. Pusch (e.g. 1983) has extensively investigated the performance and emplacement of highly precompacted bentonite plugs.

Cement remains the primary material considered for borehole plugging. clay will likely be used in multi-component plugs. The ability of clay to deform without cracking makes it particularly valuable as a seal 
component and complements the greater mechanical strength, but more brittle nature of cement.

\subsubsection{Studies Regarding Borehole Sealing for Nuclear Waste Isolation}

The Department of Energy studies borehole plugging in relation to highlevel nuclear waste isolation. Studies have been concerned with material selection, material development and laboratory and field testing. The literature on this subject is voluminous, both due to the many researchers involved and due to the fact that the work is reported in a series of quarterly, annual, and final reports. A brief review of typical reports from the main lines of investigation follows.

\subsubsection{The Bell Canyon Test and Subsequent WIPP Studies}

Perhaps the most significant test performed to date in the Department of Energy's program has been the Bell Canyon Test (BCT). This test was performed by Sandia National Laboratories at the WIPP site. The purpose of the test was, "To evaluate in situ the state of the art in borehole plugs and to identify and resolve problems encountered in evaluating a 'typical' plug installation in anhydrite" (Christensen and Peterson, 1981). A condensed status report has been presented by Christensen (1980b), while program plans and earlier status are documented by Christensen and Hunter (1979), and Christensen (1979a; 1980a). Detailed analyses of the results, including complete test results and analytical and numerical analysis techniques, as well as associated plug performance evaluation assessments, are given by Peterson and Christensen (1980). The authors discuss problems encountered in performing microdarcy range permeability measurements, data discrepancies, and impact on plug performance assessment.

In this (BCT) test a two meter long plug of cement was placed in a 20 $\mathrm{cm}$. diameter hole at a depth of 1370 meters. The plug was placed in the lowest anhydrite of the Castile Formation, directly above the Bell Canyon aquifer. The aquifer provided a $12.4 \mathrm{MPa}$ (1800 psi) differential fluid pressure across the plug and had a production capability of 38,000 liters/day.

Statler (1980) describes the field preparations and operations for plug emplacement and testing. The plug has been emplaced in an abandoned exploratory hole which was reentered and reconditioned. The hole was characterized by means of drill stem testing, geophysical logs, gas permeability and hydrology testing, as well as downhole television inspection. The latter proved invaluable for test preparation, and further details are given in Christensen et al. (1980). The test installation is described, as well as some problems encountered.

A fresh-water grout mix, designated $\mathrm{BCT}-1 \mathrm{FF}$, was selected to plug the hole. The composition of this mix was (Christensen and Peterson, 1981, p. 9):

Class H cement $52.2 \%$

Expansive agent $7.0 \%$ 


$\begin{array}{lc}\text { Fly ash } & 17.6 \% \\ \text { Dispersant } & 0.2 \% \\ \text { Defoamer } & 0.02 \% \\ \text { Water } & 23.0 \%\end{array}$

giving a water/cement ratio of $0.30^{1}$ and a fluid density of $1.98 \mathrm{~g} / \mathrm{cc}$ (17.0 1b/gal).

The plug was installed to isolate the upper regions of the borehole from the Bell Canyon aquifer. Measurements were made of both the volumetric flow and the velocity of fluid flowing from the aquifer through, or around, the plug into the upper wellbore. Because the upper portions of the borehole produce fluid, an umbrella packer was installed to provide an isolated test chamber for measurement purposes.

Four distinct fluid paths exist from the aquifer through, or around, the plug into the test region: through the plug itself, along the plug/borehole interface, through a possible damaged region along the borehole wall (for example resulting from drilling and coring operations, stress relief, and fluid circulation), and through the undisturbed formation surrounding the plug. The total flow occurring along all these paths was measured.

Additional flow paths along which fluid can enter or leave the test region include flow from above the umbrella packer through the surrounding formation or wellbore damage region, flows occurring along some formation discontinuity leading to a distant source, and leakage from the umbrella packer and attached tubing assembly.

The field data obtained during the Bell Canyon Test, along with laboratory data obtained in the course of the program, suggest that the predominant flow into the test region occurs through the plug/borehole interface region, with smaller contributions attributable to flow through the wellbore damage zone, the plug core, and the surrounding undisturbed anhydrite formation. A computer simulation was performed to demonstrate that the measured data were consistent with having a predominant interface flow and to establish an upper bound on the wellbore damage region flow properties.

In this simulation the undisturbed anhydrite was assumed to have zero permeability. No flow was permitted from above the umbrella packer, and the umbrella packer was simulated as a region having zero permeability. Typical faboratory values of 1 microdarcy permeability and .001 porosity ${ }^{2}$ were taken for the cement plug core. The predominant flow

${ }^{1}$ As reported in the Bell Canyon Test Summary report. This figure (0.30) is with respect to cement plus additives. Water/Class $\mathrm{H}$ cement ratio = $23.0 / 52.2=.44$.

${ }^{2}$ No details or references are given for this (presumably interconnected) porosity, which appears exceedingly small for a cement plug. 
into the test region was modeled to occur through microstructure existing in the plug/borehole bond region. The cross-sectional area of this region was arbitrarily taken as $10 \%$ of that of the wellbore. This corresponds to a $0.5 \mathrm{~cm}$ wide microstructure region in the $20 \mathrm{~cm}$ diameter borehole. Properties of the wellbore damage region were unknown, and arbitrarily assumed to have a cross-sectional area equal to that of the wellbore, and a permeability and porosity of 8 microdarcies and 0.01 , respectively. This corresponds to a wellbore damage region $4.4 \mathrm{~cm}$ thick. Agreement of the experimental data with the simulation was good, indicating the experimental data are compatible with the hypothesis that flow occurs predominantly through a small plug/borehole interface zone. The solutions are not unique, and any reasonable combination of flow zone properties, consistent with the field values measured will provide test pressure histories consistent with the measured data. Further calculations indicated that the permeability of any possible wellbore damage region surrounding the packer must be less than the eight microdarcy value used in the initial calculation.

The Bell Canyon Test effort has been accompanied by extensive supporting investigations addressing a series of sealing related issues.

Hunter (1980) presents a description of the WIPP site, repository design, and the 1980 status of the research and development program. The author presents potential breach scenarios involving boreholes, and cites consequence analyses with respect to radionuclide releases (from TRU wastes) that indicate exceedingly minor human exposure, even with borehole plugs of very high permeability.

Lambert (1980a) recommends a series of analyses to be performed on an overcore of a four-year old cementitious grout plug installed in potash. The primary objective of the proposed analyses is to identify reactions that have taken place in the grout-rock-groundwater system, and thus obtain a case study of long-term compatibility between grout and rock. An underlying strategy, the use of thermodynamics of multiphase equilibria, is proposed as a technique for evaluating the long-term stability of hole-plugging materials in their geological environments by Lambert $(1980 \mathrm{~b})$. The detailed test plan for the core is described by Christensen (1979b).

The initial five-year cement development work for the Bell Canyon Test is reviewed by Gulick et al. (1980a). The introduction to this paper states the purposes of the Borehole Plugging Program (BHP), lists desirable grout properties, and the initial materials selection. The extensive laboratory investigations on numerous potential grout candidates are summarized, as well as the selection of the ultimately emplaced grout. Details of the field emplacement are included, as well as laboratory experiments performed on field samples. The paper concludes with a description of long-term durability studies. A considerably expanded version of this paper is available (Gulick et al., 1980b). Gulick et al. (1982) can be considered as a follow-up report, and gives results for up to 4 year durability studies on several primary cementitious grout candidates. 
A broad outline of sealing concepts for the Waste Isolation Pilot Plant (WIPP) Site is given by Christensen et al. (1983). The report describes the site and identifies specific objectives of the Plugging and Sealing Program. Materials for seals are discussed, as well as sealing of vertical and of horizontal penetrations. Plugging criteria are outlined. Appendix A gives estimates of the vertical penetration growth that might result from freshwater intrusion.

The Plugging and Sealing Program for WIPP has been updated, expanded, and detailed by Stormont (1984). This report includes a discussion of sealing performance requirements, of fundamental sealing aspects, and of seal design concepts for a variety of penetrations. Issues are identified, as well as activities planned to resolve them. Primary sealing materials proposed are salt, cements, and clays.

Results from the first in a series of in-situ tests on candidate seal materials are presented in Stormont (1986a). Expansive salt-water based concrete plugs have been placed in boreholes drilled in the floor of the WIPP facility. Size effects are studied by varying diameters from $15 \mathrm{~cm}$ (6 inches) to $91 \mathrm{~cm}(3 \mathrm{ft})$, lengths from $30 \mathrm{~cm}(1 \mathrm{ft})$ to $91 \mathrm{~cm}(3 \mathrm{ft})$. Substantial plug-rock pressure results from salt creep. Gas and brine permeability measurements indicate excellent barrier performance. A detailed description of the grout, of emplacement procedures, and of the instrumentation is given in Stormont, 1986b. Two-dimensional axisymmetric and plane strain scoping calculations for the mechanical response of the plugs and adjacent rock are given by Torres (1986).

In addition to cementitious materials, crushed salt and clays are primary sealant candidates. Krumhansl (1986) presents obervations regarding stability of bentonite backfill in a high-level waste repository in rock salt, with emphasis on an environment (temperature, radiation) which suggests close proximity to a waste package. Zeuch et a1. (1985) discuss he use of a simple hot-pressing model to describe crushed salt consolidation, and find promising agreement with experimental observations.

\subsubsection{The Work of D'Appolonia Consulting Engineers, Inc./IT Corporation}

D'Appolonia Consulting Engineers, Inc., and its successor organization, IT Corporation, under contract with the Office of Nuclear Waste Isolation (ONWI) has studied repository sealing. The work involved extensive literature review and conceptual design of borehole and shaft seals, and is discussed in a series of ONWI reports.

D'Appolonia (1979) points out that the objective of borehole (and shaft) sealing as related to nuclear waste isolation is to provide an assured seal of any man-made penetrations to prevent or retard (i.e., keep below acceptable levels) the passage of radionuclides from the repository to the accessible environment. Sealing for nuclear waste isolation differs from other areas in that a greater degree of assurance that sealing has been accomplished is necessary. 
D'Appolonia (1979) identified three important issues that needed quantification: (1) overall sealing program objectives and requirements; (2) importance of plugging boreholes and of sealing shafts in the area of a nuclear waste repository; (3) longevity requirements for penetration seals. The report further points out the necessity for both site specific and general research and recommends that the exact results required of seals be established. If the consequence of significant harm due to an unplugged borehole can be shown to be smal1, plugging requirements may be less stringent.

D'Appolonia (1980a, 1980b) concern design approaches and evaluation of materials research objectives and requirements. Four basic alternative design goals were considered, varying from "returning the repository formation to its original permeability" to "providing seals which control potential radioactivity release to an acceptable level with a margin of safety". The latter was recommended. To limit the consequences to acceptable limits a seal would be placed either as a barrier against fluid flow into the repository or as a barrier against radionuclide migration out of the repository. Radionuclide migration could be prevented using multiple seal components with either low permeability or high radionuclide adsorption capacity.

In their evaluation of materials research objectives and requirements D'Appolonia recommended a materials program based upon two major considerations: (1) establishing which engineering properties of seals are useful in determining the applicability and performance of a penetration seal or material, and (2) establishing a range of candidate sealing materials that are potentially capable of providing the basic seal functions: prevention or retardation of fluid flow or sorption of radionuclides.

D'Appolonia (1980c) summarizes the objectives, conclusions, presentations and discussions of a two-day workshop held to discuss field testing aspects of repository penetration sealing. The four sessions conducted at the workshop addressed (1) Review of Existing and Planned Field Test Programs at NWTS (National Waste Terminal Storage) sites, (2) Fracture Characterization, (3) Permeability Testing, and (4) Overview. The workshop focused primarily on borehole characterization.

General conclusions include:

- need for seal designers to direct site characterization activities needed for seal design,

- need to establish quantitative seal performance requirements,

- need for theoretical and laboratory studies to evaluate the probable nature of the disturbed zone, specifically the type of fractures that might be present,

- only flow testing can characterize relative fracture conductivity, 
- flow testing can not distinguish disturbed zone and undisturbed zone permeability,

- general requirement for more field and in-situ testing.

D'Appolonia (1981) presents the results of studies carried out in response to recommendations made in the earlier evaluation report (D'Appolonia, 1980b). From the range of materials considered, cement and sodium bentonite clay were chosen as having priority.

The design parameters thought important are:

(1) Site geology, stratigraphy, and general hydrology.

(2) Host rock chemical, physical, mechanical, and thermal properties.

(3) Groundwater chemistry.

(4) Undisturbed host rock permeability.

(5) Host rock sorption properties.

(6) Penetration geometry.

(7) Penetration sidewall characteristics.

(8) Disturbed zone pore and fracture characteristics and extent.

(9) Disturbed zone permeability.

(10) Penetration deformability.

(11) Seal-host rock interface characteristics.

D'Appolonia (1981b) presents sealing considerations for potential repository shafts in a bedded salt site in southeastern New Mexico, and at four salt domes (Richton and Cypress Creek, Mississippi; Vacherie, Louisiana; Oakwood, Texas). The report summarizes the geologic and hydrologic data for the sites, and relates these in-situ characteristics to schematic penetration seal designs and to information needs for conceptual, preliminary, and final seal designs. The report emphasizes past experience with shafts in potash mines in southern New Mexico and at salt mines in the Gulf Coast region. The need for adequate sealing at the salt top is stressed, as is the need for proper construction procedures and maintenance during operations. The report includes an extensive discussion of the implications of various construction methods with regard to sealing needs and performance. The beneficial effects of salt creep on sealing are pointed out.

Kelsall et al. (1982a) describe schematic seal designs for a repository in bedded salt. Borehole seal designs include cement, clay, and crushed salt as potential sealing materials. The borehole would be sealed in stages:

(1) "Characterize the hole by examining drilling records and, if necessary, by running additional logs. Particular attention is paid to identifying the permeable zones and to describing the hole geometry using caliper logs and downhole television." 
(2) "Perform packer tests to identify permeable zones."

(3) "Flush the hole to remove debris and clean the surface with brushes or reamers."

(4) "Squeeze grout with cement in the more permeable zones, as appropriate."

(5) "Drill out the hole and repeat packer tests in permeable zones; repeat the squeeze grouting if necessary."

(6) "Drill out the hole and grout with bentonite or chemical grout (as necessary, if cement grouting does not eliminate water losses)."

(7)- "Drill out the hole and part fill from the bottom with an expansive cement."

(8) "Fill section of hole above first cement stage with crushed salt or clay, densely-compacted in place."

(9) "Fill remaining section of hole to ground surface with expansive cement."

Coons et al. (1982) evaluate the use of polymer concrete for potential repository sealing. Based on an extensive literature survey they conclude that polymer concrete might have some advantages (e.g. higher strength, short-term resistance to hydrothermal conditions) over portland concrete, but that the disadvantages (e.g. introduction of polymers into the repository environment, uncertainties about durability, health and safety considerations during installation, high cost) outweigh the advantages to the point where the authors recommend that research emphasis remain focused on portland cements.

Kelsall et al. (1982b) present a preliminary evaluation of the rock mass disturbance resulting from shaft, tunnel, or borehole excavation. The authors evaluate disturbed zone characteristics for shafts, tunnels and boreholes, by analysis and by review of published laboratory and field tests. Mechanisms for creation of a disturbed zone include stress changes, damage induced by the excavation, process, weathering, and rockground water interaction. The authors conclude from laboratory tests that the disturbed zone associated with small-diameter boreholes is probably insignificant. (The tests quoted study drilling damage in intact rock only.) The likelihood for fundamental differences between damage mechanisms around shafts (and tunnels) as compared to boreholes are described, and the dearth of actual data on damage, and particularly on permeability changes, is noted. The authors integrate an analysis of stress redistribution around underground excavations with relations between stress in rock, and particularly on discontinuities and rock permeability, to derive estimates of the permeability in disturbed zones around underground excavations. A separate discussion is presented of damage that might be induced by blasting. The results of this 
"fractured rock" analysis are illustrated by the example of a 1,000 m deep shaft in fractured basalt under an initially hydrostatic stress state. The fundamentally different analysis presented for shafts and tunnels in salt postulates that the most likely mechanism for disturbance in salt is loosening of the crystal fabric in response to stress relief, and recognizes that additional damage may result from blasting or slabbing. The authors conclude that the disturbed zone in salt may be insignificant with respect to long-term seal performance because the combination of salt fracture healing and salt creep will rapidly produce sealing against any rigid inclusions (e.g. concrete plugs).

A variety of shaft (and tunnel) disturbed zone characterization methods are discussed, including hydrological tests, geologic tests and observations, geophysical methods, and mechanical methods, and specific test programs are outlined for fractured rock and for salt. Also presented are methods for the treatment of any disturbed zone, notably rock support, grouting, precipitation of secondary minerals, bulkheads and drilled cutoffs.

The authors conclude that the disturbed zone is potentially a significant pathway for flow along sealed zones, and that stress redistribution is a significant disturbance mechanism, making the disturbance independent, to a significant degree, of the excavation method. Sitespecific further analyses are recommended, as well as validation by insitu testing.

Kelsall et al. (1983) describe the technical programs needed to complete seal designs for a salt repository. They outline the salt repository sealing program and status, the reference repository schematic seal designs (Kelsall et al., 1982a), the technical approach to be taken to develop performance requirements and seal performance outline. A technical plan is outlined to address the technical issues by means of the following major technical programs:

(1) Update designs to incorporate site-specific geologic and hydrologic characteristics;

(2) Reference designs to site-specific repository designs;

(3) Develop site-specific performance requirements;

(4) Salt consolidation testing and modeling;

(5) Materials development;

(6) Design analyses;

(7) Verification testing.

Meyer and Howard (1983; prepared jointly by D'Appolonia Consulting Engineers, Inc., and Material Research Laboratory, The Pennsylvania State University - see Section 2.3.3.4) present an evaluation of the use of clays and clay minerals for repository sealing. Clays are candidate 
sealant materials for repository penetrations because they can be effective fluid flow barriers, chemical barriers, or both. Major chapters of the report are devoted to each of these primary barrier functions. The report recognizes that not all clay stability issues are resolved, but postulates that long-term sealing potential can be inferred, and can be enhanced by prudent selection of components and emplacement design. High priority research issues identified include:

(1) Thermodynamic properties of clays, and their thermal stabilities and phase transformations, bearing on longevity;

(2) Seal-rock interface permeability, and permeability at extended times and elevated temperatures, bearing on performance of clay as a barrier to ground water movement;

(3) Sorptivity under realistic repository conditions, bearing on performance as a chemical barrier.

IT Corporation (1984) studies two aspects of salt behavior that are expected to enhance waste isolation in a salt repository: consolidation of crushed salt backfill due to creep closure of the openings, resultig in a backfill with very low permeability, and healing of fractures around the openings, resulting in a very low permeability in salt surrounding the backfill. The report integrates an extensive experimental data base from a variety of sources, e.g. with respect to salt consolidation and with respect to underground opening creep closure in order to arrive at generic assessments of likely performance of crushed salt barriers and surrounding healed salt, as well as to identify further information and research needs.

Kelsall et a1. (1985a, 1985b, 1985c) present schematic designs for penetration (shaft, tunnel and borehole) seals for a repository in Richton Dome, the Paradox Basin, and the Permian Basin, respectively. Each report first identifies seal performance requirements, and the reference seal design conditions, the latter including repository design, site geology, host rock properties, in-situ stresses, and temperatures. The chapter on schematic penetration seal design starts with general considerations for shaft and tunnel seals, in which seal functions, materials and components are addressed. Sections on shaft and tunnel seal design and on borehole seals follow. Proposed shaft seals consist of concrete bulkheads and of dense earthen backfill. Cement grout and clay are recommended for (redundant) seals for vertical boreholes, and a strong recommendation is given to minimize the need for sealing long horizontal holes. The concluding chapter outlines future activities, based on an introductory identification of remaining uncertainties. Future activities include updating designs to incorporate site-specific characteristics, reference designs to updated repository designs, the development of site-specific performance requirements and the updating of the general design strategy, further study of salt consolidation and fracture healing, (seal) materials development, design analyses, and verification testing. The reports include an appendix on the consolidation of crushed salt (superseded by IT Corporation, 1984) and on stress build-up on bulkheads placed in 
salt, as well as an appendix which includes peer review comments and reponses thereto.

Discussion. The D'Appolonia reports represent some of the more extensive work on borehole sealing for nuclear waste isolation to date. Although a considerable amount is performed for salt primarily, much of the work applies generally, or has broader implications. Three important issues identified in the 1979 report - overall objectives and requirements, importance of plugging, and longevity - are still under discussion.

\subsubsection{Wellbore Damage Zone Studies by Terra Tek}

The extent and nature of the drilling induced damage zone around a borehole was investigated by Lingle et al. (1982) of Terra Tek, Inc. (see also Burns et al., 1982). Full-scale drilling tests were conducted on samples of anhydrite, salt, basalt, and tuff. Cores $34 \mathrm{~cm}$. in diameter and $91 \mathrm{~cm}$. long were drilled under simulated downhole conditions using $20 \mathrm{~cm}$. diameter bits., Roller-cone bits and diamond bits were used along with three different drilling fluids: mud, water, and air.

Damage assessment included dye-penetrant inspections, microscopic examinations, and laboratory permeability measurements. The techniques indicated damage only on the order of grain dimensions around the borehole in the anhydrite, granite, and basalt. No damage was observed in the tuff, but damage could not be ruled out. Damage was not detected in the salt by microscopic or dye penetrant techniques, but laboratory permeability measurements showed increased flow.

The laboratory permeability test results on granite, basalt, and tuff are of direct interest for experimental work described later. The granite tested is described as "fine-grained granodiorite with abundant dark-gray hornblende and biotite-rich inclusions; it has uniform texture and is fairly isotropic". The granite was obtained from the Cold spring Granite Company, Cold Spring, Minnesota, and may be the same rock, or similar to, the Charcoal Granite obtained from the Cold Spring Granite Company used in the work reported herein. Granite permeabilities reported by Terra Tek range from $1.0 \times 10^{-6}$ to $2.8 \times 10^{-6}$ darcy.

The basalt used was dark gray to black with interlocking crystalline texture and was collected from the Columbia River basalt plateau flows near the John Day Dam. This rock exhibited permeabilities ranging from $0.2 \times 10^{-6}$ to $0.7 \times 10^{-6}$ darcy.

The tuff was a light grayish pink, partially welded tuff with volcanic rock fragments and glass shards. The rock was obtained from the Upper Provo River Canyon near Kamas, Utah. Permeability values measured ranged from $0.5 \times 10^{-6}$ to $8.40 \times 10^{-6}$ darcy.

A flow test on a plugged anhydrite using fresh water containing a tracer dye indicated all flow occurred at the grout/rock interface. In this test a $20 \mathrm{~cm}$ diameter hole was drilled with a roller cone bit into an 
anhydrite core $39 \mathrm{~cm}$ in diameter and $91 \mathrm{~cm}$ long. The anhydrite was from the Winn Rock Quarry, Winnfield, Louisiana. BCT-1FF grout (the same grout used in the Bell Canyon Test) was used to form a $48 \mathrm{~cm}$ long plug in the sample. Under a pressure differential of $13.8 \mathrm{MPa}$ across the plug a fracture aperture at the interface of $4.1 \times 10^{-6}$ meters was calculated. This assumes all flow is through an aperture between the plug and the anhydrite, i.e., along the grout/rock interface. Similar calculations using data from two measurements made during the Bell Canyon Test give similar results: $3.2 \times 10^{-6}$ meters and $6.1 \times 10^{-6}$ meters.

More recently, Terra Tek, Inc. (Bush and Piele, 1986; Bush and Lingle, 1986) has reported additional sealing studies, on cement plugs in salt and in anhydrite, respectively. These have included investigations of damage in the rock walls. Salt damage observed includes crystal structure and crystal interface dissolution, and crystal interface crushing. Crushing is attributed to high confining pressures applied to open hole cylinders, dissolution to incomplete brine saturation. Salt permeability, subsequent to plug flow testing, is anisotropic, of the order of 2 to 4 millidarcy; grout permeability ranges from 0.6 to less than 0.1 microdarcy. Fairly large interface flows have been observed durig flow testing of the plug in anhydrite. Post-test observations reveal extensive fracturing of the anhydrite, and fracture flow, as well as highly preferential flow along the plug-anhydrite interface and in channels with the plug grout along the interface. A detailed plug materials characterization has been performed by Scheetz et al. $(1986 \mathrm{a}, \mathrm{b})$, briefly summarized in Section 2.3.3.4 of this report, and by Buck et al. (1985c), summarized in Section 2.3.3.6.

\subsubsection{Research at The Pennsylvania State University}

The Materials Research Laboratory at The Pennsylvania State University has been performing research on cementitious materials for use in sealing applications with respect to nuclear waste isolation since the mid '70's. Their work has considered both physical properties which allow.a plug to be emplaced and function as desired and chemical properties which affect the longevity of the plug.

In one of the early reports (Roy et al., 1977) the effect of cement paste admixtures on the rheology and cement properties, chemical shrinkage, permeability, and cement-rock interaction is discussed. Cement permeabilities were measured using a method developed by Klinkenberg (1941) in which a gas is used as the permeant. Permeabilities of 2 to 3 microdarcies are reported for cements with 0.3 water/cement ratio after 60 days of curing. Sample preparation included drying for one hour at $110^{\circ} \mathrm{C}$ and placing in a dessicator until testing.

Also of interest in this report is a summary of results on cement/rock bonding from Chatterji and Jeffery (1971) which, "indicate that aggregate of sand, basalt, granite, and limestone showed no signs of chemical bonding with portland cement hydration products, but did show evidence of chemical etching. [This] suggests that the cement/aggregate bond is mainly due to the free surface energy of the cement hydration 
products and the viscosity effect of the surrounding liquid phase present in the mortar."

Roy et al. (1979) outline a strategy for demonstrating the geochemical longevity of selected best-candidate cement-based materials for plugging boreholes and sealing shafts. It is necessary to consider the repository system environment as well as the plug. Factors are examined that relate to the stable equilibrium of the system. Information sources, required studies, and proposed laboratory investigations are identified.

Scheetz et al. (1979) characterize rock and plug samples recovered from an eighteen-year-old cement-based plug in a predominantly halite formation. The plug was weak and permeable relative to the surrounding bedded salt. Characterization included compressive strength, permeability, density and porosity, thermal measurements, $\mathrm{X}$-ray diffraction, electron and optical microscopy, and chemical composition.

Wakeley, Roy, and Grutzeck (1981) reported on "Experimental Studies of Seal Materials for Potential Use in a Los Medanos-Type Bedded Salt Repository". Of most interest in the present context are the data on cement porosity, permeability, and bonding. The porosities of hardened cement pastes were calculated from measured evaporable water and varied from about 30 to 45 per cent as water/cement ratios varied from 0.35 to 0.50. Lower water/cement ratios yielded lower porosities. In addition, samples cured at higher temperatures had lower porosities, due to a greater degree of hydration in a short curing time. Porosity decreased with increased hydration. (After longer curing times, however, the degree of hydration for samples cured at a higher temperature is expected to be less than that of samples cured at a lower temperature (Brunauer and Kantro, 1964).)

Permeabilities reported ranged from about $5 \times 10^{-9}$ to $1 \times 10^{-7}$ darcy for water/cement ratios of 0.35 to 0.45 , cured at $27^{\circ} \mathrm{C}$, and $1 \times 10^{-7}$ to $1 \mathrm{x}$ $10^{-5}$ for water/cement ratios of 0.35 to 0.45 , cured at $60^{\circ} \mathrm{C}$. Lower curing temperatures and lower water/cement ratios resulted in lower permeabilities.

The pore-size distributions in samples with a water/cement ratio of 0.40 cured at $27^{\circ} \mathrm{C}$ and $60^{\circ} \mathrm{C}$ were determined by mercury intrusion porosimetry, which only measures pores less than 7.5 microns in radius. The sample cured at $27^{\circ} \mathrm{C}$ had a peak in the pore size distribution between $7.5 \mathrm{x}$ $10^{-3}$ and $14 \times 10^{-3}$ microns and absence of pores having radii larger than 430 microns. The sample cured at $60^{\circ} \mathrm{C}$ had two peaks, between $7.5 \times 10^{-3}$ and $14 \times 10^{-3}$ microns and between $140 \times 10^{-3}$ and $230 \times 10^{13}$ microns. The values of total pore volumes measured by mercury intrusion porosimetry were less than those measured from the content of evaporable water, reflecting the inclusion of pores having radii greater then 7.5 microns in pore volumes calculated from evaporable water.

Wakeley, Roy, and Grutzeck (1981) conclude that pore structure, rather than total porosity, is the controlling factor for permeability. 
Samples with substantial volumes of pores with radii greater than $75 \mathrm{x}$ $10^{-3}$ microns, that is, those samples cured at $60^{\circ} \mathrm{C}$ which exhibited a second peak in the pore size distribution measured by mercury porosimetry, had larger permeabilities. It is the interconnected porosity that contributes significantly to permeability.

Investigations concerning the nature and integrity of interfacial regions and rock indicated that the morphology and mode of fracture at the interfacial region between portland cement paste and rock were dependent on both the reactivity of the rock and the degree of hydration of the cement. The report continues, "A two-layered zone developed in the interfacial region between non-reactive rock (aggregate) and portland cement paste. The interfacial region is characterized by a thin film of silica-containing calcium hydroxide, from which calcium silicate hydrate particles appear to be growing. In addition to the calcium silicate hydrate, larger crystals of calcium hydroxide appear to attach the interfacial region to the bulk matrix material, and thereby the aggregate to the bulk matrix. As the degree of hydration increased, more bulk material became attached to the interfacial region. When the interfacial region was exposed in six month runs it still appeared as a two layer zone. The effect of elevated pressures was to increase the contact between the matrix and the rock surface and, when combined with elevated temperature, to increase also the hydration rate. Surface roughness of the rock resulted in no major effect upon the basic structure of the interface."

Permeabilities of the interface have been estimated. One 18-year old plug of cement in salt yielded a salt permeability of $2 \times 10^{-6}$ darcy, a cement permeability of $1 \times 10^{-3}$ darcy, and an interface permeability of $3 \times 10^{-3}$ darcy.

A further test was performed in which grout was cast against dolostone, forming an interface. Both the grout and the dolostone had shown essentially no flow when tested individually; the sample with the interface showed a permeability of approximately $2.5 \times 10^{-7}$ darcy. Finally, tests on an expansive grout indicated permeabilities of less than $10^{-8}$ darcy for samples cured in various aqueous solutions. A sample cured in air and allowed to dry was not tested because of shrinkage which caused a gap between the sample and the ring in which it was cast.

Roy and Langton (1982) discuss the Iongevity of borehole and shaft sealing materials. In this study ancient cement-based building materials, some older than 2500 years, were characterized. Longevity is obviously of concern in the context of long-term waste isolation. The results obtained emphasize the necessity of specifying borehole environmental conditions prior to attempting to extrapolate durability data for cementitious borehole sealing materials on a long-term basis. The temperature, wall rock mineralogy, pore fluid composition, and hydrostatic or lithostatic load should be known. Physical properties of the specific seal material of importance are porosity, permeability, expansion/shrinkage characteristics, and the influence of thermal effects. The phase stability of the borehole sealing material must be 
considered with respect to pressure, temperature, wall rock, and ground water composition.

Other items of interest contained in this report are, first, that some degree of carbonation occurred in the samples studied, increasing with the age of the sample. Roy and Langton suggest that, "The extended durability and remarkable longevity of certain ancient plasters, mortars, and concretes in fact may be at least partially attributed to the development of phase assemblages which include calcite (matrix) plus siliceous aggregates such as quartz." Crystalline calcium silicate hydrate compounds were not detected in any of the samples analyzed, but particle morphologies generally were better defined in older samples. Finally, in interfacial regions formed between the matrix material and siliceous aggregates such as quartz, the aggregate surfaces appeared etched and had crystals (primarily calcite) growing on them. Zoned or layered interfacial regions, such as those observed in earlier work at The Pennsylvania State University on reactive aggregate surfaces in the early stages of cement hydrations were not observed in this study.

Roy and Langton (1983) chemically, mineralogically and microstructurally characterize ancient ( $v 5500$ B.C.) cementitious materials in order to determine the reasons for the outstanding longevity of some of these mortars and plasters. The remarkable properties of the materials are attributed to a combination of chemical (mineralogical) and microstructural factors. Method of placement and exposure conditions, as well as matrix mineralogy, particle size and porosity, aggregate type, grading, and proportioning affect durability. The authors state that similar factors govern the potential durability of repository sealing candidates that contain portland cement.

Grutzeck and Roy (1985) experimentally characterize sanded salted and nonsalted cementitious mixtures related to the grouts used for the BCT (Section 2.3.3.1). Mechanical properties, expansion, and physical properties, as well as scanning electron microscopy and X-ray diffraction phase composition, are given. An appendix includes an extensive discussion of the thermodynamic stability of ettringite, the component responsible for inducing swelling of sealants.

Wakely and Roy (1986) study the interfacial region between cementitious mixtures and evaporite and clastic rocks from the Palo Duro Basin as well as between the mixtures and steels. Sanded Class $H$ cement grout with Class $\mathrm{C}$ fly ash and selected additives have been tested in contact with anhydrite, salt, and siltstone or mudstone, and with two steels. Detailed interface microstructural and chemical characterization has been performed, as well as determination of the interface bond strength and permeability.

Scheetz et al. (1986a,b) present detailed post-test characterizations of the grouts used in the large-scale Terra Tek flow tests (Bush and Piele, 1986; Bush and Lingle, 1986 - Section 2.3.3.3) Post-test characterization includes detailed studies of the rock/grout interface, physical and mechanical property testing on grouts, and visual descriptions. Scheetz et a1. (1986a) conclude that the salt grout used produced the most 
impermeable grout/rock sealing system yet tested on scale, but that it proved exceptionally sensitive to mixing and curing conditions. Scheetz et al. (1986b) tentatively attribute the well-marked interface flowpaths in the anhydrite plug test to migration of coalescing air bubbles, and suggest additional work on the grout formulation to prevent channeling and void formation.

\subsubsection{The PSU/WES Interlaboratory Study}

In conjunction with the investigations at The Pennsylvania State University (PSU) of portland cement as a repository sealing material, studies also are being conducted by the Structures Laboratory of the U.S. Army Engineers Waterways Experiment Station (WES). A comparative study (Roy et a1., 1980) was performed to determine the ability of these two laboratories to obtain accurate and similar results from tests performed upon the same potential seal materials. Testing included characterization of the materials by chemical, physical, and petrographic procedures. Tests performed on hardened specimens included restrained expansion, compressive strength, modulus of elasticity, density, permeability, $X$-ray diffraction, and scanning electron microscopy. The final results of this comparative interlaboratory study are presented in Roy et al. (1982). The authors conclude that there generally was good agreement between the results of the tests that were performed by both laboratories.

Of most immediate interest in the present context are permeability tests. PSU performed permeability measurements on samples cured for 3 through 365 days. No samples cured restrained or semirestrained showed water flow, at a pressure of up to $6.9 \mathrm{MPa}(1,000 \mathrm{psi})$ for periods up to 94 hours, indicating a permeability significantly below $10^{-8}$ darcys. Expansion-induced cracks are observed after several months curing without restraint, and increase the permeability significantly. The cracks appear to heal after several more months. Permeabilities of $6 \mathrm{x}$ $10^{-8}$ and $2 \times 10^{-7}$ darcys, respectively, were measured at WES on samples cured (apparently unrestrained) for 8 and for 29 days (prior to the 14 day testing period).

A synopsis of early cementitious salt repository seal materials development performed by PSU and by WES for ONWI and for WIPP(SNL) has been published by Roy et al. (1985). As pointed out by the authors in the introduction, the large volume and subject diversity of reports (on research associated with salt repository sealing) make the data difficult to use fully. Data on selected physical properties, chemistries, mineralogies, and long-term stability of grouts used in ONWI-supported studies have been compiled and interpreted. Other important documents are included in the bibliography.

\subsubsection{Research at the Waterways Experiment Station}

The Structures Laboratory of the U.S. Army Engineers Waterways Experiment Station (WES) has been closely involved in the grouting and concreting technology used in underground weapons testing and has continued to be involved in borehole plugging and in other uses of grout 
and concrete with experiments related to nuclear waste isolation (e.g. Polatty and Bendinelli, 1962, 1965). Much of the work is unpublished, but is available for reference.

Recent work has been supported by the U.S. Department of Energy, through the Office of Nuclear Waste Isolation, Battelle Memorial Institute, Columbus, Ohio, for civilian salt repository work, and through Sandia National Laboratories, Albuquerque, New Mexico, for the Waste Isolation Pilot Plant (WIPP). Many of the references quoted on WIPP (Section 2.3.3.1) include WES studies. The work progressed in close coordination with studies at PSU, and several of the references given in Section 2.3.3.4 include WES work. Similarly, grouts used by Terra Tek (Section 2.3.3.3) were designed by WES.

Buck and Burkes (1979) petrographically examined a grout specimen that had been emplaced 17 years earlier in a borehole in salt. Visual observation showed a tight contat between grout and salt. Chemical composition indicates satisfactory stability of the material in a salt environment.

In the context of waste isolation, the Waterways Experiment Station has reviewed approximately 67 laboratory mixtures; 13 are being subjected to long-term physical testing and periodic petrographic examination. Extensive testing indicates that the phase composition and microstructure of the range of materials examined are similar, and each grout tends toward uniformity with time (Buck and Mather, 1982). Buck and Mather further recommend that control parameters for a grout mixture such as flow time, setting time, compressive strength, and permeability be specified before a grout mixture is formulated and used. In addition, knowledge of the longevity of specific mixtures in the applicable environment is required.

Rhoderick (1981) examined, by X-ray diffraction and by scanning electron microscopy, a portland cement grout from a core containing part of a steel anchor that had been grouted in rock in 1915. The exposure in a hole in rock, adjacent to steel (i.e. similar to grout behind a borehole or shaft casing), for 63 years, under water, has not appreciably changed or harmed this grout.

Rhoderick et al. (1981) examined samples of the Bell Canyon Test grout (Section 2.3.3.1) by means of $\mathrm{X}$-ray diffraction and uniaxial compressive strength testing. Variables studied included temperature, pressure and curing in fresh water or in brine (for up to 90 days). Most of the effects, if any, over the test ranges included, were minor.

The quality of the contact between portland cement grout borehole plugs and surrounding rock has been studied by Rhoderick and Buck (1981a). Simulated borehole specimens were prepared by pouring grout into a hole in anhydrite core. The core was grouted in a steel pipe to provide constraint. The authors point out the need to eliminate drying during any of the phases of preparation of samples for inspection, as well as the need to prevent stress relief. 
Rhoderick and Buck (1981b) examined five different approximately fouryear old grout mixtures. Some specimens were stored dry at ambient laboratory temperature, and companion specimens were stored in simulated brine ground water, also at ambient laboratory temperature. Most of both the wet and the dry storage specimens showed cracking for all five mixtures. Rhoderick and Buck attributed this to moisture and/or temperature changes.

Buck et al. (1981) also observed cracking in specimens obtained from plugs in the ERDA-10 experimental borehole in New Mexico as well as in samples of the plug materials cast at the surface at the time when the hole was plugged. They considered the cracks normal for the materials under the storage and test conditions used, and did not believe that similar cracking would occur downhole.

Burkes and Rhoderick (1983) report petrographic examinations of Bell Canyon Test (BCT) grout specimens cast in the field and stored in the laboratory in a site-specific brine. Extensive cracking was observed, and is attributed to unrestrained storage of high cement content grout specimens under variable temperature and subject to temporary drying. Some composition changes are believed due to close proximity of the examined pieces to storage brine. Interface and anhydrite cracking in simulated borehole samples resulted in high water and gas permeability, but probably was due to the removal of the confining steel cylinder, inadequate anhydrite thickness, and drying. Grout samples from satellite holes near the BCT hole revealed considerable brine and sand contamination, resulting in incompetent grout.

Buck et al. (1983) report tests and examinations for workability, compressive strength, restrained expansion, permeability, phase composition, and microstructure on the Bell Canyon Test (BCT) grout and on modifications thereof. The latter included three other cements, two other fly ashes, a silica fume, different water contents, and different amounts of expansive additive. In general, the results indicate that most modifications produced grouts as good as the BCT grout.

Buck et al. (1984) note that salt must be added to fluid hydraulic cement mixtures to be emplaced in contact with salt in order to prevent the development of solution cavities at the cement-salt contact. This in turn necessitates the use of additives in order to overcome likely negative effects of salt additives on workability.

Buck (1985a) gives a detailed description of experiments and examinations performed on a sanded nonsalt expansive grout modified from the Bell Canyon Test grout. A large scale flow test performed on a plug of this grout emplaced in anhydrite (Bush and Lingle, 1986b) has resulted in rapid large flows, primarily through channels along the pluganhydrite interface (Section 2.3.3.3 of this report). The comprehensive suite of various samples cast at the time the plug was installed are described, as well as the experiments and examinations to which they have been subjected. Tests confirm satisfactory performance of the grout. Issues raised include size effects, particularly with regard to expansion, thermal or drying shrinkage, and potential for interface dissolutioning. 
Buck et al. (1985b), as part of the study of hydraulic cement systems for repository applications, investigate the thermal stability of ettringite and chloroaluminate cement components. X-ray diffraction, compressive strength and restrained expansion have been monitored on 16 mixtures at temperatures up to $170^{\circ} \mathrm{C}$ and pressures up to $0.7 \mathrm{MPa}$ (100 psi). Component decomposition ranges are identified.

Buck and Reinhold (1985) have characterized four Class H High SulfateResistant portland cements by a combination of chemical-physical testing and X-ray diffraction. Cements of this type are likely to be used for salt repository sealing, particularly in anhydrite formations.

Buck (1985b) describes the development of two candidate concrete mixtures (salt, nonsalt) for repository sealing applications. Both are adaptations of Bell Canyon Test grouts, obtained by adding aggregates and admixtures to assure meeting basic performance requirements. Basic objectives were to produce a nonshrinking mixture that should remain workable for several hours. Although difficulties in achieving these objectives have been encountered, it is believed that they have been or can readily be overcome.

Buck et al. (1985c) have characterized plasters from six sources and one plaster retarder by chemical and physical testing and by petrographic examination. The objective was to determine the interchangeability of various plasters in cementitious sealing grouts.

Buck et al. (1985a) describe the development of a sanded expansive salt grout for repository sealing application. The material was used in an unsatisfactory (i.e. large flow) anhydrite plugging test at Terra Tek. The report discusses possible explanations, in particular mixing problems, and need for temperature and expansion control. The authors conclude from their own laboratory testing and characterization that the grout probably is satisfactory for repository sealing application.

Wakeley and Roy (1985) developed and tested slightly expansive cementitious mixtures for repository sealing in evaporites and related rock strata. A salt-free and a salt-containing mixture were used in contact with anhydrite, siltstone and halite. Bond integrity and low interface permeability suggest a high probability of achieving durable sealing by means of such chemically tailored cement-based mixtures.

\subsubsection{Research at Oak Ridge National Laboratory}

The overa11 program described by Moore, et al (1979) was initiated to develop and test cementitious mixtures suitable for plugging holes in the area of a radioactive waste repository, particularly one in bedded salt. Data were obtained from physical and chemical tests and from parametric studies involving cement/fly-ash concretes and saltcretes ${ }^{1}$.

${ }^{1}$ Saltcrete is a standard mortar with 10 to 30 wt $\%$ salt added. Such a mix is used in the oil industry to bond set cement to salt sections and
shales. 
The addition of $10 \mathrm{wt} \%$ salt doubled the initial and final set times. The set time could be increased or decreased by the addition of a lignite fly ash or a bituminous fly ash, respectively.

The compressive strength of cement/fly-ash concrete varied with curing time and depended upon fly ash composition. Saltcrete strengths decreased with increasing salt content, but increased if fly ash was added; the effect of fly ash composition was insignificant.

Thermal conductivities of cementitious solids were found to increase with density and with sand and/or salt concentration. Over a temperature range of 30 to $300^{\circ} \mathrm{C}$ the thermal conductivities of saltcrete decreased with increasing temperature but were almost constant for neat cement pastes. The conductivity values ranged from 0.4 Watts/meter-K for a neat cement to 1.8 Watts/meter-K for a saltcrete.

Shrinkage-of neat cement pastes and saltcretes varied approximately linearly with time,- but cement/fly-ash solids exhibited a high rate of shrinkage for the first few weeks, followed by a lower rate of shrinkage for a longer time period.

McDaniel (1980) reported details of the permeability testing. Type I, Class $\mathrm{C}$, and Class $\mathrm{H}$ cements were used with a bituminous fly ash and a lignite/subbituminous fly ash. Permeabilities ranged from a high value of $3 \times 10^{-4}$ darcy for a neat cement paste to a low of $5 \times 10^{-8}$ darcy for a saltcrete containing 30 wt $\%$ salt. Samples were vacuum dried at $100^{\circ} \mathrm{C}, 50$ microns pressure and tested using gas. Some samples were subsequently tested using water. Results were similar.

The drying procedure was a critical step in the test procedure. Preliminary results showed that the gas permeability could vary by as much as three orders of magnitude, depending on the drying technique. Air-drying of a cementitious solid results in the loss of water hydration, with possible collapse of gel structure and microcracking (e.g. Neville, 1973, pp. 386, 390; 1981, pp. 438, 442).

of most interest are data on the permeability of plug-wall rock junctions. Studies were made in which boreholes in $2.54 \mathrm{~cm}$ diameter specimens of Westerly Granite, Dresser Basalt, Sioux Quartzite, and St. Cloud Granodiorite were plugged with a mortar containing 23 wt \% Type I portland cement, 20 wt $\%$ bituminous fly ash, 43.2 wt $\%$ sand, and 13.8 wt $\%$ water. With the exception of the Sioux Quartzite, the plug-wall rock junctions exhibited water permeabilities of less than $6 \times 10^{-6}$ darcy after curing for 91 days at ambient temperature and pressure. The Sioux Quartzite specimen, which showed a plug-wall rock permeability of $3 \mathrm{x}$ $10^{-5}$ darcy, was believed to have contained a crack. In order to measure the permeability of the rocks used, thin samples $(0.6 \mathrm{~cm})$ were used. At the pressures used for measurements there is a good possibility of altering the internal structure by mechanisms such as gel-pore collapse of the cement. In addition, the plug-wall rock specimens were not dried 
to a constant weight prior to measurements made with gas. The drying tended to cause cracking at the junction, resulting in extremely high permeability values. McDaniel recommended that larger specimens (on the order of $5 \mathrm{~cm}$ in diameter) be used in future tests.

\subsubsection{Studies by Woodward-Clyde Consultants for the Basalt Waste Isolation Project}

Woodward-Clyde Consultants (WCC) has performed studies regarding plugging of boreholes, shafts, and tunnels for the Basalt Waste Isolation Project (Taylor et al., 1979; Smith and McCare1, 1980; Hodges et al., 1980; Taylor et al., 1980). For sealing shafts and tunnels natural materials were preferred because they can be shown to have existed for a long period of time. WCC cautions that processed materials (e.g. cement, processed bentonite, pozzolans) have not been shown to be unstable, however. Natural materials considered included basalt, smectite clays, clinoptilolite (a zeolite mineral), and selected aggregates.

Seepage control criteria were emphasized as the most significant design function. The principal design criteria adopted include:

" (1) Design life of 10,000 years.

(2) Maximum seepage through the plug, after saturation, of one cubic meter per year with a 160 meter head across the plug.

(3) Maximum credible radioactive waste leakage from the repository at one end of the plug must be reduced to proposed regulatory agency permissible levels at the other end of the plug.

(4) Plug must sustain a thermomechanical loading cycle from a $50^{\circ} \mathrm{C}$ temperature change without compromising other performance criteria.

(5) Plug must have suitable bond strength to resist maximum credible axial forces ( $1,000 \mathrm{~m}$ of fluid pressure head)."

Borehole plug design suggested by WCC includes alternately (1) a zone of pea gravel with a mixture of compressed bentonite pellets and bentonite slurry, and (2) a zone of cement grout. The nominal length for all plugs is 300 meters.

Other points of interest in their studies are:

(1) Placing and compacting materials, inspection of plugs, and quality control are difficult in plugs placed down boreholes. The only methods available that have been shown by experiment and practical use to produce a plug of the necessary characteristics are those of the oil and gas industry.

(2) At the time of the WCC studies no performance data were available regarding flow rates through plugs, or regarding plug stability. 
(3) Possible design criteria for flow considered were (i) allowable seepage would be kept below a maximum annual rate, (ii) seepage travel time through the plug would be specified, (iii) the plug should be able to resist flow at least as well as the intact rock, or (iv) the amount of radioactive material which could allowably pass through the plug in one year would be specified, taking material sorptive capacities into account.

(4) Proposed design values of the permeabilities of materials to be used in repository sealing ranged from $1 \times 10^{-7}$ to $1 \times 10^{-9}$ $\mathrm{cm} / \mathrm{sec}$.

(5) Plug performance may be divided into five design functions: core barrier performance, plug/wallrock performance disturbed zone cutoff performance, mechanical stability performance, and long-term integrity.

(6) For long-term integrity, compacted earth and clay slurries are preferred.

(7) Recommendations for needed research included the need for an early, shallow borehole plugging test, the need for instrumentation data concerning the performance of large excavations in basalt (for shaft and tunnel sealing), and the need to investigate a wider range of potential failure modes such as creep failure of soft plugs, piping, plug solutioning, or dispersion.

\subsubsection{Information Base for Waste Repository Design}

In 1979 The Analytic Sciences Corporation prepared for the U.S. Nuclear Regulatory Commission a seven volume. document on nuclear waste repository design issues entitled "Information Base for Waste Repository Design". Volume 1 of this document, by Koplik et al. (1979) concerns borehole and shaft sealing. The main conclusions regarding borehole sealing were as follows:

"(1) No method currently exists for ensuring the long-term (thousands of years) performance of the borehole seal. Even when properly placed, borehole seals are likely to deteriorate during the first 1000 years following repository decommissioning.

(2) Sealing a borehole for its entire, length would reduce the impact of seal failure or deterioration.

(3) It is recommended that an unmined pillar of rock be left around boreholes at the repository location to provide an additional barrier to waste transport.

(4) Cement appears to offer the best chance of achieving durable borehole seals using existing technology, at an acceptable cost. 
(5) With the exception of compaction of natural earth material, advanced techniques for sealing borehole such as rock melting or plugging by hydrothermal transport cannot be recommended at this time. The technique of sealing by compaction of natural earth materials still requires considerable test work to demonstrate that satisfactory performance can be achieved."

Two other points are worth noting in this report. First, regarding seal failures, Koplik et al. (1979) indicate that the most common cause of seal failure during emplacement is by contamination and/or transport of the seal material by ground water. Failure to achieve seal effectiveness usually results from underestimating the difficulties of emplacement.

Second, failure to match thermal expansion characteristics of the seal with the rock may result in cracking due to temperature loading.

\subsubsection{Research at the University of Arizona}

Other aspects of borehole sealing have been studied at the University of Arizona. Jeffrey (1980) studied the mechanical interaction between a shaft or borehole plug and the surrounding rock. He found that if plug and rock mechanical properties are not matched, the stresses are less severe when the inclusion is stiffer than the surrounding rock, when the applied stress field is hydrostatic, and when the interface condition is welded. Plug and rock materials that display continuous creep must be matched closely in viscous material properties if the development of adverse stress conditions is to be avoided. Because of inherent uncertainties associated with long-term prediction of stresses and rock and plug properties Jeffrey recommended that shafts and boreholes be plugged with multisection seals.

Cobb and Daemen (1982) developed a test facility to determine the effectiveness of borehole plugging materials in rock samples subjected to three independent orthogonal stresses, a true triaxial test. Only a small amount of experimental data were obtained, but the data collected indicated that varying the applied loads resulted in less than an order of magnitude change in rock permeability for Charcoal Granite. The permeability of a plugged rock sample also varied by less than an order of magnitude. This suggests that the performance of a borehole plug in stiff rock can be estimated with only a minimum knowledge of the in-situ stresses or even changes in stresses around the borehole.

Mathis and Daemen (1982) performed an experimental and theoretical study of the damage induced by percussion and diamond drilling in the walls of holes in granite. Percussion drilling induces more damage than does diamond drilling, but the width of damage was small and primarily restricted to cracks within grains. Fuenkajorn and Daemen (1986a,b) draw similar conclusions for drilling damage in basaltic rocks.

Stormont and Daemen (1983) performed laboratory tests in which cement plugs in model boreholes were pushed out of the borehole to evaluate the mechanical strength of the plug/rock system. The plugs had a high peak 
strength and a residual strength of $30-50 \%$ of the peak strength. Stormont and Daemen concluded that cement plugs at repository depths can have strengths well in excess of anticipated loads.

Size effects on cementitious plugs have been investigated by Akgun and Daemen (1986), and scoping experiments on rock fracture grouting by Schaffer and Daemen (1986).

Field testing of borehole plugs has been described in a series of annual reports (Daemen et al., 1983, 1985, 1986). 
CHAPTER THREE

\section{EXPERIMENTAL METHODS}

To evaluate borehole seal performnace the flow through a sealed borehole in rock is compared with flow through intact rock. Rock cores $15 \mathrm{~cm}$ (6 inches) in diameter and $30 \mathrm{~cm}$ (12 inches) long (nominal dimensions) have $2.54 \mathrm{~cm}$ ( 1 inch) diameter holes drilled from each end, leaving a rock bridge in the center of the specimen (Figure 3.1a). Water pumped into the top hole flows through the specimen to the bottom hole. Once steady-state flow rates are measured, the rock bridge is drilled from the sample and replaced with a seal, and the experiment is repeated (Figure $3.1 \mathrm{~b})$. This allows direct comparison of flow rate through rock with flow rate through a seal which replaces a small portion of the same rock.

One of the main areas of interest is the performance of the seal within the rock cylinder under varying stress conditions. The rock specimen is placed under axial and confining stresses approximating a lithostatic stress field at a depth of about $1000 \mathrm{~m}$. The rock is tested, the rock bridge cored from the specimen, and a plug placed and tested while the specimen remains under this stress field. Axial and confining stresses are then lowered to simulate depths of about 600 and $300 \mathrm{~m}$, and flow through the plug/rock system is measured. Lowering the external stress field is a more severe condition with respect to the plug/rock interface because it lessens compressive radial stresses across the interface.

The method of investigation was chosen to meet two criteria. First, experimental data were desired, as opposed to computer simulation. Measurements on rocks similar to those considered for repository host rocks and on commonly used seal materials were wanted. The test procedure has the advantage of including a rock-plug interface, as opposed to measurements on individual rock cores and cement cylinders. Second, the method permits simple, straightforward data analyses which require few assumptions. The main disadvantage of the method is the long time required to complete the experiments.

Intact rock was chosen, as opposed to fractured rock, because a borehole plug seals against the intact zone of a rock mass. That is, the area in-between joints and fissures is the area in which sealing occurs. Plug material adjacent to a fracture will result in the diversion of fluid reaching that point into the fracture and out of the borehole. This raises the question of what to consider intact rock. In this work rock is considered intact if no fractures were visible, prior to testing, upon careful examination by the unaided eye.

In the following paragraphs details of the materials, apparatus, and experimental methods used are described. 


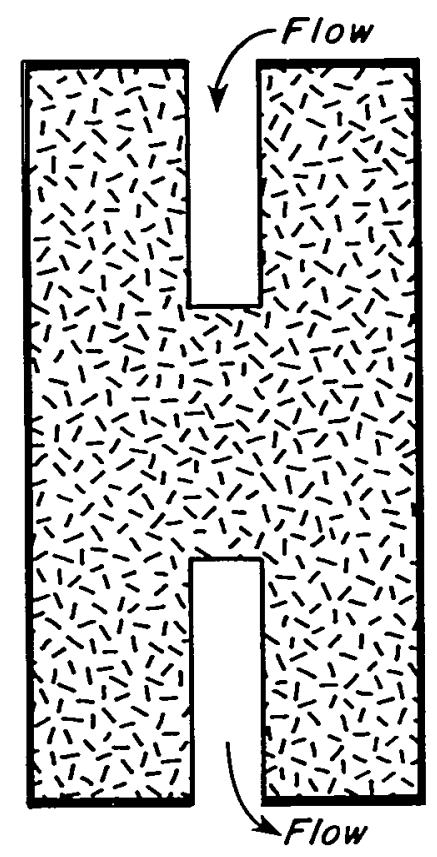

a. Sample with rock bridge.

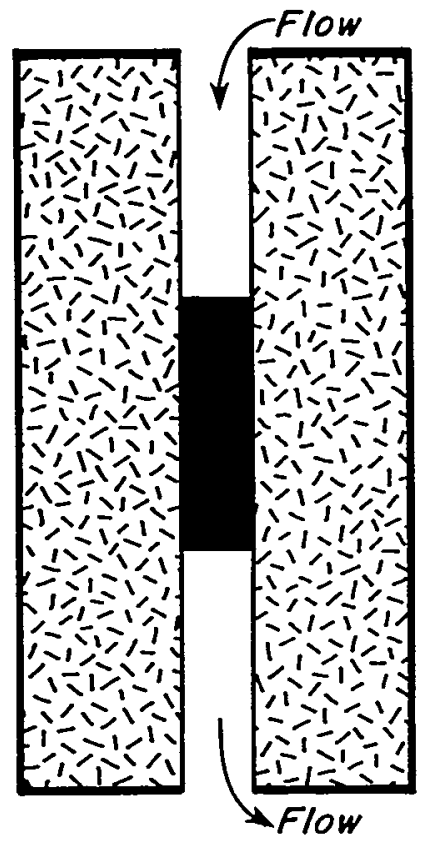

b. Sample with seal replacing rock bridge.

Figure 3.1 Experimental method: flow through intact rock is compared to flow through sealed rock. Heavy lines indicate no flow boundaries.

Rock cylinders have co-axial holes drilled from each end (a). For second sequence of experiments, rock bridge is cored out and replaced by a borehole plug. 


\subsection{Materials}

Five rock types and two seal materials were used. Rock types include three granites (Oracle granite, Charcoal granite, and Catalina granite), a basalt from the Sentinel Gap area on the Columbia Plateau, and the Topopah Spring Member of the Paintbrush tuff. Portland cement and bentonite were the two seal materials used.

A11 petrographic descriptions were provided by Laurel B. Goodwin.*

\subsubsection{Rock Types}

\subsubsection{Oracle Granite}

The Oracle granite was obtained by core drilling at a field site near Oracle, Arizona (NW1/4, S15, T10S, R16E, Campo Bonito Quadrangle, Arizona, USGS 7-1/2' Topographic Map Series). The hole cored at this site has been used for field testing by the Hydrology Department, University of Arizona (e.g. Neuman et al., 1985).

The Oracle granite is Precambrian and petrologically is a holocrystalline, hypidiomorphic-granular porphyritic quartz monzonite. The porphyritic texture is formed by phenocrysts of potassium feldspar (and possibly perthite) up to $2 \mathrm{~cm}$ in size in a medium-grained phaneritic groundmass. Figure 3.2 is a photomicrograph of the rock. Petrographic examination indicates it is $74 \%$ subhedral feldspar, $0.1-2 \mathrm{~cm}$ in size. The potassium feldspar is probably microcline with some perthite, and the plagioclase has composition $\mathrm{An}_{9}$. The feldspars have been strongly sericitized, but not completely replaced. The rock contains $20 \%$ anhedral quartz, 1-5 mm; $3 \%$ chlorite (probably pennine), 0.5-3 mm, which is probably altered biotite; $2 \%$ opaque minerals, $0.5-2 \mathrm{~mm}$, including some anhedral magnetite and pyrite and some secondary hematite; and less than $1 \%$ sphene, 0.5-0.7 mm, and zircon, $0.25 \mathrm{~mm}$.

A distinct set of roughly parallel fractures, about $0.1 \mathrm{~mm}$ or less in width cross the slide. Their spacing is $1-5 \mathrm{~mm}$ The fractures are filled with an anhedral carbonate mineral which is not identifiable petrographically, but which is probably calcite. Other signs of deformation include breaking off of small pieces of quartz and feldspar along intergrain boundaries, bending of twin lamellai, strain shadows in quartz and feldspar, and fractures in quartz, opaque minerals, and feldspars, not necessarily parallel to cleavage.

The cores of the feldspars seem more altered than the rims. Opaque minerals, probably magnetite, sphene, and sericite occur along (001) in chlorite. Cleavage planes in chlorite are bent and chlorite and sericite may be found as fine anhedral material along grain boundaries.

*1983, personal communication. 


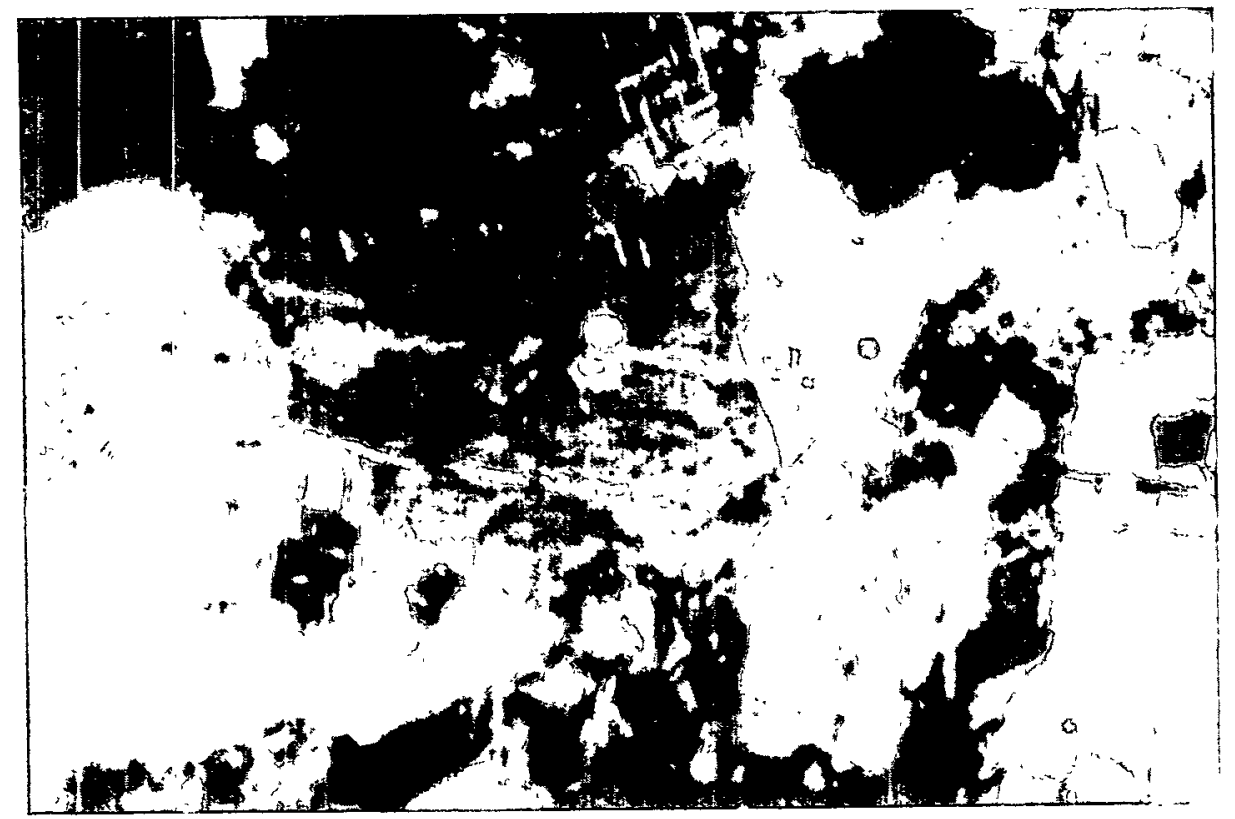

Figure 3.2 Photomicrograph of Oracle Granite. Picture is about $2.75 \mathrm{~mm}$ across.

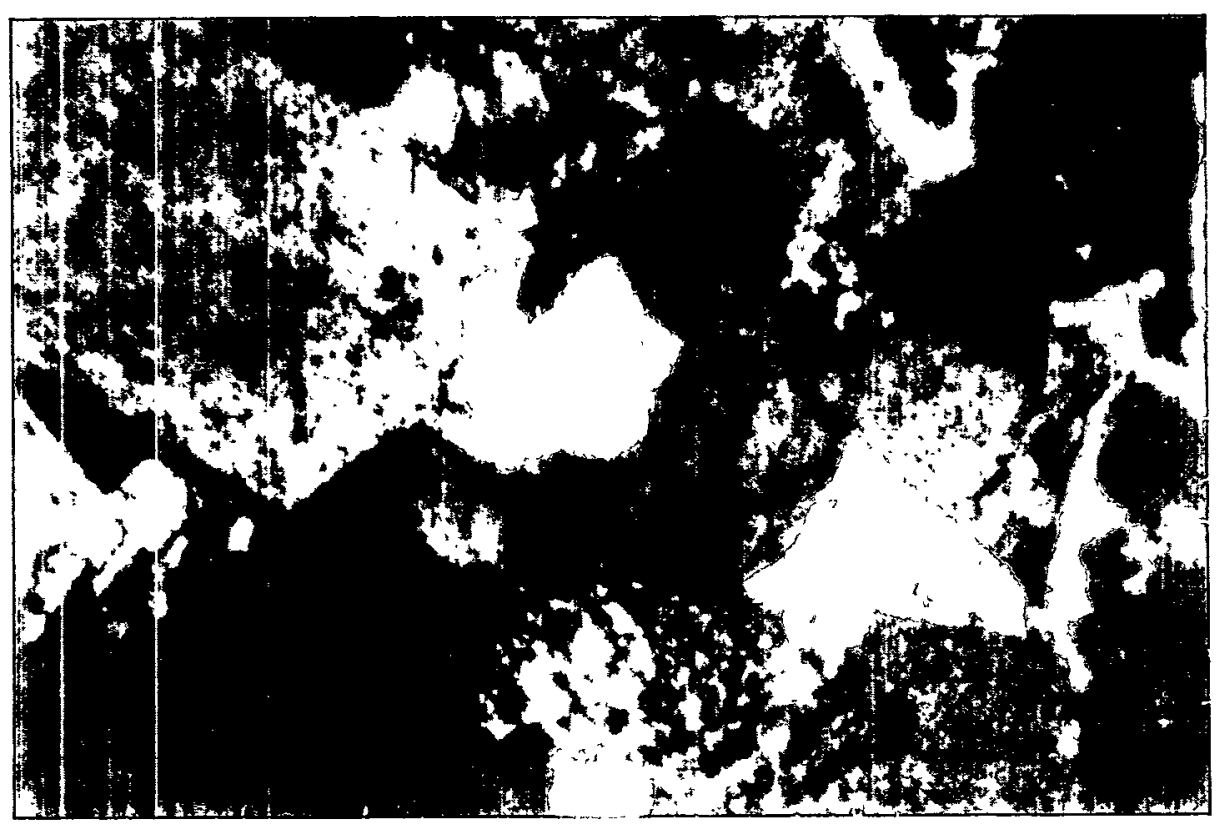

Figure 3.3 Photomicrograph of Charcoal Granite. Picture is about 2.75 mm across. 
Table 3.1 presents measured physical properties of the Oracle granite. The elastic moduli were measured for stresses up to only $24.1 \mathrm{Mpa}$, the range in which the rock is stressed in the permeameter. Throughout this range the rock is linearly elastic.

\subsubsection{Charcoal Granite}

Cores of Charcoal granite were purchased from the Cold Spring Granite Company, St. Cloud, Minnesota. The rock was quarried from their Charcoal Black Quarry, which is in the St. Cloud Gray System. The rock is Precambrian. It is a quartz monzonite and is described by the Cold Spring Granite Company as containing $68 \%$ feldspar, $18 \%$ quartz, $6 \%$ biotite, and $6 \%$ hornblende.

Figure 3.3 (previous page) is a photomicrograph of the rock. Petrographic examination indicates the samples obtained for this work are $66-67 \%$ feldspar up to $3 \mathrm{~mm}$ in size; $18 \%$ quartz up to $2.5 \mathrm{~mm}$; $5 \%$ anhedral hornblende, $0.3-3 \mathrm{~mm} ; 5 \%$ anhedral to subhedral biotite, $0.3-3$ mm.; $1 \%$ pyroxene, $0.3-3 \mathrm{~mm}$; $2 \%$ predominantly subhedral opaque minerals, $0.1-2 \mathrm{~mm}$; and less than $1 \%$ subhedral apatite, $0.1-0.2 \mathrm{~mm}$. The feldspars are composed of anhedral to euhedral plagioclase $\left(A n_{18-19}\right)$ and anhedral to subhedral potassium feldspar, probably microcline. They appear to be fractured in many places and exhibit strain shadows. Some compositional zoning and some sericitization, particularly along fractures and cleavages, was observed. Biotite in many places contains opaque minerals, possibly ilmenite, which appear to be exolved parallel to the cleavage plane (001). Pleochhroism indicates the biotite does not contain high amounts of $\mathrm{Fe}^{+3}$ or $\mathrm{Ti}$. The hornblende has characteristic green to brown pleochroism and also contains opaque inclusions. It may occur in clusters and appears to be altering to biotite at the crystal edges. Apatite is found clustered with mafic and opaque minerals, and may be included in both. Some relict clinopyroxene has been almost completely replaced by hornblende, and includes opaque minerals.

Table 3.2 presents measured physical properties of the Charcoal granite. The elastic moduli were measured for stresses up to $24.1 \mathrm{MPa}$, the maximum to which the rock is stressed in the permeameter.

\subsubsection{Catalina Granite}

The Catalina granite was obtained by core drilling at a field site near Catalina, Arizona (SE1/4,S25 (unsurveyed), T11S, R14E, Mt. Lemon, AZ, Quadrangle, USGS 15' Topographic Map Series ). The site is described in South, et al. (1982, Section 4.2.6. pp. 85-88).

The samples tested were the fine-grained phase of the Catalina granite. Figure 3.4 is a photomicrograph of the rock. The rock contains $75-80 \%$ subhedral feldspar, up to $2 \mathrm{~mm}$ in size, and $20-25 \%$ quartz, up to $1 \mathrm{~mm}$ in size, as well as about $1 \%$ biotite, up to $1 \mathrm{~mm}, 1 \%$ opaque minerals, up to $1 \mathrm{~mm}$, and accessory (less than $1 \%$ ) chlorite, apatite, sphene, rutile, and zircon. Accessory minerals are $0.1-0.5 \mathrm{~mm}$ in size. The feldspars are orthoclase and plagioclase $\left(\mathrm{An}_{14}\right)$, both of which exhibit some sericitization. 
Table 3.1 Physical Properties of Oracle Granite

\begin{tabular}{cccc} 
Sample Number & $\begin{array}{c}\text { Young's Modulus } \\
(\mathrm{MPa})\end{array}$ & $\begin{array}{c}\text { Poisson's } \\
\text { Ratio }\end{array}$ & $\begin{array}{c}\text { Density } \\
(\mathrm{gm} / \mathrm{cc})\end{array}$ \\
\hline $\mathrm{OAZ}-\mathrm{Ml}-1$ & $60.4 \times 10^{3}$ & 0.12 & 2.66 \\
$\mathrm{OAZ}-\mathrm{Ml}-2$ & $65.8 \times 10^{3}$ & 0.16 & 2.67 \\
\hline
\end{tabular}

Table 3.2 Physical Properties of Charcoal Granite

\begin{tabular}{|c|c|c|c|c|}
\hline Sample No. & $\begin{array}{l}\text { Young 's } \\
\text { Modulus } \\
(\mathrm{MPa})\end{array}$ & $\begin{array}{c}\text { Poisson's } \\
\text { Ratio }\end{array}$ & $\begin{array}{c}\text { Unconfined } \\
\text { Compressive } \\
\text { Strength } \\
\text { (MPa) }\end{array}$ & $\begin{array}{c}\text { Density } \\
\mathrm{gm} / \mathrm{cc} \\
\end{array}$ \\
\hline CG-1 & $62.46 \times 10^{3}$ & 0.25 & - & 2.70 \\
\hline $\mathrm{CG}-2$ & $58.67 \times 10^{3}$ & 0.21 & - & 2.70 \\
\hline CG-3 & $60.39 \times 10^{3}$ & 0.12 & - & 2.72 \\
\hline$C G-4$ & $53.84 \times 10^{3}$ & 0.18 & - & 2.69 \\
\hline CG-5 & $47.29 \times 10^{3}$ & 0.17 & - & 2.71 \\
\hline CG-101a & - & - & 65.90 & - \\
\hline CG-101b & - & - & 177.66 & - \\
\hline CG-101c & - & - & 131.10 & - \\
\hline$C G-102 a$ & - & - & 96.23 & - \\
\hline$C G-102 b$ & - & - & 99.23 & - \\
\hline CG-2000 & - & - & 169.60 & - \\
\hline Average: & $56.53 \times 10^{3}$ & 0.19 & 123.31 & 2.70 \\
\hline Std Dev: & $6.07 \times 10^{3}$ & 0.05 & 44.18 & 0.01 \\
\hline
\end{tabular}




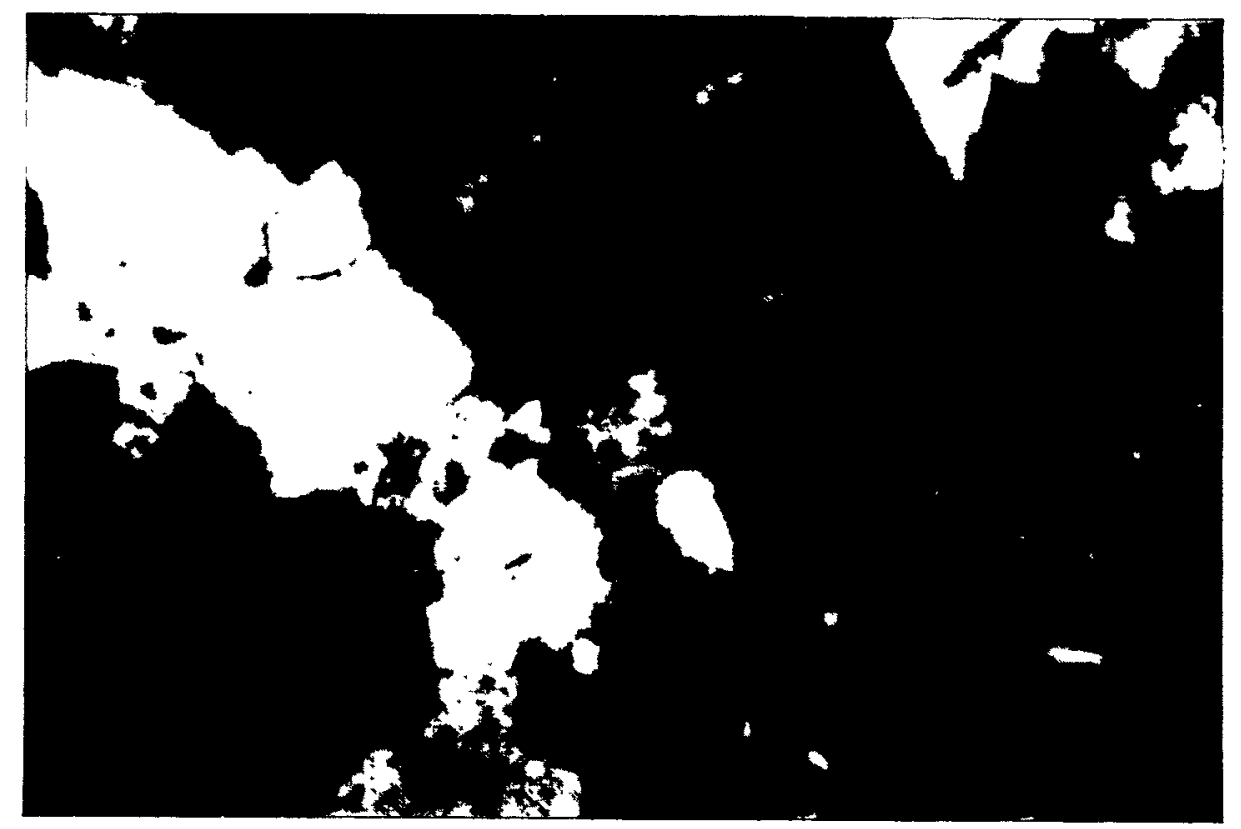

Figure 3.4 Photomicrograph of Cataline Granite. Picture is about 2.75 $\mathrm{mm}$ across.

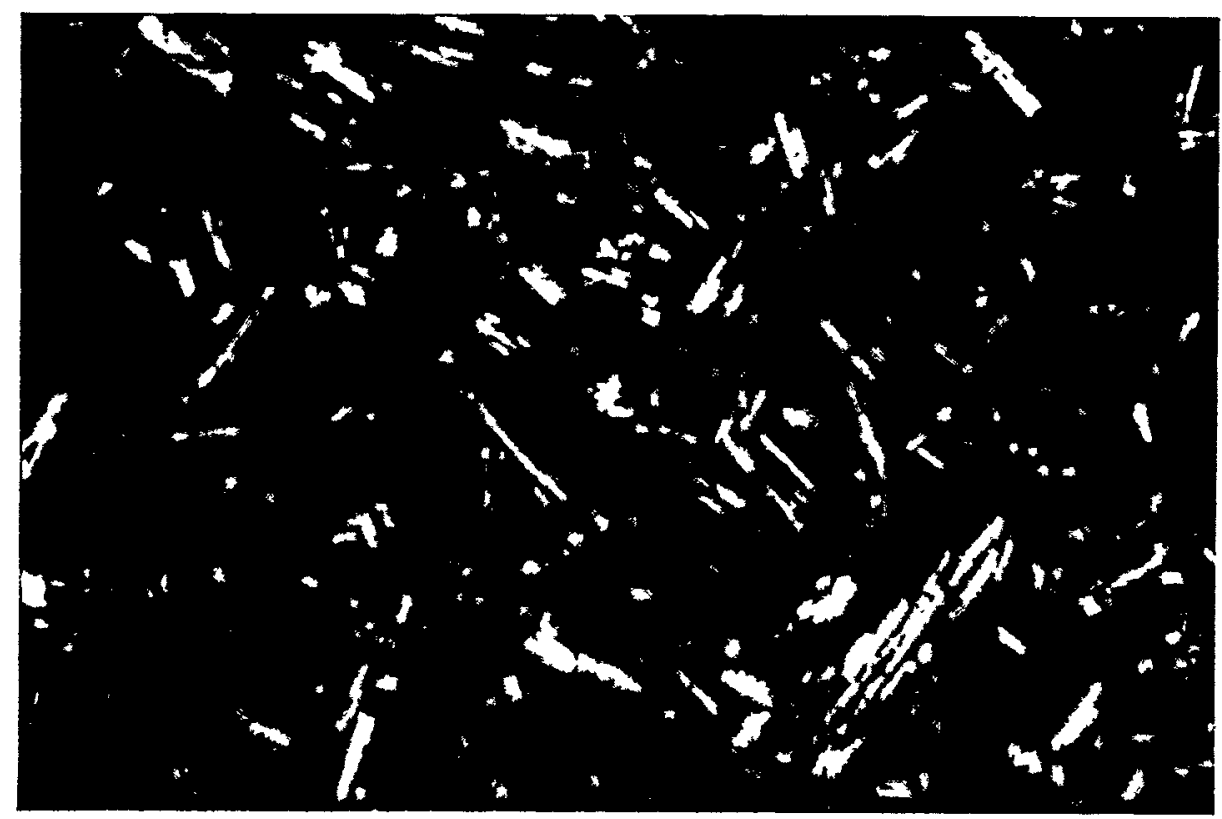

$\circ$

Figure 3.5 Photomicrograph of Sentinel Gap Basalt. Picture is about $2.75 \mathrm{~mm}$ across. 
Some of the feldspars exhibit fractures which are not parallel to cleavage; quartz is also fractured in places. Breakage along crystal boundaries is infrequent and the rock is not as deformed as the Charcoal granite. Some recrystallization has occurred, resulting in overgrowths on quartz and feldspar.

\subsubsection{Sentinel Gap Basalt}

The samples of basalt tested were all drilled from the same block, which was collected from Sentinel Bluffs, Washington (SE1/4, S15, T15N, R23E, Beverly, Washington, Quadrangle, USGS 7-1/2' Topographic Map Series). The block was collected from the bottom colonnade of flow SG/GR-8(E), as designated on "Sentinel Bluffs Stratigraphic Section, Plate III-3b, Geologic Studies of the Columbia Plateau (Rockwell International, 1979). Both samples were drilled parallel to the axis of the column from which the block came, i.e. normal to the flow layers.

The rock is dense, very dark gray to black basalt. Vugs and vesicles are absent. Figure 3.5 (previous page) is a photomicrograph of the rock. Petrographically it is $50 \%$ subhedral, randomly oriented laths of plagioclase $\left(\mathrm{An}_{40-60}\right), 0.1-0.5 \mathrm{~mm}$ in long dimension; $32-38 \%$ augite, less than $0.5 \mathrm{~mm} ; 3-15 \%$ subhedral opaque minerals, less than $0.5 \mathrm{~mm}$, some of which is magnetite; and $2-10 \%$ glass. It has an intergranular texture showing laths of subhedral plagioclase with smaller anhedral grains of augite, opaque minerals, and greenish-brown glass in the interstices. Most of the glass is fresh or just beginning to devitrify. The rock is very fresh, shows no deformation, and is fairly homogeneous.

Tables 3.3 and 3.4 present physical properties of the rock. The elastic moduli were measured for stresses of up to only $24.1 \mathrm{MPa}$, the maximum rock stress in the permeameter.

The basalt tested is in the same group as one preferred candidate repository horizon at the BWIP, but stratigraphically is lower (U.S. Department of Energy, 1984, Section 3.2.2).

\subsubsection{Topopah Spring Welded Tuff}

Blocks of welded tuff from the Topopah Spring member of the Paintbrush tuff were collected from the Nevada Test Site. This tuff is a potential candidate repository horizon (e.g. Johnstone et al., 1984). 'The blocks were collected from a surface outcrop in the eastern part of T13S, R49E of the Topopah Spring SW Quadrangle, Nevada (USGS 7-1/2' Topographic Map Series). The outcrop is shown on GQ-439, Geologic Map of the Topopah Spring Quadrangle, Nye County, Nevada (Lipman and McKay, 1965). It is on the south end of the mountain just west of Fortymile Canyon, about $2.4 \mathrm{~km}$ ( 1.5 miles) south of VABM Fran. The outcrop is faulted. The blocks collected were loose on the surface, not broken from outcrop.

The Topopah Spring member of the Paintbrush tuff is an approximately 700 ft. thick multiple flow compound cooling unit of ash flow tuff. $\circ$ The blocks collected were from the sparse lithophysal zone. "The rock is a red-brown devitrified welded tuff with gray-white eutaxitic pumice 
Table 3.3 Physical Properties of Sentinel Gap Basalt

\begin{tabular}{|c|c|c|c|c|}
\hline Sample No. & $\begin{array}{l}\text { Young's } \\
\text { Modulus } \\
\text { (MPa) }\end{array}$ & $\begin{array}{c}\begin{array}{c}\text { Poisson's } \\
\text { Ratio }\end{array} \\
\end{array}$ & $\begin{array}{c}\text { Unconfined } \\
\text { Compressive } \\
\text { Strength } \\
\text { (MPa) }\end{array}$ & $\begin{array}{c}\text { Density } \\
\mathrm{gm} / \mathrm{cc}\end{array}$ \\
\hline$S G E-2-1$ & - & - & - & 2.86 \\
\hline$S G E-2-2$ & - & - & - & 2.86 \\
\hline$S G E-2-3$ & - & - & - & 2.87 \\
\hline UNX-1 & $11.37 \times 10^{6}$ & 0.31 & - & - \\
\hline UNX-2 & $11.91 \times 10^{6}$ & 0.28 & & \\
\hline SGE--2-3-U-C3 & - & - & 376.83 & - \\
\hline$S G E-2-4-U-C 2$ & - & - & 274.53 & - \\
\hline$S G E-2-2-U$ & - & - & 109.81 & - \\
\hline SGE-2-4-U-C1 & - & - & 116.08 & - \\
\hline SGE-2-1-U-C1 & - & - & 252.08 & - \\
\hline$S G E-2-3-U-C 1$ & - & - & 321.58 & - \\
\hline SGE-2-3-U-C2 & - & - & 272.95 & - \\
\hline$S G E-1-2-U-C 1$ & - & - & 384.33 & - \\
\hline SGE-2-2-U-C2 & - & - & 315.31 & - \\
\hline Average: & $11.64 \times 10^{6}$ & 0.30 & 296.28 & \\
\hline Std Dev: & $0.38 \times 10^{6}$ & & 99.31 & \\
\hline
\end{tabular}


Table 3.4 Brazilian Tensile Strengths, $\mathrm{T}_{0}$, Sentinel Bluffs Basalt

\begin{tabular}{|c|c|c|c|}
\hline Sample No. & $\begin{array}{l}\text { Length } \\
(\mathrm{cm})\end{array}$ & $\begin{array}{c}\text { Diameter } \\
(\mathrm{cm})\end{array}$ & $\begin{array}{c}\mathrm{T}_{0} \\
\text { (MPa) } \\
\end{array}$ \\
\hline SGE-2-2-C1-B1 & 0.806 & 1.896 & 33.35 \\
\hline$S G E-2-2-C 1-B 2$ & 0.980 & 1.895 & 27.14 \\
\hline$S G E-2-2-C 1-B 3$ & 1.090 & 1.892 & 29.93 \\
\hline $\mathrm{SGE}-2-2-\mathrm{Cl}-\mathrm{B} 4$ & 0.948 & 1.896 & 25.52 \\
\hline$S G E-2-2-C 2-B 1$ & 1.034 & 1.890 & 17.39 \\
\hline$S G E-2-2-C 2-B 2$ & 0.972 & 1.903 & 28.93 \\
\hline$S G E-2-2-C 2-B 3$ & 1.214 & 1.905 & 28.89 \\
\hline$S G E-2-3-C l-B 1$ & 0.948 & 1.901 & 17.28 \\
\hline$S G E-2-3-C 1-B 2$ & 1.152 & 1.902 & 23.84 \\
\hline SGE-2-3-C1-B3 & 0.955 & 1.902 & 27.75 \\
\hline SGE-1-2-Cl-BI & 0.914 & 1.902 & 30.46 \\
\hline $\mathrm{SGE}-1-2-\mathrm{Cl}-\mathrm{B} 2$ & 0.923 & 1.902 & 23.87 \\
\hline $\mathrm{SGE}-1-2-\mathrm{Cl}-\mathrm{B} 3$ & 0.828 & 1.902 & 28.04 \\
\hline $\mathrm{SGE}-2-3-\mathrm{C} 2-\mathrm{B} 1$ & 0.780 & 1.902 & 26.72 \\
\hline$S G E-2-3-C 2-B 2$ & 0.848 & 1.906 & 37.14 \\
\hline$S G E-2-3-C 2-B 3$ & 0.983 & 1.903 & 22.11 \\
\hline$S G E-2-3-C 2-B 4$ & 0.828 & 1.904 & 33.41 \\
\hline$S G E-2-3-C 3-B 1$ & 1.048 & 1.894 & 26.82 \\
\hline$S G E-2-4-C l-B 3$ & 0.990 & 1.902 & 27.37 \\
\hline$S G E-2-4-C 1-B 4$ & 0.939 & 1.903 & 31.67 \\
\hline$S G E-2-4-C 2-B 1$ & 0.972 & 1.906 & 35.75 \\
\hline$S G E-2-4-C 2-B 2$ & 1.025 & 1.903 & 30.34 \\
\hline$S G E-2-3-C 3-B 2$ & 0.986 & 1.898 & 33.01 \\
\hline$S G E-2-3-C 3-B 3$ & 0.951 & 1.888 & 33.12 \\
\hline $\mathrm{SGE}-2-1-\mathrm{C} 1-\mathrm{B} 1$ & 1.008 & 1.904 & 37.44 \\
\hline $\mathrm{SGE}-2-1-\mathrm{C} 1-\mathrm{B} 2$ & 1.050 & 1.905 & 22.38 \\
\hline $\mathrm{SGE}-2-4-\mathrm{Cl}-\mathrm{B} 1$ & 1.034 & 1.903 & 24.16 \\
\hline $\mathrm{SGE}-2-4-\mathrm{C} 1-\mathrm{B} 2$ & 0.926 & 1.905 & 32.11 \\
\hline Average & & & 28.43 \\
\hline Std Dev: & & & 5.23 \\
\hline
\end{tabular}


comprising about $35 \%$ of the rock. The pumice is flattened at a ratio of $4: 1$ to $7: 1$ and is up to $5 \mathrm{~cm}$ in longest dimension. Lithophysal cavities may be several centimeters in size. The rock contains $1-2 \%$ lithic fragments, $0.2-1 \mathrm{~cm}$ in size.

Figure 3.6 is a photomicrograph of the rock. Petrographically a crystal vitric tuff, it is $35 \%$ glass, $60 \%$ cryptocrystalline to microcrystalline devitrified material, $5 \%$ sanidine, and less than $1 \%$ euhedral sphene, hornblende, and anhedral opaque minerals, including hematite. Glass shards are well flattened and devitrification processes have begun. Crystals radiate perpendicular to shard walls. Fiamme are largely devitrified and are probably flattened pumice fragments. Devitrification in the fiamme consists of fans of microcrystalline material radiating inward from the wall. The sanidine is anhedral to euhedral and exhibits both baveno and carlsbad twinning. Fine opaque inclusions occur, largely along cleavage planes.

\subsubsection{Seal Materials}

\subsubsection{Cement}

The cement mix used is a proprietary formulation provided by Dowell, a Division of Dow Chemical, Tulsa, Oklahoma. It is composed of Ideal Class A cement (Tijeras Canyon), and is mixed with $50 \%$ water and proprietary Dowell additives D53 (10\%), an expansive agent, and D65 (1\%), a dispersant. A11 percentages are weight percent with respect to cement. The cement is mixed according to American Petroleum Institute specifications (American Petroleum Institute, 1977). Dowell indicates that the slurry has a density of $15.7 \mathrm{lb} / \mathrm{gal}$, a strength of $26.20 \mathrm{Mpa}$ ( $3800 \mathrm{psi}$ ) after 14 days of curing at $110^{\circ} \mathrm{F}\left(43^{\circ} \mathrm{C}\right)$, and $0.18 \%$ expansion (1inear, unconfined) after 14 days.

Results of uniaxial compression tests performed for this research are summarized in Table 3.5. The Young's modulus and Poisson's ratio are secant values at peak strength. The variability of the data suggests they be regarded with caution, but estimates of $\left(10^{6}\right)$ psi for Young's modulus and 0.16 for Poiss on's ratio are probably reasonable.

The permeability of Cement System 1 has been evaluated. A sample core $3.80 \mathrm{~cm}$ in diameter was prepared in a plastic cylinder sealed on the bottom with rubber gasket material and covered on the top with plastic film. After allowing the cement to cure for 7 days under a pressure of 1 atm and at a temperature of $21 \pm 2{ }^{\circ} \mathrm{C}$ (ambient laboratory conditions), the core was removed from the cylinder and cut to $3.35 \mathrm{~cm}$ in length.

The core was placed in the coreholder of a Ruska liquid permeameter (Figure 3.7). The water column was kept at a pressure of $1.98 \mathrm{~atm}$.

\footnotetext{
${ }^{*}$ R. Spengler, 1982, personal communication.
} 


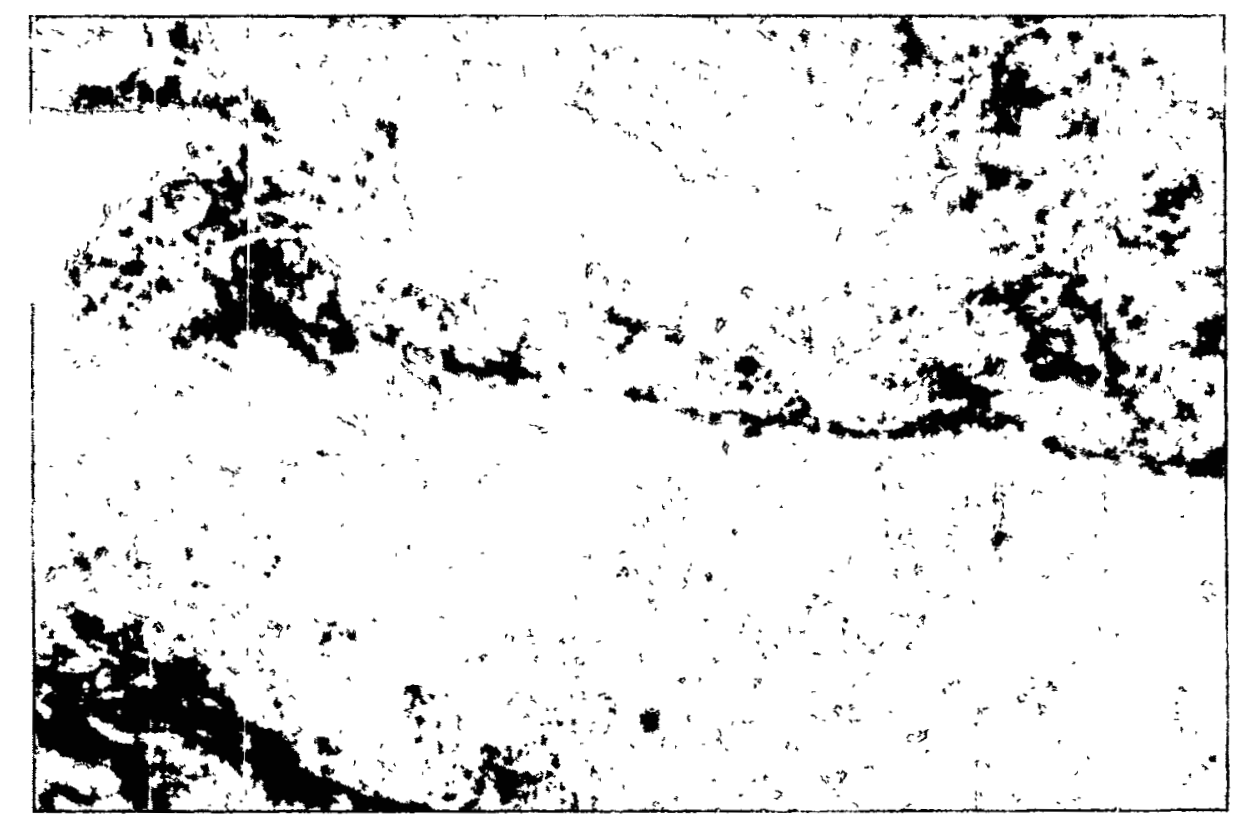

Figure 3.6 Photomicrograph of the Topopah Spring Tuff. Picture is about $2.75 \mathrm{~mm}$ across. Lower part is flattened pumice fragment, upper part shows feldspar phenocryst in glassy matrix.

Table 3.5 Mechanical Properties of System 1 Cement

\begin{tabular}{ccccc}
$\begin{array}{c}\text { Sample } \\
\text { No. }\end{array}$ & $\begin{array}{c}\text { Young's } \\
\text { Modulus } \\
\text { Gpa; }(p s i)\end{array}$ & $\begin{array}{c}\text { Poisson's } \\
\text { Ratio }\end{array}$ & $\begin{array}{c}\text { Compressive } \\
\text { Strength } \\
\text { MPa; }(p s i)\end{array}$ & $\begin{array}{c}\text { Curing } \\
\text { time } \\
\text { (days) }\end{array}$ \\
\hline 1 & $6.68 ;\left(0.97 \times 10^{6}\right)$ & 0.17 & $26.2 ;(3800)$ & 10 \\
2 & $6.89 ;\left(1.00 \times 10^{6}\right)$ & 0.15 & $16.5 ;(2390)$ & 10 \\
3 & $9.30 ;\left(1.35 \times 10^{6}\right)$ & 0.10 & $48.2 ;(7000)$ & 7 \\
\hline
\end{tabular}




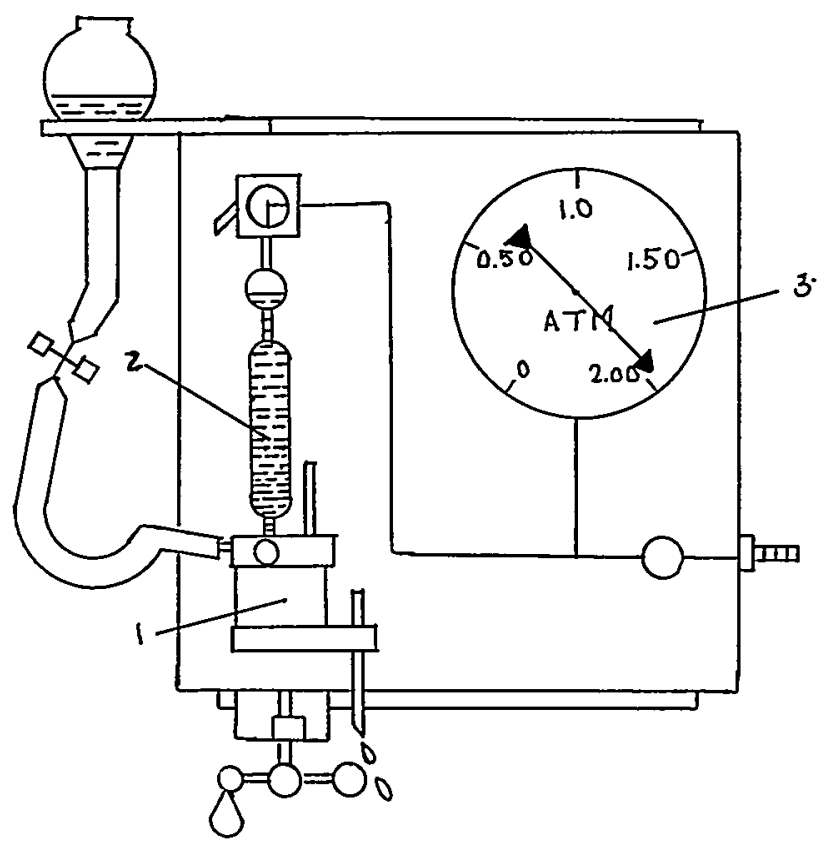

Figure 3.7 Diagram of Ruska liquid permeameter. (1) coreholder; (2) water column, (3) pressure gage. 
The test was continued 163 days, at which time $10 \mathrm{ml}$ of water had flowed through the core. An estimate of the permeability has been calculated using the Darcy formula (De Wiest, 1965, eqtns. 4.15, 4.20):

$$
\mathrm{K}=\frac{\mu \mathrm{VL}}{\mathrm{APt}}
$$

$$
\text { where, } \begin{aligned}
\mathrm{K}= & \text { permeability in darcy, } \\
\mu= & \text { viscosity in centipoise, } \\
\mathrm{V}= & \text { volume } \mathrm{in} \mathrm{cc} \text { of water which flowed through the sample, } \\
\mathrm{t}= & \text { time in seconds for the water to flow through the } \\
& \text { sample, } \\
\mathrm{L}= & \text { length of sample in } \mathrm{cm}, \\
\mathrm{A}= & \text { cross-sectional area of the sample in square } \mathrm{cm} \text {, and } \\
\mathrm{P}= & \text { pressure in atm. }
\end{aligned}
$$

The permeability of Cement System 1 was calculated to be $95 \times 10^{-9}$ darcy $\left(0.1 \times 10^{-9} \mathrm{~cm} / \mathrm{sec}\right)$.

Experiments were performed to measure the expansive stress generated by Cement System 1. Slurry was mixed and poured into three steel pipes of different thicknesses and cured for 16 days. Expansive stresses generated during curing were calculated.

The test was performed under 1 atm pressure and at a temperature of $21 \pm$ $2{ }^{\circ} \mathrm{C}$ (ambient laboratory conditions).

The tangential strain on the outside of the pipe was measured with strain gages. The expansive stress generated by the cement was calculated from the measured tangential strain according to a formula derived from Jaeger and Cook (1979, Section 5.11):

$$
\sigma_{r}=\frac{E \varepsilon}{\left(2 R_{1}^{2}\right) /\left(R_{2}{ }^{2}-R_{1}^{2}\right)}
$$

$$
\text { where, } \begin{aligned}
\sigma_{r} & =\text { expansive stress, } \\
\mathrm{E} & =\text { Young's modulus, } \\
\varepsilon & =\text { induced tangential strain, } \\
\mathrm{R}_{1} & =\text { inside radius of pipe, and } \\
\mathrm{R}_{2} & =\text { outside radius of pipe. }
\end{aligned}
$$

Figure 3.8 and Table 3.6 present the results obtained from this experiment. The highest expansive stress generated was $2.26 \mathrm{MPa}$ for the thickest (most rigid) pipe. 


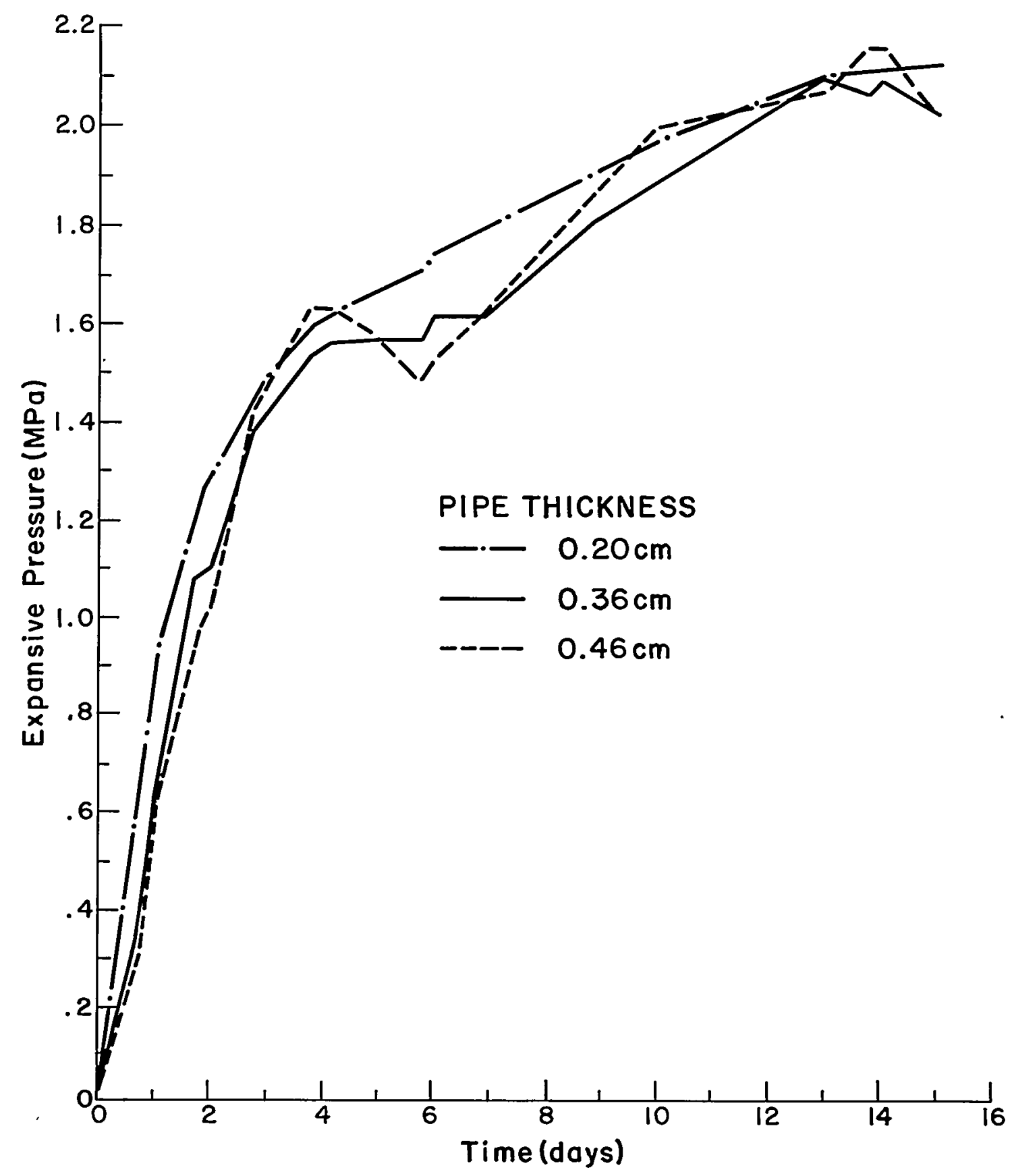

Figure 3.8 Expansive stress vs. time for Cement System 1. Expansive stress is calculated from tangential strain measured on steel pipe in which grout is cured. 
Table 3.6 Expansion Experiment Data - System 1 Cement

\begin{tabular}{|c|c|c|c|c|c|c|}
\hline Height & $\begin{array}{l}\text { Pipe Dime } \\
\text { Outside } \\
\text { Diameter }\end{array}$ & 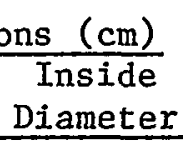 & Thickness & $\begin{array}{c}\text { Measured } \\
\text { Tangential } \\
\text { Strain } \\
\end{array}$ & $\begin{array}{c}\text { Expansive } \\
\text { Stre'ss (MPa) } \\
\end{array}$ & $\begin{array}{c}\text { Radial } \\
\begin{array}{c}\text { Displacement } \\
(\mathrm{cm})\end{array} \\
\end{array}$ \\
\hline 12.50 & 7.26 & 6.35 & 0.46 & $71 \times 10^{6}$ & 2.26 & $6.38 \times 10^{-3}$ \\
\hline 12.47 & 7.04 & 6.32 & 0.33 & $82 \times 10^{6}$ & 2.01 & $7.04 \times 10^{-3}$ \\
\hline 12.47 & 6.71 & 6.32 & 0.20 & $172 \times 10^{6}$ & 2.04 & $12.75 \times 10^{-3}$ \\
\hline
\end{tabular}

NOTES:

* System 1 Cement: Ideal Type A cement, 50\% water, 10\% D53 (expansive agent), 1\% D65 (dispersant). Provided by Dowell, Tulsa, Oklahoma.

Tangential strain measured 16 days after pouring

Tangential strain is approximately equal to half the relative volume increase (in-plane volumetric strain) of the cement within a plane normal to the sample axis. 
Comparison of the cement expansive stresses calculated from the tangential strains measured from different thickness steel pipes indicates that the radial expansive stress of a cement plug decreases linearly as the radial strain increases. Therefore, one of the factors governing the expansion characteristic of a borehole cement plug is the stiffness of the surrounding rock (Fuenkajorn and Daemen, 1986a; Daemen et al., 1986, Ch. 7).

The swe1ling pressure of System 1 cement measured by Fuenkajorn and Daemen (1986a), up to nearly $5 \mathrm{MPa}$, clearly is of a sufficient magnitude to raise concern about what the effect of excessive swelling pressures might be on the rock barrier directly adjacent to any seals. Related laboratory experiments (e.g. Akgun and Daemen, 1986; Daemen et al., 1986, Ch. 5) have resulted in tensile fracture of rock samples. It can be visualized that the tangential tensile stress induced by seal swelling could have the effect of increasing the aperture of unfavorably oriented rock fractures, particularly so around underground excavations in a rock mass subjected to highly anisotropic stressfields.

\subsubsection{Clay}

The clay chosen as a seal material was bentonite in tablet form. Bentonite is sodium montmorillonite, a highly swelling clay. The tablet form is a commercial product of the American Colloid Company, Skokie, Illinois, marketed under the name "Volclay Tablet". These preformed compressed tablets are made of high-swelling sodium bentonite which swells up to 15 times its dry volume when hydrated by fresh water. (The performance is affected by water quality.) The tablets may be dropped through standing water and are assumed to reach full swell in 24 hours. One of the purposes for which the tablets are marketed is, "Sealing abandoned wells, maintaining aquifer yield and head". In practice the tablets are simply tremied to the desired depth.

Physical properties of the tablets are:

Size: $13 \mathrm{~mm}(1 / 2$-inch) diameter tablet

Density: $2.3-2.5 \mathrm{gm} / \mathrm{cc}$

Composition: Bentonite, a hydrous silicate of alumina comprised essentially of the clay mineral montmorillonite.

Purity: Montmorillonite content about 90\% minimum. Contains small portions of feldspar, biotite, selenite, etc.

$\mathrm{pH}: \quad 8.5-10.5$

Dry density: $1.31 \mathrm{~g} / \mathrm{cc}(82 \mathrm{Ib} / \mathrm{cu}$. ft.)

*No endorsement is expressed or implied. 
Some geotechnical properties (e.g. shrinkage limit, plastic limit, liquid limit, optimum water content, etc.) of this bentonite are given by Sawyer and Daemen (1986) and Daemen et al. (1985, Ch. 5; 1986, Ch. 3).

A falling head test (Lambe and Whitman, 1969, p. 281) has been performed to measure the permeability of a plug formed by the bentonite tablets under low head.

Fourteen tablets were placed on a rubber stopper inside a $2.54 \mathrm{~cm}$ diameter plexiglass tube, covered with distilled water and let stand overnight. The tablets swelled to form a plug about $8.3 \mathrm{~cm}$. long; the top and bottom were somewhat irregular. The rubber stopper was removed and the tube filled with distilled water and covered with a small layer of vacuum pump oil to prevent evaporation. The bottom of the tube was placed in a shallow pan of water. The initial head was $58.7 \mathrm{~cm}$.

After 42 days the head had declined to $57.9 \mathrm{~cm}$ and the plug length increased to $14 \mathrm{~cm}$. Permeability of the plug was calculated according to the formula:

$$
\mathrm{K}=\frac{\mathrm{L} \ln \left(\mathrm{h}_{0} / \mathrm{h}_{1}\right)}{\mathrm{t}}
$$

$$
\text { where, } \begin{aligned}
\mathrm{L} & =\text { plug length, } \\
\mathrm{t} & =\text { elapsed time, } \\
\mathrm{h}_{0} & =\text { initial head, and } \\
\mathrm{h}_{1} & =\text { final head. }
\end{aligned}
$$

This formula yields a permeability of $31 \times 10^{-9} \mathrm{~cm} / \mathrm{sec}\left(30 \times 10^{-6}\right.$ darcy) for $a$ plug length of $8.3 \mathrm{~cm}$, and a permeability of $53 \times 10^{-9} \mathrm{~cm} / \mathrm{sec}$ ( 50 $\times 10^{-6}$ darcy) for a plug length of $14 \mathrm{~cm}$.

The test was continued, but the water in the bottom pan was allowed to evaporate. Some clay fell from the bottom of the plug, and the plug length shortened to $13.5 \mathrm{~cm}$. After 185 days the head had fallen from 56.6 to $49.7 \mathrm{~cm}$. Calculated plug permeability was $110 \times 10^{-9} \mathrm{~cm} / \mathrm{sec}$ (100 $\times 10^{-6}$ darcy).

A subsequent test, run for 35 days, resulted in a head drop from 49.9 to $48.9 \mathrm{~cm}$. Plug length was still $13.5 \mathrm{~cm}$. The permeability calculated from these data was $90 \times 10^{-9} \mathrm{~cm} / \mathrm{sec}$ ( $85 \times 10^{-6}$ darcy).

\subsection{Experimental Apparatus}

Two main items of apparatus, a permeameter and a constant pressure pump, were designed for this research and four each were constructed by the Central Machine Shop, University of Arizona Instrument Shops. A data acquisition system was assembled and software written to collect the required data. Design and construction was performed using English 
units, as is the case in most American machine shops, and English units will be cited in this section where appropriate.

\subsubsection{Permeameter Design}

An assembly drawing of the permeameter design is shown in Figure 3.9; small black rectangles indicate 0-ring seals. The permeameter is designed to accept a $15.24 \mathrm{~cm}$ ( 6 inch) diameter, $30.48 \mathrm{~cm}$ (12 inch) 1ong cylindrical rock specimen with a 1 inch diameter hole drilled along at both ends along the longitudinal cylinder axis. There is enough travel in the piston to accept samples between $27.94 \mathrm{~cm}$ (11 inches) and 31.12 $\mathrm{cm}$ (12 1/4 inches) long, using a $10.64 \mathrm{~cm}$ (1/4 inch) thick platen at the bottom of the pressure cell. Shorter specimens require a thicker platen. Longer specimens may interfere with the cell cap. The specimen diameter should be as close to $15.24 \mathrm{~cm}$ ( 6 inches) as possible to match the diameter of the piston. Aluminum platens, as indicated on Figure 3.9, are usually closer to the stiffness properties of rock; stainless steel platens were used for most of this work, however, because they are more chemically inert.

A nominal axial stress of up to $21 \mathrm{MPa}$ (3000 psi) may be applied to the rock cylinder by tightening the bolts. The load thus applied is measured with a load cell. A loading platen on top of the load cell has a hemispherical top which matches a hemispherical seat in the bottom of the top plate.

Fluid may be pumped into the top hole, the bottom hole, and the annulus between the rock cylinder and the pressure cell. (Fittings through the cell to the annulus are not shown on the assembly drawing because they are out of the plane of the section.) Neoprene gaskets are cut as needed from a $0.16 \mathrm{~cm}(1 / 16$ inch) thick sheet and used to seal the ends of the rock cylinder, isolating the annulus from the top hole and bottom hole. These gaskets are shown as heavy lines on the assembly drawing.

Nominal maximum fluid pressure is $21 \mathrm{MPa}$ (3000 psi). The permeameter was designed to operate at room temperature, but will perform at temperatures of up to $80^{\circ} \mathrm{C}$. It may be possible to use higher temperatures, but additional safety analyses should be performed, particularly if temperatures above the vaporization point of water are involved.

Access to the interior of the specimen is provided by removing the piston plug and the bottom plug. This may be done while the specimen is under an axial stress and, if pressure is maintained about the annulus, under a confining stress.

A centering pin in the bottom plug is used to align the specimen when it is placed in the permeameter; the pin is removed during testing.

The specimen is coated with epoxy on the outside to prevent fluid seepage from the annulus through the rock to the center holes. An axial stress is applied by tightening the bolts and a confining.stress applied by pressurizing water in the annulus between the specimen and the 


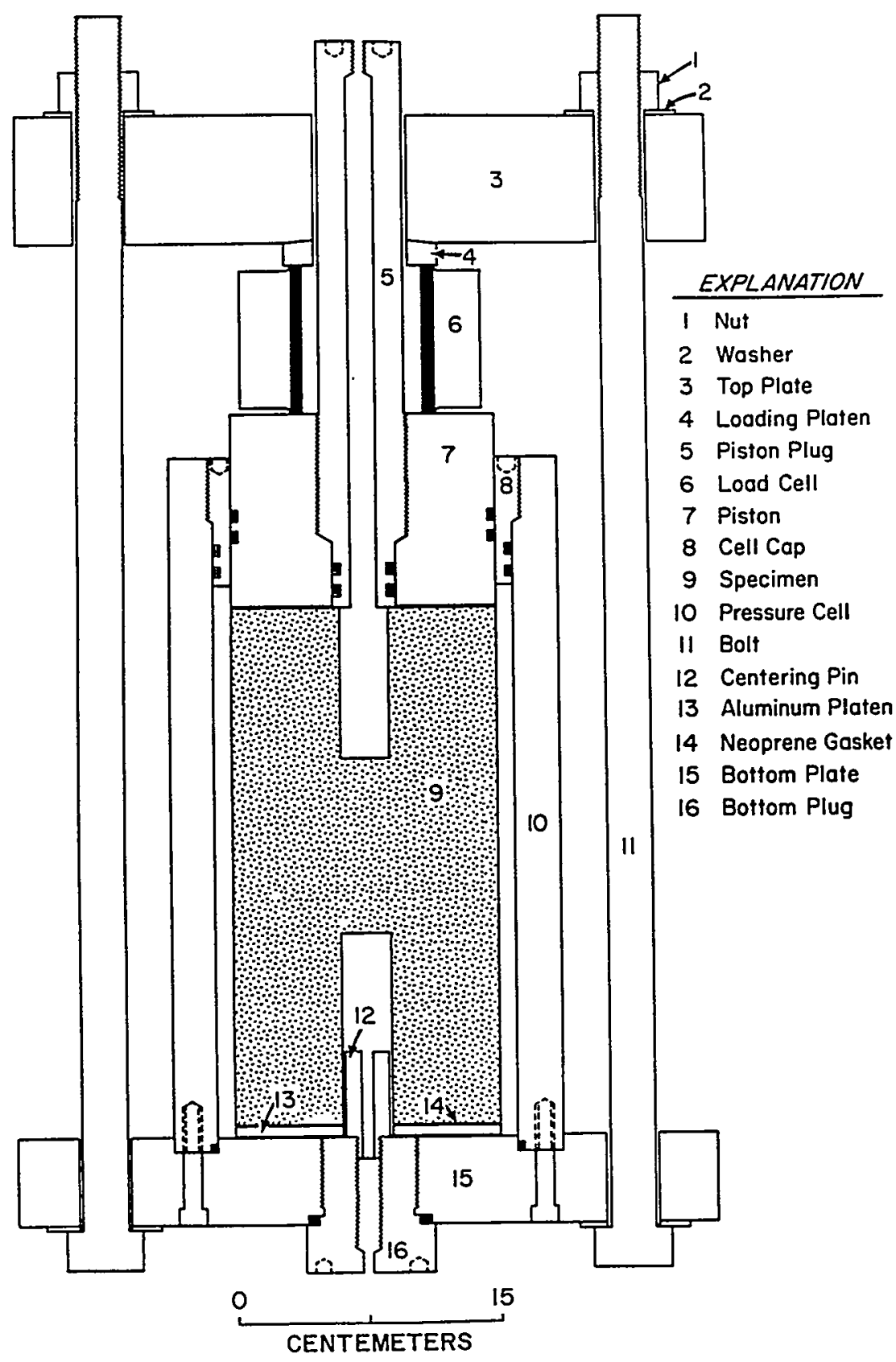

Figure 3.9 Radial permeameter assembly drawing. Small black rectangles indicate 0-ring seals. 
pressure ce11. At this point, pressure in the top and bottom holes of the specimen may be zero. The neoprene gaskets at the ends of the specimen maintain the confining pressure. Sealing by the gaskets depends upon an axial stress higher than the confining stress. It is not possible to maintain a higher confining stress than axial stress. Using an axial stress of $22.8 \mathrm{MPa}$ it is possible to maintain a confining stress of $19.6 \mathrm{MPa}$ within $2 \%$ over a period of 24 hours. The confining stress is applied with a manual pump, which is disconnected after pressurization so that there is no continuous supply of water to the annulus. Thus, pressure is either maintained or drops as water leaks through the sample end seals. A pressure drop of $0.01 \mathrm{MPa}$ corresponds to a leakage of about $0.007 \mathrm{cc}$ of water through the end seals.

Good sealing can be obtained only if the ends of the specimen are parallel. Care must be taken to ensure parallelism when specimens are prepared, as discussed under sample preparation techniques.

The permeameter AISI ${ }^{*}-4140$ steel has a tensile strength of $1000 \mathrm{MPa}$ $(145,000 \mathrm{psi})$ and a yield point of $900 \mathrm{MPa}(131,000 \mathrm{psi})$. The bolts were heat-treated to obtain a tensile strength of $1310 \mathrm{MPa}(190,000$ psi). No other pieces were heat-treated. SAE Grade $8,2.54 \mathrm{~cm}$ ( 1 inch) diameter, 14 thread-per-inch nuts, are used on the bolts. These have a minimum tensile strength of $1035 \mathrm{MPa}$ (150,000 psi) (Baumeister and Marks, 1967, pp. 8-35, Table 30) and were purchased commercially. The bolts are made by threading a nut on one end of a piece of 1-inch round stock and welding it in place. The other end is then threaded and the bolt sent to be heat treated.

Table 3.7 lists the parts necessary to construct one permeameter. Flareless tube fittings and $3.2 \mathrm{~mm}$ (1/8 inch) diameter high-strength stainless steel tubing are used to connect the permeameter to other equipment. For this work, Hoke Gyrolok brand fittings and needle valves (D3712G2Y) were used. The tubing was $3.2 \mathrm{~mm}\left(1 / 8\right.$-inch $0 . \mathrm{D}_{\text {. }}$ ) seamless, annealed 316 stainless steel tubing with an allowable working stress of $87 \mathrm{MPa}(12,641 \mathrm{psi}$ ) (ASTM A-213). Tubing with a higher working stress than necessary for safety was used to make the system as rigid as possible (that is, to minimize expansion of the tubing as pressure is applied).

Design calculations were based on a $21 \mathrm{MPa}$ ( $3000 \mathrm{psi}$ ) axial stress and a $21 \mathrm{MPa}$ (3000 psi) fluid confining pressure.

The highest stresses occur in the bolt threads, which have a factor of safety (FS) of 2.6 assuming a stress concentration on threads of 4 (Spotts, 1971, p. 227) and a single nut. The nonthreaded portion of the bolts has FS $=10.6$.

\footnotetext{
*American Iron and Steel Institute
} 
Table 3.7 Radial Permeameter Parts List

\begin{tabular}{|c|c|c|}
\hline Part & Number Needed & Made From \\
\hline SAE Grade 81 1" Nuts & 18 & Purchase commercially \\
\hline $1 "$ Washers & 12 & Purchase commercially \\
\hline Bolts & 6 & $I^{\prime \prime}$ round stock \\
\hline Top Plate & 1 & $\begin{array}{l}15-1 / 4^{\prime \prime} \text { diameter, } \\
3^{\prime \prime} \text { thick piece }\end{array}$ \\
\hline Bottom P1ate & 1 & $\begin{array}{l}15-1 / 4 " \text { diameter, } \\
2^{\prime \prime} \text { thick piece }\end{array}$ \\
\hline Loading Platen & 1 & $\begin{array}{l}1-1 / 4^{\prime \prime} \text { thick, } \\
3-1 / 2^{\prime \prime} \text { diameter piece }\end{array}$ \\
\hline 50 Ton Load Ce11 & 1 & Purchase commercially \\
\hline Piston Plug & 1 & $2-1 / 4^{\prime \prime}$ round stock \\
\hline Piston & 1 & $6-1 / 4^{\prime \prime}$ round stock \\
\hline Cell Cap & 1 & $\begin{array}{l}7-1 / 4^{\prime \prime} \text { o.D. tubing, } \\
0.875^{\prime \prime} \text { wa11 }\end{array}$ \\
\hline Pressure Cel1 & 1 & $\begin{array}{l}8-3 / 4^{\prime \prime} \text { o.D. tubing, } \\
1-1 / 2 " \text { wal1 }\end{array}$ \\
\hline Bottom plug & 1 & $3 "$ round stock \\
\hline $\begin{array}{l}\text { A-320 0-Ring } \\
\text { (for Piston PIug) }\end{array}$ & 2 & Purchase commercially \\
\hline $\begin{array}{l}\text { A-331 0-Ring } \\
\text { (for Bottom Plug) }\end{array}$ & 1 & Purchase commercially \\
\hline $\begin{array}{l}\text { A-358 0-Ring } \\
\text { (for Piston) }\end{array}$ & 2 & Purchase commercially \\
\hline $\begin{array}{l}\text { A-362 0-Ring } \\
\text { (for Cell Cap) }\end{array}$ & 2 & Purchase commercially \\
\hline $\begin{array}{l}\text { A-363 0-Ring } \\
\text { (for Bottom Plate) }\end{array}$ & 1 & Purchase commercially \\
\hline
\end{tabular}

Material used is AISI ${ }^{*}-4140$ steel. Stock must be sufficiently over the final dimensions to allow for clean-up and machining. Dimensions given in this table are stock dimensions, not final dimensions.

*American Iron and Steel Institute 
The top plate, $7.62 \mathrm{~cm}$ ( 3 inches) thick, $38.74 \mathrm{~cm}$ (15 $1 / 4$ inches) diameter, was designed using formulae from Roark and Young (1975, p. 334, Table 24, Load Case 1a). The loading on the plate was approximated as a line load at the inner circumference of the plate and the bolts were approximated as a simply supported outer edge. This resulted in FS =5.9. The bottom plate $5.08 \mathrm{~cm}$ (2 inches) thick, $38.74 \mathrm{~cm}(151 / 4$ inches) diameter, was designed similarly, except that a $21 \mathrm{MPa}$ (3000 psi) stress on a $15.24 \mathrm{~cm}$ ( 6 inch) diameter rock cylinder was approximated as an annular line load of radius $7.62 \mathrm{~cm}$ ( 3 inches). This assumes the plate will tend to rotate about the outer edge of the cylinder. This design has FS $=5.4$. The top plate is thicker than the bottom plate because the inner load on the top plate is much more concentrated than the inner load on the bottom plate, resulting in higher bending stresses.

The critical point on the cell cap is at the threads, which hold the cap into the pressure cell. For $21 \mathrm{MPa}$ (3000 psi) exerted upward on the bottom of the cap, FS $=43.1$. The piston plug may also have $21 \mathrm{MPa}$ (3000 psi) exerted upward on its $3.81 \mathrm{~cm}$ ( $11 / 2$ inch) diameter base; this results in FS $=78.4$. Similarly, $21 \mathrm{MPa}(3000 \mathrm{psi})$ exerted on the bottom plug results in $F S=32.5$. Eighteen $3 / 8$-inch cap screws must resist the force being exerted on the cell cap. This results in FS= 30.8 with respect to the metal in the cylinder. The stress in the cap screws is $112 \mathrm{MPa}(16,200 \mathrm{psi})$ based on a stress-bearing area of $.047 \mathrm{sq}$ cm (0.0733 sq inch) (Baumeister and Marks, 1967, pp. 8-14, Table 1).

The pressure cell has an outside diameter of $22.23 \mathrm{~cm}$ ( $83 / 4$ inches), $3.81 \mathrm{~cm}$ ( $11 / 2$ inch) thick walls, and an overall length of $40.64 \mathrm{~cm}$ (16 inches). It was designed using Equation 174 of Timoshenko (1976, p. 208) and has FS $=11$.

The 0-ring seals must hold $21 \mathrm{MPa}$ (3000 psi) water pressure. The dimensions given above are nominal. Machining to close tolerances is required only for the 0-ring seals. Tolerances may be obtained by referring to manufacturer's specifications. The inside of the pressure cell does not have to be machined to close tolerances except at the ends. The top plug, bottom plug, and pressure cell were tapped to accept 1/8-inch NPT (National Pipe Thread) fittings. The bolts were threaded to fit the commercially purchased nuts. All other threads were 10 threads per inch. Holes were tapped in the top plug, the bottom plug, and the cell cap to accept a spanner wrench. In the case of the cell cap a spanner wrench was made from a piece of pipe. The outside of the permeameters was painted for corrosion resistance. Engine paint resistant to temperatures up to $315^{\circ} \mathrm{C}$ was used. Parts not painted were cadmium plated.

Steel pallets were constructed on which to place the permeameters, and a pallet truck used to move them about. Holes for lifting are tapped on the top plate for drop-forged eyebolts. The weight of the assembly is about $230 \mathrm{~kg}$ ( $500 \mathrm{lbs}$ ), and access to the bottom is obtained by turning the entire permeameter over when it is assembled, using an overhead crane. 


\subsubsection{Pump Design}

Water must be supplied to a specimen in the permeameter at a constant pressure and a very slow rate. To be able to compare experiments it is desirable to set the pressure and let flow rates be controlled by the permeability of the rock/plug system, as opposed to injecting water at a constant rate and letting pressure fall where it may.

A constant pressure pump was designed and four were constructed by the Central Machine Shop, University of Arizona Instrument Shops. Figure 3.10 is an assembly drawing of the pump. Compressed nitrogen is supplied to a large diameter cylinder, forcing a piston downward. A smaller piston is thus forced into a cylinder containing water, forcing water out of the bottom of the small cylinder at constant pressure. The fitting connected to the bottom of the water cylinder is connected with tubing to a fitting on the permeameter.

Pressure intensification is approximately 11-1/2. A nitrogen pressure of $1.38 \mathrm{MPa}$ (200 psi) yields a water pressure of $15.86 \mathrm{MPa}$ (2300 psi). At these values the gas cylinder has a safety factor of 176 and the water cylinder a safety factor of 34. The pumps are made of stainless steel, and the safety factors were calculated using a tensile strength of $586 \mathrm{MPa}(85,000 \mathrm{psi})$. The gas cylinder and water cylinder are connected by eight $1.91 \mathrm{~cm}(3 / 4 \mathrm{inch})$ diameter rods through flanges welded to the cylinder ends. The other end of each cylinder is capped by a round plate held on with cap screws. The capping plates are drilled and tapped for 1/8-inch NPT fittings and use an 0 -ring to provide a static seal. At the flange end of the cylinders sliding seals are necessary as the pistons must slide back and forth. Two 0-rings, separated by spacers, and a packing nut are used to provide these seals. In the case of the gas cylinder "Bal Seal" brand teflon 0-rings are used. Standard teflon 0-rings are used to provide the seal on the water cylinder to avoid the use of grease which could contaminate the water.

The main pump limitation is that pressures below about $1 \mathrm{MPa}$ (150 psi) cannot be maintained constant because of 0-ring friction. 0-ring friction is responsible for pressure fluctuations of 0.1 to $0.2 \mathrm{MPa}$ (10 to 20 psi) at higher pressures as well.

The pistons and the 0-ring seals at the cylinder ends require precise machining. The cylinders do not require precision machining throughout most of their length; it is sufficient that there is enough clearance for the pistons to travel freely. The pistons are chromed and the surface finished to a roughness of less than 2 microns to lower friction at the 0-rings.

The volume of water pumped must be measured precisely. The piston has a stroke of $25.40 \mathrm{~cm}$ (10 inches) and a diameter of $2.49 \mathrm{~cm}(0.980$ inches). A travel of $0.003 \mathrm{~cm}(0.001$ inch) corresponds to a volume of $0.0124 \mathrm{cc}$. Piston travel is measured using a linear encoder interfaced with the microcomputer controlled data acquisition system. 


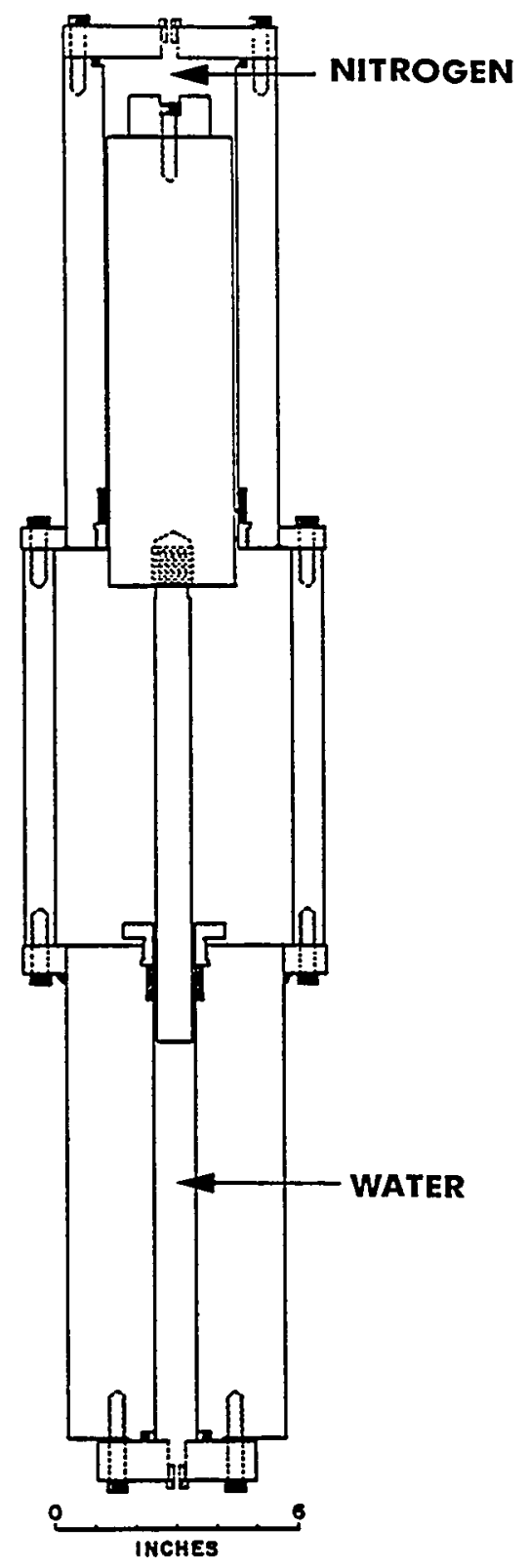

Figure 3.10 Constant pressure pump assembly drawing. Gas pressurized in the top cylinder forces the large diameter piston down, pressurizing water in the bottom cylinder. Pressure intensification is 11.5 . 
Provision is also made on the pumps for mounting a long-range dial indicator which measures to the nearest $0.003 \mathrm{~cm}(0.001$ inch).

\subsubsection{Data Acquisition System}

Data are collected using an automatic data logging system. A Model PC100B microcomputer made by Applied Microtechnology, Tucson, Arizona, monitors transducers to measure the necessary values.

The volume of water pumped into the sample is measured by monitoring the pump piston displacement with a Heidenhain Pos-Econ Model 501 linear encoder connected to a circuit card designed by Applied Microtechnology.

The water flowing out of the sample is collected in a flask which sits on a Gould Model UC-3 force transducer. This analog device is connected to an analog-to-digital voltage converter card in the microcomputer. Reading the force transducer yields the amount of water which has flowed out of the sample. Evaporation is controlled by a thin layer of vacuum pump oil on top of the water.

Fluid pressure is measured using National semiconductor Model LX-1450AF and LX-1460AF pressure transducers. The Model LX-1450AF has a range of 0-14 $\mathrm{MPa}$ (0-2000 psi) and the Model $\mathrm{LX}-1460 \mathrm{AF}$ a range of $0-21 \mathrm{MPa}$ (0$3000 \mathrm{psi})$. The lower pressure range is used to measure pressure in the top hole and the higher pressure range to measure pressure in the annulus. The pressure transducers are also analog devices and are connected to the analog-to-digital voltage converter card.

As connected, the linear encoder has an accuracy of $0.0020 \mathrm{~cm}(0.0008$ inch), the force transducers of $0.02 \mathrm{gm}$, and the pressure transducers of 0.07 and $0.10 \mathrm{MPa}$ ( 10 and $15 \mathrm{psi}$ ) for the $\mathrm{LX}-1450 \mathrm{AF}$ and the LX-1460AF, respectively.

Axial stress is monitored using fifty ton ( $445 \mathrm{kN}$ ) capacity load cells. These are not connected to the data acquisition system. Each load cell is connected by a cable and junction box to a strain indicator unit which, when read, allows the total axial load on a sample to be calculated. Axial stress depends on the exact sample diameter. Loads are accurate to about $400 \mathrm{~N}(90 \mathrm{1b})$. This equipment was furnished by Terrametrics, Inc., Golden, Colorado.

\subsection{Experimental Procedure}

\subsubsection{Sample Preparation and Loading}

$15.24 \mathrm{~cm}$ ( 6 inch) diameter samples are obtained either by laboratory coring of boulders collected from the field or by field drilling. The cylinders are cut to length, $30 \mathrm{~cm}$ (12 inches) with a diamond saw and the ends ground flat and parallel.

Grinding is one of the more important steps, as flat, parallel ends are necessary to obtain good end seals and to insure a uniform stress distribution. Sample ends are prepared to specifications set forth by 
the International Society for Rock Mechanics (1978) for preparing samples for uniaxial compressive strength testing. This specification states that the ends shall be flat to $0.02 \mathrm{~mm}$ and shall be parallel to within $0.10 \mathrm{~mm}$ in $50 \mathrm{~mm}$. Samples are prepared and flatness and parallelism checked with a dial gage.

Next, $2.54 \mathrm{~cm}$ ( 1 inch) diameter holes are drilled along the sample axis from each end to a depth of one-third the total sample length. Centering is aided by means of a jig made for this purpose. The holes are drilled with a core drill. When the desired depth is reached the core drill is withdrawn and the core broken off. A blind bit is then used to flatten the bottom of the hole.

In order to prevent seepage of water into the sides and ends of the sample, several coats of epoxy (Scotch Weld Structural Adhesive 2216) are applied. Next, the sample is placed in the permeameter and a small axial load is applied to keep the top plate secure. The permeameter is turned over, the bottom plug removed, and the bottom hole filled with distilled water. Enough water is poured into the bottom hole so that when the bottom plug is replaced, water is forced from the valve, ensuring that no air is entrapped.

The permeameter is righted and connected to a pump, ready for saturation and testing.

\subsubsection{Testing}

Initial testing of a cylinder is with a rock bridge in place. First axial and confining stresses are applied to the sample. A vacuum pump is connected to the top hole. At this time the bottom hole is filled with water and its valve is closed. The vacuum draws the air from the top hole and from the sample's pore space. Distilled water is then injected into the top hole through a manifold which allows the water to be injected without admitting air to the top hole. Hence, the air has been withdrawn from the sample and water is now injected to saturate it.

Once the sample has been saturated, as evidenced by water flowing from the bottom hole of the sample at the same rate as it is injected into the top hole, formal testing begins.

Table 3.8 summarizes the nominal test schedule. With the sample under an axial stress of $23 \mathrm{MPa}$ and a confining stress of $20 \mathrm{MPa}$, a fluid pressure of $10.0 \mathrm{MPa}$ is applied to the top hole by the constant pressure pump. Water flows through the sample to the bottom hole, which is at zero pressure. Flow from the bottom hole is collected in a flask and weighed; flow into the top hole is measured by pump piston displacement.

During the test, axial stress is maintained by the permeameter bolts and confining stress is maintained by fluid pressure in the annulus. No pump is permanently connected to the annulus. Any leakage results in a drop in annulus pressure and is detected by this pressure drop. Annular pressure is kept higher than top and bottom hole pressures. 
This table summarizes the nominal test schedule for one experiment on one-rock-type/one-plug-type combination.

\section{$\underline{\text { Tasks }}$}

1. Load permeameters, check seals

2. Saturate, establish flow

3. Test at axial stress $=23 \mathrm{MPa}$, confining stress $=20 \mathrm{MPa}$

$$
\begin{aligned}
& \text { Injection Pressure }=10.0 \mathrm{MPa} \\
& \text { Injection Pressure }=7.0 \mathrm{MPa} \\
& \text { Injection Pressure }=3.5 \mathrm{MPa}
\end{aligned}
$$

4. Core out sample, place plug

5. Cure cement

6. Re-establish flow

7. Test at axial stress $=23 \mathrm{MPa}$, confining stress $=20 \mathrm{MPa}$

$$
\begin{aligned}
& \text { Injection Pressure }=10.0 \mathrm{MPa} \\
& \text { Injection Pressure }=7.0 \mathrm{MPa} \\
& \text { Injection Pressure }=3.5 \mathrm{MPa}
\end{aligned}
$$

8. Reduce stress; axial stress $=15.0 \mathrm{MPa}$, confining stress $=13.5 \mathrm{MPa}$

$$
\begin{aligned}
& \text { Injection Pressure }=10.0 \mathrm{MPa} \\
& \text { Injection Pressure }=7.0 \mathrm{MPa} \\
& \text { Injection Pressure }=3.5 \mathrm{MPa}
\end{aligned}
$$

9. Reduce stress; axial stress $=8.5 \mathrm{MPa}$, confining stress $=7.0 \mathrm{MPa}$

$$
\begin{aligned}
& \text { Injection Pressure }=3.5 \mathrm{MPa} \\
& \text { Injection Pressure }=1.7 \mathrm{MPa}
\end{aligned}
$$


Following the test at $10 \mathrm{MPa}$ top hole pressure, tests are performed at 7 $\mathrm{MPa}$ and $3 \mathrm{MPa}$ to provide data on the variation in flow rate with fluid pressure. Upon completion of the tests at the three different top hole fluid pressures, the rock bridge is cored from the sample. Axial and confining stress are maintained during this operation. A cement plug cement is then placed. The cement is mixed according to American Petroleum Institute specifications (American Petroleum Institute, 1977). A rubber stopper is placed at the location of the bottom of the rock bridge. The cement is covered with water and allowed to cure. Following curing the rubber stopper is removed and the same series of tests performed on the rock bridge is performed on the cement plug. Flow through the plug will thus be directly comparable with flow through the intact rock.

Next the axial and confining stresses to which the sample is subjected are reduced and the test series repeated. This will test the effect of varying (decreasing) stress fields on the plug. Axial stress is reduced to about $15 \mathrm{MPa}$ and confining stress to about $13.5 \mathrm{MPa}$. Following this test series axial and confining stress are again reduced, to 8.5 and 7.0 $\mathrm{MPa}$, respectively. To avoid inducing tensile stresses, and to maintain the end seals, injection pressures of 3.5 and $1.7 \mathrm{MPa}$ are used. 
CHAPTER FOUR

EXPERIMENTAL RESULTS

Ten sets of experiments were performed, each taking several months. Nine of the experiments used cement system 1 plugs; bentonite tablets were used in the other one. Data collected were as follows:

(1) Date: Dates over which data were collected. Each experiment consisted of a sequence of tests at a combination of axial stress, confining stress, and top injection pressure. An individual test ususally was performed overnight or for several days, although some tests took only a few hours.

(2) Elapsed time: Total time test ran.

(3) Axial stress: Axial stress on the rock sample. Ideally constant, the axial stress in fact varied slightly throughout a test. Values reported are averages. Variation is on the order of $1 \%$, and is linked to variation in confining stress.

(4) Confining stress: Stress applied about the annulus of a sample. Confining stress varied by about $2 \%$, occasionally more. Usually confining stress decreased as a test proceeded, probably due to slight leakage through the end seals of the sample. Due to the Poisson effect, this caused a smaller decrease in axial stress. Although creep would have similar effects, creep of this exceedingly strong rock with linear stress-strain behavior appears unlikely, especially at the low stress levels applied here.

(5) Top pressure: Pressure at which water is injected into the top hole of the sample. The value shown is the average over the test. Top pressure may vary by 0.1-0.2 $\mathrm{MPa}$ due to 0-ring friction in the pump. Top pressure is also referred to as injection pressure.

(6) Bottom pressure: Pressure in the bottom hole of the sample. A tube leads from the bottom hole to a flask where water flowing out is collected. The flask is open to the atmosphere, so bottom pressure is always zero (gage).

(7) Flow rate in: The volume of water injected into the top hole divided by the elapsed time.

(8) Flow rate out: The volume of water flowing out of the bottom hole divided by the elapsed time. 
In steady-state saturated conditions the amount of water flowing into the sample should equal the amount flowing out. This mass balance was usually within $10 \%$. Discrepancies were due to end seal leakage and to losses when connecting and disconnecting lines. The confining stress was supplied by a manual pump which was connected repeatedly to the annulus to replenish water lost by end seal leakage. The water loss resulted in annular pressure drop. The amount of water required to replenish annular pressure was not recorded in the earlier experiments, but was recorded in the later ones. Sometimes the mass balance was very good if the volume of water added to the annulus to replenish pressure was accounted for, but in some cases this did not totally explain a mass imbalance. Mass balances were generally better at higher flow rates.

The confining stress (water pressure in the annulus) was kept higher than the top pressure and the bottom pressure (bottom pressure was always zero). Thus, leakage could occur from the annulus to the top hole, to the bottom hole, or to both, but no leakage to the annulus could occur. As no pump was permanently connected to replenish annular water, the annular pressure (confining stress) fell when leakage occurred.

If annular water leaked into the top hole and flowed out to the bottom flask, it had to flow through the rock. This resulted in less "flow in water" as measured by the top hole injection pump. In this case the flow rate out is probably closest to the true intended value, i.e. flow through plug (or rock bridge) and through the rock cylinder, and flow rate in is low. Conversely, if annular water leaked into the bottom hole, it did not flow through the rock. In this case, the flow rate in is closest to the true value and flow rate out is high. Thus, the flow rate in and the flow rate out bracket the true value of flow rate through the rock when the difference between them is due to annular leakage.

In other cases of mass balance discrepancy water may not be accounted for due to changes in water storage in the rock. In this case the greatest of the in or out values places an upper bound on the true value.

Line leakage results in water loss. Lines are frequently inspected and few, if any, line losses are expected to have gone unnoticed. Line losses result once again in the highest flow rate being an upper bound on the true value.

This chapter gives a summary table and graph of each experiment and of the results. The graph is a least squares fit of a power law curve to the data collected showing variation of flow rate in vs. top pressure at various triaxial stress states. Details of each experiment are shown in Appendix A. 


\subsection{Tests on Cement Plugs}

\subsubsection{Oracle Granite}

The first experiment, on Oracle Granite, had as its purpose not only the gathering of data, but also developing experimental procedures. Figure 4.1 shows the specimen configuration. This specimen was not coated with epoxy, and flow could occur between the annular region and the top and bottom holes.

\subsubsection{Tests with Rock Bridge in Place}

The first tests were performed with a rock bridge in place. The axial stress was $18.6 \mathrm{MPa}$. It was quickly apparent that there was rapid hydraulic connection between the top hole of the specimen and the annular space, while the hydraulic connection between the bottom hole and the annulus was much "tighter". This difference was due to a thin, partially healed fissure, less than $1 \mathrm{~mm}$ in aperture, which intersected the top hole, but not the bottom hole. The fissure was barely visible upon visual inspection prior to testing, and was not detected during routine core logging.

The first test performed was to determine the flow rate from the annulus to the top hole of the specimen in convergent flow. The piston plug was removed from the permeameter and the top hole bailed dry. Water was then pumped into the annulus and the time for the top hole to fill was recorded. Flow to the bottom hole was negligible. The results of the convergent flow test are summarized in Table 4.1. The results are presented in the order in which the tests were performed.

During this testing flow occurred mostly through hairline fractures. While watching the water level rise in the top hole, it clearly could be seen that water was seeping into the hole along fine fractures fractures not discernible when the specimen was first examined. The flow was not a pervasive flow through a medium with random distribution of interconnected pores. Following the convergent flow test the specimen was tested in divergent flow. In this test, fluid was pumped under pressure into the top hole and the amount flowing to the annulus and to the bottom hole was measured. Again, flow to the bottom hole was negligible. Test results are summarized in Table 4.2.

The flow rates measured in divergent flow are more than an order of magnitude greater than for convergent flow. In convergent flow the fluid pressure induces compressive tangential and radial stresses in the cylindrical specimen whereas in divergent flow tensile tangential stresses are induced. Tensile tangential stresses tend to open radial fractures and voids, increasing permeability; compressive tangential stresses tend to close radial fractures and voids, decreasing permeability (Bernaix, 1969).

Next the bottom hole was tested in convergent flow. For this test a pressure of $4.83 \mathrm{MPa}$ was applied to both the top hole and the annulus, and no pressure to the bottom hole. In this configuration, flow occurs both radially into the bottom hole from the annulus and axially into the 

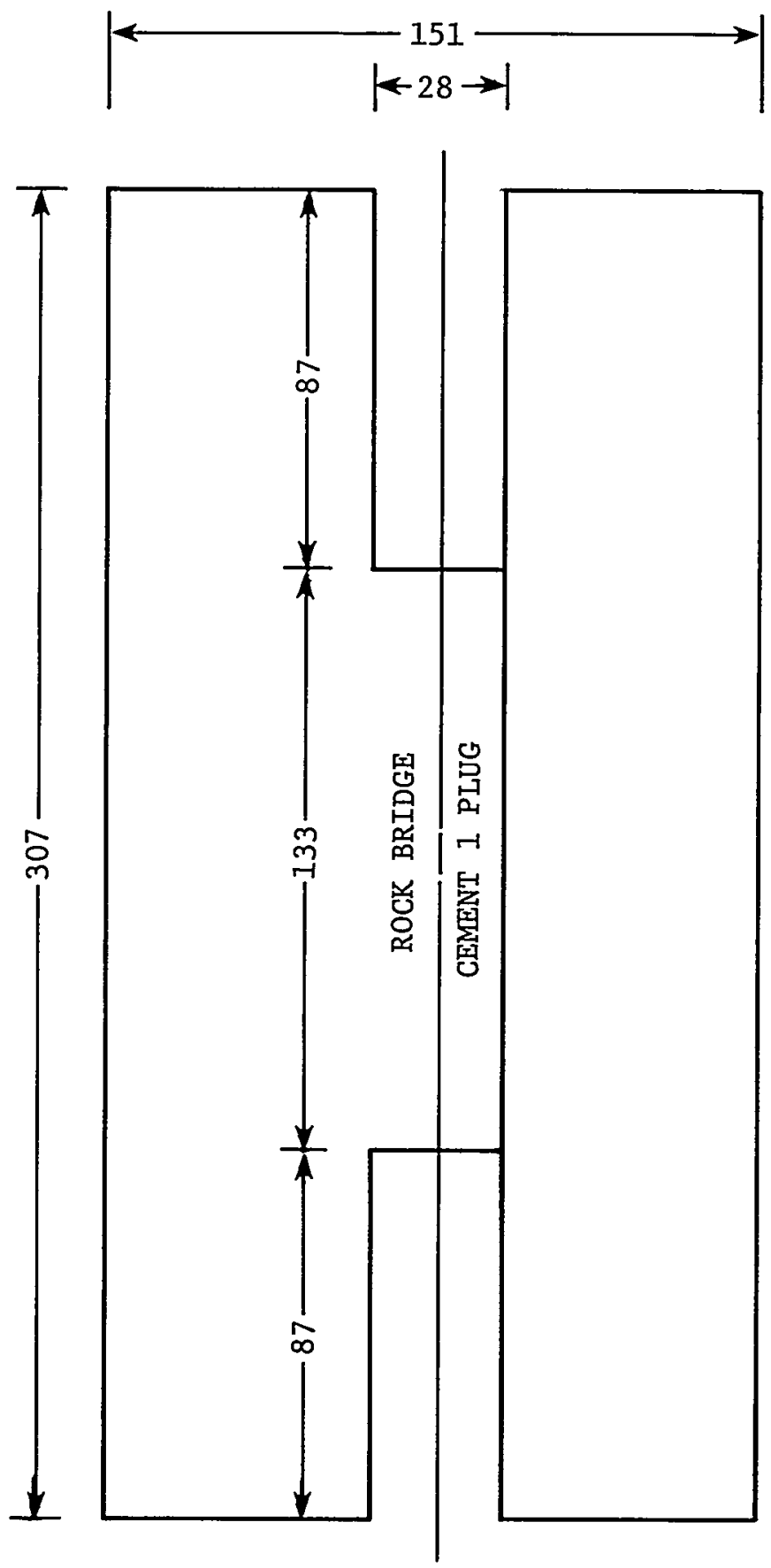

All dimensions in millimeters.

Figure 4.1 Sample OAZ-M1 (Oracle Granite cylinder) - dimensions. 
Table 4.1 Oracle Granite Cylinder - Test results for Convergent Flow with Rock Bridge

Pressure (MPa)

0.69

1.72

2.41

3.45

1.03

1.38

0.69
Flow Rate (cc/min)

0.99

2.49

2.98

3.92

1.24

1.61

0.87

Axial stress $=18.6 \mathrm{MPa}$

Table 4.2 Oracle Granite Cylinder - Test results for Divergent Flow with Rock Bridge

Pressure (MPa)

0.69

1.38

2.07
Flow Rate (cc/min)

15.04

27.94

100.26

Axial stress $=18.6 \mathrm{MPa}$ 
bottom hole from the top hole. The measured flow rate was $0.75 \times 10^{-3}$ $\mathrm{cc} / \mathrm{min}$. This flow rate will be compared to the flow rate under the same test conditions, but with a cement plug replacing the rock bridge.

\subsubsection{Tests without Rock Bridge}

Following the tests with the rock bridge in place, the bridge was cored from the sample. The specimen then had the shape of a hollow rock cylinder, $30.5 \mathrm{~cm}$ long, $15.2 \mathrm{~cm}$ in diameter, with a $2.5 \mathrm{~cm}$ diameter center hole extending the length of the cylinder.

The specimen was tested under both convergent and divergent flow conditions under an axial stress of $18.6 \mathrm{MPa}$. The results are summarized in Tables 4.3 and 4.4 .

The difference in flow rates under convergent flow compared to divergent flow. is smaller than expected when considered in conjunction with the test performed on the top hole.

\subsubsection{Tests with Cement Plug}

Following the tests on the hollow cylinder the center hole of the rock was plugged with Cement System 1, which was covered with water and allowed to cure for three days under atmospheric pressure and at a temperature of $24^{\circ} \mathrm{C}$.

In order to place the plug, gravel, water, and a fine wire mesh screen were placed in the bottom of the center hole, filling one-third of it. The center third was filled with cement.

The test was performed identically to the rock bridge test. A fluid pressure of $4.83 \mathrm{MPa}$ was applied to both the top hole and the annulus, and no pressure to the bottom hole, while the specimen was under an axial stress of $18.6 \mathrm{MPa}$. A flow of $11.53 \times 10^{-3} \mathrm{cc} / \mathrm{min}$ was measured in the test on the cement plug, an increase in the flow of more than one order of magnitude compared to the $0.75 \times 10^{-3} \mathrm{cc} / \mathrm{min}$ measured when the rock bridge was in place.

\subsubsection{Experimental Procedure Modifications}

This Oracle Granite/Cement Plug experiment was the first one, and it was performed in the prototype radial permeameter. As a result some modifications were made in the permeameter to facilitate machining, but the permeameter basically performed as expected.

Modifications were made in the way in which the experiments were performed. This experiment indicated that flow from the annulus to the center holes would most likely dominate the flow from the top hole to the bottom hole. Therefore, the decision was made to coat the specimens with epoxy to prevent flow from the annulus, making the outside radius of the sample a no-flow boundary. The ends, which were already sealed with a neoprene gasket, were also coated with epoxy. Thus, the sample was to approximate a right-circular cylinder, the sides and ends of which were no-flow boundaries, the top hole being a flow source, and the bottom hole a sink. All subsequent tests used this configuration. 

Table 4.3 Oracle Granite - Test results for Convergent
Flow - Hollow Cylinder

Pressure (MPa)

0.34

0.69

1.03

0.34

0.69

1.03
Flow Rate (cc/min)

$4 \cdot 17$

7.43

10.53

3.41

6.10

7.93

Axial stress $=18.6 \mathrm{MPa}$

Table 4.4 Oracle Granite - Test results for Divergent Flow - Hollow Cylinder

Pressure (MPa)

0.34

0.69

1.03
Flow Rate (cc/min)

4.33

8.68

13.56

Axial stress $=18.6 \mathrm{MPa}$ 


\subsubsection{Charcoal Granite}

Three samples of Charcoal granite, CG-101, CG-102, and CG-103 have been tested using cement system 1. All showed similar results: a decrease in flow through the plugged sample as compared to flow through the rock sample with rock bridge at the initial axial and confining stresses. As the axial and confining stresses were reduced, flow through the plugged sample increased. Only when axial and confining stresses were reduced to about one-third their initial values did flow through the plugged sample exceed flow through the intact rock at the initial stress level. The increased flow may have been due to either increased hydraulic conductivity along the rock/plug interface or due to opening of pores and fractures in the rock or in the plug as the stress levels decreased.

Flow rates measured during the experiments ranged from $0.5 \times 10^{-3}$ to $6 \mathrm{x}$ $10^{-3} \mathrm{cc} / \mathrm{min}$.

Microscopic examination of the cement plug of sample CG-102 revealed a distinct crack along the interface between the plug and the rock. It is believed this crack resulted from drying of the cement during preparation for microscopic examination. It is quite likely that drying of expansive cements will result in shrinkage. Drying of the plug resulted in complete decoupling of the cement from the rock. No bond existed between the cement and the rock. In disks cut from the sample the plug section which had been tightly held in the central hole became loose after only a few days of drying and was retained in the hole only by irregularities left by the drilling operation.

Fuenkajorn and Daemen (1986a) and Daemen et al. (1986, Ch. 7) used petrographic microscopy to investigate the interface between a borehole cement plug and Grande basaltic andesite. A System 1 cement plug was cured under atmospheric pressure, at room temperature, in a $38 \mathrm{~mm}$ hole, for 16 months. The widths of the rock cement plug interface are $0.1 \mathrm{~mm}$ for samples dried at $45^{\circ} \mathrm{C}$ and $0.2 \mathrm{~mm}$ for samples dried at $260^{\circ} \mathrm{C}$. Higher drying temperatures induce wider interface apertures, wider cement shrinkage cracks and higher crack densities within the cement. Fifty percent of the microcracks (induced by drilling near the borehole wall Fuenkajorn and Daemen, 1986b; Mathis and Daemen, 1982) and all rock flow layers in the borehole wall are penetrated by cement particles.

\subsubsection{Sample CG-101}

The results of this experiment are presented in Table 4.5 and on Figure 4.2. Figure 4.3 shows the sample dimensions. Testing began on January 13, 1982, and was completed on May 13, 1982. The cement plug was poured on January 25, covered with water, and cured at atmospheric pressure until February 5, 1982, a total of 11 days. On April 14, 1982, the annular valve was opened at the wrong time, letting the confining pressure drop to zero. Confining pressure was immediately re-applied. Flow rates subsequently increased to almost four times their previous value, but within three days had returned to the previous values. This occurred at axial and confining stresses of 15.5 and $13.8 \mathrm{MPa}$, 
Table 4.5 Summary of Test Results for Sample CG-101 (Charcoal Granite)

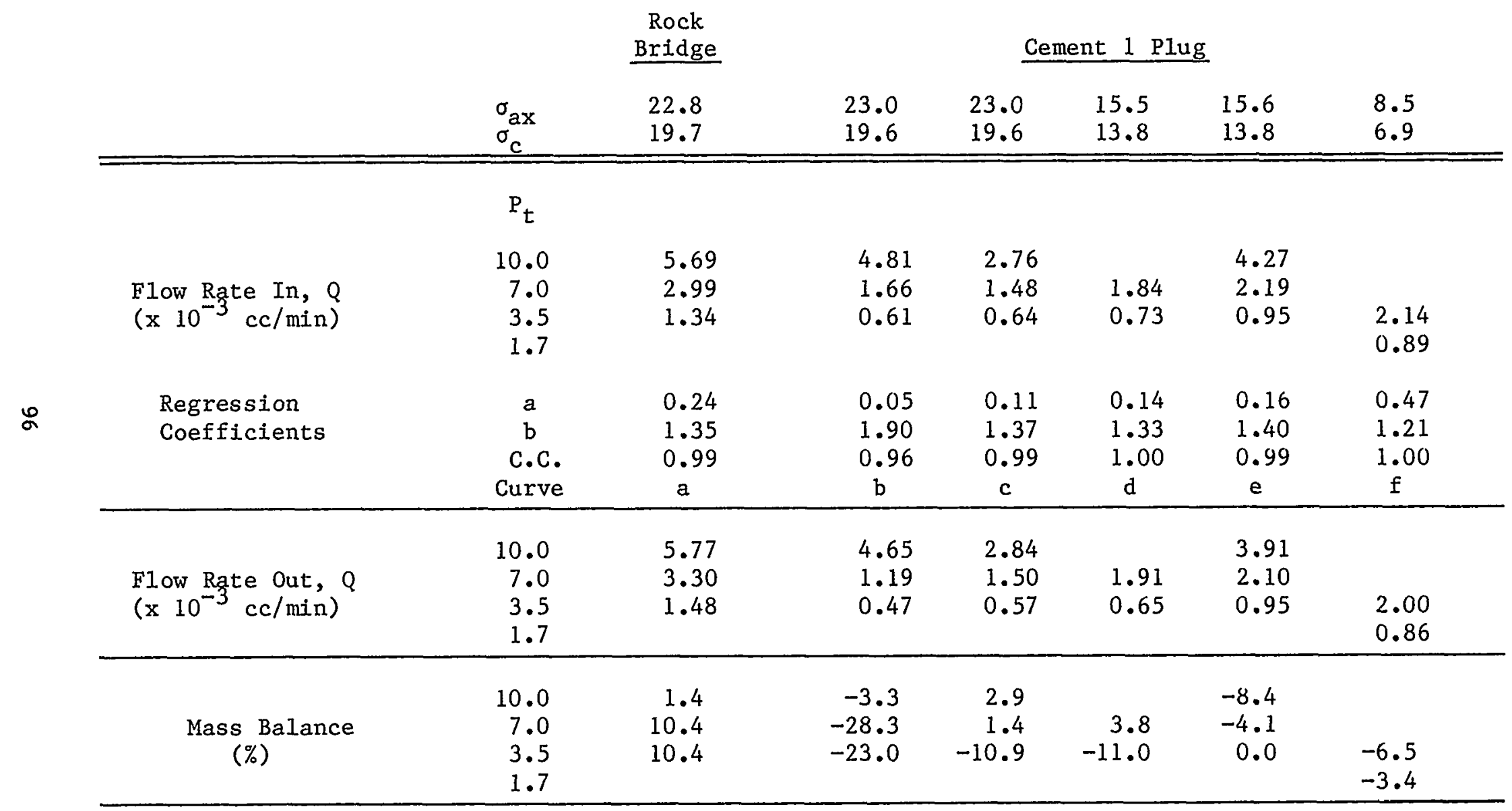

$\sigma_{a x}=$ axial stress (MPa); $\sigma_{c}=$ confining stress (MPa); $P_{t}=$ top hole injection pressure (MPa); regression coefficients $a$ and $b$ are for the equation $Q={ }_{a}\left(P_{t}\right)$. C.C. is the correlation coefficient. Curve identification letters $a, b, c, d, e, f$ refer to Figure 4.2. 


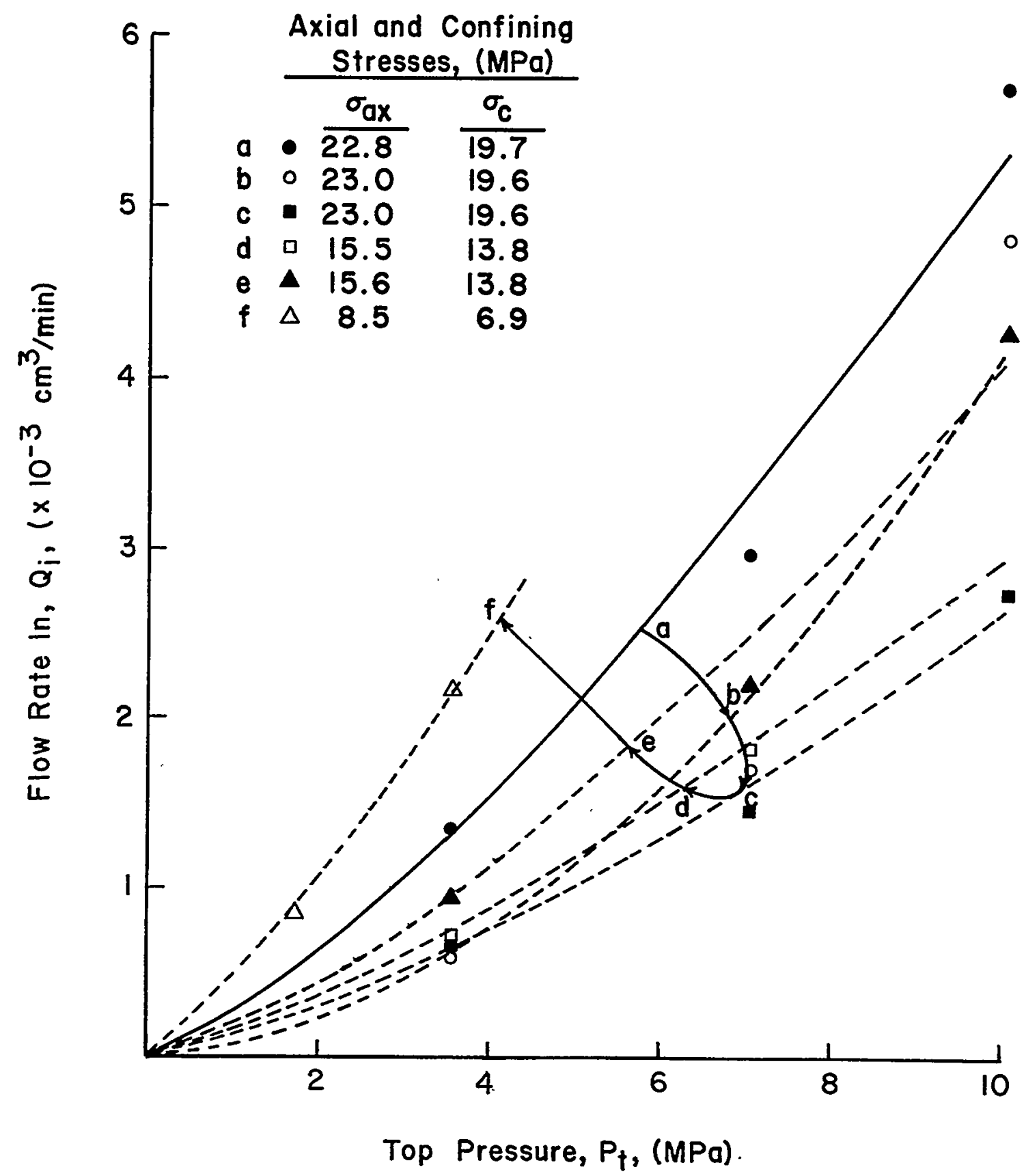

Figure 4.2 Sample CG-101, flow rate in vs. injection pressure, Charcoal granite. Solid line indicates rock bridge, dashed lines indicate cement plug. Letters indicate order of testing, as identified in Table 4.5, where numerical results are summarized. 

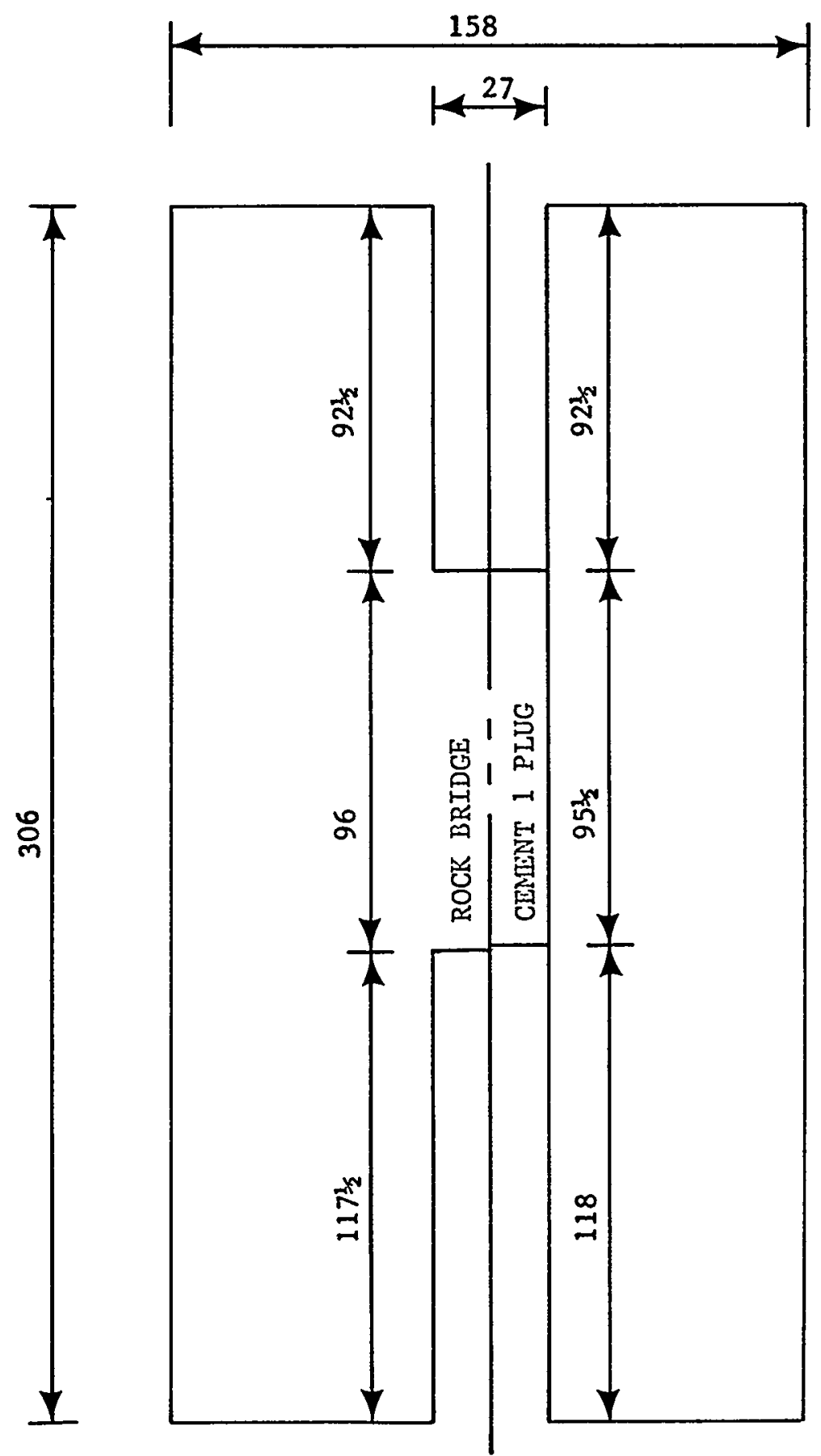

All dimensions in millimeters

Figure 4.3 Sample CG-101 (Charcoal granite cylinder) - dimensions. 
respectively, and the flow rates are illustrated by curves $d$ and $e$ on the graph.

The summary table shows that mass balance magnitudes were $11 \%$ or less for all but the 7.0 and $3.5 \mathrm{MPa}$ injection pressures, which had mass balances of about $-25 \%$.

Results are best reviewed by studying the graph of flow rate in vs. top pressure (Figure 4.2). Data from tests on the rock bridge are shown as a solid line, curve a. Dashed lines show data from tests on the cement plug. The letters $a, b, c, d, e$, and $f$ are ordered in time (i.e., a was run first, then $b$, etc.; Table 4.5).

Curve $a$, flow rate through the rock bridge, is the baseline. Curve $b$ shows a lower flow through the cement plug than the rock bridge under similar axial and confining stresses. Curve $c$ repeats the conditions of curve $b$ to check repeatability. Curve $c$ shows a lower flow rate than curve b. This is believed to be due to decreasing cement plug permeability resulting from forcing water through the plug.

Flow rates decreased from a to $b$ to $c$. Next, axial and confining stresses were reduced. Flow rates increased (curves $d$ and $e$ ) as the reduction in stress allowed fractures and pores to open. The difference between curve $d$ and $e$ is due to the abnormal stress placed on the system by mistakenly opening the annular valve on April 14. Even such a severely abnormal stress state did not result in a flow rate greater than through the rock bridge. Only when axial and confining stresses were reduced to 8.5 and $6.9 \mathrm{MPa}$, resectively, did the flow rate through the plug/rock system exceed flow through the intact rock.

Details of the testing are presented in Appendix A, Table A.1.

\subsubsection{Sample CG-102}

The results of this experiment are presented in Table 4.6 and on Figure 4.4. Figure 4.5 shows the sample dimensions. Testing began on January 20, 1982, and was completed on April 14, 1982. The cement plug was poured on February 6, covered with water, and cured at atmospheric pressure until February 13, a total of 7 days. The summary table shows that mass balance magnitudes were less than $17 \%$ except for one test at 3.5 $\mathrm{MPa}$ top pressure on the rock bridge, which had a mass balance of $25.0 \%$.

Referring to Figure 4.4, curve a again corresponds to the rock bridge. The dashed lines represent tests on the cement plug, ordered temporally by letter. As with $\mathrm{CG}-101$, sample CG-102 showed a reduced flow rate under the same axial and confining stress for the cement plug (curve b) as compared to the rock bridge (curve a), and an even lower rate after high pressure water had flowed through the plug (curve c). Reducing the axial and confining stresses increased the flow rate (curve d), but not until axial and confining stresses were reduced to about one-third their initial values did flow rate through the plug/rock system exceed the initial flow rate through intact rock. 
Table 4.6 Summary of Test Results for Sample CG-102 (Charcoal Granite)

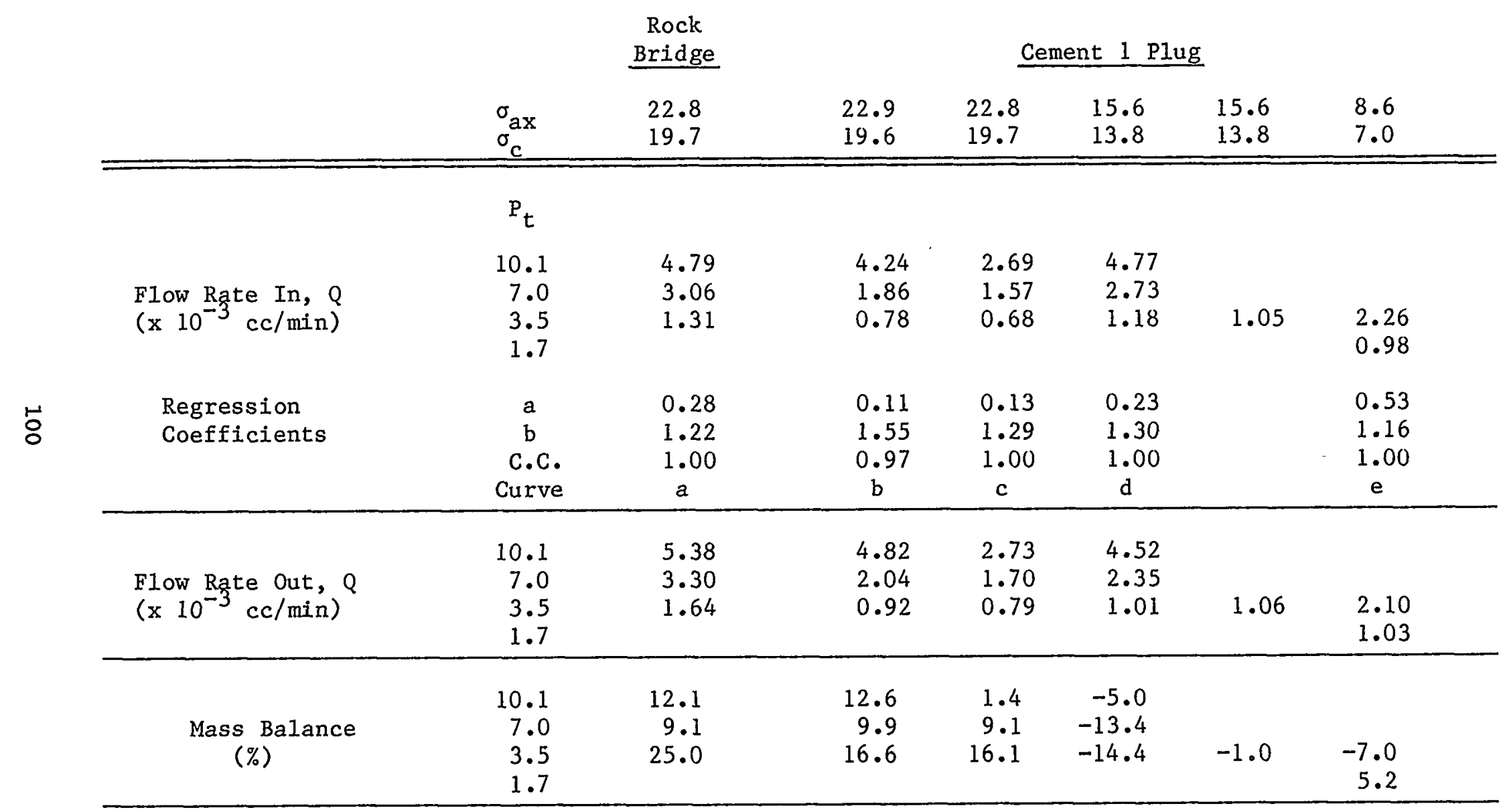

$\sigma_{a x}=$ axial stress (MPa); $\sigma_{c}=$ confining stress (MPa); $P_{t}=$ top hole injection pressure (MPa); regression coefficients $a$ and $b$ are for the equation $Q=a\left(P_{t}\right)^{b}$. C.C. is the correlation coefficient. Curve identification letters $a, b, c, d, e$ refer to Figure 4.4. 


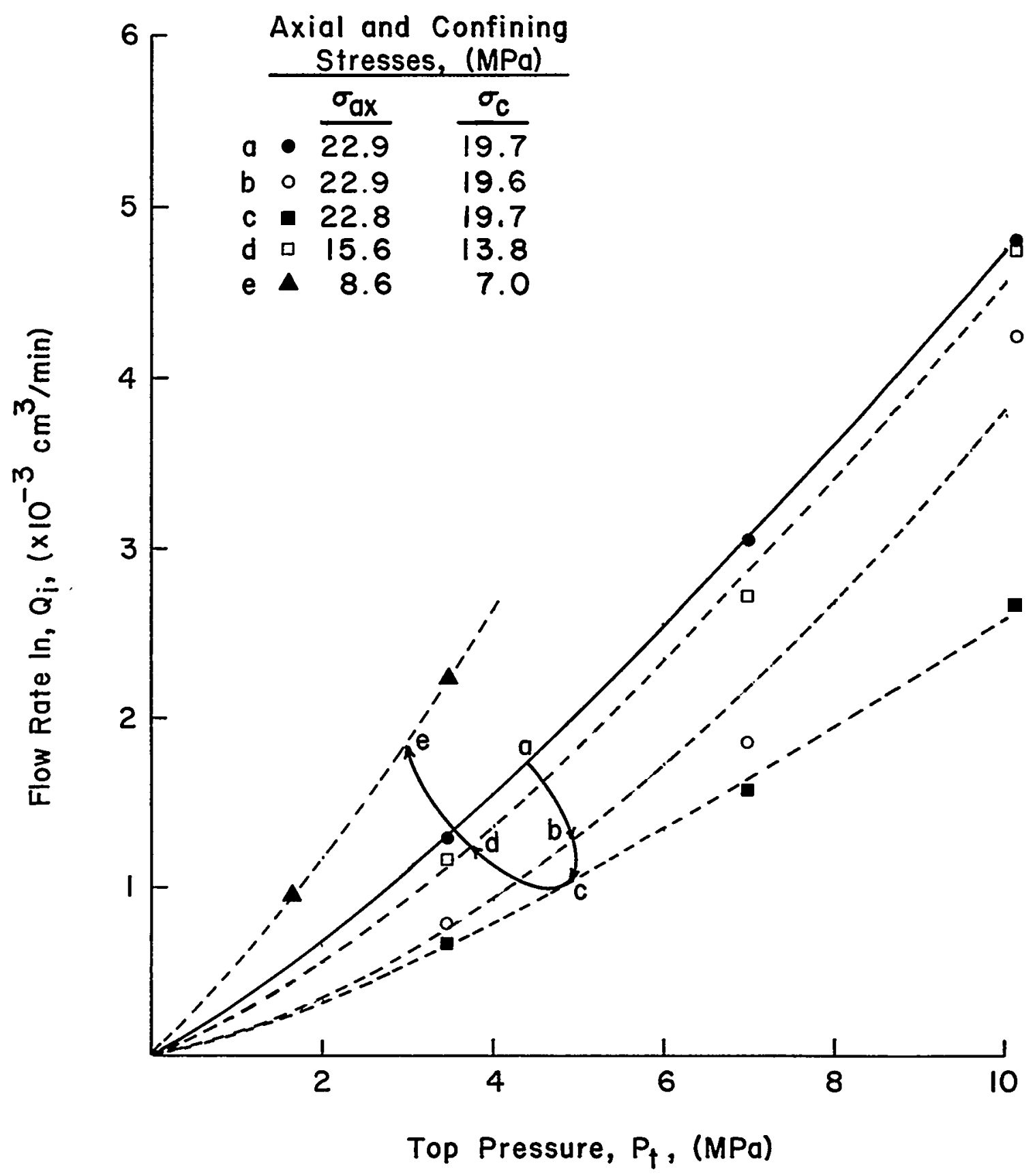

Figure 4.4 Sample CG-102, flow rate in vs, injection pressure, Charcoal Granite. Solid line indicates rock bridge, dashed lines indicate cement plug. Letters indicate order of testing. Results are summarized in Table 4.6; details are given in Table A.2. 

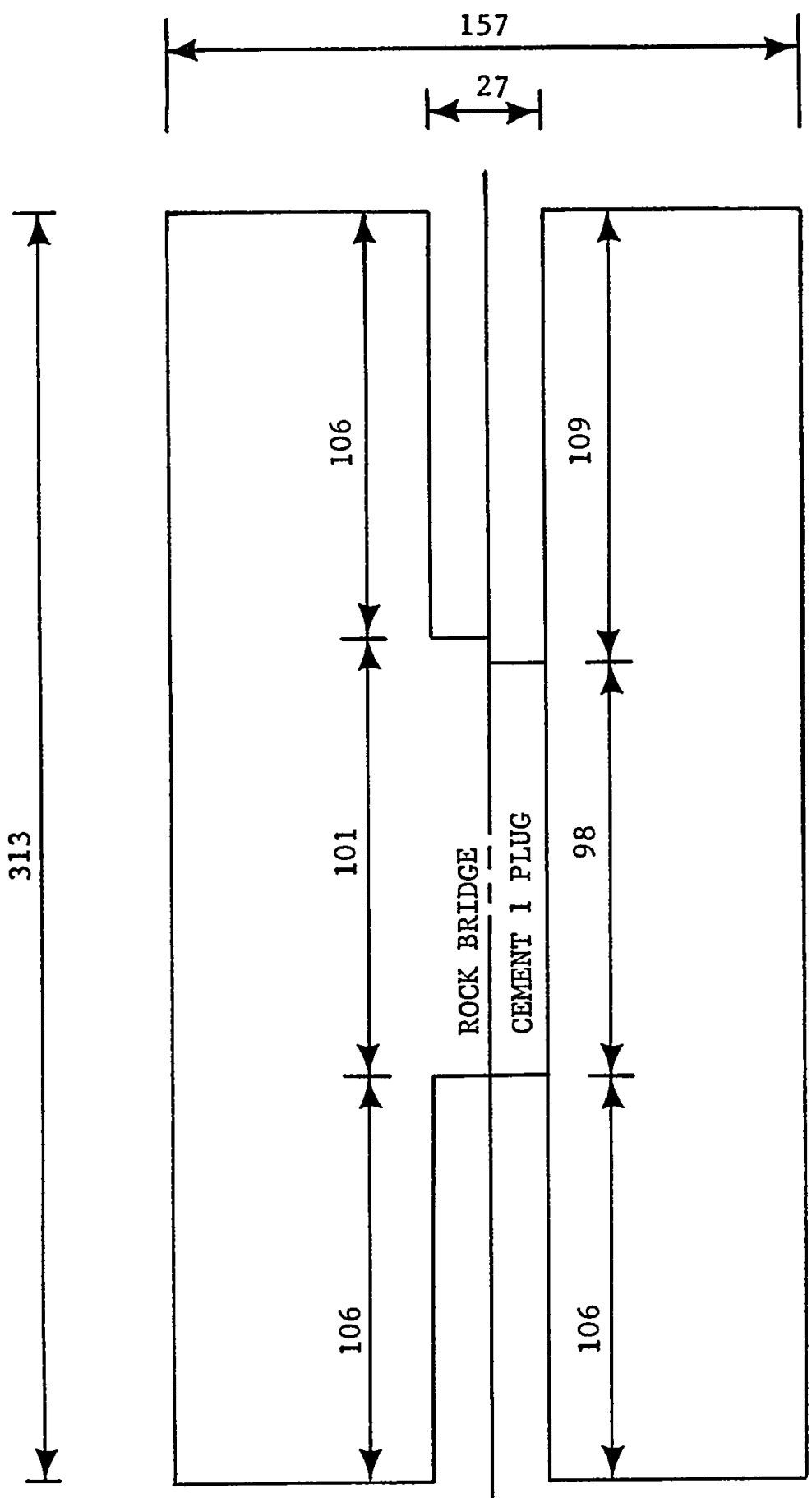

All dimensions in millimeters

Figure 4.5 Sample CG-102 (Charcoal granite cylinder) - dimensions. 
Figures 4.6 , through 4.8 are photographs of the interface between the granite and the cement plug. After testing, the sample was removed from the permeameter and submerged in water. On May 12 it was removed from the water and sectioned with an oil-cooled diamond saw. This was completed on May 14. Oil was wiped from the sections and the sections were kept on a shelf at room temperature, open to the atmosphere until the photographs were taken on May 17. Humidity during this time ranged between $5 \%$ and $30 \%$ (from newspaper weather reports). On May 14 the samples were examined with a binocular microscope, but no pictures were taken.

Figure 4.6 shows the top half of the plug. The plug was dense and uniform throughout except for a $4.5 \mathrm{~mm}$ thick zone of laitance at the top. The small crack at the top right was not noted during the May 14 examination and apparently opened as a result of the dry storage conditions.

Figure 4.7 is a view of the plug in the plane of a disc cut from the sample. The interface appears as a white line with no discernable crack. A photomicrograph of the plug and the rock is shown in Figure 4.8. The crack along the interface occurred during preparation of the thin section.

Details of the testing are giveu in Appendix A, Table A.2.

\subsubsection{Sample CG-103}

The results of this experiment are summarized in Table 4.7 and on Figure 4.9. Figure 4.10 shows the sample configuration. Testing began on January 28, 1982, and was completed on June 1, 1982. The cement plug was poured on February 13, covered with water, and cured at atmospheric pressure, $21^{\circ} \mathrm{C}$, until February 20, a total of 7 days. The summary table shows that mass balance magnitudes were $13 \%$ or less except for the 3.5 $\mathrm{MPa}$ test on the rock bridge, which had a mass balance of $23.2 \%$.

Test results for $C G-103$ are similar to those for CG-101 and CG-102. Referring to Figure 4.9, curve $a$ is again for the rock bridge. After plugging, flow rates under the same axial and confining stresses were again less than for the rock bridge, curves $b$ and $c$. Reducing the axial and confining stresses caused an increase in flow rates, curves $d$ and e. Curves $b$ and $c$ are $a$ plot of test results under the same axial and confining pressures and, as noted for samples CG-101 and CG-102, the decrease in flow rate from curve $b$ to curve $c$ is believed to be due to decreasing permeability of the cement as high pressure water flowed through it.

After steady-state testing was completed, a pulse test was performed on the plugged sample. The objective of this test was to gain familiarity with the test, to determine the time it took to perform, and to evaluate whether it might be useful in comparing plug performance to that of intact rock. Two tests were performed, both under an axial stress of $8.9 \mathrm{MPa}$ and a confining stress of $7.3 \mathrm{MPa}$. 


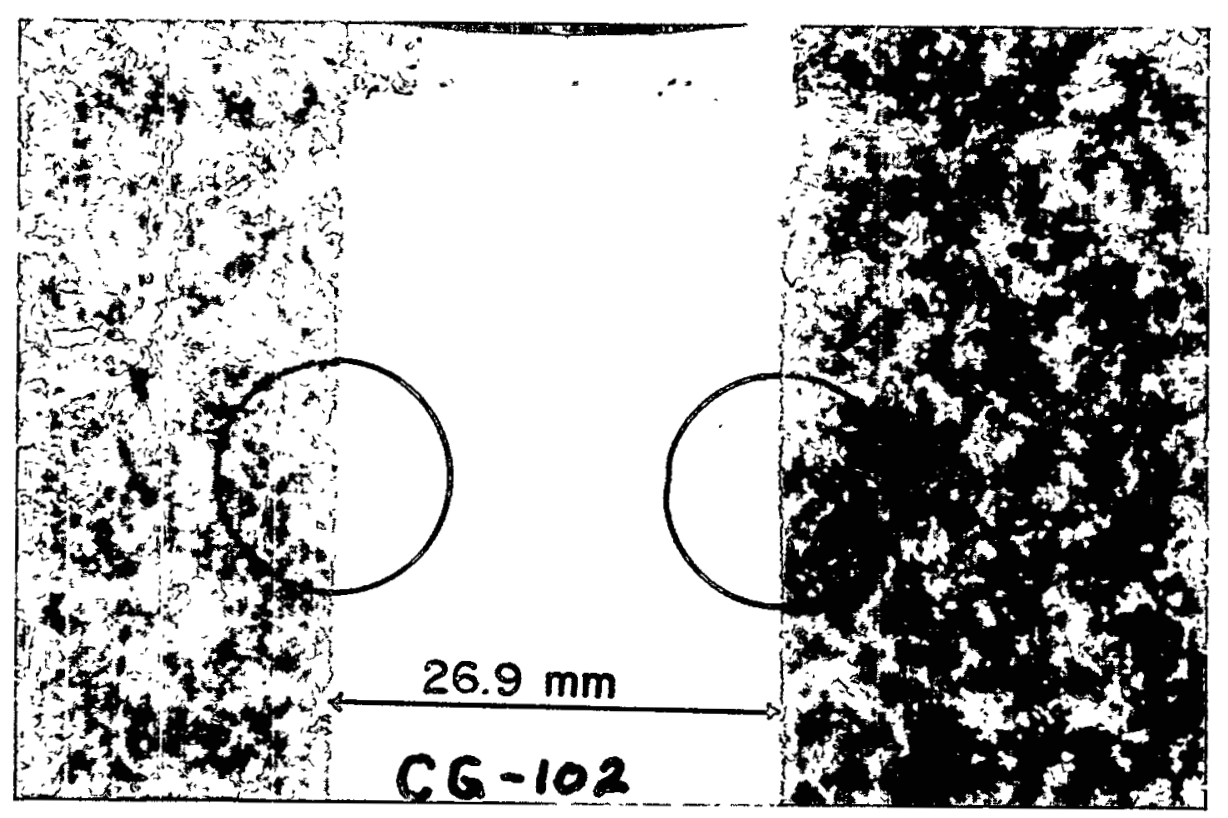

Figure 4.6 System 1 cement plug in Sample CG-102. 


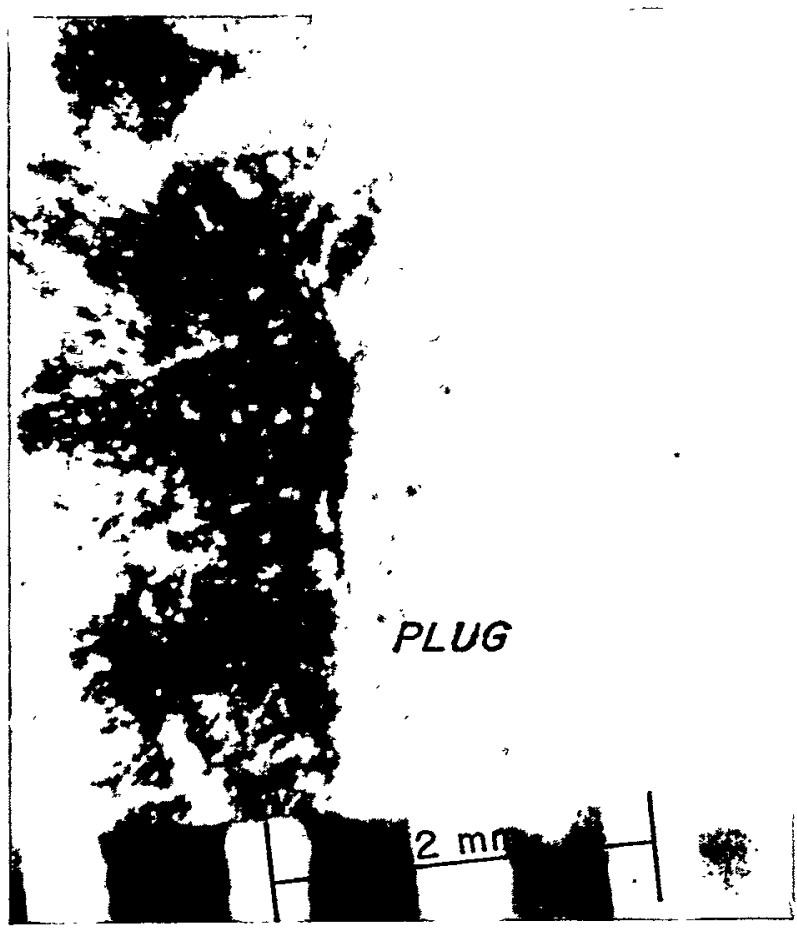

Figure 4.7 (left)

Diametric view of

cement plug, Sample CG102.

Figure 4.8 (right)

Photomicrograph of plug in Sample CG-102, showing cement plug, upper, crack, believed to be due to sample preparation, and rock, lower.

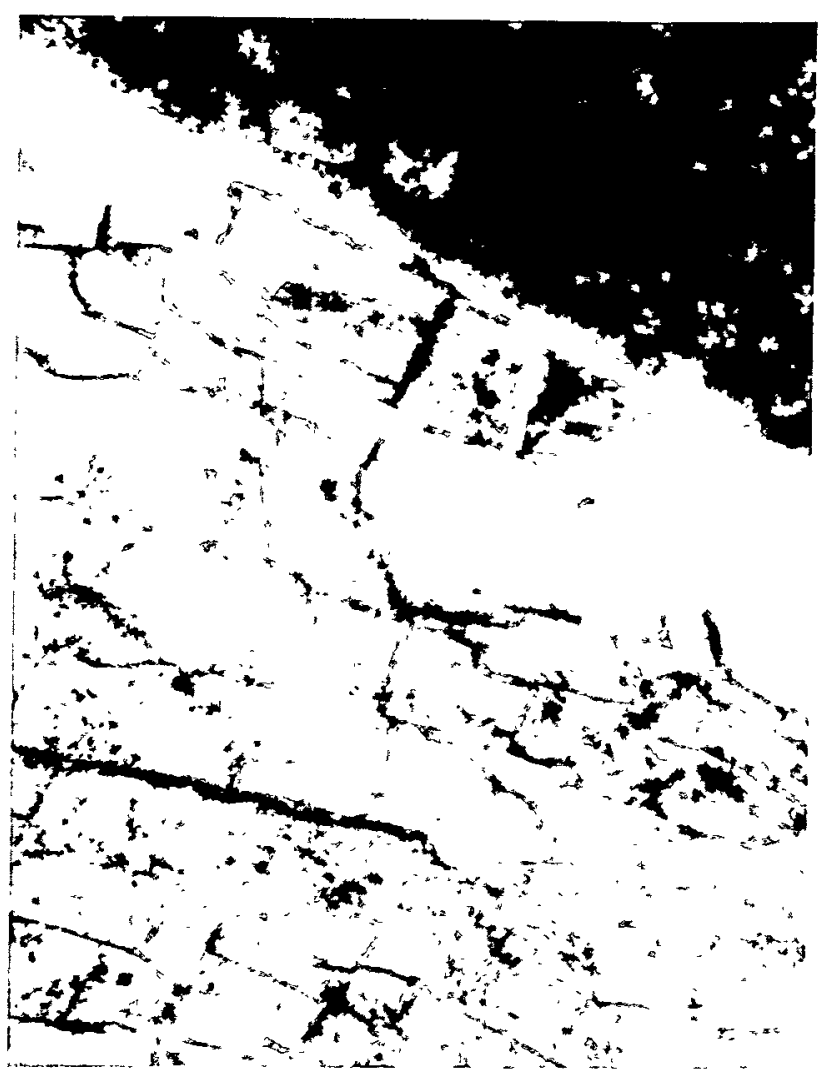


Table 4.7 Summary of Test Results for Sample CG-103 (Charcoal Granite)

\begin{tabular}{|c|c|c|c|c|c|c|}
\hline & & $\begin{array}{l}\text { Rock } \\
\text { Bridge }\end{array}$ & & Cemen & Plug & \\
\hline & $\begin{array}{l}\sigma_{\mathrm{ax}} \\
\sigma_{\mathrm{c}}\end{array}$ & $\begin{array}{l}22.8 \\
19.6 \\
\end{array}$ & $\begin{array}{l}22.8 \\
19.6 \\
\end{array}$ & $\begin{array}{l}22.8 \\
19.5 \\
\end{array}$ & $\begin{array}{l}15.4 \\
13.7 \\
\end{array}$ & $\begin{array}{l}8.6 \\
7.1 \\
\end{array}$ \\
\hline & $P_{t}$ & & & & & \\
\hline $\begin{array}{l}\text { Flow Rate In, Q } \\
\left(\times 10^{-3} \mathrm{cc} / \mathrm{min}\right)\end{array}$ & $\begin{array}{r}10.1 \\
7.0 \\
3.4 \\
1.8\end{array}$ & $\begin{array}{l}5.59 \\
3.25 \\
1.25\end{array}$ & $\begin{array}{l}6.17 \\
2.24 \\
0.56\end{array}$ & $\begin{array}{l}2.91 \\
1.50 \\
0.54\end{array}$ & $\begin{array}{l}5.20 \\
1.94 \\
0.73\end{array}$ & $\begin{array}{l}2.14 \\
0.92\end{array}$ \\
\hline $\begin{array}{l}\text { Regression } \\
\text { Coefficients }\end{array}$ & $\begin{array}{c}a \\
b \\
\text { C.c. } \\
\text { Curve } \\
\end{array}$ & $\begin{array}{c}0.23 \\
1.37 \\
1.00 \\
a \\
\end{array}$ & $\begin{array}{c}0.04 \\
2.16 \\
0.99 \\
b\end{array}$ & $\begin{array}{c}0.08 \\
1.53 \\
1.00 \\
c \\
\end{array}$ & $\begin{array}{c}0.08 \\
1.74 \\
0.96 \\
d\end{array}$ & $\begin{array}{c}0.42 \\
1.33 \\
1.00 \\
\mathrm{e}\end{array}$ \\
\hline $\begin{array}{l}\text { Flow Rate Out, Q } \\
\left(\times 10^{-3} \mathrm{cc} / \mathrm{min}\right)\end{array}$ & $\begin{array}{r}10.1 \\
7.0 \\
3.4 \\
1.8 \\
\end{array}$ & $\begin{array}{l}6.18 \\
3.51 \\
1.54\end{array}$ & $\begin{array}{l}5.76 \\
2.20 \\
0.49\end{array}$ & $\begin{array}{l}2.74 \\
1.45 \\
0.61\end{array}$ & $\begin{array}{l}5.24 \\
1.94 \\
0.75\end{array}$ & $\begin{array}{l}2.24 \\
0.97 \\
\end{array}$ \\
\hline $\begin{array}{l}\text { Mass Balance } \\
(\%)\end{array}$ & $\begin{array}{r}10.1 \\
7.0 \\
3.4 \\
1.8\end{array}$ & $\begin{array}{r}10.6 \\
8.0 \\
23.2\end{array}$ & $\begin{array}{r}-6.6 \\
-1.8 \\
-12.5\end{array}$ & $\begin{array}{l}-5.8 \\
-3.3 \\
13.0\end{array}$ & $\begin{array}{l}0.8 \\
0.0 \\
2.7\end{array}$ & $\begin{array}{l}4.7 \\
5.4\end{array}$ \\
\hline
\end{tabular}

$\sigma_{a x}=$ axial stress $(\mathrm{MPa}) ; \sigma_{c}=$ confining stress $(\mathrm{MPa}) ; \mathrm{P}_{t}=$ top hole injection pressure (MPa); regression coefficients $a$ and $b$ are for the equation $Q=a\left(P_{t}\right)^{b}$. C.C. is the correlation coefficient. Curves $a, b, c, d, e$ are shown in Figure 4.9 . 


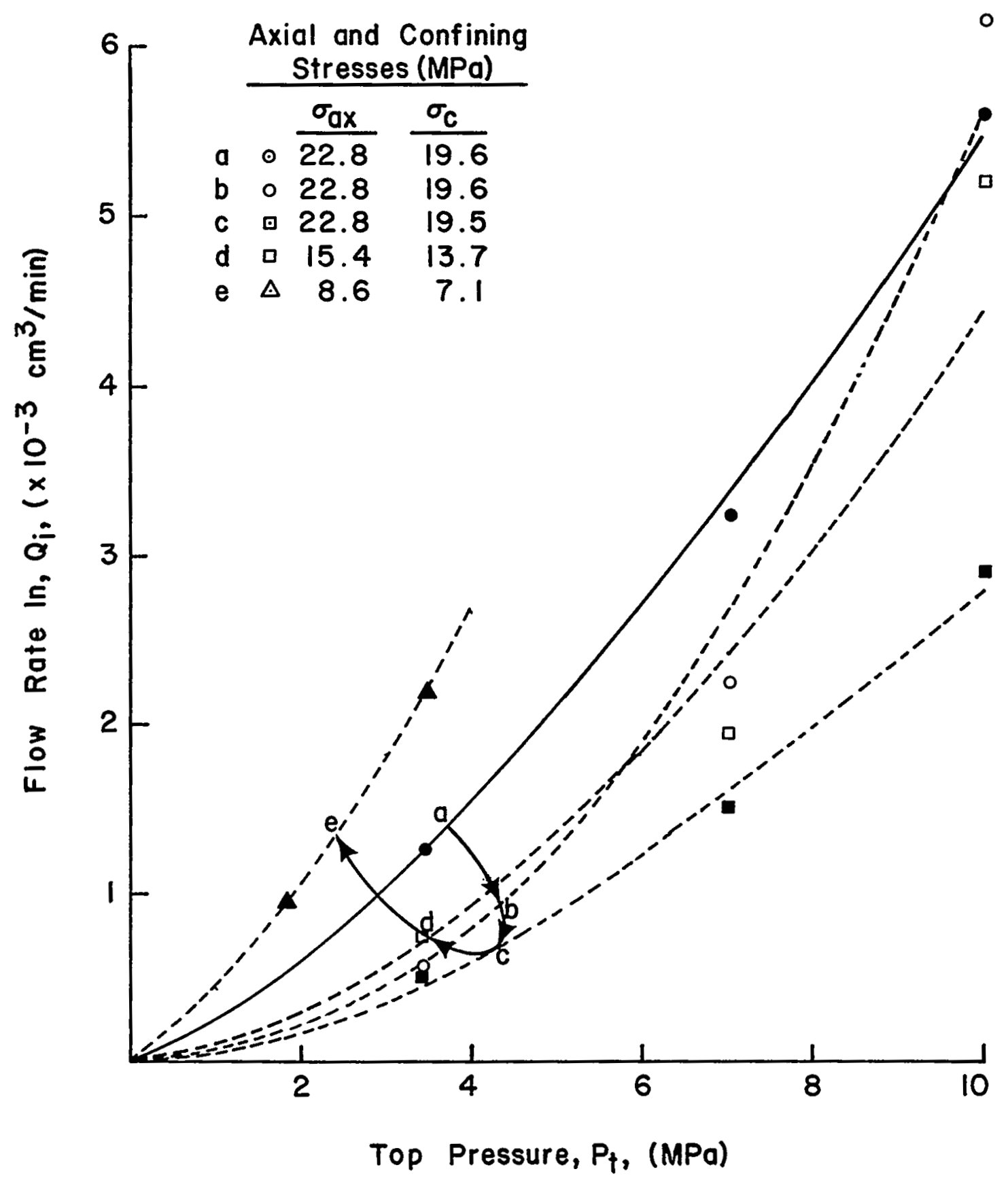

Figure 4.9 Sample CG-103, flow rate in vs, injection pressure, Charcoal Granite. Solid line indicates rock bridge; dashed lines indicate Cement 1 plug. Letters indicate order of testing. Results are summarized in Table 4.7; details are given in Table A.3. 

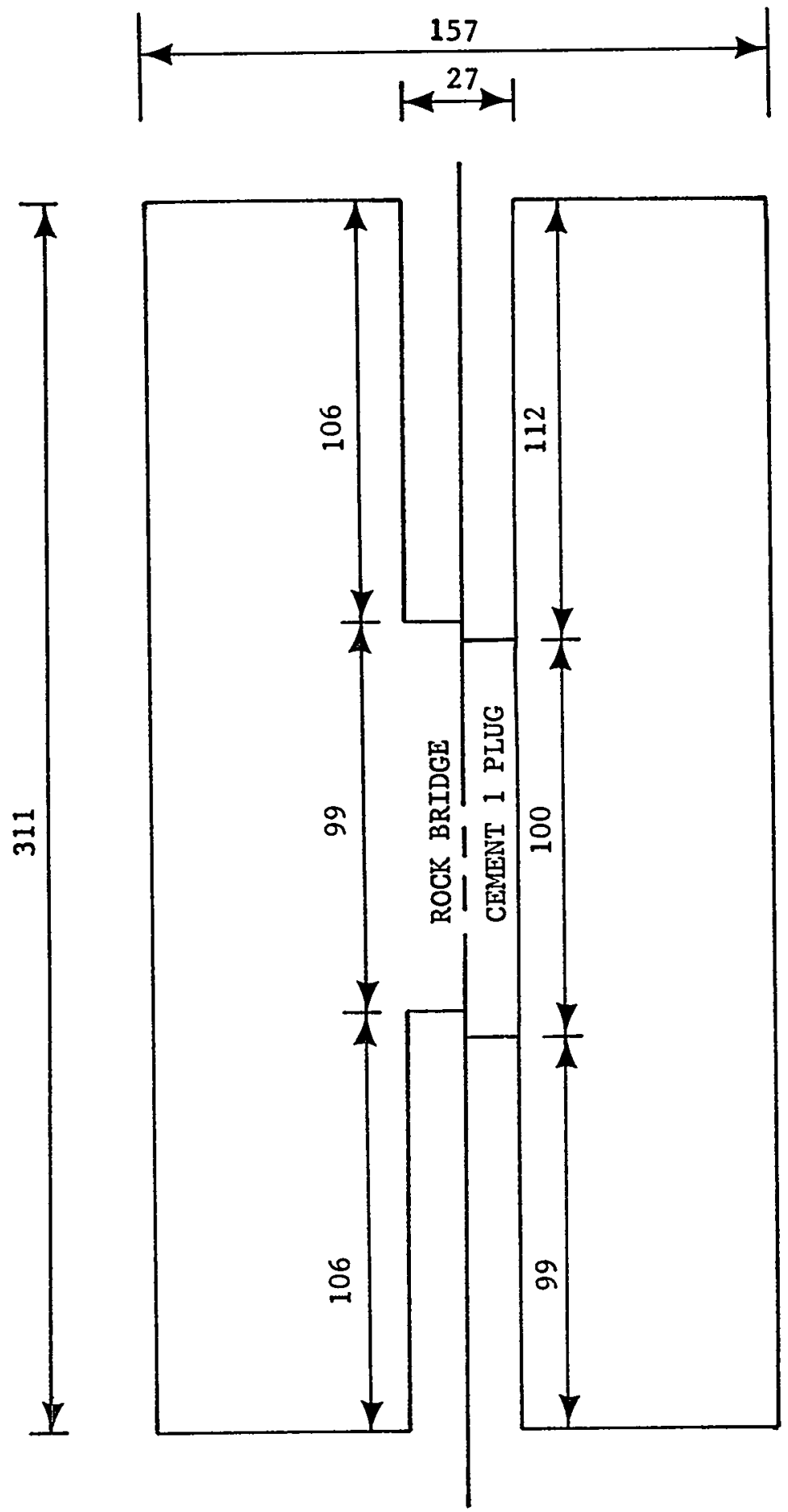

All dimensions in millimeters

Figure 4.10 Sample CG-103 (Charcoal granite) - dimensions. 
Test results are presented in Figures 4.11 and 4.12. The first test, on June 9, 1982, was started with the sample at an equilibrium pressure of $2.3 \mathrm{MPa}$. That is, pressure throughout the sample was $2.3 \mathrm{MPa}$, with a pressure of $2.3 \mathrm{MPa}$ in both the top and bottom holes. It took 8 days to reach this equilibrium from the established gradient of $1.8 \mathrm{MPa}$ top hole pressure and $0.0 \mathrm{MPa}$ bottom hole pressure.

At the start of the test, pressure in the top hole was quickly raised to $5.5 \mathrm{MPa}$ and the top valve closed. The bottom valve was already closed. As Figure 4.11 shows, pressure in the top hole decreased much more rapidly than pressure in the bottom hole increased. This occurred as water from the top hole flowed through the rock to the bottom hole. Much of the pressure decay in the top hole was apparently accommodated by water storage in the rock, which is believed to be the reason there was less pressure rise in the bottom hole: This would imply, however, that the sample was still not saturated.

Figure 4.12 shows the results of a second, shorter test performed on June 10, 1982. The results are similar.

Following the pulse tests the top hole pressure was released, dye poured into the top hole, and the top hole repressurized. The dye used was Magnaflux Spotcheck SKL-W Water Washable Penetrant. Injection took place under an axial stress of $8.9 \mathrm{MPa}$, a confining stress of $6.8 \mathrm{MPa}$, and an injection pressure (top hole pressure) of $3.4 \mathrm{MPa}$. Bottom hole pressure was atmospheric. After ten days a slight coloration from the dye was observed in the flask collecting water from the bottom hole.

The sample was removed from the permeameter and sawed in half lengthwise. In the sectioned sample dye was clearly visible for the first 6 $\mathrm{mm}$ on top of the cement plug and for $19 \mathrm{~mm}$ along the interface on one side of the $102 \mathrm{~mm}$ long cement plug. The dye in the top $6 \mathrm{~mm}$ of the plug is interpreted as outlining a zone of laitance.

In order to better see the dye, Magnaflux $\mathrm{ZP}-9 \mathrm{~B}$ developer was sprayed on the surface of the specimen. The developer provides a white background against which the red dye is more visible. After spraying on the developer, the dye was seen to have penetrated the plug for $12 \mathrm{~mm}$, being more intense in the top $6 \mathrm{~mm}$. However, the dye was observed throughout the rock, being most apparent in the top of the specimen around the injection hole. Most of the dye had flowed around the plug, through the rock. Dye coloration in the plug, below the top $12 \mathrm{~mm}$, was less than in the rock, indicating more flow through the rock than through the plug. This accords with the observations of reduced flow through the sample after plug emplacement. Figure 4.13 is a sketch of the sample showing dye penetration.

Details of the testing are given in Appendix A, Table A.3.

\subsubsection{Sentinel Gap Basalt}

Two samples of basalt, drilled from the same block, have been tested using cement system 1 as the plug material. Both samples were drilled parallel to the axis of the column from which the block came. 


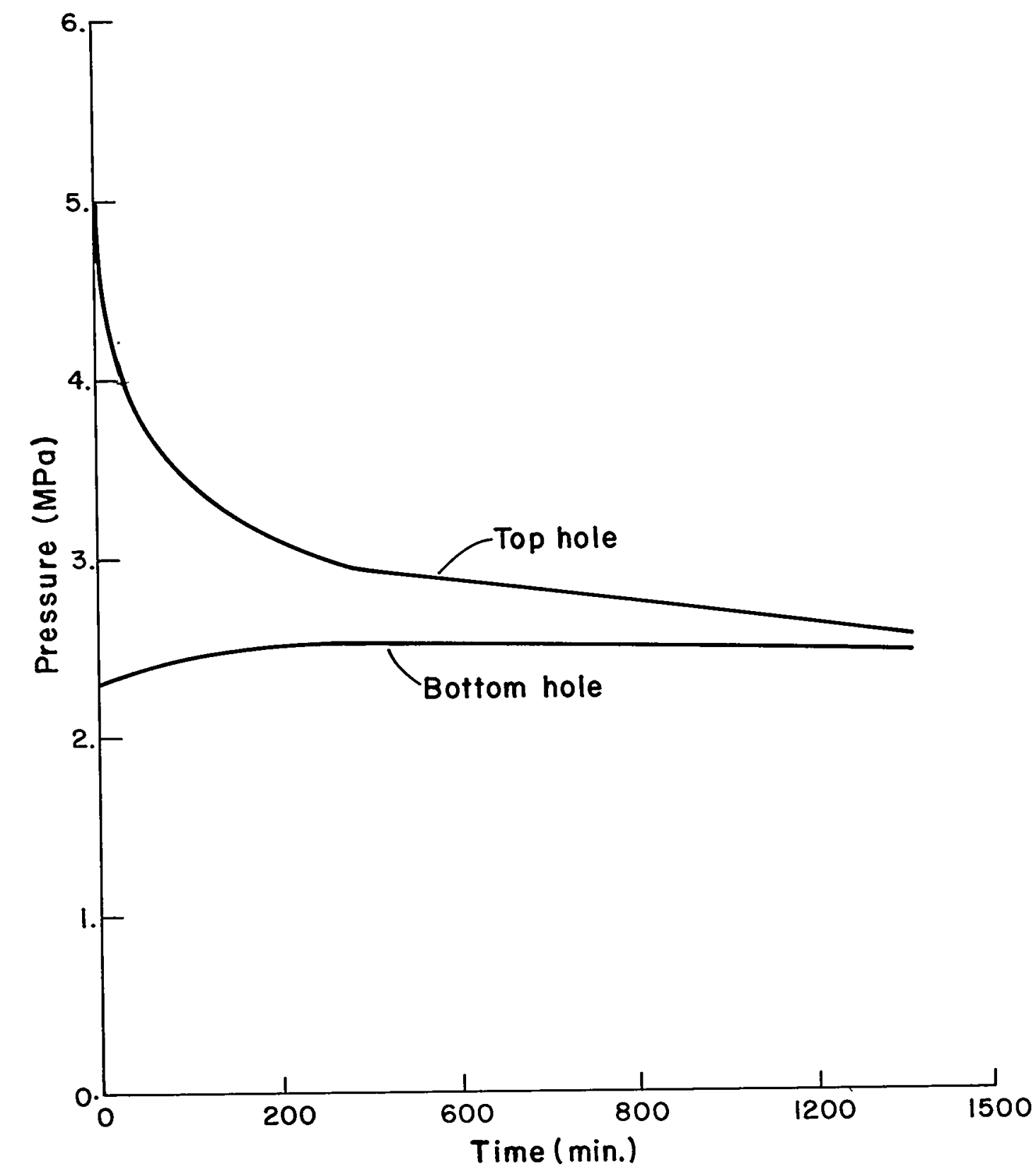

Figure 4.11 Pulse test data, Charcoal granite sample CG-103, Cement 1 plug, June 9, 1982. Pore pressure of $2.3 \mathrm{MPa}$ throughout the sample prior to test initiation. At the start of the test the injection (top hole) pressure is raised suddenly to $5.5 \mathrm{MPa}$. 


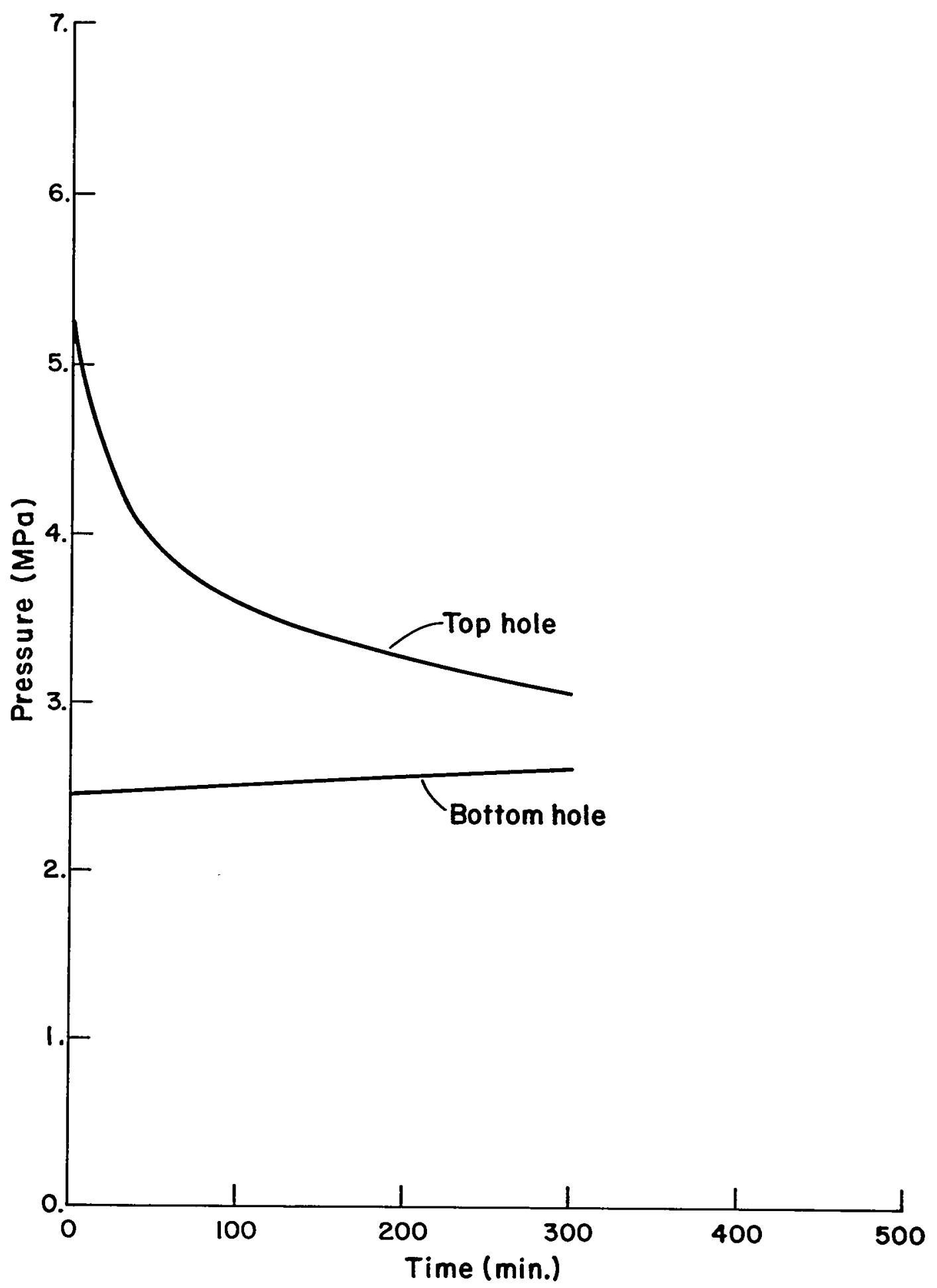

Figure 4.12 Pulse test data, Charcoal granite sample CG-103, Cement 1 plug, June 10, 1982. 

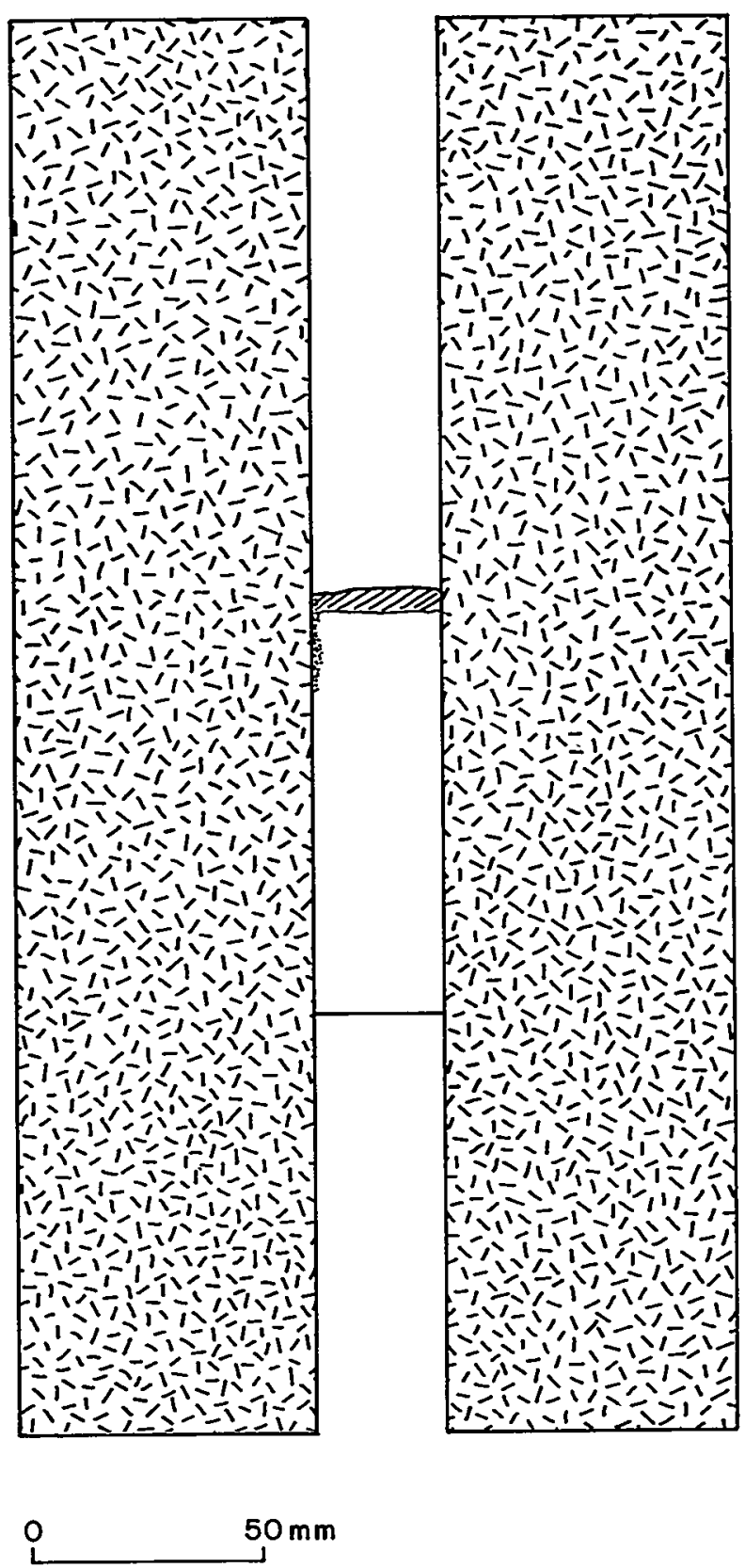

Figure 4.13 Sample CG-103, sketch of dye penetration. Dye pervaded the rock and penetrated $12 \mathrm{~mm}$ into the plug and $19 \mathrm{~mm}$ along one side of the interface. 
The samples exhibited very fow flow rates when the rock bridge was in place, less than $0.05 \times 10^{-3} \mathrm{cc} / \mathrm{min}$. Since flow rates were so low, their variation with axial and confining stress could not be measured. In addition, flow rates measured were somewhat erratic, probably reflecting the lower limits of sensitivity of the measuring apparatus.

Flow rates increased greatly after emplacement of the cement plug, to rates on the order of $0.2 \times 10^{-3} \mathrm{cc} / \mathrm{min}$. Flow through the basalt with cement plug is greater than through intact basalt, but still less than the flow rates measured for the Charcoal granite samples. The erratic nature of the measurements is believed to be due to stick-slip in the pumps, to having to disconnect the water lines to the permeameters several times for gage calibration, and to leakage from the annulus.

Because of the extremely low flow rates, even very small errors are reflected as major discrepancies in the mass balance. It is probable that the measurement error equals or exceeds the measured values, making the "instantaneous" mass balance fairly meaningless. A glance at the data tables A.4 and A.5 in Appendix A will confirm, however, that even an integrated measurement over the total duration of the experiments, integration which should average out random measurement errors, does not improve the mass balance. The flow out consistently exceeds the flow in. It is probable that this is due to a small leakage flow from the annulus, as is confirmed by a systematic, although very minor, pressure drop in the annulus during the course of the tests. The annulus pressure is "maintained" by an occasional manual repressurization. Measurements of the water injected into the annulus show that accounting for such annulus injections does not improve the mass balance.

$4 \cdot 1 \cdot 3 \cdot 1 \quad$ SGE-2-2

The results of the experiment performed on sample SGE-2-2 are presented in Table 4.8 and on Figure 4.14.' The sample configuration is shown in Figure 4.15 .

The sample was allowed to saturate for seven days with water being injected under pressure in both the top and bottom holes. On May 27, 1982, testing began. The basalt exhibited very low flow rates. With the rock bridge in place and under an axial stress of $22.7 \mathrm{MPa}$, a confining stress of $19.0 \mathrm{MPa}$, and an jinjection pressure of $10.3 \mathrm{MPa}$, the flow rates in and out were $0.01 \times 10^{-3}$ and $0.07 \times 10^{-3} \mathrm{cc} / \mathrm{min}$, respectively. A greater flow out was observed throughout the test and is likely due at least in part to slight leakage through the end seals. Since the rock was of very low permeability and had very low flow rates, the slight end seal leakage was a large part of the total flow. The amounts of water pumped into the annulus to replenish pressure were recorded, but this still did not account for the total discrepancy between the amounts flowing into the sample (as measured by the constant pressure pumps) and the amounts flowing out. This is probably due to inaccuracies in the measurement of the water necessary to replenish the annulus. Inaccuracies result because the injection pump used to replenish the annulus has to be used for other purposes, and hence has to be reconnected and disconnected for each replenishment. The slight water losses incurred during this process appear to be a significant fraction of the total flow in this system. 
Table 4.8 Summary of Test Results for Sample SGE-2-2 (Sentinel Gap Basalt)

\begin{tabular}{|c|c|c|c|c|c|c|c|c|}
\hline & $\begin{array}{c}\text { Rock } \\
\text { Bridge }\end{array}$ & Ceme & $t$ System & 1 Plug & \multicolumn{4}{|c|}{$\begin{array}{l}\text { Cement System } 1 \text { Plug } \\
\text {. After Drying }\end{array}$} \\
\hline$\sigma_{\mathrm{ax}}(\mathrm{MPa})$ & 22.7 & 23.4 & 14.9 & 7.5 & 8.9 & 9.0 & 14.5 & 23.2 \\
\hline$\sigma_{c}(\mathrm{MPa})$ & 19.0 & 19.6 & 13.8 & 6.9 & 7.1 & 7.0 & 11.0 & 19.5 \\
\hline $\mathrm{P}_{\mathrm{t}}(\mathrm{MPa})$ & 10.3 & 10.2 & 9.9 & 6.9 & 7.0 & 7.0 & 10.1 & 10.0 \\
\hline$Q_{I N}\left(x 10^{-3} \mathrm{cc} / \mathrm{min}\right)$ & 0.01 & $0.05^{*}$ & 0.06 & 0.03 & $52.85^{a}$ & $58.70^{\mathrm{b}}$ & 94.87 & 82.27 \\
\hline $\mathrm{Q}_{\text {OUT }}\left(\mathrm{x} 10^{-3} \mathrm{cc} / \mathrm{min}\right)$ & 0.07 & $0.24^{*}$ & 0.15 & 0.12 & $55.46^{\mathrm{a}}$ & $58.85^{b}$ & 96.34 & 81.90 \\
\hline
\end{tabular}

$\#_{\text {For }} 42$ days at $54^{\circ} \mathrm{C}$.

* Last 10 readings.

$a, b$ Annular pressure released suddenly, then restored, between readings for a and $b$. 


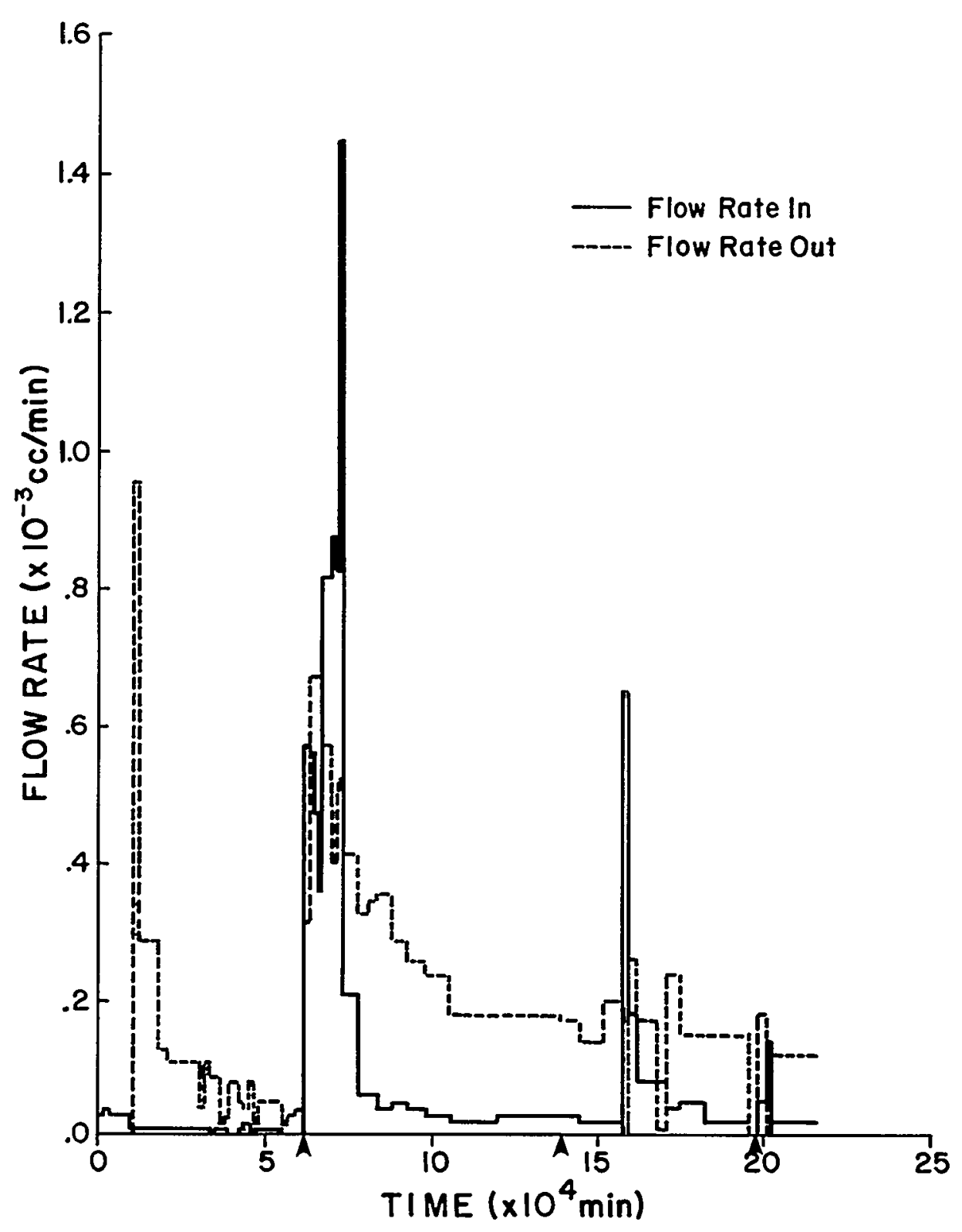

Figure 4.14 Flow rate vs. time, sample SGE-2-2. Arrows indicate (a) cement plug emplacement, 7/7; (b) stress change, 9/14; and (c) stress change, $10 / 25$. 

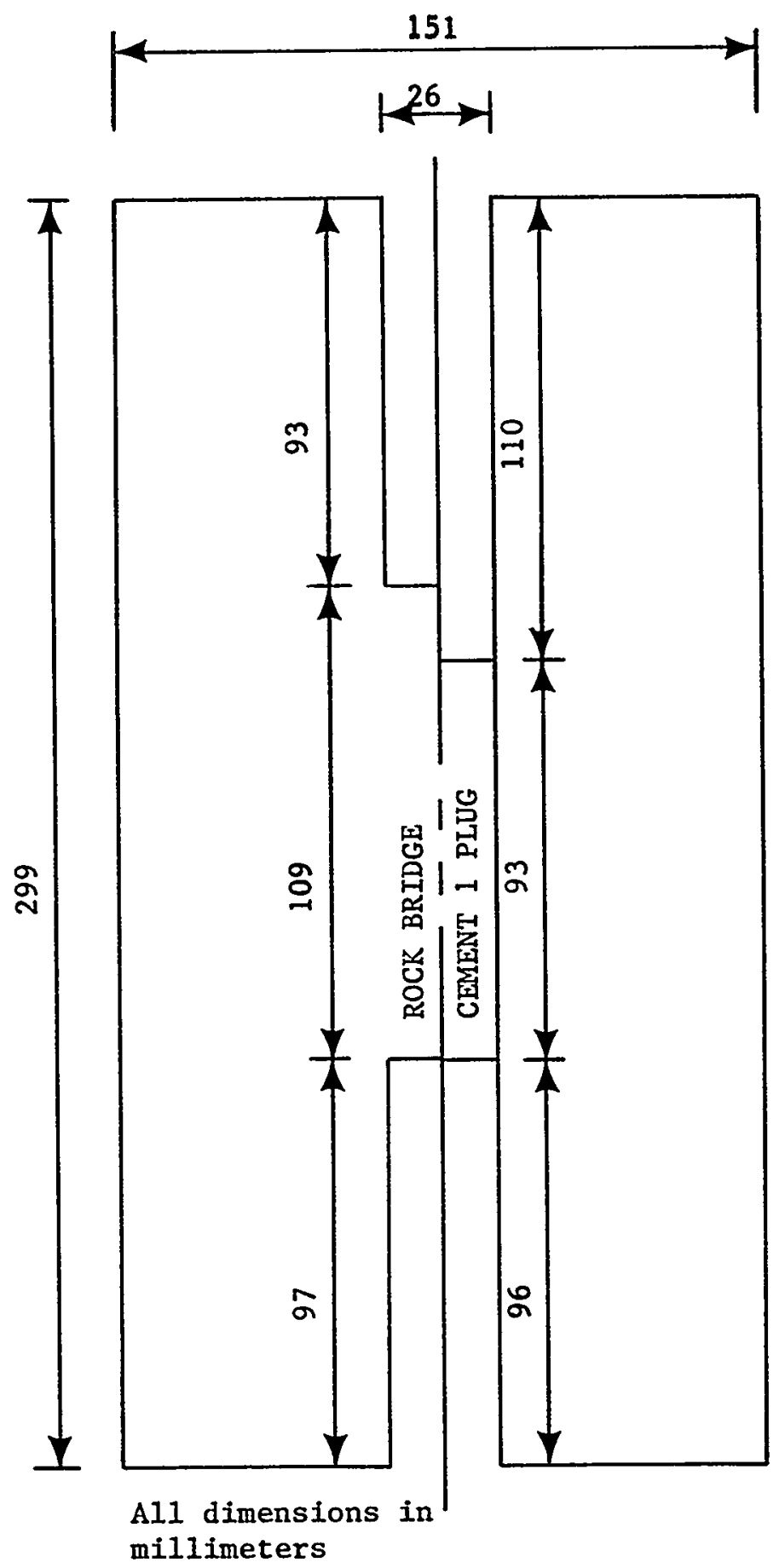

Figure 4.15 Sample SGE-2-2 (Sentinel Gap basalt) - dimensions. 
Since flow rates through the sample with rock bridge were so low, at the lower limits of the sensitivity of the equipment, the axial and confining stresses and injection pressure were not varied. After testing the rock bridge at the single injection pressure of $10.3 \mathrm{MPa}$ for 39 days, the rock bridge was cored from the sample and a plug of cement system 1 emplaced.

The cement plug was tested under axial and confining stresses of 23.4 $\mathrm{MPa}$ and 19.6 $\mathrm{MPa}$, respectively, and an injection pressure of $10.2 \mathrm{MPa}$. The averages of the last ten flow rate measurements were $0.05 \times 10^{-3}$ and $0.24 \times 10^{-3} \mathrm{cc} / \mathrm{min}$, respectively. This is higher than the intact basalt, but still lower than the measurements for any of the intact or plugged Charcoal granite samples. Lowering the axial and confining stresses to 15.0 and $13.8 \mathrm{MPa}$, respectively, resulted in flow rates in and out of $0.06 \times 10^{-3}$ and $0.15 \times 10^{-3} \mathrm{cc} / \mathrm{min}$, respectively, using an injection pressure of $10.0 \mathrm{MPa}$. These flow rates are similar to the ones at the higher axial and confining stress level, indicating no measurable variation in permeability with variations in axial and confining stresses.

Finally, axial and confining stresses were lowered to $7.5 \mathrm{MPa}$ and 6.9 $\mathrm{MPa}$, respectively, and top injection pressure lowered to $6.9 \mathrm{MPa}$. Flow rates in and out were $0.03 \times 10^{-3}$ and $0.12 \times 10^{-3} \mathrm{cc} / \mathrm{min}$, respectively.

The sample was removed from the permeameter and placed in an oven at a temperature of $54^{\circ} \mathrm{C}$ for 42 days. This subjected the cement plug both to drying and to higher temperatures. The sample was removed from the oven and stored at room temperature and ambient humidity for six days before being replaced in the permeameter on Dec. 27, 1982, for saturation. Testing was resumed on January 12, 1983, and continued until March 16, 1983.

Figure 4.16 preşents the test results obtained between January 12 and March 2. During this time the sample was subjected to axial and confining stresses of $8.8 \mathrm{MPa}$ and $7 \mathrm{MPa}$, respectively, and $2 \mathrm{MPa}$ injection pressure. The initial flow rate was about $900 \times 10^{-3}$ $\mathrm{cc} / \mathrm{min}$. This decreased to about $15 \times 10^{-3} \mathrm{cc} / \mathrm{min}$, presumably as the cement resaturated and/or rehydrated. The $15 \times 10^{-3} \mathrm{cc} / \mathrm{min}$ flow rate obtained for-nine days and was considered a limiting value.

Tests were then performed at 8.9 and $7.1 \mathrm{MPa}$ axial and confining stress, respectively, and at an jinjection pressure of $7.0 \mathrm{MPa}$. Flow rates in and out were $52.85 \times 10^{-3}$ and $55.46 \times 10^{-3} \mathrm{cc} / \mathrm{min}$, respectively, readings a in Table 4.8. On March 4 the annular pressure was released and annular pressure dropped suddenly to about $4.12 \mathrm{MPa}$ but was quickly restored. Flow rates were then slightly higher, reading $b$.

Tests were then performed at an injection pressure of $10 \mathrm{MPa}$ for $(14.5,11.0)$ and $(23.2,19.5) \mathrm{MPa}$ axial and confining stresses, respectively, to compare with similar conditions prior to testing. As Table 4.8 shows, in all cases flow rates through the plug after drying were over two orders of magnitude greater than before drying. 


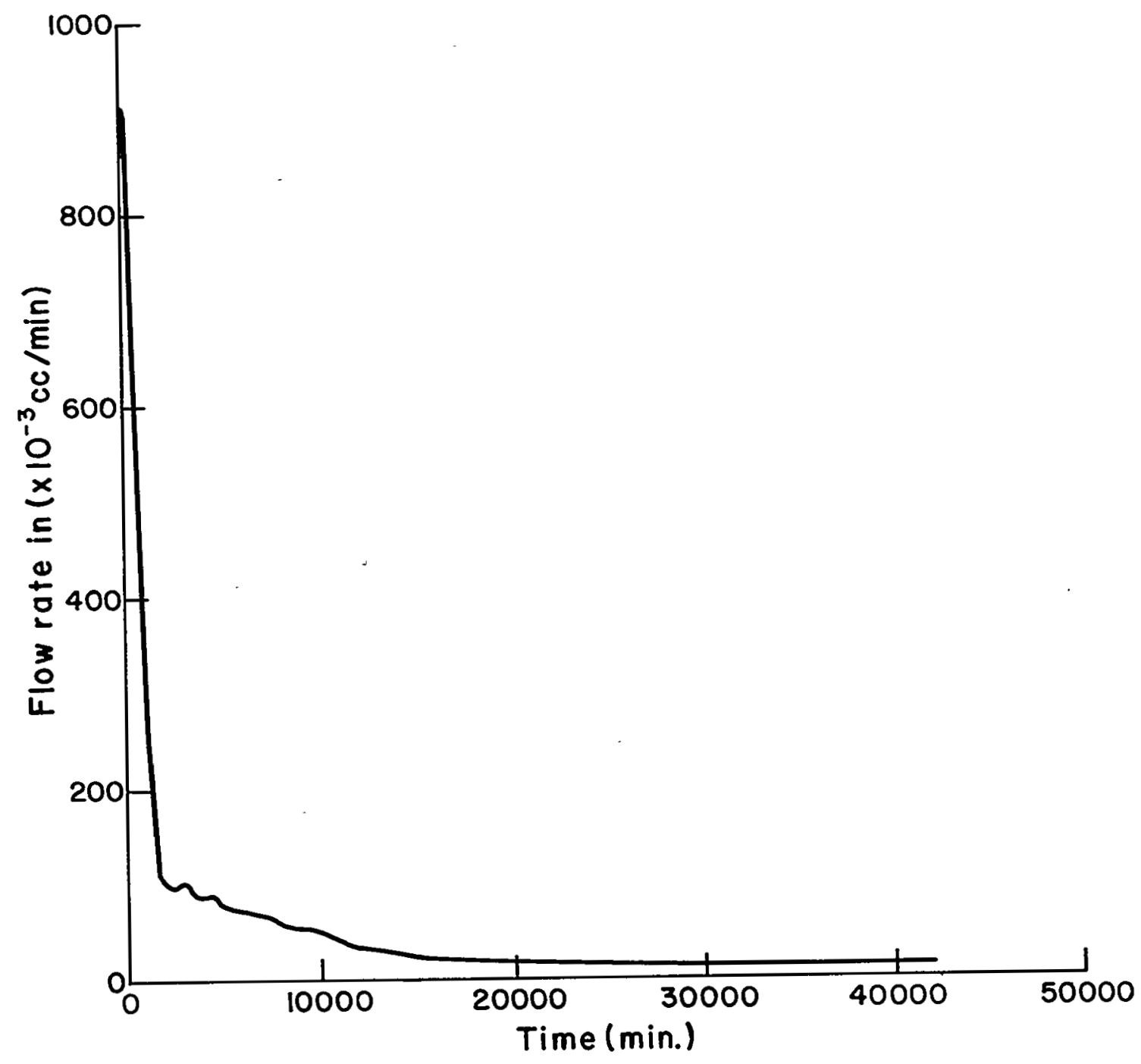

Figure 4.16 Sample SGE-2-2, flow rate vs. time, Cement 1 plug, after drying for 42 days at $54^{\circ} \mathrm{C}$. Test period January 12 - March 2 , 1983. 
Also worth noting is that the increase of triaxial stress state between the last two columns resulted in a lower flow rate for the higher stress level. Details of the testing are presented in Appendix A, Table A.4.

\section{$4 \cdot 1 \cdot 3 \cdot 2 \quad \mathrm{SGE}-2-3$}

Results of the experiment on sample SGE-2-3 are presented in Table 4.9 and on Figure 4.17. Figure 4.18 shows the sample configuration.

Testing began on June 13, 1982, and continued until October 14, 1982. At that time dye was injected into the top hole. Flow rates were very low from the start of the test, indicating the very low permeability of the intact rock. With the rock bridge in place a triaxial stress state of about $12 \mathrm{MPa}$ axial stress and $10 \mathrm{MPa}$ confining stress was applied. Measured flow rates under an injection pressure of 9.8 and $7.0 \mathrm{MPa}$ were $0.01 \times 10^{-3}$ to $0.02 \times 10^{-3} \mathrm{cc} / \mathrm{min}$ in and out, respectively. These flow rates are at the lower limits of resolution of the equipment. Since the flow rates were so low it was not considered worthwhile to vary the triaxial stresses and it was also not worthwhile to test at lower injection pressures.

On July 7, 1982, the rock bridge.was drilled from the sample and a plug of cement system 1 emplaced and cured seven days with the rock sample under 23.1 MPa axial stress and 19.6 MPa confining stress. The plug was placed and cured under a higher triaxial stress state than that under which the rock bridge was tested to allow greater variations of the triaxial stresses during plug testing.

As Figure 4.17 shows, flow rates were considerably higher after plug emplacement than through the sample with rock bridge. The average of a11 data taken after plug emplacement (Table A.5, Appendix A), 7/19$9 / 28$, gave flow rates of $0.44 \times 10^{-3}$ and $0.64 \times 10^{-3} \mathrm{cc} / \mathrm{min}$ in and out, respectively. However, if only the last 10 measurements, 8/17-9/28, are considered, flow rates of $0.27 \times 10^{-3}$ and $0.35 \times 10^{-3} \mathrm{cc} / \mathrm{min}$ are obtained. This is probably a better estimate of the long term, stabilized flow rate and it is these values which are presented in the Summary, Table 4.9. If the water pumped to the annulus $(4.65 \mathrm{cc})$ is added to the water pumped into the top hole $(15.17 \mathrm{cc})$ the total $(19.82$ cc) compares quite well with the amount of water which flowed out of the bottom hole (19.57 cc).

Lowering the triaxial stress state to 15.2 and $10.4 \mathrm{MPa}$, axial and confining stresses, ${ }_{3}$ respectively, had little effect on the flow rate, a value of $0.30 \times 10^{-3} \mathrm{cc} / \mathrm{min}$ being obtained for both flow rate in and flow rate out.

As the triaxial stress state was lowered further problems were encountered with end seal leakage. This was overcome by applying a greater differential between the axial and confining stresses, and the final test was performed at an axial stress of $10.3 \mathrm{MPa}$ and a confining stress of $5.2 \mathrm{MPa}$. Using an injection pressure of $3.4 \mathrm{MPa}$, flow rates of 0.10 $\mathrm{x} 10^{-3}$ and $0.11 \times 10^{-3} \mathrm{cc} / \mathrm{min}$ in and out, respectively, were obtained. 

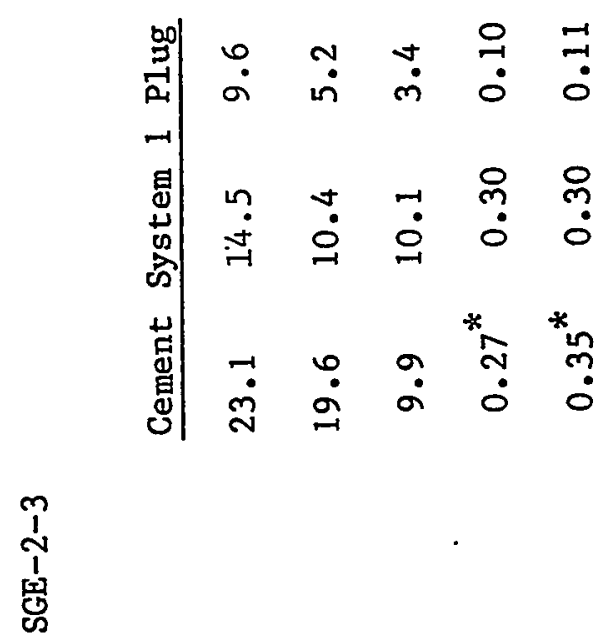

命

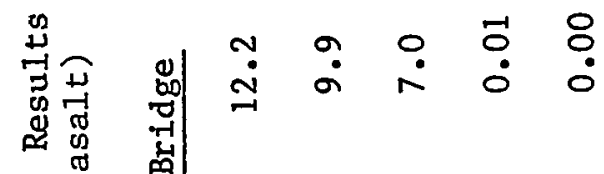

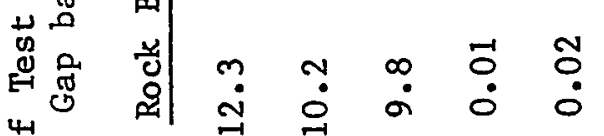

岁

고

幽

毒

क्

g

离

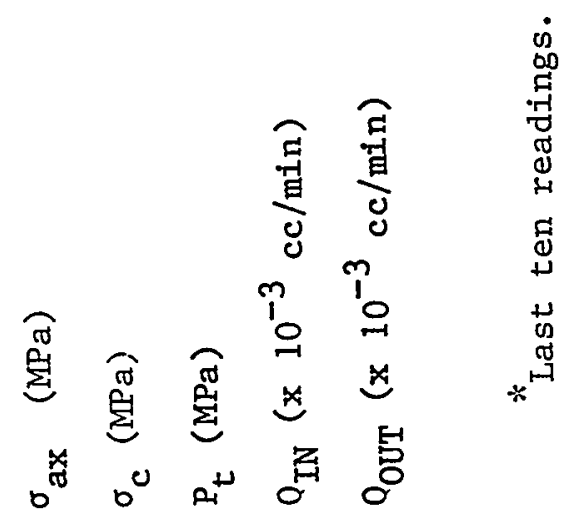




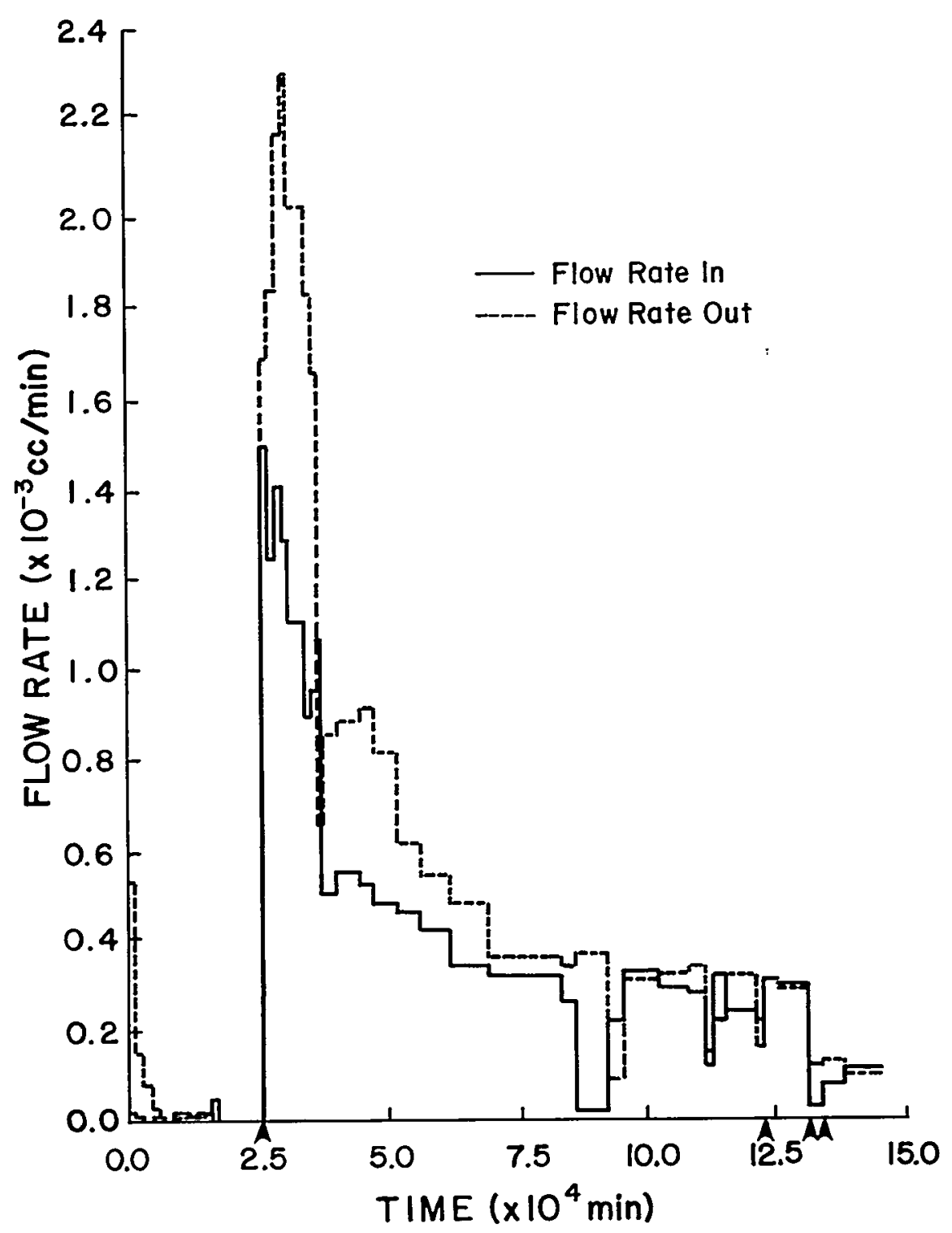

Figure 4.17 Flow rate vs. time, Sample SGE-2-3. Arrows indicate (a) cement plug emplacement, $7 / 7$; (b) stress change, $9 / 28$; (c) stress change, $10 / 4$; and (d) stress change, $10 / 6$. 


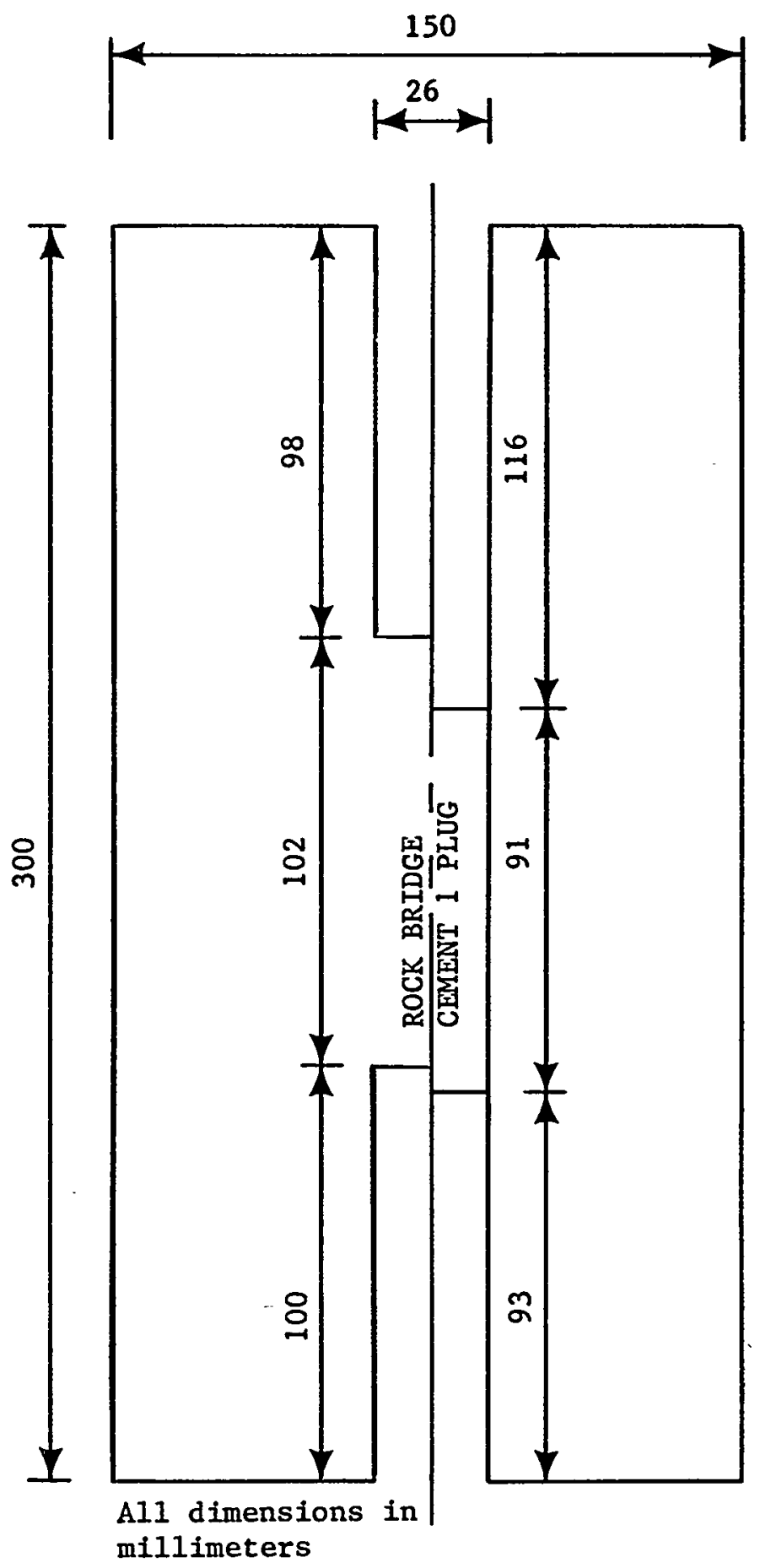

Figure 4.18 Sample SGE-2-3 (Sentinel Gap basalt) - dimensions. 
If it is assumed that flow rate varies linearly with injection pressure, then a measured flow rate of $0.10 \times 10^{-3} \mathrm{cc} / \mathrm{min}$ at an injection pressure of $3.4 \mathrm{MPa}$ may be extrapolated to a flow rate of $0.29 \times 10^{-3} \mathrm{cc} / \mathrm{min}$ at an injection pressure of $10 \mathrm{MPa}$, similar to the flow rates obtained in the previous tests. This assumes permeability is independent of triaxial stress state, and this seems to be true in the ranges considered in this experiment, at least within the sensitivity of measurement.

In summary, the basalt of SGE-2-3 has a very low permeability, as reflected by the low flow rates. Flow rates after plug emplacement were roughly 30 times that for the intact rock. Decreasing the triaxial stress state on the plugged sample did not increase the measured flow rate.

Following plug testing, Magnaflux Spotcheck Water Washable Penetrant SKL-W was injected in the top hole for 24 days under a pressure of 5.1 $\mathrm{MPa}$. During this time axial stress was $9.6 \mathrm{MPa}$ and confining stress was $5.2 \mathrm{MPa}$. Figure 4.19 shows the results of this test. The rock has been sprayed with Zyglo ZP-9B developer to highlight the penetrant. The hole is $2.6 \mathrm{~cm}$ in diameter and the plug $9.2 \mathrm{~cm}$ long. The dye has penetrated a $1.1 \mathrm{~cm}$ zone of laitance at the top of the plug and has penetrated along the left interface between the rock and the plug for an additional $0.3 \mathrm{~cm}$. There is some penetration of the rock adjacent to the plug top and some penetration of the very top of the sample around the empty top hole.

In this test the penetrant indicates that the plug-rock interface is a slightly preferential migration path. Invasion of the rock by the penetrant at the plug top and at the sample top is believed due to increased rock permeability at these points, possibly due to stress interaction effects between the rock and the plug and between the rock and the loading piston.

Details of the testing are given in Appendix A, Table A.5.

\subsubsection{Topopah Spring Tuff}

One sample of the Topopah Spring tuff, designated NTS-TPTS-101, was tested. Results are presented in Tables 4.10 and 4.11 , and on Figures 4.20 and 4.21. Figure 4.22 shows the sample dimensions.

This sample contained two lithophysal cavities in the bottom and a steeply dipping joint intersected the bottom part of the sample, Figure 4.23. In addition, a joint which was not throughgoing intersected the middle of the sample. The cavities were filled with epoxy and the sample coated well with epoxy. Nevertheless, annular leakage was a continuing problem with this sample. The sample was unloaded from the permeameter and re-epoxied twice in an effort to correct the leakage. In order to eliminate two interfaces, the stainless steel platens used on the sample ends were epoxied to the sample.

Testing of the rock bridge began on December 18, 1982, and continued until February 24, 1983. The rock bridge was cored from the sample and a cement plug placed on February 25. Testing resumed on March 8 . 


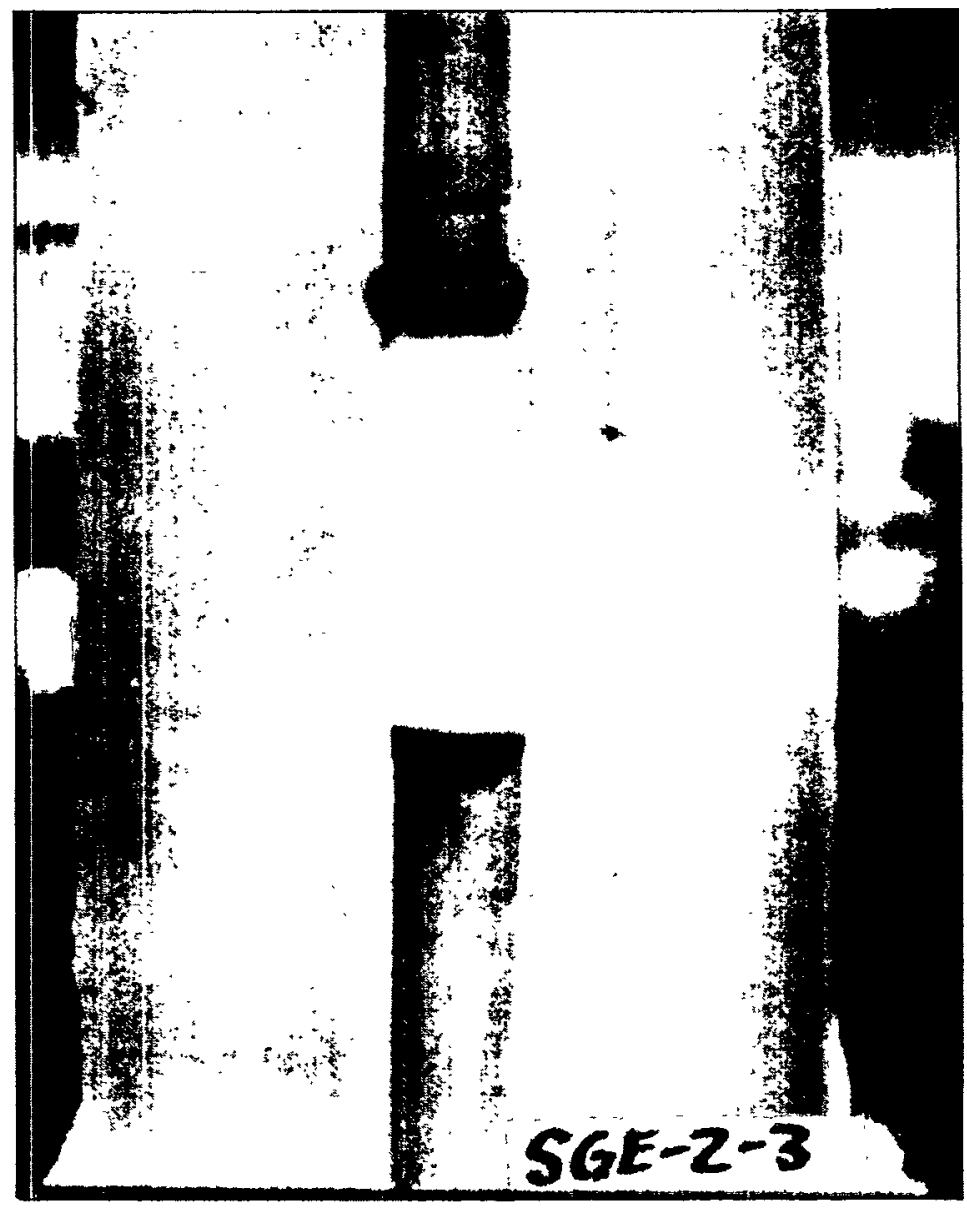

Figure 4.19 Sample SGE-2-3, dye test. Dye has been injected in top hole, at $5.1 \mathrm{MPa}$, for 24 days. Hole diameter is $2.6 \mathrm{~cm}$. 
Table 4.10 Summary of Test Results for Sample NTS-TPTS-101 (Topopah Spring Tuff)

\begin{tabular}{|c|c|c|c|c|c|}
\hline & & \multicolumn{3}{|c|}{ Rock Bridge } & \multirow{2}{*}{$\begin{array}{c}\text { Cement } 1 \text { Plug } \\
19.1 \\
7.6\end{array}$} \\
\hline & $\begin{array}{l}\sigma_{\mathrm{ax}} \\
\sigma_{\mathrm{c}} \\
\end{array}$ & $\begin{array}{l}8.6 \\
6.6 \\
\end{array}$ & $\begin{array}{l}15.7 \\
13.2 \\
\end{array}$ & $\begin{array}{l}23.4 \\
19.6\end{array}$ & \\
\hline & $P_{t}$ & & & & \\
\hline $\begin{array}{l}\text { Flow Rate In, } Q \\
\left(\times 10^{-3} \mathrm{cc} / \mathrm{min}\right)\end{array}$ & $\begin{array}{r}10.0 \\
7.0 \\
6.1 \\
3.5 \\
1.8\end{array}$ & $\begin{array}{l}165.65 \\
72.75 \\
37.12\end{array}$ & $\begin{array}{l}167.15 \\
101.83 \\
43.48\end{array}$ & $\begin{array}{l}135.20 \\
84.38 \\
33.98\end{array}$ & 87.29 \\
\hline $\begin{array}{l}\text { Regression } \\
\text { Coefficients }\end{array}$ & $\begin{array}{l}a \\
b \\
\text { C.c. } \\
\text { Curve }\end{array}$ & $\begin{array}{c}17.37 \\
1.22 \\
0.99 \\
a\end{array}$ & $\begin{array}{l}8.73 \\
1.28 \\
1.00 \\
b\end{array}$ & $\begin{array}{l}6.54 \\
1.32 \\
1.00 \\
c\end{array}$ & \\
\hline $\begin{array}{l}\text { Flow Rate Out, Q } \\
\left(\times 10^{-3} \mathrm{cc} / \mathrm{min}\right)\end{array}$ & $\begin{array}{r}10.0 \\
7.0 \\
6.1 \\
3.5 \\
1.8\end{array}$ & $\begin{array}{r}157.75 \\
76.47 \\
39.43\end{array}$ & $\begin{array}{l}166.24 \\
102.41 \\
49.34\end{array}$ & $\begin{array}{c}138.62 \\
88.97 \\
47.22\end{array}$ & 239.42 \\
\hline $\begin{array}{l}\text { Mass Balance } \\
(\%)\end{array}$ & $\begin{array}{r}10.0 \\
7.0 \\
6.1 \\
3.5 \\
1.8\end{array}$ & $\begin{array}{c}-4.8 \\
5.1 \\
6.2\end{array}$ & $\begin{array}{l}-0.5 \\
0.6 \\
13.5\end{array}$ & $\begin{array}{l}2.5 \\
5.4 \\
39.0\end{array}$ & 174.4 \\
\hline
\end{tabular}

$\sigma_{a x}=$ axial stress $(\mathrm{MPa}) ; \sigma_{c}=$ confining stress $(\mathrm{MPa}) ; \mathrm{P}_{t}=$ top hole injection pressure (MPa); a and $b$ are regression coeffictents for the equation $Q=a\left(P_{t}\right)^{b}$. C.C. is the correlation coefficient. Curves $a, b$, and $c$ are plotted in Figure 4.20. 
Table 4.11 Test Results for Sample NTS-TPTS-101, Cement System 1 P1ug

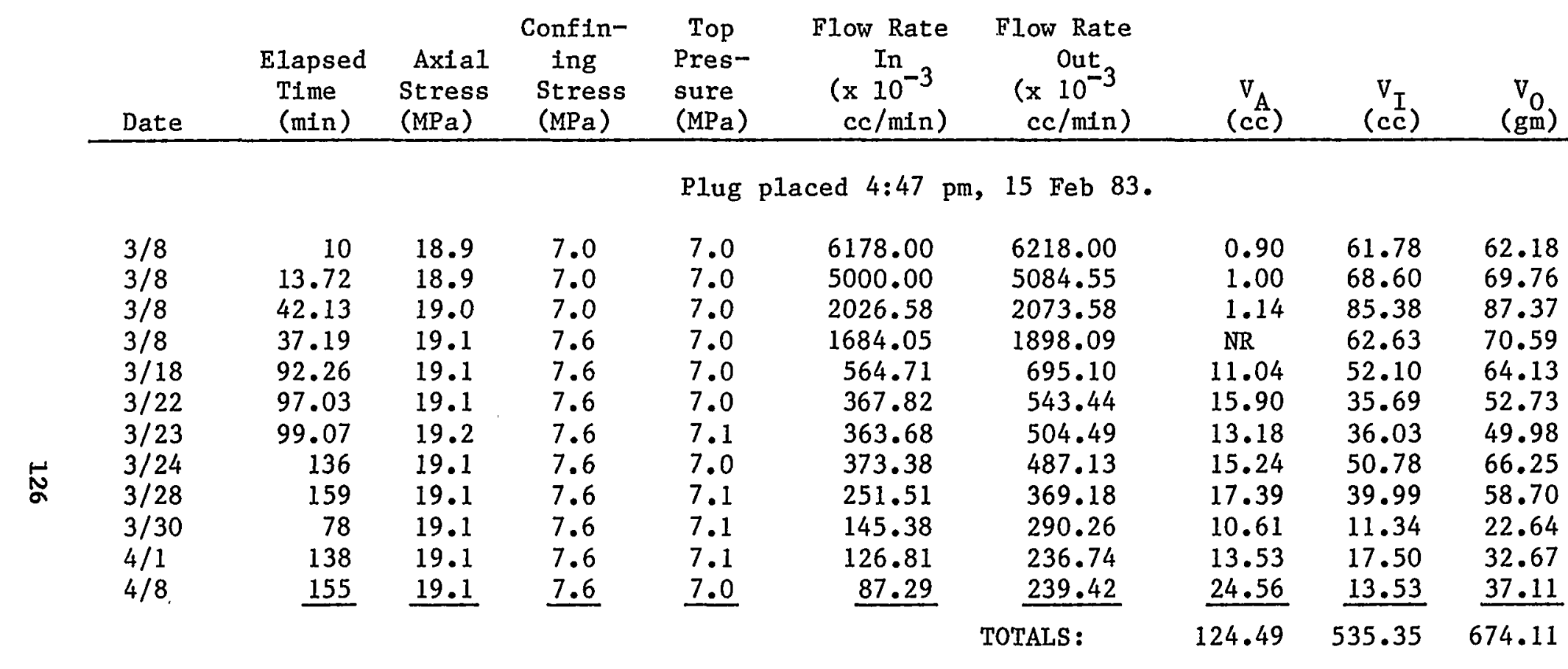

NOTES :

$\mathrm{V}_{\mathrm{A}}=$ volume of water added to annulus

$\mathrm{V}_{\mathrm{I}}=$ volume of water pumped into top hole

$\mathrm{V}_{0}=$ weight of water flowing from bottom hole

Bottom pressure is always $0 \mathrm{MPa}$. 


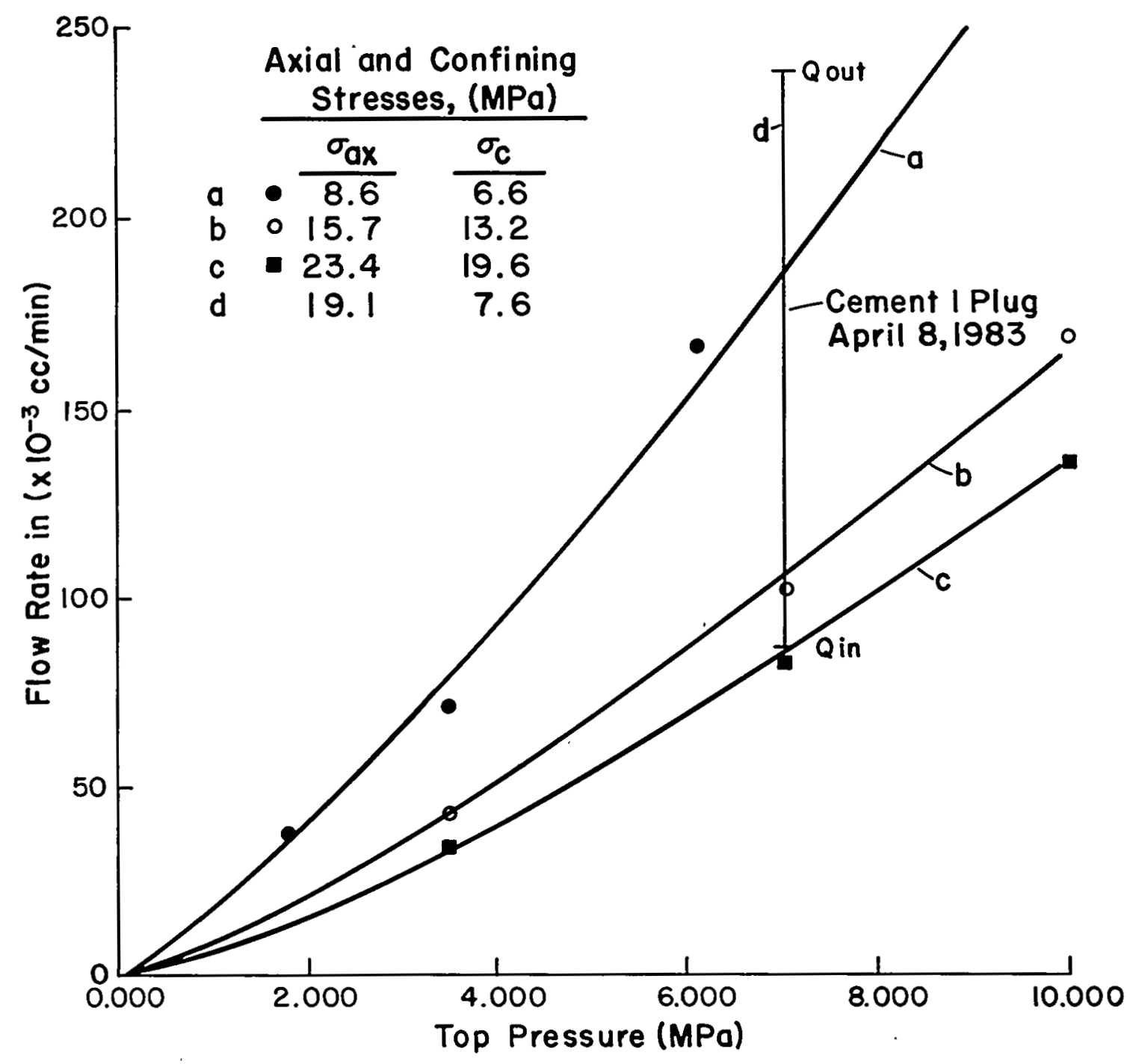

Figure 4.20 Topopah Spring welded tuff Sample NTS-TPTS-101, flow rate in vs. top pressure for rock bridge (curves $a, b$, and $c$ in Table 4.10). Line d represents range of flow rates for cement plug tests one month after plug tests had started. 


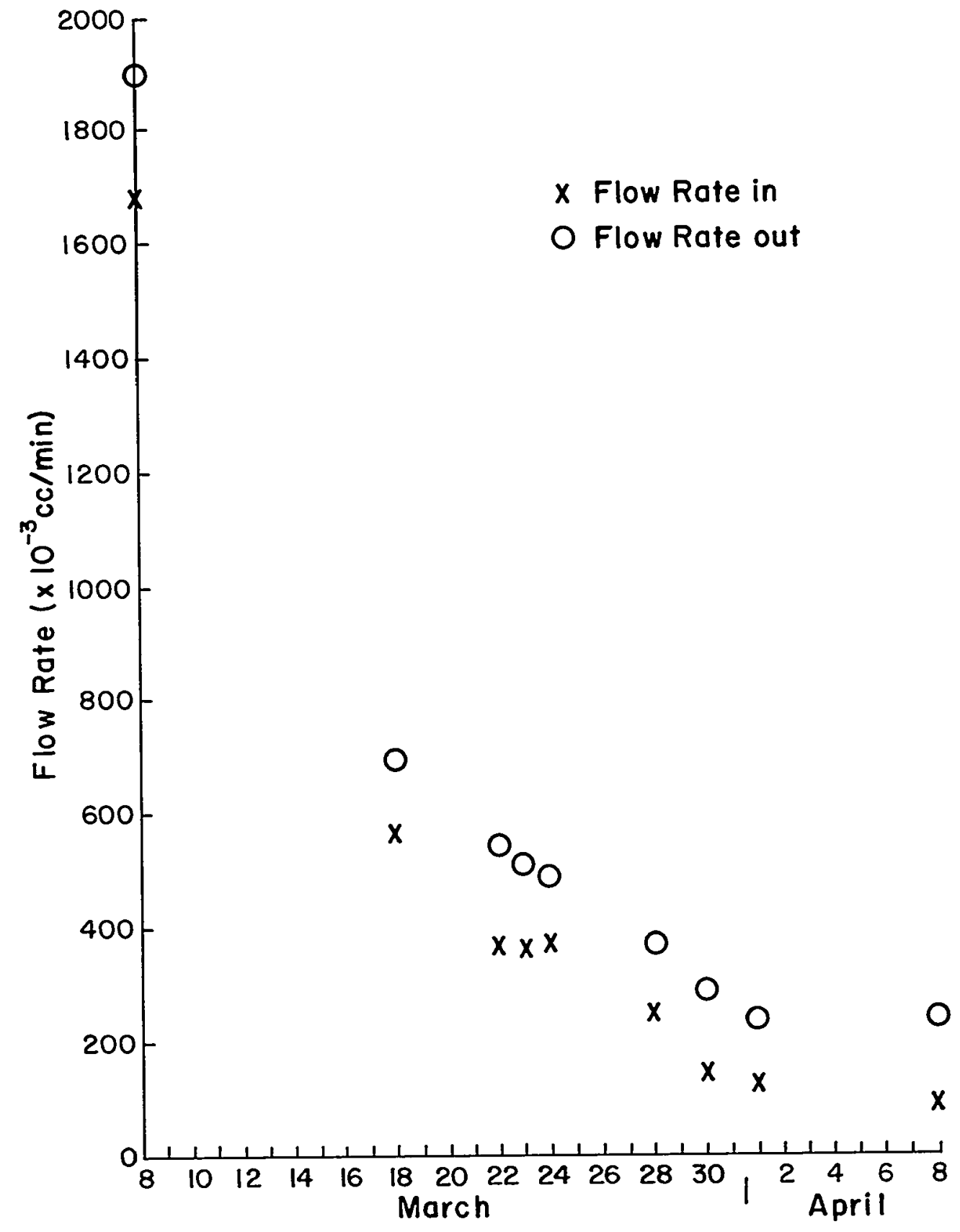

Figure 4.21 Topopah Spring welded tuff Sample NTS-TPTS-101, flow rate vs. time, Cement System 1 plug. Very high flow rates measured in initial tests are not plotted (Table 4.11; Text Section 4.1 .4 ). 


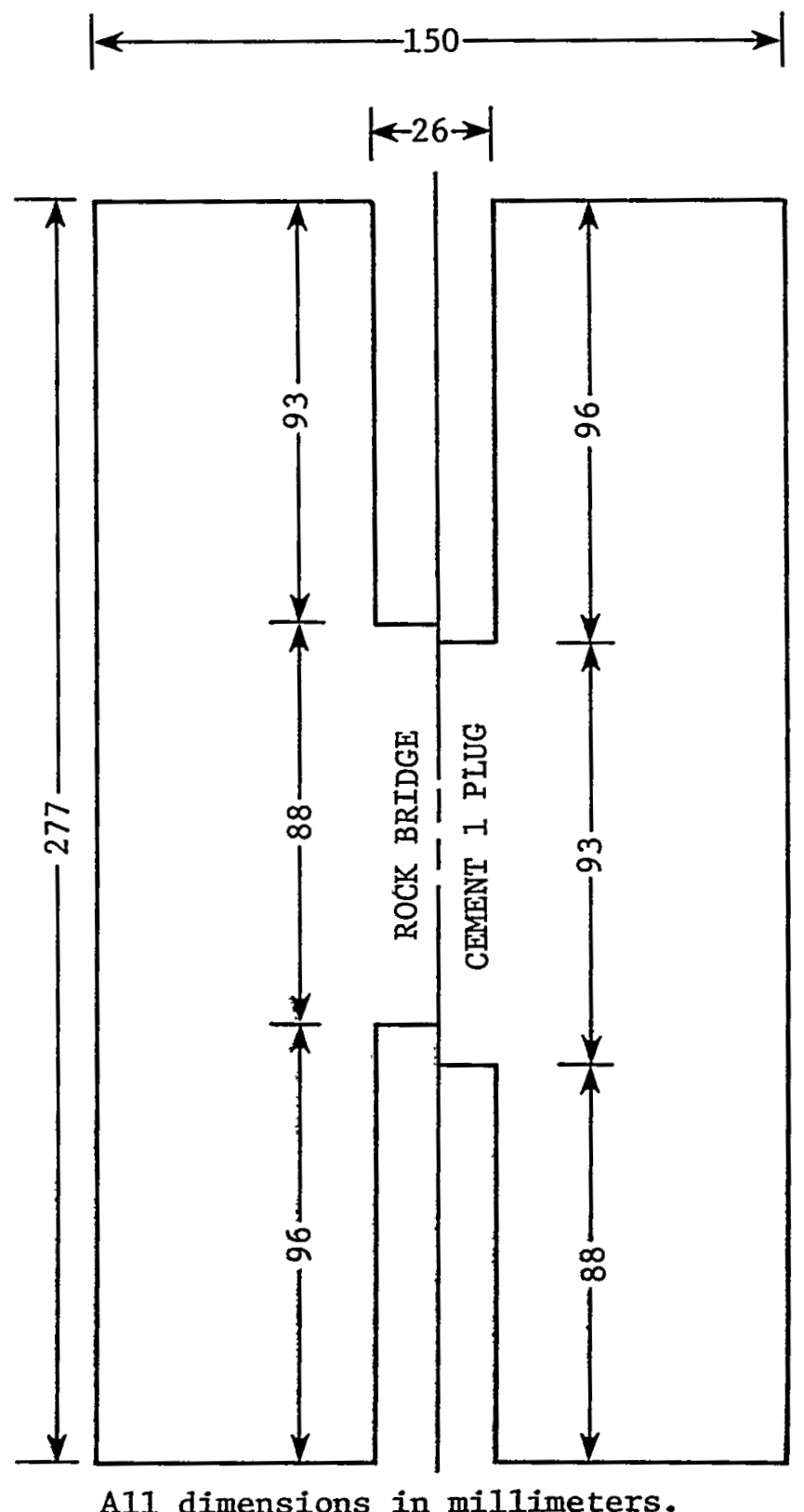

Figure 4.22 Sample NTS-TPTS-101 (Topopah Spring welded tuff) dimensions. 

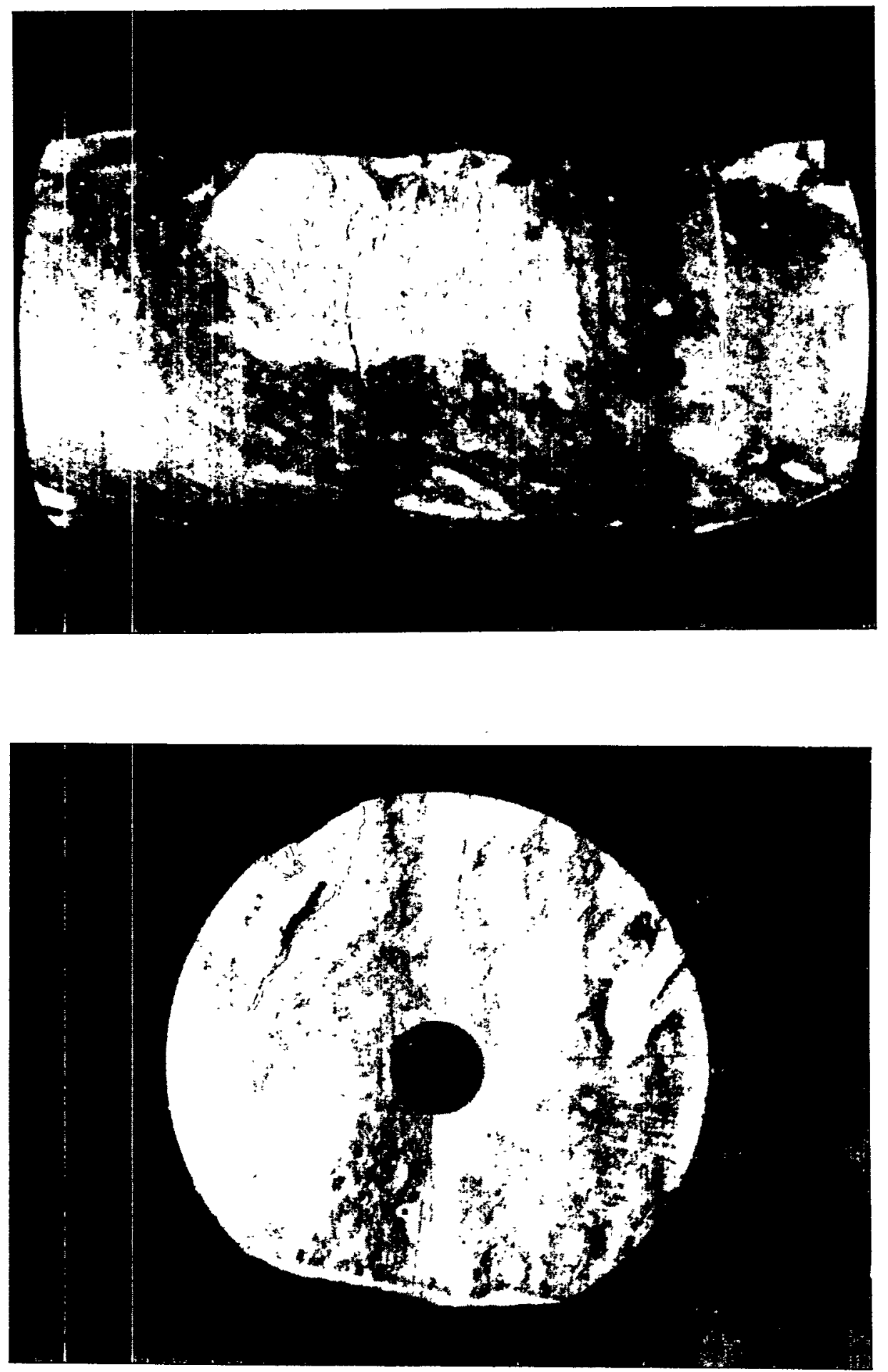

Figure 4.23 Topopah Spring welded tuff Sample NTS-TPTS-101, showing fractures and lithophysal cavities. Center hole diameter is $26 \mathrm{~mm}$. 
Results of the rock bridge testing show a decrease in flow rate with increasing triaxial stress state, Table 4.10 and Figure 4.20. Although some annular leakage occurred, the mass balance for this part of the test was generally better than $10 \%$.

Resumption of testing after plug emplacement showed greatly increased flow rates, Table 4.11. Flow rates were initially over an order of magnitude greater than for the rock bridge under a similar injection pressure. In addition, annular leakage was higher, great enough that water had to be continually supplied to the annulus to maintain confining stress.

Four individual tests were performed on March 8. Tests were then performed for durations of up to 159 minutes at intervals of a few days. When not being tested the sample was left in the permeameter under a hydrostatic pressure of about $7 \mathrm{MPa}$ (i.e., confining stress, top pressure, bottom pressure, and pressure throughout the rock were all 7 $\mathrm{MPa}$ ). Overall mass balance was $25.9 \%$, calculated using the amount of water pumped in to the top and the amount flowing out. If the amount added to the annulus is included in the amount pumped in, mass balance is about $2 \%$.

The first test performed on March 8 had a flow rate of about $6200 \times 10^{-3}$ $\mathrm{cc} / \mathrm{min}$. By the fourth test on March 8 this had declined to about $1750 \mathrm{x}$ $10^{-3} \mathrm{cc} / \mathrm{min}$. Figure 4.21 presents the measured flow rates for the cement plug, starting with the fourth test of March 8 .

The measured flow rates decreased markedly with time. The last values measured, $87 \times 10^{-3}$ and $239 \times 10^{-3} \mathrm{cc} / \mathrm{min}$, April 8 , are plotted on Figure 4.20 with the rock bridge curves. Flow rates at this time were of the same order of magnitude as for the intact rock.

Following the test on April 8 the sample was removed from the permeameter of examination. There were two pinhole leaks in the epoxy, explaining the annular pressure 1oss. Since annular pressure was being maintained at $7.6 \mathrm{MPa}$, communication with the top hole should have caused top pressure to increase or top inflow to be measured as negative. Since it did not it may be inferred that the annular leakage was through the sample to the bottom hole.

Details of the testing are given in Appendix A, Table A.6.

\subsubsection{Catalina Granite}

Two samples of Catalina granite were tested, CCR-P-100 and CCR-D-100. The first, CCR-P-100, had a $3.9 \mathrm{~cm}$ diameter center hole which was percussion drilled in the field. This sample was obtained by overcoring the percussion hole with a diamond bit. Sample CCR-D-100 was $15.2 \mathrm{~cm}$ diameter core diamond drilled in the field which had holes drilled into each end in the laboratory with a diamond bit, leaving a rock bridge in place. 


\subsubsection{Sample CCR-P-100}

Figure 4.24 shows the sample dimensions. Since the center hole was percussion drilled in the field, there was no rock bridge to test. The sample was plugged with System 1 Cement, which was cured 24 days.

Table 4.12 shows the flow test results. The sample was first tested at axial and confining stresses of 7.7 and $2.0 \mathrm{MPa}$, respęctively, Measured flow rates in and out were $8.73 \times 10^{-3}$ and $7.84 \times 10^{-3} \mathrm{cc} / \mathrm{min}$, respectively.

The sample was then removed from the permeameter and the plug allowed to dry for 27 days at a temperature of $21^{\circ} \mathrm{C}$. Humidity was $50-70 \%$ the first six days of drying and $35-40 \%$ thereafter. The sample was then reloaded in the permeameter and the plug tȩsted again. This time measured flow rates in and out were $11.91 \times 10^{-3} \mathrm{cc} / \mathrm{min}$ and $12.09 \times 10^{-3} \mathrm{cc} / \mathrm{min}$, respectively. The measured flow rates for the dried plug were slightly higher than for the plug initially, but still of the same order of magnitude. These data indicate that drying at room temperature impairs plug performance somewhat.

Following the flow measurements, Magnaflux Spotcheck Water Washable Penetrant, SKL-W (a red-colored dye) was injected into the top hole of the sample. Figure 4.25 shows the result. The sample half on the left shows the rock and the darker dye patches. The sample half on the right has been sprayed with a white developer, Magnaflux Zyglo ZP-9B, which highlights the red dye. The dye has penetrated a $1.1 \mathrm{~cm}$ thick zone of laitance at the top of the cement plug but has neither penetrated the main body of the plug nor penetrated along the rock-plug interface.

Details of the testing are given in Appendix A, Table A.7.

\subsubsection{Sample CCR-D-100}

Figure 4.26 shows the dimensions of this sample. Holes $3.8 \mathrm{~cm}$ in diameter were drilled from each end of the sample to provide a sample with rock bridge. The $3.8 \mathrm{~mm}$ diameter holes were used for compatibility with Sample CCR-P-100. Following testing with the rock bridge in place a $2.5 \mathrm{~cm}$ diameter hole was cored through the rock bridge and a cement plug emplaced.

Results are presented in Tables 4.13 and A.8 and in Figure 4.27. Testing began on October 10, 1982, and was completed on April 8, 1983. The cement plug was poured on January 18, 1983, covered with water, and cured at atmospheric pressure until February 3, 1983, a total of 16 days. Mass balances were generally better than $5 \%$, but were higher at the lowest triaxial stress state and low injection pressures.

This sample behaved similarly to the Charcoal granite samples. In Figure 4.27 the solid lines are for testing with the rock bridge in place and the dashed lines represent results from the cement plug testing. As the triaxial stress state on the sample with rock bridge is increased the flow rate lessens as pores and fissures are closed (see discussion for CG-104, below). Upon plugging, flow rates are even 

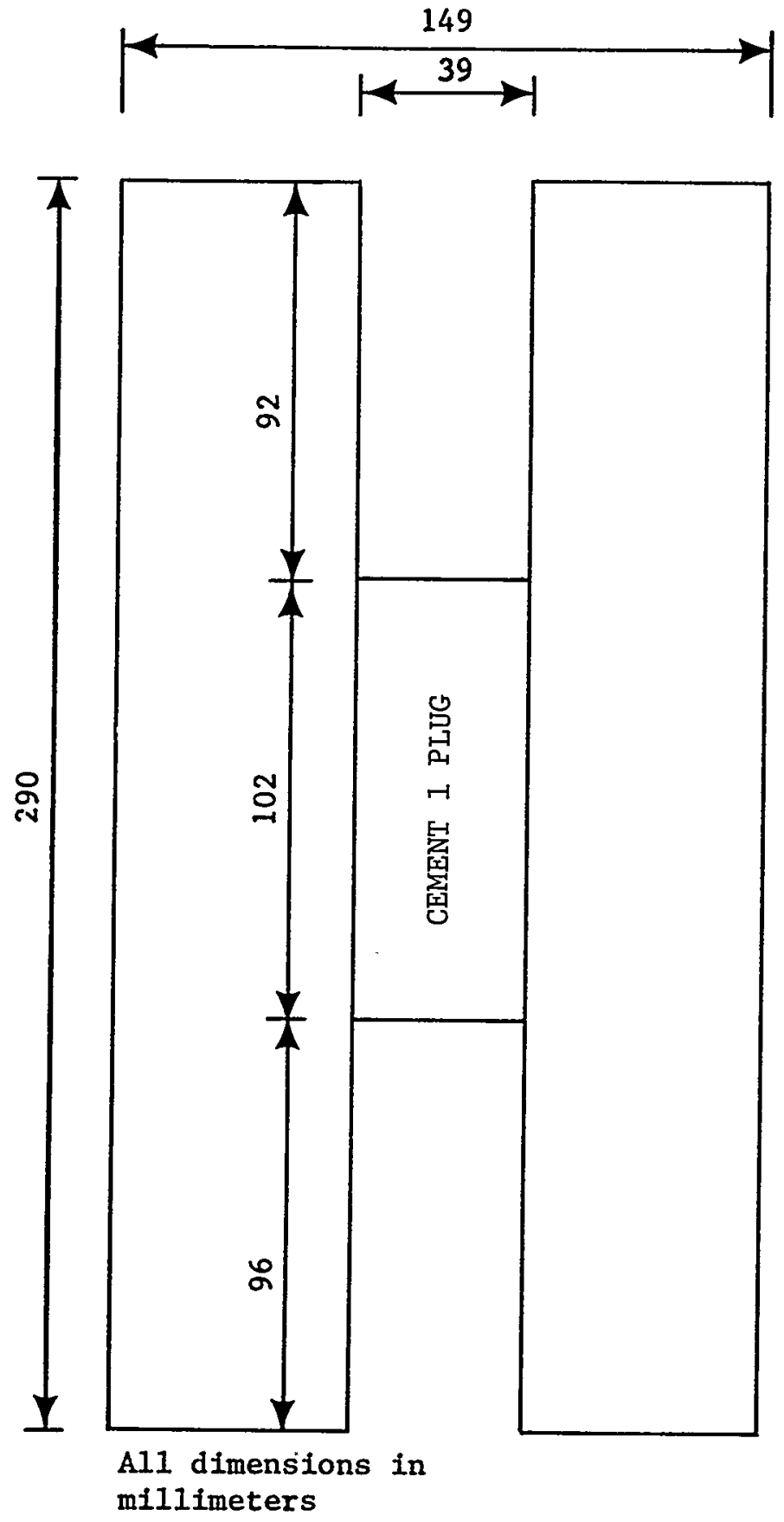

Figure 4.24 Sample CCR-P-100 (Catalina granite, percussion drilled hole) - dimensions. 
Table 4.12 Test Results for Sample CCR-P-100 (Catalina Granite)

\begin{tabular}{|c|c|c|c|c|c|c|c|c|c|c|}
\hline Date & $\begin{array}{l}\text { Elapsed } \\
\text { Time } \\
\text { (min) }\end{array}$ & $\begin{array}{l}\text { Axial } \\
\text { Stress } \\
\text { (MPa) }\end{array}$ & $\begin{array}{l}\text { Confin- } \\
\text { ing } \\
\text { Stress } \\
\text { (MPa) }\end{array}$ & $\begin{array}{l}\text { Top } \\
\text { Pres- } \\
\text { sure } \\
\text { (MPa) }\end{array}$ & $\begin{array}{c}\text { Flow Rate } \\
\text { In } \\
\left(x 10^{-3}\right. \\
\mathrm{cc} / \mathrm{min})\end{array}$ & $\begin{array}{c}\text { Flow Rate } \\
\text { Out } \\
\left(\times 10^{-3}\right. \\
\text { cc/min) }\end{array}$ & $\begin{array}{l}\mathrm{V}_{\mathrm{A}} \\
(\mathrm{cc})\end{array}$ & $\begin{array}{l}V_{I} \\
(c c)\end{array}$ & $\begin{array}{c}\mathrm{V}_{0} \\
(\mathrm{gm})\end{array}$ & Notes \\
\hline
\end{tabular}

Cement 1 Plug, Before Drying

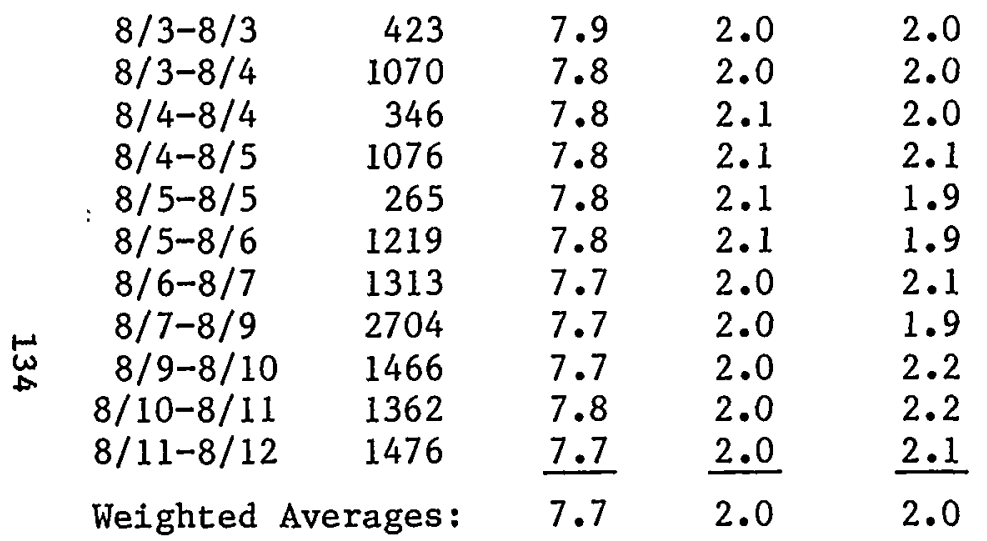

\begin{tabular}{cc}
10.35 & 9.60 \\
8.67 & 8.23 \\
2.86 & 5.61 \\
9.40 & 7.27 \\
8.34 & 8.38 \\
7.91 & $\mathrm{NR}$ \\
8.40 & 7.82 \\
7.27 & 7.17 \\
NR & 8.10 \\
10.79 & 8.58 \\
10.36 & 8.45 \\
\hline 8.73 & 7.84 \\
& Totals:
\end{tabular}

\begin{tabular}{lrl}
0.00 & 4.38 & 4.06 \\
0.26 & 9.28 & 8.81 \\
0.00 & 0.99 & 1.94 \\
0.00 & 10.11 & 7.82 \\
0.00 & 2.21 & 2.22 \\
0.00 & 9.64 & NR \\
0.00 & 11.03 & 10.27 \\
0.00 & 19.60 & 19.33 \\
0.00 & NR & 11.88 \\
0.00 & 14.69 & 11.68 \\
0.11 & 15.29 & $\underline{12.47}$ \\
\hline
\end{tabular}

2.1

2.2

Totals:

$\begin{array}{lll}0.37 \quad 97.22 & 90.48\end{array}$

Cement 1 Plug, Afer Drying

$\begin{array}{crrrrrr}9 / 10-9 / 11 & 1386 & 7.5 & 2.2 & 1.9 & 11.93 & 10.49 \\ 9 / 11-9 / 12 & 1157 & 7.5 & 2.2 & 1.8 & 10.82 & 11.31 \\ 9 / 12-9 / 13 & 1318 & 7.5 & 2.1 & 1.8 & 10.86 & 11.39 \\ 9 / 13 & 387 & 7.5 & 2.1 & 1.8 & 10.72 & 12.79 \\ 9 / 13-9 / 14 & 1087 & 7.5 & 2.1 & 1.7 & 10.71 & 10.95 \\ 9 / 14-9 / 15 & 1365 & 7.4 & 2.1 & 1.7 & 10.53 & 11.00 \\ 9 / 15-9 / 15 & 250 & 7.4 & 2.1 & 1.7 & 10.44 & \text { NR } \\ 9 / 15-9 / 16 & 1082 & 7.4 & 2.1 & 2.1 & \text { NR } & 13.61 \\ 9 / 16-9 / 16 & 476 & 7.4 & 2.1 & 2.1 & \text { NR } & 13.68\end{array}$

$\begin{array}{lrr}0.00 & 16.54 & \cdots 14.54 \\ 0.00 & 12.52 & 13.08 \\ 0.00 & 14.31 & 15.01 \\ 0.00 & 4.15 & 4.95 \\ 0.00 & 11.64 & 11.90 \\ 0.00 & 14.37 & 15.01 \\ 0.00 & 2.61 & \text { NR } \\ 0.00 & \text { NR } & 14.73 \\ 0.00 & \text { NR } & 6.51\end{array}$

3.61

0.00

$\mathrm{NR}$

6.51 
Table 4.12 Test Results for Sample CCR-P-100--Continued

\begin{tabular}{|c|c|c|c|c|c|c|c|c|c|c|}
\hline Date & $\begin{array}{c}\text { Elapsed } \\
\text { Time } \\
\text { (min) }\end{array}$ & $\begin{array}{l}\text { Axial } \\
\text { Stress } \\
(\mathrm{MPa}) \\
\end{array}$ & $\begin{array}{l}\text { Confin- } \\
\quad \text { ing } \\
\text { Stress } \\
\text { (MPa) } \\
\end{array}$ & $\begin{array}{l}\text { Top } \\
\text { Pres- } \\
\text { sure } \\
(\mathrm{MPa}) \\
\end{array}$ & $\begin{array}{c}\text { Flow Rate } \\
\text { In } \\
\left(\times 10^{-3}\right. \\
\mathrm{cc} / \mathrm{min})\end{array}$ & $\begin{array}{c}\text { Flow Rate } \\
\text { Out } \\
\left(\mathrm{x} 10^{-3}\right. \\
\mathrm{cc} / \mathrm{min})\end{array}$ & $\begin{array}{c}\mathrm{V}_{\mathrm{A}} \\
(\mathrm{cc})\end{array}$ & $\begin{array}{l}V_{I} \\
(c c)\end{array}$ & $\begin{array}{c}\mathrm{V}_{0} \\
(\mathrm{gm})\end{array}$ & Notes \\
\hline $\begin{array}{l}9 / 16-9 / 17 \\
9 / 17-9 / 18 \\
9 / 18-9 / 19 \\
9 / 18-9 / 20 \\
9 / 20-9 / 21\end{array}$ & $\begin{array}{l}1040 \\
1572 \\
1320 \\
2818 \\
1401\end{array}$ & $\begin{array}{l}7.4 \\
7.4 \\
7.4 \\
7.4 \\
7.4 \\
\end{array}$ & $\begin{array}{l}2.0 \\
2.0 \\
2.1 \\
2.1 \\
2.1 \\
\end{array}$ & $\begin{array}{l}1.9 \\
2.0 \\
2.1 \\
2.1 \\
2.1 \\
\end{array}$ & $\begin{array}{l}12.15 \\
14.04 \\
14.02 \\
\text { NR } \\
13.80 \\
\end{array}$ & $\begin{array}{c}12.55 \\
14.08 \\
N R \\
14.30 \\
14.13 \\
\end{array}$ & $\begin{array}{l}0.00 \\
0.38 \\
0.00 \\
0.00 \\
0.00 \\
\end{array}$ & $\begin{array}{c}12.64 \\
22.07 \\
18.50 \\
\text { NR } \\
19.34 \\
\end{array}$ & $\begin{array}{c}13.05 \\
22.14 \\
N R \\
40.30 \\
19.80 \\
\end{array}$ & $\begin{array}{l}\text { a } \\
\text { a }\end{array}$ \\
\hline Weighted & erages: & 7.5 & 2.1 & 1.9 & 11.91 & $\begin{array}{l}12.09 \\
\text { Totals: }\end{array}$ & 0.38 & 148.69 & 191.02 & b \\
\hline
\end{tabular}

$\underset{\omega}{\omega}$

$\begin{array}{lrllllllll}9 / 22-9 / 23 & 1161 & 7.0 & 1.9 & 1.9 & 2.23 & 1.98 & 0.90 & 2.59 & 2.30 \\ 9 / 23-9 / 28 & 7343 & 7.0 & 1.9 & 1.8 & 0.79 & 0.78 & 0.55 & 5.78 & 5.76 \\ 9 / 28-9 / 29 & 1370 & 7.0 & 2.1 & 2.2 & 0.58 & \text { NR } & 0.00 & 0.79 & \text { NR } \\ 9 / 29-9 / 30 & 932 & 7.0 & 2.0 & 2.2 & 0.69 & \text { NR } & 0.00 & 0.64 & \text { NR } \\ 9 / 30-10 / 4 & 5832 & 7.0 & 1.9 & 2.1 & 0.65 & 0.63 & 0.38 & 3.79 & 3.70\end{array}$

NOTES:

(a) Datum not included in average.

(b) Averages weighted with respect to elapsed time.

$\mathrm{NR}=$ Not recorded

Bottom pressure is always $0 \mathrm{MPa}$.

$\mathrm{V}_{\mathrm{A}}$ is volume of water added to annulus.

$V_{T}$ is volume of water pumped into top hole.

$v_{0}$ is weight of water flowing from bottom hole. 


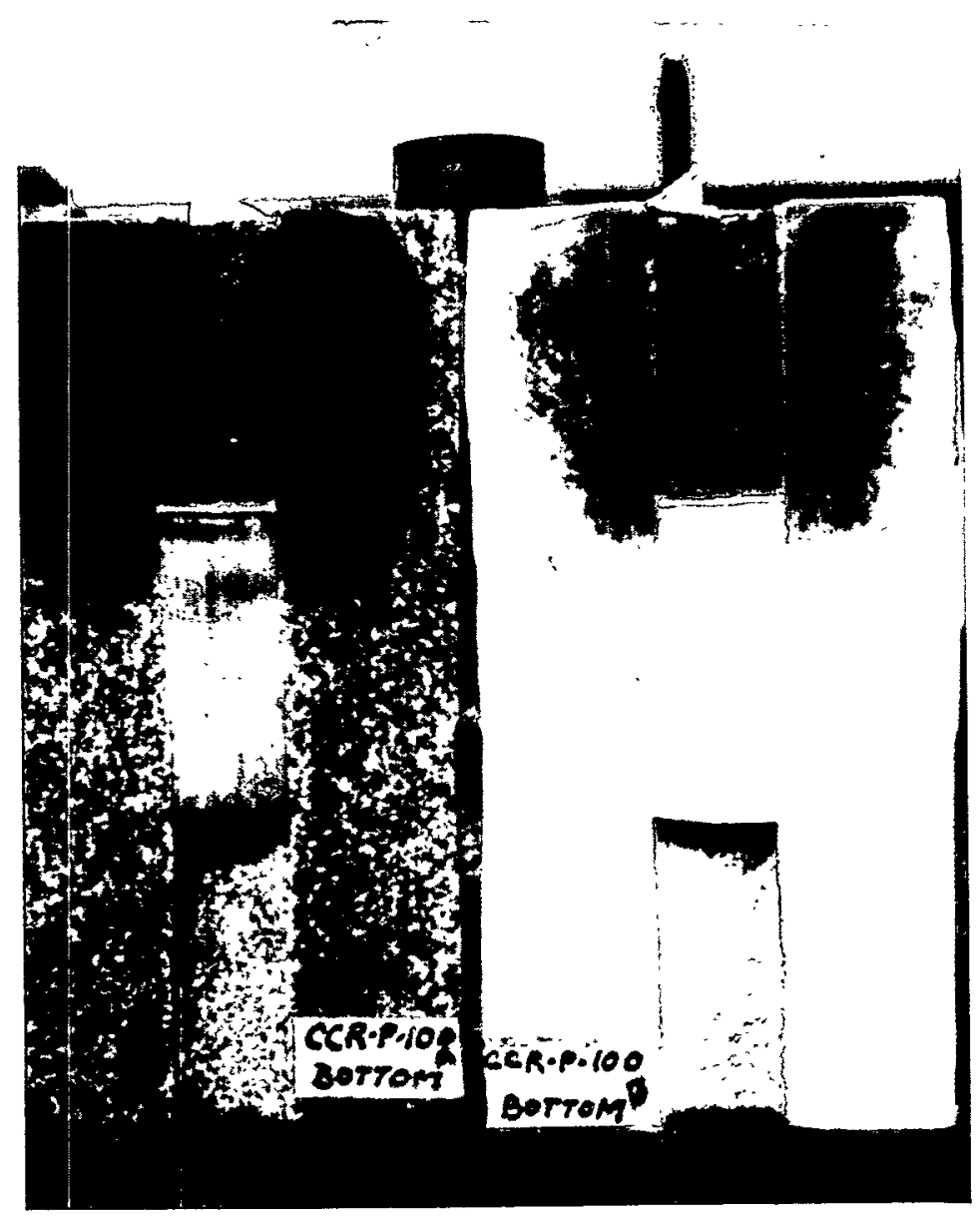

Figure 4.25 Sample CCR-P-100, dye test, showing greater penetration of the granite than of the cement plug. The dye has penetrated a $1.1 \mathrm{~cm}$ thick zone of laitance at the top of the plug, but has neither penetrated along the main body of the plug, nor penetrated along the rock-plug interface.

Catalina granite cylinder. Percussion drilled $3.9 \mathrm{~cm}$ diameter hole. Dye injected at $2 \mathrm{MPa}$ for 12 days. Drying cracks appeared after sample had been cut and exposed to a room environment for several days. 


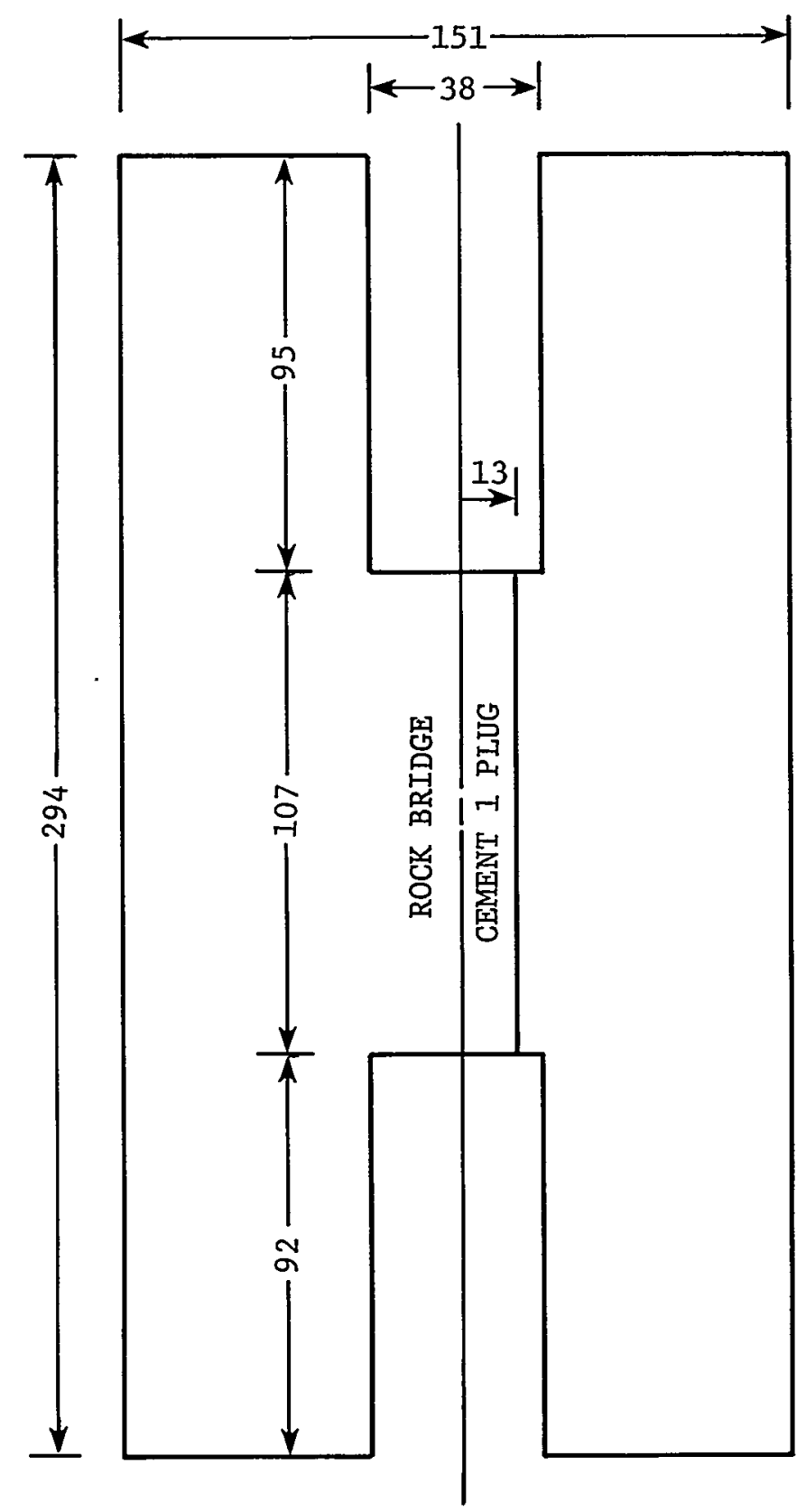

All dimensions in millimeters.

Figure 4.26 Sample CCK-D-100 (Catalina granite cylinder with diamond cored holes) - dimensions. 
Table 4.13 Summary of Test Results for Sample CCR-D-100

Rock Bridge

Cement 1 Plug

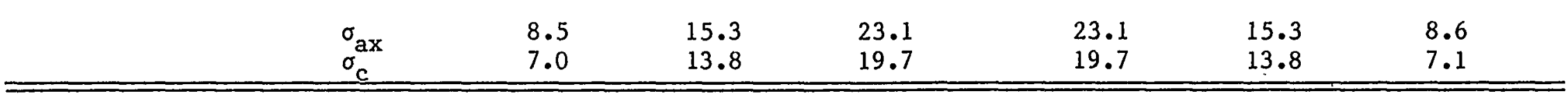

$\begin{array}{ll}\text { Flow Rate In, Q } & 10 \\ \left(x 10^{-3} \mathrm{cc} / \mathrm{min}\right) & 3 \\ & 1\end{array}$

\begin{tabular}{|c|c|c|c|c|c|c|c|}
\hline $\begin{array}{l}\text { Regression } \\
\text { Coefficients }\end{array}$ & $\begin{array}{l}a \\
b \\
\text { C.c. } \\
\text { Curve }\end{array}$ & $\begin{array}{l}9.47 \\
1.09 \\
1.00 \\
a\end{array}$ & $\begin{array}{l}6.38 \\
1.08 \\
1.00 \\
b\end{array}$ & $\begin{array}{c}4.79 \\
1.04 \\
1.00 \\
c\end{array}$ & $\begin{array}{c}4.11 \\
0.95 \\
1.00 \\
\text { d }\end{array}$ & $\begin{array}{c}3.42 \\
1.12 \\
1.00 \\
\mathrm{e}\end{array}$ & $\begin{array}{c}5.28 \\
1.49 \\
0.99 \\
f\end{array}$ \\
\hline $\begin{array}{l}\text { Flow Rate out, Q } \\
\left(\times 10^{-3} \mathrm{cc} / \mathrm{min}\right)\end{array}$ & $\begin{array}{r}10.0 \\
7.0 \\
3.5 \\
1.6\end{array}$ & $\begin{array}{c}75.38 \\
37.78 \\
12.71\end{array}$ & $\begin{array}{l}76.96 \\
50.83 \\
24.40\end{array}$ & $\begin{array}{l}52.87 \\
36.57 \\
17.82\end{array}$ & $\begin{array}{l}36.73 \\
26.05 \\
13.75\end{array}$ & $\begin{array}{l}45.35 \\
29.79 \\
14.02\end{array}$ & $\begin{array}{c}103.13 \\
26.76 \\
8.11\end{array}$ \\
\hline $\begin{array}{l}\text { Mass Balance } \\
(\%)\end{array}$ & $\begin{array}{r}10.0 \\
7.0 \\
3.5 \\
1.6\end{array}$ & $\begin{array}{r}-4.4 \\
3.3 \\
-1.3\end{array}$ & $\begin{array}{l}-4.1 \\
-0.3 \\
-1.3\end{array}$ & $\begin{array}{c}-0.5 \\
0.8 \\
0.5\end{array}$ & $\begin{array}{r}0.1 \\
-0.5 \\
1.7\end{array}$ & $\begin{array}{r}-0.8 \\
-1.2 \\
0.1\end{array}$ & $\begin{array}{r}0.4 \\
-11.1 \\
-28.3\end{array}$ \\
\hline
\end{tabular}

$\sigma_{a x}=$ axial stress $(\mathrm{MPa}) ; \sigma_{c}=$ confining stress ( $\mathrm{MPa}$ ); $\mathrm{P}_{\mathrm{t}}=$ top hole injection pressure (MPa); a and b are regression coefficients for the equation $Q=a\left(P_{t}\right)^{b}$. C.C. is the correlation coefficient. Curve identification letters $a, b, c, d, e, f$ refer to Figure 4.27 


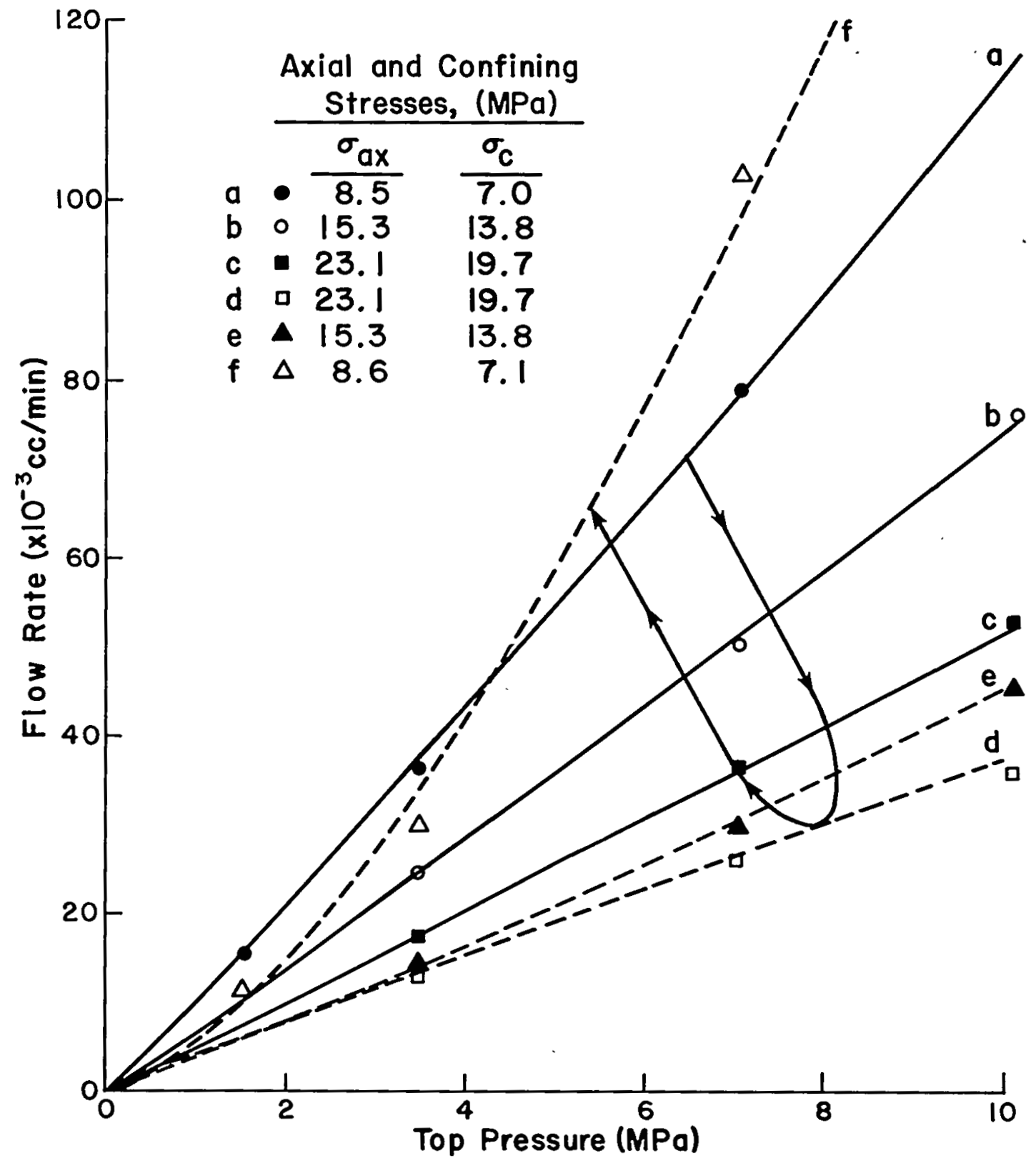

Figure 4.27 Sample CCR-D-100, flow rate in vs. injection pressure. Solid lines indicate rock bridge, dashed lines indicate Cement 1 plug. Test summary is given in Table 4.13, details in Table A.8. 
lower, indicating the plug is less permeable than the granite. Only when the triaxial stress state is lowered to its lowest value does flow through the plugged sample exceed flow through the intact rock, and even then only at the higher injection pressures.

4.2 Tests on Bentonite Plugs in a Charcoal Granite Cylinder

One Charcoal granite cylinder, Sample CG-104, was tested using bentonite tablets as the plugging material. It was first tested with a rock bridge in place at different axial and confining stresses to measure the variation in flow rate at different triaxial stress states for the intact rock. Subsequently, three clay plugs were tested. Table 4.14 is a summary of the data collected during the experiment and Figures 4.28 and 4.29 present the data graphically. Figure 4.30 shows the sample dimensions. Table A.9 in Appendix A presents the details of the test.

The solid lines on the figures indicate flow rate vs. top pressure for the intact rock. Increased flow occurs at lower triaxial stress levels, probably as a result of microfissures widening in the rock. (This variation in flow rate with triaxial stress state in intact Charcoal granite will be compared with that in plugged Charcoal granite in the next chapter.)

Following the intact rock testing the rock bridge was cored from the sample and a clay plug emplaced using bentonite tablets. Figure 4.30 shows a sketch of the plug. Ten bentonite tablets ("Volclay Tablets", American Colloid Company) were dropped through water on top of a column of $3 \mathrm{~mm}$ diameter glass beads in the bottom hole. Mirafi $140 \mathrm{~N}$ filter cloth was placed at the bottom and top of the glass bead column. After swelling two days the plug was $109 \mathrm{~mm}$ long. On $8 / 22 / 82$ a top pressure of $2 \mathrm{MPa}$ was placed on the clay plug. The plug would not hold this pressure so the pressure was lowered to zero (gauge) and the plug allowed to stand overnight. The plug was then able to hold 0.1-0.3 $\mathrm{MPa}$. No data were collected at this time due to equipment problems. Some channeling and loss of clay occurred throughout the test, possibly similar to failures observed on other clay plugs (Daemen et al., 1986, Section 9.5.4.4).

On $9 / 1$ a top pressure of about $1 \mathrm{MPa}$ was placed on the plug. The plug was tested for two weeks. The test results are represented by points $d$ on Figure 4.28. Flow rates are of the same order of magnitude as for intact rock. During this test there was considerable leakage from the annulus. On $9 / 15$ the annular pressure was lowered and the test continued.

The results of the test at a lower annular pressure are represented by points e. Even though the triaxial stress state for points e is lower than for curve $c$ for intact rock, the flow rate through the plugged sample is less than the flow rate through the rock bridge (i.e., points e fall below curve c).

On 9/18 leakage from the annulus increased the pressure on the clay plug until the plug failed by excessive channeling at a top pressure of 4.2 $\mathrm{MPa}$. The plug was allowed to stand two days at zero pressure (gage); upon reloading it again failed, at $2.0-2.5 \mathrm{MPa}$. 


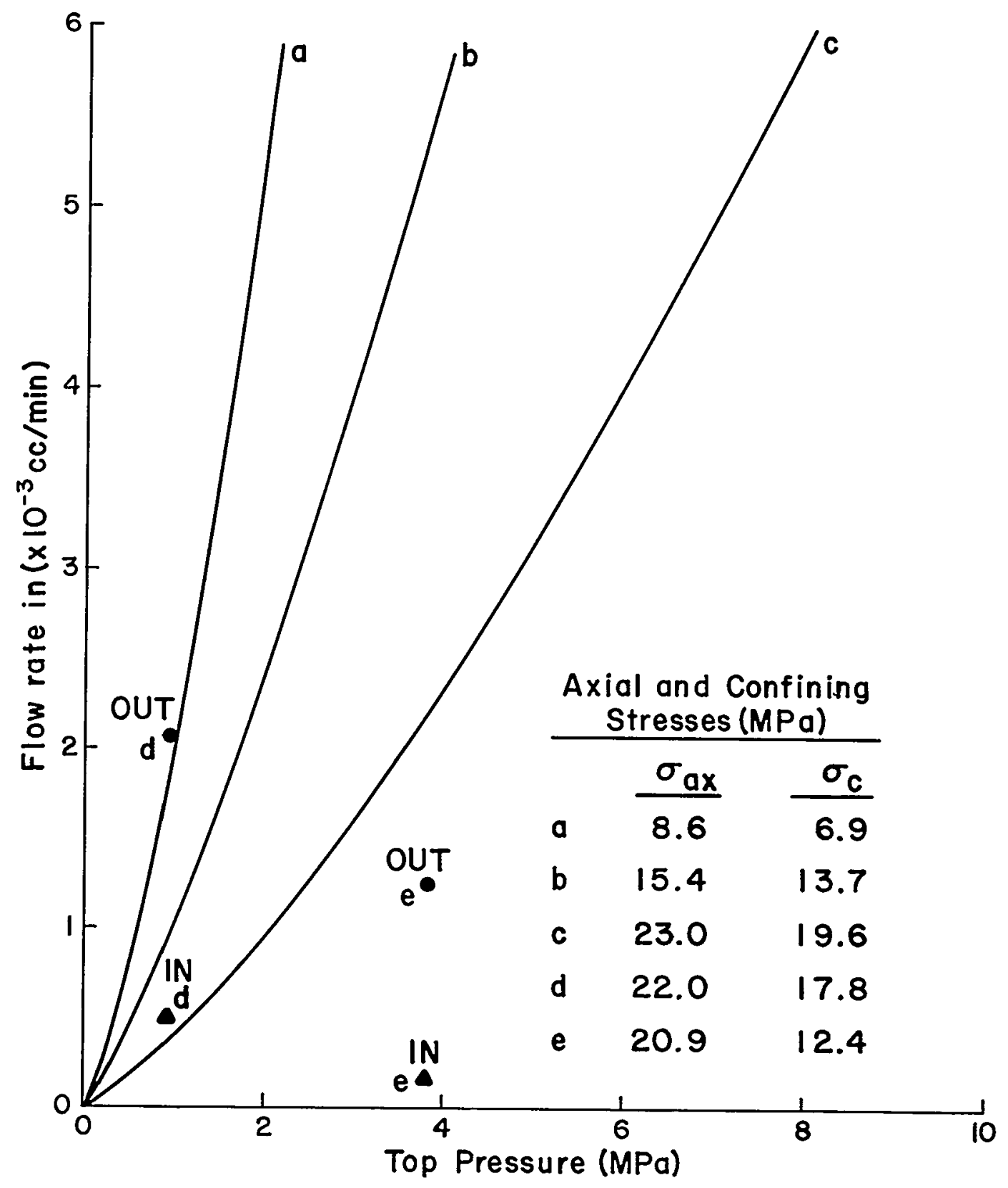

Figure 4.28 Sample CG-104, flow rate in vs. injection pressure, Charcoal Granite. Solid lines indicate tests on rock bridge. Triangles and circles indicate tests on bentonite plug for both flow rate in and flow rate out. Letters indicate order of testing and correspond to curves (points) identified in Table 4.14. 


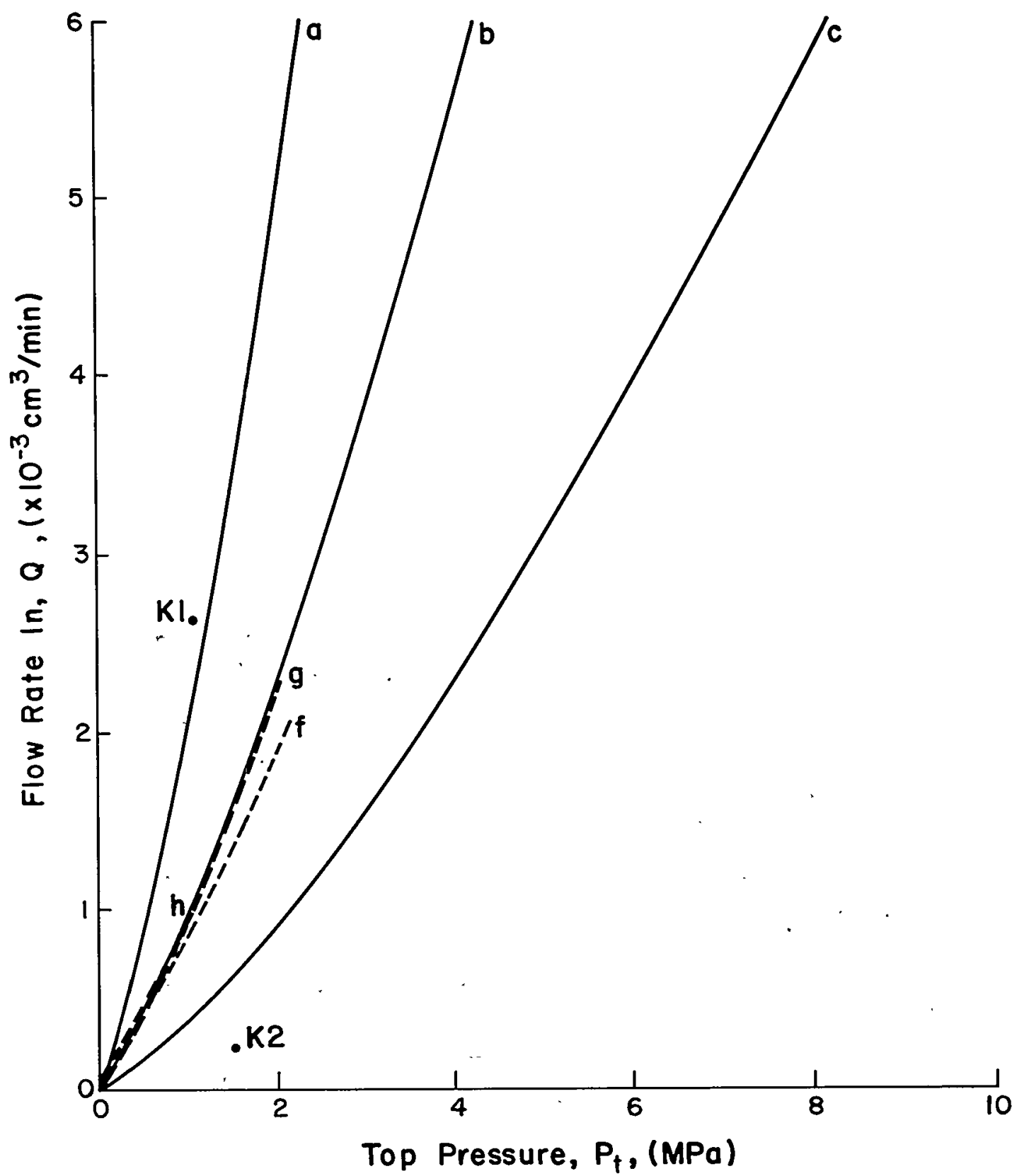

Figure 4.29 Sample CG-104 test results on second and third clay plugs (dots and dashed.lines; solid lines are for granite bridge). Letters indicate order of testing, and correspond to test conditions identified in Table 4.14 . 


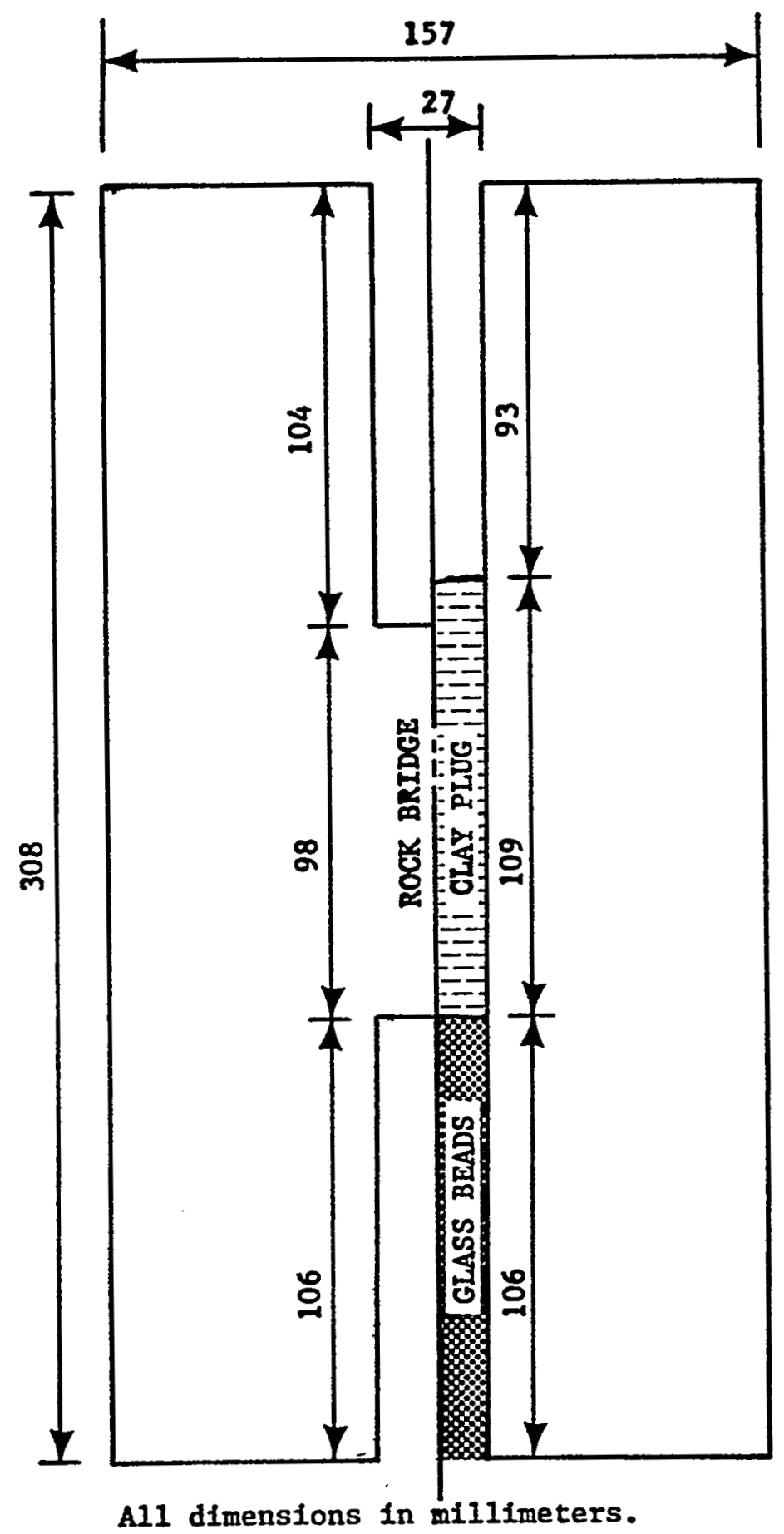

Figure 4.30 Sample CG-104 (Charcoal granite) - dimensions. Clay plug formed of bentonite tablets placed on $3 \mathrm{~mm}$ diameter glass beads. Mirafi $140 \mathrm{~N}$ filter at top and bottom of glass bead column. 
The sample was removed from the permeameter. The clay had been forced down into the void space of the glass bead column. The clay was carefully cleaned from the sample and the sample placed back in the permeameter.

On 10/12/82 the second clay plug was placed. Glass beads were used to fill the bottom hole, as before, but a filter layer using 200 mesh brass screen and filter paper was placed on top of the beads. The purpose of the brass screen was to provide strength. Ten bentonite tablets were allowed to swell eleven days to form the plug.

The results of testing this second clay plug are shown on Table 4.14 and as curve $f$ on Figure 4.29. Flow rates through the plugged sample were higher than, but within the same order of magnitude as, flow rates through intact rock at a similar triaxial stress state. The second plug also failed by excessive channeling.

The sample was again removed from the permeameter and the clay cleaned from the sample. In order to observe what happened to the ends as the sample was loaded it was placed in a uniaxial compression machine and stressed to $14.19 \mathrm{MPa}$. Subsequently, probably as a result of this loading, a hairline fracture was observed in the top half of the sample, Figure 4.31. The fracture extended halfway down the sample and cut the top along a diameter.

Since a clay plug would extend across the bottom of the fracture a new plug was installed. Glass beads were again used to fill the bottom hole. Two pieces of 200 mesh stainless-steel screen and three pieces of Whatman GF/F filter paper were placed on the glass beads and ten Volclay Tablets used to form the plug. This time the tablets were allowed to swell three days.

The test results for this third clay plug are also shown in Table 4.14. Curves $g$ and $h$, Figure 4.29, indicate flow rates at axial and confining stresses of $(21.0,14.1)$ and $(20.8,12.2)$ Mpa, respectively. Lower confining stress was applied than in previous tests to prevent annular leakage. Again, flow rates were of the same order of magnitude as for intact granite. The plug was allowed to sit under zero top pressure for eight days between tests $g$ and $h$.

Lowering the triaxial stress state to $12.3 \mathrm{MPa}$ axial stress and $5.9 \mathrm{MPa}$ confining stress resulted in increased flow, Kl (Figure 4.29; Table 4.14). Allowing the plug to sit under zero pressure for three days resulted in reduced flow, K2 (Figure 4.29; Table 4.14). Upon removal from the permeameter the third clay plug was seen to have been forced down into the bottom third of the specimen. The plug extended from a depth of $153 \mathrm{~mm}$ below the sample top to the sample bottom. This probably occurred between $12 / 22 / 82$ and $1 / 8 / 83$, when the top pressure was increased from 1.2 to $2.0 \mathrm{MPa}$. The plug failed by channeling, probably on $1 / 8 / 83$, and top pressure was reduced to zero so the plug could reswell. This corresponds to the time between curves $g$ and $h$. 
Table 4.14 Summary of Test Results for Sample CG-104

\begin{tabular}{|c|c|c|c|c|c|c|}
\hline & & & $\mathrm{k}$ Brid & & $\begin{array}{r}\mathrm{F} \\
\mathrm{Cla} \\
\end{array}$ & \\
\hline & $\begin{array}{l}\sigma_{\mathrm{ax}} \\
\sigma_{\mathrm{c}} \\
\end{array}$ & $\begin{array}{l}8.6 \\
6.9\end{array}$ & $\begin{array}{l}15.4 \\
13.7\end{array}$ & $\begin{array}{l}23.0 \\
19.6\end{array}$ & $\begin{array}{l}22.0 \\
17.8\end{array}$ & $\begin{array}{l}20.9 \\
12.4 \\
\end{array}$ \\
\hline & $\mathrm{P}_{\mathrm{t}}$ & & & & & \\
\hline $\begin{array}{l}\text { Flow Rate In, } Q \\
\left(\times 10^{-3} \mathrm{cc} / \mathrm{min}\right)\end{array}$ & $\begin{array}{r}10.0 \\
7.0 \\
3.8 \\
3.4 \\
1.6 \\
1.0\end{array}$ & $\begin{array}{r}11.67 \\
4.02\end{array}$ & $\begin{array}{r}19.35 \\
11.08 \\
4.85\end{array}$ & $\begin{array}{l}8.44 \\
4.66 \\
1.93\end{array}$ & 0.34 & 0.15 \\
\hline $\begin{array}{l}\text { Regression } \\
\text { Coefficients }\end{array}$ & $\begin{array}{c}a \\
b \\
\text { C.C. } \\
\text { Curve }\end{array}$ & $\begin{array}{c}2.07 \\
1.41 \\
1.00 \\
a\end{array}$ & $\begin{array}{c}1.01 \\
1.26 \\
0.99 \\
b\end{array}$ & $\begin{array}{c}0.36 \\
1.34 \\
0.99 \\
c\end{array}$ & $\mathrm{~d}$ & e \\
\hline $\begin{array}{l}\text { Flow Rate Out, Q } \\
\left(\times 10^{-3} \mathrm{cc} / \mathrm{min}\right)\end{array}$ & $\begin{array}{r}10.0 \\
7.0 \\
3.8 \\
3.4 \\
1.6 \\
1.0 \\
\end{array}$ & $\begin{array}{r}11.75 \\
4.09\end{array}$ & $\begin{array}{r}19.83 \\
11.65 \\
5.05\end{array}$ & $\begin{array}{l}8.65 \\
4.74 \\
2.03\end{array}$ & 2.04 & 1.27 \\
\hline $\begin{array}{l}\text { Mass Balance } \\
(\%)\end{array}$ & $\begin{array}{r}10.0 \\
7.0 \\
3.8 \\
3.4 \\
1.6 \\
1.0\end{array}$ & $\begin{array}{l}0.7 \\
1.7\end{array}$ & $\begin{array}{l}2.5 \\
5.1 \\
\\
4.1\end{array}$ & $\begin{array}{l}2.5 \\
1.8 \\
5.2\end{array}$ & & \\
\hline
\end{tabular}

$\sigma_{a x}=$ axial stress $(\mathrm{MPa}) ; \sigma_{c}=$ confining stress (MPa); $P_{t}=$ top hole injection pressure (MPa); regression coefficients $a$ and $b$ are for the equation $Q=a\left(P_{t}\right)^{b}$. c.c. is the correlation coefficient. Curves $a$, $b$ and $c$ and points $d$ and $e$ are plotted in Figure 4.28 . 
Table 4.14 Summary of Test Results for Sample CG-104--Continued

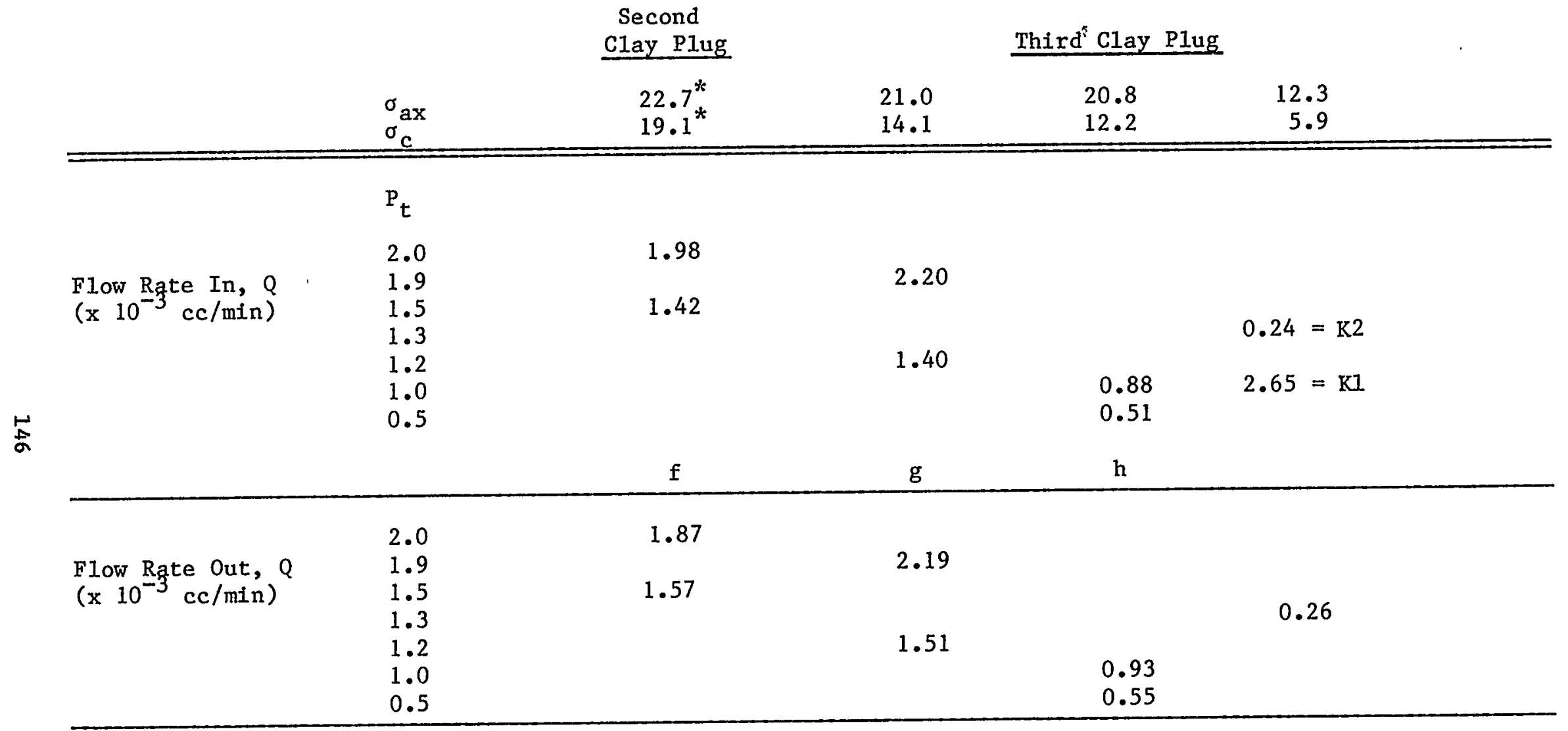

*Average for tests made $10 / 23-11 / 10$ and $11 / 10-11 / 13$

$\sigma_{a x}=$ axial stress $(\mathrm{MPa}) ; \sigma_{c}=$ confining stress $(\mathrm{MPa}) ; \mathrm{P}_{\mathrm{t}}=$ top hole injection pressure (MPa); $a$ and $b$ are regression coefficients for the equation $Q=a\left(P_{t}\right)^{b}$. C.C. is the correlation coefficient.

Curves $f, g$ and $h$, as well as points $K 1$ and $K 2$, are plotted in Figure 4.29. 


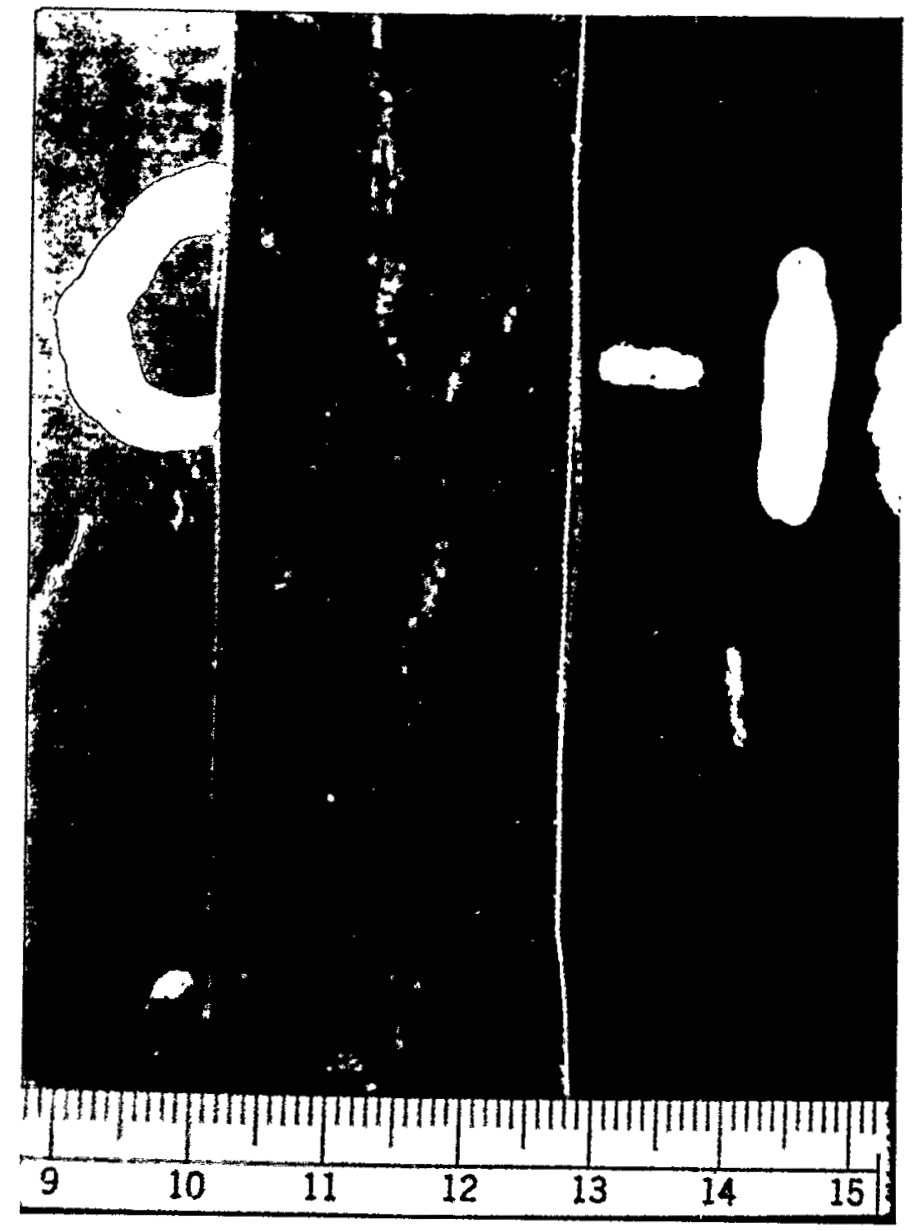

Figure 4.31 Fracture in Charcoal granite cylinder Sample CG-104. Scale is $1 \mathrm{~mm}$ per division. 


\section{CHAPTER 5}

\section{ANALYSIS OF EXPERIMENTAL RESULTS}

Experimental results have been analyzed using FREESURF I, a finite element model used to solve both two dimensional and axisymmetric flow problems (Science Applications, Inc., 1981). The program was obtained from Dr. Shlomo P. Neuman, Hydrology Department, University of Arizona, Tucson, and is discussed in Neuman and Witherspoon (1970).

The axisymmetric finite element mesh shown in Figure 5.1 is for a 15.24 $\mathrm{cm}$ ( 6 inches) diameter, $30.48 \mathrm{~cm}$ (12 inches) long cylinder with top and bottom holes one-third the sample length. In practice the mesh is adjusted slightly to match individual sample dimensions.

The sample was modeled as two materials, the rock and the plug. To model a sample with rock bridge, permeability of the two materials was kept equal. Both the plug and the rock were assumed to be saturated isotropic, homogeneous and incompressible. Neither rock stress nor effective stress are explicitly taken into account. The side and ends of the sample are no-flow boundaries (heavy lines in Figure 5.1). The boundaries of the top and bottom holes are constant-head boundaries, the top hole at the head matching the injection pressure, the bottom hole at zero (gage). The analysis calculations are explained by an example, discussed in the next section for Charcoal granite Sample CG-101.

\subsection{Analysis of Tests on Cement Plugs}

\subsubsection{Charcoal Granite}

\subsubsection{Sample CG-101}

Analysis is started by calculating the rock permeability. In order to use FREESURF I, permeabilities must be input; the program calculates flow rates and heads. Figure 5.2 shows the procedure and results of such a calculation. The flow rate as a function of permeability was calculated for the sample geometry of CG-101. at injection pressures of $3.5,7.0$, and $10.0 \mathrm{MPa}$, the top hole injection pressures used in the experiment. As Figure 5.2 shows, the flow rate is a linear function of the permeability at a given injection pressure. This is to be expected as the calculation is based on Darcy's law.

Permeabilities input must be such that the calculated flow rates span the measured flow rate, because the next step is to use the measured flow rate to read the rock permeability from the graph. Alternatively, any two flow rates will define a linear relation between flow rate and permeability at a given injection pressure, and that relation can be used to calculate the permeability. 


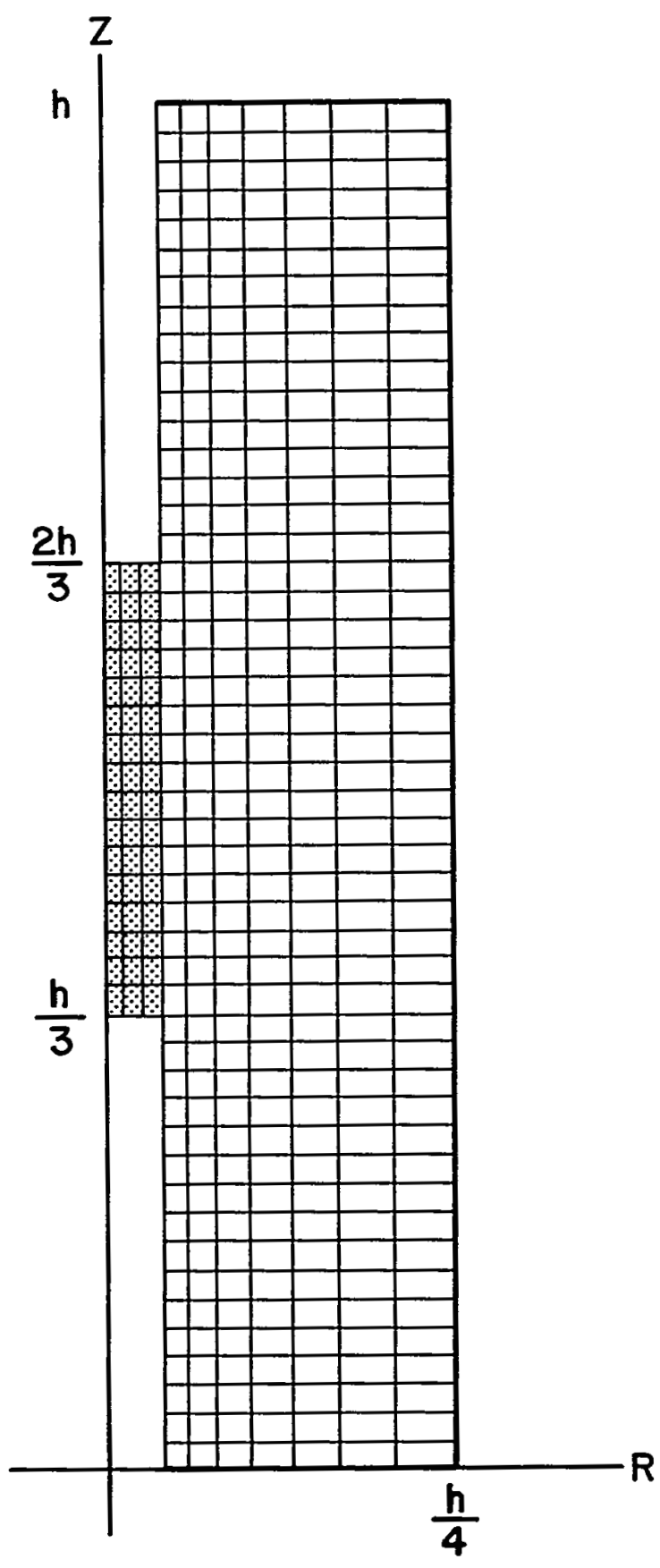

Figure 5.1 Axisymetric finite element mesh used with program FREESURF I to simulate radial permeameter tests of rock bridge and plug flow rates. Plug position and length adjusted as appropriate for specific calculations. Heavy lines are noflow boundaries. $\mathrm{Z}$-axis represents center line of the cylinder. 


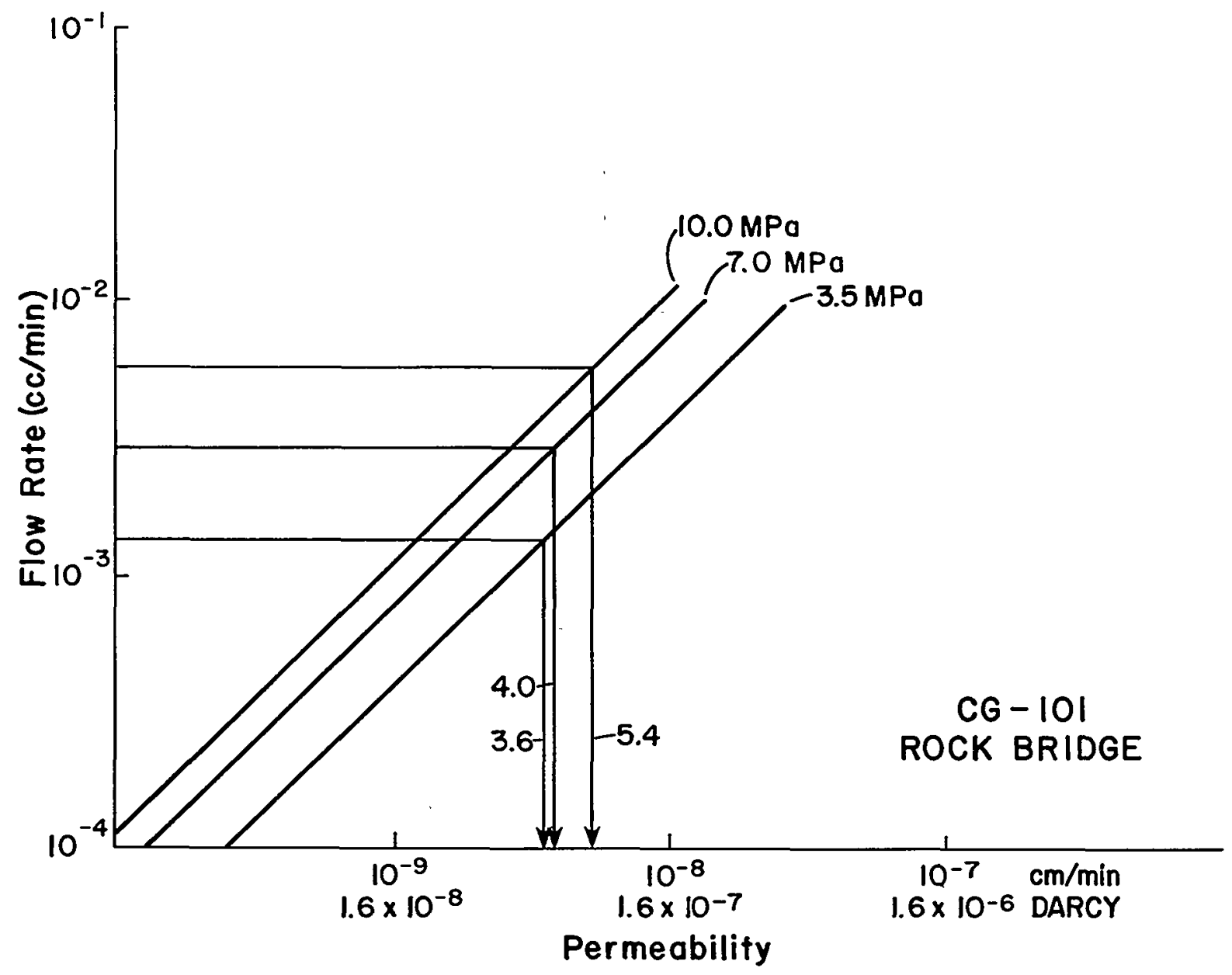

Figure 5.2 Sample CG-101, calculated flow rate vs. permeability for injection (top) pressure, $\mathrm{P}_{\mathrm{T}}$, of $10.0,7.0$ and $3.5 \mathrm{MPa}$. Axial cylinder stress $\sigma_{\mathrm{ax}}=22.8 \mathrm{MPa}$, lateral stress $\sigma_{\mathrm{c}}=$ $19.6 \mathrm{MPa}$. 
In either case, the measured flow rates for Sample CG-101 indicate that
the sample has permeabilities of $3.6 \times 10^{-9}, 4.0 \times 10^{-9}$ and $5.4 \times 10^{-9}$ $\mathrm{cm} / \mathrm{min}\left(59.4 \times 10^{-9}, 65.9 \times 10^{-9}\right.$, and $89.0^{\prime} \times 10^{-9}$ darcy) for top hole injection pressures of $3.5,7.0$, and $10.0 \mathrm{MPa}$, respectively. The permeability increases with increasing injection pressure because the higher pore water pressure tends to increase the size of the connected pore space in the sample, increasing its permeability.

Permeability is also a function of the triaxial stress state of the sample, which for CG-101 with the rock bridge in place was 22.8 and 19.7 $\mathrm{MPa}$ axial and confining stress, respectively.

Figure 5.3 shows the variation in flow rate with variation in plug permeability. The absissa is the ratio of plug permeability to intact rock permeability, $\mathrm{K}_{\mathrm{P}} / \mathrm{K}_{\mathrm{R}}$. The intact rock permeability, $\mathrm{K}_{\mathrm{R}}$, is that permeability determined for the sample with rock bridge in place. At $\mathrm{K}_{\mathrm{p}} / \mathrm{K}_{\mathrm{R}}=1\left(10^{0}\right)$, the plug and rock permeabilities are equal, the case for intact rock. The $10.0 \mathrm{MPa}$ injection pressure curve was calculated using $K_{R}=5.4 \times 19^{-9} \mathrm{~cm} / \min \left(89.0 \times 10^{-9}\right.$ darcy), and the 7.0 and 3.5 $\mathrm{MPa}$ curves using their corresponding intact rock permeabilities of 4.0 and $3.6 \times 10^{-9} \mathrm{~cm} / \mathrm{min}$, respectively. The measured flow rates through the plugged samples at $10.0,7.0$, and $3.5 \mathrm{MPa}$, with axial and confining stresses of 23.0 and $19.6 \mathrm{MPa}$, respectively, are shown as arrows pointing to the $\mathrm{K}_{\mathrm{P}} / \mathrm{K}_{\mathrm{R}}=1$ line. All measured flow rates through the plugged samples fell below the theoretical curves, possibly due to stress redistributions resulting from the coring out of the rock bridge and the expansiveness of the cement used as the plug material.

\subsubsection{Samples CG-102 and CG-103}

The experimental results from Sample CG-102 and Sample CG-103 are similar to those for CG-101. Rock permeabilities for CG-102 were calqulated to be $3.3 \times 10^{-9} 4.2 \times 10^{-9}$ and $4.6 \times 10^{-9} \mathrm{~cm} / \mathrm{min}(54.4 \mathrm{x}$ $10^{-9}, 69.2 \times 10^{-9}$, and $75.8 \times 10^{-9}$ darcy) for injection pressures of $3.5,7.0$, and $10.1 \mathrm{MPa}$, respectively (Figure 5.4). Curves showing the relation between the flow rate and the ratio $\mathrm{K}_{\mathrm{P}} / \mathrm{K}_{\mathrm{R}}$ are shown on Figure 5.5. Once again the measured flow rates through the plugged sample fell below the theoretical curves. The axial stress. on the plugged sample was $22.8 \mathrm{MPa}$ axial and the confining stress $19.7 \mathrm{MPa}$, the same as for the rock bridge.

Figures 5.6 and 5.7 show similar results for Sample CG-103. Permeabilities for this sample were calculated to be $3.5 \times 10^{-9}, .4 .5$
$10^{-9}$ and $5.3 \times 10^{-9} \mathrm{~cm} / \mathrm{min}\left(57.7 \times 10^{-9} 74.2 \times 10^{-9}\right.$ and $87.4 \times 10^{-9}$ darcy) for injection pressures of $3.5,7.0$, and $10.1 \mathrm{MPa}$, respectively; the measured flow rates through the plugged sample were all less than the $\mathrm{K}_{\mathrm{P}} / \mathrm{K}_{\mathrm{R}}$ theoretical curves.

Table 5.1 is a summary of the permeability values calculated for Samples CG-101, CG-102, and CG-103 with the rock bridge in place. 


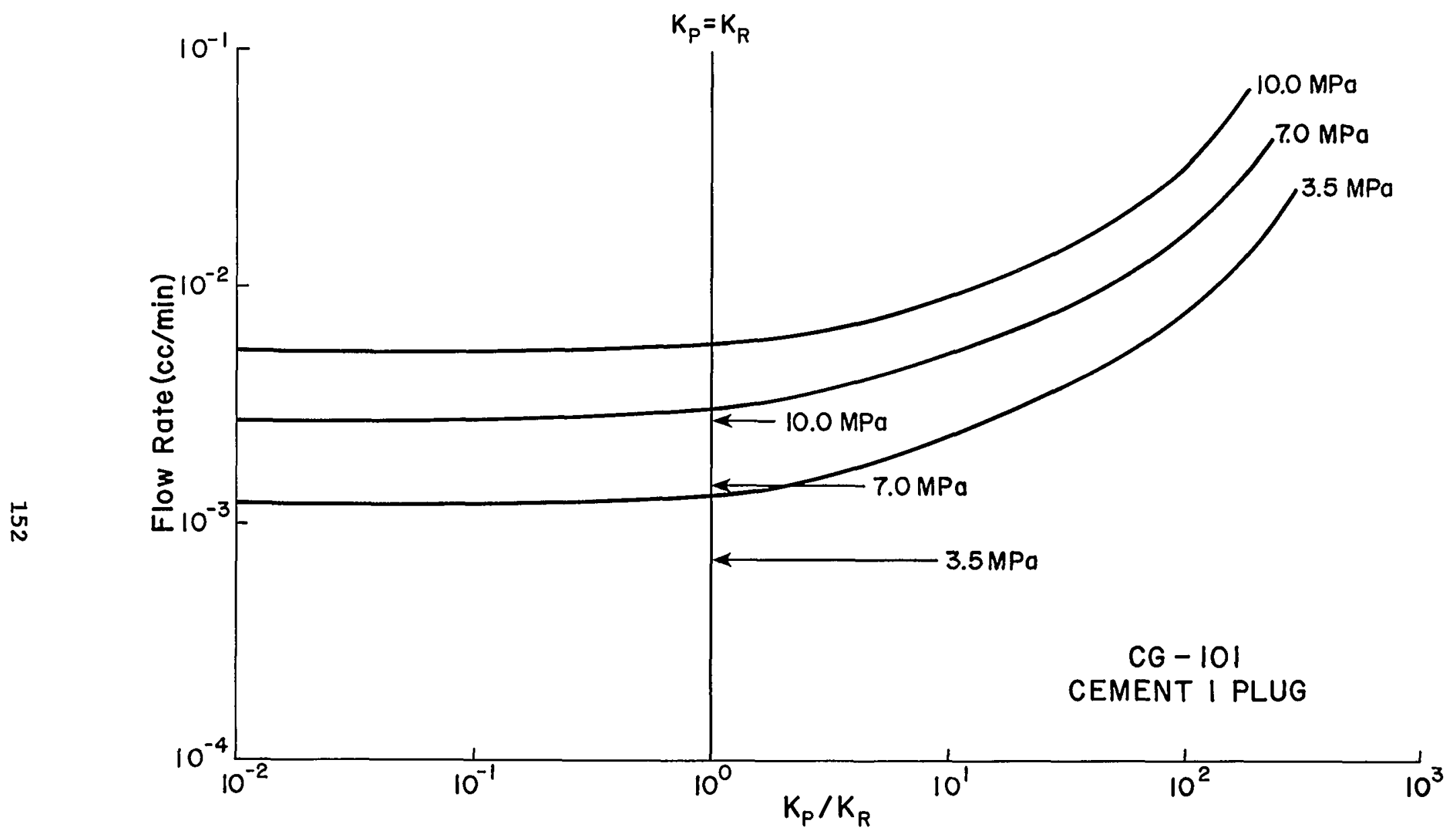

Figure 5.3 Sample CG-101, calculated variation in flow rate with variation in the ratio of the plug permeabiltiy, $\mathrm{K}_{\mathrm{p}}$, to rock permeability, $\mathrm{K}_{\mathrm{R}}$. For each curve at a different injection pressure, $\mathrm{P}_{\mathrm{T}}$, of $10.0,7.0$ and $3.5 \mathrm{MPa}$, the corresponding rock permeability, $\mathrm{K}_{\mathrm{R}}$, from Figure 5.2 was used. Arrows at $10.0,7.0$ and $3.5 \mathrm{MPa}$ indicate measured (experimental) flowrates. 


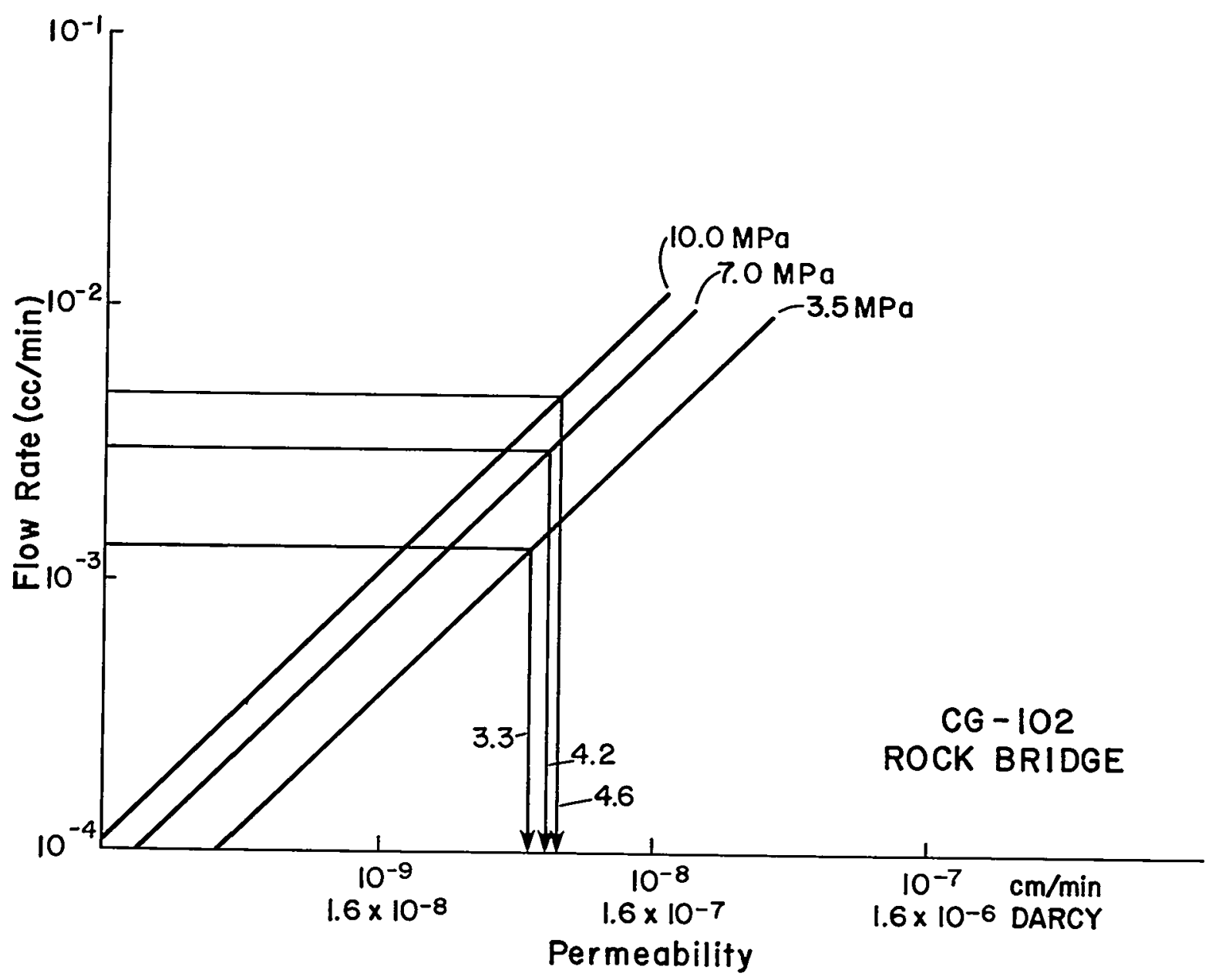

Figure 5.4 Charcoal granite Sample CG-102, flow rate vs. permeability for injection pressures, $\mathrm{P}_{\mathrm{T}}$, of $10.1,7.0$ and $3.5 \mathrm{MPa}$. 


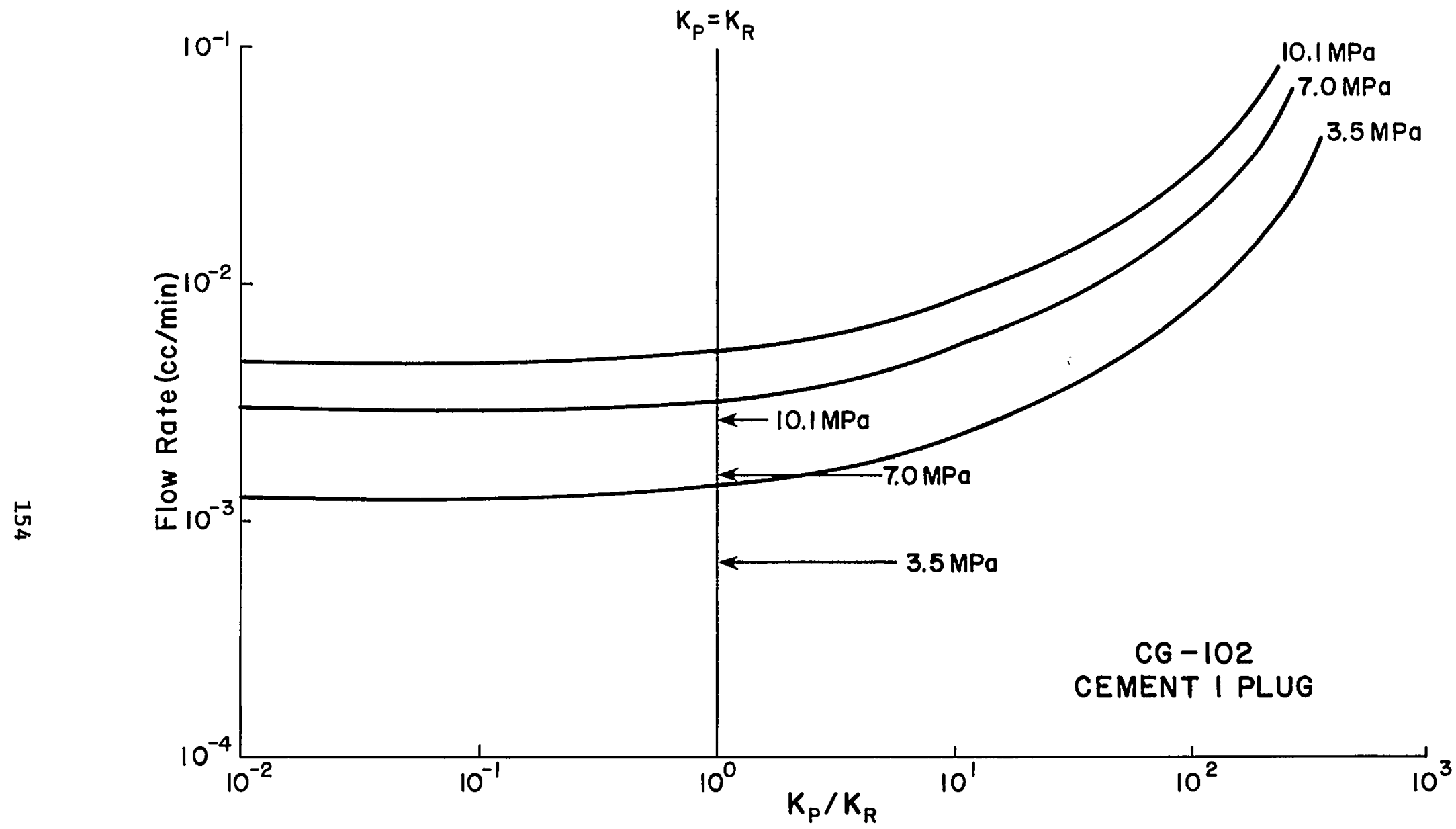

Figure 5.5 Charcoal Granite Sample CG-102, calculated variation in flow rate with variation in the ratio of plug permeability, $\mathrm{K}_{\mathrm{P}}$, to rock permeability, $\mathrm{K}_{\mathrm{R}}$. For each curve at a different injection pressure, $\mathrm{P}_{\mathrm{T}}$, of $10.1,7.0$ and $3.5 \mathrm{MPa}$, the corresponding rock permeability, $\mathrm{K}_{\mathrm{R}}$, from the previous figure was used. Arrows at $10.1,7.0$, and $3.5 \mathrm{MPa}$ indicate measured flowrates at these injection pressures. 


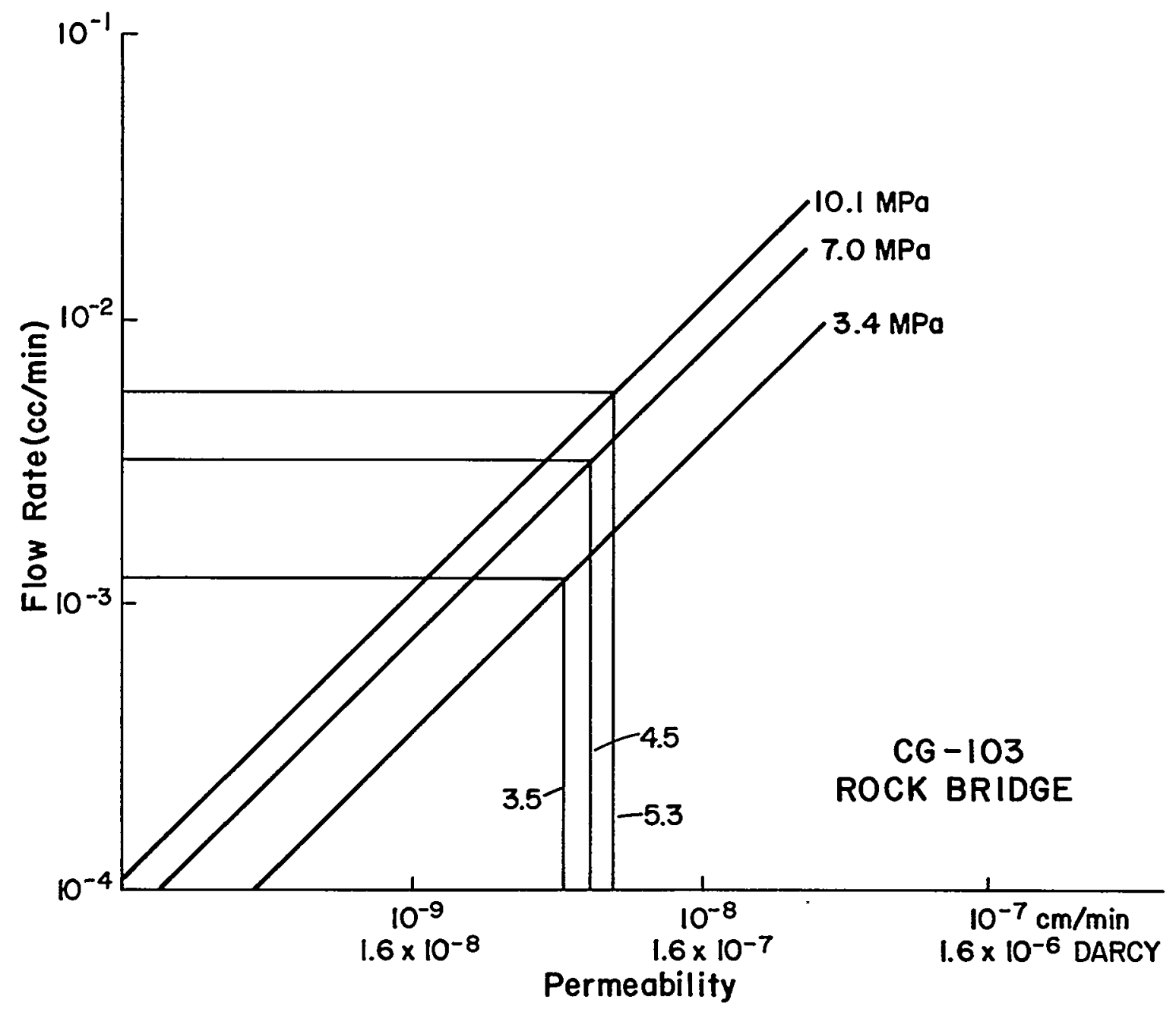

Figure 5.6 Charcoal granite Sample CG-103, flow rate vs. permeabilty for injection pressures, $\mathrm{P}_{\mathrm{T}}$, of $10.1,7.0$ and $3.4 \mathrm{MPa}$. 


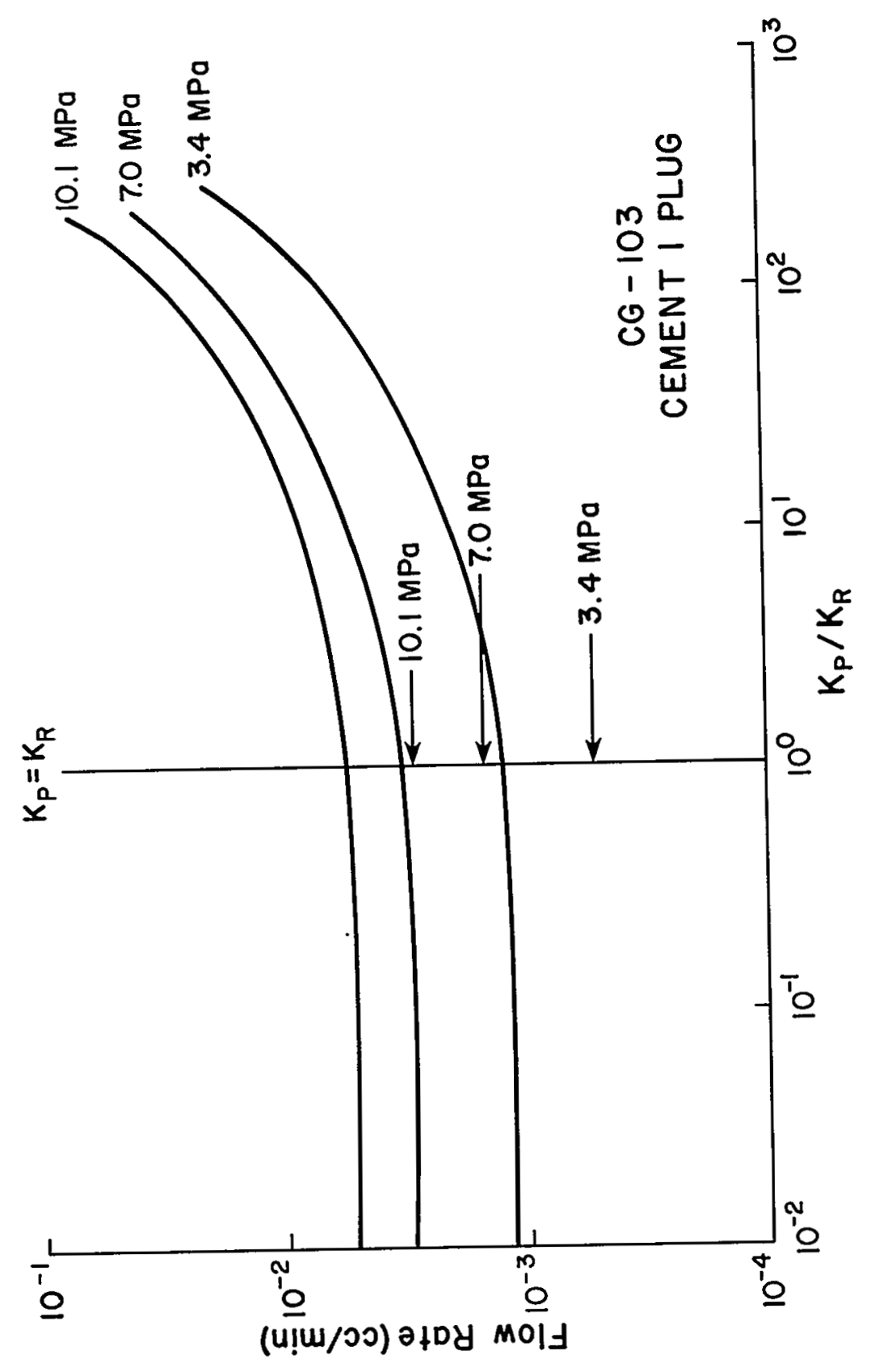

苟

牙员

동 岂运焉

भो

范口西

我出步焉

ग न न्न

牙苋白

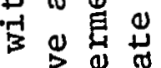

0

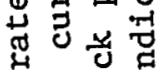

동요

氙告

4

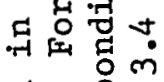

ธ็.

年话资

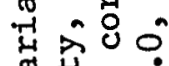

$>$ 品

वृ

崩

북역

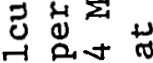

गु प्रुण

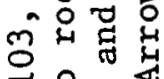

강요

y.

ब

茴

की

0. 겅 峁

म्न त्रे

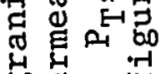

㟧皆出

-1 a g o

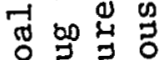

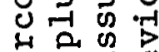

牙嵒

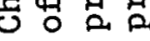

in 


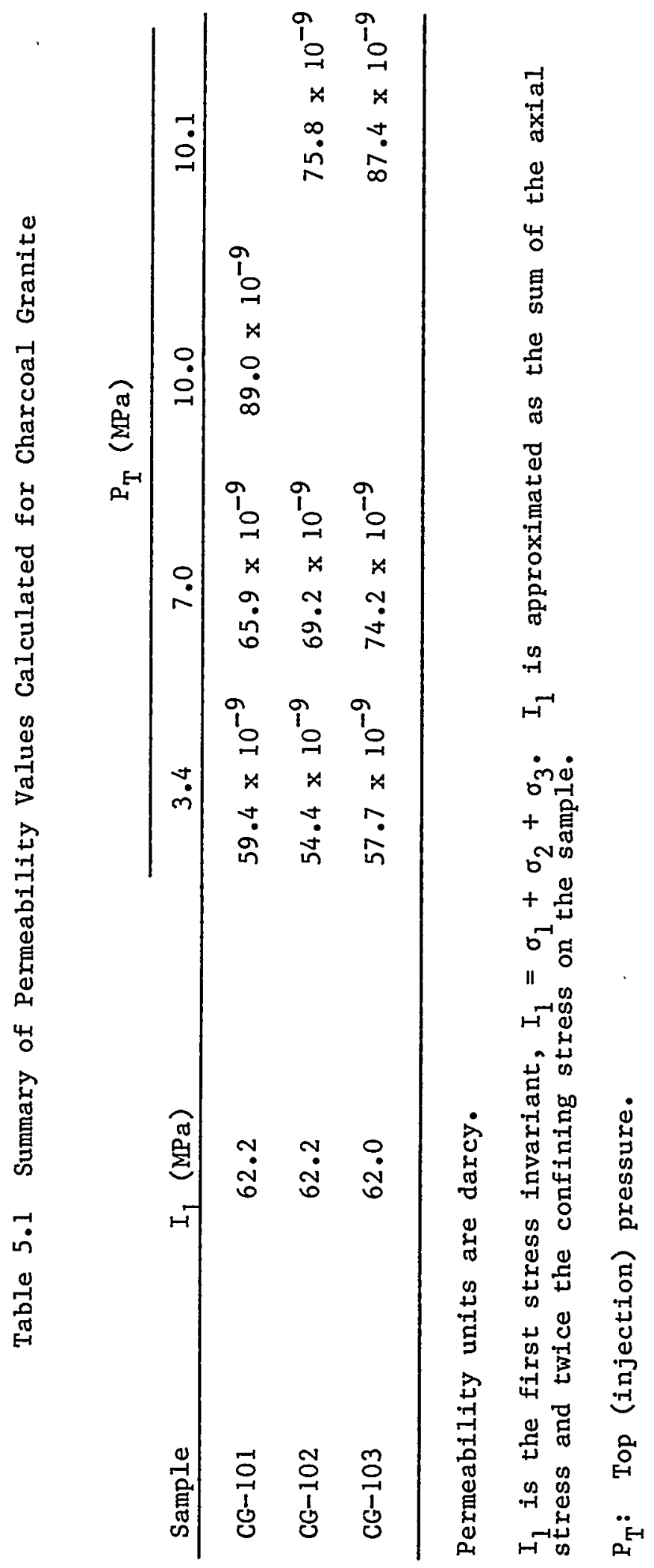




\subsubsection{Sample CG-104}

Charcoal granite Sample CG-104, which was plugged with bentonite tablets, was initially tested to determine the variation in flow rate with variation in triaxial stress state with a rock bridge in place. A summary of the results of this experiment and a graph of the flow rate vs. top hole injection pressure for different triaxial stress states are shown in Table 4.14 and on Figure 4.28.

Table 5.2 summarizes the results of testing on the intact rock (sample with rock bridge) in a slightly different manner. The first stress invariant, $I_{1}$, is calculated for each axial stress and confining stress combination as:

$$
I_{1}=\sigma_{a x}+2 \sigma_{c}
$$

$$
\text { where, } \begin{aligned}
\sigma_{a x} & =\text { axial stress, and } \\
\sigma_{c} & =\text { confining stress. }
\end{aligned}
$$

The flow rates for various top hole injection pressures associated with each value of $\mathrm{I}_{1}$ are tabulated. Values in parentheses were calculated from the power law curves in Figure 4.28, whose coefficients are given in Table 4.14. All the other flow rate values are measured values.

The permeabilities of Sample CG-104 have been determined from the flow rate data. These values are also shown on Table 5.2. Since CG-104 has almost the same dimensions as CG-103, and the same top hole injection pressures were used, the equations relating flow rate and permeability developed using FREESURF I for Sample CG-103 were used to calculate the permeabilities of Sample CG-104. These equations are also shown on Table 5.2.

Figure 5.8 shows the variation in sample permeability with the first stress invariant at each top hole injection pressure. As the sample is subjected to higher stress conditions, that is, as $I_{1}$ increases, the sample permeability decreases, probably due to decreasing pore sizes and fracture widths within the sample. Permeability increases as the injection pressure increases at a given stress level, $I_{1}$, because increasing the injection pressure decreases the effective stress; increasing injection pressure tends to open pores and microfractures.

\subsubsection{Comparison of CG-103 and CG-104}

Tests on CG-103 with the rock bridge in place were performed only at an axial and confining stress level of 22.8 and $19.6 \mathrm{MPa}$, respectively $\left(\mathrm{I}_{1}\right.$ $=62.0 \mathrm{MPa}$ ). At this triaxial stress level, flow rates at injection pressures of $3.4,7.0$, and $10.1 \mathrm{MPa}$ were measured, and a power law curve fit to those data used to estimate what the flow rate would have been at an injection pressure of $1.6 \mathrm{MPa}$. Permeability values determined for these flow rates are shown as the points on Figure 5.9 . 
Table 5.2 Estimated and Measured Flow Rates and Permeabilities for Charcoal Granite Sample CG-104 with Rock Bridge

\begin{tabular}{|c|c|c|c|c|c|c|}
\hline \multirow{2}{*}{$\begin{array}{l}\sigma_{\mathrm{ac}}, \sigma_{\mathrm{c}} \\
(\mathrm{MPa}) \\
\end{array}$} & \multirow{2}{*}{$\begin{array}{c}I_{1}= \\
\sigma_{\mathrm{ax}}+2 \sigma_{c} \\
(\mathrm{MPa})\end{array}$} & \multicolumn{4}{|c|}{$P_{T}(M P a)$} & \multirow{5}{*}{$\begin{array}{l}\text { Flow Rate In } \\
\left(\times 10^{-3}\right.\end{array}$} \\
\hline & & 1.6 & 3.4 & 7.0 & 10.1 & \\
\hline $86.6,6.9$ & 22.4 & 4.02 & 11.67 & $(32.40)$ & $(54.40)$ & \\
\hline $15.5,13.7$ & 42.9 & $(1.85)$ & 4.85 & 11.08 & 19.35 & \\
\hline \multirow[t]{2}{*}{$\begin{array}{l}\text { cc/min) } \\
23.0,19.6\end{array}$} & 62.2 & $(0.69)$ & 1.93 & 4.66 & 8.44 & \\
\hline & 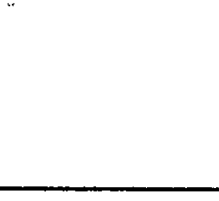 & $K=10^{\log Q-5.22}$ & $K=10^{\log Q-5.55}$ & $\mathrm{~K}=10^{\log Q-5.86}$ & $K=10^{\log Q-6.02}$ & $\begin{array}{l}\text { Equations from } \\
\text { CG-103 } \\
\text { (Q in cc/min) } \\
\mathrm{K} \text { in } \mathrm{cm} / \mathrm{min} \text { ) }\end{array}$ \\
\hline $86.6,6.9$ & 22.4 & $399 \times 10^{-9}$ & $542 \times 10^{-9}$ & $\left(737 \times 10^{-9}\right)$ & $\left(857 \times 10^{-9}\right)$ & \\
\hline $15.5,13.7$ & 42.9 & $\left(183 \times 10^{-9}\right)$ & $225 \times 10^{-9}$ & $252 \times 10^{-9}$ & $305 \times 10^{-9}$ & Permeabilities \\
\hline $23.0,62.2$ & 62.2 & $\left(69 \times 10^{-9}\right)$ & $90 \times 10^{-9}$ & $106 \times 10^{-9}$ & $133 \times 10^{-9}$ & (darcy) \\
\hline
\end{tabular}




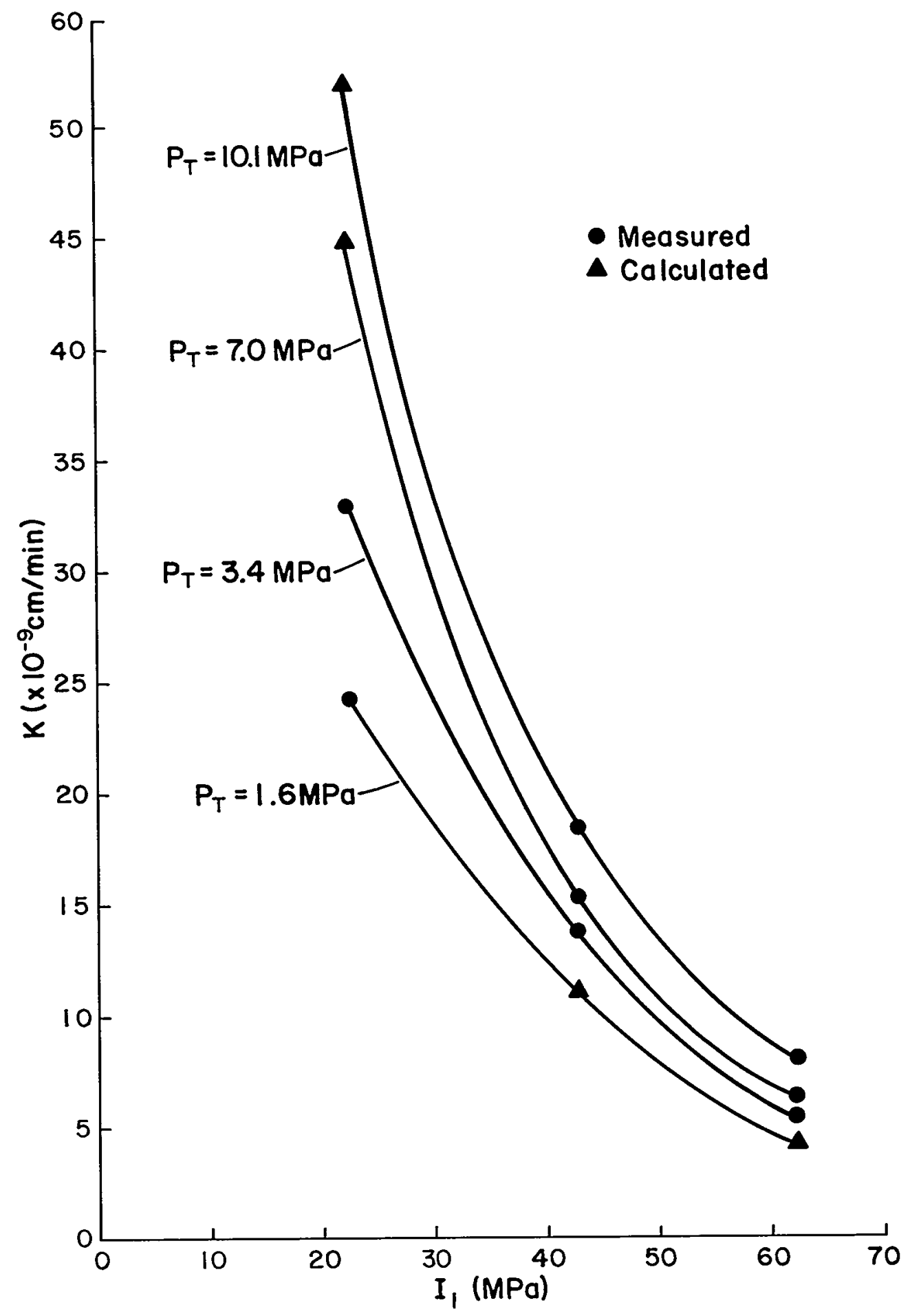

Figure 5.8 Charcoal granite Sample CG-104, rock bridge, permeability vs. first stress invariant, $I_{1}$. Methods used to obtain "Measured" and "Calculated" curves are explained in Section 5.1.1.4. $\mathrm{P}_{\mathrm{T}}$ : Injection (top hole) pressure. 


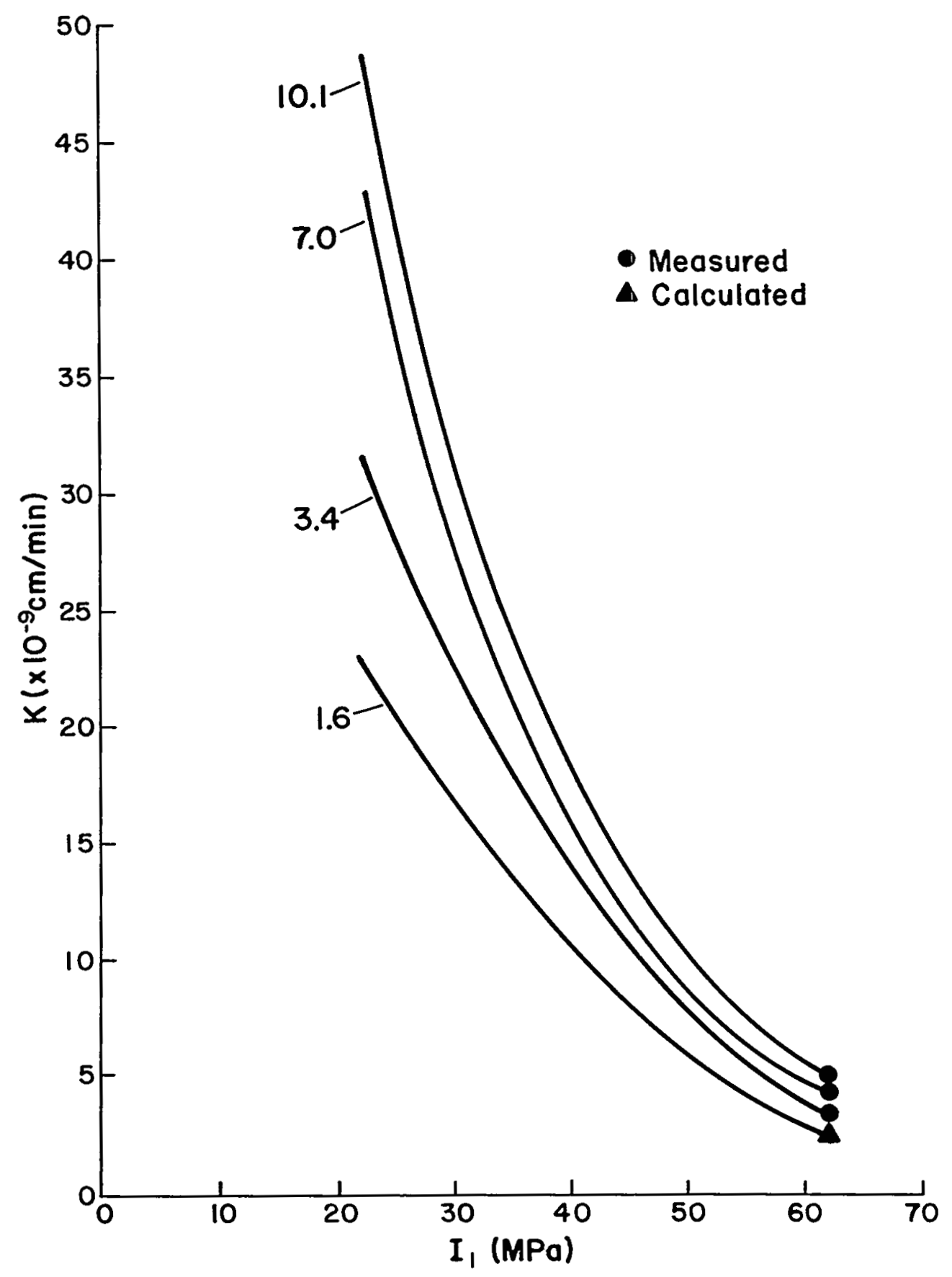

Figure 5.9 Charcoal granite Sample CG-103, rock bridge, permeability vs. first stress invariant, $I_{1}$. Numbers on curves are injection (top hole) pressures in MPa. Curve determination is discussed in Section 5.1.1.4. 
Curves were then drawn through each point to show the relationship between the permeability of CG-103 as a function of $I_{1}$. It was assumed that each curve at each injection pressure had the same shape as for CG104. The curves shown on Figure 5.9 were traced from Figure 5.8 by matching the point on Figure 5.9 with the corresponding curve and $\mathrm{I}_{1}$ on Figure 5.8. The graphs were shifted parallel to the permeability axis to make the match.

By so doing the permeability, and thus the flow rate, for intact rock at lower stress levels may be estimated for CG-103. This estimated flow rate for the sample with rock bridge may then be compared with the flow rate through the plugged sample at these stress levels.

Figure 4.11 shows the manner in which flow through the plugged sample varied with triaxial stress state at various confining pressures. At the highest stress levels, flow through the plugged sample was less than flow through the sample with rock bridge (intact rock). The flow rate through the plugged sample increased as the triaxial stress state was lowered. As will be shown below, the increased flow at lower stress states is most likely due to increased rock permeability.

Consider the flow rate of $0.92 \times 10^{-3} \mathrm{cc} / \mathrm{min}$ measured for Sample cG-103 at a triaxial stress state of 8.6 and $7.1 \mathrm{MPa}$, axial and confining stress and $1.8 \mathrm{MPa}$ injection pressure (Table 4.7). For this stress state, $I_{1}=22.8 \mathrm{MPa}$. From Figure 5.9 , at an injection pressure of 1.6
$\mathrm{MPa}$ and $I_{1}=22.8 \mathrm{MPa}$, the rock permeability should equal $22.3 \times 10^{-9}$ $\mathrm{cm} / \mathrm{min}\left(368 \times 10^{-9}\right.$ darcy).

The estimated flow rate through the sample with rock bridge may be calculated using the appropriate equation from Table 5.2. This yields $Q$ $=3.7 \times 10^{-3} \mathrm{cc} / \mathrm{min}$ as the estimated flow rate through CG-103 with the rock bridge in place under 8.6 and $7.1 \mathrm{MPa}$ axial and confining stress. The flow through the plugged sample under this triaxial stress state and a slightly higher injection pressure, $1.8 \mathrm{MPa}$, was measured as $0.92 \mathrm{x}$ $10^{-3} \mathrm{cc} / \mathrm{min}$.

Table 5.3 shows the estimated flow rates in through CG-103 with the rock bridge in place compared to the measured flow rates in through the plugged sample. In all cases the estimated flow rates through the sample with rock bridge are higher than the flow rate measured for the plugged sample. This strongly suggests that the increase in flow rate with decreasing triaxial stress state is due to increased permeability of the rock itself. These calculations indicate that even at decreased stress levels the overall permeability of the cement plug, interface included, is less than that of the intact rock.

\section{1 .1 .5 Discussion}

Samples CG-101 and CG-102 show similar results to Sample CG-103 (Figures 4.4 and 4.9), and it may be inferred that the increased flow through these samples is also due to increased rock permeability. 
Table 5.3 Sample CG-103. Comparison of Measured Flow Rate through Plugged Sample with Estimated Flow Rate through Sample with Rock Bridge

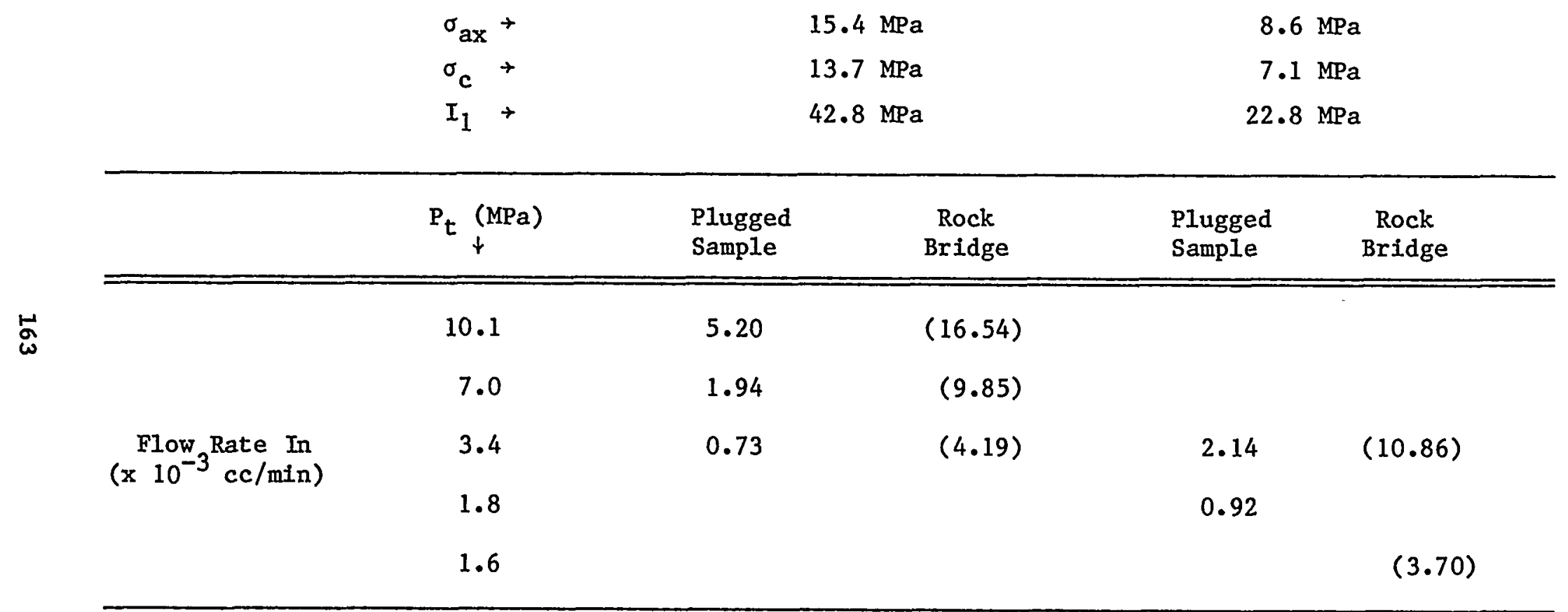

$\sigma_{a x}=$ axial stress, $\sigma_{c}=$ confining stress, $I_{1}=$ first stress invariant

5.20 - measured value

(16.54) - estimated value 
The dependence of rock permeability on the stress state has been described by Brace, Walsh, and Frangos (1968). They found that the permeability of Westerly granite varied from 350 nanodarcy at 100 bars to 4 nanodarcy at 4000 bars, and that Darcy's law apparently held even at the lowest permeability values. Further, permeability depends strongly on the effective stress state, rather than the total stress state, so that increasing the pore water pressure increases the permeability of a rock.

Bernaix (1969) investigated the variation in rock permeability with effective stress by using a hollow cylindrical sample. Water was injected in convergent flow from the annulus about the sample to the center hole, and in divergent flow from the center hole to the annulus. The convergent flow condition induces compressive stresses in the sample and yields lower permeabilities than the divergent flow condition, which induces tensile stresses, widening cracks and pores.

Paterson (1978, p. 80) indicates that Terzaghi's concept of effective stress is clearly obeyed in low permeability rock at low strain rates. At higher strain rates, laboratory observations of departures from the effective stress rule may be due to the actual pore pressures within a sample being different from the measured pore pressure at the surface of the sample.

\subsubsection{Sentinel Gap Basalt}

The two experiments in which a cement plug was placed in samples of Sentinel Gap Basalt were analyzed in a similar manner to the Charcoal Granite samples.

\section{1 .2 .1 Sample SGE-2-2}

The permeability of this sample was calculated to be $1.04 \times 10^{-11} \mathrm{~cm} / \mathrm{min}$ $\left(0.17 \times 10^{-9}\right.$ darcy) using the flow rate in $\left(Q_{i n}\right)$ data. The permeability did not vary with the triaxial stress state within the sensitivity of the equipment.

Figure 5.10 shows the variation in flow rate with $\mathrm{K}_{\mathrm{p}} / \mathrm{K}_{\mathrm{R}}$ ratio for two injection pressures. The two lower horizontal lines correspond to the $Q_{\text {in }}$ plug data and the two upper horizontal lines to the $Q_{\text {out }} p l u g$ data. For the $Q_{\text {in }}$ data, $K_{\mathrm{P}} / \mathrm{K}_{\mathrm{R}}$ values of 54 and 63 yield overall plug permeabilities of $5.6 \times 10^{-10}$ and $6.6 \times 10^{-10} \mathrm{~cm} / \mathrm{min}\left(9.2 \times 10^{-9}\right.$ and 10.9 $\times 10^{-9}$ darcy). The $Q_{\text {out }}$ data lead to plug permeabilities of $2.7 \times 10^{-9}$ and $3.6 \times 10^{-9} \mathrm{~cm} / \min \left(44.5 \times 10^{-9}\right.$ and $\left.59.4 \times 10^{-9} \mathrm{darcy}\right)$. Thus, the overall plug permeability is likely between $0.6 \times 10^{-9}$ and $3.6 \times 10^{-9}$ $\mathrm{cm} / \min \left(10 \times 10^{-9}\right.$ to $\left.60 \times 10^{-9} \mathrm{darcy}\right)$. This compares with a permeabi1ity of $95 \times 10^{-9}$ darcy measured for the cement core in the Ruska permeameter (Section 3.1.2.1). 


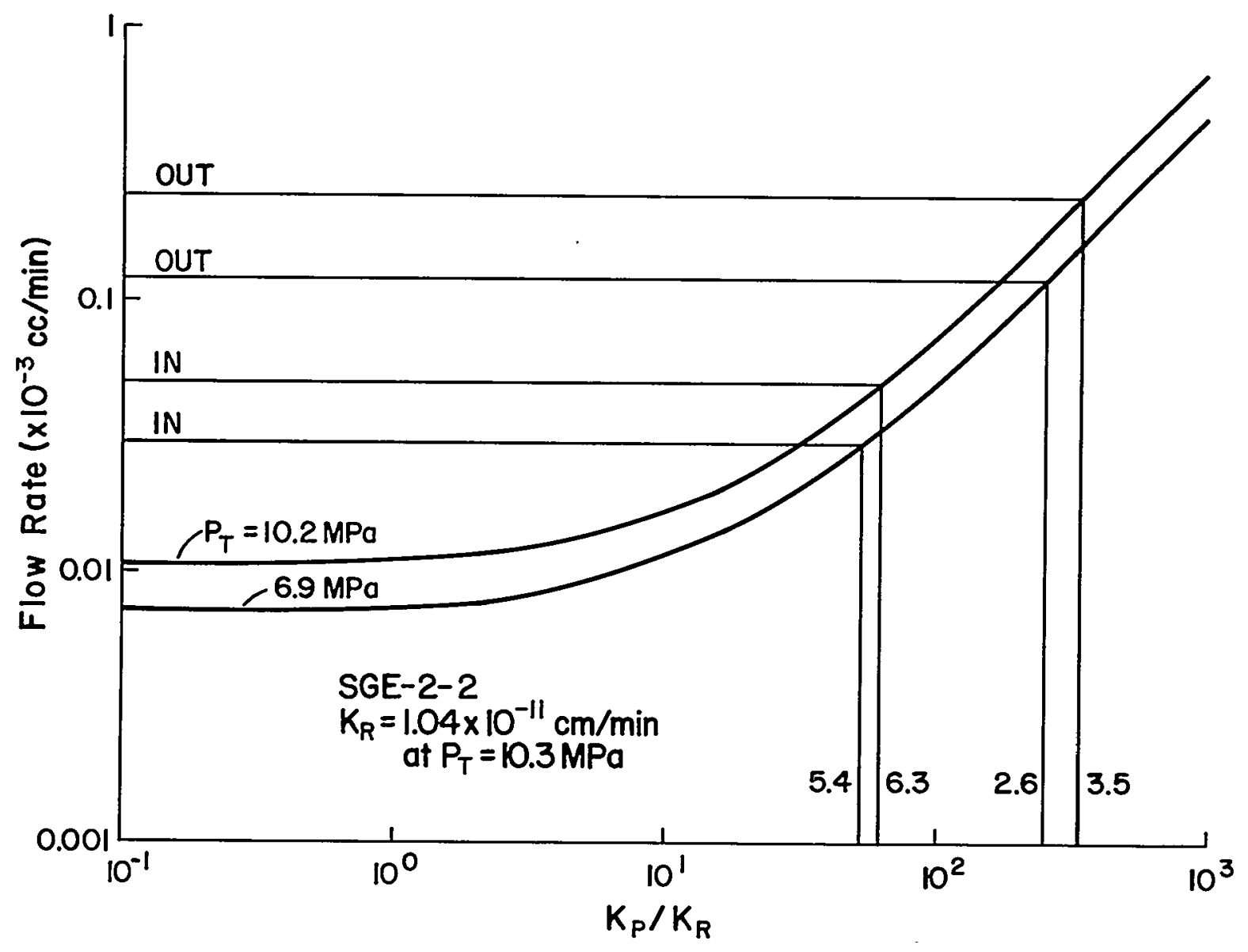

Figure 5.10 Sentinel Gap basalt Sample SGE-2-2, variation in flow rate with variation in the ratio of $\mathrm{plug}$ permeability, $\mathrm{K}_{\mathrm{P}}$, to rock permeabilty, $\mathrm{K}_{\mathrm{R}} \cdot \mathrm{P}_{\mathrm{T}}$ : injection (top hole) pressure. 
Drying of the plug in an oven ( $T=54^{\circ} \mathrm{C}, 42$ days) caused the permeability of the plug to increase greatly. Test results are shown in Table 4.18, and on Figure 4.16. Since the flow through the plug was much greater than flow through the basalt, the plug permeability can be calculated using the one-dimensional form of Darcy's law:

$$
\mathrm{K}=\frac{\mathrm{QL}}{\mathrm{HA}}
$$

$$
\text { where, } \begin{aligned}
\mathrm{K} & =\text { permeability, } \\
\mathrm{Q} & =\text { flow rate, } \\
\mathrm{L} & =\text { length of } \mathrm{plug}, \\
\mathrm{H} & =\text { head differential, and } \\
\mathrm{A}_{\mathrm{p}} & =\text { area of } \mathrm{plug} .
\end{aligned}
$$

The initial flow rate was (using $Q_{i n}$ ) $917.04 \times 10^{-3} \mathrm{cc} / \mathrm{min}$ at $P_{T}=1.6$ MPa, which corresponds to a permeability of $1.9 \times 10^{-4}$ darcy. After 50 days the flow rate in had decreased to $15.39 \times 10^{-3} \mathrm{cc} / \mathrm{min}$ with $\mathrm{P}_{\mathrm{T}}=2.1$ $\mathrm{MPa}$, with a corresponding permeability of $2.4 \times 10^{-6}$ darcy. The permeability of the plug decreased two orders of magnitude in 50 days. This is thought to be due to swelling of the plug components upon rewetting, and has been observed in other re-wetting experiments (e.g. Daemen et al., 1985, Section 3.2; Daemen et al., 1986, Chapter Four).

After the flow rate had stabilized the triaxial stress state on the sample was increased. Table 5.4 shows the permeabilities calculated from the flow rates at these stress states. At first the injection pressure only was increased and the permeability did not change significantly. At the intermediate triaxial stress state $(14.5 \mathrm{MPa}$ axial, $11.01 \mathrm{MPa}$ confining stress) and an injection pressure of $10.1 \mathrm{MPa}$ the permeability increased slightly, to $3.1 \times 10^{-6}$ darcy, but at the highest triaxial stress state the measured permeability value declined to $2.7 \mathrm{x}$ $10^{-6}$ darcy.

Drying significantly increased the permeability of the plug, from $60 \mathrm{x}$ $10^{-9}$ darcy before drying to about $3000 \times 10^{-9}$ darcy afterwards. However, a permeability of $3000 \times 10^{-9}$ darcy (= 3 microdarcy) is still a very low permeability.

\subsubsection{Sample SGE-2-3}

The rock permeability of SGE-2-3 was calculated as $1.06 \times 10^{-11} \mathrm{~cm} / \mathrm{min}$ $\left(0.17 \times 10^{-9}\right.$ darcy) using the flow rate in data. Figure 5.11 presents the $\mathrm{K}_{\mathrm{P}} / \mathrm{K}_{\mathrm{R}}$ vs. Flow Rate curves. Measured flow rates at both $10.0 \mathrm{MPa}$ and $3.4 \mathrm{MPa}$ yield $\mathrm{Kp} / \mathrm{Kr}=420$, and thus a plug permeability of $4.45 \mathrm{x}$ $10^{-9} \mathrm{~cm} / \mathrm{min}\left(73 \times 10^{-9} \mathrm{darcy}\right)$. These results compare well with those of Sample SGE-2-2, and the cement permeability in the Ruska permeameter. 
Table 5.4 Sample SGE-2-2: Permeability of Cement System 1 Plug After Drying

\begin{tabular}{|c|c|c|c|c|c|c|}
\hline \multirow[b]{2}{*}{$\sigma_{\mathrm{ax}}(\mathrm{MPa})$} & \multirow{2}{*}{$\frac{\text { Initial }}{8.7}$} & \multirow{2}{*}{$\frac{\begin{array}{c}50 \\
\text { Days }\end{array}}{8.8}$} & \multicolumn{4}{|c|}{$\begin{array}{c}\text { More Than } \\
50 \text { Days }\end{array}$} \\
\hline & & & 8.9 & 9.0 & 14.5 & 23.2 \\
\hline$\sigma_{c}(\mathrm{MPa})$ & 7.2 & 7.0 & 7.1 & $7, .0$ & 11.0 & 19.5 \\
\hline $\mathrm{P}_{\mathrm{T}}(\mathrm{MPa})$ & 1.6 & 2.1 & 7.0 & 7.0 & 10.1 & 10.0 \\
\hline $\mathrm{K}$ (Darcy) & $1.9 \times 10^{-4}$ & $2.4 \times 10^{-6}$ & $2.5 \times 10^{-6}$ & $2.8 \times 10^{-6}$ & $3.1 \times 10^{-6}$ & $2.7 \times 10^{-6}$ \\
\hline
\end{tabular}




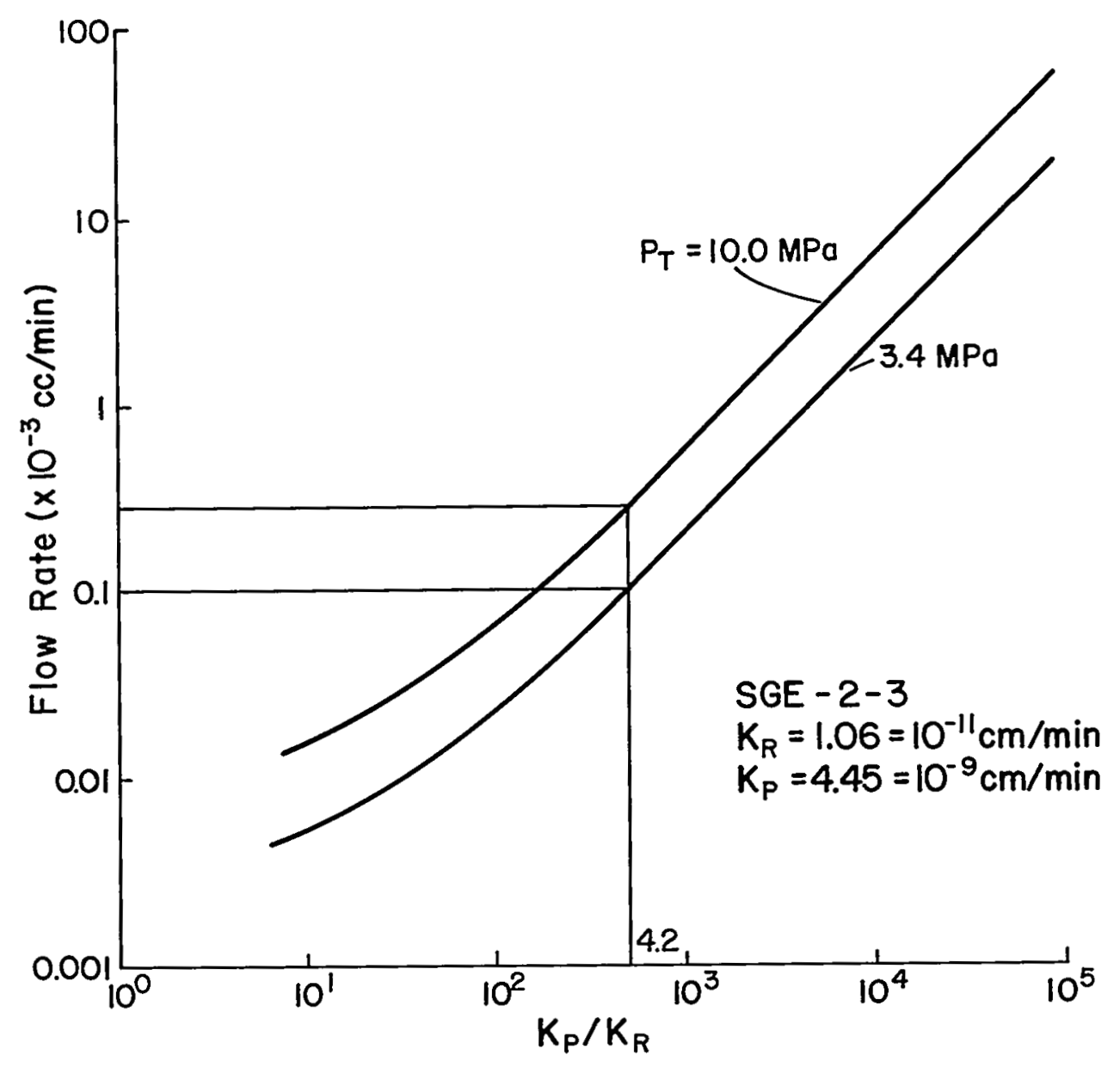

Figure 5.11 Sentinel Gap basalt Sample SGE-2-3, variation in flow rate with variation in the ratio of plug permeability, $\mathrm{K}_{\mathrm{p}}$, to rock permeability, $\mathrm{K}_{\mathrm{R}} \cdot \mathrm{P}_{\mathrm{T}}$ : injection (top hole) pressure. 
The dye injection test (Figure 4.19) indicates that the rock/plug interface is a preferential fluid migration path, although one of very low permeability.

\subsubsection{Oracle Granite}

As discussed in Chapter 4, the Oracle granite specimen was the first one tested, and tests were performed in a different manner than for subsequent samples. The analysis of the test results also differs from that for the previously discussed experiments.

In the first series of tests, flow rates between the top hole and the annulus were measured in both convergent and divergent flow. The flow occurred through a hairline fracture in the top part of the rock cylinder. In a second series of tests, flow rates were measured from the annulus and the top hole to the bottom hole in convergent flow.

The flow from the first and second series of tests may be compared by calculating the rock permeability using the equation (Bernaix, 1969):

$$
\mathrm{K}=\frac{\mathrm{Q} \ln \left(\mathrm{R}_{2} / \mathrm{R}_{1}\right)}{2 \pi \mathrm{LH}}
$$

$$
\text { where, } \begin{aligned}
\mathrm{K} & =\text { permeability, } \\
\mathrm{Q} & =\text { flow rate, } \\
\mathrm{R}_{1} & =\text { inside radius, } \\
\mathrm{R}_{2} & =\text { outside radius, } \\
\mathrm{L} & =\text { length, and } \\
\mathrm{H} & =\text { head differential. }
\end{aligned}
$$

This equation is for pure radial flow in a homogeneous, isotropic, porous medium. This is not strictly applicable to the first series of tests because flow occurred along a fracture. The equation yields the permeability of an equivalent porous medium, that is, a medium which, if it occupied the top third of the specimen, would allow the same flow rate as occurred through the actual rock, including fracture, in the top third of the specimen. Tables 5.5 and 5.6 give the equivalent permeabilities for both convergent and divergent flow. The data are given in the order of testing and tests using the convergent flow mode were performed first. As annular pressure is increased the equivalent permeability decreases as the fracture closes. Lessening the annular pressure results in increased equivalent permeability, but not to previous levels, probably reflecting inelastic deformation of the fracture.

In divergent flow the equivalent permeabilities are more than an order of magnitude greater than for convergent flow, reflecting the tendency of the higher pressure in the top hole to create tensile tangential stresses in the rock, widening the fracture. 
Table 5.5 Oracle Granite; Top Hole, Radial Permeability in Convergent Flow with Rock Bridge

$\begin{array}{cc}\begin{array}{c}\text { Annular Pressure } \\ (\mathrm{MPa})\end{array} & \begin{array}{c}\text { Permeability } \\ \text { (microdarcy) }\end{array} \\ 0.69 & 68.2 \\ 1.72 & 68.8 \\ 2.41 & 58.8 \\ 3.45 & 54.0 \\ 1.03 & 57.2 \\ 1.38 & 55.4 \\ 0.69 & 59.9 \\ \text { Axial stress }= & \\ 18.6 \mathrm{MPa} & \\ & \end{array}$

Table 5.6 Oracle Granite; Top Hole, Radial Permeability in Divergent Flow with Rock Bridge

Top Hole Pressure

$(\mathrm{MPa})$

0.69

1.38

2.07
Permeability

(microdarcy)

1036

962

2302

Axial stress $=18.6 \mathrm{MPa}$ 
The equivalent permeability of the lower section of the cylinder may also be calculated, using Bernaix's equation. Again, the equation is not strictly applicable, because, although no fracture is present, the flow is not purely radial. Some flow comes from the top hole through and around the rock bridge. However, if all flow is assumed to come in a purely radial path through the bottom third of the sample the equivalent permeability will be an upper bound. With these caveats, the "upper bound equivalent permeability" may be calculated as 0.0086 microdarcy for the rock in the bottom third of the sample (and by inference, for the intact Oracle granite). This compares with a value of around 60 microdarcy for the equivalent permeabilities of the part of the sample containing the fracture.

These calculations illustrate the great increase in water flow through fractured rock as compared to intact rock. Even a hairline fracture results in equivalent permeabilities orders of magnitude greater than for intact rock, in this case almost four orders of magnitude.

Brace (1980) indicates that the in situ permeability of crystalline rocks ranges from 1 to 100,000 microdarcy and that in situ values for crystalline rocks are high because of natural fractures. "Based on observed variation in wells, permeability at particular sites in crystalline rock is not predictable within a factor of $10^{5}$."

Following the tests with the rock bridge in place, tests were performed on the hollow cylinder (bridge cored out). Tables 5.7 and 5.8 give the equivalent permeabilities calculated from Bernaix's equation. The difference between the rock's equivalent permeability under convergent flow compared to divergent flow is smaller than expected when considered in conjunction with the test performed in the top hole. It may reflect the fact that the fracture did not penetrate the entire sample, but only the upper part, as well as the fact that the compressive stress concentration on the fracture, induced by the annular pressure, is smaller when the rock bridge is in place. The flow values do fall between the convergent and divergent top hole tests on the sample with rock bridge in place, as they should.

A plug of cement system 1 was installed and tested in a manner similar to the convergent flow test on the bottom hole of the sample with rock bridge. As discussed in Chapter 4, a flow rate of $11.53 \times 10^{-3} \mathrm{cc} / \mathrm{min}$ was measured in the test on the cement plug compared to $0.75 \times 10^{-3}$ $\mathrm{cc} / \mathrm{min}$ measured when the rock bridge was in place. If the increased flow was coming through the plug it may not be appropriate to calculate equivalent permeabilities as has been done previously. If all flow is assumed to be coming through the cement plug, an upper bound on the plug permeability may be calculated using Darcy's law:

$$
Q=\frac{K H}{L A}
$$


Table 5.7 Oracle Granite; Radial Permeability in Convergent Flow - Hollow Cylinder

Annular Pressure
$(\mathrm{MPa})$

0.34

0.69

1.03

0.34

0.69

1.03
Permeability
(microdarcy)

165.2

145.0

137.7

135.1

119.1

103.7

Axial stress $=18.6 \mathrm{MPa}$

Table 5.8 Oracle Granite; Radial Permeability in Divergent Flow - Hollow Cylinder

Center Hole Pressure
$(\mathrm{MPa})$

0.34

0.69

1.03
Permeability

(microdarcy)

171.5

169.4

177.3

Axial stress $=18.6 \mathrm{MPa}$ 


$$
\text { where, } \begin{aligned}
\mathrm{Q} & =\text { flow rate, } \\
\mathrm{K} & =\text { permeability } \\
\mathrm{H} & =\text { head differential, } \\
\mathrm{L} & =\text { plug length, and } \\
\mathrm{A}_{\mathrm{p}} & =\text { cross-sectional area of plug. }
\end{aligned}
$$

This calculation yields a cement plug permeability of about 8 microdarcy, which is still less than the equivalent permeability calculated for the section of rock with the fracture. Thus, the cement plug has a permeability about three orders of magnitude greater than the intact rock, but still almost an order of magnitude less than the part of the rock with a small fissure.

Alternatively, it is possible that the swelling of the cement has opened up the fracture (i.e. increased its aperture), or even propagated the fracture somewhat (e.g. Akgun and Daemen, 1986; Daemen et al., 1985, Section 7.5.2). Either of these occurrences would have facilitated bypass flow around the plug.

\subsubsection{Topopah Spring Tuff}

The test performed on the Topopah Spring tuff sample was most interesting because flow rates after plugging were at first much higher than for the sample with rock bridge, but after a month had decreased to a flow rate similar to that of the rock bridge.

To calculate permeabilities for this sample an equation derived using FREESURF I for Sample SGE-2-3 was used,

$$
\log \mathrm{K}=\mathrm{C}_{1}(\log (\mathrm{Q})-5.975)
$$

where, $\mathrm{K}=$ permeability in microdarcy,

$$
Q=\text { scaled flow rate in } c c / m i n \text {, and }
$$

$\mathrm{C}_{1}=16.487$, a constant to convert permeability units of $\mathrm{cm} / \mathrm{min}$ to darcy at a water temperature of $22^{\circ} \mathrm{C}$.

This equation somewhat overestimates the permeability of NTS-TPTS-101 because this sample has shorter flow paths than SGE-2-3. A comparison of the two samples (Figures 4.18 and 4.22) shows that the shortest flow path, through the rock bridge, is $8.8 \mathrm{~cm}$ for NTS-TPTS-101 and $10.2 \mathrm{~cm}$ for SGE-2 3, a difference of $16 \%$ with respect to NTS-TPTS-101. The longest flow paths, around the periphery from the top hole to the bottom hole, have lengths of $40.1 \mathrm{~cm}$ and $42.4 \mathrm{~cm}$ for NTS-TPTS-101 and SGE-2-3, respectively, a difference of $6 \%$. Thus, the error in using this equation is between $6 \%$ and $16 \%$, probably closer to $16 \%$, and the permeability calculated is an upper bound because a longer flow path requires a higher permeability for a given flow rate. 
The equation was derived using an injection pressure $P_{T}$ of $9.8 \mathrm{MPa}$, and the measured flow must be linearly scaled to that pressure. A measured flow rate at $P_{T}=3.5 \mathrm{MPa}$ would be multiplied by $(9.8 / 3.5)$ and the resulting scaled flow rate used in the calculation. This implies that flow rate is a linear function of head, an assumption implicit in Darcy's law if the permeability is constant.

Table 5.9 gives the results of this calculation. Upper bound permeabilities ranged from 4.6 microdarcy to 1.7 microdarcy, exhibiting the expected pattern of being highest for lower triaxial stress states and higher injection pressures.

After plug emplacement flow rate through the sample increased by over an order of magnitude. The initial flow rate in after plug emplacement was $6178 \times 10^{-3} \mathrm{cc} / \mathrm{min}$, which corresponds to a plug permeability of 2500 microdarcy assuming all flow through the rock and using the onedimensional form of Darcy's law.

After one month the flow rate had decreased to $87 \times 10^{-3} \mathrm{cc} / \mathrm{min}$, at 7.0 MPa injection pressure, similar to the flow rate measured for the rock bridge at the highest triaxial stress state and $7.0 \mathrm{MPa}$ injection pressure (Table 4.10). In addition, the triaxial stress state on the plugged sample was lower than the highest triaxial stress state on the sample with rock bridge, the confining stress being quite a bit lower to control leakage from the annulus. It may be inferred that the plug permeability was approaching that of the rock, about 2 microdarcy, since the flow rates were similar.

This type of behavior was observed for a dried plug in Sample SGE-2-2, discussed previously (Section 5.1.2.1). In that case the cement plug, after drying, had a permeability of 190 microdarcy, which, after 50 days of re-wetting, reduced to 3 microdarcy, a value obviously close to the 2 microdarcy final value for the NTS-TPTS-101 plug.

The reason for the reduction in plug permeability with time is unknown. This plug was not dried. It is speculated that water flow through the plug causes continued hydration of the cement and thus reduces its permeability. For this sample it is likely that flow was dominantly along the rock-plug interface. When the high flow rates were first observed the permeameter was turned over and the bottom plug removed so that the cement plug could be observed. Water was injected into the top hole and seepage of water could be clearly seen coming from the circumference of the bottom of the cement plug.

The initial high flow rates may be due to alkali-aggregate reactivity between the rock and the cement. Bates (1969, p. 88) has described this phenomenon as the process in which alkalies liberated as cement hardens reacts with the minerals of the aggregate. Quartz, feldspar, calcite, and most dark silicate minerals do not react to a significant degree, but aggregate containing certain poorly crystalline siliceous material may react. Such materials include opalline shale, opalline and chalcedonic chert, siliceous limestone, and siliceous cryptocrystalline volcanic rocks, especially rhyolite, dacite, and andesite. In addition, 
Table 5.9 Topopah Spring Welded Tuff Sample NTS-TPTS-101, Rock Bridge; Upper Bound Permeability

\begin{tabular}{|c|c|c|c|c|c|}
\hline & & $\sigma_{a x} \rightarrow$ & 8.6 & 15.7 & 23.4 \\
\hline & & ${ }^{\sigma_{c}} \rightarrow$ & 6.6 & 13.2 & 19.6 \\
\hline \multicolumn{6}{|c|}{$\mathrm{P}_{\mathrm{T}}$} \\
\hline & 10.0 & & & 2.9 & 2.3 \\
\hline & 7.0 & & & 2.5 & 2.1 \\
\hline permeability & 6.1 & & 4.6 & & \\
\hline \multirow[t]{2}{*}{ (microdarcy) } & 3.5 & & 3.6 & 2.1 & 1.7 \\
\hline & 1.8 & & 3.5 & & \\
\hline
\end{tabular}

$\sigma_{\mathrm{ax}}=\operatorname{axial}$ stress $(\mathrm{MPa}) ; \sigma_{\mathrm{c}}=$ confining stress $(\mathrm{MPa}) ; \mathrm{P}_{\mathrm{T}}=$ top hole injection pressure (MPa).

Permeabilities were calculated using the formula obtained for Sample SGE-2-3 at $\mathrm{P}_{\mathrm{T}}=9.8 \mathrm{MPa}$; $\log K=\log Q_{i n}-5.975$, where $Q_{j n}$ is the flow rate in $\mathrm{cm} / \mathrm{min}$. Permeabilities were corrected to darcy using a temperature of $22^{\mathrm{t}} \mathrm{C}$ for the water. See text (Section 5.1.4) for further discussion. 
an alkali carbonate reaction involving dolomite in certain calcitic dolomites and dolomitic limestones may also occur.

The reaction is such that sodium and potassium released as the cement hardens react with the poorly crystalline silica, forming an alkalic silica gel. The gel absorbs water from the cement paste, generating expansive stresses that may exceed the tensile strength of the concrete. Indeed, certain cements are specially manufactured to produce high expansive stresses upon curing and are used as non-explosive demolition agents in areas where blasting cannot be employed (e.g. Ishii et a1., 1982; Dowding and Labuz, 1982).

The siliceous, rhyolitic tuff has glass and cryptocrystalline silica (devitrified material) components. Thus, alkali-aggregate reactions are likely to have occurred, particularly along the rock/plug interface.

Corrective measures to preclude these reactions are to limit the alkali content of the cement and to add pozzolanic materials to the cement (Mather, 1964). If the alkali content of the cement is low enough, no cracking of the cement will occur. Addition of finely ground reactive material - a pozzolan - will cause the reaction to first occur between the alkalies and the pozzolan, using up the alkali and spreading the reaction and reaction products throughout the cement. Deleterious effects of alkali-aggregate reactions may take two or three years to become apparent.

\subsubsection{Catalina Granite}

Catalina granite samples CCR-P-100 and CCR-D-100 were tested to evaluate the effects of differing drilling methods. The hole in CCR-P-100 was drilled using a percussion drill; the hole in CCR-D-100 was drilled using a diamond core drill. In addition, the cement plug in CCR-P-100 was subjected to drying at room temperature for 27 days.

Table 5.10 summarizes the results for the two samples. Sample CCR-P-100 had a flow rate value before drying slightly lower than the flow rate after drying. The drying slightly impaired plug performance, but not to the degree that oven drying of the plugged Sample SGE-2-2 impaired its performance. The low temperature at which CCR-P-100 was dried would not have driven off as much moisture as oven drying.

Sample CCR-D-100 was first tested with a rock bridge in place. Dimensions were similar to CCR-P-100 (Figures 4.24 and 4.26). As Table 5.10 shows, flow rates in through the intact rock of CCR-D-100 were greater than those for the cement-plugged CCR-P-100, indicating that the cemented percussion drilled hole was a lower permeability element than the rock bridge. This is also suggested by the dye test illustrated in Figure 4.25, in which the dye penetrated the rock more than the plug.

A $2.6 \mathrm{~cm}$ diameter hole drilled in CCR-D-100 was plugged with cement. Flow rate in values were less than for $C C R-D-100$ with rock bridge, but slightly greater than for the flow rate in values for CCR-P-100. Comparison is complicated by the fact that the cement plug in CCR-P-100 
Table 5.10 Test Results for Catalina Granite Samples CCR-P-100 and CCR-D-100

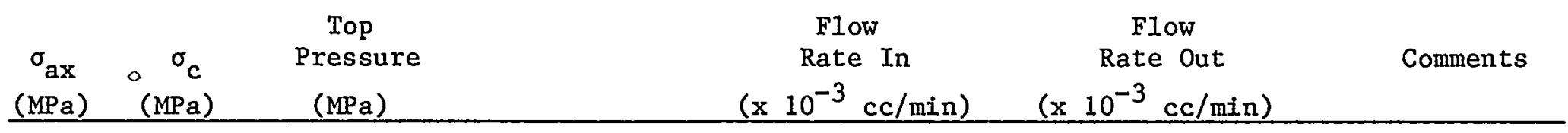

Sample CCR-P-100, Cement 1 Plug

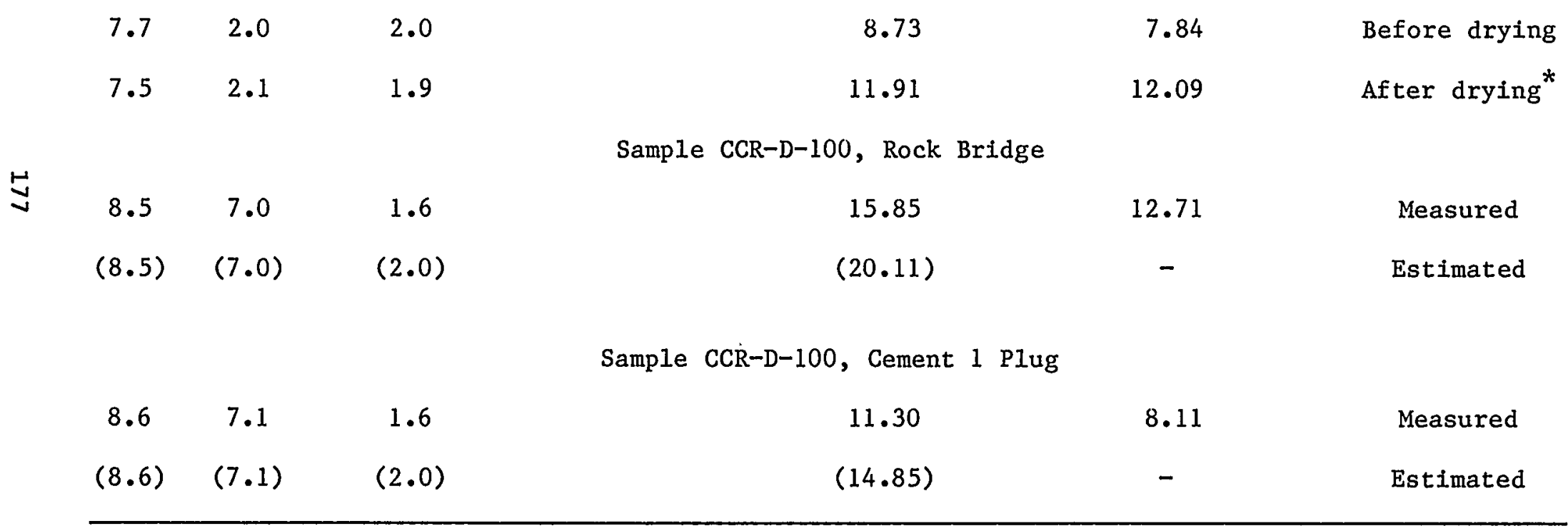

$\sigma_{\mathrm{ax}}=$ axial stress; $\sigma_{\mathrm{c}}=$ confining stress. Lines with figures in parentheses show estimated flow rate in at $2.0 \mathrm{MPa}$ top pressure. Estimates were made from curves at the same axial and confining stresses, Figure 4.27. Regression coefficients are given on Table 4.13.

Bottom hole is at atmospheric pressure.

* 27 days at room temperature in laboratory environment. 
was $3.8 \mathrm{~cm}$ in diameter whereas the one in CCR-D-100 was $2.6 \mathrm{~cm}$ in diameter. Since the cement plug lowered flow rates, a larger plug in CCR-D-100 could be expected to lower flow rates even more. Thus, the difference in flow rate through the plugged percussion-drilled hole and the plugged diamond-drilled hole is not significant, indicating that percussion drilling does not introduce a damage zone to the rock about the hole significantly greater than does a diamond drilling. This accords with the results obtained by Mathis and Daemen (1982), and by Fuenkajorn and Daemen (1986b), although the more detailed investigation in the latter has revealed significant differences between damage induced by diamond drilling and by percussion drilling.

\subsection{Tests on Bentonite P1ugs}

Test results for the Charcoal granite with rock bridge have been discussed in Section 5.1.1. In this section permeabilities for the rock under a range of triaxial stress conditions and injection pressures are calculated using equations derived for Sample CG-103, which has only slightly different dimensions.

For the analysis in this section, FREESURF I was used to calculate the permeability of intact rock for CG-104 under a triaxial stress state of 23.0 $\mathrm{MPa}$ and $19.6 \mathrm{MPa}$ axial and confining stresses, respectively, and an injection pressure of $3.4 \mathrm{MPa}$. The permeability is $5.42 \times 10^{-9} \mathrm{~cm} / \mathrm{min}$ ( 0.085 microdarcy), which is within $0.3 \%$ of the estimated value in the preceding section.

Figure 5.12 shows flow rate vs. $K_{P} / K_{R}$ at an injection pressure of 3.8 $\mathrm{MPa}$. This graph was developed using data for the first clay plug, Table 4.14; the plug length was $10.9 \mathrm{~cm}$.

Flow rates through the first clay plug were less than for the intact rock, inducating the clay is less permeable than the rock (less than 0.085 microdarcy). This is a much lower permeability than the 50-100 microdarcy permeabilities measured for the clay plug in the falling head test (Section 3.1.2.2), and is thought to result from applying a high pressure on the clay plug, thereby hydraulically compacting it prior to attainment of pore pressure equilibrium.

Alternatively, piping of the clay may have resulted in plugging of the $1 / 8$-inch diameter tubing or the valve leading from the permeameter to the bottom flask. This would have the effect of increasing the flow path by less than an order of magnitude, probably about 5 to 6 times. If this is the case it illustrates the ability of the clay to migrate into fine fissures and plug them. (Of course, if the clay continues to pipe it eventually may all wash out. Piping in this instance, however, is a result of the abnormally high gradients used in the experiment.)

The second and third clay plugs exhibited higher flow ${ }^{\circ}$ rates at lower injection pressures than the first one (Table 4.14). Linearly scaling the flow rates to estimate their yalue at $3.8 \mathrm{MPa}$, the highest scaled flow rate obtained is $10.07 \times 10^{-3} \mathrm{cc} / \mathrm{min}$, estimated for the measured value $\mathrm{k}_{1}$ of $2.65 \times 10^{-3} \mathrm{cc} / \mathrm{min}$ at $1.0 \mathrm{MPa}$ injection pressure. 


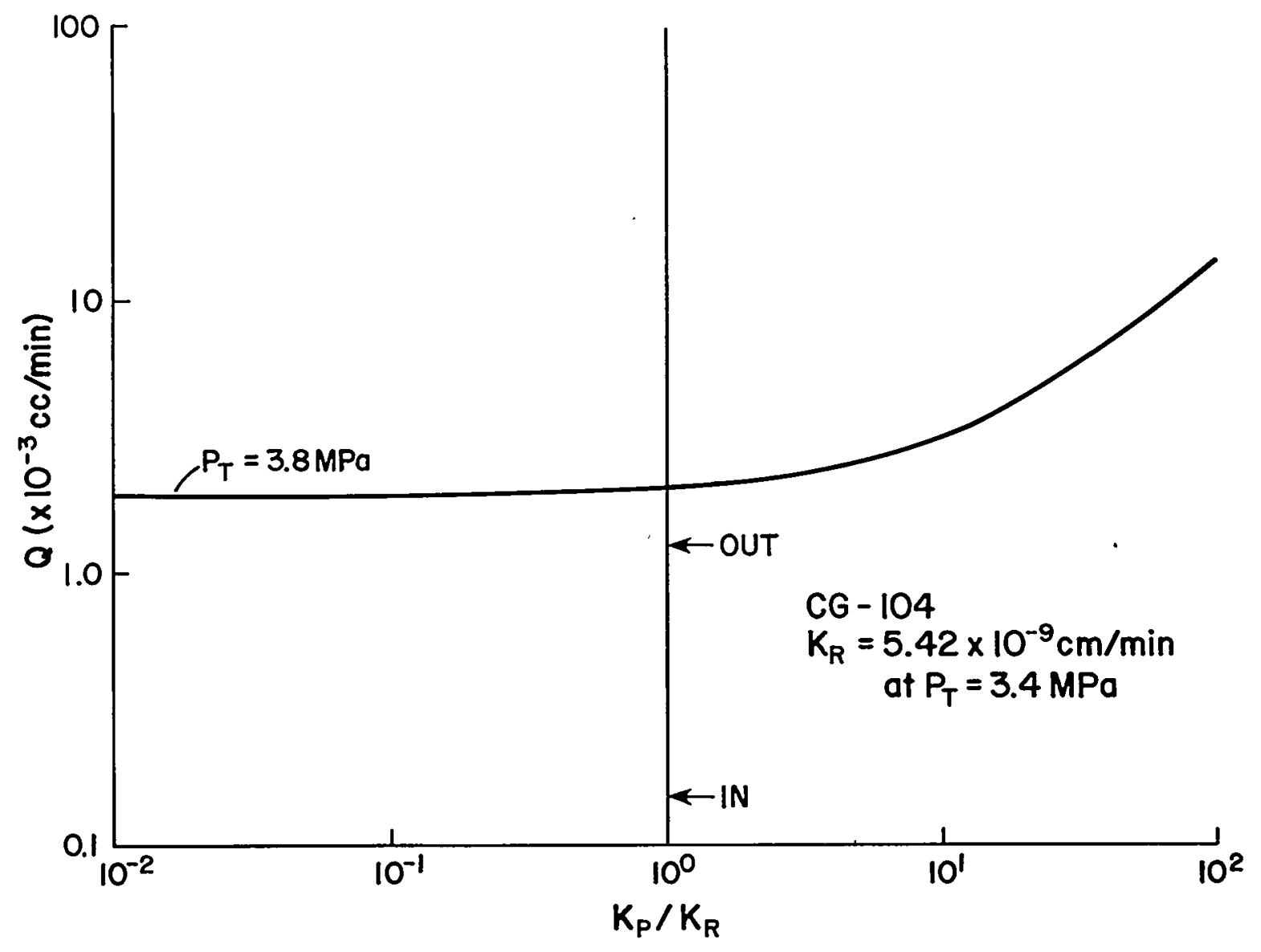

Figure 5.12 Charcoal granite Sample CG-104, calculated variation in flow rate with variation in the ratio of plug permeability, $\mathrm{K}_{\mathrm{P}}$, to rock permeability, $\mathrm{K}_{\mathrm{R}} \cdot \mathrm{P}_{\mathrm{T}}$ : top hole injection pressure. 
From Figure 5.12, this corresponds to a $\mathrm{K}_{\mathrm{P}} / \mathrm{K}_{\mathrm{R}}$ of 69 , yielding a clay plug permeability of $0.37 \mathrm{E}-06 \mathrm{~cm} / \mathrm{min}$ ( 6 microdarcy), assuming a plug length of $10.9 \mathrm{~cm}$. Actually the plug had been forced into the bottom of the sample at this time, and measurement of the sample after it was removed from the permeameter indicated a plug length of $16.3 \mathrm{~cm}$. The longer flow path would require a higher permeability for the given flow rate, and the actual plug permeability is estimated at $(16.3 / 10.9)(0.37$ $\left.\times 10^{-6}\right)=0.55 \times 10^{-6} \mathrm{~cm} / \mathrm{min}$ ( 9 microdardy). This indicates a plug permeability about two orders of magnitude greater than the granite.

\subsection{Influence of Relative Plug-Rock Permeabilities}

The influence of the relative plug-rock permeabilities on the flow pattern in a sample was evaluated using FREESURF $I$. For this work the sample was assumed to be $15.24 \mathrm{~cm}$ ( 6 inches) in diameter and $30.24 \mathrm{~cm}$ (12 inches) long.

Only the upper quarter of the sample need be modeled due to axial symmetry about the Z-axis and mirror-plane symmetry about the horizontal plane through the center of the plug and the rock cylinder. Only the upper half of the mesh shown in Figure 5.1 was used.

Figure 5.13 presents a flow net for the case of intact rock, where "plug" permeability (here a rock bridge) and rock permeability are equal $\left(\mathrm{K}_{\mathrm{P}}=\mathrm{K}_{\mathrm{R}}\right)$. The aspect ratios of the rectangles in this flow net vary due to the axial symmetry. For this work the head in the top hole was assigned a relative magnitude of 100 and equipotential lines drawn at $5 \%$ intervals of total head drop. The R-axis is the line of $50 \%$ head drop. The lower half of the sample (not shown) would have the same appearance, but with equipotentials that range from $50 \%$ along the $\mathrm{R}$-axis to $0 \%$ at the bottom hole.

The program calculates the head at each node, and the equipotentials were drawn by linear interpolation between nodes. Stream lines were drawn at $5 \%$ intervals of total flow. Flow is calculated by FREESURF I at each constant potential node, which in this instance are the nodes along the top hole and along the R-axis. Flow was distributed linearly about each constant potential node, assuming the flow assigned to each node occurred between points halfway to the adjacent nodes. Linear interpolation was used to calculate the position of the $5 \%$ contours along the constant head boundaries and the stream lines sketched orthogonal to the equipotential lines. Orthogonality is assured by the isotropy of the model.

As Figure 5.13 shows, only about $5 \%$ of the total flow occurs through the plug region for $\mathrm{K}_{\mathrm{P}}=\mathrm{K}_{\mathrm{R}}$. Most of the flow occurs through the rock surrounding the plug region. As a base, consider the relative flow magnitude for $\mathrm{K}_{\mathrm{P}}=\mathrm{K}_{\mathrm{R}}$ as 1.00 . (In the case actually modelled, the head was assigned as $100 \mathrm{~cm}$, and a permeability of $10^{-5} \mathrm{~cm} / \mathrm{sec}$ used. The total flow rate was calculated as $0.951 \times 10^{-2} \mathrm{cc} / \mathrm{sec}$.) 


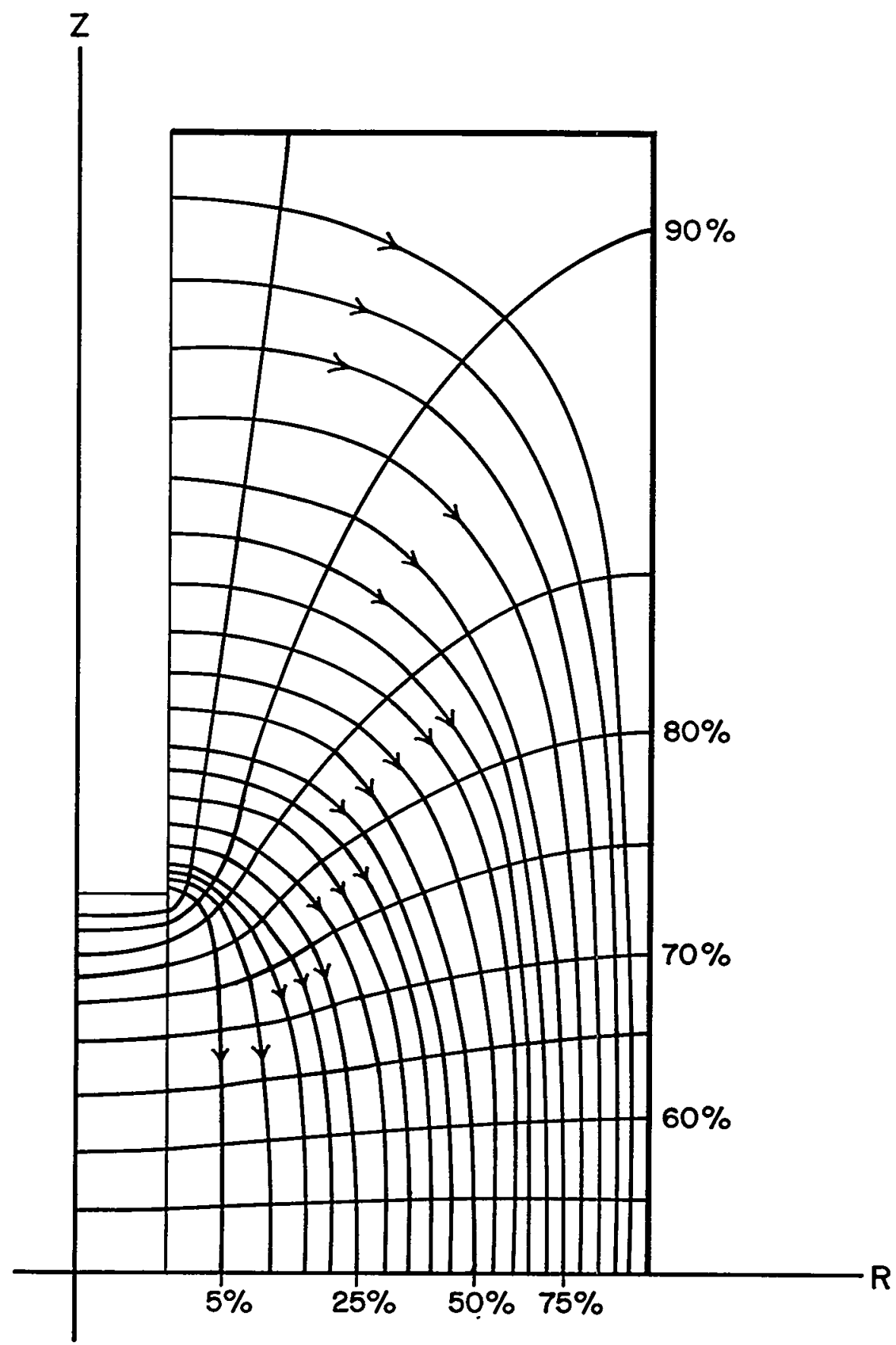

Figure 5.13 Flow net for intact rock, $K_{p}=K_{R}$. About $5 \%$ of the flow occurs through the "plug region". Equipotential lines show percent head with respect to center hole. Stream lines show percent flow occurring between the stream line and the Z-axis. Relative flow magnitude $=1.00$. 
Figure 5.14 shows the case in which the plug is one order of magnitude more permeable than the rock, $\mathrm{K}_{\mathrm{P}}=10 \mathrm{~K}_{\mathrm{R}}$. In this instance about $25 \%$ of the flow occurs through the plug. The relative flow magnitude is 1.50 ; that is, flow is $11 / 2$ times that for the intact rock case above. Calculations for a plug two orders of magnitude more permeable than the rock indicate about $75 \%$ of the flow occurs through the plug and the relative flow magnitude is 6.24 .

Figure 5.15 shows the case for a plug one order of magnitude less permeable than the rock $\left(\mathrm{K}_{\mathrm{P}}=0.1 \mathrm{~K}_{\mathrm{R}}\right)$. Less than $5 \%$ of the flow occurs through the plug, and the relative flow magnitude is 0.94 . Calculations for a plug two orders of magnitude less permeable than the rock indicate less than $5 \%$ of the flow occurs through the plug and a relative flow magnitude of 0.93 , similar to the "one order of magnitude less" case.

The implications of the above calculations are straightforward. First, a plug one order of magnitude less permeable than the rock reduces the flow through the system by only $6 \%$. A further reduction in plug permeability to two orders of magnitude less than the rock results in only another $1 \%$ reduction in flow through the plug-rock system. Making a plug less permable than the surrounding rock offers little gain in overall rock-plug system performance.

Second, a plug one order of magnitude greater in permeability than the rock results in only a one and one-half fold increase in flow rate. A plug two orders of magnitude more permeable than the rock results in about a six-fold increase in flow rate. Thus, a plug one or two orders of magnitude greater in permeability than the surrounding rock does not permit even one order of magnitude increase in flow through the system modeled, which represents a plug and the immediately surrounding rock. Since a borehole and its immediately surrounding rock is only a small part of the total rock mass, the effect of a plug permeability one or two orders of magnitude greater than the rock is even less pronounced.

Fuenkajorn and Daemen (1986b, Ch. 4, Figures 4.13 and 4.14) perform finite element analysis on similar laboratory experiments using the same program (FREESURF I). The model is an unconfined rock cylinder (152 mm diameter) subjected to an internal pressure of $7.0 \mathrm{MPa}$ in the $38 \mathrm{~mm}$ diameter coaxial hole with a cement plug in the middle third of the hole. The permeabilities of the rock and of the plug are $1.7 \times 10^{-10}$ darcy and $1 \times 10^{-8}$ darcy, respectively. The results indicate that approximately $65 \%$ of the injected water flows through the plug. Since the plug permeability is higher than the rock permeability, some water in the plug flows across the interface into the rock cylinder. The pore pressure within the plug decreases linearly from the side subjected to injected borehole pressure to the side subjected to atmospheric pressure. 


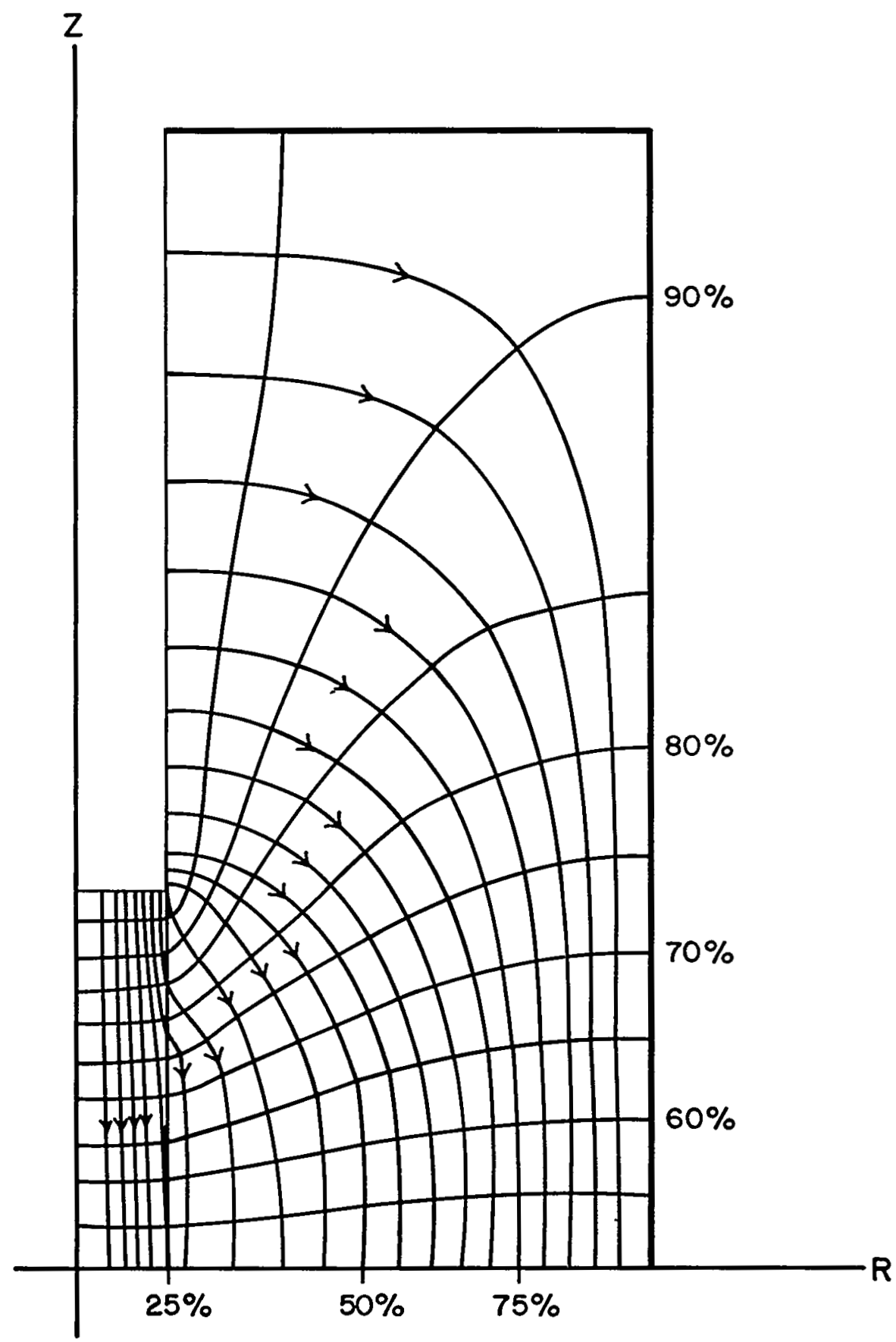

Figure 5.14 Flow net for plug more permeable than rock, $\mathrm{K}_{\mathrm{p}}=10 \mathrm{~K}_{\mathrm{R}}$. About $25 \%$ of the flow occurs through the plug. Equipotential lines show percent head with respect to center hole. Stream lines show percent flow occurring between the stream line and the Z-axis. Relative flow magnitude $=1.50$, i.e. total flow through the system is fifty percent higher than for the $K_{P}=K_{R}$ (Figure 5.13) case. 


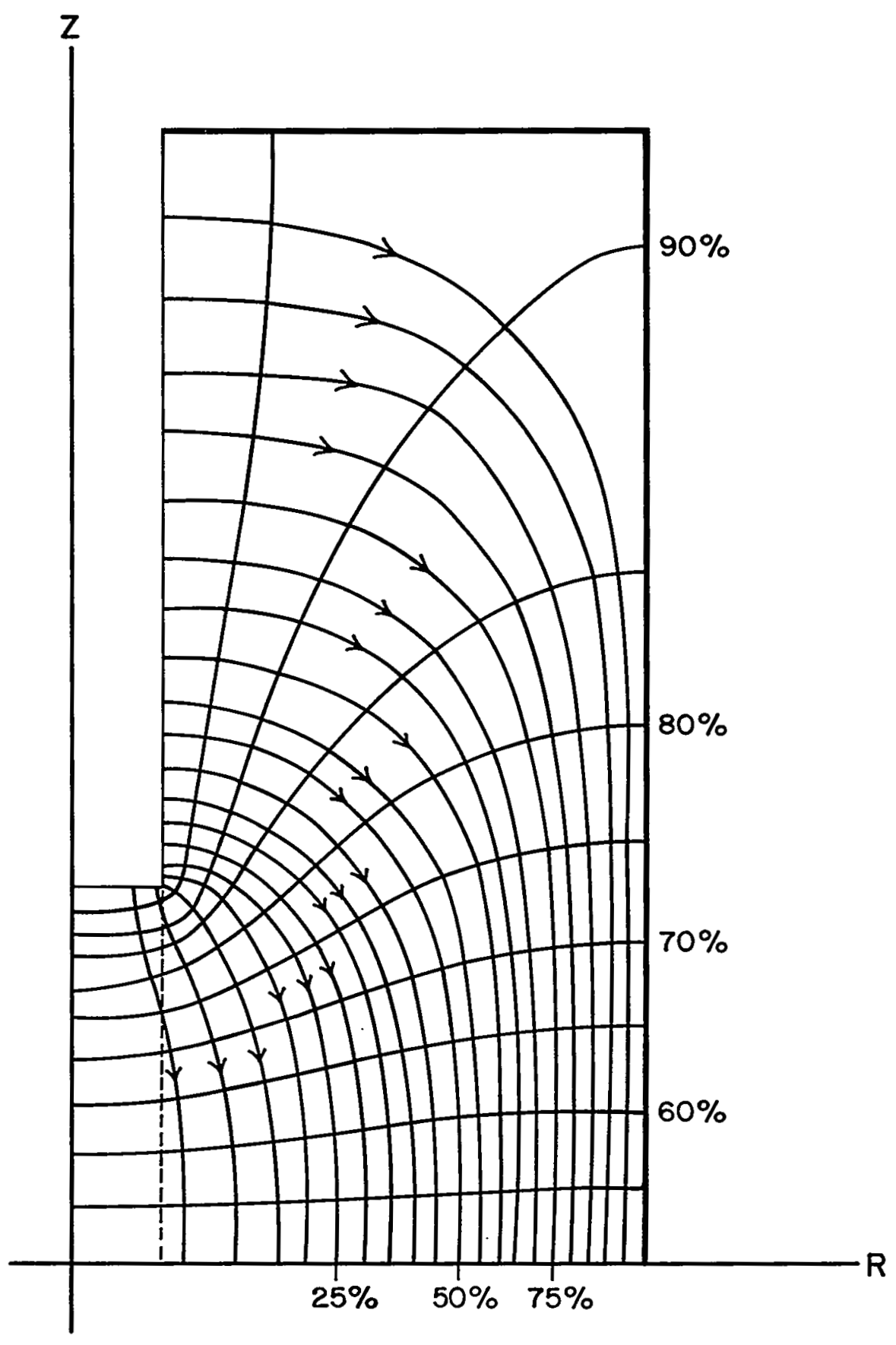

Figure 5.15 Flow net for plug less permeable than rock, $\mathrm{K}_{\mathrm{P}}=0.1 \mathrm{~K}_{\mathrm{R}}$. Less than $5 \%$ of the flow occurs through the plug. Equipotential lines show percent head with respect to the center hole. Stream lines show percent flow occurring between the stream line and the Z-axis. Relative flow magnitude $=0.94$. 


\section{CHAPTER SIX}

\section{SUMMARY AND CONCLUSIONS}

Cement and clay plugs have been tested under varying stress conditions in boreholes drilled in granite, basalt, and tuff. A cement plug in a granite cylinder and a similar plug in a basalt cylinder were subjected to temperature and moisture content variations. A test in granite compared drilling damage induced by percussion drilling to that induced by diamond drilling.

\subsection{Summary of Results}

Testing of cement plugs in Charcoal granite and in Sentinel Gap basalt indicates that flow rates through a plugged rock sample are similar to but less than those through the intact rock for the Charcoal granite, but are greater through the plugged samples of basalt compared to intact basalt.

Table 6.1 is a summary of the rock and plug permeability data. The permeability of the Charcoal granite ranged from 52 to 85 nanodarcy, depending on the effective stress state of the rock. Results for the three samples tested using cement plugs were similar. Flow rates through the plugged samples were less than through the samples with rock bridge in place, Figures 4.2, 4.4, and 4.9. Only when the triaxial stresses on the sample were lowered to about $1 / 3$ their initial value did flow through the plugged sample exceed flow through the intact rock at the highest stress level. As the data from Samples CG-104 and CG-103 show (Figures $4.28,5.8$, and 5.9), this is most likely due to increased rock permeability or increased rock-plug interface conductivity with decreasing stress level rather than increased flow through the plug.

A permeability of 0.16 to 0.17 nanodarcy was measured for the intact Sentinel Gap basalt. Replacing the rock bridge by a cement plug resulted in increased flow rate (Figures 4.14 and 4.17 ), and the measured permeability of the cement plugs was between 10 and 73 nanodarcy. Lowering the triaxial stress state on the plugged basalt samples did not significantly affect the flow rate, indicating that a cement plug placed in a rock mechanically similar to this basalt will not be adversely affected by a decrease in stress state. (The basalt used in this experiment is a stiff rock, having a Young's modulus of $11.5 \times 10^{6} \mathrm{MPa}$, compared to $6.89 \times 10^{3} \mathrm{MPa}$ for the cement. The basalt would not be expected to undergo large strains as it is unloaded.)

The permeability measured for the cement plugs in the basalt samples, 10 to 73 nanodarcy, is slightly lower than the range of the measured Charcoal granite permeabilities. It is also close to the 95 nanodarcy permeability measured for a cement core in a constant head test (Section 3.1.2.1). A hole in basalt plugged with cement is similar to a very small granite plug cutting the basalt. 
Table 6.1 Summary of Rock and Plug Permeability

\begin{tabular}{|c|c|c|c|}
\hline Rock Type & $\begin{array}{l}\text { Rock Permeability } \\
\left(\mathrm{x} 10^{-9} \text { darcy }\right)\end{array}$ & $\begin{array}{l}\text { Equivalent } \\
\text { Plug Permeability } \\
\text { (x } 10^{-9} \text { darcy) }\end{array}$ & Comments \\
\hline Charcoal granite & $52-85$ & Less than rock & Cement plugs \\
\hline Sentinel Gap basalt & $0.16-0.17$ & $10-73$ & Cement plugs \\
\hline $\begin{array}{l}\text { Oracle Granite } \\
\text { with fracture } \\
\text { without fracture }\end{array}$ & $\begin{array}{c}60,000 \\
9\end{array}$ & $8,000^{* *}$ & Cement plug \\
\hline Topopah Spring tuff & $1700-4800$ & $\left(2.5 \times 10^{-6}\right)-2000$ & Cement plug \\
\hline & & 95 & $\begin{array}{c}\text { Cement core tested } \\
(\mathrm{Ch} .3)\end{array}$ \\
\hline Charcoal granite & 85 & 9,000 & Bentonite plug \\
\hline
\end{tabular}

* Permeabilities were calculated assuming the plug body and the rock/plug interface are one porous body. ** This permeability was calculated from flow assumed to be exclusively through a plug. The value is highly uncertain for reasons discussed in Section 6.1. 
Results obtained for the Oracle granite are somewhat at variance with those obtained for the Charcoal granite. An intact rock permeability of 9 nanodarcy was measured. In addition, an equivalent porous medium permeability of 60,000 nanodarcy was measured for a portion of the rock containing a fracture, illustrating the great increase in permeability of a fractured rock compared to intact rock. The cement permeability measured in this test was 8000 nanodarcy.

Since the boundary conditions on this sample were different from the other samples tested - it was the first sample tested and the sides were not sealed with epoxy - comparisons are complicated. The intact rock was almost an order of magnitude less permeable than the Charcoal granite. This was somewhat unexpected, since the Oracle granite was much coarser-grained than the Charcoal granite and it was expected that coarser- grained rocks would be more permeable, based on the greater permeabilities measured for the phaneritic Charcoal Granite as compared to the aphanitic Sentinel Gap Basalt. Examination of the photomicrographs (Figures 3.2 and 3.3) also would seem to indicate that the fissured Oracle granite should not be less permeable than the Charcoal granite. It is, however, possible that ground water flowing through the rock has effectively sealed many of the microfissures with mineral deposits such as calcite.

The apparent permeability calculated for the cement plug placed in the Oracle granite is two orders of magnitude greater than the measured permeability of any of the cement plugs placed in the Charcoal Granite and Sentinel Gap basalt, as well as than the value measured on the cement core. It deserves pointing out that the plug was installed in a rock cylinder with a fracture, albeit of limited extent and aperture. Nevertheless, it would seem entirely possible that swelling of the plug, subsequent to installation, particularly when combined with an injection pressure, might have propagated or widened the fracture. Such occurrences have been observed in basalt blocks (Akgun and Daemen, 1986; Daemen et al., 1986, Section 5.2.2), admittedly while the blocks were not confined. Certainly this cement permeability value must be considered as highly uncertain and suspect.

Further testing of the Oracle granite is necessary if the reason for the variance in data between it and the Charcoal granite is to be established. However, a permeability of 8000 nanodarcy ( 8 microdarcy) is still a very low permeability, less than the permeability of what is generally considered "impervious" clay (e.g. Sowers and Sowers, 1970, p. 93).

The permeability of the Topopah Spring tuff was measured as $1700-4800$ nanodarcy. Plugging of the tuff resulted in an initial cement plug permeability of $2.5 \times 10^{6}$ nanodarcy. The permeability decreased to that of the tuff within a month. The initial high permeability of the plug is believed to have resulted from an alkali-aggregate reaction between the cement and the rock. The reason for the reduction in permeability with time is not known. 
Several clay plugs were placed in a Charcoal granite sample. All had permeabilities of less than 9000 nanodarcy, in agreement with the range of permeability of "impervious" clay reported by Sowers and Sowers (1970, p. 93) of less than 100,000 nanodarcy. Permeability of the clay plug tested in the falling head test was 50,000 to 100,000 nanodarcy. The lower permeability of the plugs placed in the Charcoal granite may be due to a denser emplacement or to densification of the clay by hydraulic pressure as the injection pressure was increased.

Two samples were subjected to drying. Sample CCR-P-100 was dried at room temperature for 27 days. This slightly impaired the performance of its cement plug. Sample SGE-2-2 was dried for 42 days at a temperature of $54^{\circ} \mathrm{C}$. This severely impaired plug performance, increasing plug permeability from about 10 to 60 nanodarcy to a value of 190,000 nanodarcy. As flow continued the plug became less permeable, reaching a value of 2500 nanodarcy after 50 days.

The effect of different drilling methods was evaluated using samples CCR-P-100 and CCR-D-100. The center hole in Sample CCR-P-100 was drilled using a percussion drill and the center hole in Sample CCR-D-100 was drilled using a diamond core bit. Flow rates through both samples after plugging were similar, indicating the percussion-drilled hole does not have a surrounding damage zone significantly different, in terms of permeability, from the diamond-drilled hole. Flow rates through both plugged samples were less than the flow rate through intact rock (Sample CCR-D-100 with rock bridge).

Mathis and Daemen (1982) and Fuenkajorn and Daemen (1984, 1986b) perform similar flow tests and conclude that the permeability of drillinginduced damage zone in 38-102 $\mathrm{mm}$ diameter holes has an insignificant effect on borehole plug performance. These conclusions agree with the conclusions drawn by Lingle et al. (1982) and Burns et al. (1982). The low permeability of the damaged zone might be due to (1) the small aperture and length of the cracks, (2) lack of connectivity between the cracks, (3) closure of the cracks due to swelling pressure of the cement plug, (4) infiltration of cement particles into the cracks, or (5) secondary mineralization within the cracks (Fuenkajorn and Daemen, 1986a).

\subsection{Conclusions}

\subsubsection{Cement Plugs}

The cement plugs tested performed about as well as intact Charcoal granite, but not as well as intact basalt. A plug of this cement, if properly placed in a fractured rock mass (and all rock masses are fractured to some degree), could reasonably be expected to be considerably less permeable than the rock mass. The highest permeability measured was the equivalent porous medium permeability of the fractured portion of the Oracle granite.

Based on dye tests, the rock/plug interface zone is not a preferential migration path in the granites tested. Some dye did penetrate along the 
plug/basalt interface in Sample SGE-2-3, but this was a sample of intact basalt, i.e. a rock with exceedingly low permeability. It is expected that if a fracture were intersected the dye would flow into it, leaving the interface region. Variation of the triaxial (1ithostatic) stress state on the two basalt samples did not significantly affect flow through the cement plugs, nor was the basalt permeability measurably affected. Increased flow rates in the Charcoal and Catalina granites with decreasing triaxial stress state is attributed to variation of rock permeability, rather than plug permeability.

The rock samples used had a higher Young's modulus than the cement plugs. Decreasing the triaxial stress state on a rock/plug combination in which the rock is softer than the plug could yield different results.

Finally, (1) More work is needed to ascertain why the results obtained in the test using Oracle Granite are at variance with the tests on the other rock types that used cement as the plug material; (2) Damage about a borehole induced by percussion drilling is comparable to that produced by diamond drilling, and is very small in both cases; (3) Temperature and moisture variations (drying) seem more important in degrading plug quality than do stress variations. The stress variations experimented with here could be analyzed in terms of induced (interface, plug) displacements and deformations, and hence related to thermally induced repository opening deformations to evaluate plug deformations and their potential consequences on sealing performance; (4) Low alkali cement, or another type of sealant, should be used in rocks containing amorphous or cryptocrystalline silica, such as the Topopah Spring Tuff. This may be even more important for shaft and tunnel linings than borehole seals.

\subsubsection{Bentonite Plugs}

Plugs formed by bentonite tablets are more permeable than intact rock, but probably no more permeable than a fractured rock mass. The bentonite tablets are easy to place and form a clay seal of low permeability.

\subsubsection{Discussion}

The main conclusion reached as a result of these experiments is that currently available materials are capable of forming high quality seals when placed under laboratory conditions. Variation of triaxial stress state about a borehole does not significantly affect seal performance if the rock is stiffer than the seal material. Heating in air and allowing the cement to dry degraded cement plug performance significantly over even the relatively short term of six weeks. Performance partially recovered upon resaturation.

This work has involved testing seals placed in intact rock. In a field situation the rock being sealed would be a fractured rock mass. As the experiments involving Oracle Granite showed, even minute fractures in a rock mass greatly increase its permeability. A skillfully sealed borehole may reasonably be expected to be at least as impermeable as a fractured rock mass, and fluid flowing through the seal would likely 
leave the seal through fractures intersecting the borehole. of course, site specific verification of this expectation must be performed.

The analysis of relative plug-rock permeabilities, Section 5.3, provides insight to important seal parameters. As long as the seal is not more than one order of magnitude more permeable than the rock through which it passes, the flow through the plug and the rock immediately surrounding it is not greatly affected. Since a sealed borehole (shaft, drift) and its immediately surrounding rock are only a small part of the total rock mass, the global effect is even less pronounced. In addition, the model used is for a plug sealing the center third of a rock cylinder. The simplest way to decrease flow through the system would be to increase the length of the plug.

The generic analysis clearly confirms (or is confirmed by) practical underground plug design methods (e.g. Garrett and Campbell Pitt, 1961; National Coal Board, 1982; Chamber of Mines of South Africa, 1983; Auld, 1983). These all emphasize the need for sufficient plug length, primarily to preclude excessive bypass flow through the adjacent rock, as well as the need to provide adequate treatment (grouting) of this rock, as this usually is a highly preferential, flowpath, and frequently is difficult to seal (e.g. Moller et al., 1983). The analysis also confirms the conclusion reached by Vaughan (1969), based on a highly simplified analysis, in reponse to concerns expressed by Bishop (1964) about the feasibility of installing piezometers with seals of exceedingly low permeability that the seal permeability can exceed that of the surrounding ground substantially, yet have only a modest effect on pressure (head) readings.

6.3 Uncertainties, Information Needs, and Research Recommendations

Significant remaining questions include field emplacement techniques; field verification of plug quality; plug performance over long time periods, particularly with respect to temperature/moisture variations, chemical stability, and deformations induced by rock movement; and radionuclide sorption capabilities of the plug material. Scale effects are also important, as shafts and drifts must be sealed as well as larger diameter boreholes.

Cement and clay have a very small grain size with respect to the borehole dimensions used in these experiments, so size effects would not be expected in this regard. However, a larger plug involves more volume, and there is a greater chance of having a defect in the plug. In addition, scale effects upon emplacement techniques could be significant, as different emplacement techniques are likely to be used in larger, more readily accessible openings. A large pour of concrete to form a shaft plug would result in a greater thermal effect from the heat of hydration than placing a cement borehole plug.

Scale effects include both the greater volume of material involved and the greater interface area between the plug and the rock. Scale effects due to volume would be related to the cube of the opening size, whereas interface effects would vary as the square of the opening size. Thus, 
defects involving the interface could be expected to have lesser impact on the system performance than defects involving the plug body. Conversely, practical experience indicates the great difficulty in maintaining good contact and good material in the upper region of horizontal plugs, and the general need for remedial treatment (e.g. pressure grouting) of the interface.

\subsection{Suggestions for Further Research}

Suggestions for further research are:

(1) A high priority for further laboratory research is to simulate field emplacement techniques and to evaluate failure modes. For example, plugs should be placed under water, and in holes filled with drilling mud, and cured under simulated downhole fluid pressures.

(2) Field tests to evaluate emplacement techniques and quality verification procedures should be conducted. The effect of leaving steel casing in a hole should be evaluated. In this regard a test facility in which holes could be drilled into underground workings to allow access to both ends of the hole is highly desirable.

(3) The need for further laboratory tests at higher stress levels should be evaluated. Heating of the rock due to waste emplacement as well as stress redistributions due to mining may lead to higher stress levels than used in these experiments. In addition, the effect of various rock/plug stiffness combinations on sealing performance should be evaluated.

(4) Numerical analysis should be performed to evaluate the effective stress distribution throughout a plugged sample. This would be an important addition to the data base regarding borehole sealing. The effective stress distribution will depend on the stiffness of both the rock and plug material and on the permeability of the rock and plug material. The stiffness of the rock and plug material will determine the stress distribution due to the imposed triaxial stress state. The relative permeabilities of the rock and plug material will determine the pore pressure distribution due to the water flowing through the rock and may be subtracted point-wise from the stress distribution due to the imposed triaxial stress state to determine the effective stress distribution.

(5) Numerical flow analyses should be performed on plug sealing performance by considering various plug lengths, plug and rock permeabilities. This in particular should include the effects of stress redistribution and rock failure, and hence, ideally, should be a flow analysis coupled with the stress analysis recommended in (4).

(6) Tests of borehole plugs in fractured rock samples should be performed to evaluate the relative flow amounts through the plug as compared to the fractures. In addition, fracture grouting experiments would help ascertain the effectiveness of sealing the rock around boreholes. 
Although it can be argued that seals should be emplaced in intact rock, that option may not always be available. Of particular concern might be repository sites where substantial borehole wall spalling occurs. As pointed out succinctly by Hoek and Brown (1980, p. 215), the failure mechanism is poorly understood. A fortiori, implications for permeability are even less certain. Similar uncertainties of bypass flow paths due to jointing have been discussed in more detail in an earlier report (Daemen et al., 1983, Ch. 10).

(7) The effects of water, rock and seal material chemistry on curing of cement, swelling of clay, and longevity of plug materials should be evaluated in the context of long-term sealing against radionuclide migration.

(8) A borehole plug is likely to involve both cement, for its strength and low permeability properties, and clay, for its sorptive properties and ability to deform without cracking. Experiments should include interaction effects of multi-component plugs.

(9) Plugging techniques useful in horizontal holes and "up" holes (e.g. exploratory holes drilled upward from underground workings) should be evaluated.

(10) Size effects should be investigated. Concrete and clay may be used to seal both shafts and tunnels. This has the effect of increasing plug volume with respect to interface area. In the case of concrete, temperatures due to the heat of hydration would be higher in a shaft than in a borehole as a result of the greater mass of cement required.

(11) Any actual repository will require site specific testing of the rocks and the seal materials to be used. Development of testing procedures is necessary. 


\section{REFERENCES}

Adisoma, G.S. and J.J.K. Daemen, 1984, "Laboratory Assessment of the Effect of Drying on the Performance of Cement Borehole Plugs," Waste Management ' 84 Symposium, Tucson, AZ, March 11-15, Vol. 1, pp. 579-583.

Akgun, H. and J.J.K. Daemen, 1986, "Size Influence on the Sealing Performance of Cementitious Borehole Plugs," Technical Report to the U.S. Nuclear Regulatory Commission, Division of Radiation Programs and Earth Sciences, Contract NRC-04-78-271, by the Department of Mining and Geological Engineering, University of Arizona, Tucson. (Submitted)

Allen, T.P. and A.P. Roberts, 1982, Production Operations - Well Completions, Workover, and Stimulation, Second Edition, 0il and Gas Consultants International, Inc., Tulsa, Oklahoma.

American Petroleum Institute, 1977, "Specification 10B, Testing 0i1-We11 Cements and Cement Additives," American Petroleum Institute, Twentieth Edition, Dallas, Texas, April.

Anderson, F.M., 1955, "A Study of Surface Casing and Open-Hole Plug-Back Cementing Practices in the Mid-Continent District," Drilling and Production Practice, American Petroleum Institute, pp. 312-325.

Anderson, W.J., L.G. Clayton, A.E. Cottam, G.K. Jacobs, W.W. Scheely, and W.A. Watrous, 1982, "Nuclear Waste Repository in Basalt Seal Development Studies," DOE/NWTS-30, Proc. of the 1982 National Waste Terminal Storage Information Meeting, U.S. Department of Energy, pp. 58-61.

Arnett, R.C., R.G. Baca, J.A. Caggiano, and D.J. Carre11, 1980, "Radionuclide Release Scenario Selection Process for a Possible Basalt Repository," pp. 13I-140, Radioactive Release Scenarios for Geologic Repositories, Proceedings of the NEA Workshop, Paris, September 1980. Published by The OECD Nuclear Energy Agency, Paris, 1981.

Arnold, D.M. and H.J. Paap, 1979, "Quantitative Monitoring of Water Flow Behind and in Wellbore Casing," Transactions of the Society of Petroleum Engineers, v. 267, pp. 121-130.

Atomic Energy of Canada Limited, 1978, "Management of Radioactive Fuel Wastes: The Canadian Disposal Program," AECL-6314, J. Boulton, ed., Atomic Energy of Canada Research Company, Whiteshe11 Nuclear Research Establishment, Pinawa, Manitoba, Canada, Oct. .

Aul, G.N., and J. Cervik, 1979, "Grouting Horizontal Drainage Holes in Coalbeds," U.S. Bureau of Mines Report of Investigations RI 8375. 
Auld, F.A., 1983, "Design of Underground Plugs," International Journal of Mining Enginering, Vol. 1, Number 3, pp. 189-228.

Austin, E.H., 1983, Drilling Engineering Handbook, International Human Resources Development Corporation, Boston, Massachusetts.

Barbreau, A., R. Heremans, and B. Skytte Jensen, 1980, "Radionuclide Migration in Geological Formations," in Radioactive Waste Management and Disposal, R. Simon and S. Orlowski, editors, Proc. of the First European Community Conference, Luxembourg, May 20-23, pp. 515-530. Harwood Academic Publishers for the Commission of the European Communities, Brussels.

Bartlett, J.W., and C.M. Koplik, 1979, "Information Base for Waste Repository Design, Volume 7 - Executive Summary," Report No. NUREG/CR-0495, TR-1210-1, Prepared by The Analytical Sciences Corporation for the Division of Waste Management, Office of Nuclear Material Safety and Safeguards, U.S. Nuclear Regulatory Commission.

Bates, R.L., 1969, Geology of the Industrial Rocks and Minerals: Dover Publications, New York, $459^{\circ}$ pp.

Baumeister, T., and L.S. Marks, (Eds.), 1967, Standard Handbook for Mechanical Engineers, Seventh Edition: McGraw-Hill Book Company, San Francisco.

Bechtel National, Inc., 1979, "An Assessment of LWR Spent Fuel Disposal Options," ONWI-39, 3 vols., prepared for Office of Nuclear Waste Isolation, Battelle Memorial Institute, Columbus, Ohio.

Bernaix, J., 1969, "New Laboratory Methods of Studying the Mechanical Properties of Rocks," Int. J. Rock Mech. Min. Sci., Vol 6, pp. 43-90.

Bishop, A.W., 1964, "Contribution to Discussion," Transactions 8th Congress on Large Dams, Edinburgh, Vol. 5, p. 318.

Bowen, R., 1975, Grouting in Engineering Practice: Applied Sciences Publishers, Ltd., London.

Bowen, R., 1981, Grouting in Engineering Practice, Second Edition, Applied Science Publishers Ltd., London.

Brace, W.F., 1980, "Permeability of Crystalline and Argillaceous Rocks," Int. J. Rock Mech. Min. Sci. \& Geomech. Abstr., Vol 17, No. 5, pp 241-251.

Brace, W.F., J.B. Walsh, and W.T. Frangos, 1968, "Permeability of Granite Under High Pressure," Journal of Geophysical Research, Vol 73, No. 6, pp. 2225-2236. 
Bredehoeft, J.D., A.W. England, D.B. Stewart, N.J. Trask, and I.J. Winograd, 1978, "Geologic Disposal of High-Level Radioactive Wastes - Earth-Science Perspectives," Geological Survey Circular $779,15+v$ pp., U.S. Geological Survey.

Brereton, N.R. and M.A. Brightman, 1986, "The Assessment of Borehole Cement Sealing Characteristics by Acoustic Waveform Analysis," FLPU 86-1, Fuid Processes Research Group, British Geological Survey, Natural Environment Research Council, Keyworth, England.

Brunauer, S. and D.L. Kantro, 1964, "The Hydration of Tricalcium Silicate and B-Dicalcium Silicate from $5^{\circ} \mathrm{C}$ to $50^{\circ} \mathrm{C}$," Ch. 7, pp. 287-309, Vo1. 1, in The Chemistry of Cements: H. F. W. Taylor, editor, Academic Press, London.

Buck, A.D. and J.P. Burkes, 1979, "Examination of Grout and Rock from Duval Mine, New Mexico," Miscellaneous Paper SL-79-16, Structures Laboratory, U.S. Army Engineer Waterways Experiment Station, Vicksburg, Mississippi. Prepared for U.S. Deparment of Energy - Sandia National Laboratories, Albuquerque, New Mexico.

Buck, A.D. J.P. Burkes, and J.E. Rhoderick, 1981, "Examination of ERDA10 Grout Specimens at Different Ages," Report No. ONWI-341, Office of Nuclear Waste Isolation, Battelle Memorial Institute, Columbus, Ohio. USAE-WES SL-81-20, Structures Laboratory, U.S. Army Engineer Waterways Experiment Station, Vicksburg, Mississippi.

Buck, A.D. and K. Mather, 1982, "Grout Formulations for Nuclear Waste Isolation," Report No. ONWI-413, Office of Nuclear Waste Isolation, Battelle Memorial Institute, Columbus, Ohio. Miscellaneous Paper SL-82-6, Structures Laboratory, U.S. Army Engineer Waterways Experiment Station, Vicksburg, Mississippi.

Buck, A.D., J.E. Rhoderick, J.P. Burkes, K. Mather, R.E. Reinhold, and J.A. Boa, Jr., 1983, "Modification of Bell Canyon Test (BCT) 1FF Grout," Miscellaneous Paper SL-83-18, prepared for Office of Nuclear Waste Isolation, Battelle Memorial Institute, Columbus, Ohio, and Sandia National Laboratories (Report No. SAND 837097), by Structures Laboratory, U.S. Army Engineer Waterways Experiment Station, Vicksburg, Mississippi.

Buck, A.D., J.A. Boa, Jr., and D.M. Walley, 1984, "Workability of Fluid Hydraulic Cement Systems Containing Salt," Miscellaneous Paper SL-84-10, prepared by Structures Laboratory, Department of the Army, Waterways Experiment Station, Corps of Engineers, Vicksburg, Mississippi, for Office of Nuclear Waste Isolation, Battelle Memorial Institute, Columbus, Ohio.

Buck, A.D., 1985a, "Development of a Sanded Non-salt Expansive Grout for Repository Sealing Application," Miscellaneous Paper SL-85-6, prepared by Structures Laboratory, Department of the Army, Waterways Experiment Station, Vicksburg, Mississippi, for Department of Energy, Columbus, Ohio. 
Buck, A.D., 1985b, "Development of Two Candidate Concrete Mixtures (Salt, Nonsalt) for Repository Sealing Applications," Miscellaneous Paper SL-85-8, prepared by Structures Laboratory, Department of the Army, Waterways Experiment Station, Vicksburg, Mississippi, for Department of Energy, Columbus, Ohio.

Buck, A.D. and R.E. Reinhold, 1985, "Characterization of Four Class H High Sulfate-Resistant Portland Cements," Miscellaneous Paper SL-85-9, prepared by Structures Laboratory, Department of the Army, Waterways Experiment Station, Vicksburg, Mississippi, for Department of Energy, Columbus, Ohio.

Buck, A.D., J.A. Boa, Jr., and D.M. Walley, 1985a, "Development of a Sanded Expansive Salt Grout for Repository Sealing Application," Miscellaneous Paper SL-85-11, prepared by Structures Laboratory, Department of the Army, Waterways Experiment Station, Vicksburg, Mississippi, for Department of Energy, Columbus, Ohio.

Buck, A.D., J.P. Burkes, and T.S. Poole, 1985b, "Thermal Stability of Certain Hydrated Phases in Systems made using Portland Cement," Miscellaneous Paper SL-85-7, prepared by Structures Laboratory, Department of the Army, Waterways Experiment Station, Vicksburg, Mississippi, for Department of Energy, Columbus, Ohio.

Buck, A.D., J.P. Burkes, and R.E. Reinhold, 1985c, "Characterization of Several Plasters and one Retarder for Repository Sealing Mixtures," Miscellaneous Paper SL-85-10, prepared by Structures Laboratory, Department of the Army, Waterways Experiment Station, Vicksburg, Mississippi, for Department of Energy, Columbus, Ohio.

Burkes, J.P. and J.E. Rhoderick, 1983, "Petrographic Examination of Be11 Canyon Tests (BCT) 1-FF Field Grouts Over a Three-Year Period," Miscellaneous Paper SL-83-12, Structures Laboratory, U.S. Army Engineer Waterways Experiment Station, Vicksburg, Mississippi, prepared for Office of Nuclear Waste Isolation, Battelle Memorial Institute, Columbus, Ohio, and Sandia National Laboratories, Albuquerque, New Mexico.

Burkholder, H.C., 1980, "The Development of Release Scenarios for Geologic Nuclear Waste Repositories," pp. 13-26, Radionuclide Release Scenarios for Geologic Repositories, Proceedings of the NEA Workshop, Paris, September, 1980. Published by The OECD Nuclear Energy Agency, Paris, 1981.

Burns, F.L., R. Lingle, and A. Andrews, 1982, "Cement-Plug Leakage and Drilling Damage Evaluated," Oil and Gas Journa1, Nov. 22, Vol. 80 , no. 22 , pp. 120-129.

Bush, D.D. and R. Lingle, 1986, "A Full-Scale Borehole Sealing Test in Anhydrite Under Simulated Downhole Conditions," Volume 1, Technical Report BMI/ONWI-581(1), prepared by Terra Tek, Inc., 
for Office of Nuclear Waste Isolation, Battelle Memorial Institute, Columbus, Ohio.

Bush, D.D. and S. Piele, 1986, "A Full-Scale Borehole Sealing Test in Salt Under Simulated Downhole Conditions," Volume 1, Technical Report BMI/ONWI-573(1), prepared by Terra Tek, Inc., for Office of Nuclear Waste Isolation, Battelle Memorial Institute, Columbus, Ohio.

Chamber of Mines of South Africa, 1983, "Construction of Underground Plugs and Bulkhead Doors Using Grout Intrusion Concrete, Code of Practice," 10 pp., February.

Chatterji, S. and J.W. Jeffery, 1971, "The Nature of the Bond Between Different Types of Aggregates and Portland Cement," Indian Concrete Journa1, August, 1971, p. 346.

Christensen, C.L., 1979a, "Test Plan - Bell Canyon Test - WIPP Experimental Program - Borehole Plugging," SAND 79-0739, prepared by Sandia National Laboratories, Albuquerque, New Mexico, for U.S. Department of Energy.

Christensen, C.L., 1979b, "Test Plan - Potash Core Test - WIPP Experimental Program - Borehole Plugging," SAND 79-1306, prepared by Sandia National Laboratories, Albuquerque, New Mexico, for U.S. Department of Energy.

Christensen, C.L. and T.0. Hunter, 1979, "Waste Isolation Pilot Plant (WIPP) Borehole Plugging Program Description," SAND 79-0640, Sandia National Laboratories, Albuquerque, New Mexico.

Christensen, C.L., 1980a, "Borehole Plugging Program Status Report, October 1, 1978 - September 30, 1979," SAND 79-2141, prepared by Sandia National Laboratories, Albuquerque, New Mexico, for the U.S. Department of Energy.

Christensen, C.L., 1980b, "Sandia Borehole Plugging Program for the Waste Isolation Pilot Plant (WIPP)," Paper presented at the Workshop on Borehole and Shaft Plugging, Columbus, Ohio, May 79, 1980, Proceedings pp. 225-231, Report No. SAND80-0390C, Sandia National Laboratories, Albuquerque, New Mexico.

Christensen, C.L., R.D. Statler, and E.W. Peterson, 1980, "Downhole Television (DHTV) Applications in Borehole Plugging," SAND 800459C, prepared by Sandia National Laboratories, Albuquerque, New Mexico, for the U.S. Department of Energy. Also in Borehole and Shaft Plugging, Proceedings of the Workshop on, Columbus, May 7-9, 1980, published by the Organization for Economic CoOperation and Development (OECD), Paris.

Christensen, C.L. and E.W. Peterson, 1981, "The Bell Canyon Test Summary Report," SAND80-1375, prepared by Sandia National Laboratories, Albuquerque, New Mexico, for the U.S. Department of Energy. 
Christensen, C.L., C.W. Gulick, and S.J. Lambert, 1983, "Sealing Concepts for the Waste Isolation Pilot Plant (WIPP) Site," SAND 81-2195 Revised, prepared by Sandia National Laboratories, Albuquerque, New Mexico, for the U.S. Department of Energy.

Cobb, S.L. and J.J.K. Daemen, 1982, "Polyaxial Testing of Borehole Plug Performance," Topical Report to the U.S. Nuclear Regulatory Commission, SAFER Division, Contract NRC-04-78-271, by the Department of Mining and Geological Engineering, University of Arizona, Tucson.

Committee on Radioactive Waste Management, 1978, "Geologic Criteria for Repositories for High-Level Radioactive Wastes," $19+$ vii pp., National Academy of Sciences, Washington, DC, August 3.

Cook, C.W., C.B. Kinabrew, P.L. Lagus, and R.D. Broce, 1980, "Be11 Canyon Test (BCT) Instrumentation Development," pp. 299-320, Borehole and Shaft Sealing, Proceedings of the Workshop, Columbus, May 7-9, 1980, jointly organized by the OECD Nuclear Energy Agency and the U.S. Department of Energy. Published by Organization for Economic Co-Operation and Development (OECD), Paris.

Coons, W.E., D. Meyer, and P.C. Kelsal1, 1982, "Evaluation of Polymer Concrete for Application to Repository Sealing," ONWI-410, Technical Report by D'Appolonia Consulting Engineers, Inc., for Office of Nuclear Waste Isolation, Battelle Memorial Institute, Columbus, Ohio.

Daemen, J.J.K., D.L. South, R.G. Jeffrey, and L.W. Klejbuck, 1979, "Rock Mass Sealing, Annual Report, October 1, 1978 - September 30, 1979," prepared for U.S. Nuclear Regulatory Commission, by Department of Mining and Geological Engineering, University of Arizona, Tucson.

Daemen, J.J.K., D.L. South, W.B. Greer, J.C. Stormont, S.A. Dischler, G.S. Adisoma, N.I. Colburn, K. Fuenkajorn, D.E. Miles, B. Kousari, and J. Bertuca, 1983, "Rock Mass Sealing, Annual Report, June 1, 1982 - May 31, 1983," NUREG/CR-3473, prepared for the U.S. Nuclear Regulatory Commission, Division of Health, Siting and Waste Management, by the Department of Mining and Geological Engineering, University of Arizona, Tucson.

Daemen, J.J.K., W.B. Greer, G.S. Adisoma, K. Fuenkajorn, W.D. Sawyer, Jr., A. Yazdandoost, H. Akgun, and B. Kousari, 1985, "Rock Mass Sealing - Annual Report, June 1, 1983 - May 31, 1984," NUREG/CR4174, prepared for the U.S. Nuclear Regulatory Commission, Division of Radiation Programs and Earth Sciences, by the Department of Mining and Geological Engineering, University of Arizona, Tucson. 
Daemen, J.J.K., W.B. Greer, K. Fuenkajorn, H. Akgun, T.S. Avery, J.R. Williams, A.F. Kimbre1l, A. Schaffer, and B. Kousari, 1986, "Rock Mass Sealing - June 1, 1984 - May 31, 1985," NUREG/CR4642, prepared for the U.S. Nuclear Regulatory Commission, Division of Radiation Programs and Earth Sciences, by the Department of Mining and Geological Engineering, University of Arizona, Tucson.

D'Appolonia Consulting Engineers, Inc., 1979, "The Status of Borehole Plugging \& Shaft Sealing for Geologic Isolation of Radioactive Waste," Report No. ONWI-15, Office of Nuclear Waste Isolation, Battelle Memorial Institute, Columbus, Ohio.

D'Appolonia Consulting Engineers, Inc., 1980a, "Repository Sealing Design Approach - 1979," Report No. ONWI-55, Office of Nuclear Waste Isolation, Battelle Memorial Institute, Columbus, Ohio.

D'Appolonia Consulting Engineers, Inc., 1980b, "Repository Sealing: Evaluation of Materials Research Objectives \& Requirements 1980," ONWI-108, Battelle Memorial Institute, Office of Nuclear Waste Isolation, Columbus, Ohio.

D'Appolonia Consulting Engineers, Inc., 1980c, "Repository Sealing Field Testing Workshop: Proceedings," ONWI-239, prepared for office of Nuclear Waste Isolation, Battelle Memorial Institute, Columbus, Ohio.

D'Appolonia Consulting Engineers, Inc., 1981a, "Draft Report Geotechnical Services for Repository Sealing, FY Summary Report," Prepared for Battelle Memorial Institute, Project Management Division, Office of Nuclear Waste Isolation, Columbus, Ohio.

D'Appolonia Consulting Engineers, Inc., 1981b, "Sealing Considerations for Repository Shafts in Bedded and Dome Salt," ONWI-255, prepared for Office of Nuclear Waste Isolation, Battelle Memorial Institute, Columbus, Ohio.

Davenport, B., 1984, Handbook of Drilling Practices, Gulf Publishing Company, Houston, Texas.

Deju, R.A., 1983, Testimony by Dr. Raul A. Deju, Basalt Waste Isolation Project, before the Subcommittee on Energy Research and Production, Committee on Science and Technology, United States House of Representatives, Washington, DC, March 2, 9:30 am. RHO-BW-SA-293 P, Rockwell Hanford Operations, Hanford, Washington.

De Wiest, R.J., 1965, Geohydrology: John Wiley \& Sons, New York.

Dowding, C.H., and J.F. Labuz, 1982, "Fracturing of Rock with Expansive Cement," pp. 1288-99, Paper 17404, Journal of the Geotechnical Engineering Division, Proceedings of the American Society of Civil Engineers, Vol. 108, No. GT10, October. 
Eilers, L.H., 1973, "Borehole Sealing Final Report," Report No. ORNL/Sub/15966-73/1, Office of Waste Isolation, Oak Ridge National Laboratories, Oak Ridge, Tennessee.

Eilers L.H., 1974, "Sealing AEC \#1 We11, Lyons, Kansas - Final Report: Report No. ORNL/Sub/33542-74/1, Office of Waste Isolation, Oak Ridge National Laboratories, Oak Ridge, Tennessee.

EPA, 1980, "Research Summary: Controlling Hazardous Wastes," Report No. EPA-600/8-80-017, U.S. Environmental Protection Agency.

EPA, 1978, "State of Geological Knowledge Regarding Potential Repositories," Office of Radiation Programs, Environmenta1 Protection Agency, Washington, D.C. Available from National Technical Information Service, Report No. PB-289947.

Fernandez, R., C. McGowen, E. Nolan, R. Moray, and A. Palty, 1976, "Borehole Plugging by Compaction Process," Y-OWI-SUB-7087-1, by Charles Stark Draper Laboratory, Inc., MIT, Cambridge, Mass., for Office of Waste Isolation, Oak Ridge, Tennessee.

Fernandez, J.A. and M.D. Freshley, 1984, "Repository Sealing Concepts for the Nevada Nuclear Waste Storage Investigations Project," SAND 83-1778, prepared by Sandia National Laboratories, Albuquerque, New Mexico, for the U.S. Department of Energy.

Fernandez, J.A., 1985, "Repository Sealing Plan for the Nevada Nuclear Waste Storage Investigations Project Fiscal Years 1984 Through 1990," SAND 84-0910, prepared by Sandia National Laboratories, Albuquerque, New Mexico, for the U.S. Department of Energy.

Fuenkajorn, K. and J.J.K. Daemen, 1984, "Experimental Assessment of Borehole Drilling Damage in Basaltic Rocks," Proceedings of the 25th U.S. Symposium on Rock Mechanics, Northwestern University, Evanston, Illinois, pp. 774-783.

Fuenkajorn, K. and J.J.K. Daemen, 1986a, "Rock-Cement Interface Effects on Borehole Plug Permeability," Waste Management '86 Symposium, Tucson, Arizona, March 2-6, Proceedings, Vol. 2, pp. 251-256.

Fuenkajorn, K. and J.J.K. Daemen, 1986b, "Borehole Drilling Damage in Basaltic Rocks," NUREG/CR-4641, Technical Report to the U.S. Nuclear Regulatory Commission, Division of Radiation Programs and Earth Sciences, by the Department of Mining and Geological Engineering, University of Arizona, Tucson.

Garrett, W.S. and L.T. Campbell Pitt, 1961, "Design and Construction of Underground Bulkheads and Water Barriers," pp. 1283-1299, Discussion pp. 1300-1, Vol. III, Transactions of the Seventh Commonwealth Mining and Metallurgical Congress, South African Institute of Mining and Metallurgy, Johannesburg. 
Greer, W.B. and J.J.K. Daemen, 1987, "Field Testing of Borehole Plug Performance," Technical Report to the U.S. Nuclear Regulatory Commission, Division of Radiation Programs and Earth Sciences, Contract NRC-04-78-271, by the Department of Mining and Geological Engineering, University of Arizona, Tucson. (In preparation)

Grutzeck, M.W., and D.M. Roy, 1985, "Experimental Characterization and Stability of Salt- and Nonsalt-Containing Grouts and Mortars (BCT-IF- and BCT-IFF-Related)," Technical Report BMI/ONWI-568, prepared by Materials Research Laboratory, Pennsylvania State University, for Office of Nuclear Waste Isolation, Battelle Memorial Institute, Columbus, Ohio.

Gulick, C.W., J.A. Boa, Jr., and A.D. Buck, 1980a, "Bell Canyon Test (BCT) - Cement Development Report," SAND 80-0358C, prepared by Sandia Laboratories, Albuquerque, New Mexico for the U.S. Department of Energy. Also published as pp. 277-297, Proceedings, Borehole and Shaft Plugging, Workshop, Columbus, May 7-9, by Organization for Economic Co-Operation and Development, OECD, Paris.

Gulick, C.W., J.A. Boa, Jr., and A.D. Buck, 1980b, "Bell Canyon Test (BCT) - Cement Grout Development Report," SAND 80-1928, prepared by Sandia National Laboratories, Albuquerque, New Mexico for the U.S. Department of Energy.

Gulick, C.W., J.A. Boa, Jr., and A.D. Buck, 1982, "Borehole P1ugging Materials Development Program Report 3," SAND 81-0065, prepared by Sandia National Laboratories, Albuquerque, New Mexico, for the U.S. Department of Energy.

Heineman, R.E., W.A. Carbiener, and S.J. Basham, 1978, "The Technical Program for Establishing the Scientific Basis for Geologic Disposal," DOE Environmental Control Symposium, Washington, DC, Nov. 28-30.

Hodges, F.N., J.E. O'Rourke, and G.J. Anttonen, 1980, "Sealing a Nuclear Waste Repository in Columbia River Basalt: Preliminary Results," pp. 143-160, Borehole and Shaft Sealing, Proceedings of the Workshop, Columbus, May 7-9, 1980, jointly organized by the OECD Nuclear Energy Agency and the U.S. Department of Energy. Published by Organization for Economic Co-Operation and Development (OECD), Paris.

Hoek, E. and E.T. Brown, 1980, Underground Excavations in Rock, The Institution of Mining and Metallurgy, London.

Hunter, T.0., 1980, "Role of Borehole Plugging in the Evaluation of the Waste Isolation Pilot Plant," SAND 80-0502C, prepared by Sandia National Laboratories, Albuquerque, New Mexico, for the U.S. Department of Energy. Also in Borehole and Shaft Plugging, Proceedings of the Workshop on, Columbus, May 7-9, 1980, pp. 
199-215, published by the Organization for Economic Co-Operation and Development (OECD), Paris.

IAEA, 1981, "A Guide to Site Investigations of Repositories for Solid Low- and Intermediate-Level Radioactive Wastes in Rock Cavities," Working Draft for the IAEA Advisory Group Meeting to be Held in Otaniemi, Finland, 22-26 June, 1981. International Atomic Energy Agency.

IAEA, 1980, "Waste Management and Disposal," Report of INFCE Working Group 7, International Nuclear Fuel Cycle Evaluation, Published by the International Atomic Energy Agency, Vienna.

Intera Environmental Consultants, Inc., 1981, "Consequence Assessment of Hydrological Communications Through Borehole Plugs," Contractor Report SAND 81-7164, prepared for Sandia National Laboratories, Albuquerque, New Mexico, November.

International Society for Rock Mechanics, 1978, "Suggested Methods for Determining the Uniaxial Compressive Strength and Deformability of Rock Materials," International Journal of Rock Mechanics and Mining Sciences \& Geomechanics Abstracts, Vol. 16, pp. 135-140.

Irish, E.R., 1980, "Safety Assessment for the Underground Disposal of Radioactive Wastes - The IAEA Programme," pp. 39-43, Radionuclide Release Scenarios for Geologic Repositories, Proceedings of the NEA Workshop, Paris, September 1980. Published by The OECD Nuclear Energy Agency, Paris, 1981.

Ishii, S., K. Hitotsuya, Y. Izume, and K. Soeda, 1982, "Development and Application of Non-explosive Demolition Agent Used Limestone as Main Material," Preprint No. 82-330, First International SMEAIME Fall Meeting, Honolulu, Hawaii, September 4-9, 1982.

IT Corporation, 1984, "Assessment of Crushed Salt Consolidation and Fracture Healing Processes in a Nuclear Waste Repository in Salt," BMI/ONWI-546, prepared for Office of Nuclear Waste Isolation, Battelle Memorial Institute, Columbus, Ohio.

Jaeger, J.C., and N.G.W. Cook, 1976, Fundamentals of Rock Mechanics: Halsted Press, John Wiley \& Sons, Inc., New York.

Jeffrey, R.G., 1980, "Shaft or Borehole Plug-Rock Mechanical Interaction," Topical Report to the U.S. Nuclear Regulatory Commission, SAFER Division, Contract NRC-04-78-271, by the Department of Mining and Geological Engineering, University of Arizona, Tucson.

Johnstone, J.K., R.R. Peters, and P.F. Gnirk, 1984, "Unit Evaluation of Yucca Mountain, Nevada Test Site: Summary Report and Recommendation," SAND 83-0372, prepared for U.S. Dept. of Energy, by Sandia National Laboratories, Albuquerque, NM. 
Kalia, H.N., 1986, "ERG and CRG Review of the Draft of 'Preliminary Test Plan for In Situ Testing From an Exploratory Shaft in Salt October 1983'," BMI/ONWI-591, Technical Report, Office of Nuclear Waste Isolation, Battelle Memorial Institute, Columbus, Ohio, March.

Kelsall, P.C., J.B. Case, D. Meyer, and W.E. Coons, 1982a, "Schematic Designs for Penetration Seals for a Reference Repository in Bedded Salt," Report No. ONWI-405, prepared by D'Appolonia Consulting Engineers, Inc., Albuquerque, New Mexico, for Office of Nuclear Waste Isolation, Battelle Memorial Institute, Columbus, Ohio.

Kelsall, P.C., J.B. Case, and C.R. Chabannes, 1982b, "A Preliminary Evaluation of the Rock Mass Disturbance Resulting from Shaft, Tunnel or Borehole Excavation," ONWI-411, prepared by D'Appolonia Consulting Engineers, Inc., for Office of Nuclear Waste Isolation, Battelle Memorial Institute, Columbus, Ohio.

Kelsa11, P.C., W.E. Coons, and D. Meyer, 1983, "Repository Sealing Program Plan: Repository in Salt," ONWI-414, prepared by D'Appolonia Consulting Engineers, Inc., Albuquerque, New Mexico, for Office of Nuclear Waste Isolation, Battelle Memorial Institute, Columbus, Ohio.

Kelsa11, P.C., J.B. Case, D. Meyer, J.G. Franzone, and W.E. Coons, 1985a, "Schematic Designs for Penetration Seals for a Repository in Richton Dome," BMI/ONWI-562, Technical Report by IT Corporation for Office of Nuclear Waste Isolation, Battelle Memorial Institute, Columbus, Ohio.

Kelsal1, P.C., D. Meyer, J.B. Case, and W.E. Coons, 1985b, "Schematic Designs for Penetration Seals for a Repository in the Paradox Basin," BMI/ONWI-563, Technical Report by IT Corporation for Office of Nuclear Waste Isolation, Battelle Memorial Institute, Columbus, Ohio.

Kelsall, P.C., J.B. Case, W.E. Coons, J.G. Franzone, and D. Meyer, 1985c, "Schematic Designs for Penetration Seals for a Repository in the Permian Basin," BMI/ONWI-564, Technical Report by IT Corporation for Office of Nuclear Waste Isolation, Battelle Memorial Institute, Columbus, Ohio.

Klingsberg, C. and J. Duguid, 1980, "Status of Technology for Isolating High-Level Radioactive Wastes in Geologic Repositories," DOE/TIC 11207 (Draft), U.S. Department of Energy, Office of Waste Isolation, Washington, DC, October.

Klinkenberg, L.J., 1941, "The Permeability of Porous Media to Liquids and Gases," pp. 200-213, Drilling and Production Practice, Presented at 11th Mid-year Meeting, Tulsa, American Petroleum Institute. 
Kocher, D.C., A.L. Sjoreen, and C.S. Bard, 1983, "Uncertainties in Geologic Disposal of High-Level Wastes - Groundwater Transport of Radionuclides and Radiological Consequences," NUREG/CR-2506; ONRL-5838; 214 + xiv pp., prepared for the U.S. Nuclear Regulatory Commission by Oak Ridge National Laboratory, Oak Ridge, Tennessee, July.

Koplik, C.M., D.L. Pentz, and R. Talbot, 1979, "Information Base for Waste Repository Design, Volume I - Borehole and Shaft Sealing," Report No. NUREG/CR-0495, TR-1210-1, Division of Waste Management, Office of Nuclear Material Safety and Safeguards, U.S. Nuclear Regulatory Commission, Washington, D.C.

Krumhans1, J., 1986, "Observations Regarding the Stability of Bentonite Backfill in a High-Level Waste (HLW) Repository in Rock Salt," SAND 83-1293, prepared by Sandia National Laboratories, Albuquerque, New Mexico, for the U.S. Department of Energy •

Lambe, W.T., and R.B. Whitman, 1969, Soil Mechanics: John Wiley \& Sons, New York, 553 pp.

Lambert, S.J., 1980a, "Recommended Analysis P1an for the Borehole Plugging Program Potash Core Test," SAND 80-0812, prepared by Sandia National Laboratories, Albuquerque, New Mexico, for the U.S. Department of Energy.

Lambert, S.J., 1980b, "A Strategy for Evaluating the Long-Term Stability of Hole-Plugging Materials in Their Geological Environments," SAND 80-0359C, prepared by Sandia National Laboratories, Albuquerque, New Mexico, for the U.S. Department of Energy. Also in Borehole and Shaft Plugging, Proceedings of the Workshop on, Columbus, May 7-9, 1980, pp. 343-352, published by the Organization for Economic Co-Operation and Development (OECD), Paris.

Levine, D.C., E.W. Thomas, H.P. Bezner, and G.C. Tolle, 1980, "How to Prevent Annular Gas Flow Following Cementing Operations," World Oil, Vo1. 191, No. 5, p. 85-94, October.

Lingle, R., K.L. Stanford, P.E. Peterson, and S.F. Woodhead, 1982, "Wellbore Damage Zone Experimental Determination," Report No. ONWI-349, Office of Nuclear Waste Isolation, Battelle Memorial Institute, Columbus, Ohio.

Lipman, P.W., and E.J. McKay, 1965, "Geologic Map of the Topopah Spring SW Quadrangle, Nye County, Nevada," GQ-439, U.S. Geological Survey.

Martin, R.T., 1975, "Feasibility of Sealing Boreholes with Compacted Natural Earthen Material," MIT Research Report 75-28. Report No. ORNL/SUB-3960/2, Office of Waste Isolation, Oak Ridge National Laboratories, Oak Ridge, Tennessee. 
Mather, K., 1964, "Cement-Aggregate Reaction: What is the Problem?," pp. 83-85, Engineering Geology Case Histories, No. 2, P.D. Trask, ed., The Geological Society of America, Inc.

Mathis, S.P. and J.J.K. Daemen, 1982, "Rock Mass Sealing - Borehole Wa11 Damage Induced by Drilling: An Assessment of Diamond and Percussion Drilling Effects," Topical Report to the U.S. Nuclear Regulatory Commission, SAFER Division, by the Department of Mining and Geological Engineering, University of Arizona, Tucson.

McDaniel, E.W., 1980, "Cement Technology for Borehole Plugging: An Interim Report on Permeability of Cementitious Solids," Report No. ORNL/TM-7092, Oak Ridge National Laboratories, Oak Ridge, Tennessee.

Meyer, D. and J.J. Howard, eds., 1983, "Evaluation of Clays and Clay Minerals for Application to Repository Sealing," ONWI-486, Technical Report by D'Appolonia Consulting Engineers, Inc., and Material Research Laboratory, The Pennsylvania State University, for Office of Nuclear Waste Isolation, Battelle Memorial Institute, Columbus, $\mathrm{OH}$.

Moller, D.W., H. Minch, J.P. Welsh, and R.M. Rubright, 1983, "Pressure Grouting to Control Ground Water in Fractured Granite Rock, Helms Pumped Storage Project," American Concrete Institute Fall Convention, Kansas City, Sept. 25-30. Published in Innovative Cement Grouting, Publication SP-83, American Concrete Institute, Detroit, 1984.

Moore, J. G., M.T. Morgan, E.W. McDaniel, H.B. Greene, and G.A. West, 1979, "Cement Technology for Plugging Boreholes in Radioactive Waste Repository Sites: Progress Report for the Period October 1, 1977, to September 30, 1978," ORNL-5524, Oak Ridge National Laboratory, Oak Ridge, Tennessee.

National Coal Board, 1982, "The Treatment of Disused Mine Shafts and Adits," Mining Department, National Coal Board, London, 88 pp.

National Research Council, 1983, "A Study of the Isolation System for Geologic Disposal of Radioactive Wastes," Waste Isolation Systems Pane1, Board of Radioactive Waste Management, Commission on Physical Sciences, Mathematics, and Resources, National Academy Press, Washington, DC.

Neville, A. M., 1973, Properties of Concrete: Second (metric) Edition, Pitman Publishing Company, London.

Neville, A.M., 1981, Properties of Concrete; Third Edition, Pitman Publishing Company, London.

Neuman, S.P. and P.A. Witherspoon, 1970, "Finite Element Method of Analyzing Steady Seepage with a Free Surface," Water Resources Research, Vol. 6, No. 3, pp. 889-897. 
Neuman, S.P., 1976, "User's Guide for FREESURF I," Department of Hydrology and Water Resources, University of Arizona, Tucson.

Neuman, S.P., E.S. Simpson, P.A. Hsieh, J.W. Jones, and C.L. Winter, 1985, "Statistical Analysis of Hydraulic Test Data from Fractured Crystalline Rock near Oracle, Arizona," pp. 289-300, Vo1. XVII, Part 1, Proceedings, Hydrogeology of Rocks at Low Permeability, Tucson, Arizona, Congress, Internationa1 Association of Hydrogeologists.

OECD, 1980, Borehole and Shaft Plugging, Proceedings of the Workshop on, organized by the OECD Nuclear Energy Agency and the U.S. Department of Energy, Columbus, Ohio. Published by The OECD Nuclear Energy Agency, Paris.

OECD, 1984, Geological Disposal of Radioactive Waste, An overview of the current status of understanding and development. An Experts' Report sponsored by the Commission of the European Communities and the OECD Nuclear Energy Agency. Published by Organization for Economic Co-Operation and Development, Paris, February.

Olsen, J.M. and R.T. Martin, 1976, "Feasibility of Sealing Boreholes with Compacted Natural Earthen Materials," Vol. III, MIT Research Report R 76-26, ORNL/SUB-3960, Office of Waste Isolation, Oak Ridge.

Olsen, J.M., 1978, "Lateral Stresses around a Borehole in Shale During Plugging," Ph.D. Thesis, Massachusetts Institute of Technology, Cambridge, MA.

Olsen, J.M. and R.T. Martin, 1980, "Feasibility of Sealing Boreholes with Compacted Earth to Protect Underground Nuclear Waste Repositories," ASCE Preprint 80-166, American Society of Civil Engineers Convention and Exposition, Portland, Oregon.

O1sen, J.M., 1981, "The Effect of Lateral Stress Changes Around a Borehole in Shale During Plugging on Plug Adequacy," pp. 819824 , Vol. 2, Proceedings of the International Symposium on Weak Rock, Tokyo, September 21-24, K. Akai, M. Hayashi, and Y. Nishimatsu, eds., A.A. Balkema, Rotterdam.

Oyler, D.C., 1984, "Use of Sodium Silicate Gel Grout for Plugging Horizontal Methane-Drainage Holes," U.S. Bureau of Mines Report of Investigations RI 8843.

Paterson, M.S., 1978, Experimental Rock Deformation - The Brittle Field: Springer-Verlag, New York, p. 80 .

Pedersen, A. and K.E. Lindstrom-Jensen, 1980, "Selection of Release Scenarios for a Danish Waste Repository in a Salt Dome," pp. 181-196, Radioactive Release Scenarios for Geologic Repositories, Proceedings of the NEA Workshop, Paris, September 1980. Published by The OECD Nuclear Energy Agency, Paris, 1981. 
Peterson, E.W. and C.L. Christensen, 1980, "Analysis of Bell Canyon Test Results," SAND $80-7044 \mathrm{C}$, prepared by Sandia National Laboratories, Albuquerque, New Mexico, for the U.S. Department of Energy. Also in Borehole and Shaft Plugging, Proceedings of the Workshop on, pp. 247-275, Columbus, May 7-9, 1980, published by the Organization for Economic Co-Operation and Development (OECD), Paris.

Piper, A.M., 1969, "Disposal of Liquid Wastes by Injection Underground Neither Myth nor Millenium," U.S. Geological Survey Circular $631,15 \mathrm{pp}$.

Polatty, J.M. and R.A. Bendinelli, 1962, "Project Gnome - Design, Testing, and Field Pumping of Grout Mixtures," Miscellaneous Paper No. 6-514, U.S. Army Corps of Engineers Waterways Experiment Station, Vicksburg, Mississippi.

Polatty, J.M. and R.A. Bendine1li, 1965, "Project Dribble, Salmon Event - Laboratory Design, Analysis, and Field Control of Grouting Mixtures Employed at a Nuclear Test in Salt," Miscellaneous Paper No. 6-773, U.S. Army Engineer Waterways Experiment Station, Corps of Engineers, Vicksburg, Mississippi.

Powers, T.C., 1958, "Structure and Physical Properties of Hardened Portland Cement Paste," Journal of the American Ceramic Society, Vol. 41, No. 1, January, 1958, pp. 38-48.

Pugh, T.D., 1967, "What to Consider When Cementing Deep Wells," World 0il, September, 1967, p. 52.

Pusch, R., 1983, "Borehole Sealing for Underground Waste Storage", Journal of the Geotechnical Engineering Division, ASCE, Vol. 104, No. 1, pp. 113-119, January.

Rennick, G. E., J. Pasini, III, F.E. Armstrong, and J.R. Abrams, 1972, "Demonstration of Safety Plugging of Oil Wells Penetrating Appalachian Coal Mines": U.S. Bureau of Mines Technical Progress Report, July, 1972.

Rhoderick, J.E., 1981, "Examination of Sample of Grout after 63 Years Exposure Underground," Report No. ONWI-248, Office of Nuclear Waste Isolation, Battelle Memorial Institute, Columbus, Ohio. Miscellaneous Paper SL-81-6, prepared by Structures Laboratory, U.S. Army Engineer Waterways Experiment Station, Vicksburg, Mississippi.

Rhoderick, J.E., and Buck, A.D., 1981a, "Examination of Simulated Borehole Specimens" Report No. ONWI-247, Office of Nuclear Waste isolation, Battelle Memorial Institute, Columbus, Ohio. Sandia National Laboratories SAND 81-7109, Albuquerque, New Mexico. Miscellaneous Paper USAE-WES SL-78-1, prepared by Structures Laboratory, U.S. Army Engineer Waterways Experiment Station, Vicksburg, Mississippi. 
Rhoderick, J. E., and A.D. Buck, 1981b, "Petrographic Examination of Several Four-Year-01d Laboratory Developed Grout Mixtures," Report No. ONWI-342, Office of Nuclear Waste Isolation, Battelle Memorial Institute, Columbus, Ohio. USAE-WES C-78-1, prepared by Structures Laboratory, U.S. Army Engineer Waterways Experiment Station, Vicksburg, Mississippi.

Rhoderick, J.E., G.S. Wong, and A.D. Buck, 1981, "Examination of Samples of Bell Canyon Test 1-FF Grout," ONWI-246, prepared by the Structures Laboratory of the U.S. Army Engineer Waterways Experiment Station (Miscellaneous Paper USAE-WES SL-81-5) for the Office of Nuclear Waste Isolation, Battelle Memorial Institute, Columbus, Ohio, and for Sandia National Laboratories (SAND 81-7110), Albuquerque, New Mexico.

Roark, R.J., and W.C. Young, 1975, Formulas for Stress and Strain, Fifth Edition: McGraw-Hill Book Company, San Francisco.

Rockwell Internationa1, 1979, "Geologic Studies of the Columbia Plateau, A Status Report," Basalt Waste Isolation Project, Geosciences Group, Rockwell Hanford Operations, Energy Systems Group, Richland, WA, Report No. RHO-BWI-ST-4 .

Roy, D.M., G.W. Brindley, J.V. Biggers, G.J. McCarthy, H.A. McKinstry, B. Voight, W.B. White, B.E. Scheetz, S. Komarneni, and J. Perison, 1977, "Borehole Cement and Rock Properties Studies," Report No. Y/OWI/Sub-4091/6, Office of Waste Isolation, Oak Ridge National Laboratory, Oak Ridge, Tennessee. Prepared by Materials Research Laboratory, The Pennsylvania State University, University Park, PA 16802.

Roy, D.M., M.W. Grutzeck, and P.H. Licastro, 1979, "Evaluation of Cement Borehole Plug Longevity," Technica1 Report ONWI-30, prepared by Materials Research Laboratory, The Pennsylvania State University, for Office of Nuclear Waste Isolation, Battelle Memorial Institute, Columbus, Ohio.

Roy, D.M., M.W. Grutzeck, and K. Mather, 1980, "PSU/WES Interlaboratory Comparative Methodology Study of an Experimental Cementitious Repository Seal Material," Report No. ONWI-198, Office of Nuclear Waste Isolation, Battelle Memorial Institute, Columbus, Ohio.

Roy, D.M., and C.A. Langton, 1982, "Longevity of Borehole and Shaft Sealing Materials: Characterization of Cement-Based Ancient Building Materials," Report No. ONWI-202, prepared by The Pennsylvania State University for Office of Nuclear Waste Isolation, Battelle Memorial Institute, Columbus, Ohio.

Roy, D.M., M.W. Grutzeck, K. Mather, and A.D. Buck, 1982, "PSU/WES Interlaboratory Comparative Methodology Study of an Experimental Cementitious Repository Seal Material," Miscellaneous Paper SL81-2, Structures Laboratory, Waterways Experiment Station, 
Vicksburg, Mississippi. Also ONWI-324, Office of Nuclear Waste Isolation, Battelle Memorial Institute, Columbus, Ohio.

Roy, D.M., and C.A. Langton, 1983, "Characterization of Cement-Based Ancient Building Materials in Support of Repository Seal Materials Studies," BMI/ONWI-523, prepared by Materials Research Laboratory, The Pennsylvania State University, for Office of Nuclear Waste Isolation, Battelle Memorial Institute, Columbus, Ohio.

Roy, D.M., M.W. Grutzeck, and L.D. Wakeley, 1983, "Selection and Durability of Seal Materials for a Bedded Salt Repository: Preliminary Studies," ONWI-479, Technical Report by Materials Research Laboratory, The Pennsylvania State University, for office of Nuclear Waste Isolation, Battelle Memorial Institute, Columbus, Ohio.

Roy, D.M., M.W. Grutzeck, and L.D. Wakeley, 1985, "Salt Repository Seal Materials: A Synopsis of Early Cementitious Materials Development," Technical Report BMI/ONWI-536, prepared by Materials Research Laboratory of The Pennsylvania State University, for Office of Nuclear Waste Isolation, Battelle Memorial Institute, Columbus, Ohio.

Sarkar, A.K., M.W. Barnes, and D.M. Roy, 1980, "Longevity of Borehole and Shaft Sealing Materials: 1. Thermodynamic Properties of Cements and Related Phases Applied to Repository Sealing," ONWI201, prepared by Materials Research Laboratory, The Pennsylvania State University, for Office of Nuclear Waste Isolation, Battelle Memorial Institute, Columbus, Ohio.

Sawyer, W.D., Jr., and J.J.K. Daemen, 1986, "Bentonite Borehole Sealing Performance," Technical Report to the U.S. Nuclear Regulatory Commission, Division of Radiation Programs and Earth Sciences, NRC-04-78-271, by the Department of Mining and Geological Engineering, University of Arizona, Tucson. (In preparation)

Schaffer, A. and J.J.K. Daemen, 1986, "An Experimental Assessment of the Effectiveness of Rock Fracture Grouting," Technical Report to the U.S. Nuclear Regulatory Commission, Division of Radiation Programs and Earth Sciences, Contract NRC-04-78-271, by the Department of Mining and Geological Engineering, University of Arizona, Tucson. (In preparation)

Scheetz, B.E., P.H. Licastro, and D.M. Roy, 1986a, "A Ful1-Scale Borehole Sealing Test in Salt Under Simulated Downhole Conditions - Volume 2," BMI/ONWI-573(2), prepared by Materials Research Laboratory, The Pennsylvania State University, for Office of Nuclear Waste Isolation, Battelle Memorial Institute, Columbus, Ohio.

Scheetz, B.E., P.H. Licastro, and D.M. Roy, 1986b, "A Full-Scale Borehole Sealing Test in Anhydrite Under Simulated Downhole 
Conditions - Volume 2," BMI/ONWI-581(2), prepared by Materials Research Laboratory, The Pennsylvania State University, for Office of Nuclear Waste Isolation, Battelle Memorial Institute, Columbus, Ohio.

Schneider, K.J., and A.M. Platt, 1974, "Advanced Waste Management Studies, High-Level Radioactive Waste Disposal Alternatives," BNWL-1900, Battelle Pacific Northwest Laboratory, Richland, Washington.

Science Applications, Inc., 1981, "Tabulation of Waste Isolation Computer Models," ONWI-78, prepared for Office of Nuclear Waste Isolation, Battelle Memorial Institute, Columbus, Ohio.

Scully, L. W. and A.J. Rothman, 1982, "Repository and Engineering Barriers Design," DOE/NWTS-30, Proc. of the 1982 National Waste Terminal Storage Information Meeting, U.S. Department of Energy, p. 15.

Smith, D.K., 1976, Cementing: Society of Petroleum Engineers of AIME, 184 pp.

Smith, D.K., 1986, "Primary Cementing," Chapter 12, pp. 400-460, of Drilling Practices Manual, Second Edition, by P.L. Moore, PennWell Publishing Company, Tulsa, Oklahoma.

Smith, M.J. and S.C. McCarel, 1980, "Basalt Waste Isolation Project Borehole Plugging Studies - An Overview," pp. 131-141, Borehole and Shaft Sealing, Proceedings of the Workshop, Columbus, May 79 , 1980, jointly organized by the OECD Nuclear Energy Agency and the U.S. Department of Energy. Published by Organization for Economic Co-Operation and Development (OECD), Paris.

South, D.L., W.B. Greer, N.I. Colburn, B. Kousari, R.G. Jeffrey, C.A. Wakely, and J.J.K. Daemen, 1982, "Rock Mass Sealing: Annual Report, June 1, 1981 - May 31, 1982," prepared for U.S. Nuclear Regulatory Commission, SAFER Division, by Department of Mining and Geological Engineering, University of Arizona.

South, D.L., 1980, "Borehole Sealing with Clay/Considerations in Clay Mineral Stability," Topical Report prepared for U: S. Nuclear Regulatory Commission by Department of Mining and Geological Engineering, University of Arizona, Tucson.

South, D.L., 1979, "Well Cementing," Topical Report prepared for SAFER Division, U. S. Nuclear Regulatory Commission by Department of Mining and Geological Engineering, University of Arizona, Tucson.

Sowers, G.B. and G.F. Sowers, 1970, Introductory Soil Mechanics and Foundations: MacMillan Publishing Co., Inc., New York. 
Spotts, M.F., 1971, Design of Machine Elements: Prentice-Hal1, Englewood Cliffs, New Jersey.

Statler, R.D., 1980, "Bell Canyon Test - Field Preparation and Operation," pp. 233-245, Proceedings, Borehole and Shaft Plugging Workshop, Columbus, Ohio, May. Published by OECD, Paris. Also published as SAND 80-0458C, Sandia National Laboratories, Albuquerque, New Mexico.

Stormont, J.C. and J.J.K. Daemen, 1983, "Axia1 Strength of Cement Borehole Plugs in Granite and Basalt," NUREG/CR-3594, Topical Report to the U.S. Nuclear Regulatory Commission, Division of Radiation Programs and Earth Sciences, by the Department of Mining and Geological Engineering, University of Arizona, Tucson.

Stormont, J.C., 1984, "Plugging and Sealing Program for the Waste Isolation Pilot Plant (WIPP)," SAND 84-1057, prepared by Sandia National Laboratories, Albuquerque, New Mexico, for the U.S. Department of Energy.

Stormont, J.C., 1986a, "In Situ Seal Tests at the Waste Isolation Pilot Plant (WIPP)," pp. 167-i76, Vol. 2, Proceedings, R.G. Post, Editor, Waste Management '86, Tucson, Arizona, March 2-6.

Stormont, J.C., Technical Editor, 1986b, "Development and Implementation: Test Series A of the Small-Scale Seal Performance Tests," Sandia Report SAND 85-2602, prepared by Sandia National Laboratories, Albuquerque, New Mexico, for the U.S. Department of Energy.

Sultan, H.A., 1979, "Chemical Grouting for Rock Mass Sealing," Topical Report prepared for SAFER Division, U.S. Nuclear Regulatory Commission, by the Department of Mining and Geological Engineering, University of Arizona, Tucson.

Taylor, C.L., G.J. Anttonen, J.E. O'Rourke, and M.R. Niccum, 1979, "Borehole Plugging of Man-Made Accesses to a Basalt Repository: A Preliminary Study": RHO-BWI-C-49, Rockwell Hanford Operations, Richland, Washington.

Taylor, C.L., J.E. O'Rourke, D. Allirot, and K. O'Connor, 1980, "Preconceptual Systems and Equipment for Plugging of Man-Made Accesses to a Repository in Basalt," RHO-BWI-C-67, Rockwell International, Rockwell Hanford Operations, Energy Systems Group, Richland, WA 99352.

Timoshenko, S., 1976, Strength of Materials, Part II: Advanced Theory and Problems: Robert E. Krieger Publishing Company, Huntington, New York, 572 pp.

Torres, T.M., 1986, "Two-Dimensional Axisymmetric and Plane Strain Scoping Calculations for the Sma11-Scale Seal Performance Test, 
Test Series A," SAND 86-0488, prepared by Sandia National Laboratories, Albuquerque, New Mexico, for the U.S. Department of Energy.

U.S. Department of Energy, 1979, "Management of Commercially Generated Radioactive Waste," DOE/EIS-0046-D, Vo1. 1 of 2, Draft Environmental Impact Statement, Washington, DC, April.

U.S. Department of Energy, 1982, "NWTS Program Criteria for Mined Geologic Disposal of Nuclear Waste: Repository Performance and Development Criteria," DOE/NWTS-33(3), Office of NWTS Integration, Battelle Memorial Institute, Columbus, Ohio, July, Public Draft.

U.S. Department of Energy, 1983, "Summary of the Results of the Evaluation of the WIPP Site and Preliminary Design Validation Program," WIPP-DOE-161, Waste Isolation Pilot Plant, Albuquerque, New Mexico, March.

U.S. Department of Energy, 1984, "Draft Environmental Assessment Reference Repository Location, Hanford Site, Washington," DOE/RW-0017, Office of Civilian Radioactive Waste Management.

U.S. Department of Energy, 1986, "Recommendation by the Secretary of Energy of Candidate Sites for Site Characterization for the First Radioactive-Waste Repository," DOE/S-0048, Office of Civilian Radioactive Waste Management, Washington, DC, May.

U.S. Environmental Protection Agency, 1986, "Environmenta1 Standards and Federal Radiation Protection Guidance for Management and Disposal of Spent Nuclear Fuel, High-Level and Transuranic Radioactive Wastes," 40 CFR 191, Federal Register, Final Rule.

U.S. Nuclear Regulatory Commission, 1983, "Disposal of High-Level Radioactive Wastes in Geologic Repositories," Final Rule 10 CRF 60, Federal Register, Vol. 48, No. 120, June 30.

U.S. Nuclear Regulatory Commission, 1985, "Disposal of High-Leve1 Radioactive Wastes in Geologic Repositories," Final Rule, Unsaturated Zone Amendment, Federal Register, Vol. 50, No. 140, pp. 29641-8, Monday, July 22.

Vaughan, P.R., 1969, "A Note on Sealing Piezometers in Boreholes," Geotechnique, Vol. 19, No. 3, pp. 405-413.

Wakeley, L.D., D.M. Roy, and M.W. Grutzeck, 1981, "Experimental Studies of Seal Materials for Potential Use in a Los Medanos-Type Bedded Salt Repository," Technical Report No. ONWI-325, prepared by the Materials Research Laboratory, The Pennsylvania State University, for Office of Nuclear Waste Isolation, Battelle Memorial Institute, Columbus, Ohio. 
Wakeley, L.D. and D.M. Roy, 1985, "Cementitious Mixtures for Sealing Evaporative and Clastic Rocks in a Radioactive-Waste Repository," Miscellaneous Paper SL-85-16, prepared by Structures Laboratory, Department of the Army, Waterways Experiment Station, Vicksburg, Mississippi, for Department of Energy, Columbus, Ohio.

Wakeley, L.D. and D.M. Roy, 1986, "Nature of the Interfacial Region Between Cementitious Mixtures and Rocks from the Palo Duro Basin and Other Seal Components," BMI/ONWI-580, prepared by Materials Research Laboratory, The Pennsylvania State University, for Office of Nuclear Waste Isolation, Battelle Memorial Institute, Columbus, Ohio.

Zeuch, D.H., D.J. Holcomb, and H.S. Lauson, 1985, "Analysis of Consolidation of Granulated Rocksalt Using a Plastic Flow Model for Isostatic Hot-Pressing," Sandia Report SAND 84-1106, prepared by Sandia National Laboratories for the U.S. Department of Energy. 
APPENDIX A

TEST RESULTS 
Table A.1 Test Results for Sample CG-101

\begin{tabular}{|c|c|c|c|c|c|c|c|c|c|}
\hline late & $\begin{array}{l}\text { Elapsed } \\
\text { Time } \\
\text { (min) }\end{array}$ & $\begin{array}{l}\text { Axial } \\
\text { Stress } \\
\text { (MPa) }\end{array}$ & $\begin{array}{l}\text { Confin- } \\
\text { ing } \\
\text { Stress } \\
\text { (MPa) }\end{array}$ & $\begin{array}{l}\text { Top } \\
\text { Pres- } \\
\text { sure } \\
\text { (MPa) }\end{array}$ & $\begin{array}{c}\text { Bottom } \\
\text { Pres- } \\
\text { sure } \\
\text { (MPa) }\end{array}$ & $\begin{array}{l}\text { Flow Rate } \\
\text { In } \\
\left(x 10^{-3}\right. \\
\mathrm{cc} / \mathrm{min})\end{array}$ & $\begin{array}{l}\text { Flow Rate } \\
\text { Out } \\
\left(x 10^{-3}\right. \\
\mathrm{cc} / \mathrm{min})\end{array}$ & $\begin{array}{c}\text { Mass } \\
\text { Balance } \\
(\%)\end{array}$ & Notes \\
\hline
\end{tabular}

Tests on Rock Bridge

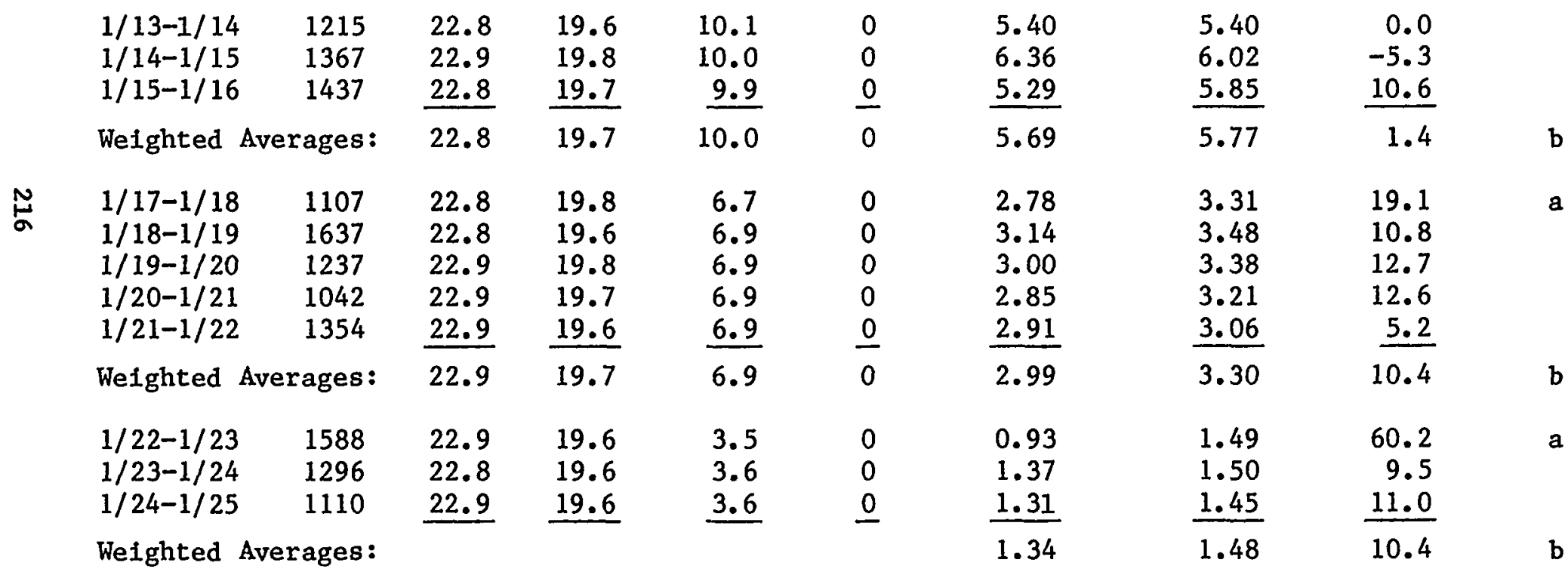

Tests on Cement 1 Plug (poured at $3: 40 \mathrm{pm}, 1 / 25 / 82$ )

$\begin{array}{rrrrrrrrrr}2 / 5-2 / 6 & 1203 & 23.0 & 19.9 & 10.1 & 0 & 6.44 & 12.38 & 92.2 & \text { a } \\ 2 / 6-2 / 7 & 1678 & 22.9 & 19.9 & 10.1 & 0 & 6.23 & 4.83 & -22.5 & \\ 2 / 7-2 / 8 & 1325 & 23.0 & 19.7 & 10.0 & 0 & 5.71 & 4.20 & -26.4 & \\ 2 / 8-2 / 9 & 1342 & 23.0 & 19.6 & 10.0 & 0 & 5.18 & 4.02 & -22.4 & \\ 2 / 9 & 151 & 23.0 & 19.6 & 10.1 & 0 & 5.17 & 3.05 & -41.0 & \end{array}$


Table A.1 Test Results for Sample CG-101--Continued

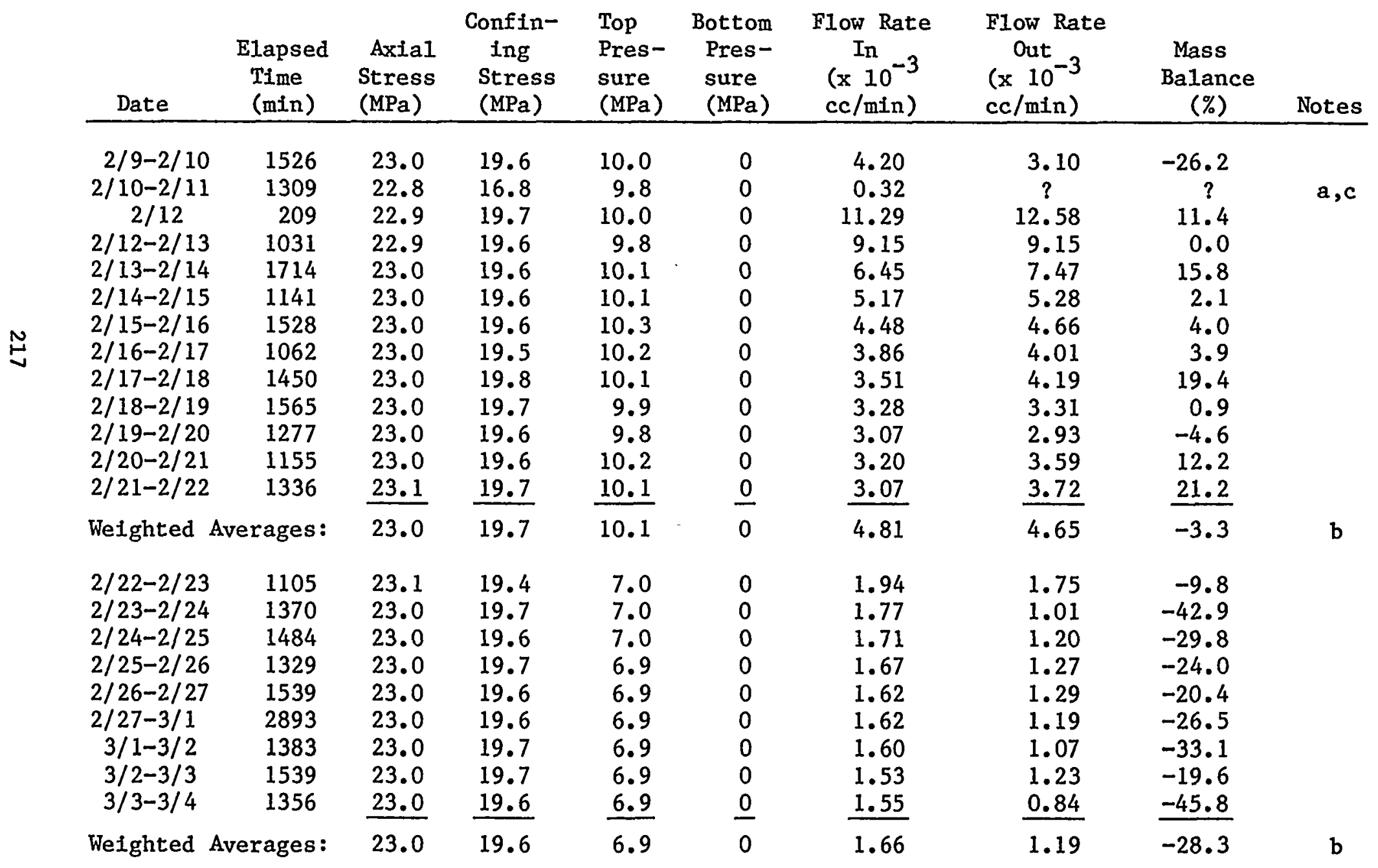


Table A.1 Test Results for Sample CG-101--Continued

\begin{tabular}{|c|c|c|c|c|c|c|c|c|c|}
\hline Date & $\begin{array}{l}\text { Elapsed } \\
\text { Time } \\
\text { (min) }\end{array}$ & $\begin{array}{l}\text { Axial } \\
\text { Stress } \\
\text { (MPa) }\end{array}$ & $\begin{array}{l}\text { Confin- } \\
\text { Ing } \\
\text { Stress } \\
\text { (MPa) } \\
\end{array}$ & $\begin{array}{l}\text { Top } \\
\text { Pres - } \\
\text { sure } \\
\text { (MPa) }\end{array}$ & $\begin{array}{c}\text { Bottom } \\
\text { Pres- } \\
\text { sure } \\
\text { (MPa) }\end{array}$ & $\begin{array}{l}\text { Flow Rate } \\
\text { In } \\
\left(\times 10^{-3}\right. \\
\mathrm{cc} / \mathrm{min})\end{array}$ & $\begin{array}{l}\text { Flow Rate } \\
\text { Out } \\
\left(\times 10^{-3}\right. \\
\mathrm{cc} / \mathrm{min})\end{array}$ & $\begin{array}{c}\text { Mass } \\
\text { Balance } \\
(\%)\end{array}$ & Notes \\
\hline $\begin{array}{c}3 / 4-3 / 5 \\
3 / 5-3 / 6 \\
3 / 6-3 / 8 \\
3 / 8-3 / 9 \\
3 / 9-3 / 11 \\
3 / 11-3 / 12 \\
3 / 12-3 / 13 \\
3 / 13-3 / 15 \\
3 / 15-3 / 16\end{array}$ & $\begin{array}{l}1449 \\
1542 \\
2875 \\
1429 \\
2872 \\
1692 \\
1237 \\
2806 \\
1519\end{array}$ & $\begin{array}{l}23.0 \\
22.9 \\
22.9 \\
22.9 \\
22.9 \\
22.9 \\
22.9 \\
22.9 \\
22.9 \\
\end{array}$ & $\begin{array}{l}19.5 \\
19.6 \\
19.6 \\
19.5 \\
19.5 \\
19.1 \\
19.6 \\
19.6 \\
19.6 \\
\end{array}$ & $\begin{array}{l}3.4 \\
3.6 \\
3.5 \\
3.5 \\
3.5 \\
3.6 \\
3.6 \\
3.4 \\
3.5 \\
\end{array}$ & $\begin{array}{l}0 \\
0 \\
0 \\
0 \\
0 \\
0 \\
0 \\
0 \\
0 \\
\end{array}$ & $\begin{array}{l}0.14 \\
0.71 \\
0.65 \\
0.69 \\
0.66 \\
0.67 \\
0.65 \\
0.56 \\
0.49 \\
\end{array}$ & $\begin{array}{r}0.01 \\
-0.08 \\
0.02 \\
0.02 \\
0.52 \\
0.44 \\
0.61 \\
0.35 \\
0.49 \\
\end{array}$ & $\begin{array}{r}-92.9 \\
- \\
-96.9 \\
-97.1 \\
-21.2 \\
-34.3 \\
-6.2 \\
-37.5 \\
0.0 \\
\end{array}$ & $\begin{array}{c}a \\
a, d \\
a \\
a\end{array}$ \\
\hline \multicolumn{2}{|c|}{ Weighted Averages: } & 22.9 & 19.5 & 3.5 & 0 & 0.61 & 0.47 & -23.0 & b \\
\hline $\begin{array}{l}3 / 16-3 / 17 \\
3 / 17-3 / 18 \\
3 / 18-3 / 19 \\
3 / 19-3 / 20\end{array}$ & $\begin{array}{l}1443 \\
1201 \\
1689 \\
1255\end{array}$ & $\begin{array}{l}23.0 \\
23.0 \\
23.0 \\
23.0 \\
\end{array}$ & $\begin{array}{l}19.6 \\
19.6 \\
19.6 \\
19.7 \\
\end{array}$ & $\begin{array}{r}9.9 \\
10.1 \\
9.9 \\
10.1 \\
\end{array}$ & $\begin{array}{l}0 \\
0 \\
0 \\
0 \\
\end{array}$ & $\begin{array}{r}14.16 \\
3.18 \\
2.57 \\
2.62 \\
\end{array}$ & $\begin{array}{l}? \\
3.27 \\
2.54 \\
2.83 \\
\end{array}$ & $\begin{array}{r}? \\
2.8 \\
-1.2 \\
8.0 \\
\end{array}$ & $a, f$ \\
\hline \multicolumn{2}{|c|}{ Weighted Averages: } & 23.0 & 19.6 & 10.0 & 0 & 2.76 & 2.84 & 2.9 & b \\
\hline $\begin{array}{l}3 / 20-3 / 22 \\
3 / 22-3 / 23\end{array}$ & $\begin{array}{l}2797 \\
1540\end{array}$ & $\begin{array}{l}23.0 \\
23.0 \\
\end{array}$ & $\begin{array}{l}19.2 \\
19.6 \\
\end{array}$ & $\begin{array}{l}7.0 \\
7.1 \\
\end{array}$ & $\begin{array}{l}0 \\
\underline{0}\end{array}$ & $\begin{array}{l}1.51 \\
1.43 \\
\end{array}$ & $\begin{array}{l}1.58 \\
1.36 \\
\end{array}$ & $\begin{array}{r}4.6 \\
-4.9 \\
\end{array}$ & \\
\hline \multicolumn{2}{|c|}{ Weighted Averages: } & 23.0 & 19.3 & 7.0 & 0 & 1.48 & 1.50 & 1.4 & b \\
\hline $\begin{array}{l}3 / 23-3 / 24 \\
3 / 24-3 / 25\end{array}$ & $\begin{array}{l}1451 \\
1020\end{array}$ & $\begin{array}{l}23.0 \\
22.9\end{array}$ & $\begin{array}{l}19.5 \\
19.6\end{array}$ & $\begin{array}{l}3.4 \\
3.4\end{array}$ & $\begin{array}{l}0 \\
0\end{array}$ & $\begin{array}{l}0.56 \\
0.68\end{array}$ & $\begin{array}{l}0 \\
?\end{array}$ & $\begin{array}{c}-100.0 \\
?\end{array}$ & $\begin{array}{c}a \\
a, g\end{array}$ \\
\hline
\end{tabular}


Table A.1 Test Results for Sample CG-101--Continued

\begin{tabular}{|c|c|c|c|c|c|c|c|c|c|}
\hline Date & $\begin{array}{c}\text { Elapsed } \\
\text { Time } \\
\text { (min) }\end{array}$ & $\begin{array}{l}\text { Axial } \\
\text { Stress } \\
(\mathrm{MPa}) \\
\end{array}$ & $\begin{array}{l}\text { Confin- } \\
\text { ing } \\
\text { Stress } \\
\text { (MPa) } \\
\end{array}$ & $\begin{array}{l}\text { Top } \\
\text { Pres- } \\
\text { sure } \\
\text { (MPa) } \\
\end{array}$ & $\begin{array}{c}\text { Bottom } \\
\text { Pres- } \\
\text { sure } \\
\text { (MPa) } \\
\end{array}$ & $\begin{array}{c}\text { Flow Rate } \\
\text { In } \\
\left(\times 10^{-3}\right. \\
\text { cc/min })\end{array}$ & $\begin{array}{l}\text { Flow Rate } \\
\text { Out } \\
\left(x 10^{-3}\right. \\
\mathrm{cc} / \mathrm{min})\end{array}$ & $\begin{array}{c}\text { Mass } \\
\text { Balance } \\
(\%)\end{array}$ & Notes \\
\hline $\begin{array}{c}3 / 25-3 / 26 \\
3 / 26-3 / 27 \\
3 / 27-3 / 29 \\
3 / 29-3 / 30 \\
3 / 30-3 / 31 \\
3 / 31-4 / 1 \\
4 / 1-4 / 2 \\
4 / 3-4 / 5\end{array}$ & $\begin{array}{l}1161 \\
1000 \\
3030 \\
1418 \\
1500 \\
1735 \\
1016 \\
2542\end{array}$ & $\begin{array}{l}22.9 \\
22.9 \\
22.9 \\
22.9 \\
22.9 \\
22.9 \\
22.9 \\
22.9 \\
\end{array}$ & $\begin{array}{l}19.7 \\
19.7 \\
19.6 \\
19.7 \\
19.6 \\
19.7 \\
19.6 \\
19.6 \\
\end{array}$ & $\begin{array}{l}3.5 \\
3.4 \\
3.4 \\
3.4 \\
3.4 \\
3.4 \\
3.4 \\
3.4 \\
\end{array}$ & $\begin{array}{l}0 \\
0 \\
0 \\
0 \\
0 \\
0 \\
0 \\
0\end{array}$ & $\begin{array}{l}0.81 \\
0.56 \\
0.58 \\
0.82 \\
0.84 \\
0.55 \\
0.52 \\
0.55 \\
\end{array}$ & $\begin{array}{c}1.39 \\
0.10 \\
0.83 \\
-0.44 \\
0 \\
1.25 \\
0 \\
0.74 \\
\end{array}$ & $\begin{array}{r}71.6 \\
-82.1 \\
43.1 \\
-153.7 \\
-100.0 \\
127.3 \\
-100.0 \\
34.5 \\
\end{array}$ & d \\
\hline \multicolumn{2}{|c|}{ Weighted Averages: } & 22.9 & 19.6 & 3.4 & 0 & 0.64 & 0.57 & -10.9 & b \\
\hline $\begin{array}{c}4 / 5-4 / 6 \\
4 / 6-4 / 7 \\
4 / 7-4 / 8 \\
4 / 8-4 / 9 \\
4 / 9-4 / 10 \\
4 / 10-4 / 12\end{array}$ & $\begin{array}{l}1592 \\
1020 \\
1804 \\
1131 \\
1491 \\
2989\end{array}$ & $\begin{array}{l}15.2 \\
15.3 \\
15.3 \\
15.3 \\
15.3 \\
15.3\end{array}$ & $\begin{array}{l}13.8 \\
13.8 \\
13.8 \\
13.8 \\
13.8 \\
13.7\end{array}$ & $\begin{array}{l}3.4 \\
3.5 \\
3.5 \\
3.5 \\
3.5 \\
3.5\end{array}$ & $\begin{array}{l}0 \\
0 \\
0 \\
0 \\
0 \\
0\end{array}$ & $\begin{array}{l}0.93 \\
0.75 \\
0.73 \\
0.68 \\
0.75 \\
0.72\end{array}$ & $\begin{array}{r}0.01 \\
-0.01 \\
0.81 \\
-0.01 \\
0.77 \\
0.59\end{array}$ & $\begin{array}{r}-98.9 \\
-101.3 \\
11.0 \\
-101.5 \\
2.7 \\
-18.1\end{array}$ & $\begin{array}{c}a \\
a, d \\
a \\
a, d\end{array}$ \\
\hline \multicolumn{2}{|c|}{ We1ghted Averages: } & 15.3 & 13.7 & 3.5 & 0 & 0.73 & 0.65 & -11.0 & $\mathrm{~b}$ \\
\hline $\begin{array}{l}4 / 12-4 / 13 \\
4 / 13-4 / 14\end{array}$ & $\begin{array}{l}1325 \\
1039\end{array}$ & $\begin{array}{l}15.5 \\
15.5 \\
\end{array}$ & $\begin{array}{l}13.8 \\
13.8 \\
\end{array}$ & $\begin{array}{l}7.0 \\
7.1 \\
\end{array}$ & $\begin{array}{l}0 \\
0 \\
\end{array}$ & $\begin{array}{l}1.78 \\
1.91 \\
\end{array}$ & $\begin{array}{l}1.95 \\
1.87 \\
\end{array}$ & $\begin{array}{r}9.6 \\
-2.1 \\
\end{array}$ & \\
\hline Weighted & Averages: & 15.5 & 13.8 & 7.0 & 0 & 1.84 & 1.91 & 3.8 & $b$ \\
\hline
\end{tabular}

NOTE: At 5:00 pm on 4/14 the annular valve was opened at the wrong time, letting the confining pressure drop to zero. The confining pressure was again applied (13.8 $\mathrm{MPa}$ ) and the test continued. 
Table A.1 Test Results for Sample CG-101--Continued

\begin{tabular}{|c|c|c|c|c|c|c|c|c|c|}
\hline Date & $\begin{array}{l}\text { Elapsed } \\
\text { Time } \\
\text { (min) }\end{array}$ & $\begin{array}{l}\text { Axial } \\
\text { Stress } \\
\text { (MPa) }\end{array}$ & $\begin{array}{l}\text { Confin- } \\
\quad \text { Ing } \\
\text { Stress } \\
\text { (MPa) }\end{array}$ & $\begin{array}{l}\text { Top } \\
\text { Pres- } \\
\text { sure } \\
\text { (MPa) }\end{array}$ & $\begin{array}{l}\text { Bottom } \\
\text { Pres- } \\
\text { sure } \\
\text { (MPa) }\end{array}$ & $\begin{array}{c}\text { F1ow Rate } \\
\text { In } \\
\left(\mathrm{x} 10^{-3}\right. \\
\mathrm{cc} / \mathrm{min})\end{array}$ & $\begin{array}{c}\text { Flow Rate } \\
\text { Out } \\
\left(\times 10^{-3}\right. \\
\mathrm{cc} / \mathrm{min})\end{array}$ & $\begin{array}{c}\text { Mass } \\
\text { Balance } \\
(\%)\end{array}$ & Notes \\
\hline $\begin{array}{l}4 / 14-4 / 15 \\
4 / 15-4 / 17 \\
4 / 17-4 / 19 \\
4 / 19-4 / 20 \\
4 / 20-4 / 21 \\
4 / 21-4 / 22\end{array}$ & $\begin{array}{l}1046 \\
2414 \\
3257 \\
1450 \\
1364 \\
1472\end{array}$ & $\begin{array}{l}15.5 \\
15.6 \\
15.6 \\
15.6 \\
15.6 \\
15.6 \\
\end{array}$ & $\begin{array}{l}13.9 \\
13.8 \\
13.8 \\
13.8 \\
13.7 \\
13.7 \\
\end{array}$ & $\begin{array}{l}7.0 \\
6.9 \\
6.7 \\
6.9 \\
6.9 \\
6.9 \\
\end{array}$ & $\begin{array}{l}0 \\
0 \\
0 \\
0 \\
0 \\
0\end{array}$ & $\begin{array}{l}7.35 \\
3.15 \\
2.32 \\
2.19 \\
2.12 \\
2.26 \\
\end{array}$ & $\begin{array}{l}7.33 \\
2.99 \\
2.32 \\
2.20 \\
2.03 \\
2.06 \\
\end{array}$ & $\begin{array}{r}-0.3 \\
-5.1 \\
0.0 \\
0.5 \\
-4.2 \\
-8.8 \\
\end{array}$ & $\begin{array}{l}a \\
a \\
a\end{array}$ \\
\hline Weighted & Averages: & 15.6 & 13.7 & 6.9 & 0 & 2.19 & 2.10 & -4.1 & b \\
\hline $\begin{array}{l}4 / 22-4 / 23 \\
4 / 23-4 / 26 \\
4 / 26-4 / 27\end{array}$ & $\begin{array}{l}1394 \\
3959 \\
1607\end{array}$ & $\begin{array}{l}15.6 \\
15.7 \\
15.7 \\
\end{array}$ & $\begin{array}{l}13.9 \\
13.5 \\
14.1 \\
\end{array}$ & $\begin{array}{r}9.9 \\
- \\
10.2 \\
\end{array}$ & $\begin{array}{l}0 \\
0 \\
0 \\
\end{array}$ & $\begin{array}{l}4.25 \\
2.19 \\
4.28 \\
\end{array}$ & $\begin{array}{l}3.97 \\
2.67 \\
3.85 \\
\end{array}$ & $\begin{array}{r}-6.6 \\
21.9 \\
-10.0 \\
\end{array}$ & $a, h$ \\
\hline Weighted & Averages: & 15.7 & 14.0 & 10.1 & 0 & 4.27 & 3.91 & -8.4 & b \\
\hline $\begin{array}{l}4 / 27-4 / 28 \\
4 / 28-4 / 29 \\
4 / 29-5 / 2\end{array}$ & $\begin{array}{l}1617 \\
1206 \\
4465\end{array}$ & $\begin{array}{l}15.7 \\
15.7 \\
15.7 \\
\end{array}$ & $\begin{array}{l}13.3 \\
13.8 \\
13.8 \\
\end{array}$ & $\begin{array}{l}3.3 \\
3.6 \\
3.6 \\
\end{array}$ & $\begin{array}{l}0 \\
0 \\
0 \\
\end{array}$ & $\begin{array}{l}0.54 \\
0.95 \\
0.95 \\
\end{array}$ & $\begin{array}{l}0.92 \\
0.95 \\
0.95 \\
\end{array}$ & $\begin{array}{r}70.4 \\
0.0 \\
0.0 \\
\end{array}$ & a \\
\hline Weighted & Averages: & 15.7 & 13.8 & 3.6 & 0 & 0.95 & 0.95 & 0.0 & $\mathrm{~b}$ \\
\hline $\begin{array}{l}5 / 2-5 / 4 \\
5 / 4-5 / 6\end{array}$ & $\begin{array}{l}2826 \\
2714\end{array}$ & $\begin{array}{l}8.4 \\
8.5 \\
\end{array}$ & $\begin{array}{l}7.1 \\
6.9 \\
\end{array}$ & $\begin{array}{l}3.6 \\
3.5 \\
\end{array}$ & $\begin{array}{l}0 \\
\underline{0}\end{array}$ & $\begin{array}{l}2.39 \\
2.14 \\
\end{array}$ & $\begin{array}{l}1.92 \\
2.00 \\
\end{array}$ & $\begin{array}{r}-19.7 \\
-6.5 \\
\end{array}$ & a \\
\hline Weighted & Averages: & 8.5 & 6.9 & 3.5 & 0 & 2.14 & 2.00 & -6.5 & b \\
\hline $\begin{array}{l}5 / 6-5 / 7 \\
5 / 7-5 / 8\end{array}$ & $\begin{array}{l}1423 \\
1477\end{array}$ & $\begin{array}{l}8.5 \\
8.5\end{array}$ & $\begin{array}{l}6.8 \\
6.8\end{array}$ & $\begin{array}{l}1.7 \\
1.7\end{array}$ & $\begin{array}{l}0 \\
0\end{array}$ & $\begin{array}{l}0.96 \\
0.89\end{array}$ & $\begin{array}{l}1.15 \\
1.08\end{array}$ & $\begin{array}{l}19.8 \\
21.3\end{array}$ & $\begin{array}{l}\mathbf{a} \\
\mathbf{a}\end{array}$ \\
\hline
\end{tabular}


Table A.1 Test Results for Sample CG-101--Continued

\begin{tabular}{|c|c|c|c|c|c|c|c|c|c|}
\hline Date & $\begin{array}{c}\text { Elapsed } \\
\text { Time } \\
\text { (min) }\end{array}$ & $\begin{array}{l}\text { Axial } \\
\text { Stress } \\
\text { (MPa) }\end{array}$ & $\begin{array}{c}\text { Confin- } \\
\text { ing } \\
\text { Stress } \\
\text { (MPa) }\end{array}$ & $\begin{array}{l}\text { Top } \\
\text { Pres- } \\
\text { sure } \\
\text { (MPa) }\end{array}$ & $\begin{array}{c}\text { Bottom } \\
\text { Pres- } \\
\text { sure } \\
\text { (MPa) }\end{array}$ & $\begin{array}{c}\text { Flow Rate } \\
\text { In } \\
\left(\times 10^{-3}\right. \\
\mathrm{cc} / \mathrm{min})\end{array}$ & $\begin{array}{l}\text { Flow Rate } \\
\text { Out } \\
\left(x 10^{-3}\right. \\
\text { cc/min) }\end{array}$ & $\begin{array}{l}\text { Mass } \\
\text { Balance } \\
(\%)\end{array}$ & Notes \\
\hline $\begin{array}{r}5 / 8-5 / 10 \\
5 / 10-5 / 13\end{array}$ & $\begin{array}{l}2975 \\
3993\end{array}$ & $\begin{array}{l}8.5 \\
8.5 \\
\end{array}$ & $\begin{array}{l}7.0 \\
6.8 \\
\end{array}$ & $\begin{array}{l}1.7 \\
1.7 \\
\end{array}$ & $\begin{array}{l}0 \\
\underline{0}\end{array}$ & $\begin{array}{l}0.90 \\
0.89 \\
\end{array}$ & $\begin{array}{l}0.91 \\
0.83 \\
\end{array}$ & $\begin{array}{r}1.1 \\
-6.7 \\
\end{array}$ & \\
\hline Weighted & verages: & 8.5 & 6.9 & 1.7 & 0 & 0.89 & 0.86 & -3.4 & $\mathrm{~b}$ \\
\hline
\end{tabular}

NOTES:

(a) Datum not included in average.

(b) Averages weighted with respect to elapsed time.

N (c) During this test (2/10-2/11) annular pressure dropped from 19.7 MPa to 13.8 Mpa, probably due to excess leakage through end seals. The flask collecting fluid from the bottom hole overflowed.

(d) Bottom flask weighed less at end of test than at beginning, indicating flow back into the sample. Possibly misread scale.*

(e) Some leakage from annular valve.

(f) Bottom flask overflowed.

(g) Bottom flask not replaced. No measurement.

(h) $\mathrm{N}_{2}$ tank exhausted. Top hole (injection) pressure $\mathrm{P}_{\mathrm{T}}$ fell from 9.9 to $1.8 \mathrm{MPa}$. $\sigma_{\mathrm{c}}$ fell from 13.9 to $13.1 \mathrm{MPa}$ as $\mathrm{P}_{\mathrm{T}}$ fell.

\footnotetext{
*During these early measurements on rock mass sealing/borehole plug testing, it came as a surprise that water might be drawn into the plug from the outflow collection system. Such occurrences have since been observed repeatedly, and are attributed to capillary action of unsaturated plugs or rocks and atmospheric pressure changes (e.g. Daemen et al., 1985, Section 6.5.2; Akgun and Daemen, 1986, Section 3.4).
} 
Table A.2 Test Results for Sample CG-102

\begin{tabular}{cccccccccc} 
& & \multicolumn{2}{c}{$\begin{array}{c}\text { Confin- } \\
\text { Elapsed }\end{array}$} & Top & Bottom & Flow Rate & Flow Rate & \\
ing & Pres- & Pres- & In & Out & Mass \\
Dime & Stress & Stress & sure & sure & $\left(\mathrm{x} 10^{-3}\right.$ & $\left(\mathrm{x} 10^{-3}\right.$ & Balance \\
& $(\mathrm{min})$ & $(\mathrm{MPa})$ & $(\mathrm{MPa})$ & $(\mathrm{MPa})$ & $(\mathrm{MPa})$ & $\mathrm{cc} / \mathrm{mIn})$ & $\mathrm{cc} / \mathrm{min})$ & $(\%)$ & Notes \\
\hline
\end{tabular}

\section{Tests on Rock Bridge}

\begin{tabular}{|c|c|c|c|c|c|c|c|c|c|}
\hline $\begin{array}{l}1 / 20-1 / 21 \\
1 / 21-1 / 22 \\
1 / 25-1 / 26 \\
1 / 26-1 / 27 \\
1 / 27-1 / 28 \\
1 / 28-1 / 29\end{array}$ & $\begin{array}{r}997 \\
1402 \\
1274 \\
1376 \\
1065 \\
1267\end{array}$ & $\begin{array}{l}21.2 \\
21.2 \\
23.0 \\
23.0 \\
23.0 \\
23.0 \\
\end{array}$ & $\begin{array}{l}19.7 \\
19.8 \\
19.7 \\
19.8 \\
19.8 \\
19.7 \\
\end{array}$ & $\begin{array}{r}10.1 \\
10.1 \\
9.4 \\
10.1 \\
10.1 \\
10.1 \\
\end{array}$ & $\begin{array}{l}0 \\
0 \\
0 \\
0 \\
0 \\
0\end{array}$ & $\begin{array}{l}4.12 \\
5.27 \\
3.30 \\
4.64 \\
4.91 \\
4.85 \\
\end{array}$ & $\begin{array}{l}4.24 \\
4.02 \\
3.77 \\
4.91 \\
6.12 \\
5.26 \\
\end{array}$ & $\begin{array}{r}2.9 \\
-23.7 \\
14.2 \\
5.8 \\
24.6 \\
8.5 \\
\end{array}$ & $\begin{array}{c}a \\
a \\
a, c\end{array}$ \\
\hline \multicolumn{2}{|c|}{ Welghted Averages: } & 23.0 & 19.7 & 10.1 & 0 & 4.79 & 5.38 & 12.1 & $\mathrm{~b}$ \\
\hline $1 / 29-1 / 30$ & 1372 & 22.9 & 19.7 & 7.0 & $\underline{0}$ & 3.06 & 3.30 & 9.1 & \\
\hline \multicolumn{2}{|c|}{ Weighted Averages: } & 22.9 & 19.7 & 7.0 & 0 & 3.06 & 3.30 & 9.1 & $\mathrm{~b}$ \\
\hline $\begin{array}{l}1 / 30-1 / 31 \\
1 / 31-2 / 1 \\
2 / 1-2 / 2 \\
2 / 2 /-2 / 3\end{array}$ & $\begin{array}{r}32 \\
1239 \\
1506 \\
972\end{array}$ & $\begin{array}{l}22.9 \\
22.9 \\
22.8 \\
22.9 \\
\end{array}$ & $\begin{array}{l}19.7 \\
19.7 \\
19.7 \\
19.6 \\
\end{array}$ & $\begin{array}{l}3.5 \\
3.5 \\
3.5 \\
3.5 \\
\end{array}$ & $\begin{array}{l}0 \\
0 \\
0 \\
0\end{array}$ & $\begin{array}{r}57.81 \\
1.32 \\
1.30 \\
1.33 \\
\end{array}$ & $\begin{array}{r}78.25 \\
0.29 \\
1.57 \\
1.75 \\
\end{array}$ & $\begin{array}{r}35.4 \\
-78.0 \\
20.8 \\
31.6 \\
\end{array}$ & $\begin{array}{l}\mathrm{a} \\
\mathrm{a}\end{array}$ \\
\hline \multicolumn{2}{|c|}{ Weighted Averages: } & 22.8 & 19.6 & 3.5 & 0 & 1.31 & 1.64 & 25.0 & $\mathbf{b}$ \\
\hline
\end{tabular}


Table A.2 Test Results for Sample CG-102--Continued

\begin{tabular}{|c|c|c|c|c|c|c|c|c|c|}
\hline te & $\begin{array}{l}\text { Elapsed } \\
\text { Time } \\
\text { (min) }\end{array}$ & $\begin{array}{l}\text { Axial } \\
\text { Stress } \\
\text { (MPa) }\end{array}$ & $\begin{array}{l}\text { Confin- } \\
\text { ing } \\
\text { Stress } \\
\text { (MPa) }\end{array}$ & $\begin{array}{l}\text { Top } \\
\text { Pres- } \\
\text { sure } \\
\text { (MPa) }\end{array}$ & $\begin{array}{c}\text { Bottom } \\
\text { Pres- } \\
\text { sure } \\
\text { (MPa) }\end{array}$ & $\begin{array}{c}\text { Flow Rate } \\
\text { In } \\
\left(\times 10^{-3}\right. \\
\mathrm{cc} / \mathrm{min})\end{array}$ & $\begin{array}{l}\text { Flow Rate } \\
\text { Out } \\
\left(\times 10^{-3}\right. \\
\mathrm{cc} / \mathrm{min})\end{array}$ & $\begin{array}{c}\text { Mass } \\
\text { Balance } \\
(\%)\end{array}$ & Notes \\
\hline
\end{tabular}

Tests on Cement 1 Plug (poured at 2:10 pm, 2/6/82)

\begin{tabular}{|c|c|c|c|c|c|c|c|c|}
\hline $\begin{array}{l}2 / 13-2 / 14 \\
2 / 14-2 / 15 \\
2 / 15-2 / 16 \\
2 / 16-2 / 17 \\
2 / 17-2 / 18 \\
2 / 18-2 / 19\end{array}$ & $\begin{array}{l}1098 \\
1280 \\
1750 \\
1147 \\
1361 \\
1597\end{array}$ & $\begin{array}{l}22.8 \\
22.8 \\
22.9 \\
22.9 \\
22.9 \\
22.9\end{array}$ & $\begin{array}{l}19.7 \\
19.7 \\
19.4 \\
19.6 \\
19.8 \\
19.7\end{array}$ & $\begin{array}{r}10.1 \\
9.9 \\
10.2 \\
9.9 \\
10.2 \\
10.2\end{array}$ & $\begin{array}{l}0 \\
0 \\
0 \\
0 \\
0 \\
0\end{array}$ & $\begin{array}{l}7.40 \\
5.84 \\
5.51 \\
4.38 \\
4.40 \\
4.01\end{array}$ & $\begin{array}{l}7.52 \\
7.89 \\
6.67 \\
5.30 \\
4.90 \\
4.48\end{array}$ & $\begin{array}{r}1.6 \\
35.1 \\
21.1 \\
21.0 \\
11.4 \\
11.7\end{array}$ \\
\hline $\begin{array}{l}2 / 19-2 / 20 \\
2 / 20-2 / 21 \\
2 / 21-2 / 22 \\
2 / 22-2 / 23 \\
2 / 23-2 / 24 \\
2 / 24-2 / 25 \\
2 / 25-2 / 26\end{array}$ & $\begin{array}{l}\text { Data } \\
1185 \\
1335 \\
1070 \\
1383 \\
1481 \\
1364\end{array}$ & $\begin{array}{l}\text { lot reco } \\
22.9 \\
23.0 \\
23.0 \\
22.9 \\
22.9 \\
22.9 \\
\end{array}$ & $\begin{array}{r}\text { ed; f } \\
19.6 \\
19.9 \\
19.5 \\
19.7 \\
19.6 \\
19.6 \\
\end{array}$ & $\begin{array}{l}\text { continued. } \\
10.0 \\
10.0 \\
10.0 \\
10.0 \\
10.0 \\
9.5 \\
\end{array}$ & $\begin{array}{l}0 \\
0 \\
0 \\
0 \\
0 \\
\underline{0}\end{array}$ & $\begin{array}{l}3.49 \\
3.32 \\
3.38 \\
3.18 \\
3.15 \\
3.07 \\
\end{array}$ & $\begin{array}{l}3.86 \\
3.87 \\
3.53 \\
3.39 \\
3.29 \\
3.20 \\
\end{array}$ & $\begin{array}{r}10.6 \\
16.6 \\
4.4 \\
6.6 \\
4.4 \\
4.2 \\
\end{array}$ \\
\hline \multicolumn{2}{|c|}{ Welghted Averages: } & 22.9 & 19.7 & 10.0 & 0 & 4.24 & 4.82 & 12.6 \\
\hline $\begin{array}{l}2 / 26-2 / 27 \\
2 / 27-3 / 1 \\
3 / 1-3 / 2 \\
3 / 2-3 / 3 \\
3 / 3-3 / 4\end{array}$ & $\begin{array}{l}1589 \\
2728 \\
1458 \\
1511 \\
1337\end{array}$ & $\begin{array}{l}22.9 \\
22.9 \\
22.9 \\
22.9 \\
22.9 \\
\end{array}$ & $\begin{array}{l}19.6 \\
19.7 \\
19.6 \\
19.7 \\
19.6 \\
\end{array}$ & $\begin{array}{l}6.8 \\
7.0 \\
7.0 \\
7.0 \\
7.0 \\
\end{array}$ & $\begin{array}{l}0 \\
0 \\
0 \\
0 \\
0 \\
\end{array}$ & $\begin{array}{l}1.81 \\
1.92 \\
1.91 \\
1.83 \\
1.82 \\
\end{array}$ & $\begin{array}{r}2.13 \\
2.02 \\
-0.09 \\
2.02 \\
2.00 \\
\end{array}$ & $\begin{array}{r}17.7 \\
5.2 \\
- \\
10.4 \\
9.9 \\
\end{array}$ \\
\hline Welghted & cages: & 22.9 & 19.7 & 7.0 & 0 & 1.86 & 2.04 & 9.9 \\
\hline
\end{tabular}


Table A.2 Test Results for Sample CG-102--Continued

\begin{tabular}{cccccccccc} 
& & \multicolumn{2}{c}{ Confin- } & Top & Bottom & Flow Rate & Flow Rate & \\
& Elapsed & Axial & Ing & Pres- & Pres- & In & Out & Mass \\
Date & Time & Stress & Stress & sure & sure & $\left(\mathrm{x} 10^{-3}\right.$ & $\left(\mathrm{x} 10^{-3}\right.$ & $\begin{array}{c}\text { Balance } \\
(\%)\end{array}$ & Notes \\
\hline
\end{tabular}

Tests on Cement 1 Plug (continued)

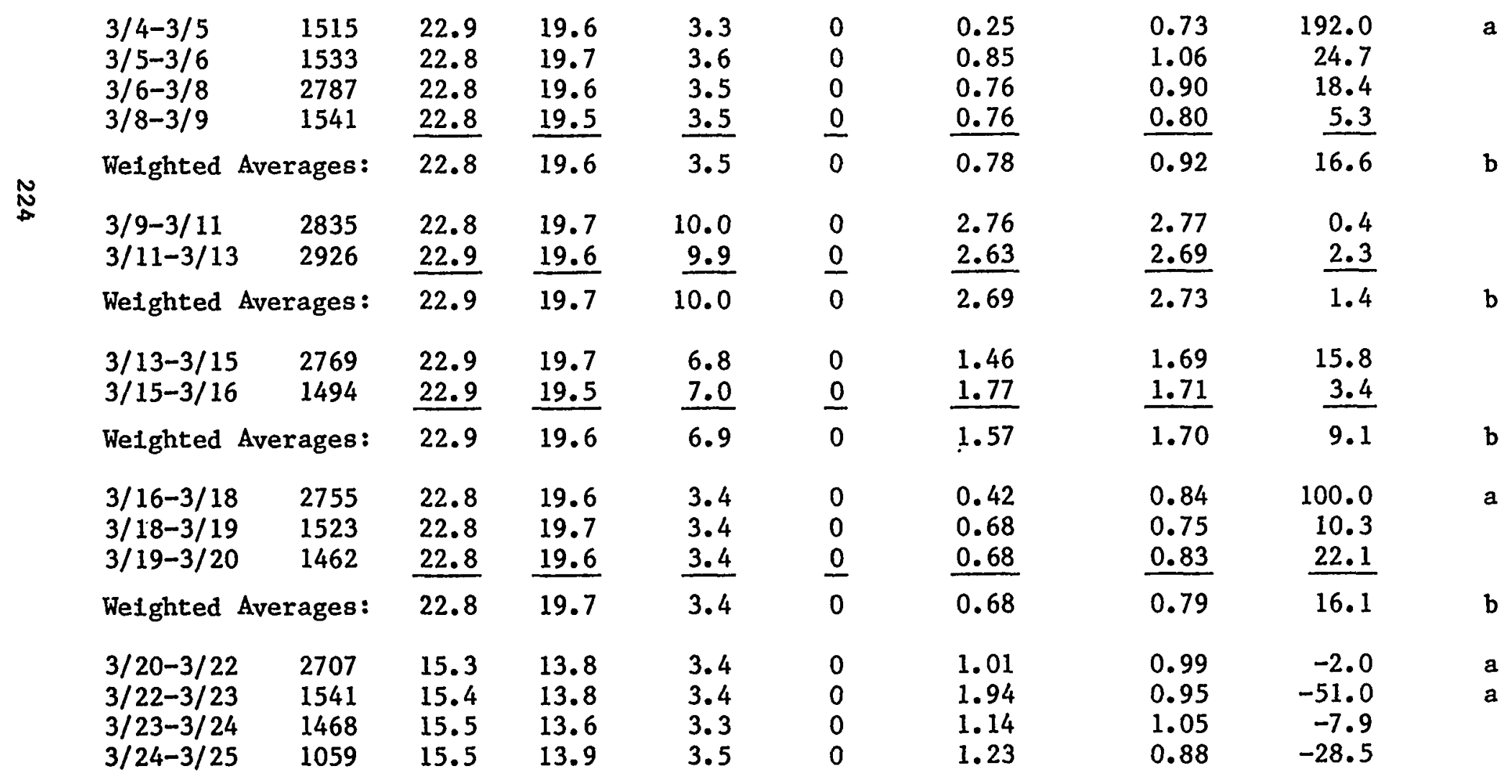


Table A.2 Test Results for Sample CG-102--Continued

\begin{tabular}{|c|c|c|c|c|c|c|c|c|c|}
\hline ate & $\begin{array}{l}\text { Elapsed } \\
\text { Time } \\
\text { (min) }\end{array}$ & $\begin{array}{l}\text { Axial } \\
\text { Stress } \\
\text { (MPa) }\end{array}$ & $\begin{array}{l}\text { Confin- } \\
\text { Ing } \\
\text { Stress } \\
\text { (MPa) }\end{array}$ & $\begin{array}{l}\text { Top } \\
\text { Pres- } \\
\text { sure } \\
\text { (MPa) }\end{array}$ & $\begin{array}{l}\text { Bottom } \\
\text { Pres- } \\
\text { sure } \\
(\mathrm{MPa})\end{array}$ & $\begin{array}{c}\text { Flow Rate } \\
\text { In } \\
\left(x 10^{-3}\right. \\
\mathrm{cc} / \mathrm{min})\end{array}$ & $\begin{array}{c}\text { Flow Rate } \\
\text { Out } \\
\left(x 10^{-3}\right. \\
\mathrm{cc} / \mathrm{min})\end{array}$ & $\begin{array}{c}\text { Mass } \\
\text { Balance } \\
(\%)\end{array}$ & Notes \\
\hline
\end{tabular}

Tests on Cement 1 Plug (continued)

\begin{tabular}{|c|c|c|c|c|c|c|c|c|}
\hline $\begin{array}{l}3 / 25-3 / 26 \\
3 / 26-3 / 27\end{array}$ & $\begin{array}{l}1187 \\
1016\end{array}$ & $\begin{array}{l}15.5 \\
15.5 \\
\end{array}$ & $\begin{array}{l}13.8 \\
13.9 \\
\end{array}$ & $\begin{array}{l}3.5 \\
3.6 \\
\end{array}$ & $\begin{array}{l}0 \\
0 \\
\end{array}$ & $\begin{array}{l}1.24 \\
1.12 \\
\end{array}$ & $\begin{array}{l}1.10 \\
0.98 \\
\end{array}$ & $\begin{array}{r}-11.3 \\
-12.5 \\
\end{array}$ \\
\hline \multicolumn{2}{|c|}{ Welghted Averages: } & 15.4 & 13.8 & 3.5 & 0 & 1.18 & 1.01 & -14.4 \\
\hline $\begin{array}{l}3 / 27-3 / 29 \\
3 / 29-3 / 30 \\
3 / 30-3 / 31\end{array}$ & $\begin{array}{l}3038 \\
1419 \\
1451\end{array}$ & $\begin{array}{l}15.5 \\
15.6 \\
15.6 \\
\end{array}$ & $\begin{array}{l}13.9 \\
13.8 \\
13.8 \\
\end{array}$ & $\begin{array}{l}7.0 \\
7.0 \\
7.0 \\
\end{array}$ & $\begin{array}{l}0 \\
0 \\
0 \\
\end{array}$ & $\begin{array}{l}2.83 \\
2.63 \\
2.53 \\
\end{array}$ & $\begin{array}{r}2.36 \\
-2.70 \\
2.34 \\
\end{array}$ & $\begin{array}{c}-16.6 \\
- \\
-7.5 \\
\end{array}$ \\
\hline \multicolumn{2}{|c|}{ Welghted Averages: } & 15.5 & 13.8 & 7.0 & 0 & 2.73 & 2.35 & -13.7 \\
\hline $\begin{array}{l}3 / 31-4 / 1 \\
4 / 1-4 / 2 \\
4 / 3-4 / 5\end{array}$ & $\begin{array}{r}1798 \\
960 \\
2588\end{array}$ & $\begin{array}{l}15.7 \\
15.8 \\
15.8 \\
\end{array}$ & $\begin{array}{l}13.9 \\
14.0 \\
13.9 \\
\end{array}$ & $\begin{array}{l}10.1 \\
10.0 \\
10.1 \\
\end{array}$ & $\begin{array}{l}0 \\
0 \\
0 \\
\end{array}$ & $\begin{array}{l}5.12 \\
4.81 \\
4.51 \\
\end{array}$ & $\begin{array}{l}4.56 \\
4.67 \\
4.44 \\
\end{array}$ & $\begin{array}{r}-10.9 \\
-2.9 \\
-1.6 \\
\end{array}$ \\
\hline \multicolumn{2}{|c|}{ Weighted Averages: } & 15.8 & 13.9 & 10.1 & 0 & 4.77 & 4.52 & -5.0 \\
\hline $\begin{array}{l}4 / 5-4 / 6 \\
4 / 6-4 / 7\end{array}$ & $\begin{array}{l}1584 \\
1099\end{array}$ & $\begin{array}{l}15.6 \\
15.7 \\
\end{array}$ & $\begin{array}{l}13.6 \\
13.8 \\
\end{array}$ & $\begin{array}{l}3.4 \\
3.5 \\
\end{array}$ & $\begin{array}{l}0 \\
0 \\
\end{array}$ & $\begin{array}{l}0.74 \\
1.05 \\
\end{array}$ & $\begin{array}{l}1.22 \\
1.06 \\
\end{array}$ & $\begin{array}{r}64.9 \\
1.0 \\
\end{array}$ \\
\hline \multicolumn{2}{|c|}{ Weighted Averages: } & 15.7 & 13.8 & 3.5 & 0 & 1.05 & $\begin{array}{l}1.06 \\
-\end{array}$ & 1.0 \\
\hline $\begin{array}{l}4 / 7-4 / 8 \\
4 / 8-4 / 9\end{array}$ & $\begin{array}{l}1638 \\
1129\end{array}$ & $\begin{array}{l}8.5 \\
8.6 \\
\end{array}$ & $\begin{array}{l}7.1 \\
6.9 \\
\end{array}$ & $\begin{array}{l}3.4 \\
3.4 \\
\end{array}$ & $\begin{array}{l}0 \\
0 \\
\end{array}$ & $\begin{array}{l}2.28 \\
2.24 \\
\end{array}$ & $\begin{array}{l}2.03 \\
2.21 \\
\end{array}$ & $\begin{array}{r}-11.0 \\
-1.3 \\
\end{array}$ \\
\hline \multicolumn{2}{|c|}{ Weighted Averages: } & 8.5 & 7.0 & 3.4 & 0 & 2.26 & 2.10 & -7.0 \\
\hline
\end{tabular}


Table A.2 Tests Results for Sample CG-102-- Continued

\begin{tabular}{|c|c|c|c|c|c|c|c|c|c|}
\hline Date & $\begin{array}{l}\text { Elapsed } \\
\text { Time } \\
\text { (min) }\end{array}$ & $\begin{array}{l}\text { Axial } \\
\text { Stress } \\
\text { (MPa) }\end{array}$ & $\begin{array}{l}\text { Confin- } \\
\quad \text { ing } \\
\text { Stress } \\
\text { (MPa) } \\
\end{array}$ & $\begin{array}{l}\text { Top } \\
\text { Pres- } \\
\text { sure } \\
\text { (MPa) } \\
\end{array}$ & $\begin{array}{c}\text { Bottom } \\
\text { Pres- } \\
\text { sure } \\
\text { (MPa) }\end{array}$ & $\begin{array}{c}\text { Flow Rate } \\
\text { In } \\
\left(\times 10^{-3}\right. \\
\text { cc/min })\end{array}$ & $\begin{array}{l}\text { Flow Rate } \\
\text { Out } \\
\left(x 10^{-3}\right. \\
\mathrm{cc} / \mathrm{min})\end{array}$ & $\begin{array}{c}\text { Mass } \\
\text { Balance } \\
(\%)\end{array}$ & Notes \\
\hline $\begin{array}{l}4 / 9-4 / 10 \\
4 / 10-4 / 12 \\
4 / 12-4 / 13 \\
4 / 13-4 / 14\end{array}$ & $\begin{array}{l}1489 \\
2963 \\
1304 \\
1073\end{array}$ & $\begin{array}{l}8.6 \\
8.5 \\
8.6 \\
8.6 \\
\end{array}$ & $\begin{array}{l}6.8 \\
6.9 \\
6.9 \\
6.9 \\
\end{array}$ & $\begin{array}{l}1.7 \\
1.8 \\
1.7 \\
1.7 \\
\end{array}$ & $\begin{array}{l}0 \\
0 \\
0 \\
0 \\
\end{array}$ & $\begin{array}{l}0.77 \\
1.00 \\
0.92 \\
0.99 \\
\end{array}$ & $\begin{array}{l}1.10 \\
1.03 \\
1.03 \\
1.02 \\
\end{array}$ & $\begin{array}{r}42.9 \\
3.0 \\
12.0 \\
3.0 \\
\end{array}$ & $a$ \\
\hline Weighted & verages: & 8.6 & 6.9 & 1.7 & 0 & 0.98 & 1.03 & 5.2 & $\mathrm{~b}$ \\
\hline
\end{tabular}

(a) Datum not included in average

(b) Averages weighted with respect to elapsed time

(c) Ran out of $\mathrm{N}_{2}$; top pressure fell from 1460 to 1280 psi.

(d) Negative flow rate out indicates flow back into sample. Possibly misread instrument.*

\footnotetext{
*During these early measurements on rock mass sealing/borehole plug testing, it came as a surprise that water might be drawn into the plug from the outflow collection system. Such occurrences have since been observed repeatedly, and are attributed to capillary action of unsaturated plugs or rocks and atmospheric pressure changes (e.g. Daemen et al., 1985, Section 6.5.2; Akgun and Daemen, 1986, Section 3.4).
} 
Table A.3 Test Results for Sample CG-103

\begin{tabular}{cccccccccc} 
& & & Confin- & Top & Bottom & Flow Rate & Flow Rate & \\
& Elapsed & Axial & ing & Pres- & Pres- & In & Out & Mass \\
Date & Time & Stress & Stress & sure & sure & $\left(\mathrm{x} 10^{-3}\right.$ & $\left(\mathrm{x} 10^{-3}\right.$ & Balance \\
& $(\mathrm{min})$ & $(\mathrm{MPa})$ & $(\mathrm{MPa})$ & $(\mathrm{MPa})$ & $(\mathrm{MPa})$ & $\mathrm{cc} / \mathrm{min})$ & $\mathrm{cc} / \mathrm{min})$ & $(\%)$ & Notes \\
\hline
\end{tabular}

Tests on Rock Bridge

\begin{tabular}{|c|c|c|c|c|c|c|c|c|}
\hline $\begin{array}{l}1 / 28-1 / 29 \\
1 / 29-1 / 30 \\
1 / 30-1 / 31 \\
1 / 31-2 / 1\end{array}$ & $\begin{array}{r}998 \\
1547 \\
1611 \\
1297\end{array}$ & $\begin{array}{l}22.8 \\
22.8 \\
22.8 \\
22.8 \\
\end{array}$ & $\begin{array}{l}19.6 \\
19.6 \\
19.6 \\
19.7 \\
\end{array}$ & $\begin{array}{l}10.2 \\
10.2 \\
10.2 \\
10.1 \\
\end{array}$ & $\begin{array}{l}0 \\
0 \\
0 \\
0 \\
\end{array}$ & $\begin{array}{l}5.80 \\
5.69 \\
5.76 \\
5.26 \\
\end{array}$ & $\begin{array}{l}7.51 \\
6.53 \\
6.29 \\
5.61 \\
\end{array}$ & $\begin{array}{r}29.5 \\
14.8 \\
9.2 \\
6.7 \\
\end{array}$ \\
\hline WeIghted & Averages: & 22.8 & 19.6 & 10.2 & 0 & 5.59 & 6.18 & 10.6 \\
\hline $\begin{array}{l}2 / 1-2 / 2 \\
2 / 2-2 / 3\end{array}$ & $\begin{array}{l}1132 \\
1034\end{array}$ & $\begin{array}{r}22.8 \\
22.7 \\
\end{array}$ & $\begin{array}{l}19.8 \\
19.6 \\
\end{array}$ & $\begin{array}{l}6.9 \\
6.8 \\
\end{array}$ & $\begin{array}{l}0 \\
0\end{array}$ & $\begin{array}{l}3.27 \\
3.23 \\
\end{array}$ & $\begin{array}{r}3.55 \\
3.46 \\
\end{array}$ & $\begin{array}{l}8.6 \\
7.1 \\
\end{array}$ \\
\hline Weighted & Averages : & 22.8 & 19.7 & 6.9 & 0 & 3.25 & 3.51 & 8.0 \\
\hline
\end{tabular}

$\begin{array}{llllllllll}2 / 3-2 / 4 & 1320 & 22.7 & 19.5 & 3.4 & 0 & 1.30 & 1.55 & 19.2 \\ 2 / 4-2 / 5 & 1121 & 22.7 & 19.6 & 3.5 & 0 & 1.32 & 1.46 & 10.6 \\ 2 / 5-2 / 5 & 1362 & 22.7 & 19.6 & 3.5 & 0 & 1.24 & 1.53 & 23.4 \\ 2 / 6-2 / 7 & 1720 & 22.7 & 19.6 & 3.5 & 0 & 1.27 & 1.58 & 24.4 \\ 2 / 7-2 / 8 & 1277 & 22.7 & 19.7 & 3.4 & 0 & 1.22 & 1.49 & 22.1 \\ 2 / 8-2 / 9 & 1326 & 22.7 & 19.6 & 3.4 & 0 & 1.22 & 1.49 & 22.1 \\ 2 / 9-2 / 10 & 1759 & 22.7 & 19.6 & 3.4 & 0 & 1.22 & 1.53 & 26.2 \\ 2 / 10-2 / 11 & 1317 & 22.7 & \frac{19.6}{3.4} & \frac{3.4}{3.4} & \frac{0}{0} & \frac{1.22}{1.25} & \frac{1.64}{1.54} & \frac{34.4}{23.2} & \text { b } \\ \text { Welghted Averages: } & 22.7 & 19.6 & 3.4 & & \end{array}$

Tests on Cement 1 Plug (Poured at 1:25 pm, 2/13/82)

$\begin{array}{crrrrrrrrr}2 / 20-2 / 21 & 1213 & 22.9 & 19.8 & 10.0 & 0 & 14.81 & - & - & \text { a,c } \\ 2 / 22-2 / 23 & 1024 & 23.0 & 19.5 & 10.2 & 0 & 10.64 & - & - \text { a,c } \\ 2 / 23 & 363 & 22.9 & 19.6 & 10.2 & 0 & 9.48 & 20.92 & 120.7 & \text { a }\end{array}$


Table A.3 Test Results for Sample CG-103-Continued

\begin{tabular}{|c|c|c|c|c|c|c|c|c|c|}
\hline Date & $\begin{array}{c}\text { Elapsed } \\
\text { TIme } \\
\text { (min) }\end{array}$ & $\begin{array}{l}\text { Axtal } \\
\text { Stress } \\
\text { (MPa) }\end{array}$ & $\begin{array}{l}\text { Confin- } \\
\text { Ing } \\
\text { Stress } \\
\text { (MPa) }\end{array}$ & $\begin{array}{l}\text { Top } \\
\text { Pres- } \\
\text { sure } \\
\text { (MPa) } \\
\end{array}$ & $\begin{array}{c}\text { Bottom } \\
\text { Pres- } \\
\text { sure } \\
\text { (MPa) }\end{array}$ & $\begin{array}{c}\text { Flow Rate } \\
\text { In } \\
\left(\times 10^{-3}\right. \\
\mathrm{cc} / \mathrm{min})\end{array}$ & $\begin{array}{l}\text { Flow Rate } \\
\text { Out } \\
\left(\times 10^{-3}\right. \\
\mathrm{cc} / \mathrm{min})\end{array}$ & $\begin{array}{c}\text { Mass } \\
\text { Ba1ance } \\
(\%)\end{array}$ & Notes \\
\hline $\begin{array}{c}2 / 23-2 / 24 \\
2 / 24 \\
2 / 24-2 / 25 \\
2 / 25-2 / 26 \\
2 / 26-2 / 27 \\
2 / 27-3 / 1 \\
3 / 1-3 / 2 \\
3 / 2-3 / 3 \\
3 / 3-3 / 4\end{array}$ & $\begin{array}{r}1002 \\
480 \\
982 \\
1404 \\
1587 \\
2642 \\
1579 \\
1385 \\
1262\end{array}$ & $\begin{array}{l}22.9 \\
22.9 \\
22.9 \\
22.9 \\
22.9 \\
22.8 \\
22.9 \\
22.9 \\
22.9 \\
\end{array}$ & $\begin{array}{l}19.6 \\
19.7 \\
19.7 \\
19.6 \\
19.6 \\
19.5 \\
19.8 \\
19.7 \\
19.6 \\
\end{array}$ & $\begin{array}{r}10.2 \\
10.3 \\
10.3 \\
10.3 \\
10.3 \\
6.5 \\
10.0 \\
10.0 \\
10.0 \\
\end{array}$ & $\begin{array}{l}0 \\
0 \\
0 \\
0 \\
0 \\
0 \\
0 \\
0 \\
0 \\
\end{array}$ & $\begin{array}{l}8.83 \\
8.21 \\
7.83 \\
7.31 \\
6.84 \\
3.02 \\
5.45 \\
5.05 \\
4.91 \\
\end{array}$ & $\begin{array}{r}15.75 \\
13.77 \\
6.51 \\
6.92 \\
7.57 \\
3.86 \\
4.56 \\
4.74 \\
4.25 \\
\end{array}$ & $\begin{array}{r}78.4 \\
67.7 \\
-16.9 \\
-5.3 \\
10.7 \\
27.8 \\
-16.3 \\
-6.1 \\
-13.4 \\
\end{array}$ & $a, d$ \\
\hline Weighted & Average: & 22.9 & 19.7 & 10.1 & & 6.17 & 5.76 & -6.6 & b \\
\hline $\begin{array}{c}3 / 4-3 / 5 \\
3 / 5-3 / 6 \\
3 / 6-3 / 8 \\
3 / 8-3 / 9 \\
3 / 9-3 / 11 \\
3 / 11-3 / 13 \\
3 / 13-3 / 15 \\
3 / 15-3 / 16\end{array}$ & $\begin{array}{l}1568 \\
1534 \\
2779 \\
1576 \\
2841 \\
2941 \\
2725 \\
1470\end{array}$ & $\begin{array}{l}22.8 \\
22.8 \\
22.8 \\
22.8 \\
22.8 \\
22.8 \\
22.8 \\
22.8 \\
\end{array}$ & $\begin{array}{l}19.7 \\
19.6 \\
19.6 \\
19.6 \\
19.6 \\
19.6 \\
19.7 \\
19.6 \\
\end{array}$ & $\begin{array}{l}6.9 \\
6.9 \\
6.9 \\
6.9 \\
6.9 \\
6.9 \\
6.9 \\
6.9 \\
\end{array}$ & $\begin{array}{l}0 \\
0 \\
0 \\
0 \\
0 \\
0 \\
0 \\
0 \\
\end{array}$ & $\begin{array}{l}2.93 \\
2.72 \\
2.47 \\
2.53 \\
2.34 \\
0.34 \\
3.08 \\
2.28 \\
\end{array}$ & $\begin{array}{l}3.13 \\
1.68 \\
2.45 \\
1.89 \\
2.92 \\
1.17 \\
2.17 \\
2.39 \\
\end{array}$ & $\begin{array}{r}6.8 \\
-38.2 \\
-0.8 \\
-25.3 \\
24.8 \\
244.1 \\
-29.5 \\
4.8 \\
\end{array}$ & \\
\hline Weighted & Averages: & 22.8 & 19.6 & 6.9 & 0 & 2.24 & 2.20 & -1.8 & b \\
\hline $\begin{array}{l}3 / 16-3 / 18 \\
3 / 18-3 / 19 \\
3 / 19-3 / 20 \\
3 / 20-3 / 22 \\
3 / 22-3 / 23\end{array}$ & $\begin{array}{l}2845 \\
1571 \\
1337 \\
2768 \\
1090\end{array}$ & $\begin{array}{l}22.8 \\
22.8 \\
22.7 \\
22.7 \\
22.7\end{array}$ & $\begin{array}{l}19.4 \\
19.6 \\
19.6 \\
19.6 \\
19.6\end{array}$ & $\begin{array}{l}3.2 \\
3.4 \\
3.4 \\
3.4 \\
3.4\end{array}$ & $\begin{array}{l}0 \\
0 \\
0 \\
0 \\
0\end{array}$ & $\begin{array}{l}0.52 \\
0.77 \\
0.78 \\
0.75 \\
0.80\end{array}$ & $\begin{array}{l}0.33 \\
0.80 \\
0.95 \\
0.95 \\
0.38\end{array}$ & $\begin{array}{r}-36.5 \\
3.9 \\
21.8 \\
26.7 \\
-52.5\end{array}$ & $a, e$ \\
\hline
\end{tabular}


Table A.3 Test Results for Sample CG-103--Continued

\begin{tabular}{|c|c|c|c|c|c|c|c|c|c|}
\hline Date & $\begin{array}{l}\text { Elapsed } \\
\text { Time } \\
\text { (min) }\end{array}$ & $\begin{array}{l}\text { Axial } \\
\text { Stress } \\
\text { (MPa) }\end{array}$ & $\begin{array}{l}\text { Confin- } \\
\quad \text { Ing } \\
\text { Stress } \\
\text { (MPa) }\end{array}$ & $\begin{array}{l}\text { Top } \\
\text { Pres- } \\
\text { sure } \\
\text { (MPa) }\end{array}$ & $\begin{array}{c}\text { Bottom } \\
\text { Pres- } \\
\text { sure } \\
\text { (MPa) }\end{array}$ & $\begin{array}{c}\text { Flow Rate } \\
\text { In } \\
\left(x 10^{-3}\right. \\
\mathrm{cc} / \mathrm{min})\end{array}$ & $\begin{array}{l}\text { Flow Rate } \\
\text { Out } \\
\left(\times 10^{-3}\right. \\
\mathrm{cc} / \mathrm{m} 1 \mathrm{n})\end{array}$ & $\begin{array}{c}\text { Mass } \\
\text { Balance } \\
(\%)\end{array}$ & Notes \\
\hline $\begin{array}{c}3 / 23-3 / 24 \\
3 / 24-3 / 25 \\
3 / 25-3 / 26 \\
3 / 26-3 / 27 \\
3 / 27-3 / 29 \\
3 / 29-3 / 30 \\
3 / 30-3 / 31 \\
3 / 31-4 / 1 \\
4 / 3-4 / 5 \\
4 / 5-4 / 6\end{array}$ & $\begin{array}{l}1478 \\
1047 \\
1212 \\
1026 \\
3041 \\
1417 \\
1408 \\
1859 \\
2656 \\
1535\end{array}$ & $\begin{array}{l}22.7 \\
22.7 \\
22.7 \\
22.7 \\
22.7 \\
22.7 \\
22.7 \\
22.7 \\
22.7 \\
22.7 \\
\end{array}$ & $\begin{array}{l}19.6 \\
19.6 \\
19.6 \\
19.5 \\
19.7 \\
19.6 \\
19.6 \\
19.6 \\
19.6 \\
19.7 \\
\end{array}$ & $\begin{array}{l}3.4 \\
3.4 \\
3.4 \\
3.4 \\
3.4 \\
3.4 \\
3.4 \\
3.4 \\
3.4 \\
3.4 \\
\end{array}$ & $\begin{array}{l}0 \\
0 \\
0 \\
0 \\
0 \\
0 \\
0 \\
0 \\
0 \\
0 \\
\end{array}$ & $\begin{array}{l}0.45 \\
0.20 \\
0.14 \\
0.11 \\
0.28 \\
0.37 \\
0.32 \\
0.44 \\
0.28 \\
0.29 \\
\end{array}$ & $\begin{array}{l}0.01 \\
0.00 \\
0.00 \\
0.01 \\
0.76 \\
0.01 \\
0.00 \\
1.60 \\
0.37 \\
1.56 \\
\end{array}$ & $\begin{array}{r}-97.8 \\
-100.0 \\
-100.0 \\
-90.9 \\
171.4 \\
-97.3 \\
-100.0 \\
263.6 \\
32.1 \\
437.9 \\
\end{array}$ & $\begin{array}{l}a, f \\
a, f \\
a, f \\
a, f \\
a, f \\
a, f \\
a, f \\
a, f \\
a, f \\
a, f\end{array}$ \\
\hline Weighted & Averages: & 22.7 & 19.6 & 3.4 & 0 & 0.43 & 0.61 & 41.9 & $b, h$ \\
\hline $\begin{array}{l}4 / 6-4 / 7 \\
4 / 7-4 / 8 \\
4 / 8-4 / 9 \\
4 / 9-4 / 10 \\
4 / 10-4 / 11 \\
4 / 12-4 / 13 \\
4 / 13-4 / 14 \\
4 / 14-4 / 15 \\
4 / 15-4 / 17\end{array}$ & $\begin{array}{l}1196 \\
1688 \\
1082 \\
1485 \\
2919 \\
1241 \\
1140 \\
1104 \\
2415\end{array}$ & $\begin{array}{l}22.7 \\
22.7 \\
22.7 \\
22.9 \\
22.9 \\
22.9 \\
22.9 \\
22.8 \\
22.7 \\
\end{array}$ & $\begin{array}{l}19.6 \\
19.6 \\
19.7 \\
19.6 \\
19.6 \\
19.6 \\
19.7 \\
19.6 \\
19.5 \\
\end{array}$ & $\begin{array}{l}3.4 \\
3.4 \\
3.4 \\
3.4 \\
3.2 \\
3.4 \\
3.4 \\
3.4 \\
3.4 \\
\end{array}$ & $\begin{array}{l}0 \\
0 \\
0 \\
0 \\
0 \\
0 \\
0 \\
0 \\
0 \\
\end{array}$ & $\begin{array}{l}0.61 \\
0.61 \\
0.59 \\
0.61 \\
0.56 \\
0.58 \\
0.57 \\
0.53 \\
0.56 \\
\end{array}$ & $\begin{array}{r}0.02 \\
-0.01 \\
0.00 \\
0.00 \\
0.64 \\
1.00 \\
0.01 \\
0.02 \\
.047 \\
\end{array}$ & $\begin{array}{r}-96.7 \\
-101.6 \\
-100.0 \\
-100.0 \\
14.3 \\
72.4 \\
-98.5 \\
-96.2 \\
-16.1 \\
\end{array}$ & $\begin{array}{c}a \\
a, g \\
a \\
a\end{array}$ \\
\hline Weighted & Averages: & 22.8 & 19.6 & 3.3 & 0 & 0.56 & 0.49 & -12.5 & b \\
\hline
\end{tabular}


Table A.3 Test Results for Sample CG-103--Continued

\begin{tabular}{|c|c|c|c|c|c|c|c|c|c|}
\hline Date & $\begin{array}{c}\text { Elapsed } \\
\text { Time } \\
\text { (min) }\end{array}$ & $\begin{array}{l}\text { Axtal } \\
\text { Stress } \\
\text { (MPa) } \\
\end{array}$ & $\begin{array}{l}\text { Confin- } \\
\quad \text { ing } \\
\text { Stress } \\
\text { (MPa) } \\
\end{array}$ & $\begin{array}{l}\text { Top } \\
\text { Pres- } \\
\text { sure } \\
\text { (MPa) }\end{array}$ & $\begin{array}{l}\text { Bottom } \\
\text { Pres- } \\
\text { sure } \\
\text { (MPa) }\end{array}$ & $\begin{array}{c}\text { F1ow Rate } \\
\text { In } \\
\left(x 10^{-3}\right. \\
\mathrm{cc} / \mathrm{min})\end{array}$ & $\begin{array}{l}\text { Flow Rate } \\
\text { Out } \\
\text { (x } 10^{-3} \\
\mathrm{cc} / \mathrm{mIn})\end{array}$ & $\begin{array}{c}\text { Mass } \\
\text { Balance } \\
(\%) \\
\end{array}$ & Notes \\
\hline $\begin{array}{l}4 / 17-4 / 18 \\
4 / 19-4 / 21\end{array}$ & $\begin{array}{l}3236 \\
2816\end{array}$ & $\begin{array}{l}22.8 \\
22.8\end{array}$ & $\begin{array}{l}19.5 \\
19.6\end{array}$ & $\begin{array}{l}10.1 \\
10.1\end{array}$ & $\begin{array}{l}0 \\
0\end{array}$ & $\begin{array}{l}2.93 \\
2.88 \\
\end{array}$ & $\begin{array}{l}2.70 \\
2.78 \\
\end{array}$ & $\begin{array}{l}-7.8 \\
-3.5 \\
\end{array}$ & \\
\hline \multicolumn{2}{|c|}{ Weighted Averages: } & 22.8 & 19.5 & 10.1 & 0 & 2.91 & 2.74 & -5.8 & b \\
\hline $\begin{array}{l}4 / 21-4 / 22 \\
4 / 22-4 / 23 \\
4 / 23-4 / 26\end{array}$ & $\begin{array}{l}1445 \\
1390 \\
3981\end{array}$ & $\begin{array}{l}22.8 \\
22.8 \\
22.8 \\
\end{array}$ & $\begin{array}{l}19.4 \\
19.6 \\
19.4 \\
\end{array}$ & $\begin{array}{l}6.9 \\
7.7 \\
7.0 \\
\end{array}$ & $\begin{array}{l}0 \\
0 \\
0 \\
\end{array}$ & $\begin{array}{l}1.44 \\
1.55 \\
1.50 \\
\end{array}$ & $\begin{array}{l}1.65 \\
1.54 \\
1.34 \\
\end{array}$ & $\begin{array}{r}14.6 \\
-0.6 \\
-10.7 \\
\end{array}$ & \\
\hline \multicolumn{2}{|c|}{ Weighted Averages: } & 22.8 & 19.4 & 7.1 & 0 & 1.50 & 1.45 & -3.3 & b \\
\hline $\begin{array}{l}4 / 26-4 / 27 \\
4 / 27-4 / 29 \\
4 / 29-5 / 2\end{array}$ & $\begin{array}{l}1571 \\
2918 \\
4483\end{array}$ & $\begin{array}{l}22.8 \\
22.7 \\
22.8 \\
\end{array}$ & $\begin{array}{l}19.8 \\
19.8 \\
19.5 \\
\end{array}$ & $\begin{array}{l}3.2 \\
3.5 \\
3.4 \\
\end{array}$ & $\begin{array}{l}0 \\
0 \\
0 \\
\end{array}$ & $\begin{array}{l}0.32 \\
0.56 \\
0.54 \\
\end{array}$ & $\begin{array}{l}0.55 \\
0.73 \\
0.61 \\
\end{array}$ & $\begin{array}{l}77.4 \\
30.4 \\
13.0 \\
\end{array}$ & $\begin{array}{l}a \\
a\end{array}$ \\
\hline Weighted & Averages: & 22.8 & 19.5 & 3.4 & 0 & 0.54 & 0.61 & 13.0 & b \\
\hline $\begin{array}{l}5 / 2-5 / 4 \\
5 / 4-5 / 6\end{array}$ & $\begin{array}{l}2809 \\
2718\end{array}$ & $\begin{array}{l}15.2 \\
15.3 \\
\end{array}$ & $\begin{array}{l}13.9 \\
13.8 \\
\end{array}$ & $\begin{array}{l}3.4 \\
3.4 \\
\end{array}$ & $\begin{array}{l}0 \\
\underline{0}\end{array}$ & $\begin{array}{l}0.85 \\
0.73 \\
\end{array}$ & $\begin{array}{l}0.70 \\
0.75 \\
\end{array}$ & $\begin{array}{r}-17.6 \\
2.7 \\
\end{array}$ & a \\
\hline \multicolumn{2}{|c|}{ Weighted Averages: } & 15.3 & 13.8 & 3.4 & 0 & 0.73 & 0.75 & 2.7 & \\
\hline $\begin{array}{l}5 / 6-5 / 7 \\
5 / 7-5 / 8 \\
5 / 8-5 / 10 \\
5 / 10-5 / 1\end{array}$ & $\begin{array}{l}1392 \\
1413 \\
3050 \\
4234\end{array}$ & $\begin{array}{l}15.3 \\
15.4 \\
15.4 \\
15.4 \\
\end{array}$ & $\begin{array}{l}13.9 \\
13.9 \\
13.8 \\
13.7 \\
\end{array}$ & $\begin{array}{l}6.7 \\
6.9 \\
6.9 \\
6.8 \\
\end{array}$ & $\begin{array}{l}0 \\
0 \\
0 \\
0 \\
\end{array}$ & $\begin{array}{l}2.12 \\
2.11 \\
0.26 \\
1.94 \\
\end{array}$ & $\begin{array}{l}2.05 \\
2.40 \\
1.71 \\
1.94 \\
\end{array}$ & $\begin{array}{r}-3.3 \\
13.7 \\
557.7 \\
0.0 \\
\end{array}$ & $\begin{array}{l}a \\
a \\
a\end{array}$ \\
\hline \multicolumn{2}{|c|}{ Weighted Averages: } & 15.4 & 13.7 & 6.8 & 0 & 1.94 & 1.94 & 0.0 & b \\
\hline
\end{tabular}


Table A.3 Test Results for Sample CG-103--Continued

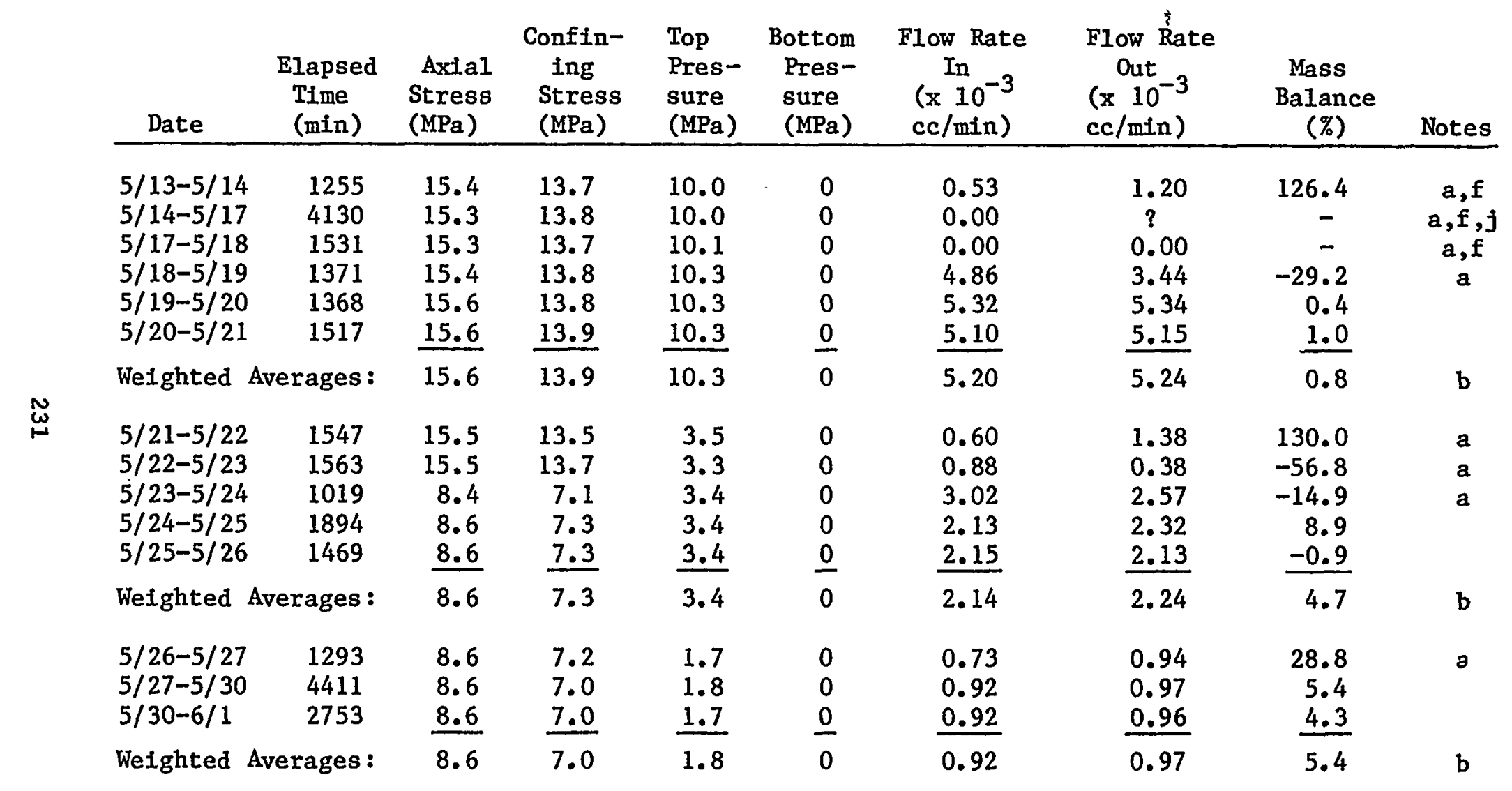

NOTES:

(a) Datum not Included in average.

(b) Averages weighted with respect to elapsed time. 
Table A.3 Test Results for Sample CG-103-- Continued

(c) Bottom flask overflowed.

(d) Ran out of $\mathrm{N}_{2}$.

(e) Linear encodẹ out or range.

(f) Error in valving arrangement.

(g) Negative flow rate out probably due to experimental error. Actual value is probably very small and positive.*

(h) Not included in summary table.

(i) Bottom flast dropped; no measurement of flow rate out.

* During these early measurements on rock mass sealing/borehole plug testing, it came as a surprise that water might be drawn into the plug from the outflow collection system. Such occurrences have since been observed repeatedly, and are attributed to capillary action of unsaturated plugs or rocks and atmospheric pressure changes (e.g. Daemen et al., 1985, Section 6.5.2; Akgun and Daemen, 1986, Section 3.4). 
Table A.4 Test Results for Sample SGE-2-2

\begin{tabular}{|c|c|c|c|c|c|c|c|c|c|c|}
\hline Date & $\begin{array}{l}\text { Elapsed } \\
\text { Time } \\
\text { (min) }\end{array}$ & $\begin{array}{l}\text { Axial } \\
\text { Stress } \\
\text { (MPa) }\end{array}$ & $\begin{array}{l}\text { Confin- } \\
\quad \text { ing } \\
\text { Stress } \\
\text { (MPa) } \\
\end{array}$ & $\begin{array}{l}\text { Top } \\
\text { Pres- } \\
\text { sure } \\
\text { (MPa) }\end{array}$ & $\begin{array}{c}\text { Flow Rate } \\
\text { In } \\
\left(\times 10^{-3}\right. \\
\mathrm{cc} / \mathrm{min})\end{array}$ & $\begin{array}{c}\text { Flow Rate } \\
\text { Out } \\
\left(\times 10^{-3}\right. \\
\mathrm{cc} / \mathrm{min})\end{array}$ & $\begin{array}{c}V_{A} \\
(c c)\end{array}$ & $\begin{array}{c}V_{I} \\
(c c)\end{array}$ & $\begin{array}{c}V_{0} \\
(\mathrm{gm})\end{array}$ & Notes \\
\hline $\begin{array}{l}5 / 19-5 / 20^{*} \\
5 / 20-5 / 21{ }^{*} \\
5 / 21-5 / 22 \\
5 / 22-5 / 25^{*}\end{array}$ & $\begin{array}{l}1432 \\
1409 \\
1607 \\
4504\end{array}$ & $\begin{array}{l}21.3 \\
22.6 \\
22.6 \\
22.5\end{array}$ & $\begin{array}{l}19.5 \\
19.9 \\
19.5 \\
18.9\end{array}$ & $\begin{array}{l}9.5 \\
9.6 \\
9.7 \\
9.7\end{array}$ & $\begin{array}{l}0.03 \\
0.04 \\
0.03 \\
0.03\end{array}$ & $\begin{array}{l}0 \\
0 \\
0 \\
0\end{array}$ & $\begin{array}{l}\text { NR } \\
0.28 \\
0.41 \\
0.16\end{array}$ & $\begin{array}{l}0.04 \\
0.05 \\
0.05 \\
0.15\end{array}$ & $\begin{array}{l}0 \\
0 \\
0 \\
0\end{array}$ & $\begin{array}{l}\mathrm{a} \\
\mathrm{a} \\
\mathrm{a} \\
\mathrm{a}\end{array}$ \\
\hline
\end{tabular}

5/26-5/27 Lowered bottom pressure to atmospheric. Let sample equilibrate overnight.

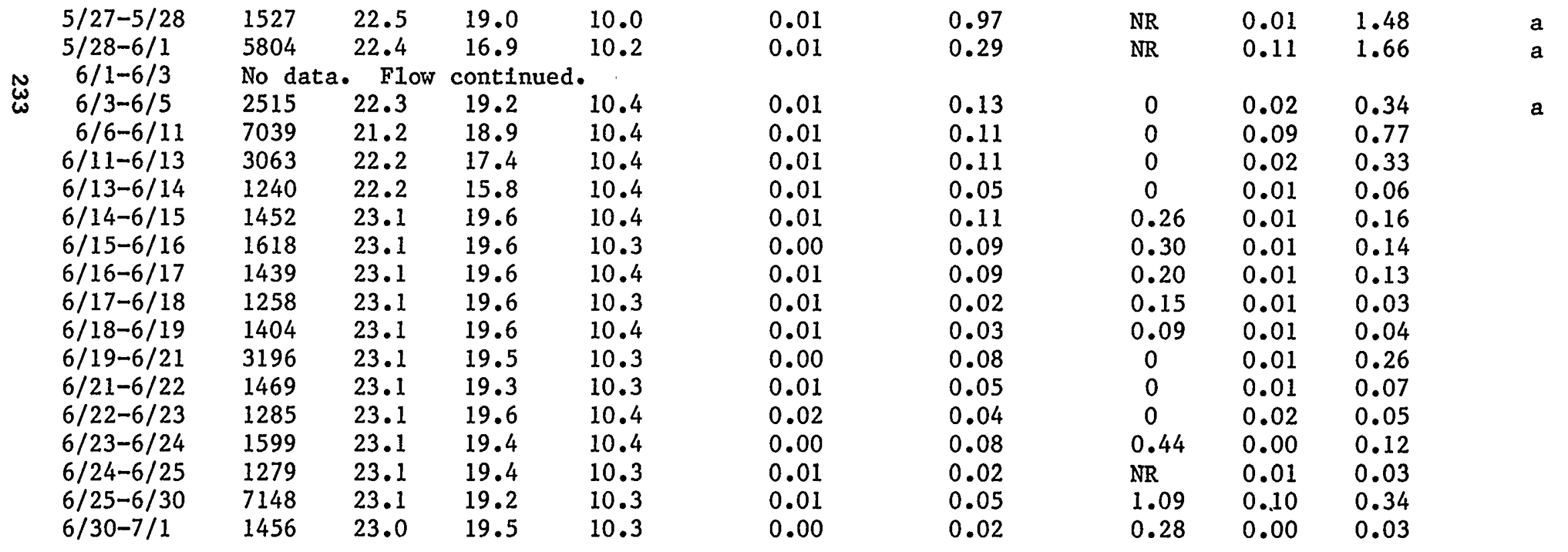


Table A.4 Test Results for Sample SGE-2-2--Continued

\begin{tabular}{|c|c|c|c|c|c|c|c|c|c|c|}
\hline Date & $\begin{array}{c}\text { Elapsed } \\
\text { Time } \\
\text { (min) }\end{array}$ & $\begin{array}{l}\text { Axlal } \\
\text { Stress } \\
\text { (MPa) }\end{array}$ & $\begin{array}{l}\text { Confin- } \\
\quad \text { ing } \\
\text { Stress } \\
(\mathrm{MPa}) \\
\end{array}$ & $\begin{array}{l}\text { Top } \\
\text { Pres- } \\
\text { sure } \\
\text { (MPa) }\end{array}$ & $\begin{array}{c}\text { Flow Rate } \\
\text { In } \\
\left(\times 10^{-3}\right. \\
\mathrm{cc} / \mathrm{min})\end{array}$ & $\begin{array}{c}\text { Flow Rate } \\
\text { Out } \\
\left(x 10^{-3}\right. \\
\text { cc/min })\end{array}$ & $\begin{array}{c}V_{A} \\
(c c) \\
\end{array}$ & $\begin{array}{c}V_{I} \\
(c c)\end{array}$ & $\begin{array}{c}V_{0} \\
(\mathrm{gm}) \\
\end{array}$ & Notes \\
\hline $\begin{array}{l}7 / 1-7 / 3 \\
7 / 3-7 / 5\end{array}$ & $\begin{array}{l}2601 \\
2737\end{array}$ & $\begin{array}{l}23.1 \\
23.0 \\
\end{array}$ & $\begin{array}{l}19.5 \\
19.5 \\
\end{array}$ & $\begin{array}{l}10.3 \\
10.3 \\
\end{array}$ & $\begin{array}{l}0.00 \\
0.00 \\
\end{array}$ & $\begin{array}{l}0.03 \\
0.04 \\
\end{array}$ & $\begin{array}{l}0.36 \\
0.39 \\
\end{array}$ & $\begin{array}{l}0.01 \\
0.01 \\
\end{array}$ & $\begin{array}{l}0.07 \\
0.10 \\
\end{array}$ & \\
\hline \multirow[t]{2}{*}{ Weighted } & Averages: & 22.7 & 19.1 & 10.3 & 0.01 & 0.07 & & & & $\mathrm{~b}$ \\
\hline & & & & & & Totals: & 4.41 & 0.77 & 6.21 & \\
\hline
\end{tabular}

Cement System 1 Plug Poured 4:45 pm, July 7, 1982

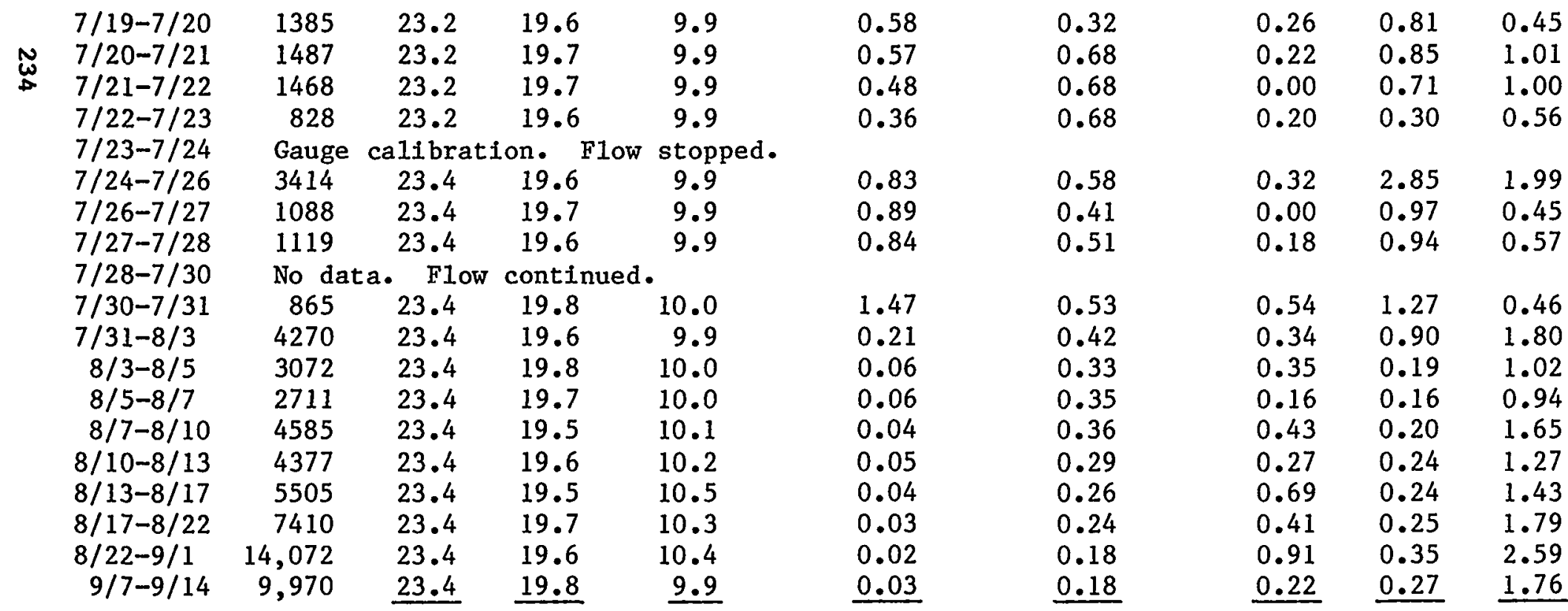


Table A.4 Test Results for Sample SGE-2-2--Continued

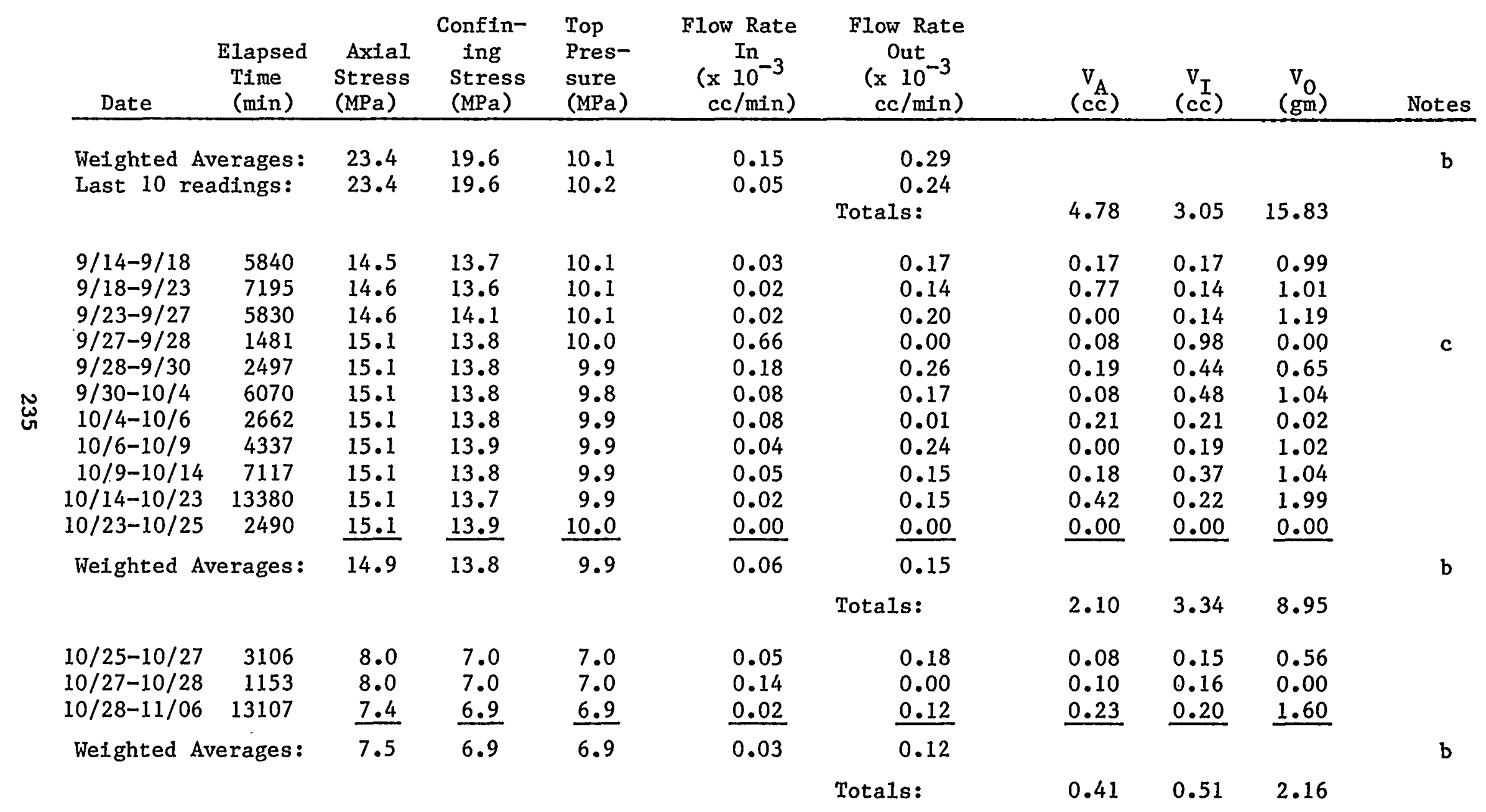


Table A.4 Test Results for Sample SGE-2-2--Continued

\begin{tabular}{|c|c|c|c|c|c|c|c|c|c|c|}
\hline Date & $\begin{array}{l}\text { Elapsed } \\
\text { Time } \\
\text { (min) }\end{array}$ & $\begin{array}{l}\text { Axial } \\
\text { Stress } \\
\text { (MPa) }\end{array}$ & $\begin{array}{l}\text { Confin- } \\
\text { Ing } \\
\text { Stress } \\
\text { (MPa) }\end{array}$ & $\begin{array}{l}\text { Top } \\
\text { Pres- } \\
\text { sure } \\
\text { (MPa) }\end{array}$ & $\begin{array}{c}\text { Flow Rate } \\
\text { In } \\
\left(x 10^{-3}\right. \\
\text { cc/min) }\end{array}$ & $\begin{array}{c}\text { Flow Rate } \\
\text { Out } \\
\left(\mathrm{x} 10^{-3}\right. \\
\mathrm{cc} / \mathrm{min})\end{array}$ & $\begin{array}{c}\mathrm{V}_{\mathrm{A}} \\
(\mathrm{cc})\end{array}$ & $\begin{array}{l}V_{I} \\
(c c)\end{array}$ & $\begin{array}{c}\mathrm{V}_{0} \\
(\mathrm{gm})\end{array}$ & Notes \\
\hline
\end{tabular}

$11 / 7-11 / 10$

$11 / 10-12 / 21$

$12 / 21-12 / 27$

$12 / 27-1 / 12$
Sample dried in lab

Sample dried in oven $@ 130^{\circ} \mathrm{F}\left(54^{\circ} \mathrm{C}\right)$

Sample dried in lab

Sample saturated in permeameter

Cement System 1 Plug, After Drying

\begin{tabular}{crr} 
& $1 / 12$ & 108 \\
$1 / 12$ & 137 \\
\multirow{\omega}{*}{$1 / 13$} & 83 \\
$1 / 13$ & 119 \\
$1 / 15$ & 179 \\
$1 / 15$ & 142 \\
$1 / 16$ & 134 \\
$1 / 17$ & 305 \\
$1 / 18$ & 284 \\
$1 / 27$ & 279 \\
$1 / 27-1 / 28$ & 1027 \\
$1 / 28$ & 400 \\
$1 / 28-1 / 29$ & 957 \\
$1 / 29$ & 714 \\
$1 / 29-1 / 30$ & 815 \\
$1 / 30-1 / 31$ & 1366 \\
$1 / 31$ & 404 \\
$1 / 31-2 / 1$ & 1423 \\
$2 / 1-2 / 2$ & 1577
\end{tabular}

$\begin{array}{lll}8.7 & 7.2 & 1.6 \\ 8.7 & 7.1 & 1.6 \\ 8.8 & 7.3 & 1.9 \\ 8.8 & 7.3 & 2.0 \\ 8.8 & 7.2 & 2.1 \\ 8.8 & 7.3 & 1.9 \\ 8.8 & 7.2 & 2.0 \\ 8.9 & 7.6 & 2.1 \\ 8.9 & 7.6 & 2.0 \\ 8.8 & 6.9 & 2.0 \\ 8.8 & 6.8 & 2.0 \\ 8.8 & 6.9 & 2.1 \\ 8.8 & 6.9 & 2.0 \\ 8.8 & 6.9 & 2.0 \\ 8.8 & 6.9 & 2.0 \\ 8.8 & 6.9 & 2.0 \\ 8.9 & 6.9 & 2.1 \\ 8.9 & 6.9 & 2.0 \\ 8.8 & 6.8 & 2.1\end{array}$

917.04
760.44
736.27
766.47
532.91
484.23
375.75
258.13
239.47
109.89
96.19
102.63
85.84
85.24
75.60
71.46
68.19
55.74
53.54

925.19
772.34
744.10
769.24
531.90
484.23
376.12
262.16
242.25
109.68
96.17
101.73
85.63
85.39
75.80
71.41
67.67
55.61
53.25

$0.00 \quad 99.04 \quad 99.92$

$0.00 \quad 104.18 \quad 105.81$

$0.00 \quad 61.11 \quad 61.76$

$0.00 \quad 91.21 \quad 91.54$

$0.00 \quad 95.39 \quad 95.21$

$0.00 \quad 68.76 \quad 68.76$

$0.00 \quad 50.35 \quad 50.40$

$\begin{array}{lll}0.00 & 78.73 & 79.96\end{array}$

$\begin{array}{lll}0.00 & 68.01 & 68.80\end{array}$

$0.00 \quad 30.66 \quad 30.60$

$\begin{array}{lll}0.15 & 98.79 & 98.77\end{array}$

$0.00 \quad 41.05 \quad 40.69$

$0.16 \quad 82.15 \quad 81.95$

$\begin{array}{lll}0.00 & 60.86 & 60.97\end{array}$

$\begin{array}{lll}0.24 & 61.61 & 61.78\end{array}$

$\begin{array}{lll}0.14 & 97.61 & 97.55\end{array}$

$0.00 \quad 27.55 \quad 27.34$

$\begin{array}{lll}0.00 & 79.32 & 79.14\end{array}$

$0.00 \quad 84.43 \quad 83.97$ 
Table A.4 Test Results for Sample SGE-2-2--Continued

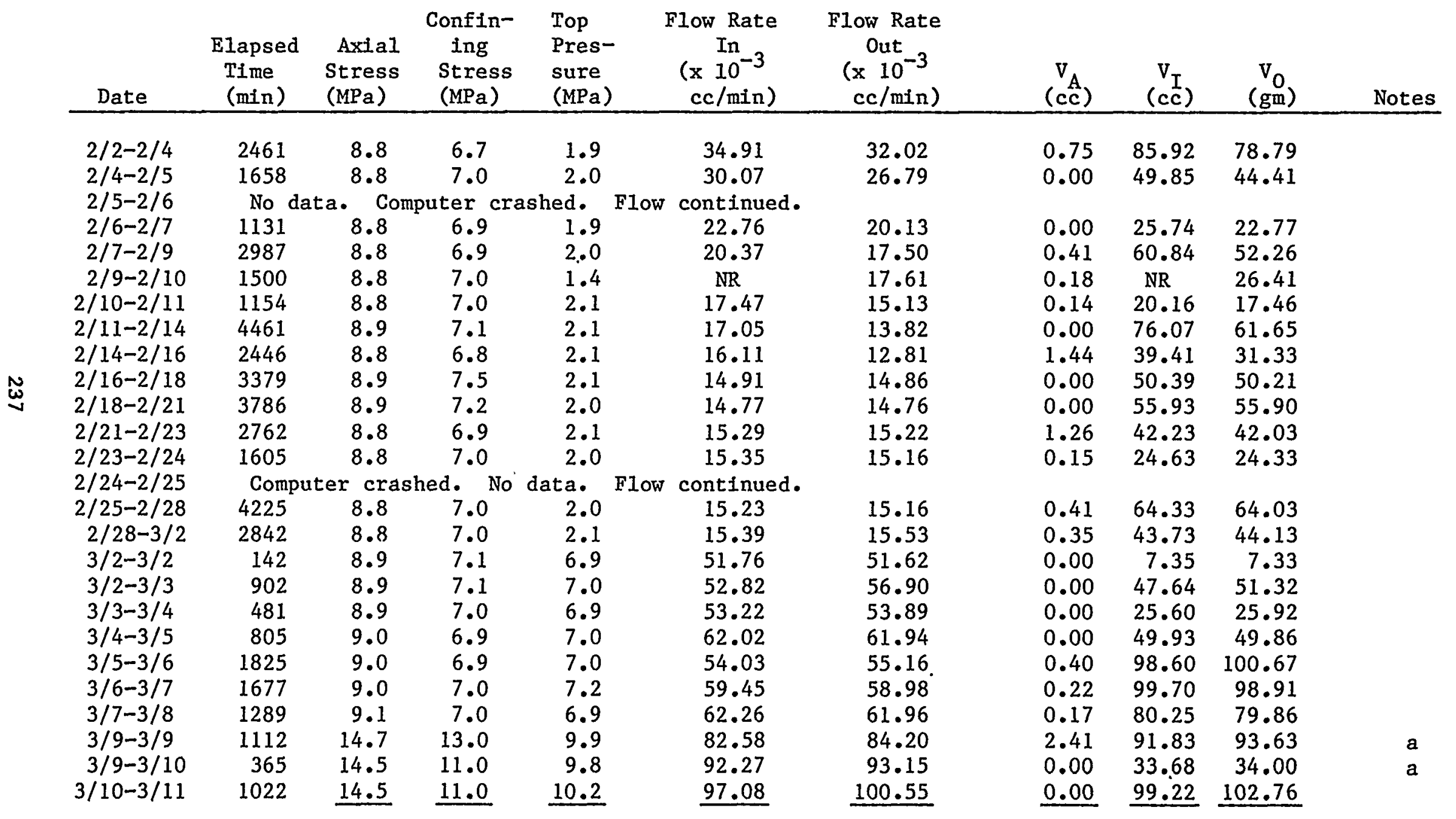


Table A.4 Test Results for Sample SGE-2-2--

\begin{tabular}{|c|c|c|c|c|c|c|c|c|c|c|}
\hline Date & $\begin{array}{c}\text { Elapsed } \\
\text { Time } \\
\text { (min) } \\
\end{array}$ & $\begin{array}{l}\text { Axial } \\
\text { Stress } \\
\text { (MPa) } \\
\end{array}$ & $\begin{array}{c}\text { Confin- } \\
\text { ing } \\
\text { Stress } \\
\text { (MPa) } \\
\end{array}$ & $\begin{array}{l}\text { Top } \\
\text { Pres- } \\
\text { sure } \\
(\mathrm{MPa}) \\
\end{array}$ & $\begin{array}{c}\text { Flow Rate } \\
\text { In } \\
\left(\mathrm{x} 10^{-3}\right. \\
\mathrm{cc} / \mathrm{min})\end{array}$ & $\begin{array}{c}\text { Flow Rate } \\
\text { Out } \\
\left(\times 10^{-3}\right. \\
\mathrm{cc} / \mathrm{min})\end{array}$ & $\begin{array}{c}\mathrm{V}_{\mathrm{A}} \\
(\mathrm{cc})\end{array}$ & $\begin{array}{c}V_{I} \\
(\mathrm{cc})\end{array}$ & $\begin{array}{c}\mathrm{V}_{0} \\
(\mathrm{gm})\end{array}$ & Notes \\
\hline $\begin{array}{c}3 / 11-3 / 12 \\
3 / 12 \\
3 / 15 \\
3 / 15-3 / 16 \\
3 / 16\end{array}$ & $\begin{array}{r}1026 \\
307 \\
490 \\
936 \\
440\end{array}$ & $\begin{array}{l}23.0 \\
23.4 \\
23.4 \\
23.2 \\
23.0 \\
\end{array}$ & $\begin{array}{l}19.1 \\
19.8 \\
19.8 \\
19.7 \\
19.8 \\
\end{array}$ & $\begin{array}{r}9.9 \\
10.0 \\
9.9 \\
10.1 \\
10.0 \\
\end{array}$ & $\begin{array}{l}86.36 \\
85.90 \\
78.94 \\
79.72 \\
79.36 \\
\end{array}$ & $\begin{array}{l}85.91 \\
87.04 \\
79.04 \\
78.62 \\
79.09 \\
\end{array}$ & $\begin{array}{l}0.82 \\
0.00 \\
0.00 \\
0.37 \\
0.00 \\
\end{array}$ & $\begin{array}{l}88.61 \\
26.37 \\
38.68 \\
74.62 \\
34.92 \\
\end{array}$ & $\begin{array}{l}88.14 \\
26.72 \\
39.73 \\
73.59 \\
34.80 \\
\end{array}$ & \\
\hline Weighted & Averages: & 23.2 & 19.5 & 10.0 & 82.27 & $\begin{array}{l}81.90 \\
\text { Totals: }\end{array}$ & 1.19 & 263.20 & 261.98 & \\
\hline
\end{tabular}

NOTES:

(a) Datum not included in average. Flow amounts included in totals (last three columns).

(b) Averages weighted with respect to time. Totals for last three columns.

(c) At beginning of this run the top seal was broken by raising the annulus pressure too high.

* Bottom pressure is 0 in all cases except for the first four dates, which had bottom pressures as follows: $6.5 \mathrm{MPa}$ for $5 / 19-5 / 20,9.4 \mathrm{MPa}$ for $5 / 20-5 / 21$ and $5 / 21-5 / 22$, and $8.7 \mathrm{MPa}$ for $5 / 22-5 / 25$.

Axial stress readings taken prior to $9 / 14$ may be about $3 \%$ too high.

$\mathrm{V}_{\mathrm{A}}$ is volume of water added to annulus. $\mathrm{V}_{\mathrm{I}}$ is volume of water pumped into top hole. $\mathrm{V}_{0}$ is weight of water collected from bottom hole. 
Table A.5 Test Results for Sample SGE-2-3

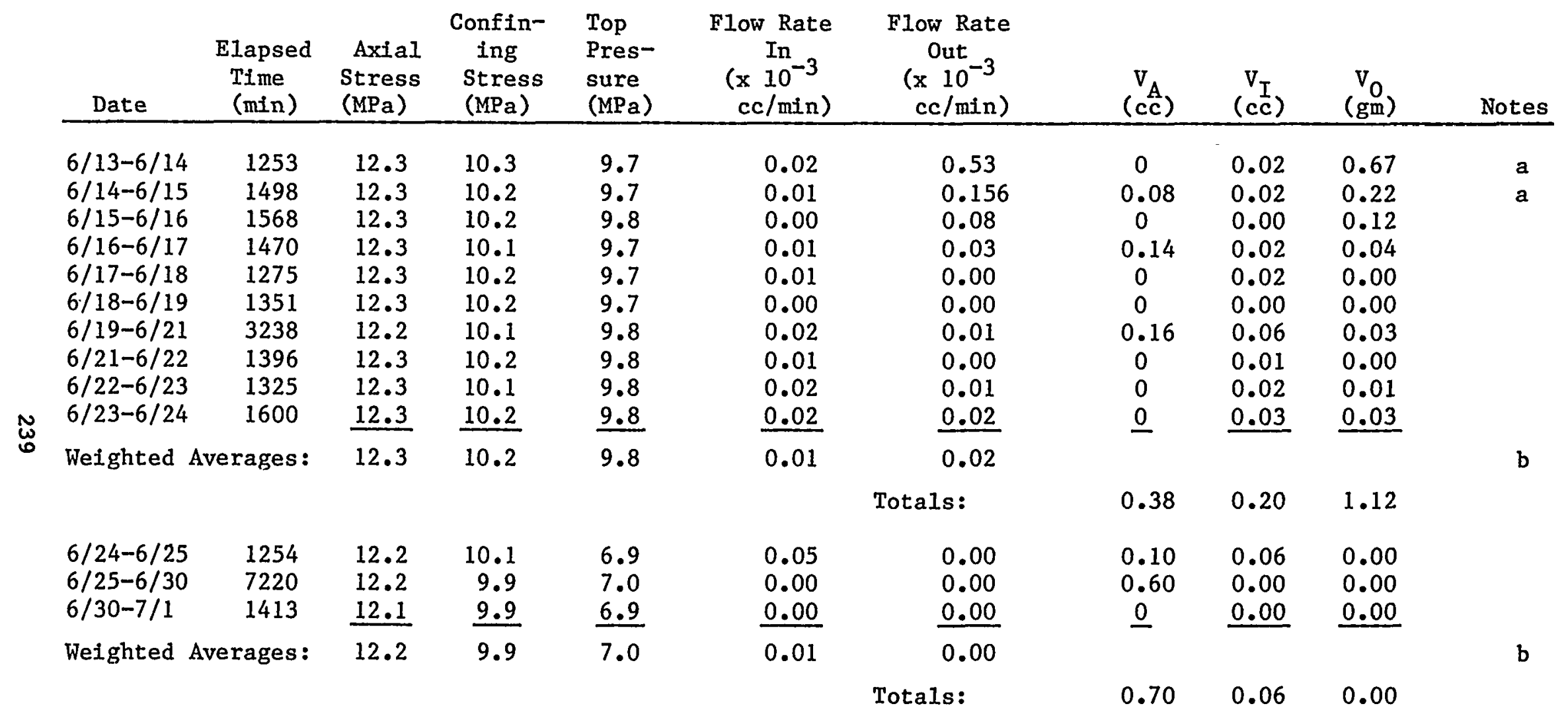

Cement System 1 poured at 4:45 pm, July 7, 1982

$\begin{array}{rrrrrrrrrr}7 / 19-7 / 20 & 1397 & 23.2 & 19.6 & 9.9 & 1.49 & 1.68 & 0.94 & 2.08 & 2.34 \\ 7 / 20-7 / 21 & 1461 & 23.3 & 19.6 & 9.8 & 1.24 & 1.83 & 0.49 & 1.81 & 2.68 \\ 7 / 21-7 / 22 & 1506 & 23.3 & 19.6 & 9.7 & 1.40 & 2.17 & 0.29 & 2.11 & 3.27 \\ 7 / 22-7 / 23 & 807 & 23.3 & 19.6 & 10.0 & 1.28 & 2.30 & 0.00 & 1.03 & 1.86\end{array}$


Table A.5 Test Results for Sample SGE-2-3--Continued

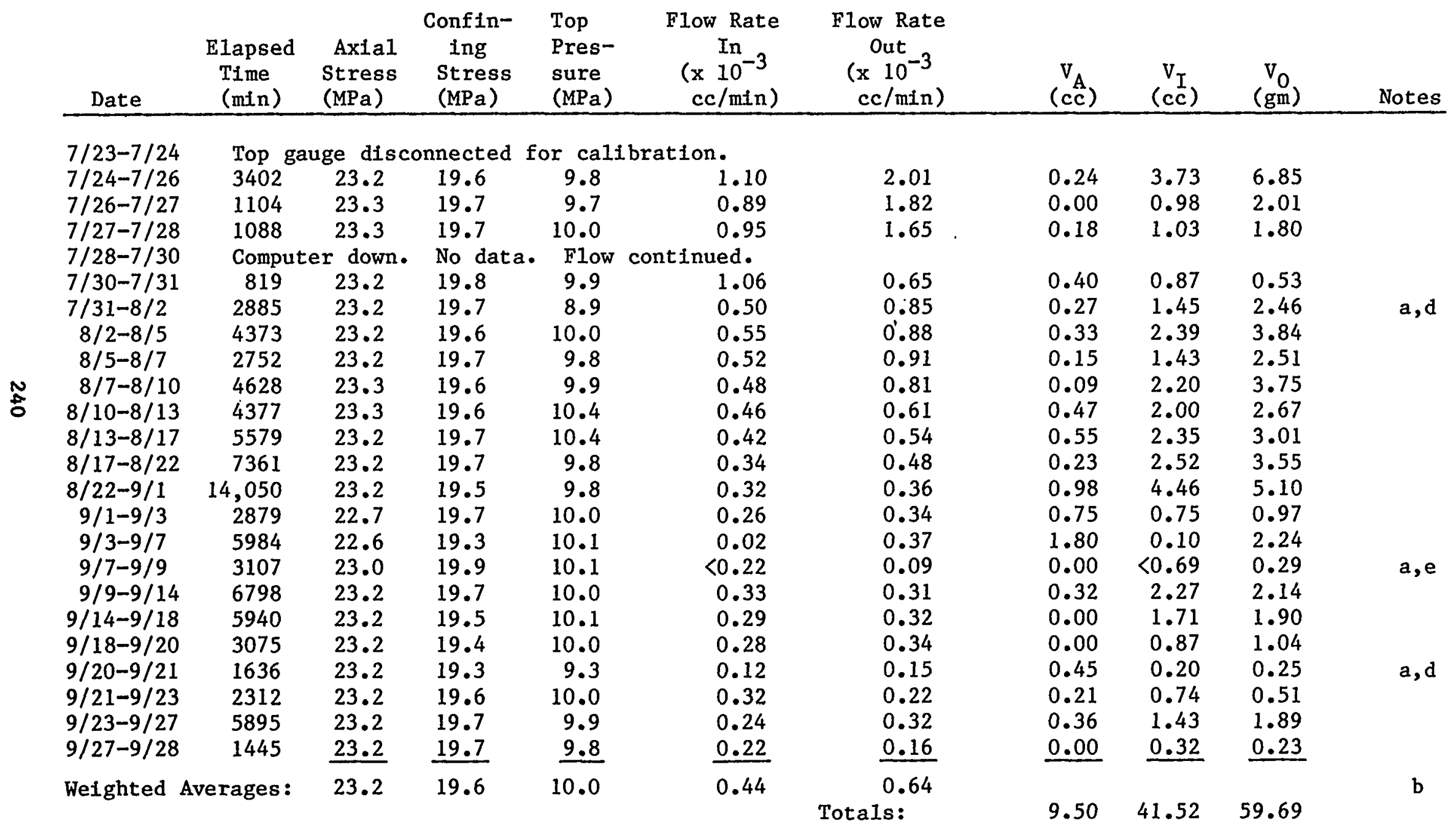


Table A.5 Test Results for Sample SGE-2-3-- Continued

\begin{tabular}{|c|c|c|c|c|c|c|c|c|c|c|}
\hline Date & $\begin{array}{l}\text { Elapsed } \\
\text { Time } \\
\text { (min) } \\
\end{array}$ & $\begin{array}{l}\text { Axial } \\
\text { Stress } \\
\text { (MPa) } \\
\end{array}$ & $\begin{array}{l}\text { Confin- } \\
\quad \text { ing } \\
\text { Stress } \\
\text { (MPa) } \\
\end{array}$ & $\begin{array}{l}\text { Top } \\
\text { Pres- } \\
\text { sure } \\
(\mathrm{MPa}) \\
\end{array}$ & $\begin{array}{c}\text { Flow Rate } \\
\text { In } \\
\left(\times 10^{-3}\right. \\
\mathrm{cc} / \mathrm{min})\end{array}$ & $\begin{array}{c}\text { Flow Rate } \\
\text { Out } \\
\left(\times 10^{-3}\right. \\
\mathrm{cc} / \mathrm{min}) \\
\end{array}$ & $\begin{array}{c}\mathrm{V}_{\mathrm{A}} \\
(\mathrm{cc})\end{array}$ & $\begin{array}{c}V_{I} \\
(c c)\end{array}$ & $\begin{array}{c}v_{0} \\
(\mathrm{gm})\end{array}$ & Notes \\
\hline Last $10 \mathrm{P}$ & $\begin{array}{l}\text { eadings: } \\
" \text { : }\end{array}$ & 23.1 & 19.6 & 9.9 & 0.27 & 0.35 & 5.10 & 16.06 & 20.11 & \\
\hline $\begin{array}{l}9 / 28-9 / 30 \\
9 / 30-10 / 4\end{array}$ & $\begin{array}{l}2551 \\
5982\end{array}$ & $\begin{array}{l}14.4 \\
14.5 \\
\end{array}$ & $\begin{array}{l}10.4 \\
10.4 \\
\end{array}$ & $\begin{array}{l}10.1 \\
10.1 \\
\end{array}$ & $\begin{array}{l}0.31 \\
0.30 \\
\end{array}$ & $\begin{array}{l}0.31 \\
0.29 \\
\end{array}$ & $\begin{array}{l}0.14 \\
0.00 \\
\end{array}$ & $\begin{array}{l}0.80 \\
1.77 \\
\end{array}$ & $\begin{array}{l}0.78 \\
1.73 \\
\end{array}$ & \\
\hline \multicolumn{2}{|c|}{ Weighted Averages: } & 14.5 & 10.4 & 10.1 & 0.30 & $\begin{array}{c}0.30 \\
\text { Totals: }\end{array}$ & 0.14 & 2.57 & 2.51 & b \\
\hline $\begin{array}{l}10 / 4-10 / 6 \\
10 / 6-10 / 9 \\
10 / 9-10 / 14\end{array}$ & $\begin{array}{l}2612 \\
4384 \\
7130\end{array}$ & $\begin{array}{l}7.8 \\
9.7 \\
9.6 \\
\end{array}$ & $\begin{array}{l}6.7 \\
5.2 \\
5.2 \\
\end{array}$ & $\begin{array}{l}6.7 \\
3.5 \\
3.4 \\
\end{array}$ & $\begin{array}{l}0.03 \\
0.08 \\
0.11 \\
\end{array}$ & $\begin{array}{l}0.12 \\
0.13 \\
0.10 \\
\end{array}$ & $\begin{array}{l}\mathrm{NR} \\
0.0 \\
0.00 \\
\end{array}$ & $\begin{array}{l}0.07 \\
0.35 \\
0.77 \\
\end{array}$ & $\begin{array}{l}0.32 \\
0.59 \\
0.73 \\
\end{array}$ & $a, f$ \\
\hline Welghted A & Averages: & 9.6 & 5.2 & 3.4 & 0.10 & $\begin{array}{c}0.11 \\
\text { Totals: }\end{array}$ & 0.00 & 1.12 & 1.32 & b \\
\hline
\end{tabular}

NOTES:

(a) Datum not included in average. Flow amounts included in totals (last three columns).

(b) Averages weighted with respect to time. Totals for last three columns.

(c) Bottom valve closed for several days prior to test. Excess water out probably due to drainage when bottom valve opened and bottom pressure fell to zero.

(d) Ran out of $\mathrm{N}_{2}$ driving injection pump.

(e) Changed $\mathrm{N}_{2}$ tank before this test. Forgot to open top valve. $Q_{\text {IN }}$ represents water injected when top valve opened.

(f) Annulus in communication with top hole through top seal. Believe bottom seal holding.

(NR) Not recorded. 
Table A.5 Test Results for Sample SGE-2-3--Notes--Continued

Bottom pressure is always $0 \mathrm{MPa}$.

Axial stress readings taken prior to $9 / 14$ may be about $3 \%$ too high.

$\mathrm{V}_{\mathrm{A}}$ is volume of water added to annulus.

$V_{I}$ is volume of water pumped into top hole.

$V_{0}$ is weight of water flowing from bottom hole. 
Table A.6 Test Results for Sample NTS-TPTS-101

\begin{tabular}{|c|c|c|c|c|c|c|c|c|c|}
\hline Date & $\begin{array}{l}\text { Elapsed } \\
\text { Time } \\
\text { (min) }\end{array}$ & $\begin{array}{l}\text { Axial } \\
\text { Stress } \\
\text { (MPa) }\end{array}$ & $\begin{array}{l}\text { Confin- } \\
\text { ing } \\
\text { Stress } \\
\text { (MPa) }\end{array}$ & $\begin{array}{l}\text { Top } \\
\text { Pres- } \\
\text { sure } \\
\text { (MPa) }\end{array}$ & $\begin{array}{c}\text { Flow Rate } \\
\text { In } \\
\left(\times 10^{-3}\right. \\
\mathrm{cc} / \mathrm{min})\end{array}$ & $\begin{array}{c}\text { Flow Rate } \\
\text { Out } \\
\text { (x } 10^{-3} \\
\text { cc/min) }\end{array}$ & $\stackrel{\mathbb{N}_{A}}{(\mathrm{cc})}$ & $\begin{array}{l}V_{I} \\
(c c)\end{array}$ & $\begin{array}{c}\mathrm{V}_{0} \\
(\mathrm{gm})\end{array}$ \\
\hline
\end{tabular}

Rock Bridge

$\begin{array}{ccccccccccc}12 / 18 & 272 & 10.5 & 7.6 & 1.8 & 99.26 & 49.72 & 0.00 & 26.97 & 13.51 & a, c \\ 12 / 18 & 194 & 10.5 & 7.1 & 1.8 & 58.71 & 56.75 & 0.00 & 11.39 & 11.01 & a, c \\ 12 / 18-12 / 19 & 696 & 10.5 & 6.5 & 1.9 & 62.60 & 61.75 & 1.49 & 43.57 & 42.98 & a, c \\ 12 / 19-12 / 21 & \text { No testing. } & \text { Flow stopped. } & & & & \end{array}$

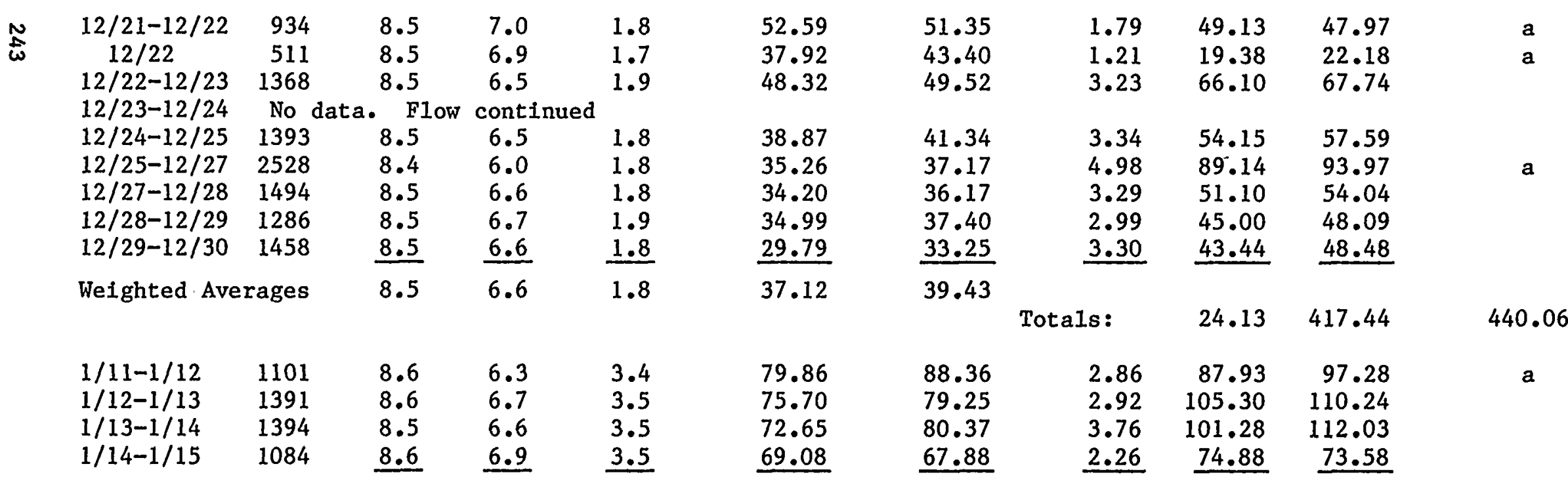


Table A.6 Test Results for Sample NTS-TPTS-101--Continued

\begin{tabular}{|c|c|c|c|c|c|c|c|c|c|c|}
\hline Date & $\begin{array}{c}\text { Elapsed } \\
\text { Time } \\
\text { (min) }\end{array}$ & $\begin{array}{l}\text { Axial } \\
\text { Stress } \\
\text { (MPa) } \\
\end{array}$ & $\begin{array}{l}\text { Confin- } \\
\quad \text { ing } \\
\text { Stress } \\
\text { (MPa) } \\
\end{array}$ & $\begin{array}{l}\text { Top } \\
\text { Pres- } \\
\text { sure } \\
\text { (MPa) }\end{array}$ & $\begin{array}{c}\text { Flow Rate } \\
\text { In } \\
\left(x 10^{-3}\right. \\
\mathrm{cc} / \mathrm{min})\end{array}$ & $\begin{array}{c}\text { Flow Rate } \\
\text { Out } \\
\left(\times 10^{-3}\right. \\
\mathrm{cc} / \mathrm{min})\end{array}$ & $\begin{array}{c}V_{A} \\
(\mathrm{cc})\end{array}$ & $\begin{array}{l}V_{I} \\
(c c) \\
\end{array}$ & $\begin{array}{c}V_{0} \\
(\mathrm{gm})\end{array}$ & Notes \\
\hline Weighted & Averages & 8.6 & 6.7 & 3.5 & 72.75 & 76.47 & Totals: & 11.80 & 369.39 & $\begin{array}{c}b \\
393.13\end{array}$ \\
\hline $\begin{array}{c}1 / 15 \\
1 / 16 \\
1 / 16-1 / 1 \\
1 / 18 \\
1 / 18 \\
1 / 18-1 / 15\end{array}$ & $\begin{array}{l}422 \\
280 \\
301 \\
338 \\
247 \\
665\end{array}$ & $\begin{array}{l}8.9 \\
8.9 \\
9.0 \\
8.8 \\
8.7 \\
8.4 \\
\end{array}$ & $\begin{array}{l}7.5 \\
7.6 \\
7.4 \\
6.3 \\
6.4 \\
5.2 \\
\end{array}$ & $\begin{array}{l}6.0 \\
6.0 \\
6.1 \\
6.1 \\
6.2 \\
6.0 \\
\end{array}$ & $\begin{array}{l}151.68 \\
152.29 \\
151.33 \\
190.89 \\
180.16 \\
168.41 \\
\end{array}$ & $\begin{array}{c}152.82 \\
159.46 \\
\text { NR } \\
147.69 \\
150.40 \\
168.00 \\
\end{array}$ & $\begin{array}{l}0.37 \\
0.00 \\
0.00 \\
1.80 \\
1.55 \\
5.80 \\
\end{array}$ & $\begin{array}{r}64.01 \\
42.64 \\
45.11 \\
64.52 \\
44.50 \\
111.99 \\
\end{array}$ & $\begin{array}{c}64.49 \\
44.65 \\
\mathrm{NR} \\
49.92 \\
37.15 \\
111.72 \\
\end{array}$ & $d$ \\
\hline Welghted & Averages & $\begin{array}{l}8.7 \\
9.0 \\
\end{array}$ & $\begin{array}{r}6.5 \\
6.9 \\
\end{array}$ & $\begin{array}{l}6.1 \\
7.0 \\
\end{array}$ & $\begin{array}{r}165.65 \\
186.67 \\
\end{array}$ & $\begin{array}{c}157.75 \\
\text { Totals: } \\
219.55 \\
\end{array}$ & $\begin{array}{l}9.52 \\
0.00 \\
\end{array}$ & $\begin{array}{r}372.77 \\
12.32 \\
\end{array}$ & $\begin{array}{r}307.93 \\
14.49 \\
\end{array}$ & b \\
\hline Welghted & Averages & 9.0 & 6.9 & 7.0 & 186.67 & $\begin{array}{l}219.55 \\
\text { Totals: }\end{array}$ & 0.00 & 12.32 & 14.49 & \\
\hline $\begin{array}{c}1 / 29 \\
1 / 29 \\
1 / 29-1 / 30 \\
1 / 30\end{array}$ & $\begin{array}{l}405 \\
267 \\
804 \\
347\end{array}$ & $\begin{array}{l}8.8 \\
8.8 \\
8.9 \\
8.9 \\
\end{array}$ & $\begin{array}{l}6.9 \\
7.1 \\
7.0 \\
7.1 \\
\end{array}$ & $\begin{array}{l}6.0 \\
5.9 \\
6.0 \\
6.0 \\
\end{array}$ & $\begin{array}{l}137.56 \\
126.59 \\
129.03 \\
121.79 \\
\end{array}$ & $\begin{array}{l}127.90 \\
128.76 \\
129.95 \\
116.43 \\
\end{array}$ & $\begin{array}{l}0.00 \\
0.45 \\
0.92 \\
0.00 \\
\end{array}$ & $\begin{array}{r}55.71 \\
33.80 \\
103.74 \\
42.26 \\
\end{array}$ & $\begin{array}{r}51.80 \\
34.38 \\
104.48 \\
40.40 \\
\end{array}$ & a \\
\hline Weighted & Averages & 8.9 & 7.0 & 6.0 & 126.80 & $\begin{array}{l}126.42 \\
\text { Totals: }\end{array}$ & 1.37 & 235.51 & 231.06 & b \\
\hline $\begin{array}{l}1 / 30-1 / 3 \\
1 / 31-2 / 1\end{array}$ & $\begin{array}{l}1282 \\
1567\end{array}$ & $\begin{array}{l}15.3 \\
14.6\end{array}$ & $\begin{array}{l}8.9 \\
5.7\end{array}$ & $\begin{array}{l}3.4 \\
3.5\end{array}$ & $\begin{array}{l}52.09 \\
55.41\end{array}$ & $\begin{array}{l}52.69 \\
51.39\end{array}$ & $\begin{array}{l}0.00 \\
0.00\end{array}$ & $\begin{array}{l}66.78 \\
86.83\end{array}$ & $\begin{array}{l}67.55 \\
80.53\end{array}$ & $\begin{array}{l}a \\
a\end{array}$ \\
\hline
\end{tabular}


Table A.6 Test Results for Sample NTS-TPTS-101--Continued

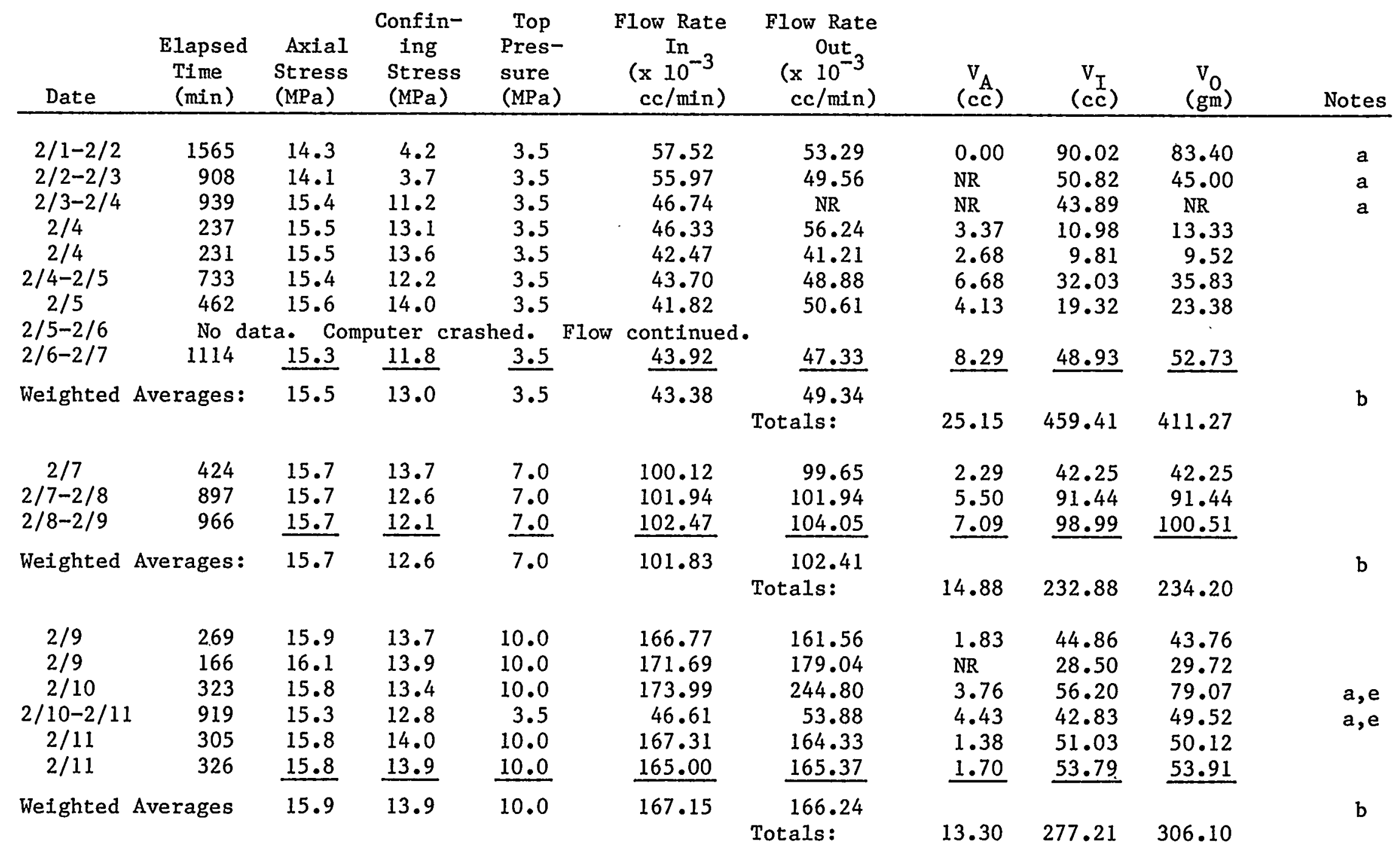


Table A.6 Test Results for Sample NTS-TPTS-101--Continued

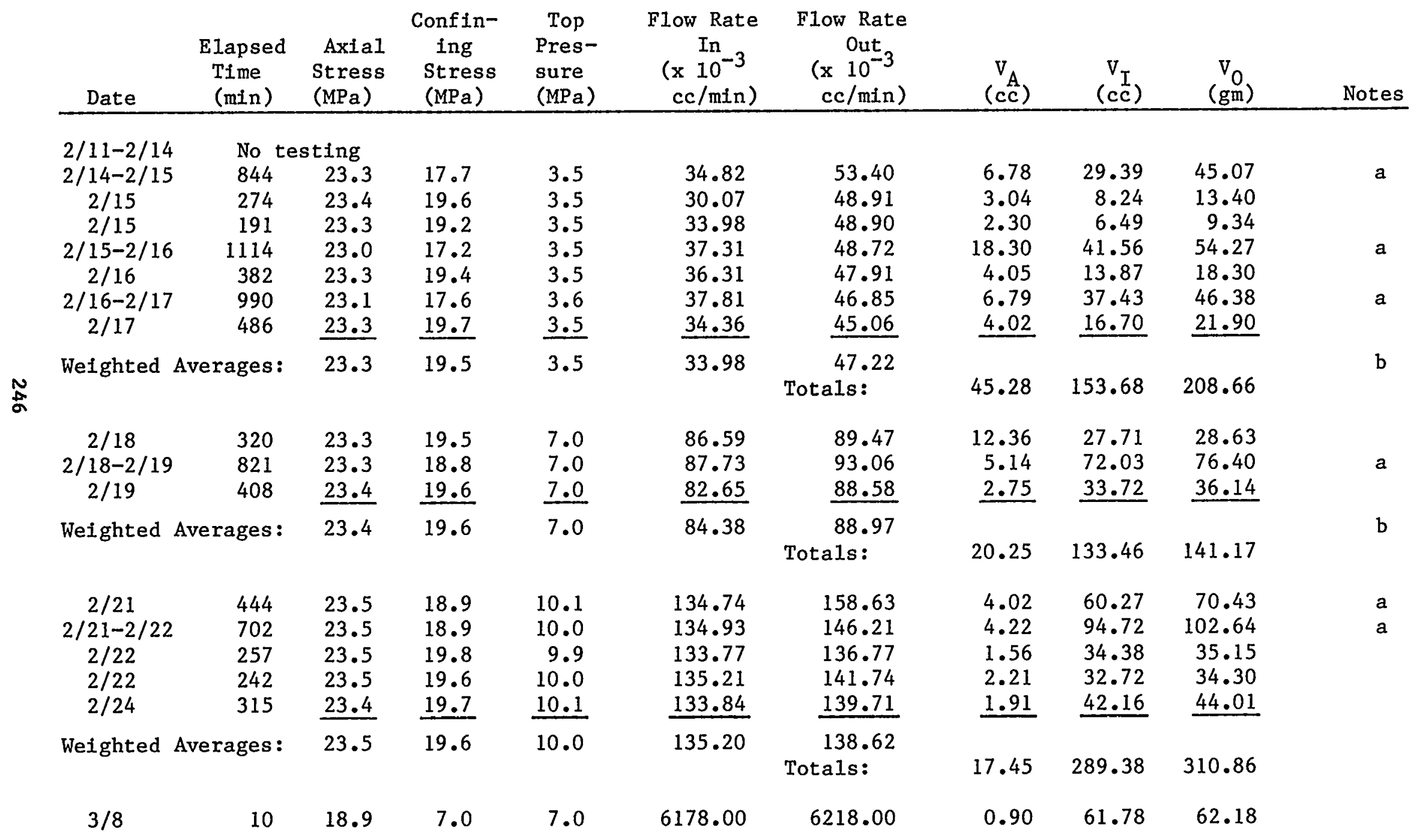


Table A.6 Test Results for Sample NTS-TPTS-101--Continued

\begin{tabular}{|c|c|c|c|c|c|c|c|c|c|c|}
\hline Date & $\begin{array}{c}\text { Elapsed } \\
\text { Time } \\
\text { (min) } \\
\end{array}$ & $\begin{array}{l}\text { Axial } \\
\text { Stress } \\
\text { (MPa) } \\
\end{array}$ & $\begin{array}{l}\text { Confin- } \\
\text { ing } \\
\text { Stress } \\
\text { (MPa) } \\
\end{array}$ & $\begin{array}{l}\text { Top } \\
\text { Pres- } \\
\text { sure } \\
\text { (MPa) } \\
\end{array}$ & $\begin{array}{c}\text { Flow Rate } \\
\text { In } \\
\left(x 10^{-3}\right. \\
\mathrm{cc} / \mathrm{min}) \\
\end{array}$ & $\begin{array}{c}\text { Flow Rate } \\
\text { Out } \\
\left(x 10^{-3}\right. \\
\text { cc/min) }\end{array}$ & $\begin{array}{c}\mathrm{V}_{\mathrm{A}} \\
(\mathrm{cc})\end{array}$ & $\begin{array}{c}V_{I} \\
(c c)\end{array}$ & $\begin{array}{r}V_{0} \\
(\mathrm{gm})\end{array}$ & Notes \\
\hline $\begin{array}{l}3 / 8 \\
3 / 8 \\
3 / 8 \\
3 / 18 \\
3 / 22 \\
3 / 23 \\
3 / 24 \\
3 / 28 \\
3 / 30 \\
4 / 1 \\
4 / 8\end{array}$ & $\begin{array}{r}13.72 \\
42.13 \\
37.19 \\
92.26 \\
97.03 \\
99.07 \\
136 \\
159 \\
78 \\
138 \\
155 \\
\end{array}$ & $\begin{array}{l}18.9 \\
19.0 \\
19.1 \\
19.1 \\
19.1 \\
19.2 \\
19.1 \\
19.1 \\
19.1 \\
19.1 \\
19.1 \\
\end{array}$ & $\begin{array}{l}7.0 \\
7.0 \\
7.6 \\
7.6 \\
7.6 \\
7.6 \\
7.6 \\
7.6 \\
7.6 \\
7.6 \\
7.6 \\
\end{array}$ & $\begin{array}{l}7.0 \\
7.0 \\
7.0 \\
7.0 \\
7.0 \\
7.1 \\
7.0 \\
7.1 \\
7.1 \\
7.1 \\
7.0 \\
\end{array}$ & $\begin{array}{r}5000.00 \\
2026.58 \\
1684.05 \\
564.71 \\
367.82 \\
363.68 \\
373.38 \\
251.51 \\
145.38 \\
126.81 \\
87.29 \\
\end{array}$ & $\begin{array}{r}5084.55 \\
2073.82 \\
1898.09 \\
695.10 \\
543.44 \\
504.49 \\
487.13 \\
369.18 \\
290.26 \\
236.74 \\
239.42 \\
\end{array}$ & $\begin{array}{l}1.00 \\
1.14 \\
\text { NR } \\
11.04 \\
15.90 \\
13.18 \\
15.24 \\
17.39 \\
10.61 \\
13.53 \\
24.56 \\
\end{array}$ & $\begin{array}{l}68.60 \\
85.38 \\
62.63 \\
52.10 \\
35.69 \\
36.03 \\
50.78 \\
39.99 \\
11.34 \\
17.50 \\
13.53 \\
\end{array}$ & $\begin{array}{l}69.76 \\
87.37 \\
70.59 \\
64.13 \\
52.73 \\
49.98 \\
66.25 \\
58.70 \\
22.64 \\
32.67 \\
37.11 \\
\end{array}$ & \\
\hline & & & & & & TOTALS: & 124.49 & 535.35 & 674.11 & \\
\hline
\end{tabular}

NOTES :

a) Not included in weighted average.

b) Averages weighted with respect to time.

c) Rock still saturating.

d) Pump ran out of water; Flow Rate In from data logger.

e) Poor mass balance.

NR) not recorded

$\mathrm{V}_{\mathrm{A}}=$ water added to annulus

$\mathrm{V}_{\mathrm{I}}^{\mathrm{A}}=$ water pumped into top hole

$\mathrm{V}_{0}^{\mathrm{I}}=$ outflow water collected

Bottom pressure is 0 throughout test sequence 
Table A.7 Test Results for Sample CCR-P-100

\begin{tabular}{|c|c|c|c|c|c|c|c|c|c|c|}
\hline Date & $\begin{array}{l}\text { Elapsed } \\
\text { Time } \\
\text { (min) }\end{array}$ & $\begin{array}{l}\text { Axial } \\
\text { Stress } \\
(\mathrm{MPa})\end{array}$ & $\begin{array}{l}\text { Confin- } \\
\text { ing } \\
\text { Stress } \\
\text { (MPa) }\end{array}$ & $\begin{array}{l}\text { Top } \\
\text { Pres- } \\
\text { sure } \\
\text { (MPa) }\end{array}$ & $\begin{array}{c}\text { Flow Rate } \\
\text { In } \\
\left(\mathrm{x} 10^{-3}\right. \\
\mathrm{cc} / \mathrm{min})\end{array}$ & $\begin{array}{c}\text { Flow Rate } \\
\text { Out } \\
\left(\mathrm{x} 10^{-3}\right. \\
\mathrm{cc} / \mathrm{min})\end{array}$ & $\begin{array}{c}\mathrm{V}_{\mathrm{A}} \\
(\mathrm{cc})\end{array}$ & $\left(\begin{array}{l}V_{I} \\
(\mathrm{cc})\end{array}\right.$ & $\begin{array}{c}V_{0} \\
(\mathrm{gm})\end{array}$ & Notes \\
\hline
\end{tabular}

\begin{tabular}{|c|c|c|c|c|}
\hline $8 / 3-8 / 3$ & 423 & 7.9 & 2.0 & 2.0 \\
\hline $8 / 3-8 / 4$ & 1070 & 7.8 & 2.0 & 2.0 \\
\hline $8 / 4-8 / 4$ & 346 & 7.8 & 2.1 & 2.0 \\
\hline $8 / 4-8 / 5$ & 1076 & 7.8 & 2.1 & 2.1 \\
\hline $8 / 5-8 / 5$ & 265 & 7.8 & 2.1 & 1.9 \\
\hline $8 / 5-8 / 6$ & 1219 & 7.8 & 2.1 & 1.9 \\
\hline $8 / 6-8 / 7$ & 1313 & 7.7 & 2.0 & 2.1 \\
\hline $8 / 7-8 / 9$ & 2704 & 7.7 & 2.0 & 1.9 \\
\hline $8 / 9-8 / 10$ & 1466 & 7.7 & 2.0 & 2.2 \\
\hline $8 / 10-8 / 11$ & 1362 & 7.8 & 2.0 & 2.2 \\
\hline $8 / 11-8 / 12$ & 1476 & 7.7 & 2.0 & 2.1 \\
\hline Weighted & iges: & 7.7 & 2.0 & 2.0 \\
\hline
\end{tabular}

Cement 1 Plug, Before Drying

\begin{tabular}{rrr}
2.0 & 10.35 & 9.60 \\
2.0 & 8.67 & 8.23 \\
2.0 & 2.86 & 5.61 \\
2.1 & 9.40 & 7.27 \\
1.9 & 8.34 & 8.38 \\
1.9 & 7.91 & $\mathrm{NR}$ \\
2.1 & 8.40 & 7.82 \\
1.9 & 7.27 & 7.17 \\
2.2 & $\mathrm{NR}$ & 8.10 \\
2.2 & 10.79 & 8.58 \\
2.1 & 10.36 & 8.45 \\
\hline 2.0 & $\mathbf{8 . 7 3}$ & 7.84 \\
& & Totals:
\end{tabular}

\begin{tabular}{lrr}
0.00 & 4.38 & 4.06 \\
0.26 & 9.28 & 8.81 \\
0.00 & 0.99 & 1.94 \\
0.00 & 10.11 & 7.82 \\
0.00 & 2.21 & 2.22 \\
0.00 & 9.64 & NR \\
0.00 & 11.03 & 10.27 \\
0.00 & 19.60 & 19.33 \\
0.00 & NR & 11.88 \\
0.00 & 14.69 & 11.68 \\
0.11 & 15.29 & 12.47 \\
\hline
\end{tabular}

$\begin{array}{lll}0.37 \quad 97.22 & 90.48\end{array}$

Cement 1 Plug, Afer Drying

$\begin{array}{crrrrrr}9 / 10-9 / 11 & 1386 & 7.5 & 2.2 & 1.9 & 11.93 & 10.49 \\ 9 / 11-9 / 12 & 1157 & 7.5 & 2.2 & 1.8 & 10.82 & 11.31 \\ 9 / 12-9 / 13 & 1318 & 7.5 & 2.1 & 1.8 & 10.86 & 11.39 \\ 9 / 13 & 387 & 7.5 & 2.1 & 1.8 & 10.72 & 12.79 \\ 9 / 13-9 / 14 & 1087 & 7.5 & 2.1 & 1.7 & 10.71 & 10.95 \\ 9 / 14-9 / 15 & 1365 & 7.4 & 2.1 & 1.7 & 10.53 & 11.00 \\ 9 / 15-9 / 15 & 250 & 7.4 & 2.1 & 1.7 & 10.44 & \text { NR } \\ 9 / 15-9 / 16 & 1082 & 7.4 & 2.1 & 2.1 & \text { NR } & 13.61 \\ 9 / 16-9 / 16 & 476 & 7.4 & 2.1 & 2.1 & \text { NR } & 13.68\end{array}$

$\begin{array}{lcc}0.00 & 16.54 & 14.54 \\ 0.00 & 12.52 & 13.08 \\ 0.00 & 14.31 & 15.01 \\ 0.00 & 4.15 & 4.95 \\ 0.00 & 11.64 & 11.90 \\ 0.00 & 14.37 & 15.01 \\ 0.00 & 2.61 & \text { NR } \\ 0.00 & \text { NR } & 14.73 \\ 0.00 & \text { NR } & 6.51\end{array}$


Table A.7 Test Results for Sample CCR-P-100--Continued

\begin{tabular}{|c|c|c|c|c|c|c|c|c|c|c|}
\hline Date & $\begin{array}{c}\text { Elapsed } \\
\text { Time } \\
\text { (min) }\end{array}$ & $\begin{array}{l}\text { Axial } \\
\text { Stress } \\
\text { (MPa) }\end{array}$ & $\begin{array}{l}\text { Confin- } \\
\quad \text { ing } \\
\text { Stress } \\
\text { (MPa) } \\
\end{array}$ & $\begin{array}{l}\text { Top } \\
\text { Pres- } \\
\text { sure } \\
\text { (MPa) } \\
\end{array}$ & $\begin{array}{c}\text { Flow Rate } \\
\text { In } \\
\left(\times 10^{-3}\right. \\
\mathrm{cc} / \mathrm{min})\end{array}$ & $\begin{array}{c}\text { Flow Rate } \\
\text { Out } \\
\left(\times 10^{-3}\right. \\
\mathrm{cc} / \mathrm{min})\end{array}$ & $\begin{array}{c}\mathrm{V}_{\mathrm{A}} \\
(\mathrm{cc})\end{array}$ & $\begin{array}{c}V_{I} \\
(c c)\end{array}$ & $\begin{array}{r}V_{0} \\
(\mathrm{gm}) \\
\end{array}$ & Notes \\
\hline $\begin{array}{l}9 / 16-9 / 17 \\
9 / 17-9 / 18 \\
9 / 18-9 / 19 \\
9 / 18-9 / 20 \\
9 / 20-9 / 21\end{array}$ & $\begin{array}{l}1040 \\
1572 \\
1320 \\
2818 \\
1401\end{array}$ & $\begin{array}{l}7.4 \\
7.4 \\
7.4 \\
7.4 \\
7.4 \\
\end{array}$ & $\begin{array}{l}2.0 \\
2.0 \\
2.1 \\
2.1 \\
2.1 \\
\end{array}$ & $\begin{array}{l}1.9 \\
2.0 \\
2.1 \\
2.1 \\
2.1 \\
\end{array}$ & $\begin{array}{l}12.15 \\
14.04 \\
14.02 \\
\text { NR } \\
13.80 \\
\end{array}$ & $\begin{array}{c}12.55 \\
14.08 \\
N R \\
14.30 \\
14.13 \\
\end{array}$ & $\begin{array}{l}0.00 \\
0.38 \\
0.00 \\
0.00 \\
0.00 \\
\end{array}$ & $\begin{array}{c}12.64 \\
22.07 \\
18.50 \\
\text { NR } \\
19.34 \\
\end{array}$ & $\begin{array}{c}13.05 \\
22.14 \\
N R \\
40.30 \\
19.80 \\
\end{array}$ & $\begin{array}{l}a \\
a\end{array}$ \\
\hline \multicolumn{2}{|c|}{ Weighted Averages: } & 7.5 & 2.1 & 1.9 & 11.91 & $\begin{array}{c}12.09 \\
\text { Totals: }\end{array}$ & 0.38 & 148.69 & 191.02 & $\mathrm{~b}$ \\
\hline
\end{tabular}

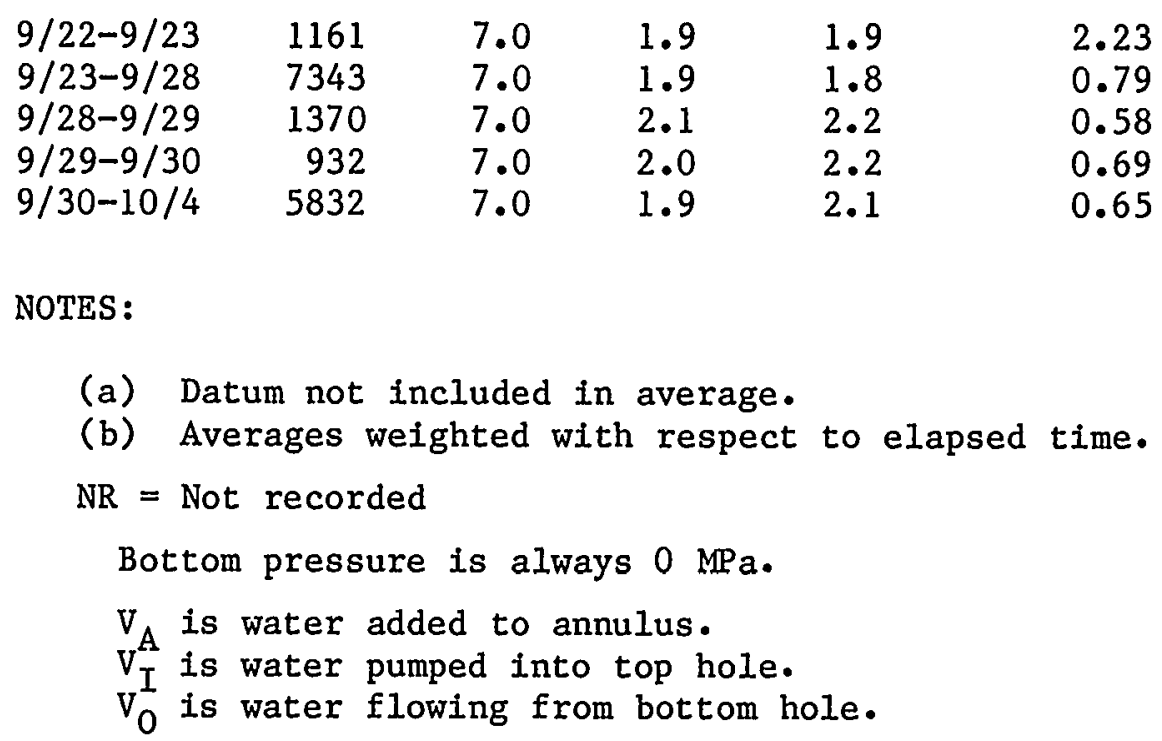

$\begin{array}{ll}7.0 & 1.9 \\ 7.0 & 1.9 \\ 7.0 & 2.1 \\ 7.0 & 2.0 \\ 7.0 & 1.9\end{array}$

$1.9 \quad 1.9$

1.9

1.8
2.2

$9 / 29-9 / 30$

5832

7.0

1.9

2.2

NOTES:

(a) Datum not included in average.

(b) Averages weighted with respect to elapsed time.

$\mathrm{NR}=$ Not recorded

Bottom pressure is always $0 \mathrm{MPa}$.

$\mathrm{V}_{\mathrm{A}}$ is water added to annulus.

$\mathrm{V}_{\mathrm{I}}^{\mathrm{A}}$ is water pumped into top hole.

$\mathrm{V}_{0}$ is water flowing from bottom hole.

Begin Dye Injection

$\begin{array}{lllll}2.23 & 1.98 & 0.90 & 2.59 & 2.30 \\ 0.79 & 0.78 & 0.55 & 5.78 & 5.76 \\ 0.58 & \text { NR } & 0.00 & 0.79 & \text { NR } \\ 0.69 & \text { NR } & 0.00 & 0.64 & \text { NR } \\ 0.65 & 0.63 & 0.38 & 3.79 & 3.70\end{array}$


Table A.8 Test Results for Sample CCR-D-100

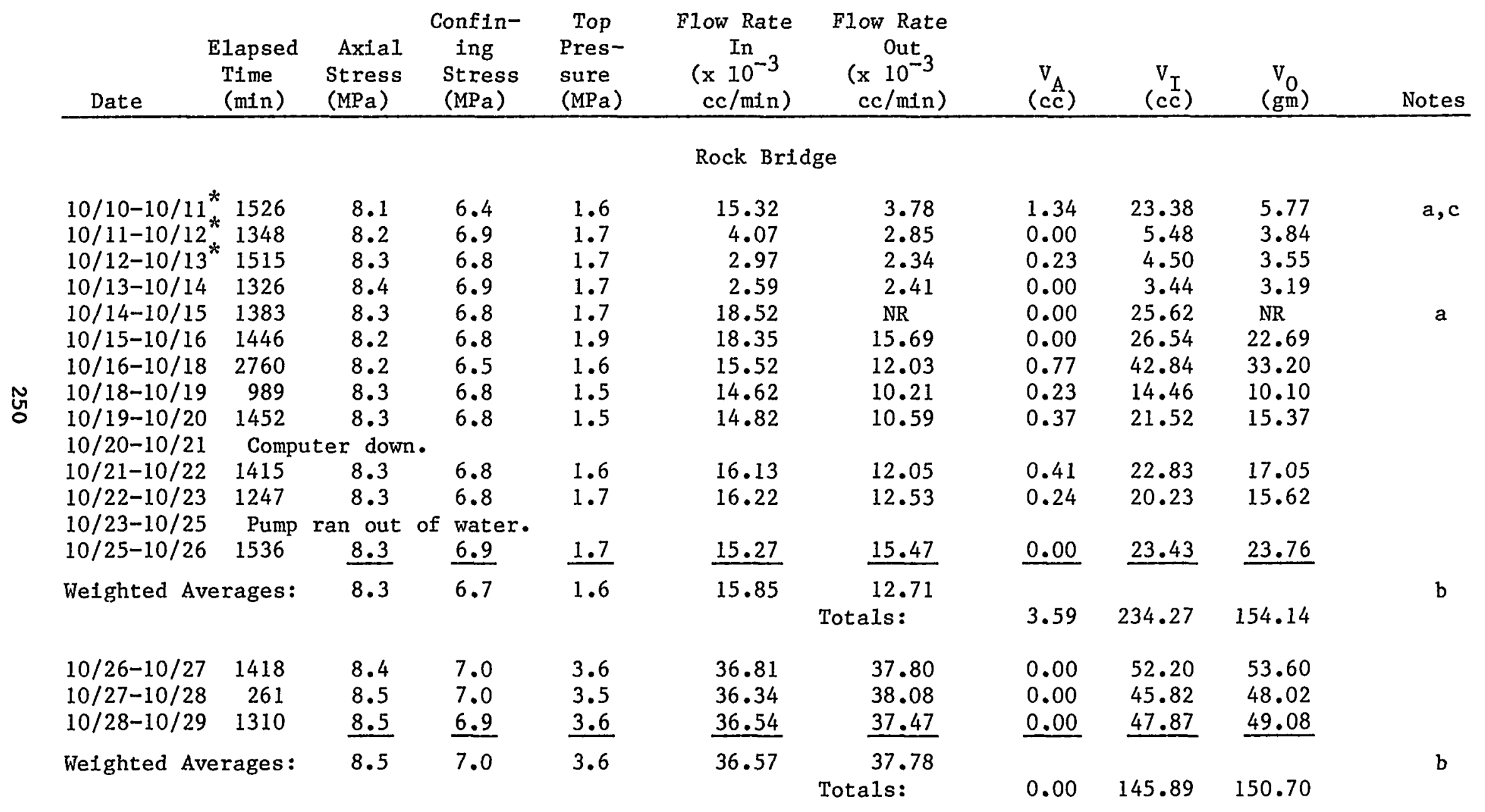

10/29-11/2 Testing set-up (valving) incorrect. 
Table A.8 Test Results for Sample CCR-D-100--Continued

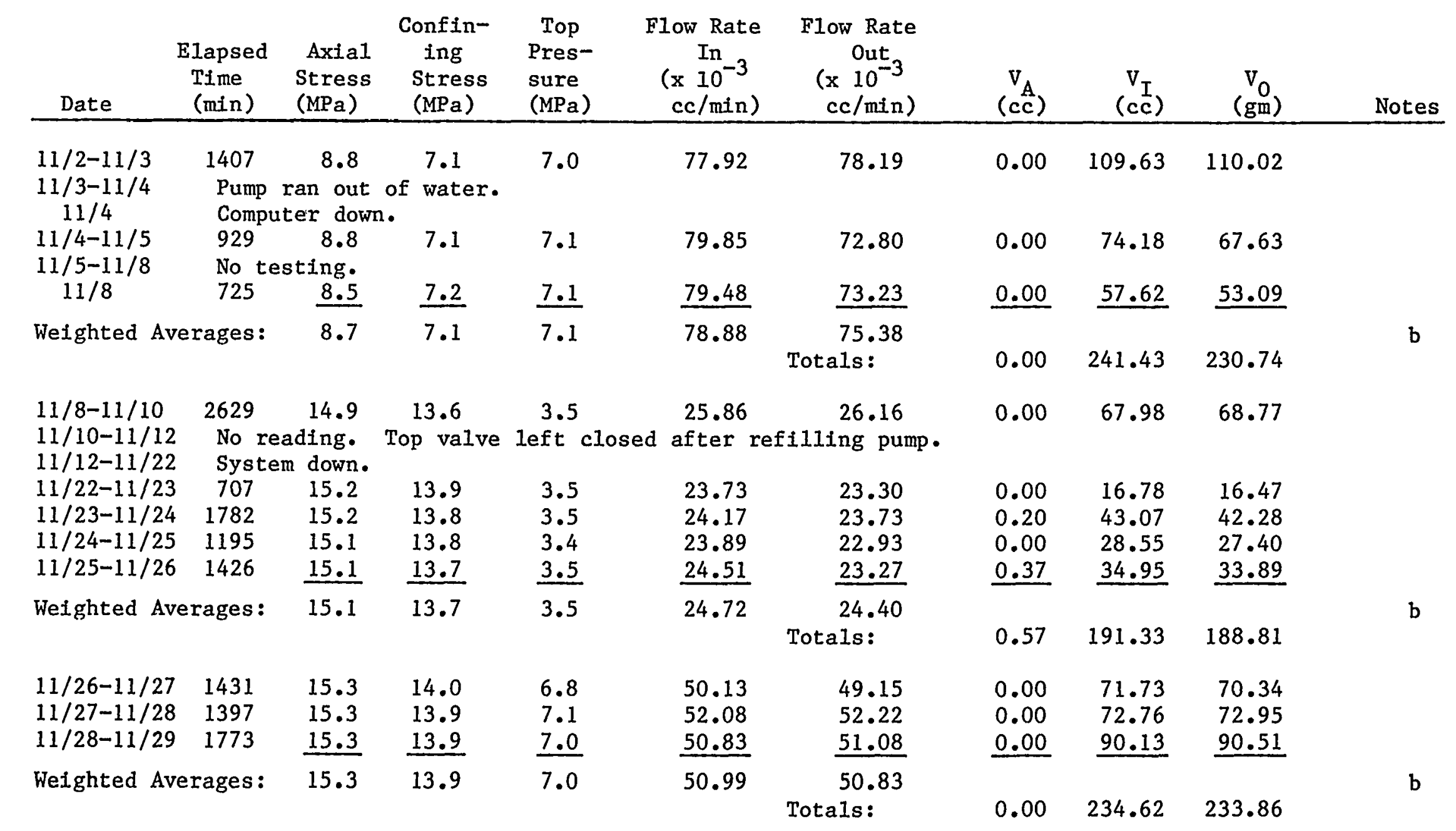


Table A.8 Test Results for Sample CCR-D-100-- Continued

\begin{tabular}{|c|c|c|c|c|c|c|c|c|c|c|}
\hline Date & $\begin{array}{l}\text { Elapsed } \\
\text { Tíme } \\
\text { (min) }\end{array}$ & $\begin{array}{l}\text { Axial } \\
\text { Stress } \\
\text { (MPa) }\end{array}$ & $\begin{array}{l}\text { Confin- } \\
\text { ing } \\
\text { Stress } \\
\text { (MPa) } \\
\end{array}$ & $\begin{array}{l}\text { Top } \\
\text { Pres- } \\
\text { sure } \\
\text { (MPa) } \\
\end{array}$ & $\begin{array}{c}\text { Flow Rate } \\
\text { In } \\
\left(\times 10^{-3}\right. \\
\mathrm{cc} / \mathrm{min}) \\
\end{array}$ & $\begin{array}{c}\text { Flow Rate } \\
\text { Out } \\
\left(\times 10^{-3}\right. \\
\mathrm{cc} / \mathrm{min})\end{array}$ & $\begin{array}{c}\mathrm{V}_{\mathrm{A}} \\
(\mathrm{cc})\end{array}$ & $\begin{array}{l}V_{I} \\
(\mathrm{cc})\end{array}$ & $\begin{array}{r}V_{0} \\
(\mathrm{gm}) \\
\end{array}$ & Notes \\
\hline $\begin{array}{l}11 / 29-11 / 30 \\
11 / 30-12 / 1\end{array}$ & $\begin{array}{l}1214 \\
1426\end{array}$ & $\begin{array}{l}15.5 \\
15.5 \\
\end{array}$ & $\begin{array}{l}13.9 \\
13.8 \\
\end{array}$ & $\begin{array}{r}10.0 \\
9.9 \\
\end{array}$ & $\begin{array}{l}76.85 \\
76.51 \\
\end{array}$ & $\begin{array}{l}77.29 \\
76.68 \\
\end{array}$ & $\begin{array}{l}0.00 \\
0.00 \\
\end{array}$ & $\begin{array}{r}93.30 \\
109.10 \\
\end{array}$ & $\begin{array}{r}93.83 \\
109.34 \\
\end{array}$ & \\
\hline \multicolumn{2}{|c|}{ Weighted Averages: } & 15.5 & 13.8 & 9.9 & 76.67 & $\begin{array}{l}76.96 \\
\text { Totals: }\end{array}$ & 0.00 & 202.40 & 203.17 & $b$ \\
\hline $\begin{array}{l}12 / 1-12 / 3 \\
12 / 3-12 / 4 \\
12 / 4-12 / 6 \\
12 / 6-12 / 7\end{array}$ & $\begin{array}{l}2667 \\
1578 \\
2746 \\
1516\end{array}$ & $\begin{array}{l}22.6 \\
23.8 \\
23.2 \\
23.0 \\
\end{array}$ & $\begin{array}{l}19.8 \\
19.8 \\
19.7 \\
19.6 \\
\end{array}$ & $\begin{array}{l}3.5 \\
3.6 \\
3.5 \\
3.5 \\
\end{array}$ & $\begin{array}{l}18.09 \\
17.17 \\
17.72 \\
17.77 \\
\end{array}$ & $\begin{array}{l}18.06 \\
17.80 \\
17.72 \\
17.61 \\
\end{array}$ & $\begin{array}{l}0.00 \\
0.00 \\
0.00 \\
0.00 \\
\end{array}$ & $\begin{array}{l}48.25 \\
27.09 \\
48.67 \\
26.94 \\
\end{array}$ & $\begin{array}{l}48.16 \\
28.09 \\
48.66 \\
26.70 \\
\end{array}$ & \\
\hline \multicolumn{2}{|c|}{ Weighted Averages: } & 23.1 & 19.7 & 3.5 & 17.74 & $\begin{array}{l}17.82 \\
\text { Totals: }\end{array}$ & 0.00 & 150.95 & 151.61 & $\mathrm{~b}$ \\
\hline $\begin{array}{l}12 / 7-12 / 8 \\
12 / 8-12 / 10\end{array}$ & $\begin{array}{l}1267 \\
2807\end{array}$ & $\begin{array}{l}23.0 \\
22.9 \\
\end{array}$ & $\begin{array}{l}19.6 \\
19.7 \\
\end{array}$ & $\begin{array}{l}7.0 \\
7.0 \\
\end{array}$ & $\begin{array}{l}35.65 \\
36.57 \\
\end{array}$ & $\begin{array}{l}36.54 \\
36.58 \\
\end{array}$ & $\begin{array}{l}0.00 \\
0.00 \\
\end{array}$ & $\begin{array}{r}45.17 \\
102.65 \\
\end{array}$ & $\begin{array}{r}46.30 \\
102.68 \\
\end{array}$ & \\
\hline \multicolumn{2}{|c|}{ Weighted Averages: } & 22.9 & 19.7 & 7.0 & 36.28 & $\begin{array}{l}36.57 \\
\text { Totals: }\end{array}$ & 0.00 & 147.82 & 148.92 & $\mathrm{~b}$ \\
\hline $\begin{array}{l}12 / 10-12 / 13 \\
12 / 13-12 / 14 \\
12 / 14-12 / 15 \\
12 / 15-12 / 16\end{array}$ & $\begin{array}{l}\text { Compu } \\
1532 \\
1314 \\
1593\end{array}$ & $\begin{array}{l}\text { ter down. } \\
23.1 \\
23.1 \\
23.1 \\
\end{array}$ & $\begin{array}{l}\text { No da } \\
19.7 \\
19.7 \\
19.6 \\
\end{array}$ & $\begin{array}{r}10.0 \\
9.9 \\
10.0 \\
\end{array}$ & $\begin{array}{l}53.20 \\
52.75 \\
53.35 \\
\end{array}$ & $\begin{array}{l}52.98 \\
52.28 \\
53.24 \\
\end{array}$ & $\begin{array}{l}0.00 \\
0.00 \\
0.00 \\
\end{array}$ & $\begin{array}{l}81.51 \\
69.32 \\
84.98 \\
\end{array}$ & $\begin{array}{l}81.16 \\
68.69 \\
84.81 \\
\end{array}$ & \\
\hline Weighted Av & erages: & 23.1 & 19.7 & 10.0 & 53.12 & $\begin{array}{l}52.87 \\
\text { Totals: }\end{array}$ & 0.00 & 235.81 & 234.66 & $\mathrm{~b}$ \\
\hline
\end{tabular}


Table A.8 Test Results for Sample CCR-D-100--Continued

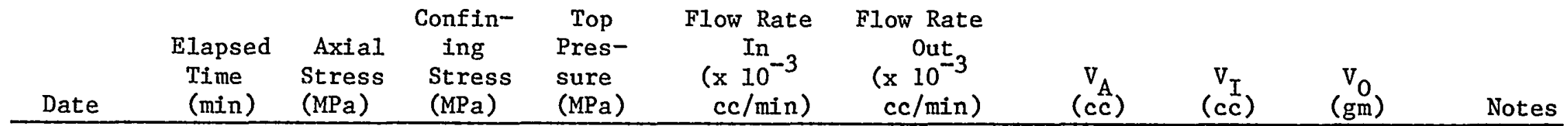

Cement System 1 Plug Poured at 10:45 a.m., January 18, 1983

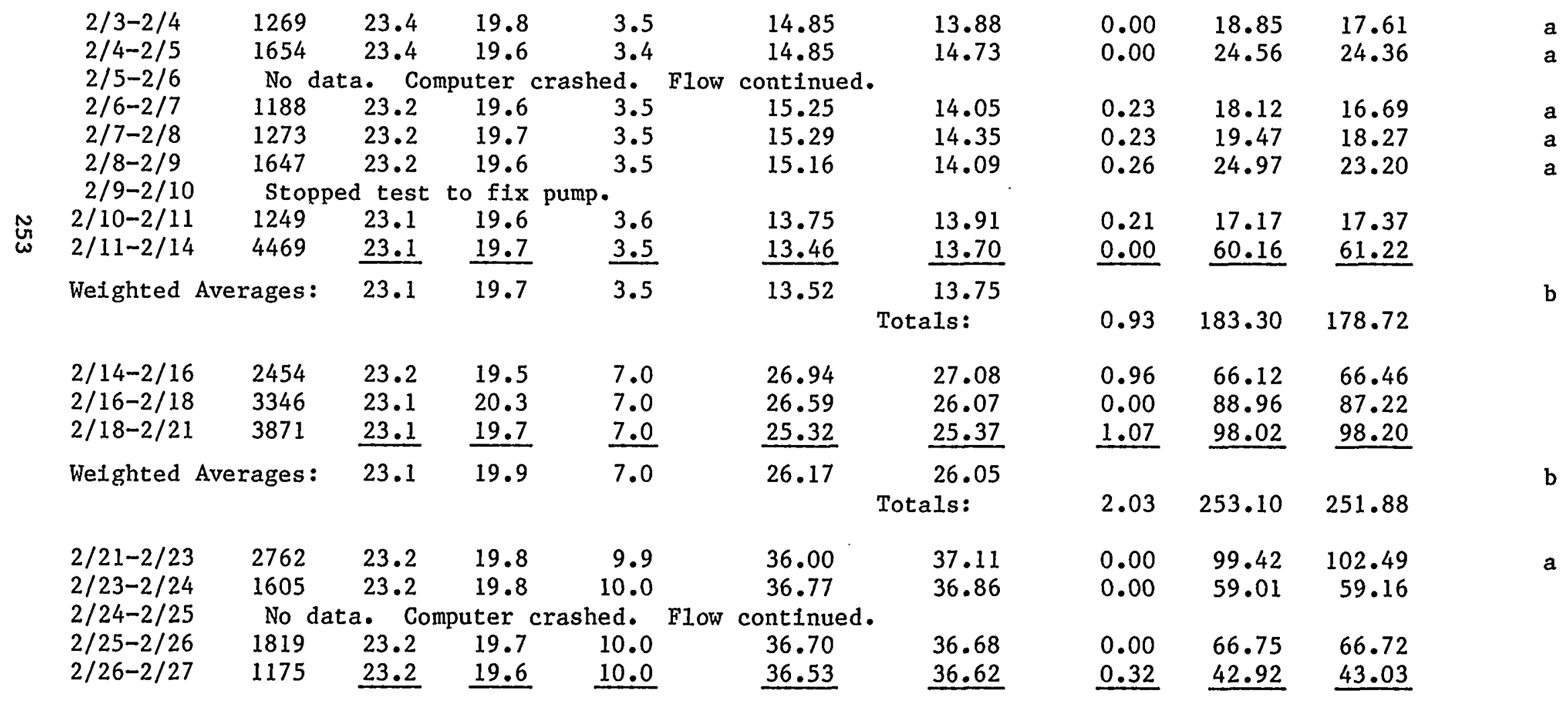


Table A.8 Test Results for Sample CCR-D-100-Continued

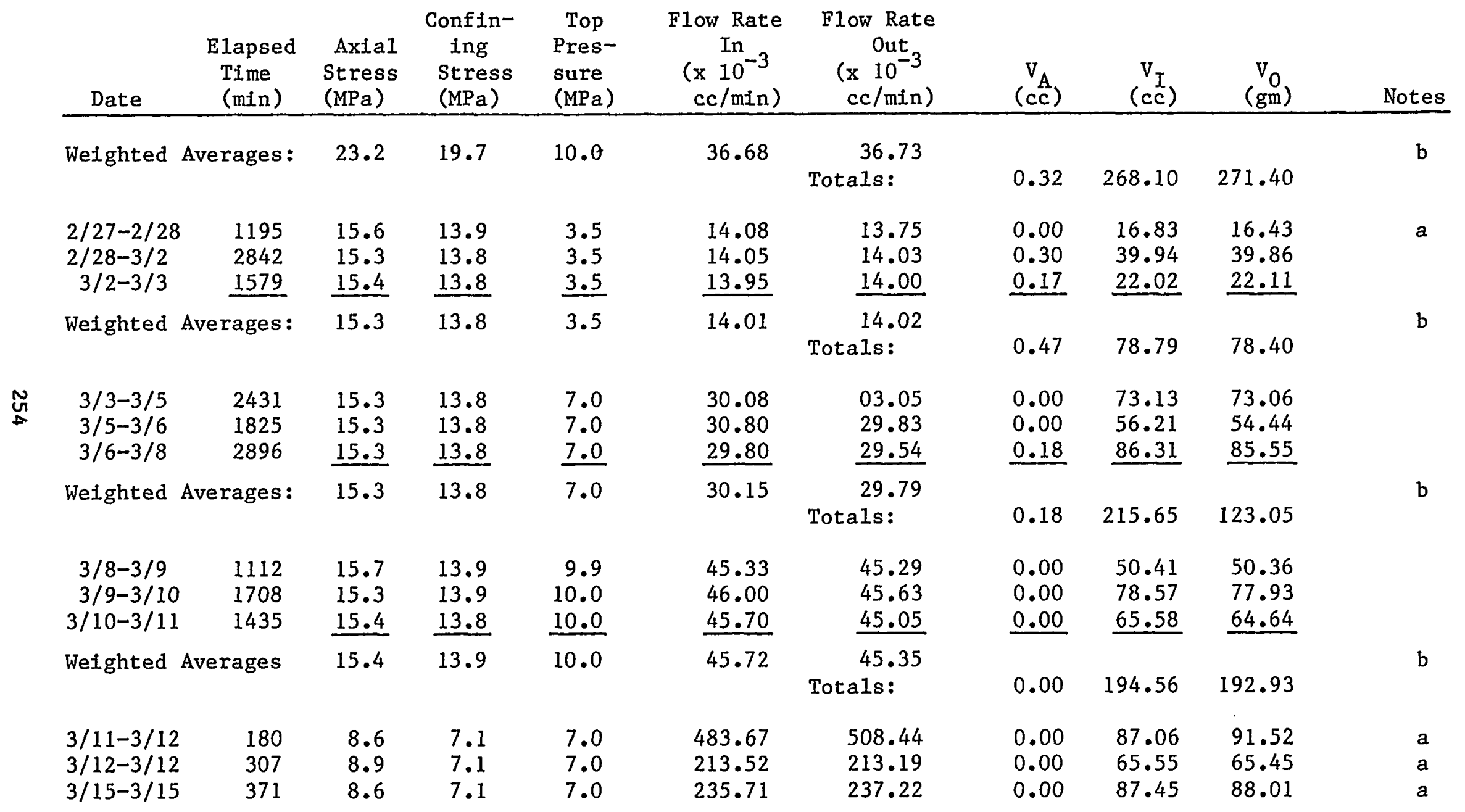


Table A.8 Test Results for Sample CCR-D-100--Continued

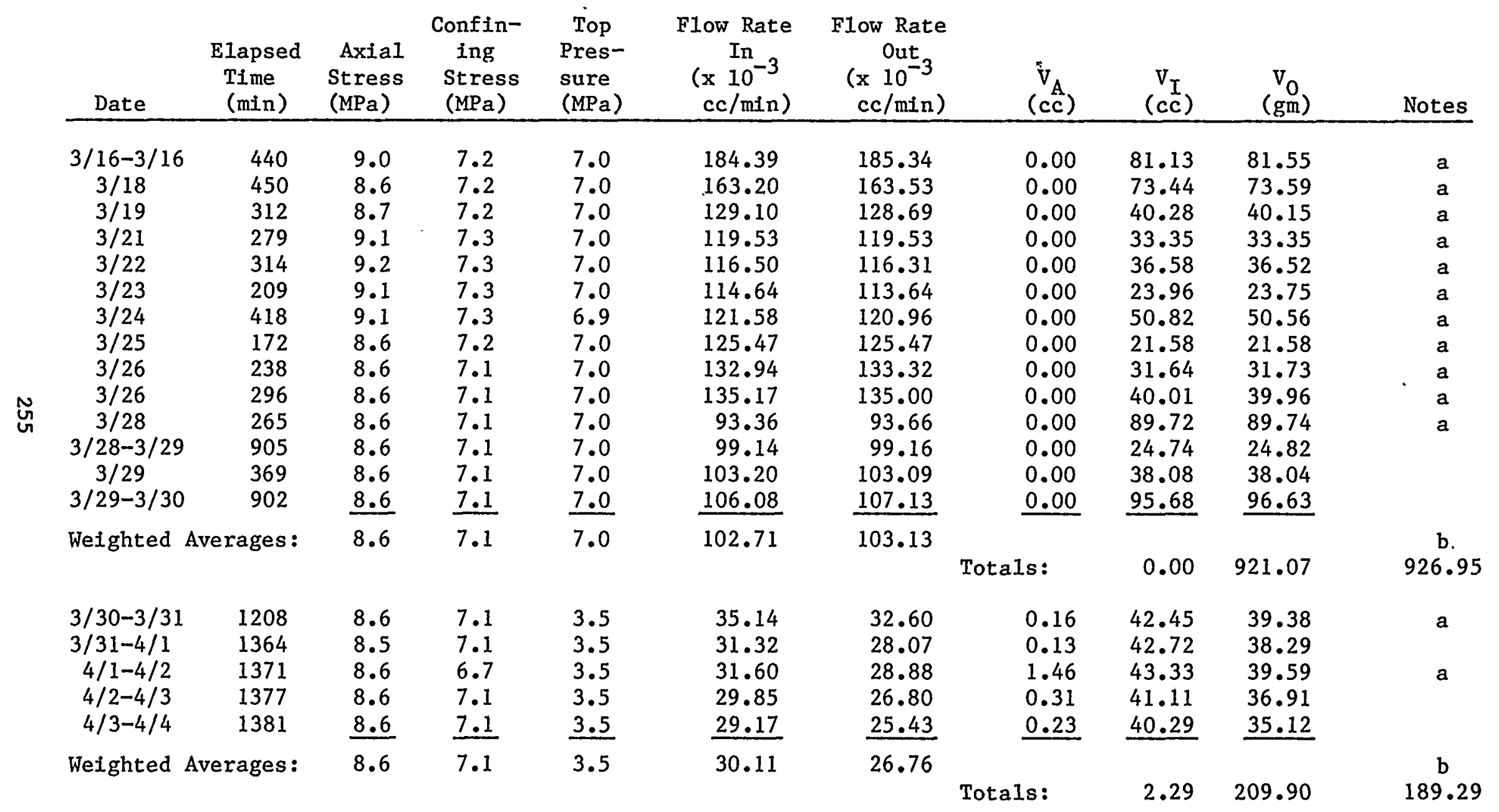


Table A.8 Test Results for Sample CCR-D-100-- Continued

\begin{tabular}{|c|c|c|c|c|c|c|c|c|c|c|}
\hline Date & $\begin{array}{c}\text { Elapsed } \\
\text { Time } \\
\text { (min) }\end{array}$ & $\begin{array}{r}\text { Axial } \\
\text { Stress } \\
\text { (MPa) } \\
\end{array}$ & $\begin{array}{c}\text { Confin- } \\
\text { ing } \\
\text { Stress } \\
\text { (MPa) } \\
\end{array}$ & $\begin{array}{l}\text { Top } \\
\text { Pres- } \\
\text { sure } \\
\text { (MPa) } \\
\end{array}$ & $\begin{array}{c}\text { Flow Rate } \\
\text { In } \\
\left(x 10^{-3}\right. \\
\mathrm{cc} / \mathrm{min})\end{array}$ & $\begin{array}{c}\text { Flow Rate } \\
\text { Out } \\
\left(x 10^{-3}\right. \\
\mathrm{cc} / \mathrm{min})\end{array}$ & $\begin{array}{c}\mathrm{V}_{\mathrm{A}} \\
(\mathrm{cc})\end{array}$ & $\begin{array}{l}V_{I} \\
(\mathrm{cc})\end{array}$ & $\begin{array}{r}V_{0} \\
(\mathrm{gm}) \\
\end{array}$ & Notes \\
\hline $\begin{array}{l}4 / 4-4 / 5 \\
4 / 5-4 / 6 \\
4 / 6-4 / 7 \\
4 / 7-4 / 8\end{array}$ & $\begin{array}{r}1687 \\
1023 \\
867 \\
1426\end{array}$ & $\begin{array}{l}8.7 \\
8.7 \\
8.7 \\
8.7 \\
\end{array}$ & $\begin{array}{l}7.0 \\
7.1 \\
7.2 \\
7.1 \\
\end{array}$ & $\begin{array}{l}1.6 \\
1.6 \\
1.6 \\
1.6 \\
\end{array}$ & $\begin{array}{l}11.98 \\
11.26 \\
11.07 \\
10.67 \\
\end{array}$ & $\begin{array}{l}8.16 \\
8.36 \\
8.35 \\
7.73 \\
\end{array}$ & $\begin{array}{l}0.60 \\
\mathrm{NR} \\
0.00 \\
0.18 \\
\end{array}$ & $\begin{array}{r}20.21 \\
11.52 \\
9.60 \\
15.21 \\
\end{array}$ & $\begin{array}{r}13.77 \\
8.55 \\
7.24 \\
11.03 \\
\end{array}$ & \\
\hline Weighted & Averages: & 8.7 & 7.1 & 1.6 & 11.30 & $\begin{array}{c}8.11 \\
\text { Totals: }\end{array}$ & 0.78 & 56.54 & 40.59 & b \\
\hline
\end{tabular}

NOTES :
a) Not included in weighted average.
b) Averages weighted with respect to time.
c) Bottom valve closed.
NR) not recorded

* Bottom pressure is always $0 \mathrm{MPa}$, except for the first three dates, for which it is uncertain. 
Table A.9 Test Results for Sample CG-104

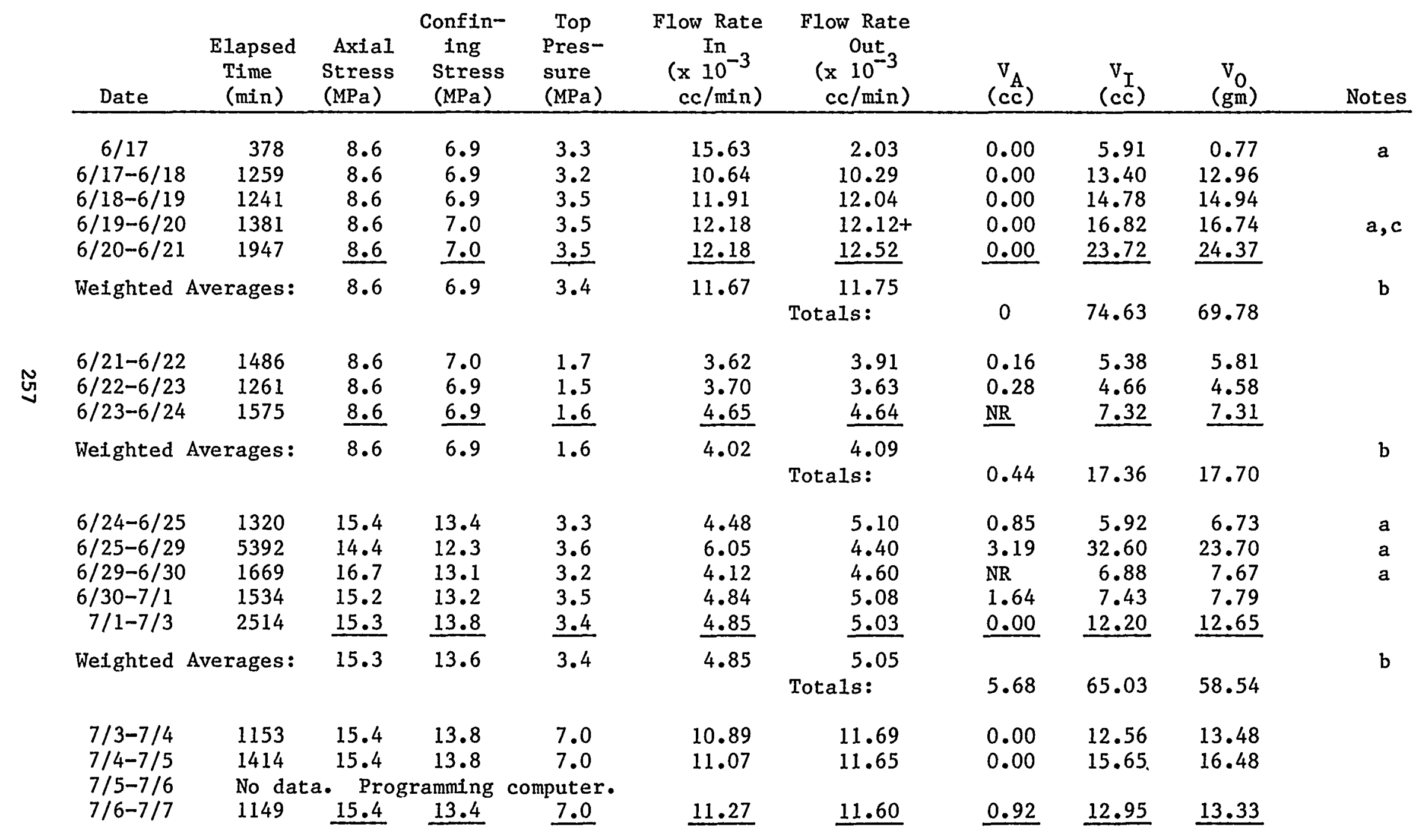


Table A.9 Test Results for Sample CG-104--Continued

\begin{tabular}{|c|c|c|c|c|c|c|c|c|c|c|}
\hline Date & $\begin{array}{l}\text { Elapsed } \\
\text { Time } \\
\text { (min) }\end{array}$ & $\begin{array}{l}\text { Axial } \\
\text { Stress } \\
\text { (MPa) }\end{array}$ & $\begin{array}{l}\text { Confin- } \\
\text { ing } \\
\text { Stress } \\
\text { (MPa) }\end{array}$ & $\begin{array}{l}\text { Top } \\
\text { Pres- } \\
\text { sure } \\
\text { (MPa) }\end{array}$ & $\begin{array}{c}\text { Flow Rate } \\
\text { In } \\
\left(\times 10^{-3}\right. \\
\mathrm{cc} / \mathrm{min})\end{array}$ & $\begin{array}{c}\text { Flow Rate } \\
\text { Out } \\
\left(x 10^{-3}\right. \\
\text { cc/min) }\end{array}$ & $\begin{array}{c}\mathrm{V}_{\mathrm{A}} \\
(\mathrm{cc})\end{array}$ & $\begin{array}{l}V_{I} \\
(c c)\end{array}$ & $\begin{array}{c}V_{0} \\
(\mathrm{gm})\end{array}$ & Not \\
\hline
\end{tabular}

$\begin{array}{llll}\text { Weighted Averages: } & 15.4 & 13.7 & 7.0\end{array}$

$11.08 \quad 11.65$

\begin{tabular}{rrr}
0.92 & 41.16 & 43.29 \\
0.00 & 23.59 & 24.29 \\
0.30 & 8.02 & 11.98 \\
0.78 & 23.28 & 23.87 \\
0.00 & 21.99 & 22.54 \\
0.00 & $\underline{30.48}$ & $\underline{31.10}$ \\
\hline
\end{tabular}

\begin{tabular}{crrrr}
$7 / 7-7 / 8$ & 1280 & 15.5 & 13.8 & 9.9 \\
$7 / 8$ & 425 & 15.6 & 13.7 & 10.0 \\
$7 / 8-7 / 9$ & 1183 & 15.6 & 13.4 & 10.1 \\
$7 / 9-7 / 10$ & 1105 & 15.6 & 13.8 & 10.2 \\
$7 / 10-7 / 11$ & 1566 & $\underline{15.6}$ & $\underline{14.1}$ & $\underline{10.1}$ \\
\multicolumn{7}{l}{ Weighted } & Averages: & 15.6 & 13.8 & 10.1
\end{tabular}

\begin{tabular}{lr}
18.43 & 18.98 \\
18.87 & 28.19 \\
19.68 & 20.18 \\
19.89 & 20.39 \\
19.46 & 19.86 \\
\hline 19.35 & 19.83 \\
& Totals:
\end{tabular}

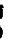

\begin{tabular}{lrrrr}
$7 / 11-7 / 12$ & 1100 & 22.6 & 19.1 & 7.2 \\
$7 / 12$ & 268 & 23.2 & 19.6 & 10.0 \\
$7 / 12-7 / 13$ & 1460 & 23.1 & 19.6 & 10.1 \\
$7 / 13-7 / 14$ & 1295 & 23.0 & 19.6 & 10.1 \\
$7 / 14-7 / 15$ & 1409 & $\underline{23.0}$ & $\frac{19.6}{19.6}$ & $\frac{10.0}{10.1}$ \\
\multicolumn{7}{l}{ Weighted Averages: } & 23.0 & &
\end{tabular}

\begin{tabular}{lr}
8.76 & 10.34 \\
8.90 & 8.47 \\
8.66 & 8.94 \\
7.75 & 8.02 \\
8.76 & 8.96 \\
\hline 8.44 & 8.65 \\
& Totals:
\end{tabular}

1.08

5.72

5.68

4.63

4.66

4.69

4.66

\begin{tabular}{lr}
1.20 & 9.63 \\
0.19 & 2.38 \\
0.16 & 12.65 \\
0.14 & 10.03 \\
0.07 & 12.35 \\
\hline
\end{tabular}

113.78

11.37
2.27

13.05

10.39

12.62

$\begin{array}{lllll}7 / 15-7 / 16 & 1028 & 22.9 & 19.6 & 7.1 \\ 7 / 16-7 / 19 & \text { Programming } & \text { computer. } & \text { No data. } \\ 7 / 19-7 / 20 & 1353 & 23.0 & 19.8 & 7.0 \\ 7 / 20-7 / 21 & 1535 & 23.0 & 19.5 & 7.0 \\ 7 / 21-7 / 22 & 1420 & \underline{23.0} & \underline{19.8} & \underline{7.0} \\ \text { Weighted Averages: } & 23.0 & 19.7 & 7.0\end{array}$

1.76

47.04

49.70

$\begin{array}{lll}0.08 & 5.88 & 5.84\end{array}$

\subsection{2}

4.78

4.73

0.00

6.27

7.16

6.38

0.46

0.12

6.66

7.34

Totals:

0.66

25.97

26.28 
Table A.9 Test Results for Sample CG-104-- Continued

\begin{tabular}{|c|c|c|c|c|c|c|c|c|c|c|}
\hline Date & $\begin{array}{c}\text { Elapsed } \\
\text { Time } \\
\text { (min) } \\
\end{array}$ & $\begin{array}{l}\text { Axial } \\
\text { Stress } \\
\text { (MPa) }\end{array}$ & $\begin{array}{l}\text { Confin- } \\
\text { ing } \\
\text { Stress } \\
\text { (MPa) } \\
\end{array}$ & $\begin{array}{l}\text { Top } \\
\text { Pres- } \\
\text { sure } \\
\text { (MPa) }\end{array}$ & $\begin{array}{c}\text { Flow Rate } \\
\text { In } \\
\left(x 10^{-3}\right. \\
\mathrm{cc} / \mathrm{min}) \\
\end{array}$ & $\begin{array}{c}\text { Flow Rate } \\
\text { Out } \\
\left(\times 10^{-3}\right. \\
\mathrm{cc} / \mathrm{min})\end{array}$ & $\begin{array}{c}\mathrm{V}_{\mathrm{A}} \\
(\mathrm{cc})\end{array}$ & $\begin{array}{l}V_{I} \\
(c c)\end{array}$ & $\begin{array}{c}\mathrm{v}_{0} \\
(\mathrm{gm})\end{array}$ & Notes \\
\hline $\begin{array}{l}7 / 22-7 / 23 \\
7 / 23-7 / 24 \\
7 / 24-7 / 26 \\
7 / 26-7 / 27 \\
7 / 27-7 / 28\end{array}$ & $\begin{array}{l}\quad 858 \\
\text { Testing } \\
3446 \\
1070 \\
1148\end{array}$ & $\begin{array}{l}22.9 \\
\text { interr } \\
22.9 \\
22.9 \\
22.9 \\
\end{array}$ & $\begin{array}{l}19.6 \\
\text { apted for } \\
19.6 \\
19.7 \\
19.6 \\
\end{array}$ & $\begin{array}{r}3.6 \\
\text { gauge } \\
3.4 \\
3.4 \\
3.4 \\
\end{array}$ & $\begin{array}{r}2.06 \\
\text { calibration. } \\
1.92 \\
1.86 \\
1.92 \\
\end{array}$ & $\begin{array}{l}2.00 \\
2.06 \\
1.93 \\
\end{array}$ & $\begin{array}{l}0.36 \\
0.00 \\
0.22 \\
\end{array}$ & $\begin{array}{l}1.77 \\
6.61 \\
1.99 \\
2.20 \\
\end{array}$ & $\begin{array}{l}1.91 \\
6.89 \\
2.20 \\
2.22 \\
\end{array}$ & \\
\hline Weighted & Averages: & 22.9 & 19.6 & 3.4 & $\begin{array}{c}1.93 \\
\text { Total fo }\end{array}$ & $\begin{array}{l}2.03 \\
\text { Totals: } \\
\text { rock bridge: }\end{array}$ & $\begin{array}{r}0.83 \\
11.37\end{array}$ & $\begin{array}{r}12.57 \\
391.12\end{array}$ & $\begin{array}{r}13.22 \\
392.29\end{array}$ & b \\
\hline
\end{tabular}

U్ $7 / 28-8 / 19$ Perform pulse tests.

$8 / 20$ Drill out rock bridge. Place bentonite tablets and cure.

8/22 Put $P_{T}=2 \mathrm{MPa}$. Clay plug will not hold. Lower pressure to zero and let plug heal,

8/23-9/1 $\mathrm{P}_{\mathrm{T}}=0.1-0.3 \mathrm{MPa}$ on clay plug. No data due to equipment problems. Some piping of clay plug.

\begin{tabular}{|c|c|c|c|c|c|c|c|c|c|c|}
\hline $\begin{array}{c}9 / 1-9 / 2 \\
9 / 2-9 / 3 \\
9 / 3-9 / 4 \\
9 / 4-9 / 6 \\
9 / 6-9 / 7 \\
9 / 7-9 / 8 \\
9 / 8-9 / 9 \\
9 / 9-9 / 11 \\
9 / 11-9 / 14\end{array}$ & $\begin{array}{l}1545 \\
\text { Ran out } \\
1746 \\
2929 \\
1223 \\
1782 \\
1420 \\
2855 \\
4372\end{array}$ & $\begin{array}{l}21.1 \\
\text { of } \mathrm{N}_{2} \\
21.0^{2} \\
20.9 \\
23.0 \\
22.7 \\
22.7 \\
22.6 \\
22.1 \\
\end{array}$ & $\begin{array}{c}\sim 18.4 \\
\text { driving } \\
18.1 \\
17.1 \\
18.6 \\
18.2 \\
18.4 \\
17.3 \\
15.4 \\
\end{array}$ & $\begin{array}{l}\sim 0.8 \\
\text { pump. } \\
\sim 0.9 \\
\sim 1.1 \\
1.0 \\
1.0 \\
0.9 \\
1.1 \\
2.1 \\
\end{array}$ & $\begin{array}{l}1.65 \\
1.00 \\
0.65 \\
0.31 \\
0.00 \\
0.03 \\
0.00 \\
0.03 \\
\end{array}$ & $\begin{array}{l}2.14 \\
2.68 \\
2.19 \\
1.95 \\
1.70 \\
1.49 \\
1.66 \\
\end{array}$ & $\begin{array}{r}3.18 \\
2.13 \\
3.45 \\
4.90 \\
3.10 \\
4.09 \\
2.97 \\
6.18 \\
10.22 \\
\end{array}$ & $\begin{array}{l}2.55 \\
0.00 \\
1.74 \\
1.89 \\
0.38 \\
0.00 \\
0.04 \\
0.00 \\
0.15 \\
\end{array}$ & $\begin{array}{l}4.36 \\
3.17 \\
3.74 \\
7.85 \\
2.68 \\
3.48 \\
2.41 \\
4.26 \\
7.25 \\
\end{array}$ & a \\
\hline Weighted & es: & 22.0 & 17.8 & 1.0 & 0.34 & $\begin{array}{l}2.04 \\
1 s:\end{array}$ & 40.22 & 6.75 & 39.20 & b \\
\hline
\end{tabular}


Table A.9 Test Results for Sample CG-104-- Continued

\begin{tabular}{|c|c|c|c|c|c|c|c|c|c|c|}
\hline Date & $\begin{array}{l}\text { Elapsed } \\
\text { Time } \\
\text { (min) }\end{array}$ & $\begin{array}{l}\text { Axial } \\
\text { Stress } \\
\text { (MPa) }\end{array}$ & $\begin{array}{l}\text { Confin- } \\
\text { ing } \\
\text { Stress } \\
\text { (MPa) }\end{array}$ & $\begin{array}{l}\text { Top } \\
\text { Pres- } \\
\text { sure } \\
(\mathrm{MPa})\end{array}$ & $\begin{array}{c}\text { Flow Rate } \\
\text { In } \\
\left(\times 10^{-3}\right. \\
\mathrm{cc} / \mathrm{min})\end{array}$ & $\begin{array}{c}\text { Flow Rate } \\
\text { Out } \\
\text { (x } 10^{-3} \\
\mathrm{cc} / \mathrm{min})\end{array}$ & $\begin{array}{c}\mathrm{V}_{\mathrm{A}} \\
(\mathrm{cc})\end{array}$ & $\begin{array}{c}V_{I} \\
(c c)\end{array}$ & $\begin{array}{c}V_{0} \\
(\mathrm{gm})\end{array}$ & Notes \\
\hline
\end{tabular}

9/14-9/15 Annulus leaking badly. Lower $\sigma_{c}$ to $13.8 \mathrm{MPa}$ and set $\mathrm{P}_{\mathrm{T}}=3.5 \mathrm{MPa}$.

\begin{tabular}{|c|c|c|c|c|c|c|c|c|c|c|}
\hline $\begin{array}{c}9 / 15 \\
9 / 15-9 / 16 \\
9 / 16-9 / 18\end{array}$ & $\begin{array}{r}140 \\
1289 \\
2644\end{array}$ & $\begin{array}{l}21.0 \\
21.0 \\
20.9 \\
\end{array}$ & $\begin{array}{l}13.8 \\
13.1 \\
12.3 \\
\end{array}$ & $\begin{array}{l}3.5 \\
3.5 \\
3.8 \\
\end{array}$ & $\begin{array}{l}1.71 \\
\mathrm{NR} \\
0.07 \\
\end{array}$ & $\begin{array}{l}1.50 \\
1.08 a, d \\
1.26 \\
\end{array}$ & $\begin{array}{l}0.00 \\
\mathrm{NR} \\
3.12 \\
\end{array}$ & $\begin{array}{l}0.24 \\
\mathrm{NR} \\
0.19 \\
\end{array}$ & $\begin{array}{l}0.21 \\
1.39 \\
3.33 \\
\end{array}$ & $a, d$ \\
\hline Weighted & Averages: & 20.9 & 12.4 & 3.8 & 0.15 & $\begin{array}{l}1.27 \\
1 s:\end{array}$ & 3.12 & 0.43 & 4.93 & $\mathrm{~b}$ \\
\hline
\end{tabular}

9/18 Leakage from annulus raised $\mathrm{P}_{\mathrm{T}} \cdot$ Plug failed at $\mathrm{P}_{\mathrm{T}} \sim 4.2 \mathrm{MPa}$.

9/20 Allowed plug to heal two days. Failure now occurred between 2.0 and $2.5 \mathrm{MPa}$.

9/21-10/23 Sample removed from permeameter. Permeameter down for servicing. Replaced sample in permeameter on 10/12 and placed new bentonite plug. Let bentonite plug swell 11 days.

$\begin{array}{llllllllll}10 / 23-10 / 25 & 2486 & 22.2 & 14.4 & 0.7 & 2.83 & 2.35 & 5.73 & 7.03 & 5.85 \\ 10 / 25-10 / 26 & 1609 & 22.2 & 19.3 & 1.2 & 2.25 & 2.01 & 1.05 & 3.62 & 3.24 \\ 10 / 26-10 / 27 & 1333 & 22.4 & 19.5 & 1.5 & 1.95 & 2.09 & 0.00 & 2.60 & 2.78 \\ 10 / 27-10 / 28 & 1354 & 22.4 & 19.2 & 1.4 & 1.72 & 1.91 & \text { NR } & 2.33 & 2.59 \\ 10 / 28-10 / 29 & 1407 & 22.4 & 18.9 & 1.4 & 1.33 & 1.65 & \text { NR } & 1.87 & 2.32 \\ 10 / 29-11 / 1 & 3895 & 22.3 & 18.2 & 1.5 & 1.54 & 1.62 & 0.00 & 6.01 & 6.32 \\ 11 / 1-11 / 2 & 1437 & 22.3 & 17.7 & 1.5 & 1.43 & 1.56 & 0.00 & 2.06 & 2.25 \\ 11 / 2-11 / 3 & 1412 & 22.2 & 17.4 & 1.5 & 1.42 & 1.57 & 0.00 & 2.00 & 2.21 \\ 11 / 3-11 / 5 & 2842 & 22.2 & 17.0 & 1.5 & 1.44 & 1.54 & 0.00 & 4.08 & 4.39 \\ 11 / 5-11 / 6 & \text { Computer down. } & \text { No data. } & \text { Flow continued. } & & & \\ 11 / 6-11 / 8 & 2582 & 22.9 & 19.5 & 1.5 & 1.10 & 1.37 & 1.06 & 2.84 & 2.53 \\ 11 / 8-11 / 10 & 3231 & 22.9 & 19.5 & 1.4 & 1.18 & 1.30 & \underline{0.94} & \underline{3.81} & \underline{4}\end{array}$


Table A.9 Test Results for Sample CG-104--Continued

\begin{tabular}{|c|c|c|c|c|c|c|c|c|c|c|}
\hline Date & $\begin{array}{c}\text { Elapsed } \\
\text { Time } \\
\text { (min) }\end{array}$ & $\begin{array}{l}\text { Axial } \\
\text { Stress } \\
\text { (MPa) } \\
\end{array}$ & $\begin{array}{l}\text { Confin- } \\
\quad \text { ing } \\
\text { Stress } \\
\text { (MPa) } \\
\end{array}$ & $\begin{array}{l}\text { Top } \\
\text { Pres- } \\
\text { sure } \\
\text { (MPa) }\end{array}$ & $\begin{array}{c}\text { Flow Rate } \\
\text { In } \\
\left(\times 10^{-3}\right. \\
\text { cc/min })\end{array}$ & $\begin{array}{c}\text { Flow Rate } \\
\text { Out } \\
\left(x 10^{-3}\right. \\
\text { cc/min })\end{array}$ & $\begin{array}{c}\mathrm{V}_{\mathrm{A}} \\
(\mathrm{cc})\end{array}$ & $\begin{array}{l}V_{I} \\
(c c)\end{array}$ & $\begin{array}{c}V_{0} \\
(\mathrm{gm}) \\
\end{array}$ & Notes \\
\hline Weighted & Averages: & 22.5 & 18.5 & 1.5 & 1.42 & $\begin{array}{c}1.57 \\
\text { Totals: }\end{array}$ & 2.00 & 27.60 & 30.58 & b \\
\hline $\begin{array}{l}11 / 10-11 / \\
11 / 12-11 /\end{array}$ & $\begin{array}{ll}12 & 2710 \\
13 & 1392\end{array}$ & $\begin{array}{l}23.0 \\
23.0 \\
\end{array}$ & $\begin{array}{l}19.8 \\
19.6 \\
\end{array}$ & $\begin{array}{l}2.0 \\
2.0 \\
\end{array}$ & $\begin{array}{l}2.09 \\
1.76 \\
\end{array}$ & $\begin{array}{l}1.90 \\
1.82 \\
\end{array}$ & $\begin{array}{l}0.28 \\
0.00 \\
\end{array}$ & $\begin{array}{l}5.66 \\
2.45 \\
\end{array}$ & $\begin{array}{l}5.15 \\
2.53 \\
\end{array}$ & \\
\hline Weighted & Averages: & 23.0 & 19.7 & 2.0 & 1.98 & $\begin{array}{c}1.87 \\
\text { Totals: }\end{array}$ & 0.28 & 8.11 & 7.68 & b \\
\hline
\end{tabular}

$\stackrel{\sim}{\sim}$

11/13-12/8 Bentonite plug failed. Sample removed from permeameter, cleaned, re-epoxied. New plug placed $12 / 5 / 83$.

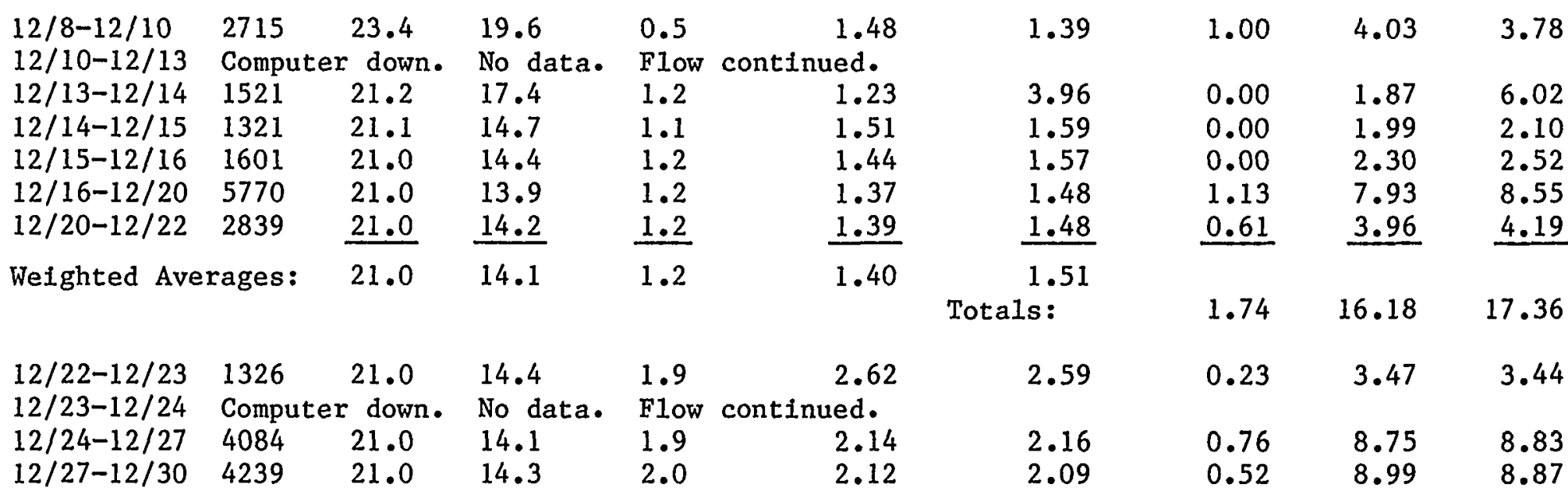


Table A.9 Test Results for Sample CG-104--Continued

\begin{tabular}{|c|c|c|c|c|c|c|c|c|c|c|}
\hline Date & $\begin{array}{c}\text { Elapsed } \\
\text { Time } \\
\text { (min) } \\
\end{array}$ & $\begin{array}{l}\text { Axial } \\
\text { Stress } \\
\text { (MPa) } \\
\end{array}$ & $\begin{array}{c}\text { Confin- } \\
\text { ing } \\
\text { Stress } \\
\text { (MPa) } \\
\end{array}$ & $\begin{array}{l}\text { Top } \\
\text { Pres- } \\
\text { sure } \\
(\mathrm{MPa}) \\
\end{array}$ & $\begin{array}{c}\text { Flow Rate } \\
\text { In } \\
\left(\times 10^{-3}\right. \\
\text { cc/min })\end{array}$ & $\begin{array}{c}\text { Flow Rate } \\
\text { Out } \\
\left(\times 10^{-3}\right. \\
\text { cc/min) }\end{array}$ & $\begin{array}{c}\mathrm{V}_{\mathrm{A}} \\
(\mathrm{cc})\end{array}$ & $\begin{array}{l}V_{I} \\
(c c)\end{array}$ & $\begin{array}{r}V_{0} \\
(\mathrm{gm}) \\
\end{array}$ & Notes \\
\hline $\begin{array}{c}12 / 30-1 / 4 \\
1 / 4-1 / 8\end{array}$ & $\begin{array}{l}7422 \\
5333\end{array}$ & $\begin{array}{l}21.0 \\
21.0 \\
\end{array}$ & $\begin{array}{l}14.0 \\
14.2 \\
\end{array}$ & $\begin{array}{l}2.0 \\
2.1 \\
\end{array}$ & $\begin{array}{l}1.59 \\
0.03 \\
\end{array}$ & $\begin{array}{l}0.91 \\
0.11 \\
\end{array}$ & $\begin{array}{l}1.00 \\
0.65 \\
\end{array}$ & $\begin{array}{r}11.81 \\
0.15 \\
\end{array}$ & $\begin{array}{l}6.78 \\
0.61 \\
\end{array}$ & $\begin{array}{l}a, e \\
a, e\end{array}$ \\
\hline Weighted & Averages: & 21.0 & 14.2 & 1.9 & $\begin{array}{l}2.20 \\
\text { Totals: }\end{array}$ & $\begin{array}{l}2.19 \\
3.16\end{array}$ & 33.17 & 28.53 & & b \\
\hline
\end{tabular}

1/8-1/10. Plug failed by piping.

1/10-1/18 Let plug heal while $\mathrm{P}_{\mathrm{T}}=0$

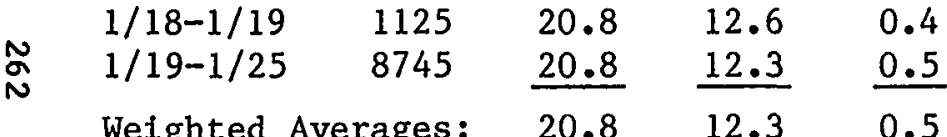

Wetghted Averages: 20.80 .12 .300

\begin{tabular}{|c|c|c|c|}
\hline $\begin{array}{l}1 / 27-1 / 29 \\
1 / 29-1 / 30\end{array}$ & $\begin{array}{l}2836 \\
1573\end{array}$ & $\begin{array}{l}20.8 \\
20.8 \\
\end{array}$ & $\begin{array}{r}12.3 \\
12.0 \\
\end{array}$ \\
\hline h & $r$ & 0.8 & 12. \\
\hline
\end{tabular}

Totals:

0.55
0.51
0.51

\begin{tabular}{l}
0.17 \\
0.55 \\
\hline 0.55 \\
0.85 \\
0.91 \\
0.97 \\
\hline 0.93 \\
0.50 \\
2.33 \\
2.81 \\
3.04 \\
\hline 2.54 \\
0.00
\end{tabular}

0.00

0.85

0.62

0.21

$\underline{4.50} \quad 4.77$

$5.12 \quad 4.98$

$0.00 \quad 2.46 \quad 2.57$

$\frac{0.90}{0.88}$

$1.42 \quad 1.52$

Totals:

\begin{tabular}{|c|c|c|c|c|}
\hline $\begin{array}{r}1 / 30-2 / 2 \\
2 / 2-2 / 3 \\
2 / 3-2 / 4\end{array}$ & $\begin{array}{r}4788 \\
872 \\
1535\end{array}$ & $\begin{array}{l}12.2 \\
12.3 \\
12.2 \\
\end{array}$ & $\begin{array}{l}6.1 \\
5.7 \\
5.7 \\
\end{array}$ & $\begin{array}{l}1.0 \\
1.0 \\
1.0\end{array}$ \\
\hline Weighte & ses: & 12.2 & 6.0 & 1.0 \\
\hline
\end{tabular}

\begin{tabular}{l}
2.52 \\
2.73 \\
3.02 \\
\hline 2.65
\end{tabular}

Totals:

0.00

3.88

4.09

$0.00 \quad 12.06$

0.00

0.00

2.38

11.16

2.45

$19.08 \quad 18.27$

b

$f$

2/4-2/7 Let plug heal while $\mathrm{P}_{\mathrm{T}}=0$. 
Table A.9 Test Results for Sample CG-104--Continued

\begin{tabular}{|c|c|c|c|c|c|c|c|c|c|c|}
\hline Date & $\begin{array}{c}\text { Elapsed } \\
\text { Time } \\
\text { (min) } \\
\end{array}$ & $\begin{array}{l}\text { Axial } \\
\text { Stress } \\
\text { (MPa) }\end{array}$ & $\begin{array}{c}\text { Confin- } \\
\text { ing } \\
\text { Stress } \\
\text { (MPa) } \\
\end{array}$ & $\begin{array}{l}\text { Top } \\
\text { Pres- } \\
\text { sure } \\
(\mathrm{MPa}) \\
\end{array}$ & $\begin{array}{c}\text { Flow Rate } \\
\text { In } \\
\left(\times 10^{-3}\right. \\
\text { cc/min) }\end{array}$ & $\begin{array}{c}\text { Flow Rate } \\
\text { Out } \\
\left(\times 10^{-3}\right. \\
\mathrm{cc} / \mathrm{min})\end{array}$ & $\begin{array}{l}V_{A} \\
(\mathrm{cc})\end{array}$ & $\begin{array}{l}V_{I} \\
(\mathrm{cc})\end{array}$ & $\begin{array}{c}v_{0} \\
(\mathrm{gm}) \\
\end{array}$ & Notes \\
\hline $\begin{array}{c}2 / 7-2 / 9 \\
2 / 9-2 / 10 \\
2 / 10-2 / 11 \\
2 / 11-2 / 14\end{array}$ & $\begin{array}{l}3018 \\
1588 \\
1044 \\
4433\end{array}$ & $\begin{array}{l}12.2 \\
12.2 \\
12.2 \\
12.4 \\
\end{array}$ & $\begin{array}{l}5.6 \\
5.4 \\
5.1 \\
6.1 \\
\end{array}$ & $\begin{array}{l}1.0 . \\
1.0 \\
1.0 \\
1.4 \\
\end{array}$ & $\begin{array}{l}0.55 \\
0.08 \\
0.86 \\
0.09 \\
\end{array}$ & $\begin{array}{c}0.02 \\
- \\
0.73 \\
0.15 \\
\end{array}$ & $\begin{array}{l}0.00 \\
\mathrm{NR} \\
0.00 \\
0.17 \\
\end{array}$ & $\begin{array}{l}1.66 \\
0.13^{\circ} \\
0.90 \\
0.41 \\
\end{array}$ & $\begin{array}{r}0.07 \\
-0.10 \\
0.76 \\
0.66 \\
\end{array}$ & $\begin{array}{l}a \\
a\end{array}$ \\
\hline Weighted & verages: & 12.4 & 5.9 & 1.3 & $\begin{array}{c}0.24 \\
\text { Totals: }\end{array}$ & $\begin{array}{l}0.26 \\
0.17\end{array}$ & 3.10 & 1.39 & & b \\
\hline
\end{tabular}

NOTES:
(a) Datum not included in average
(b) Averages weighted with respect to elapsed time.
(c) Bottom flask overflowed.
(d) Pump ran out of water.
(e) Some piping. Poor mass balance.
(f) Much piping.
$\mathrm{NR}=$ Not recorded
Bottom Pressure is always $0 \mathrm{MPa}$.
$\mathrm{V}_{\mathrm{A}}$ is water added to annulus.
$V_{T}$ is water pumped into top hole.
$V_{0}$ is water flowing from bottom hole.
$\sigma_{c}$ : confining (annulus) pressure
$\mathrm{P}_{\mathrm{T}}^{\mathrm{C}}$ : top (injection) pressure 
NRC FORM 335 (7.77)
U.S. NUCLEAR REGULATORY COMMISSION

BIBLIOGRAPHIC DATA SHEET

1. TITLE AND SUBTITLE (Add Volume No., if appropriate)

Permeameter Studies of Water Flow through Cement and Clay

Borehole Seals in Granite, Basalt and Tuff

7. AUTHOR(S)

D.L. South and J.J.K. Daemen

3. PEAFORMING ORGANIZATION NAME AND MAILING ADDRESS (Include Zip Code)

Department of Mining and Geological Engineering

University of Arizona

Iucson, AZ 85721

12. SPONSORING ORGANIZATION NAME AND MAILING ADDRESS (Include Zip Code)

Jivision of Engineering Safety

Jffice of Nuclear Regulatory Research

J.S. Nuclear Regulatory Commission

Jashington, DC 20555

13. TYPE OF REPORT

[echnical Report

PERIOD COVERED (Inclusive dates)

$1983-1985$

15. SUPPLEMENTARY NOTES

14. (Leave blank)

16. ABSTRACT (200 words or less) Boreholes near a repository must be sealed to prevent rapid migra:ion of radionuclide contaminated water to the accessible environment. The objective of :his research is to assess the performance of borehole seals under laboratory conditions, larticularly with regard to varying stress fields.

llow through a sealed borehole is compared with flow through intact rock. Cement or ientonite seals have been tested in granite, basalt, and welded tuff.

'he main conclusion is that under laboratory conditions, existing commercial materials can 'orm high quality seals. Triaxial stress changes about a borehole do not significantly iffect seal performance if the rock is stiffer than the seal. Temperature but especially loisture variations (drying) significantly degrade the quality of cement seals.

'erformance partially recovers upon resaturation.

- skillfully sealed borehole may be as impermeable as the host rock. Analysis of the nfluence of relative seal-rock permeabilities shows that a plug with permeability one rder of magnitude greater than that of the rock results in a flow increase through the ole and surrounding rock of only 1 1/2 times compared to undisturbed rock. Since a boreole is only a small part of the total rock mass, the total effect is even less pronounced.

17. KEY WORDS AND DOCUMENT ANALYSIS

17a. DESCRIPTORS

Borehole plugging.

Borehole sealing

Rock mass sealing

Permeameter testing

Seal permeability

Plug permeability

Cement borehole plug
Tuff

Rock-cement interface Cement swelling pressure Falling head test

17b, IDENTIFIERS/OPEN-ENDED TERMS

8. AVAILABILITY STATEMENT

UnIimited
Bentonite borehole plug

Plug testing

Seal testing

Seal strength

Rock permeability

Granite

Basalt

\begin{tabular}{|l|l|}
\hline $\begin{array}{l}\text { 19. SECURITY CLASS (This report) } \\
\text { UnClaSSified }\end{array}$ & 21. NO. OF PAGES \\
\hline $\begin{array}{l}\text { 20. SECURITY CLASS (This page) } \\
\text { Unclassified }\end{array}$ & $\begin{array}{c}\text { 22. PRICE } \\
\text { S }\end{array}$ \\
\hline
\end{tabular}




N

This report was prepared as an account of work sponsored by an agency of the United States Government. Neither the United States Government nor any agency thereof, or any of their employees, makes any warranty, expressed or implied, or assumes any legal liability of re. sponsibility for any third party's use. or the results of such use, of any information, apparatus, product or process disclosed in this report, or represents that its use by such third party would not infringe privately owned rights.

Availability of Reference Materials Cited in NRC Publications

Most documents cited in NRC publications will be available from one of the following sources:

1. The NRC Public Document Room, 1717 H Street, N.W. Washington, DC 20555

2. The NRC/GPO Sales Program, U.S. Nuclear Regulatory Commission, Washington, DC 20555

3. The National Technical Information Service, Springfield, VA 22161

Although the listing that follows represents the majority of documents cited in NRC publications, it is not intended to be exhaustive.

Referenced documents available for inspection and copying for a fee from the NRC Public Document Room include NRC correspondence and irternal NRC memoranda; NRC Office of Inspection and Enforcement bulletins, circulars, information notices, inspection and investigation notices: Licensee Event Reports; vendor reports and correspondence; Commission papers; and applicant and licensee documents and correspondence.

The following documents in the NUREG series are available for purchase from the NRC/GPO Sales Program: formal NRC staff and contractor reports, NRC-sponsored conference proceedings, and NRC booklets and brochures. Also available are Regulatory Guides. NRC regulations in the Code of Federal Regulations, and Nuclear Regulatory Commission Issuances.

Documents available from the National Technical Information Service include NUREG series reports and technical reports prepared by other federal agencies and reports prepared by the Atomic Energy Commission, forerunner agency to the Nuclear Regulatory Commission.

Documents available from public and special technical libraries include all open literature items. such as books, journal and periodical articles, and transactions. Federal Register notices, federal and state legislation, and congressional reports can usually be obtained from these libraries.

Documents such as theses, dissertations, foreign reports and translations, and non-NRC conference proceedings are available for purchase from the organization sponsoring the publication cited.

Single copies of NRC draft reports are available free upon written request to the Division of Technical Information and Document Control, U.S. Nuclear Regulatory Commission, Washington. DC 20555.

Copies of industry codes and standards used in a substantive manner in the NRC regulatory process are maintained at the NRC Library. 7920 Norfolk Avenue, Bethesda, Maryland, and are available there for reference use by the public. Codes and standards are usually copyrighted and may be purchased from the originating organization or, if they are American National Standards, from the American National Standards Institute, 1430 Broadway. New York, NY 10018. 